\title{
ESTUDO DE ESTRUTURAS COMPOSTAS POR LÂMINAS PLANAS DE ESPESSURAS CONSTANTES: UMA ABORDAGEM PELO MÉTODO DOS ELEMENTOS DE CONTORNO
}

\section{ÂNGELO VIEIRA MENDONÇA}

Tese apresentada à Escola de Engenharia de São Carlos da Universidade de São Paulo, como parte dos requisitos para obtenção do título de Doutor em Engenharia

ORIENTADOR: Prof. Assoc. JOÃO BATISTA DE PAIVA 


\section{AGRADECIMENTOS}

Desejo expressar meus agradecimentos a todos aqueles que ajudaram direta ou indiretamente a tornar possível este trabalho.

Sou especialmente grato ao Professor Associado João Batista de Paiva, por sua dedicada orientação e estímulo em todas as etapas deste trabalho.

Estendo meus agradecimentos aos Professores Márcio R. S. Corrêa, Wilson S. Venturini, Sérgio P. B. Proença, José E. Laier e Humberto B. Coda por suas valorosas contribuições que foram dadas a mim ao longo desses anos em que estive na Escola de Engenharia de São Carlos.

Aos amigos contemporâneos de pós-graduação do Departamento de Engenharia de Estruturas(SET) também expresso minha gratidão por suas valiosas observações e sugestões, especialmente aos paladinos da mecânica computacional, dentre eles: Alexandre Botta, Arthur Mesquita, Faustino Sanches, Luciano Gobo, Valério Almeida, Wilson Wuztow.

Aos funcionários do SET estendo meus agradecimentos pela amizade e por terem gentilmente me auxiliado em diversas situações em que fui consultá-los.

Agradeço ainda a Fundação de Amparo à Pesquisa do Estado de São Paulo pelo apoio financeiro concedido a este trabalho.

Agradeço também ao Centro Acadêmico Armando Sales de Oliveira (CAASO) por sua programação cultural que tem sido apreciada pelo autor desde os tempos da graduação em Engenharia Civil. 
Para minha maravilhosa família:

João e Geralda, meus pais;

Tamara, minha irmã. 
Homens filhos do sol,

homens filhos da lua,

homens filhos do mar,

aqui vieram sofrer, sonhar.

(Citação lida em algum lugar na infância) 
FOLHA DE JULGAMENTO

Candidato: Engenheiro ÂNGELO VIEIRA MENDONÇA

Tese defendida e julgada em 12-07-2002 perante a Comissão Julgadora:

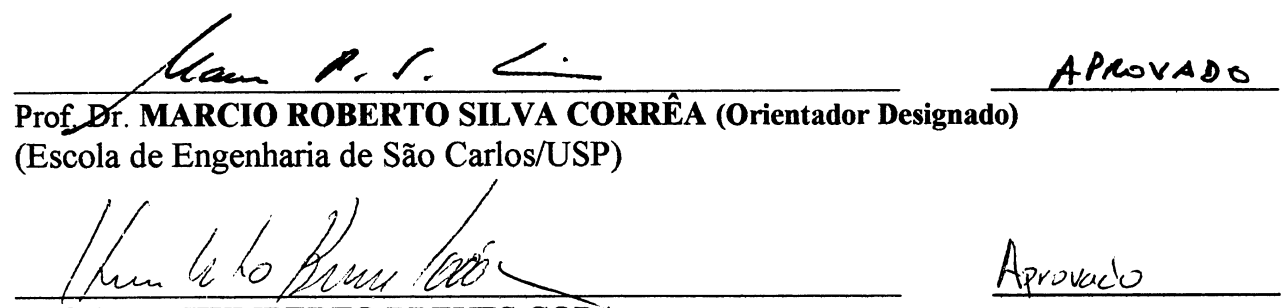

Prof. Assoc. HUMBERTO BREVES CODA

(Escola de Engenharia de São Carlos/USP)
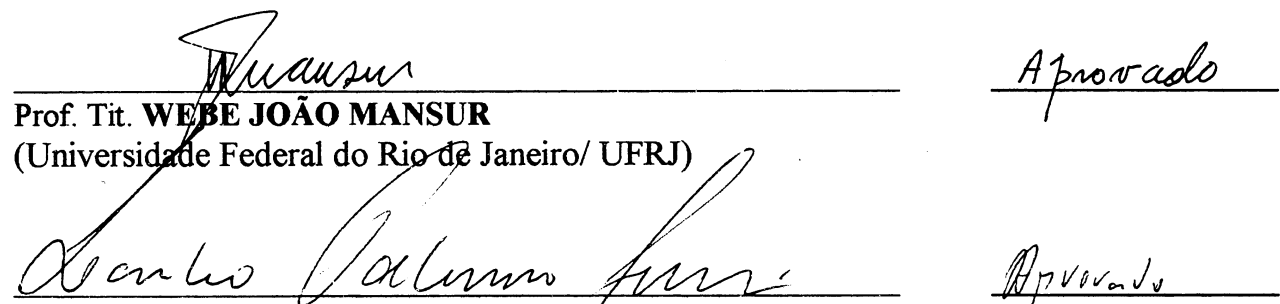

Prof. Dr. LEANDRO PALERMO JUNIOR

(Universidade Estadual de Campinas/UNICAMP)

MM

Prof. Dr. PAULO SOLLERO

(Universidade Estadual de Campinas/UNICAMP)

$\frac{h \cdot i d-C u}{\text { Profa. Doutora ANA LÚCIA HOMCE DE CRESCE EL DEBS }}$ Coordenadora do Programa de Pós-Graduação em

Engenharia Civil (Engenharia de Estruturas)

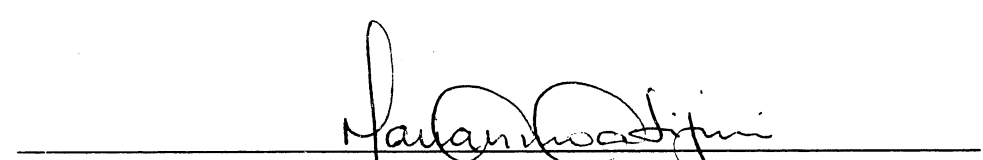

Profa. Assoc. MARIA DO CARMO OALIJURI

Presidente dal Comissão de Pós-Graduação 


\section{SUMÁRIO}

LISTA DE FIGURAS i

LISTA DE TABELAS v

LISTA DE ABREVEATURAS E SIGLAS vi

LISTA DE SÍMBOLOS vii

RESUMO xiii

ABSTRACT xiv

1 APRESENTAÇÃO 1

1.1 Generalidades 1

1.2 Revisão Bibliográfica 4

2 FUNDAMENTOS DA TEORIA DA ELASTOSTÁTICA

LINEAR $\quad 34$

$\begin{array}{lll}2.1 & \text { Introdução } & 34\end{array}$

2.2 Generalidades $\quad 34$

2.3 Relações elementares da teoria da elasticidade 35

2.3.1 Problema tridimensional 36

2.3.2 Problema bidimensional 38

2.3.3 Teoria de chapas 39

2.3.4 Teoria clássica de placas $\quad 41$

2.4 Representação de Papkovitch-Neuber 46

2.5 Problemas elásticos fundamentais 51

2.5.1 Problema de Kelvin tridimensional $\mathbf{5 2}$

2.5.1.1 Deslocamentos via vetor de Papkovitch 52

2.5.1.2 Deslocamentos via transformadas de Fourier $\mathbf{5 5}$

2.5.1.3 Tensões, deformações e forças de superfície $\mathbf{5 9}$

2.5.2 Problema de Kelvin bidimensional 59

2.5.2.1 Deslocamentos via vetor de Papkovitch 59

2.5.2.2 Deslocamentos via transformadas de Fourier 62

2.5.2.3 Tensões, deformações e forças de superfície $\mathbf{6 3}$ 
2.6 Problema fundamental de placas delgadas $\quad \mathbf{6 4}$

2.6.1 Deslocamentos via solução direta $\quad 64$

2.6.2 Deslocamentos via transformada de Fourier $\quad 67$

$\begin{array}{lll}\text { 2.6.3 Derivadas dos deslocamentos, esforços } & \mathbf{6 7}\end{array}$

3 REPRESENTAÇÕES INTEGRAIS PARA

PROBLEMAS ELASTOSTÁTICOS PLANOS 69

3.1 Introdução $\quad 69$

3.2 Equações integrais de contorno de chapas 69

3.2.1 Pontos no domínio $\quad 69$

3.2.2 Pontos no contorno 71

3.2.3 Carregamentos externos distribuídos em linha e concentrados (estados planos)

3.2.4 Representações integrais dos estados planos no sistema de referência local $\quad 77$

3.3 Equações integrais de placas delgadas $\quad \mathbf{8 0}$

3.3.1 Pontos de domínio $\quad 80$

3.3.2 Pontos no contorno $\quad 91$

3.3.3 Ações aplicadas linearmente distribuídas e concentradas $\quad \mathbf{1 0 1}$

4 REPRESENTAÇÕES ALGÉBRICAS DOS

PROBLEMAS ELÁSTICOS 103

$\begin{array}{lll}4.1 & \text { Introdução } & 103\end{array}$

4.2 Representações integrais discretizadas 103

$\begin{array}{lll}\text { 4.2.1 Discretização } & 103\end{array}$

$\begin{array}{lll}\text { 4.2.2 Aproximação das variáveis do problema } & \mathbf{1 0 5}\end{array}$

4.2.2.1 Interpolações na formulação Hexaparamétrica $\mathbf{1 0 5}$

4.2.2.2 Interpolações na formulação Tetraparamétrica $\mathbf{1 1 0}$

4.2.3 Transformação das integrais de domínio para o carregamento $\mathbf{1 1 1}$

$\begin{array}{lll}\mathbf{4 . 3} & \mathbf{1 1 4}\end{array}$

$\begin{array}{lll}\text { 4.3.1 Cálculo das integrais } & 114\end{array}$

$\begin{array}{lll}\text { 4.3.1.1 Integração singular } & 114\end{array}$

$\begin{array}{lll}\text { 4.3.1.2 } & 119\end{array}$ 
$\begin{array}{lll}\text { 4.3.2 } & \text { Sistema de equações } & \mathbf{1 2 0}\end{array}$

4.3.2.1 Formulação Hexaparamétrica 120

4.3.2.1.1 Problemas simplesmente conectados 120

4.3.2.1.2 Problemas coplanares com multirregiões 122

4.3.2.1.3 Problemas não-coplanares 125

4.3.2.2 Formulação Tetraparamétrica 136

$\begin{array}{lll}\text { 4.3.2.2.1 } & \text { Problemas com regiões simples } & 137\end{array}$

$\begin{array}{lll}\text { 4.3.2.2.2 } & \text { Estruturas coplanares } & 137\end{array}$

$\begin{array}{lll}\text { 4.2.2.2.3 } & \text { Estruturas não-coplanares } & 137\end{array}$

4.3 Determinação dos deslocamentos e esforços no domínio 138

5 REPRESENTAÇÕES INTEGRAIS E ALGÉBRICAS

PARA PROBLEMAS INELÁSTICOS 141

$\begin{array}{lll}5.1 & \text { Introdução } & 141\end{array}$

5.2 Equações integrais para problemas com campos iniciais 141

5.2.1 Equações básicas 141

$\begin{array}{lll}\text { 5.2.2 } & \text { Equações integrais } & 144\end{array}$

5.2.3 Representações Integrais Discretizadas 166

5.3.1.1 Discretização 16

$\begin{array}{lll}\text { 5.2.3.2 } & \mathbf{1 7 0}\end{array}$

$\begin{array}{lll}5.3 & \text { Representação Algébrica } & 171\end{array}$

5.3.1 Cálculo das integrais para os campos iniciais 171

5.3.2 Sistema de equações 176

5.3.2.1 Formulação hexaparamétrica 176

5.3.2.1.1 Problemas simplesmente conectados de chapas e placas 176

5.3.2.1.2 Problemas coplanares com multirregiões 186

5.3.2.2 Formulação Tetraparamétrica 192

5.3.2.2.1 Problemas com regiões simples 192

5.3.2.2.2 Problemas coplanares multiconectados 195

6 REPRESENTAÇÃO ALGÉBRICA PARA PROBLEMAS ELASTOPLÁSTICOS 196

$\begin{array}{lll}\text { 6.1 Introdução } & 196\end{array}$ 
6.2 Conceitos básicos da plasticidade 196

6.2.1 Relações tensão-deformação incremental 202

6.2.2.1 Critérios de plastificação 206

$\begin{array}{lll}\text { 6.2.2.1.1 } & \text { Critério de Tresca }\end{array}$

$\begin{array}{lll}\text { 6.2.2.1.2 } & \text { Critério de Maxwell-Huber- Mises }\end{array}$

6.2.2.1.3 Critério de Mohr-Coulomb 209

6.2.2.1.4 Critério de Drucker-Prager 209

6.2.2.1.5 Critério de Rankine 210

6.3 Algoritmos Incrementais-iterativos do Sistema de Equações 213

7 AVALIAÇÃO NUMÉRICA 219

7.1 Análise Elastolinear 219

7.1.1 Placa engastada sob carregamento uniformemente distribuído 219

$\begin{array}{lll}\text { 7.1.2 } & \text { Placa engastada submetida a um carregamento hidrostático } & \mathbf{2 2 0}\end{array}$

7.1.3 Placa apoiada sob carregamento uniformemente distribuído 221

7.1.4 Placa apoiada sob carregamento hidrostático 222

7.1.5 Placa apoiada sob carregamento concentrado 223

7.1.6 Placa apoiada nos cantos e carreg. uniformemente distribuído $\mathbf{2 2 4}$

7.1.7 Chapa simplesmente tracionada 225

7.1.8 Chapa submetida a binários nas extremidades 226

$\begin{array}{lll}\text { 7.1.9 Chapa submetida ao cisalhamento puro } & \mathbf{2 2 7}\end{array}$

$\begin{array}{lll}\text { 7.1.10 } & \mathbf{2 2 8}\end{array}$

7.1.11 Placa apoiada com 2 regiões sob carreg. distribuído em linha 229

7.1.12 Placa de espessura variável em balanço 232

7.1.13 Viga $\pi$ engastada nas extremidades $\quad \mathbf{2 3 4}$

$\begin{array}{lll}\text { 7.1.14 Viga } V \text { engastada nas extremidades } & \mathbf{2 3 8}\end{array}$

7.1.15 Viga de seção monocelular engastada nas extremidades 241

$\begin{array}{lll}\text { 7.1.16 Reservatório elevado } & \mathbf{2 4 5}\end{array}$

7.2 Lâminas planas submetidas a campos iniciais de temperatura 252

7.2.1 Chapa com acréscimos constantes de temperatura 252

7.2.2 Placa apoiada com gradiente de temperatura 253

$\begin{array}{lll}\text { 7.2.3 } & \text { Placa engastada com gradiente de temperatura }\end{array}$ 
7.3.1 Chapa em regime elastoplástico com encruamento linear $\quad 255$

$\begin{array}{lll}\text { 7.3.2 Tubo pressurizado em regime elastoplástico perfeito } & \mathbf{2 5 7}\end{array}$

$\begin{array}{lll}\text { 7.3.3 } & \mathbf{2 5 8}\end{array}$

7.3.4 Chapa com duas regiões em regime elastoplástico com encruamento linear $\mathbf{2 5 9}$

7.3.5 Placa com duas regiões em regime elastoplástico perfeito $\quad 261$

8

CONCLUSÕES

264

9

REFERÊNCIAS

267

ANEXO I

289

ANEXO II

291

ANEXO III

292

ANEXO IV

293

ANEXO V

295 


\section{LISTA DE FIGURAS}

Figura 2.1- Deslocamentos segundo as direções dos eixos cartesianos. 36

Figura 2.2-Estado de tensões em um elemento infinitesimal $\quad 37$

Figura 2.3- Resultantes de tensão em um elemento infinitesimal de chapa. $4 \mathbf{4 1}$

Figura 2.4- deslocamento vertical e rotações presentes na placa.

Figura 2.5- Esforços presentes em um elemento infinitesimal de placa. $\quad 44$

Figura 2.6- Equilíbrio no círculo auxiliar.

Figura 3.1 - Ponto fonte situado no contorno.

Figura 3.2-Ângulos presentes em $C_{i j} \quad \mathbf{7 4}$

$\begin{array}{lr}\text { Figura 3.3- Esquema representativo da chapa } & \mathbf{8 0}\end{array}$

$\begin{array}{ll}\text { Figura 3.4- Carregamentos presentes na placa } & \mathbf{8 7}\end{array}$

Figura 3.5-Contorno auxiliar $\quad 92$

Figura 3.6-Movimento de corpo rígido para a obtenção do termo livre. 96

$\begin{array}{ll}\text { Figura 3.7-Pontos anteriores e posteriores aos cantos. } & \mathbf{9 7}\end{array}$

$\begin{array}{ll}\text { Figura 4.1- Discretização de contorno e de domínio. } & 103\end{array}$

$\begin{array}{ll}\text { Figura 4.2- Funções interpoladoras lineares. } & 106\end{array}$

$\begin{array}{ll}\text { Figura 4.3- Funções Interpoladoras } \phi_{i} \text {. } & 108\end{array}$

$\begin{array}{ll}\text { Figura 4.4-Funções interpoladoras } \phi_{i}^{\prime} & 109\end{array}$

Figura 4.5- Esquema representativo da integração sobre a célula. 113

Figura 4.7-Funções interpoladoras lineares para o elemento singular $\mathbf{1 1 5}$

$\begin{array}{ll}\text { Figura 4.8- Funções } \phi_{i} \text { no Elemento Singular. } & 117\end{array}$

$\begin{array}{ll}\text { Figura 4.9-Funções Interpoladoras } \phi_{i}^{\prime} \text { no Elemento Singular. } & 118\end{array}$

$\begin{array}{lr}\text { Figura 4.10- Duas regiões coplanares } & 123\end{array}$

$\begin{array}{lr}\text { Figura 4.11- Sistemas de referências. } & \mathbf{1 2 6}\end{array}$

$\begin{array}{ll}\text { Figura 4.12-Geometria da estrutura poliédrica. } & 127\end{array}$

$\begin{array}{ll}\text { Figura 4.13- Orientação das lâminas na estrutura poliédrica. } & 128\end{array}$

Figura 4.14- Orientação da lâmina $i$ em relação ao sist. global da estrutura. 130

Figura 4.15- Definição do ângulo $\bar{\gamma} 132$

Figura 4.16- Orientação dos graus de liberdade versus sistema local.

$\begin{array}{ll}\text { Figura 4.17- Forças interativas discretas. } & 133\end{array}$ 
Figura 5.1- Diagramas tensão-deformação em problemas uniaxiais.

Figura 5.2- Esquema representativo do problema de membrana.

Figura 5.3- Esquema representativo do problema de flexão

Figura 5.4- Sistema de referências utilizado na diferenciação de Leibnitz

Figura 5.5- Discretização de contorno e de domínio.

Figura 5.6- Interpolação dos Campos Inelásticos.

Figura 5.7- Integração na célula.

Figura 5.8- Sistema de referência (resultantes de tensão no contorno).

Figura 5.9- Sistema de referência (momentos no contorno).

Figura 5.10- Duas regiões inelásticas coplanares.

Figura 5.11- Sistemas locais em uma interface com duas regiões.

Figura 6.1- Modelo isótropo (caso uniaxial)

Figura 6.2- Modelo isótropo uniaxial (elastoplástico perfeito)

Figura 6.3- Modelo Cinemático

Figura 6.4- Modelo misto

Figura 6.5- Tresca \& Mises em tensões principais $\quad \mathbf{2 0 8}$

Figura 6.6- Drucker-Prager \& Mohr-Coulomb 210

Figura 6.7-Modelo de Rankine $\quad \mathbf{2 1 1}$

Figura 6.8-Tensões em partes discretizadas ao longo da seção $\mathbf{2 1 5}$

Figura 7.1-Placa engastada com carregamento uniformemente distribuído. $\quad 219$

Figura 7.2- Carregamento linearmente distribuído aplicado $\quad \mathbf{2 2 0}$

$\begin{array}{ll}\text { Figura 7.3- Placa simplesmente apoiada uniformemente carregada. } & \mathbf{2 2 1}\end{array}$

Figura 7.4- Carregamento hidrostático em placa simplesmente apoiada. 22

Figura 7.5- Placa simplesmente apoiada sob carregamento concentrado $\quad 223$

Figura 7.6- Placa apoiada exclusivamente sobre os apoios rígidos $\quad \mathbf{2 2 4}$

Figura 7.7- Chapa apoiada ao longo da base na direção $x_{2}$

$\begin{array}{ll}\text { Figura 7.8- Viga em flexão } & \mathbf{2 2 6}\end{array}$

$\begin{array}{ll}\text { Figura 7.9- Chapa submetida ao cisalhamento } & \mathbf{2 2 7}\end{array}$

Figura 7.10- Esquema e discretização do problema de Cook 229

Figura 7.11- Placa simplesmente apoiada sob carreg.distribuído em linha. $\quad 230$

$\begin{array}{ll}\text { Figura 7.12-Tipos de Malhas } & \mathbf{2 3 1}\end{array}$

$\begin{array}{lll}\text { Figura 7.13- Coef. } \alpha \text { Versus Tipo de Malha. } & 231\end{array}$ 
Figura 7.14- Placa engastada com variação de espessura.

Figura 7.15- Deslocamento Transversal ao Longo linha A-B. 233

Figura 7.16- Esquema Representativo da Viga $\pi$. 234

Figura 7.17- Deslocamento Transversal ao Longo da Interface AB da Viga $\pi \mathbf{2 3 5}$

Figura 7.18- Deslocamento Normal ao Longo da Interface AB da Viga $\pi \quad 235$

Figura 7.19- Deslocamento Tangencial ao Longo da Interface AB da Viga $\pi .236$

Figura 7.20- Deslocamento Transversal ao Longo da Linha BC da Viga $\pi$. 237

Figura 7.21-Momentos fletores $m_{x_{2}}$ ao Longo da linha BC da Viga $\pi$. 237

$\begin{array}{ll}\text { Figura 7.22- Esquema representativo da viga } V \text {. } & \mathbf{2 3 8}\end{array}$

Figura 7.23-Deslocamento Transversal ao Longo da Interface $\mathrm{AB}$ da Viga $V \quad \mathbf{2 3 9}$

Figura 7.24- Deslocamento Tangencial ao Longo da Interface AB da Viga $V$. 239

Figura 7.25- Deslocamento Transversal ao Longo da Linha BC da Viga $V . \quad 240$

Figura 7.26- Momentos fletores $m_{x_{2}}$ ao Longo da linha BC da Viga $V$. 240

Figura 7.27- Esquema Representativo da Viga Monocelular. 241

Figura 7.28- Desloc. Transv. na Interface AB da Viga Monocelular. 242

Figura 7.29- Desloc. Tangencial na Interface AB da Viga Monocelular. $\quad 242$

Figura 7.30- Desloc. Normal na Interface AB da Viga Monocelular. 243

Figura 7.31- Momentos fletores $m_{x_{2}}$ ao longo de BC da Viga Monocelular 244

Figura 7.32- Momentos fletores $m_{x_{2}}$ ao longo de BD da Viga Monocelular $\mathbf{2 4 4}$

Figura 7.33- Esquema Representativo do Reservatório. 245

Figura 7.34- Orientação de Parte das Lâminas do Reservatório 246

Figura 7.35- Desloc. Transv. na Interface 2C do Reservatório. 246

Figura 7.36- Desloc. Tangencial na Interface 2C do Reservatório 247

Figura 7.37- Desloc. Transv. ao Longo de C'D' do Reservatório. 247

Figura 7.38- Momentos fletores $m_{x_{2}}$ ao longo de C'D' do Reservatório $\quad \mathbf{2 4 8}$

Figura 7.39- Desloc. Transv. na Interface 4A do Reservatório. 249

Figura 7.40- Desloc. Tangencial na Interface 4A do Reservatório. 249

Figura 7.41- Desloc. Transv. ao Longo de EF do Reservatório. 250

Figura 7.42- $\theta_{x_{I}}$ ao longo EF do Reservatório. 
Figura 7.43- Momentos fletores $m_{x_{2}}$ ao longo de EF do Reservatório

Figura 7.44- Chapa submetida ao campo térmico permanente

Figura 7.45- Discretização do plano médio das células

Figura 7.46 - Chapa Simplesmente Tracionada.

Figura 7.47 - Evolução Carga-Deslocamento do nó $A$. 256

Figura 7.48-Tubo Pressurizado. 257

Figura 7.49 -Curva Carga-Deslocamento do nó Pertencente ao Raio Externo. 258

Figura 7.50- Curva Deslocamento-Carregamento para o Ponto Central. 259

Figura 7.51- configuração da chapa simplesmente tracionada com 2 regiões. $\quad \mathbf{2 6 0}$

Figura 7.52- Discretização das células da chapa simpl. tracionada com 2 regiões $\mathbf{2 6 0}$

Figura 7.53 - Evolução Carga-Deslocamento do nó $A$. $\mathbf{2 6 1}$

Figura 7.54- Configuração placa com 2 duas regiões.

Figura 7.55- Curva Deslocamento-Carregamento para o Ponto central 262

Figura 8.1- Mapeamento da matriz das incógnitas 266 


\section{LISTA DE TABELAS}

Tabela 7.1 Deslocamentos e momentos adimensionalizados

Tabela 7.2 Deslocamentos e momentos adimensionalizados

Tabela 7.3 Deslocamentos e momentos adimensionalizados

Tabela 7.4 Deslocamentos e momentos adimensionalizados

Tabela 7.5 Desloc. adimensionalizados para diversas razões dos lados. 224

$\begin{array}{lll}\text { Tabela 7.6 Deslocamentos e momentos. } & 225\end{array}$

Tabela 7.7 Deslocamentos, forças de superfície e tensões 226

$\begin{array}{lll}\text { Tabela 7.8 Deslocamentos e tensões } & \mathbf{2 2 7}\end{array}$

$\begin{array}{lll}\text { Tabela 7.9 Deslocamentos e tensões } & \mathbf{2 2 8}\end{array}$

Tabela 7.10 Deslocamentos e tensões principais no problema de Cook

Tabela 7.11 Diferença relativa para campos na interface AB 236

Tabela 7.12 Diferença rel. em deslocamentos e momentos na linha BC 238

Tabela 7.13 Diferença relativa para os campos de desloc. e momentos

Tabela 7.14 Diferença relativa para deslocamentos na interface AB

Tabela 7.15 Diferença relativa para deslocamentos e momentos

Tabela 7.16 Deslocamentos e momentos

Tabela 7.17 Desloc. e resultantes de tensão verdadeiras em chapa

Tabela 7.18 Desloc. e momentos verdadeiros no ponto central da placa

Tabela 7.19 Desloc. e momentos verdadeiros no ponto central da placa 
LISTA DE SIGLAS E ABREVIATURAS

\begin{tabular}{|c|c|}
\hline $\mathrm{ABCP}$ & Associação Brasileira do Cimento Portland \\
\hline BP & Biparamétrico \\
\hline EI & Equação Integral \\
\hline EDP & Equação Diferencial Parcial \\
\hline EPD & Estado Plano de Deformação \\
\hline EPT & Estado Plano de Tensão \\
\hline $\mathrm{HC}$ & Hexaparamétrica cúbica \\
\hline HL & Hexaparamétrica linear \\
\hline HP & Hexaparamétrica \\
\hline MDF & Método das Diferenças Finitas \\
\hline MEC & Método dos Elementos de Contorno \\
\hline MEF & Método dos Elementos Finitos \\
\hline MSPF & Método dos Segmentos de Parede Fina \\
\hline RRG & Representação de Rayleigh-Green \\
\hline RTP & Representação triparamétrica \\
\hline TL & Tetraparamétrica linear \\
\hline TP & Tetraparamétrica \\
\hline TRB & Teorema da Reciprocidade de Betti \\
\hline TRP & Técnica do Resíduo Ponderado \\
\hline v.p.c. & Valor Principal de Cauchy \\
\hline h. & Valor Principal de Hadamard \\
\hline
\end{tabular}




\section{LISTA DE SÍMBOLOS}

a

$b_{j}$

$d_{i}$

$d_{i j}$

$d \mu$

$d \lambda$

$D$

E

$f\left(\sigma_{i j}\right)$

$f_{i}$

$F\left(\sigma_{i j}\right)$

$F(\varsigma)$

$F_{j}(c)$

$g$

G

G

$\hat{g}[f(r)]$

$\hat{g}^{-1}[F(\varsigma)]$

$g^{*}$

$\mathrm{h}$

$H$

$H$

$i$

I

$J$

$J_{1}, J_{2}$ e $J_{3}$

$K^{*}(p, s)$
Dimensão do menor lado.

Força volumétrica.

Funções harmônicas.

Funções vetoriais harmônicas de Papkovitch.

Coeficiente de proporcionalidade do modelo de Ziegler

Fator de proporcionalidade.

Módulo de flexão da placa.

Módulo de elasticidade longitudinal.

Superfície de plastificação.

Forças de superfície do problema de chapas.

Forma da superfície de carregamento.

Função $f(r)$ no espaço transformado.

Força concentrada aplicada no ponto $\mathrm{c}$.

Energia potencial plástica.

Módulo de elasticidade transversal.

Matriz de influência dos esforços.

Transformada integral de Fourier de $f(r)$.

Transformada inversa de Fourier de $F(\varsigma)$.

Carregamento unitário fundamental.

Espessura.

Inclinação da curva do diagrama tensão-deformação.

Matriz de influência dos deslocamentos.

Número imaginário elementar igual a $\sqrt{-1}$.

Matriz identidade.

Jacobiano do sistema $\left(x_{1}, x_{2}\right)$ para o adimensional $\varepsilon$.

Invariantes do campo das tensões desviadoras.

Kernel genérico 


\begin{tabular}{|c|c|}
\hline$K_{i j k l}$ & Componentes do tensor momento-curvatura. \\
\hline$L$ & Comprimento do elemento de contorno. \\
\hline$L_{i}$ & Vetor de Galerkin. \\
\hline$m_{n}$ & Momento fletor. \\
\hline$m_{n s}$ & Momento volvente. \\
\hline$N_{m q}$ & Resultante do campo das tensões(chapas). \\
\hline$n_{i j}$ & Eixos normais ao contorno da lâmina. \\
\hline$p$ & Carregamento distribuído; tensão normal ao plano; ponto-fonte. \\
\hline$q$ & Direção genérica. \\
\hline$q_{i}$ e $m_{i}$ & $\begin{array}{l}\text { Co-senos diretores das direções } q \text { e } m \text { em relação ao } \\
\text { sistema }\left(x_{1}, x_{2}\right) .\end{array}$ \\
\hline$Q(s)$ & Matriz de transformação entre os sistemas $\left(x_{1}, x_{2}\right)$ e $(\tau, \eta)$. \\
\hline$q_{n}$ & Força cortante. \\
\hline$r$ & Distância entre o ponto-fonte $p$ e o ponto-campo $s$. \\
\hline$R(i)$ & Resíduo associado à solução aproximada da EDP no ponto $i$. \\
\hline $1 / R$ & Curvatura do contorno. \\
\hline$R_{c}$ & Reação de canto. \\
\hline$R_{c e}, R_{c d}$ & Reações de canto anterior e posterior à angulosidade. \\
\hline$r_{, i}$ & Co-seno diretor do raio vetor $r$. \\
\hline$R_{m}$ & Resíduo ponderado médio global \\
\hline$s, S$ & Pontos-campo associados ao contorno e ao domínio. \\
\hline$S_{i j}$ & Eixos tangenciais ao contorno da lâmina. \\
\hline$S_{i j}$ & Campo das tensões desviadoras. \\
\hline$(s, n)$ & Sistema de referências do contorno $(s, n)$. \\
\hline $\mathrm{t}$ & Espessura. \\
\hline$u_{i, j}$ & Gradientes dos deslocamentos na direção do plano médio.. \\
\hline$u_{q}(p)$ & Deslocamento do ponto-fonte segundo a direção $q$. \\
\hline$u_{q, m}(p)$ & Derivada direcional na direção $m$ de deslocamento na direção $q$. \\
\hline$\left(u_{1}, u_{2}, u_{3}\right)$ & Componentes de deslocamento segundo o sistema $\left(x_{1}, x_{2}, x_{3}\right)$. \\
\hline
\end{tabular}




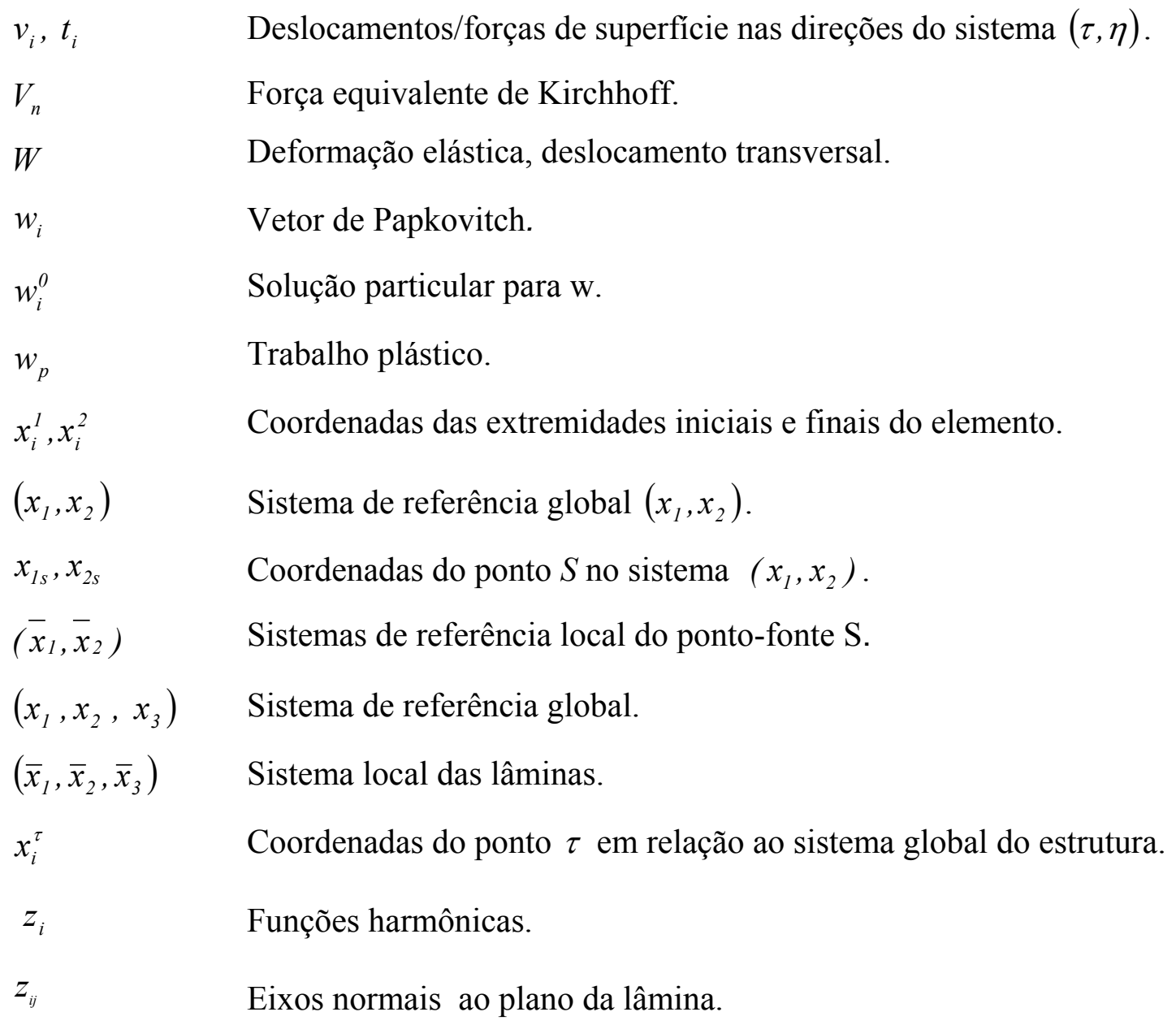

Coeficiente associado ao deslocamento transversal máximo; coesão.

$\alpha_{i j} \quad$ Coordenada do centro da superfície de carregamento.

$\alpha_{1}, \alpha_{2} \quad$ Ângulos tangenciais ao contorno anterior e posterior à angulosidade.

Versor normal ao contorno de $\Omega_{d}$, Menor ângulo entre as normais de dois planos da folha poliédrica.

$\Gamma_{d c e l} \quad$ Contorno da célula $d$.

$\delta(p, s) \quad$ Delta de Dirac. 


\begin{tabular}{|c|c|}
\hline$\delta_{i j}$ & Delta de Krönecker. \\
\hline$\varepsilon_{i j}$ & Componentes das deformações. \\
\hline $\bar{\varepsilon}_{p}$ & Deformação efetiva. \\
\hline$(\varepsilon, \theta, \phi)$ & Sistema de coordenadas em coordenadas esféricas. \\
\hline$\eta$ & Direção normal ao contorno. \\
\hline$\theta_{p}$ & Rotação normal. \\
\hline$\theta_{t}$ & Rotação tangencial. \\
\hline$\theta_{z}$ & Rotação zenital. \\
\hline$\Theta_{i}$ & Funções harmônicas. \\
\hline$\kappa$ & $\kappa$ Parâmetro de encruamento. \\
\hline$\lambda$ & Coeficiente do termo livre de integral. \\
\hline$\lambda_{\theta}$ & Coeficiente do termo livre de integral. \\
\hline$v$ & Coeficiente de Poisson \\
\hline$v_{p}$ & Coeficiente aparente de Poisson \\
\hline$\rho$ & Valor do raio-vetor $\boldsymbol{r}$ no contorno da célula. \\
\hline $\bar{\sigma}_{e}$ & Tensão efetiva \\
\hline$\sigma_{i j}$ & Campo de tensões \\
\hline$\sigma_{m q}^{f}$ & Tensões mobilizadas pelo regime de flexão \\
\hline$\sigma_{m q}^{m}$ & Tensões mobilizado pelo regime de membrana \\
\hline$\tau$ & Direção tangencial ao contorno. \\
\hline$\phi_{i}$ & Funções de forma. \\
\hline$\phi_{i}^{\prime}$ & Funções de forma. \\
\hline$\phi$ & Ângulo de atrito interno. \\
\hline$\chi$ & Constante para o modelo de encruamento cinemático. \\
\hline$\chi_{1}, \chi_{2}$ & Variáveis arbitrárias dos esforços. \\
\hline$\psi$ & Função escalar obtida da divergência de $t_{i}$ \\
\hline$\Omega$ & Domínio do problema \\
\hline$\Omega_{d}$ & Domínio de uma região da célula $d$ \\
\hline
\end{tabular}


$\varphi_{i}$

$\varsigma$

$\circ$

$\otimes$

$u_{i j}^{*}, f_{i j}^{*}$,

$\varepsilon_{i j k}^{*}, N_{i j k}^{*} ; \lambda$

$u_{i j k}^{*}, f_{i j k}^{*}$,

$\lambda_{i j k r}^{*}, \kappa_{i j k m}^{*}$;

$\lambda_{\theta}, E_{i j k r}, D_{i j k \alpha}$

$s_{i j k}^{*}, d_{i j k}^{*}$,

$\varepsilon_{i j k l}^{*}, N_{i j k r}^{*}$;

$L_{i j k r} Z_{i j k r}$,

$q_{n}^{*}, m_{n s}^{*}$

$w^{*}, \theta_{p}^{*}$,

$R_{c}^{*}, w_{, i j}^{*}$,

$m_{i j}^{*} ; k$

$q_{n, m}^{*}, \quad V_{n, m}^{*}, \quad \operatorname{Kernels}(*)$ da EI das rotações (placas); termos livres.

$m_{n s, m}^{*} ; R_{c, m}^{*}$,

$w_{, m}{ }^{*}, \theta_{p, m}^{*}$,

$m_{i j, m}^{*}, w_{, i j m}^{*}$; funções harmônicas arbitrárias.

Variável do domínio transformado de $r$.

Produto escalar.

Produto tensorial.

Kernels $(*)$ da EI dos deslocamentos(chapas); termos livres. livres.

Kernels $(*)$ da EI das resultantes de tensão(chapas); termos livres.

Kernels $(*)$ da EI dos deslocamentos (placas); termos livres.

Co-seno diretor da nornal ao contorno no ponto posterior ao canto;

Kernels (*) da EI dos gradientes de deslocamentos(chapas); termos 
$k_{3}, k_{4}$

$q_{n, m q}^{*}, m_{n, m q}^{*}, \quad \operatorname{Kernels}(*)$ da EI das curvaturas(placas); termos livres.

$m_{n s, m q}^{*}, w_{, m q}^{*}$,

$\theta_{p, m q}^{*}, V_{n, m q}^{*}$,

$m_{i j, m q}^{*}, w_{, i j m q}^{*}$,

$R_{c, m_{q}}^{*} ; j_{i j k m}$,

$Y_{i j k \alpha}$

$\mu q_{n, m q}^{*}, \mu V_{n, m q}^{*}, \quad \operatorname{Kernels}(*)$ da EI dos momentos(placas);termos livres.

$\mu m_{n, m q}^{*}, \mu m_{n s, m q}^{*}$,

$\mu w_{, m q}^{*}, \mu \theta_{p, m q}^{*}$,

$\mu m_{i j, m q}^{*}, \mu w_{, i j m q}^{*}$,

$\mu R_{c, m_{q}}^{*} ; \mu j_{i j k m}$,

$\mu Y_{i j k \alpha}$. 


\section{RESUMO}

MENDONÇA, A. V. Estudo de estruturas compostas por lâminas planas de espessuras constantes: uma abordagem pelo método dos elementos de contorno. São Carlos, 2002. 296p. Tese (Doutorado)- Escola de Engenharia de São Carlos, Universidade de São Paulo.

Inicialmente, são apresentadas neste trabalho duas formulações do método dos elementos de contorno para análise elástica de estruturas compostas por lâminas planas de espessuras constantes. Em ambos modelos, o comportamento de cada lâmina-base é analisado levando-se em conta os efeitos de placa e de chapa. A lâmina em flexão é assumida sob as hipóteses de Kirchhoff.

$\mathrm{Na}$ primeira abordagem, as variáveis do problema são representadas por um conjunto de quatro graus de liberdades (GLs) em deslocamentos e forças associadas a chapas (deslocamentos normal, tangencial e suas respectivas forças de superfície) e a placas (deslocamento transversal, rotação normal e seus respectivos esforços representados pela força de Kirchhoff e momento fletor). Esta abordagem foi chamada de modelo tetraparamétrico. Na segunda abordagem, duas variáveis adicionais são inseridas na formulação tetraparamétrica, resultando em uma técnica hexaparamétrica. Com isso, o vetor de deslocamentos é composto pelos deslocamentos normal, tangencial, transversal e pelas rotações normal, tangencial e zenital. Essa última variável é associada a uma rotação que atua ao longo da direção perpendicular ao plano médio da lâmina-base. Além disso, no modelo hexaparamétrico o vetor das forças tem apenas quatro GLs (forças normal e tangencial no problema de chapa; força de Kirchhoff e momento fletor no caso de flexão). Inicialmente, as matrizes de influência são montadas para ambos modelos e então técnicas especiais são empregadas somente para a abordagem hexaparamétrica, a fim de resolver a incompatibilidade de ordens entre as matrizes de influência dos deslocamentos e das forças. Em seguida, a técnica da subregião é utilizada para montar o sistema final de equações da estrutura não-coplanar.

A partir dos modelos tetra e hexaparamétricos elásticos para problemas nãocoplanares, o comportamento elastoplástico é incorporado nessas abordagens como campos tensoriais iniciais (tensão/momento ou deformação/curvatura) para analisar problemas coplanares utilizando representações clássicas para a superfície de plastificação. 


\begin{abstract}
MENDONÇA, A. V. Study of plated structures of constant thicknesses: a boundary element method approach. São Carlos, 2002. 296p. Tese (Doutorado)Escola de Engenharia de São Carlos, Universidade de São Paulo.
\end{abstract}

Firstly in this work, two formulations of the boundary element method for the linear elastic analysis of plated structures of uniform thicknesses are presented. In both models, the behaviour of each plate unit is analysed taken into account the effects from the plate in bending and the plate in tension. The bending plate is assumed under Kirchhoff's hypotheses.

In the first approach, the variables of the problem are represented by a set of four degrees of freedom(DOFs) in displacements and forces associated with the plate in tension (normal and tangential displacements and their respective tractions) and the plate in bending (transverse displacements, normal slope and their efforts represented by Kirchhoff force and bending moment). This approach was called four-parameter model. In the second approach, two further variables are inserted into the four-parameter model, resulting in a six-parameter technique. Hence, the displacement vector is populated by normal, tangential, transverse displacements and by normal, tangential and zenithal slopes. The last variable is associated with a rotation acting along the perpendicular direction to median plane of the plate unit. In addition, for the six-parameter model the force vector has only four DOFs (normal, tangential forces in tension plate problem and bending moment and Kirchhoff force in bending case). Initially, the influence matrices are assembled for both models and then special techniques are only employed into six-parameter approach in order to solve an incompatibility of orders between the influence matrices of displacements and forces. Then the subregion technique is used to assemble the final system of equations of the noncoplanar plated structure.

From the four and six parameter elastic models for noncoplanar plated structures, the elastoplastic behaviour is incorporated into these approaches as initial tensor fields (stress/moment or strain/curvature) in order to analyse coplanar problems using classical representations for the loading surface. 


\section{APRESENTAÇÃO}

\subsection{GENERALIDADES}

As estruturas formadas por folhas poliédricas são amplamente empregadas em diversos problemas da engenharia civil, aeronáutica, naval e outras. Essas estruturas em engenharia civil são usadas como opção de sistema estrutural, principalmente, em estruturas de grande porte, por exemplo, pontes, silos, núcleos de rigidez, etc.

Dentre diversos trabalhos que descrevem o emprego da terminologia estrutural, no padrão adotado pela Associação Brasileira do Cimento Portland ABCP(1967): lâmina é definida como um elemento em que uma das dimensões é bem menor que as demais; uma estrutura formada por uma ou mais lâminas, cujas superfícies médias sejam planas, recebe a denominação de folha poliédrica. Um subconjunto dessas estruturas - em que a geometria de cada lâmina é formada por arestas paralelas - é denominado folha prismática.

$\mathrm{O}$ assunto de folhas poliédricas já foi abordado em diversos trabalhos voltados, tanto para o desenvolvimento/aperfeiçoamento das representações físicomatemáticas dos modelos(teorias), quanto para os procedimentos empregados para a obtenção das soluções das equações diferenciais advindas delas, entre os quais, constam os métodos numéricos. Uma dessas técnicas numéricas é o então denominado Método dos Elementos Finitos(MEF), pertencente aos métodos de domínio, cuja aplicação em estruturas poliédricas é um assunto que tem sido amplamente pesquisado. Outra técnica numérica alternativa para os métodos de domínio é o então denominado Método dos Elementos de Contorno(MEC).

As formulações do MEC têm sido desenvolvidas de forma intensa para aplicação em diversos problemas de engenharia. Contudo, o aperfeiçoamento e aplicabilidade do MEC não tem sido homogêneo em muitas áreas da mecânica dos sólidos. Nesse contexto, um dos problemas que tem recebido pouca atenção dos pesquisadores está associado à análise de folhas poliédricas. Um número consideravelmente reduzido de formulações é encontrado para a análise desses problemas, quer modelados apenas pelo MEC, quer em combinação desse com outros métodos numéricos.

Assim, neste trabalho foram desenvolvidas (e/ou estendidas) duas 
formulações do método dos elementos de contorno para folhas poliédricas, a partir de representações integrais para os regimes desacoplados de membrana e flexão, então, disponíveis na literatura. Empregando-se uma conveniente hierarquia de sistemas de referência e/ou funções interpoladoras para as variáveis do problema, os estados de flexão e membrana são acoplados para a análise elástica de problemas compostos por lâminas planas de espessuras constantes.

$\mathrm{Na}$ revisão bibliográfica realizada, bem poucos trabalhos foram encontrados envolvendo aplicações do MEC em folhas poliédricas submetidas a campos iniciais, o que pode ser até compreensível devido ao número reduzido de formulações para análise elastolinear. Assim, neste trabalho, também são analisados problemas coplanares submetidos a campos iniciais, envolvendo fluxo plástico, a partir da extensão das abordagens propostas para problemas em regime elástico.

Os capítulos deste trabalho foram organizados utilizando-se a seguinte a disposição:

No capítulo 1, são definidos os problemas e seus modelos abordados por este trabalho. Além disso, é apresentada a evolução de algumas formulações disponíveis na literatura de problemas correlatos.

No capítulo 2, são apresentadas tanto as relações básicas da teoria da elasticidade quanto de seus problemas fundamentais, que têm papel importante na representação matemática dos problemas descritos nos capítulos subseqüentes.

No capítulo 3, são apresentadas as técnicas de obtenção das representações integrais para os problemas elásticos de chapas e de placas.

No capítulo 4, as equações integrais explicitadas no capítulo 3 são transformadas em representações algébricas mediante a discretização do contínuo e o do cálculo das integrais envolvidas. Inicialmente, esses procedimentos são discutidos individualmente para os problemas de flexão e para os estados planos (de deformação ou de tensão). Em seguida, são apresentadas as técnicas empregadas para análise desses problemas compostos por regiões com propriedades geométricas e mecânicas distintas. Por fim é discutido o acoplamento membrana/flexão para os problemas não-coplanares.

No capítulo 5, as representações integrais e algébricas do regime elastolinear são estendidas para o regime inelástico em problemas coplanares. 
No capítulo 6, as representações algébricas para problemas coplanares inelásticos são particularizadas para o regime plástico onde modelos clássicos são utilizados para a representação da superfície de plastificação.

No capítulo 7, são apresentados os exemplos numéricos para problemas nos regimes elastolinear e elastoplástico.

Apresentada a disposição dos assuntos ao longo do texto deste trabalho, passa-se agora para algumas observações referentes à plataforma computacional utilizada nas formulações: O código computacional foi escrito na linguagem Fortran. Convém ressaltar que todas as rotinas foram planejadas, editadas e depuradas pelo Autor, exceto nos casos abaixo relacionados:

a) Resolução do sistema linear (eliminação de Gauss): extraído de DOMINGUEZ \& BREBBIA et al.(1989), p.65-66, e cuja rotina tem o nome de SLNPD.

b) Inversão de matriz: fornecida gentilmente pelo Prof. João Batista de Paiva.

c) Processo incremental-iterativo: extraído de OWEN \& HINTON(1980) onde as rotinas ( INV, p.240; YIELDF, p.241-242; FLOWPL, p.243-244 e RESIDU, p.253255) foram adaptadas para as formulações do MEC empregadas neste trabalho.

d) Criação de arquivos de formato DXF (visualização da geometria, das numerações de nós e de células): rotinas foram gentilmente cedidas e compatibilizadas com o sistema gerenciador (programa principal) pelo Eng. Valério S. Almeida (atualmente matriculado no programa de doutorado em Engenharia de Estruturas da EESC-USP).

e) Mapeamento dos valores nas matrizes: rotinas foram gentilmente cedidas pelo Eng. Wilson Wesley Wurztow (atualmente matriculado no programa de mestrado em Engenharia de Estruturas da EESC-USP).

Nesse trabalho, parte das respostas obtidas pela presente abordagem foram comparadas com as do Software Ansys, cuja utilização foi legalmente concedida ao Departamento de Engenharia de Estruturas mediante assinatura de contrato. 


\subsection{REVISÃO BIBLIOGRÁFICA}

O emprego de equações integrais não é uma técnica recente e tem sido usada desde o século XIX para representar alguns problemas da física-matemática tais como: pêndulo isócrono, ABEL(1881); elastostática, BETTI(1872), BOUSSINESQ(1885), CERRUTI(1882), SOMIGLIANA(1886); em 1884, alguns problemas da eletrostática, VOLTERRA(1856) e outros. No início do século XX, FREDHOLM(1903) demonstrou, por meio do uso de uma técnica de discretização, a existência de soluções para equações integrais decorrentes da representação de funções harmônicas, utilizando-se ou potenciais de camada simples ou de camadas duplas. LAURICELLA(1909) estendeu a abordagem de Fredholm para placas elásticas engastadas. Alternativamente à abordagem de Fredholm, KELLOG(1929) utilizou uma superposição dessas duas classes de potenciais, empregando os teoremas de Green, para a representação integral de funções harmônicas envolvendo a teoria potencial.

Os métodos de TREFFTZ(1917) e PRAGER (1928), aplicados na resolução das equações integrais envolvendo a teoria de fluxo de fluidos, podem ser considerados os precursores das técnicas atuais aplicadas ao MEC.

No início da segunda metade do século XX, contribuições expressivas da escola russa, MIKHLIN(1957), MUSKHELISHVILI(1945,1953), impulsionaram a técnica da representação integral empregando uma abordagem em que foram utilizadas equações integrais singulares associadas a potenciais complexos. Este último trabalho, de 1953, é de grande importância para a engenharia estrutural, uma vez que representações complexas foram elegantemente aplicadas à análise de problemas elásticos bidimensionais.

$\mathrm{Na}$ década de 1960, com o surgimento das primeiras gerações de computadores, as técnicas numéricas tornaram-se uma ferramenta viável na busca de soluções das equações governantes de muitos problemas. HESS \& SMITH(1962) resolveram, numericamente, uma equação integral de segunda espécie de Fredholm associada a um problema de um fluxo uniforme de ar sobre uma superfície de revolução; JASWON(1963) analisou o problema de capacitância eletrostática utilizando equações integrais de Fredholm de primeira espécie para a determinação da distribuição de carga. 
As técnicas numéricas também despertaram interesse em parte dos pesquisadores pelas representações integrais de alguns problemas elásticos. JASWON \& PONTER(1963) analisaram um problema de torção em que equações integrais foram usadas para representar as funções de empenamento. Esse foi um dos trabalhos pioneiros, que explorou a segunda identidade de Green associando pontos-fonte no contorno. Em JASWON et al.(1967), foi apresentada uma formulação em que os problemas biarmônicos eram escritos em função de duas de equações de Laplace, via representação de Almansi. Nesse trabalho foram analisados tanto problemas associados a um meio semi-infinito, contendo um orifício elíptico, quanto outros associados a uma chapa retangular finita chanfrada em um dos cantos. RIZZO(1967) analisou numericamente os problemas elásticos bidimensionais explorando a identidade de SOMIGLIANA(1886). Esse trabalho teve um papel importante na representação integral dos problemas elásticos, uma vez que as densidades utilizadas para a montagem dos problemas sãos suas próprias variáveis físicas. Essa técnica é denominada método direto. CRUSE(1969) estendeu a representação de Rizzo para problemas elásticos tridimensionais. JASWON(1981) apontou algumas analogias que podem ser observadas na confecção de equações integrais, utilizando a segunda identidade de Green na teoria potencial escalar e a identidade Somigliana na teoria potencial vetorial, a partir do trabalho de KUPRADZE(1965).

As representações integrais também podem ser estruturadas envolvendo densidades fictícias, isto é, que não estão diretamente relacionadas com as variáveis físicas do problema, de forma que essas técnicas são classificadas como métodos indiretos.

Em algumas formulações indiretas, os campos de deslocamentos e tensões são escritos a partir das representações de Muskhelishvili envolvendo potenciais complexos. Esses potenciais podem ser obtidos empregando-se a fórmula integral de Cauchy, cujo integrando é formado por densidades fictícias em variáveis complexas. MCCARTNEY(1983) apresentou uma formulação para problemas com domínio finito ou problemas interiores utilizando-se de uma discretização em que as densidades fictícias são representadas por polinômios complexos e por curvas splines ponderadas por coeficientes complexos arbitrários, que são determinados a partir da 
imposição das condições de contorno. MCCARTNEY(1984) estendeu a formulação indireta, apresentada em 1983, a problemas infinitos, utilizando-se de duas curvas splines distintas para a composição da densidade fictícia complexa. Nesse artigo são analisados problemas de fratura em placas circulares e retangulares.

Uma das características marcantes do método dos elementos de contorno é a presença de singularidades nos kernels de sua representação integral. Desde as primeiras formulações, os pesquisadores do método apontaram a dependência do desempenho da solução numérica em relação à técnica aplicada no cálculo das integrais, principalmente, quando o ponto-fonte é aproximado do ponto-campo. Nas últimas décadas, diversos trabalhos foram direcionados especialmente para o tratamento desses casos.

Uma das primeiras abordagens para esse tema é a então chamada técnica $\boldsymbol{d a}$ subelementação descrita em LACHAT \& WATSON(1976, 1977), JUN et al. (1985). Nessa técnica, à medida que a colocação do ponto-fonte torna-se crítica, o elemento de contorno é fragmentado em regiões menores, e o número de pontos de integração é gradualmente densificado no sentido do subelemento mais próximo do ponto-fonte.

Muitas outras técnicas surgiram com o intuito de aumentar a eficiência do cálculo das integrais, entre as quais, constam: transformações exponenciais HIGASHIMACHI et al.(1983), transformações cúbicas TELLES(1987), transformações de coordenadas HAYAMI \& BREBBIA(1987).

Outra maneira de lidar com o cálculo das integrais é aplicando-se técnicas para reduzir a ordem das singularidades. Essas abordagens são denominadas técnicas de regularização. SISSON (1990) propôs uma estratégia de regularização, classificada como numérica, em que é utilizada uma superposição das tensões obtidas da representação integral em um ponto no contorno com os valores das tensões atuantes na vizinhança desse ponto.

Além da regularização numérica, outra técnica que tem sido desenvolvida é a então chamada regularização analítica. Um dos primeiros trabalhos em que se aplicou uma classe dessa técnica foi apresentada por GHOSH et al. (1986). Nesse trabalho, a regularização é obtida a partir de relações geométricas, envolvendo as direções do raio vetor, dos versores normais e tangenciais ao contorno, e aplicando- 
se a técnica de integração por partes na integral de contorno que contém a singularidade mais severa. Esse procedimento conduz a um novo integrando formado por um kernel com uma singularidade logarítmica e pela derivada tangencial da variável primitiva (deslocamentos). Com isso, é necessário utilizar uma estratégia adicional para viabilizar a aplicação de condições de contorno associadas aos deslocamentos na representação algébrica, uma vez que as representações integrais são escritas em função das derivadas tangenciais dos deslocamentos.

Três anos depois, em BALAS et al.(1989), foi apresentada uma regularização para a representação integral das tensões, com redução de um grau na ordem das singularidades dos kernels, aplicando-se o teorema de Stokes. Essa abordagem conduziu a modificações no kernel mais crítico e ao aparecimento de um operador envolvendo derivadas direcionais tangenciais dos deslocamentos. $\mathrm{Na}$ discretização do problema, a representação algébrica é formada pelos valores nodais associados às derivadas tangenciais dos deslocamentos e às forças de superfície. Assim, uma estratégia adicional, análoga à de Ghosh, é utilizada para possibilitar a imposição das condições de contorno em deslocamento. SLADEK \& SLADEK(1992) apresentaram uma extensão da formulação regularizada, proposta pelo mesmos autores em 1982 e 1989, para a obtenção de uma representação integral não-singular para as tensões. Em YOUNG (1996), é utilizado o teorema de Stokes em combinação com certos termos, que incorporam todas as integrais singulares das equações integrais e íntegro-diferenciais de contorno, de forma que eles podem ser convertidos em expressões não-singulares, desde que sejam escritos sobre uma região do contorno que incorpora a vizinhança da singularidade.

Outros pesquisadores utilizaram outras técnicas para a obtenção das tensões no contorno. LEI (1994) formulou uma abordagem em que as equações integrais incorporam valores de contorno associados a tensões e ao tensor infinitesimal de rotação. Essa técnica permite que tensões no contorno sejam determinadas diretamente da solução numérica, evitando-se, com isso, as hipersingularidades dos kernels da formulação clássica. Contudo, a principal restrição da formulação é a dificuldade de impor condições de contorno genéricas. Conforme mencionado pelo próprio autor, para tais casos, essa formulação pode ser utilizada de forma conjunta com a representação clássica, isto é: para a determinação dos deslocamentos do 
contorno, é utilizada a formulação clássica, e em seguida, para a determinação das tensões, prescrevem-se os deslocamentos com os valores da análise numérica prévia; só então, aplica-se a formulação em questão para a determinação das tensões no contorno. No livro editado por SLADEK \& SLADEK(1998) são descritas algumas técnicas que podem ser aplicadas no tratamento das integrais singulares em alguns problemas da mecânica dos sólidos modelados pelo MEC.

Um outro problema que tem um papel importante na engenharia estrutural está associado às placas. Conforme mencionado anteriormente, as primeiras equações integrais para casos particulares desses problemas foram apresentadas por Lauricella no início do século XX. Contudo, só a partir da década de 1960, as técnicas numéricas foram aplicadas mais intensamente para os problemas de placas e as primeiras formulações envolveram o método indireto.

Em JASWON et al.(1967) é apresentada uma técnica, utilizando-se a representação de Almansi, para resolver casos particulares de condições de contorno em placas circulares e elípticas. SEGEDIN \& BRICKELL(1968) também apresentaram uma técnica para casos particulares de placas simplesmente apoiadas em que foi estudada a influência da variação do ângulo formado pelos bordos convergentes a um canto. A solução geral do problema é encontrada pela combinação de uma solução particular com a homogênea, que é obtida transformando a EPD biarmônica em duas equações integrais via segunda identidade de Green para o deslocamento e para seu Laplaciano. Após a discretização do problema, a solução é obtida explorando-se alguns eixos de simetria do problema. WU \& ALTIERO(1978) apresentaram uma formulação singular para a análise de casos particulares de placas engastadas. Essa formulação foi estendida para problemas que envolvem condições de contorno arbitrárias em WU \& ALTIERO(1979). Outra abordagem, distinta da apresentada em 1978, está associada ao emprego de um contorno circular fictício, que circunscreve o problema real, caracterizando-se desta forma o método regular do MEC, para evitar os problemas com as singularidades observadas no trabalho anterior. As representações integrais são escritas, para cada par específico de condições de contorno, envolvendo duas equações integrais com kernels dos deslocamentos e suas derivadas superiores. É admitido que estão aplicados força e momento fletor distribuídos ao longo do 
contorno fictício. É mostrada a dependência do desempenho da formulação para determinadas relações de dimensões entre raio do contorno fíctício e o maior lado da geometria retangular do problema real.

Outras formulações do método indireto que envolvem a aplicação de variáveis complexas foram apresentadas. VABLE \& ZHANG (1992) utilizaram uma representação integral, que é obtida a partir das equações de Fredholm de segunda espécie. Os kernels, para o deslocamento transversal e suas derivadas superiores, são montados algoritmicamente utilizando-se quatro funções em variáveis complexas. Tal procedimento permite que as integrações da representação integral sejam feitas analiticamente empregando-se as soluções algorítmicas. Um outro assunto discutido nesse artigo de Vable está relacionado com a representação integral escrita utilizando-se de variáveis adimensionais. Nesse estudo, são mostrados casos em que a solução do problema pode ser dependente da escolha dos parâmetros adimensionalizantes.

Só no final da década de 1970, é que apareceram as primeiras formulações para placas delgadas envolvendo uma representação integral direta para o problema. BEZINE(1978) e STERN (1979) apresentaram formulações diretas do MEC quase simultaneamente, contudo, concebidas independentemente a partir da forma bilinear, descrita em BERGMAN \& SCHIFFER(1958). Ambos pesquisadores escreveram uma representação integral para o deslocamento transversal e outra sua derivada direcional(rotação). Contudo, a discretização do problema recebeu tratamento distinto: Bezine utilizou uma interpolação constante, enquanto Stern aproximou linearmente as variáveis contínuas do contorno, e ainda associou um nó em cada angulosidade do contorno da placa para representar as reações de canto. Nesses trabalhos foram apresentados exemplos numéricos de placas retangulares simplesmente apoiadas e engastadas, todavia, Bezine restringiu-se aos casos de forças concentradas e Stern às forças uniformemente distribuídas sobre todo o domínio da placa.

Um outro trabalho contemporâneo aos dois anteriores foi escrito por TOTTENHAM(1979). Nesse artigo são utilizadas as formas direta e indireta via solução da equação biarmônica do problema fundamental. Na abordagem indireta, é descrita a utilização de uma expansão das densidades fictícias em série de Fourier, 
desde que a curva fictícia exterior seja um círculo. Tal procedimento viabiliza, após o cálculo das integrais envolvidas, expressar a equação integral primitiva em termos de uma série infinita. Na abordagem direta, é utilizada uma representação semelhante à de Bezine; na discretização do problema, são utilizadas funções constantes para a interpolação das variáveis e as integrações singulares são substituídas por uma análise finita de integrais.

Muitos trabalhos foram escritos envolvendo as representações integrais diretas de placas apresentadas anteriormente, principalmente a de Stern. Em geral, nesses trabalhos é investigado o desempenho da formulação em problemas com geometrias e condições de contorno, distintos daqueles apresentados nos artigos originais. Outra linha de pesquisa está associada à aplicação de técnicas alternativas para a obtenção da representação algébrica do problema.

BEZINE (1981) estendeu a formulação direta de 1978 para a análise de problemas com vínculos ou forças concentradas no domínio. Nesse artigo, o problema do acoplamento entre as incógnitas dos nós de contorno e de domínio é abordado de tal forma que o vetor das incógnitas é isolado na representação algébrica dos pontos de contorno. Em seguida, esse vetor é substituído na representação dos pontos de domínio, de forma que a representação final do sistema pode ser resolvida após a prescrição dos valores de domínio.

A representação de Stern foi aplicada no trabalho PAIVA(1987) para diversas configurações de condições de contorno e de carregamento. Além disso, foi apresentada uma formulação alternativa utilizando-se apenas equações integrais para os deslocamentos transversais. Nessa abordagem, são utilizados dois pontos-fonte distintos posicionados fora do contorno. Nesse trabalho também foi apresentada a análise da interação da placa com outros elementos estruturais de pavimentos de edifícios.

Dois anos depois, SHI \& BEZINE(1989) apresentaram a identidade de Rayleigh-Green, empregando o princípio dos trabalhos virtuais. Na discretização, é utilizada uma interpolação constante para as variáveis e os momentos volventes reais são aproximados por meio de diferenças finitas dos valores nodais da rotação normal. O termo da integral de domínio é eliminado utilizando-se uma técnica conhecida de escrever as representações integrais em função da solução homogênea da equação de 
equilíbrio de placas. A primeira restrição dessa formulação está associada à dificuldade de aplicação de uma força concentrada no canto, uma vez que os momentos volventes são aproximados por diferenças finitas das rotações normais. Outra restrição está associada à solução real do problema uma vez que esta é obtida pela superposição das soluções homogêneas e particulares. Todavia, as soluções particulares só estão disponíveis para alguns casos particulares de carregamento. Embora um dos objetivos dessa formulação seja a análise de placas com orifícios, apenas são mostrados problemas envolvendo simetria de vinculação e de posicionamento dos orifícios no domínio da placa.

Outros trabalhos também empregaram a representação integral de Stern para análise de algumas configurações geométricas de placas. Em OLIVEIRA NETO(1991), são analisadas placas com bordas curvas; CHAVES(1997) estudou casos de placas com variação linear do módulo de flexão sobre o domínio.

Já em PAIVA(1991), foi apresentada uma formulação em que a representação integral discretizada de Stern é alterada, de forma que a força equivalente de Kirchhoff é admitida concentrada nos pontos nodais ao longo do contorno.

Ainda na estratégia de composição das representações algébricas, DU et al. (1984) apresentaram uma formulação em que a discretização do problema é feita usando-se elementos retos para a geometria do problema. Os deslocamentos transversais são interpolados por polinômios cúbicos e aplicando-se funções lineares para as demais variáveis. Para a definição dos polinômios cúbicos são necessários, além dos valores nodais dos deslocamentos, os valores de suas derivadas tangenciais, conduzindo, portanto, a três graus de liberdade para o vetor associado aos deslocamentos. Assim, para cada nó, além das duas equações integrais utilizadas na representação de Stern, é escrita uma equação integral adicional associada à derivada direcional tangencial dos deslocamentos e alguns exemplos são analisados para algumas configurações de geometria e condições de contorno. Já em SONG \& MUKHERJEE(1986), a representação algébrica, obtida utilizando o modelo de DU et al. (1984), é escrita também para integrações sobre elementos circulares e exemplos foram apresentados para várias geometrias e vinculações.

Em ARISTODEMO \& TURCO(1994), é utilizada uma técnica de 
discretização em que o contorno é dividido em segmentos, então chamados macroelementos, que possuem suas próprias funções interpoladoras. Cada um deles é dividido em elementos menores pela introdução de nós e as variáveis do contorno são interpoladas por curvas 'Spline' quadráticas. Embora as variáveis sejam interpoladas por funções quadráticas, as integrais são calculadas analiticamente de tal forma que os resultados são expressos em função de parcelas polinomiais de ordem genérica. Assim, interpolações com B-splines de ordens superiores, após alguns ajustes algébricos, podem ser também obtidas e empregadas em diversas análises, principalmente, envolvendo estudos de p-adaptividade.

Em WEARING \& BETTAHAR (1995), é aplicado o método regular para diversas configurações de geometria e condições de contorno, e sua eficiência é comparada com o desempenho das formulações singulares. Além disso, é mapeado o intervalo para as distâncias de colocação dos pontos-fonte versus desempenho da formulação. HARTMANN \& ZOTEMANTEL (1986) implementaram uma formulação em que uma das representações integrais de Stern, associada à derivada direcional dos deslocamentos, tem sua singularidade reduzida pela aplicação de um dos modos de corpo rígido. Na discretização do problema, é utilizada uma interpolação hermiteana para os deslocamentos transversais, que envolvem, além de seus próprios valores nodais, outros valores associados a suas derivadas tangenciais. Esses últimos são escritos em função dos valores nodais dos primeiros através de diferenças finitas; para as demais variáveis são utilizadas interpolações lineares. Convém ressaltar que, ao contrário do trabalho de DU et al.(1984), não é utilizada nenhuma equação adicional e, sim, apenas as duas equações integrais associadas ao deslocamento transversal e à sua derivada direcional normal no contorno. Nessa formulação, Hartmann,1996, não é utilizado o então difundido conceito de nó duplo para regiões onde haja descontinuidades das tangentes do contorno. Nesse trabalho é estudado o efeito das singularidades no desempenho da formulação a partir da análise de alguns problemas: descontinuidade de vinculação, concentração de tensões devido a apoios rígidos no domínio, ângulos críticos em placas esconsas. OLIVEIRA NETO \& PAIVA (1995) apresentaram uma formulação a partir de alterações na representação integral de Stern, que conduz à associação de três graus de liberdade para o vetor de deslocamento, isto é, deslocamento transversal, rotação 
normal e rotação tangencial. Assim, para a montagem da representação algébrica são utilizadas equações integrais associadas ao deslocamento, e suas derivadas direcionais normal e tangencial ao contorno. Essa formulação foi implementada em OLIVEIRA NETO(1998) utilizando-se duas abordagens: na primeira, todas as variáveis do problema são interpoladas por funções lineares; na segunda é utilizado um polinômio cúbico para os deslocamentos transversais. As rotações tangenciais são aproximadas pela função obtida da diferenciação tangencial da função interpoladora do deslocamento; as demais variáveis são interpoladas por funções lineares. Nesse trabalho, foram estudados problemas do acoplamento da placa com outros elementos estruturais dos pavimentos de edifícios e as placas com diversas configurações de condições de contorno e de carregamento. Diferentemente da formulação de Oliveira Neto, as formulações anteriormente discutidas- DU et al.(1984), SONG \& MUKHERJEE(1986) e HARTMANN \& ZOTEMANTEL (1986) - mantêm o kernel da força equivalente de Kirchhoff e de suas derivadas inalterados nas representações integrais.

Os problemas associados às singularidades também estão presentes nos problemas de placas. Assim, algumas das técnicas de regularização, aplicadas inicialmente nos problemas elásticos, foram adaptadas para os problemas de flexão.

BALAS et al.(1989), SLADEK \& SLADEK(1992) apresentaram uma representação integral que incorpora o deslocamento transversal e duas rotações segundo as direções normal e tangencial ao contorno. A partir da EDP do problema fundamental, de manipulações algébricas envolvendo o kernel da força cortante e o delta de Dirac, a equação integral primitiva singular dos deslocamentos é transformada em uma representação não-singular. Para o caso da equação integral dos gradientes de deslocamento é aplicado o teorema de Stokes sobre a integral de contorno composta pela derivada do kernel da força cortante ponderada pelo deslocamento transversal, que após algumas manipulações algébricas a representação não-singular das rotações é obtida. $\mathrm{Na}$ representação algébrica, as derivadas tangenciais são escritas em função dos valores nodais do deslocamento, para viabilizar a aplicação das condições de contorno em deslocamento.

Uma outra técnica de regularização para placas delgadas foi apresentada por FRANGI(1996), em que são utilizados identidades auxiliares e alguns 
procedimentos da abordagem de GHOSH et al.(1986) para problemas elásticos bidimensionais. Na discretização, os deslocamentos são escritos a partir dos valores nodais dos deslocamentos e da rotação tangencial, utilizando-se um polinômio de Hermite cúbico. Os momentos fletores e força de equivalente de Kirchhoff são interpolados por polinômios de Lagrange quadráticos. Para os cantos da placa são escritas três equações: uma para os deslocamentos e duas outras para as rotações normais associadas aos pontos anterior e posterior ao canto.

Alguns pesquisadores utilizaram outras técnicas para evitar o emprego de kernels com singularidades de ordens superiores. PARIS \& LEÓN (1986) analisaram problemas de placas particulares utilizando uma técnica semidireta, em que a equação biarmônica é escrita em função de duas equações de Poisson desacopladas. Isso conduziu a uma análise de placas que utilizava a técnica do MEC para problemas potenciais, envolvendo, portanto, singularidades menores que a do problema biarmônico. PARIS \& LEÓN (1987,1996) estenderam a formulação de 1986 para problemas com condições de contorno arbitrárias. Nesses casos, as duas equações de Poisson nem sempre podem ser desacopladas. As integrais de domínio são aproximadas por equações integrais de contorno equivalentes envolvendo uma função que requer pontos de colocação tanto no domínio quanto no contorno utilizando-se um caso particular da técnica da reciprocidade dual descrito em NARDINI \& BREBBIA (1982). As equações integrais do problema envolvem uma variável especial associada à soma dos momentos fletores e à sua derivada direcional normal. Assim, a partir de expressões especiais (que relacionam a variável especial e sua derivada com esforços e rotações no contorno) é viabilizada a aplicação de condições de contorno arbitrárias. Contudo, essas expressões estão associadas a contornos curvilíneos, de forma que em contornos retos as condições de contorno são aplicadas utilizando-se diferenças finitas.

ZUO-HUI(1993) utilizou soluções fundamentais não-singulares específicas para o problema de placas. Essas soluções são obtidas utilizando-se séries de Fourier, que são tomadas como funções ponderadoras, de forma que satisfazem tanto as equações de equilíbrio quanto as condições de contorno do problema fundamental. Essas condições de contorno são coincidentes com as do problema real.

Além dos problemas com singularidades, alguns pesquisadores estudaram 
problemas específicos, tanto associados às condições de contorno quanto à geometria do problema.

RAJAMOHAN \& RAAMACHANDRAN(1997) formularam uma abordagem para placas esconsas usando uma solução fundamental apropriada para esse tipo de problema. Ao escrever-se a equação diferencial para placas isótropas em um sistema de referência oblíquo, os autores perceberam uma analogia com as equações diferenciais parciais(EDP) de placas delgadas anisótropas em um sistema cartesiano. A partir do método proposto por LEKHNITSKII(1981), em que são utilizadas variáveis complexas, a solução de placas anisótropas pode ser obtida a partir das raízes de uma equação característica de quarto grau. Assim, substituindo-se os coeficientes equivalentes entre EDPs do caso isótropo em coordenadas oblíquas por aqueles do anisótropo, a solução fundamental para as placas esconsas é obtida. Contudo, em ângulos de esconsidade, cujos senos dos arcos são nulos, ocorrem singularidades na solução fundamental de placa esconsa. Para esses casos, os autores sugeriram que a solução fundamental clássica é uma alternativa que pode ser usada. $\mathrm{Na}$ representação integral do problema, é utilizada uma formulação indireta então conhecida como Método de Simulação de Mudança(MSM), em que o deslocamento real do domínio é obtido por uma superposição de uma solução particular com uma outra obtida pela ponderação de uma densidade fictícia pelo kernel de deslocamento ao longo do contorno do problema. Embora a MSM dispense a divisão do contorno em elementos, o que elimina as integrações numéricas, um fator restritivo dessa técnica está associado à escolha e obtenção da solução particular para configurações de carregamentos genéricos, que em muitos casos, podem não estar disponíveis.

Além dos problemas de chapas e placas, cujos campos de tensão são desacoplados(quando modelados sob hipóteses de pequenos deslocamentos: análise geometricamente linear, AGL), existem outras categorias de elementos estruturais(até mesmo nos modelos da AGL) que podem exigir uma análise simultânea desses problemas: as lâminas. Conforme a terminologia adotada em ABCP(1967), as lâminas são classificadas em dois grandes grupos identificados pela curvatura da superfície média do corpo; lâminas planas, na inexistência de curvatura e casca para os demais casos. Além disso, outra classificação é dada para as 
estruturas compostas por um conjunto de lâminas: folha, no caso do elemento-base ser uma casca; folha poliédrica para elementos-base planos.

Existem diversos trabalhos em que são utilizadas formulações do MEF na análise de cascas com variadas configurações geométricas da superfície média, tais como: CHEUNG(1969), CLOUGH(1971), BERNADOU \& BOISSERIE(1982), GOULD(1985), HUANG(1989), BULL(1989), ZIENKIEWICZ(1991), NAVARRA(1995). No método dos elementos de contorno, apenas casos especiais podem ser analisados devido à complexidade matemática para a obtenção das soluções dos problemas fundamentais em casos genéricos de geometria. ANTES(1981) foi um dos pioneiros a apresentar um método direto para a representação integral de contorno para cascas, contudo, os kernels mostrados estavam associados a um problema fundamental de casca cilíndrica circular; além disso, nenhum exemplo numérico foi apresentado. Em FU \& HARB (1990), HARB \& FU(1990), alguns problemas de cascas esféricas foram representados via método direto e utilizando-se kernels especiais. Já em SIMOS \& SADEGH (1989), uma formulação indireta foi discutida para casca esférica com condições de contorno genéricas empregando-se kernels mais simples que os das técnicas diretas.

Em muitos problemas de engenharia, a geometria da casca é tal que a razão altura/vão é um valor pequeno, de forma que o elemento estrutural passa a ser denominado casca abatida. A pequena relação entre a altura e o vão conduz a simplificações importantes nas equações governantes de cascas e que foram incorporadas em teorias específicas apresentadas por Reissner e Vlazov segundo BESKOS(1991). Nesses trabalhos, a influência das tensões cisalhantes (que atuam na direção da espessura) é desprezada nas equações governantes do problema. NEWTON \& TOTTENHAM(1968) apresentaram um dos primeiros trabalhos a discutir casos particulares de problemas utilizando equações integrais via teoria de Reissner/Vlasov. Nessa formulação as EDPs foram escritas em termos dos deslocamentos transversais e de funções de tensões de Airy (denominada de formulação $w-\varphi)$. Além disso, a técnica desenvolvida foi aplicada com sucesso para analisar cascas esféricas abatidas. Para esse tipo de problema, TOSAKA \& MIYKAKE(1983) também apresentaram uma formulação em que os kernels foram obtidos utilizando variáveis complexas; em HADJIKOV et al.(1985), foram 
empregadas curvas splines e kernels específicos para análise de cascas abatidas cilíndricas circulares. GOSPODINOV(1984) apresentou os kernels e analisou problemas de cascas abatidas de curvaturas gaussiana positiva em que o estado de flexão não era mobilizado. Já TEPAVITCHAROV(1985) apresentou os kernels para cascas abatidas esféricas também submetidas ao regime de flexão. Em YE(1988), as EDPs desse problema, para o caso de contorno simplesmente apoiado, eram decompostas em equações de Laplace e Poisson, cujas soluções conduziam a kernels mais simples. Em YOKOYAMA et al.(1988), foi proposta uma representação integral, alternativa a da formulação $w-\varphi$, que foi escrita diretamente a partir do vetor de deslocamentos, cujos kernels foram obtidos a partir de técnicas empregadas em MATSUI \& MATSUOKA(1978).

Soluções fundamentais para cascas abatidas com superfícies quadráticas genéricas foram apresentadas em alguns trabalhos: ELLING(1973), SIMMONDS \& BRADLEY(1976), MATSUI \& MATSUOKA(1978). Nesses trabalhos foram empregadas diversas técnicas matemáticas arrojadas, a fim de reduzir ou simplificar as equações diferenciais parciais do problema, o que leva em grande número dos casos ao aparecimento de funções especiais, geralmente escritas em séries infinitas, conferindo ao kernel algumas dificuldades associadas à operacionalidade numérica. Em PENG \& HE(1986), são propostas algumas técnicas para facilitar o cálculo desses kernels, contudo, a maioria dos trabalhos parte para abordagens alternativas para o problema. A linha principal empregada nessas abordagens é a utilização das soluções fundamentais de placas para o regime de flexão e os kernels de chapas para o regime de membrana. Contudo, na representação integral da casca abatida surgem integrais de domínio associadas às forças de interação entre os regimes membrana/flexão, o que levou essa técnica ser chamada de Método dos Elementos de Contorno/Domínio(MEC/D) e aparentemente pioneiramente aplicada por FORBES \& ROBINSON(1969) apud STERN(1989).

Muitos outros trabalhos tem sido formulados via MEC/D tanto para cascas abatidas clássicas ZHANG \& ATLURI (1986), BESKOS(1991), WANG et at. (1998), quanto aquelas escritas em teorias que levam em conta a deformação por cortante no regime de flexão - WANG et at. (1998), DIRGANTARA \&.ALIABADI(1999), WEN et al.(2000a, 2000b) - cuja solução fundamental de 
placas baseada na teoria de Reissner, foi proposta por VANDER WEË̈N(1982). Em WEN et al.(2000a, 2000b), as integrais de domínio, associadas às forças de interação dos problemas membrana/flexão, são transformadas em integrais de contorno utilizando os Métodos de Integral Direta (MID), WEN et al.(1998), e da Reciprocidade Dual (MRD), NARDINI \& BREBBIA(1982).

Embora soluções fundamentais para cascas abatidas de superfície média quadrática genérica - em que é incorporada a deformação por cortante no regime de flexão - estejam disponíveis em LU \& HUANG(1991), LU $\quad \boldsymbol{\&}$ MAHRENHOLTZ(1994), aparentemente, formulações integrais envolvendo tais kernels não têm sido muito empregadas, principalmente devido às dificuldades encontradas no cômputo das integrais.

As estruturas em folhas poliédricas também têm um papel importante no rol dos sistemas estruturais. Um dos primeiros trabalhos a utilizar o método dos elementos de contorno para análise desses problemas foi apresentado por PALERMO JUNIOR(1989), que analisa estruturas, cujo eixo longitudinal é paralelo a um dos eixos cartesianos. $\mathrm{Na}$ montagem do sistema algébrico do problema, são escritas duas equações da representação integral clássica de placas STERN(1979), e as outras duas remanescentes são escritas a partir das equações integrais da elastostática bidimensional RIZZO(1967).

Outra formulação em que incorporou essas mesmas representações integrais foi apresentada por OHGA et al.(1991). Contudo o sistema algébrico final foi obtido utilizando-se a técnica da subestruturação ou método da transferência de matriz, que conduz a matrizes de influência menores, e, portanto, possibilita uma redução do número de operações para a resolução do sistema final de equações algébricas do problema.

O MEC é aplicado para modelar estruturas poliédricas em KRAMIN \& KRAMIN (1997). Nesse trabalho, a solução final do problema é obtida por meio da combinação de uma solução particular e da solução homogênea dos problemas fundamentais que foi introduzida nas representações de Stern e Rizzo. Na composição do sistema algébrico global do problema, as variáveis associadas aos deslocamentos de cada lâmina são escritas em relação a um sistema de coordenadas globais da estrutura tridimensional, enquanto as variáveis associadas aos esforços de 
cada lâmina são escritas a partir do respectivo sistema local de cada lâmina. No acoplamento das lâminas, é tomado um eixo, que pode ser entendido como uma “geratriz”, para aplicar a técnica das sub-regiões e, na discretização do problema, são utilizadas interpolações constantes e existindo uma restrição pelo fato de se utilizar soluções particulares para formular o problema. Em FERNANDES \& VENTURINI(2002), placas enrijecidas por vigas são analisadas utilizando-se duas abordagens. Na primeira, a viga é considerada uma região enrijecida, conduzindo, portanto, a duas linhas de interação placa-viga e com discretização possuindo duas variáveis por nó. No segundo esquema, o número de graus de liberdade é reduzido pela metade ao longo da interface ao assumir-se que o movimento da seção transversal é definido por apenas três componentes independentes. Representações integrais particulares do problema são obtidas diretamente incluindo a interação viga-placa, de forma que as condições de compatibilidade e equilíbrio são automaticamente verificadas. Assim, após a discretização do problema as incógnitas do problema podem ser determinadas.

Além das representações integrais para folhas baseadas em hipóteses simplificadoras para o contínuo (e.g., as teorias de cascas ou de folhas poliédricas), existem outras que são escritas diretamente ou com pequenas adaptações no modelo elástico tridimensional. Um dos primeiros trabalhos a aplicar essa técnica foi MUKHERJEE \& PODDAR (1986). Nesse trabalho, as equações integrais, inicialmente escritas no sistema cartesiano tridimensional, são transformadas em função de um sistema curvilinear especial definido ao longo da superfície média da casca. Além disso, a partir de hipóteses adicionais para o campo de deslocamentos na direção da espessura, deformações e tensões são determinadas no interior da casca. Já LIU(1998) aplicou as equações integrais de problemas elásticos tridimensionais diretamente em estruturas poliédricas. Inicialmente, o autor discute que o sistema algébrico formado por equações integrais para problemas de domínios finitos não é degenerado quando aplicado em problemas de paredes delgadas. Devido ao fato de alguns elementos de contorno poderem estar muito próximos de um conjunto de outros elementos, para garantir o bom desempenho da formulação, as quasesingularidades são tratadas aplicando-se uma técnica que utiliza o teorema de Stokes na vizinhança da singularidade, transformando a integral quase-singular em uma 
soma de integrais de linha não-singulares e fracamente singulares. Em SOUZA(2001), alguns exemplos numéricos - tanto para elementos estruturais correntes em edifícios(vigas, placas, etc) quanto para casos de cascas esféricas - são mostrados a partir da aplicação direta do modelo elástico tridimensional. Além das equações integrais dos deslocamentos de CRUSE(1969), a representação do problema também é modelada via equações integrais dos gradientes dos deslocamentos. Na discretização do problema foram utilizados elementos planos e interpolações constantes, lineares e quadráticas para as variáveis de contorno. $\mathrm{O}$ sistema algébrico foi montado utilizando-se o método regular para o posicionamento do ponto-fonte.

A formulação integral para sólidos tridimensionais é menos restritiva que as formulações integrais obtidas a partir das diversas teorias de lâminas, uma vez que, em muitos casos - geometria com raios de curvatura finitos, espessura não-uniforme as soluções das EDPs do problema fundamental ainda estão indisponíveis. Contudo, quando a formulação de problemas elásticos tridimensionais é aplicada nos casos em que as soluções fundamentais dos problemas laminares são conhecidas, ela pode tornar-se contraproducente, uma vez que seus elementos de contorno estão definidos no espaço bidimensional e os associados às teorias de lâmina são representados por curvas unidimensionais.

Outras formulações encontradas na literatura descrevem a análise de algumas estruturas particulares em folhas poliédricas, e o problema é modelado utilizando-se o método dos elementos de contorno combinado com outras técnicas numéricas.

KOMATSU \& NAGAI(1982) analisaram seções tubulares retangulares. Nesse trabalho, a estrutura é dividida em três regiões constituída de uma região central e duas extremas. A região central é modelada pelo Método dos Segmentos de Parede Fina (MSPF), em que é utilizada a teoria de Vlasov, e a discretização é feita em segmentos tridimensionais cujos graus de liberdade estão posicionados ao longo das seções pertencentes às extremidades de cada segmento. As duas regiões extremas são modeladas pelo método dos elementos de contorno e nas linhas de interface entre o MSPF e o MEC há necessidade da inclusão de um elemento de transição no MSPF para possibilitar a aplicação das condições de equilíbrio e de compatibilidade nos 
respectivos graus de liberdade compatíveis entre os dois métodos. Assim, um sistema algébrico que envolve as contribuições de ambos os métodos pode ser resolvido.

Já GALUTA \& CHEUNG(1995) modelaram seções celulares utilizando uma combinação entre os métodos dos elementos finitos e de contorno. Nesse trabalho, as equações integrais clássicas de placas são escritas para os nós situados na placa superior, isto é, no tabuleiro da ponte. As regiões remanescentes do problema são modeladas pelo MEF. Os graus de liberdade dos nós associados ao MEF, situados na interface de regiões comuns aos dois métodos, são transformados em parâmetros nodais compatíveis com o MEC. Com isso, a matriz de influência final das incógnitas recebe contribuições de ambos os métodos.

TANAKA \& BERCIN(1998) propuseram uma formulação para a análise de placas enrijecidas por vigas prismáticas de seção transversal aberta arbitrária. Nessa análise, o problema foi dividido em regiões enrijecidas ou não por vigas de seção aberta. A placa foi representada pelas equações integrais clássicas de Stern e foi empregada uma teoria de vigas de seção aberta composta por paredes delgadas permitindo que as rigidezes - de flexão, de torção e de empenamento - e a excentricidade da viga em relação ao plano médio da placa fossem levadas em conta. Nas regiões de interface, as condições de compatibilidade e de equilíbrio foram impostas, possibilitando que um sistema algébrico envolvendo as duas técnicas pudesse ser resolvido. Ainda no problema de placas enrijecidas, CARMO(2001) utilizou uma combinação entre o MEF e o MEC para analisar a influência da excentricidade do centro de gravidade da viga em relação ao plano médio das placas. Nessa formulação, os efeitos de membrana e flexão na lâmina são representados respectivamente pelas equações de RIZZO(1968) e STERN(1979); a viga é modelada pelo MEF. A partir da compatibilização de deslocamentos e forças nas regiões de interface e a utilização da técnica de sub-regiões, obtém-se o sistema de equações final do problema. Já em WEN et al.(2000), os enrijecedores são tratados como uma força distribuída em linha aplicada no domínio placa. A representação integral do problema é constituída de cinco equações: as duas primeiras incorpora o efeito de membrana utilizando-se as equações clássicas de RIZZO(1968). As três restantes estão associadas à representação integral de placas que incorpora a deformação por cortante descrita em VANDER WEEËN(1982). Para o enrijecedor, 
são admitidas as hipóteses clássicas de vigas prismáticas, cujo centro de gravidade possui uma excentricidade em relação plano médio da placa. Após a discretização, são impostas as condições de equilíbrio e de compatibilidade de deslocamento nos pontos nodais comuns entre a viga e placa, de forma que o sistema final fica escrito apenas em função dos nós do contorno e de domínio da placa.

Os problemas de folhas políedricas são analisados na presente formulação utilizando-se duas formulações: A primeira denominada de Tetraparamétrica utiliza duas equações integrais de RIZZO(1968) para o regime de membrana e duas adicionais para problema de flexão, a partir da representação integral de placas delgadas descrita em STERN(1979). Na segunda formulação, chamada de Hexaparamétrica, são utilizadas três equações integrais de placas descritas em OLIVEIRA NETO \& PAIVA (1995), OLIVEIRA NETO(1998) para o regime de flexão. Já os efeitos de membrana são representados pelas duas equações de Rizzo e por uma terceira equação integral adicional, que representa uma rotação no plano da chapa, obtendo-se, com isso, o total de seis equações na representação integral de cada lâmina plana. Após a montagem do sistema algébrico de cada lâmina, por meio de uma rotação conveniente dos sistemas de eixos, e aplicando-se as técnicas de subregião, um sistema algébrico global da estrutura é obtido. Após a imposição das condições de contorno e a resolução do sistema algébrico, as variáveis do contorno de cada lâmina são determinadas. E, a partir dessas, os deslocamentos, os esforços e as tensões podem ser calculados no domínio de cada lâmina.

Embora as técnicas numéricas aplicadas às equações integrais para problemas elásticos tenham recebido grande atenção durante a década de 1960, as primeiras formulações para a análise de problemas fisicamente não-lineares só apareceram na década posterior.

Um dos trabalhos pioneiros nesse campo foi apresentado por SWEDLOW \& CRUSE(1971). Nesse trabalho, os autores estenderam a identidade de Somigliana para problemas tridimensionais incorporando um fluxo plástico. Além disso, foram admitidas as hipóteses da associatividade para o fluxo plástico e da superfície de plastificação evoluindo segundo um encruamento isótropo. Embora esse trabalho tenha sido o marco inicial da utilização de representações integrais diretas para 
problemas inelásticos, tanto as equações integrais para tensões quanto as discretizações do problema não foram apresentadas.

A aplicação efetiva de técnicas numéricas para a solução do problema elastoplástico só foi apresentada com a publicação do trabalho de RICCARDELLA(1973). Nesse trabalho foram estudados problemas bidimensionais. Além da representação integral para os deslocamentos, foi escrita uma versão incompleta da equação integral das tensões para pontos internos. Os problemas na diferenciação da integral de domínio, associados à parcela plástica, foram corretamente evitados utilizando-se uma técnica de integrar analiticamente o termo plástico primeiro, e só então partiu-se para a obtenção das derivadas requeridas. Esse procedimento foi facilmente aplicado devido à utilização de uma função constante para a interpolação das deformações plásticas. A resolução do sistema algébrico foi obtida por intermédio da aplicação de uma técnica implícita trabalhosa e alguns exemplos numéricos foram apresentados.

MENDELSON(1973) apresentou e discutiu diferentes formulações integrais para problemas elastoplásticos empregando os métodos indireto e direto. Para esse último foram apresentadas as representações integrais para os deslocamentos e tensões envolvendo problemas bi e tridimensionais. As expressões para as tensões apresentavam algumas incorreções associadas ao termo de deformação plástica. MENDELSON \& ALBERS(1975) estenderam e implementaram a formulação de 1973 para a análise de alguns problemas, tais como torção de barras prismáticas, flexão simples de problemas com reentrâncias e foi admitida que o material é regido pelo modelo de Mises e pelas hipóteses de encruamento por deformação.

Dois anos depois, MUKHERJEE(1977) empregou uma técnica para o problema termoelastoplástico bidimensional. Uns dos principais fundamentos dessa formulação está associado à admissão de incompressibilidade para as deformações do fluxo plástico. Os autores corrigiram uma técnica utilizada por MENDELSON(1975), em que uma identidade para problemas bidimensionais foi obtida utilizando-se uma adaptação incorreta da representação para problemas inelásticos tridimensionais para os problemas analisados em duas dimensões. Em seguida, a representação integral para as tensões foi obtida por meio de diferenciações a partir da equação integral corrigida dos deslocamentos e das 
relações tensão-deformação utilizando-se as hipóteses do problema em campo inicial de deformações. Ao admitir-se a incompressibilidade das deformações plásticas, a aplicação da representação tornou-se restrita a modelos em que a dilatação plástica não é permitida, por exemplo, o de Von Mises . Outra restrição dessa formulação é que a representação integral para as tensões foi escrita de forma incompleta, decorrente de problemas ocorridos na manipulação matemática do termo associado à integral de domínio inelástica.

Apenas no final da década de 1970, é que a diferenciação da integral de domínio plástico foi corretamente representada com o trabalho de BUI(1978). Nesse artigo, foram analisados problemas tridimensionais com campos iniciais. $\mathrm{O}$ autor utilizou os conceitos de diferenciação de integrais singulares, apresentados por MIKHLIN(1962,1965), para escrever a representação integral completa dos gradientes de deslocamentos, em que foram explicitados os coeficientes dos termos livres de integral associados aos campos iniciais. Na formulação apresentada, o fluxo plástico é admitido como incompressível e o problema também pode estar submetido a um campo inicial térmico desacoplado. Também foi estudado um problema de inclusão esférica em um meio semi-infinito submetida a um campo inicial térmico constante, cuja solução é obtida analiticamente e comparada com aquela fornecida pela representação integral completa, demonstrando-se que, sem os termos livres associados aos campos iniciais, as equações integrais estavam incorretas.

No ano seguinte, o primeiro trabalho que utilizou as representações integrais completas para os problemas elastoplásticos bidimensionais foi apresentado em TELLES \& BREBBIA (1979). Nesse artigo, as equações integrais bidimensionais são escritas levando-se em conta campos iniciais de deformação plástica e a partir do problema tridimensional com uma restrição à dilatação do fluxo plástico, semelhante à técnica empregada em MUKHERJEE(1977). Para a diferenciação do termo plástico, foram utilizadas as técnicas de Mikhlin conforme apontado por Bui.

Neste mesmo ano, BANERJEE et al.(1979) apresentaram uma formulação direta do BEM envolvendo campos iniciais em tensão. Nesse trabalho, as deformações não são calculadas com o emprego da representação integral dos gradientes e, sim, a partir da diferenças finitas dos valores nodais dos deslocamentos. $\mathrm{Na}$ discretização do problema, são utilizadas funções interpoladoras lineares para as 
variáveis de contorno do problema. No algoritmo para a resolução do sistema de equação não-linear é utilizada a mesma estratégia empregada por ZIENKIEWICZ et al. (1969) no método dos elementos finitos. São utilizados dois modelos para o encruamento do material, dos quais o primeiro está associado à expansão estática da superfície de carregamento segundo as hipóteses do encruamento isótropo. O segundo modelo está associado a uma translação de corpo rígido da superfície de carregamento utilizando-se o modelo de ZIEGLER(1959), que é obtido a partir da introdução de algumas modificações no de PRAGER(1955). Os autores analisaram quatro exemplos, dos quais os três primeiros estão associados a um carregamento monotônico crescente. O primeiro consiste de um cilindro espesso pressurizado e regido por um modelo de plasticidade ideal. O segundo está associado à flexão de fundação apoiada em um semi-espaço elastoplástico, em que tanto a plasticidade perfeita quanto o encruamento positivo e negativo são modelados. $O$ terceiro exemplo está associado a um cubo imerso no semi-espaço. $\mathrm{O}$ último consiste em uma estaca lateralmente carregada sob um regime cíclico, considerando-se ora o problema fundamental de Kelvin, ora o de Mindlin.

No início da década de 1980, TELLES \& BREBBIA (1981a) implementaram as representações integrais, para o problema da elastoplasticidade bidimensional, escritas levando-se em conta campos iniciais de deformação plástica incompressível apresentadas no trabalho de 1979. Na discretização do problema foram utilizadas funções lineares tanto para os elementos de contorno quanto para as células. Para o cálculo das integrais de domínio foi utilizada uma técnica semianalítica, em que a ordem das singularidades dos kernels é reduzida de um grau. É admitido que o fluxo plástico seja regido pelo modelo de Von Mises, e a evolução da superfície de plastificação sob as hipóteses do encruamento isótropo por deformação. Dois exemplos numéricos são apresentados respectivamente para os estados planos de tensão e deformação. Ao assumir a incompressibilidade das deformações plásticas, a aplicação dessa formulação ficou restrita a casos em que o fluxo plástico é deviatórico. A análise de problemas submetidos a um regime de encruamento negativo também se tornou proibitiva devido à adoção de encruamento por deformação para o material.

TELLES.\& BREBBIA (1981b) apresentaram uma representação integral 
elastoplástica para problemas envolvendo semiplanos. Nas equações integrais, desses problemas para o regime elástico, são utilizados kernels para os deslocamentos e forças de superfície a partir de adaptações das soluções fundamentais de MELAN (1934) para tensões. Para a obtenção da representação integral das tensões, é utilizado o conceito de MIKHLIN(1965) para as diferenciações das integrais, obedecendo-se o contorno livre de forças de superfície do problema fundamental. O fluxo plástico é assumido como deviatórico, e a superfície de plastificação é regida pelo modelo de Von Mises; a estratégia adotada para a resolução do sistema algébrico quase-linear é a mesma utilizada por MENDELSON(1973), em que é empregada a formulação em deformações iniciais. Para o caso de campos iniciais em tensões, em que são utilizadas as superfície de plastificação de Mises, Tresca, Mohr-Coulomb e Drucker-Prager, a técnica de resolução do sistema algébrico é semelhante àquela apresentada por Zienkiewicz para o método dos elementos finitos. A discretização do problema é feita utilizandose funções de forma lineares tanto para os elementos de contorno quanto para as células, e são modelados dois exemplos, dos quais o primeiro envolve uma fundação longa e o segundo é associado a um túnel, cuja seção transversal é composta por arcos abatidos. Em VENTURINI(1982), é apresentada uma formulação para campos em que algumas não-linearidades físicas(elastoplasticidade e elasto/viscoplasticidade) são assumidas como campos inicias. Esse trabalho é voltado principalmente para problemas sob as hipóteses da formulação completa de problemas bidimensionais, constituída pelo estado plano de tensão, estado plano de deformação e o estado de deformação completo. Algumas análises numéricas são feitas para aplicações em problemas de túneis e atirantamento de encostas.

TELLES \& BREBBIA (1981c) discutem um procedimento para a discretização das representações integrais para o problema elastoplástico tridimensional. As células são divididas em tetraedros e, para o cálculo das integrais de domínio plásticas, é utilizada uma analogia da técnica semi-analítica bidimensional adaptada para os problemas tridimensionais, e funções interpoladoras constantes são utilizadas para todas as variáveis e termos de domínio. Os modelos para o material e o algoritmo de solução do problema são semelhantes ao aplicado no artigo de TELLES \& BREBBIA (1981b). Embora sejam descritos os processos de 
discretização, tratamento das integrais singulares e estratégia de resolução do sistema algébrico, nenhum exemplo numérico é apresentado.

Nesse mesmo ano, TANAKA \& TANAKA(1981) apresentaram uma estratégia para a solução do problema elastoplástico tridimensional sem procedimentos iterativos. A equação de equilíbrio do problema é transformada em um sistema de equações integrais no domínio e no contorno. Após a discretização do problema, além dos valores nodais das variáveis do contorno, os deslocamentos nodais das células também são utilizados como incógnitas na representação algébrica do problema. Por meio de manipulações algébricas nessa representação, um sistema é escrito de tal forma que as incógnitas do contorno e do domínio são reunidas em um único vetor, cuja solução é obtida utilizando-se um algoritmo incremental, que dispensa operações iterativas. Nesse artigo, nenhum exemplo numérico é apresentado.

Um ano depois, PALIZZOTO (1982) apresentou uma formulação em que o campo das tensões, para pontos de domínio, pode ser obtido diretamente das variáveis de contorno dispensando-se a utilização da representação integral de deslocamento. A representação integral para as tensões é obtida utilizando-se apenas o conceito, introduzido por Somigliana, de deformações concentradas aplicadas no problema fundamental. Os autores descreveram uma relação entre os kernels utilizados na formulação proposta e na técnica clássica, que utiliza força concentrada no problema fundamental. Contudo, nenhum exemplo numérico foi apresentado.

O MEC foi aplicado por POTR(1987) em problemas bidimensionais termoelastoplásticos, que envolvem campos iniciais de tensão e de temperatura desacoplados. Com o auxílio do teorema da reciprocidade, uma representação integral é escrita para um campo de tensão gerado por ações mecânicas e de temperatura. $\mathrm{Na}$ representação das tensões no contorno, são utilizados dois procedimentos: o primeiro consiste em equações integrais para uma parte de suas componentes; o segundo baseia-se na obtenção das demais componentes a partir dos valores nodais de deslocamentos. O algoritmo para a solução do sistema algébrico segue a mesma estratégia daquele apresentado por MENDELSON(1968). No trabalho de Potr, uma chapa é analisada, para um fluxo plástico gerado apenas por uma ação térmica, e a evolução das regiões plásticas é mapeada para determinadas 
temperaturas no intervalo de variação de $20^{\circ} \mathrm{C}$ a $500{ }^{\circ} \mathrm{C}$.

BANERJEE \& RAVEENDRA(1986a) formularam o problema elastoplástico bi e tridimensional utilizando uma discretização isoparamétrica quadrática e um algoritmo para acelerar a convergência da análise. $\mathrm{O}$ algoritmo de solução do sistema não-linear em tensões iniciais é alterado de modo que a curva das tensões reais, obtida no incremento de carga anterior, é usada para extrapolar as tensões plásticas no início do incremento corrente, antes das operações iterativas. Uma extensão desse trabalho foi apresentada em BANERJEE et al.(1986b) para incorporar carregamentos cíclicos. Dois modelos são utilizados para o encruamento do material: o primeiro assume uma expansão isótropa para a superfície de carregamento envolvendo o modelo de encruamento por deformação com a superfície de Von Mises; a segunda abordagem assume uma translação da superfície de carregamento envolvendo o modelo de duas superfícies descrito em MROZ(1967), que permite uma transição suave do comportamento elástico para o plástico. Já em BANERJEE \& RAVEENDRA(1987), foi apresentado um algoritmo incremental não-iterativo para o problema elastoplástico bidimensional a partir do trabalho de 1986(a) desses autores. Por meio de algumas manipulações das relações constitutivas elastoplásticas na representação algébrica do problema, as operações iterativas são eliminadas do procedimento utilizado na solução do sistema de equações final.

Em VENTURINI(1988), são discutidas formulações que permitem levar em conta comportamentos elastoplásticos e viscoplásticos - assumidos como campos iniciais em tensão - para alguns problemas bidimensionais, destacando-se abordagens alternativas para a modulação de juntas com ou sem a introdução de elementos especiais.

TANG \& KITCHING(1993) formularam uma abordagem direta para o problema elastoplástico utilizando variáveis complexas. As representações integrais diretas são escritas envolvendo campos iniciais em tensão; os kernels dos problemas são expressos em função de soluções fundamentais de potenciais complexos. Para os problemas analisados nesse artigo, essas soluções envolvem dois casos. O primeiro está associado a um plano infinito, em que as soluções dos potenciais complexos podem ser utilizadas para obter os kernels de Kelvin; o segundo está associado a um 
plano infinito com orifício circular, cujos kernels podem ser obtidos pela superposição das soluções dos potenciais complexos do plano infinito com as respectivas soluções de suas imagens ao longo do orifício. Um exemplo de uma chapa com um orifício é apresentado via estado plano de tensão, e os resultados são comparados tanto com outras formulações como com dados experimentais. Outro exemplo analisado envolve uma chapa infinita para o caso em que o carregamento é aplicado ao longo do contorno do orifício; para o material é admitida uma superfície de carregamento elastoplástica perfeita utilizando-se o modelo de Von Mises.

Algumas formulações para o problema elastoplástico foram direcionadas principalmente para a aumentar a eficiência do cálculo da integral do termo plástico. MATSUMOTO \& YUUKI(1986) empregaram expressões analíticas para as integrais de domínio plásticas para o problema bidimensional. $\mathrm{Na}$ representação integral dos deslocamentos, a integral de domínio associada à parte singular dos kernels foi escrita como um somatório de funções auxiliares. As expressões analíticas para essas funções são obtidas com o auxílio de um aplicativo matemático(software) para o cálculo das integrais, em que as singularidades dos integrandos primitivos foram decrescidas de um grau por intermédio da utilização de um sistema de referência triangular em coordenadas polares. $\mathrm{Na}$ representação integral das tensões, a integração sobre a parte singular da integral de domínio é obtida pela diferenciação das funções auxiliares combinadas com as relações constitutivas. Embora os valores das funções auxiliares sejam explicitamente mostrados no artigo, o mesmo não ocorre com os valores de suas derivadas. Dois exemplos são mostrados para problemas de cilindro espesso pressurizado. No primeiro exemplo, admitiu-se que o problema está submetido a um campo em deformações iniciais e que o carregamento externo é aplicado integralmente em um único incremento. $\mathrm{O}$ segundo exemplo foi analisado para casos em que a superfície de plastificação era perfeitamente plástica, e o carregamento externo foi aplicado em incrementos; a solução do sistema algébrico foi obtida utilizando-se um algoritmo incremental-iterativo.

HENRY \& BANERJEE (1988) apresentaram uma formulação em que a integral plástica de domínio é substituída por integrais particulares, que não requerem integração no domínio. A solução geral do problema é obtida utilizando-se 
a superposição da solução homogênea, que envolve apenas o problema elástico linear, e uma solução particular para o problema elastoplástico. A solução particular é assumida como uma força volumétrica na equação de Navier e escrita em termos das componentes do vetor de Galerkin. Em CISILINO et al.(1998), é apresentada uma formulação para alguns problemas elastoplásticos que envolvem campos iniciais em deformações. Os valores principais das integrais de domínio são calculados por meio de uma técnica apresentada por ALIABADI et al. (1985), em que são aplicadas expansões de Taylor sobre os kernels para o tratamento das singularidades. As tensões no contorno são determinadas a partir de diferenciações das funções de forma dos deslocamentos, e são utilizadas aproximações isoparamétricas para as variáveis de contorno. É apresentado um exemplo de cilindro espesso pressurizado, em que a plasticidade é admitida como ideal. Um outro exemplo é o de uma chapa com um orifício, utilizando-se o modelo isótropo com encruamento por deformação.

O problema elastoplástico bidimensional foi descrito em OCHIAI \& KOBAYASHI(1998) utilizando-se uma técnica do método da reciprocidade múltipla. Uma abordagem do problema elastoplástico bidimensional em tensões iniciais, com a eliminação da discretização do domínio, é obtida a partir da extensão da formulação proposta por OCHIAI \& SEKYIA(1995) para o problema bidimensional de condução de calor forçada. Nessa técnica, as distribuições arbitrárias da fonte interna de calor são interpoladas por equações integrais de contorno construídas a partir da aplicação da segunda identidade de Green e envolvendo funções poliarmônicas. Um cilindro espesso pressurizado é analisado para uma superfície de carregamento perfeitamente plástica e regida pelo modelo de Von Mises.

Alguns procedimentos de regularização foram aplicados aos problemas nãoelásticos. Em NING(1992), o problema elastoplástico é formulado a partir da extensão da representação integral regularizada elástica de GHOSH et al.(1986) para problemas com campos iniciais. Essa técnica conduz à obtenção das tensões no contorno diretamente das equações integrais que envolvem singularidades mais brandas. HUBER et al.(1996) implementaram uma representação integral regularizada das tensões. As tensões no contorno são obtidas a partir da técnica de 
regularização de integrais fortes e hipersingulares proposta por GUIGGIANI et al. (1992) combinada com a abordagem empregada em DALLNER \& KUHN(1993). $\mathrm{Na}$ discretização, é utilizada uma interpolação isoparamétrica quadrática. $\mathrm{Na}$ avaliação do desempenho da técnica, são apresentados dois exemplos: o primeiro para uma chapa tensionada com um orifício em seu centro; o segundo para um problema da mecânica da fratura.

Um outro tipo de problema que tem sido abordado por muitos pesquisadores está relacionado com a análise fisicamente não-linear de placas. MORJARIA \& MUKHERJEE(1980) apresentaram uma formulação semidireta, em que o deslocamento transversal em regime inelástico é dependente do tempo. A equação diferencial de placas, envolvendo as contribuições elásticas e as inelásticas, é transformada em duas equações integrais acopladas: a primeira está associada ao deslocamento transversal; a segunda está associada ao Laplaciano dos deslocamentos, que restringe a aplicação dessa formulação a problemas com condições de contorno particulares, principalmente aquelas em que as curvaturas no contorno são nulas. Na discretização do problema, são utilizadas funções de forma lineares para as variáveis do contorno e uma quadrática para os termos de domínio em cada célula triangular. O fluxo plástico é regido pelo modelo de HART(1976), em que se admite a dilatação como elástica.

Alguns pesquisadores apresentaram formulações diretas para o problema elastoplástico de placas. MOSHAIOV \& VORUS(1986a) estenderam o problema de flexão de placas de Stern para campos iniciais em momentos plásticos. Admite-se que o fluxo plástico é regido pelas hipóteses do modelo de Von Mises. $\mathrm{Na}$ discretização do problema, são utilizadas funções interpoladoras constantes e para a avaliação numérica da formulação são apresentados problemas com dois tipos de geometria: o primeiro envolve placas circulares engastadas, com o material regido pelos modelos de plasticidade perfeita e encruamento isótropo linear; o segundo está associado a uma placa quadrada engastada submetida a um carregamento distribuído monotonicamente crescente utilizando-se o modelo de encruamento isótropo.

Neste mesmo ano, MOSHAIOV \& VORUS(1986b) estenderam a formulação elastoplástica de placas do trabalho (1986a) para alguns problemas em que os efeitos térmicos introduzem perturbações nas hipóteses associadas à 
homogeneidade do modelo primitivo. No desenvolvimento da formulação, é admitido que a não-homogeneidade é introduzida apenas ao longo da direção da espessura, e a equação diferencial global do problema é transformada em equações de integrais de contorno utilizando-se convenientemente a identidade de RayleighGreen. Quatro anos depois, CHUEIRI(1994) apresentou uma formulação envolvendo momentos iniciais, em que a representação integral era composta de duas equações integrais em deslocamento. $\mathrm{Na}$ discretização, foram utilizadas funções quadráticas para os elementos de contorno, e interpolações lineares para as células. Para a representação da superfície de plastificação, foram admitidos os modelos de Mises e Tresca. Um modelo simplificado para o concreto armado, descrito em CORRÊA(1991), foi implementado na formulação. Na análise numérica, foi modelada uma placa simplesmente apoiada, em que o fluxo inelástico é regido por uma superfície perfeitamente plástica. Outra análise foi apresentada para uma placa de concreto armado e os resultados numéricos da formulação foram comparados com valores obtidos experimentalmente. FERNANDES(1998), incorporou na formulação de CHUIERI(1994) o modelo de MAZARS(1984) para a perda de rigidez devido à danificação do concreto. Já em BACARJI(2001), é proposta uma análise fisicamente não-linear para pavimentos de edifícios utilizando-se o MEC - a partir da incorporação de modelos constitutivos do concreto e do aço nas técnicas adotadas por RIBEIRO(1992) e SILVA(1996) para representar o problema de flexão sob as hipóteses de Reissner.

Já em SONG \& MUKHERJEE(1989), problemas elastoplásticos são analisados utilizando-se uma extensão do modelo de três equações integrais para problemas elásticos inicialmente proposto em DU et al. (1984). Alguns exemplos são apresentados, principalmente, envolvendo casos de placas quadradas com algumas configurações de vinculações tais como: simplesmente apoiada, engastada, apoidada/engastada.

A análise numérica de folhas em regime elastoplástico tem recebido uma tímida atenção dos pesquisadores, quando comparada com o intenso estudo de soluções numéricas para outros problemas da engenharia estrutural. Até mesmo em formulações envolvendo o MEF, o número de publicações para esses problemas não é grande. Tal fato também pode ser estendido à análise desses problemas pelo MEC. 
Em MUKHERJEE \& PODDAR (1989), é encontrada uma extensão da formulação elástica descrita no trabalho de 1986 (em que as equações integrais para problemas tridimensionais escritas no sistema cartesiano são transformadas em função de um sistema curvilinear especial associada à superfície média da casca) para problemas inelásticos e um exemplo é modelado envolvendo a análise elastoviscoplástica de um cilindro submetido a uma variação linear da pressão interna.

Neste presente trabalho, as técnicas empregadas nas formulações tetra e hexaparamétrica para o regime elástico são estendidas e aplicadas em problemas elastoplásticos com geometria composta por lâminas coplanares de espessuras constantes utilizando-se os modelos clássicos disponíveis na literatura. 


\section{FUNDAMENTOS DA TEORIA DA ELASTOSTÁTICA LINEAR}

\section{1) Introdução}

Neste capítulo, inicialmente, são apresentadas as relações básicas da teoria da elasticidade linear, em especial, envolvendo os problemas bidimensionais representados pelas lâminas isoladas. Finalizando o capítulo, são apresentados os problemas fundamentais elásticos tri e bidimensionais e suas respectivas soluções.

\section{2) Generalidades}

Um sistema estrutural pode ser composto por uma ou mais categoria de elementos estruturais. Tais categorias podem ser classificadas em três grupos, a saber:

Elementos lineares: quando uma das dimensões é bem maior que as demais.

Elementos de superfície: quando uma das dimensões é desprezível ao ser comparada às demais.

Elementos volumétricos ou tridimensionais: quando todas as dimensões têm a mesma ordem de grandeza.

Geometricamente, a lâmina é um elemento estrutural de superfície, que satisfaz a seguintes prescrições:

a) É limitada por duas superfícies planas, onde o plano eqüidistante entre elas é chamado plano médio.

b) A distância entre as superfícies simétricas ao plano médio, chamada de espessura, não necessariamente constante, é pequena quando comparada às demais dimensões, caracterizando-se um elemento de superfície.

A lâmina recebe a seguinte classificação em relação às propriedades do material constituinte, a saber:

Anisótropa: quando apresenta propriedades diferentes em qualquer direção.

Isótropa: quando apresenta as mesmas propriedades em qualquer direção.

Pode-se ainda, classificar a lâmina quanto às ações, a saber:

Chapa: a lâmina plana é solicitada segundo as direções do plano médio.

Placa: a lâmina plana é solicitada segundo transversalmente ao plano médio.

Alguns autores ainda classificam a placa, segundo a relação entre a espessura (h) e a dimensão do menor lado $(a)$, e sugerem os seguintes valores limites: 
Muito delgada: $\quad h / a \leq 0,01$.

Delgada: $\quad 0,01<h / a \leq 0,2$.

Espessa: $\quad h / a>0,2$.

A análise clássica do comportamento mecânico macroscópico de um corpo sólido submetido a configurações de ações de naturezas diversas, em geral, visa determinar o efeito dessas "perturbações" sob três aspectos, isto é: o campo dos deslocamentos, o campo das deformações e o campo das tensões. Segundo LOVE(1944) "Tem-se que distinguir dois estados de um corpo -o primeiro e o segundo. As partículas do corpo passam de suas posições iniciais no primeiro estado para posições finais no segundo estado através de um deslocamento.” Se qualquer distância entre as partículas sofrer alteração, isto é, implicar uma mudança da forma ao passar do primeiro para o segundo estado, diz-se que o corpo sofreu deformação. Essa mudança de forma do corpo mobiliza forças internas entre as partículas caracterizando-se o campo das tensões. Em geral, as equações para descrição do comportamento do problema podem ser classificadas em três categorias, a saber:

a)Condições de equilíbrio.

b)Relações deformação-deslocamento.

c)Reologia.

As equações terão de satisfazer as condições de equilíbrio uma vez que é desta forma que todas as forças admitidas presentes no problema estarão verificadas. O equacionamento do problema também é afetado pelas relações deformaçãodeslocamento uma vez que essas indicam a maneira em que as deformações são medidas a partir dos deslocamentos. A reologia ou lei constitutiva, ou ainda as relações tensão-deformação descrevem a evolução das tensões em função do estado de deformações presente no problema.

\section{3) Relações elementares da teoria da elasticidade}

Uma das abordagens macroscópicas empregadas para descrição do comportamento dos corpos sólidos é a teoria da elasticidade. 
Inicialmente, as hipóteses dessa teoria são aplicadas a corpos tridimensionais e em seguida, algumas simplificações adicionais são introduzidas nesse problema a fim de abordar os corpos bidimensionais.

\subsection{1) Problema tridimensional}

Seja um corpo tridimensional tendo associado a ele um sistema de referência cartesiano dextrógiro $\left(x_{1}, x_{2}, x_{3}\right)$ e as componentes de deslocamento $\left(u_{1}, u_{2}, u_{3}\right)$ conforme indicado na figura 2.1 .

Figura 2.1- Deslocamentos segundo as direções dos eixos cartesianos.

Definido o campo de deslocamentos, uma alternativa para o equacionamento das relações deformação-deslocamento é admiti-las sob as hipóteses do tensor de pequenas deformações conhecido como tensor de Cauchy, isto é:

$$
\varepsilon_{i j}=\frac{1}{2}\left(u_{i, j}+u_{j, i}\right) ; \quad i, j=1,2,3
$$

Conforme citado anteriormente, uma outra entidade empregada para a descrição do comportamento do sólido está associada às relações tensão-deformação. Um dos modelos para a reologia do material é fundamentado nas hipóteses da teoria da elasticidade linear, a saber:

a) Material homogêneo e contínuo.

b) Relação linear entre os campos das deformações e das tensões

c) Material ao ser solicitado, deforma-se; aliviado dessa ação, retorna à sua posição inicial antes da solicitação. 
$\mathrm{Na}$ figura 2.2, um estado de tensão é mostrado segundo um sistema de referência $\left(x_{1}, x_{2}, x_{3}\right)$ para um elemento infinitesimal.
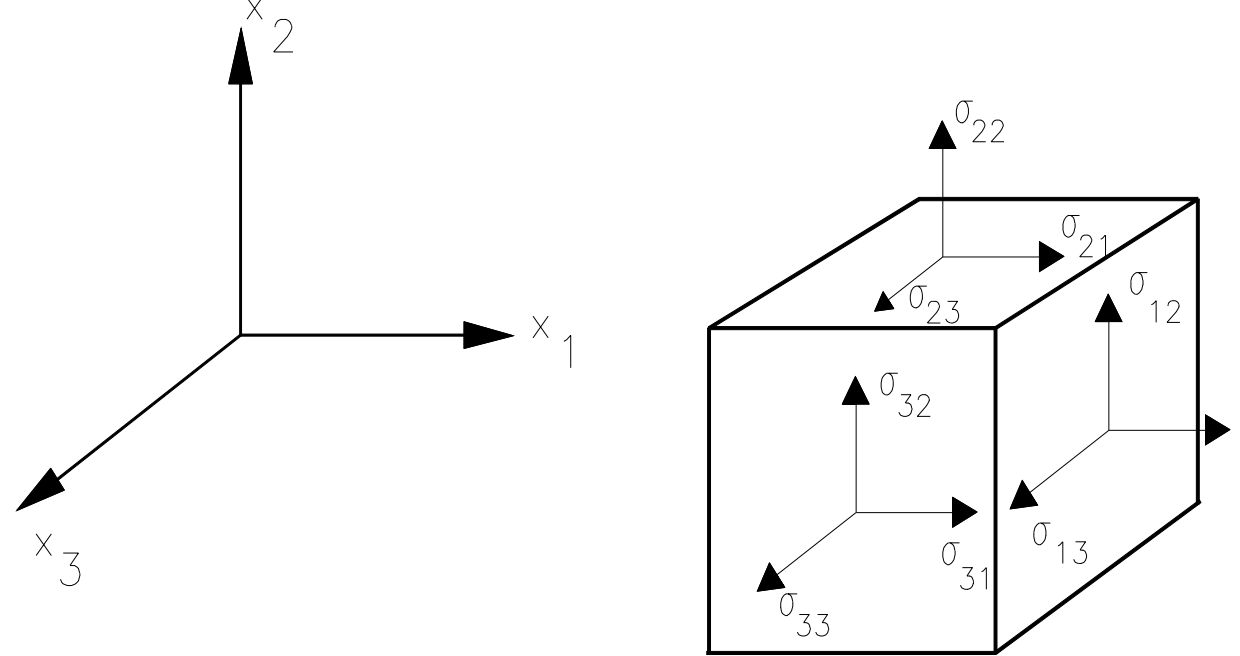

Figura 2.2-Estado de tensões em um elemento infinitesimal

O regime elástico linear, sob uma transformação isotérmica, é regido pela lei de Hooke, isto é:

$$
\sigma_{i j}=C_{i j m q} \varepsilon_{m q} ; \quad i, j, m, q=1,2
$$

onde o tensor $C_{i j m q}$ para casos de materiais elásticos e isótropos é dado por:

$$
C_{i j m q}=\frac{2 G v}{1-2 v} \delta_{i j} \delta_{m q}+G\left(\delta_{i m} \delta_{j q}+\delta_{i q} \delta_{j m}\right) ; \quad i, j, m, q=1,2
$$

em que $\sigma_{i j}, \varepsilon_{i j}$ e $\delta_{i j}$ são as componentes das tensões, das deformações e o delta de Krönecker, respectivamente. O módulo de elasticidade transversal G está relacionado com o módulo de elasticidade longitudinal E e com o coeficiente de Poisson $v$ pela seguinte expressão:

$$
G=\frac{E}{2(1+v)}
$$

Quando houver forças de volume que não produzam momentos distribuídos por unidade de volume ${ }^{1}$, a simetria do tensor das tensões pode ser obtida por meio

\footnotetext{
${ }^{1}$ Em REISSNER(1944), são discutidos alguns problemas que produzem momentos por unidade de volume
} 
das condições de equilíbrio dos momentos no elemento infinitesimal mostradas na figura 2.2, isto é:

$$
\sigma_{i j}=\sigma_{j i} ; \quad i, j=1,2,3
$$

Em um ponto na superfície do corpo, sujeito a um campo de tensões, uma relação entre as componentes de forças de superfície $\hat{p}_{i}$ e de tensões $\sigma_{i j}$ pode ser escrita a partir de equações conhecidas como fórmula de tensão de Cauchy, isto é:

$$
p_{i}=\sigma_{i j} n_{j} ; \quad i, j=1,2,3
$$

onde $\eta_{i}$ é o co-seno diretor da normal à superfície no ponto.

Impondo-se as condições de equilíbrio estático no elemento mostrado na figura 2.1, obtêm-se as equações de equilíbrio da elastostática dadas por:

$$
\sigma_{i j, j}+b_{i}=0 ; \quad i, j=1,2,3
$$

onde $b_{i}$ são as componentes das forças volumétricas segundo as três direções dos eixos cartesianos.

Levando-se as equações (2.1) e (2.2) na equação de equilíbrio(2.7), obtém-se a equação de Navier :

$$
\frac{1}{1-2 v} u_{i, i j}+u_{i, j j}+\frac{b_{i}}{G}=0 ; \quad i, j=1,2,3
$$

\subsection{2) Problema bidimensional}

A teoria da elastostática aplicada a problemas bidimensionais pode ser abordada a partir de restrições aplicadas nas hipóteses dos corpos tridimensionais. Uma das opções de abordagem é o Estado Plano de Deformação(EPD). A restrição característica para a obtenção desse tipo de análise é admitir ser nula a deformação atuante em uma mesma direção e sentido do eixo longitudinal do problema. Em geral, na literatura, é eleito o eixo $x_{3}$, com isso, tem-se que $\varepsilon_{33}=0$. Os problemas analisados segundo essa hipótese são representados por corpos onde uma das dimensões é muito superior às demais e submetidos a ações perpendiculares ao seu eixo longitudinal e constantes ao longo de seu comprimento. Os exemplos clássicos 
desses problemas são as barragens de usinas hidrelétricas, tubulações sob pressão, e outros. Substituindo-se a deformação nula $\varepsilon_{33}$ em (2.2), obtém-se uma equação similar a essa última, contudo a variação dos índices $(i, j, k)$ fica restrita aos valores 1 e 2. As equações de equilíbrio e as de Navier para o EPD podem ser escritas de uma forma análoga a (2.7) e (2.8), respectivamente. Necessitando-se apenas um ajuste no intervalo da variação dos índices, conforme comentado anteriormente.

Outra abordagem para a análise de corpos bidimensionais é o Estado Plano de Tensão (EPT). A restrição característica desse tipo de abordagem é admitir ser nula a tensão atuante na direção e sentido do eixo perpendicular ao plano médio, por exemplo, a direção $x_{3}$. Os problemas representados por esse tipo de hipótese são aqueles que possuem uma das dimensões muito menor que as demais. Os exemplos clássicos são os diversos tipos de estruturas de coberturas em membranas. Ao substituir $\sigma_{33}=0$ em (2.2), obtém-se uma relação tensão-deformação como:

$$
\sigma_{i j}=\bar{C}_{i j m q} \varepsilon_{m q} ; \quad i, j, m, q=1,2
$$

onde

$$
\bar{C}_{i j m q}=\frac{2 G v}{1-v} \delta_{i j} \delta_{m q}+G\left(\delta_{i m} \delta_{j q}+\delta_{i q} \delta_{j m}\right) ; \quad i, j, m, q=1,2
$$

Já que a introdução das hipóteses do EPT promoveu alterações na representação matemática da reologia problema, a equação de Navier também deve ser ajustada à novas condições, passando a ser escrita como:

$$
\frac{1}{1-v} u_{i, i j}+u_{i, j j}+\frac{b_{i}}{G}=0, \quad i, j=1,2
$$

\subsection{3) Teoria de chapas}

Conforme descrito na definição geométrica das lâminas, elas são delimitadas por duas superfícies planas, caracterizando-se, com isso, uma das dimensões do problema: a espessura. Sendo as chapas um subconjunto das lâminas planas, que têm 
carregamentos aplicados apenas na direção de seus planos médios, é necessário adaptar o equacionamento dos estados planos para incorporar uma dada espessura finita $t$.

As resultantes de tensão por unidade de comprimento da chapa podem ser escritas a partir do campo de tensões submetido ao corpo:

$$
N_{i j}=\int_{-t / 2}^{t / 2} \sigma_{i j} d x_{3} ; \quad i, j=1,2
$$

Admitindo-se que as tensões estão uniformemente distribuídas ao longo da espessura $t$, logo a equação (2.12) pode ser expressa mais simplesmente por:

$$
N_{i j}=t \sigma_{i j} ; \quad i, j=1,2
$$

Em um ponto na superfície do corpo, uma relação entre as forças de superfície e as resultantes de tensão pode ser estabelecida como:

$$
f_{i}=N_{i j} n_{j} ; \quad i, j=1,2
$$

As relações resultantes de tensão-deformação podem ser escritas substituindo-se as equações (2.3) ou (2.9) em (2.13), conforme o estado plano analisado. No entanto, ambos podem ser genericamente representados se for associado a cada estado plano um coeficiente de Poisson aparente $v_{p}$. Com isso, a equação (2.13) pode ser escrita a partir de (2.3), a saber:

$$
N_{i j}=t C_{i j m q} \varepsilon_{m q} ; \quad i, j, m, q=1,2
$$

onde $C_{i j m q}=\frac{2 G v_{p}}{1-2 v_{p}} \delta_{i j} \delta_{m q}+G\left(\delta_{i m} \delta_{j q}+\delta_{i q} \delta_{j m}\right)$; convém ressaltar que no caso de $E P D$ tem-se $v_{p}=v$ e para o EPT, o coeficiente de Poisson aparente vale $v_{p}=\frac{v}{1+v}$. A representação matemática do módulo de elasticidade transversal $G$ permanece invariante em ambos estados planos.

A equação de equilíbrio de chapas pode ser obtida impondo-se as condições de equilíbrio estático no elemento mostrado na figura 2.3, isto é: 


$$
N_{i j, j}+b_{i}=0 ; \quad i, j=1,2
$$

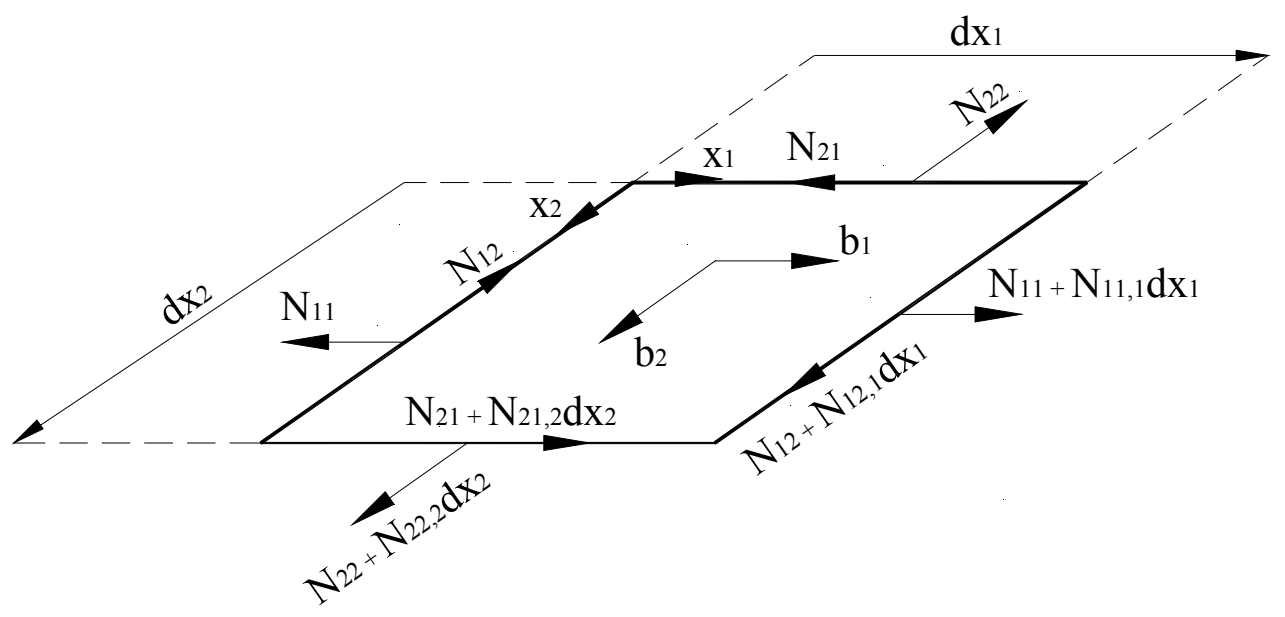

Figura 2.3- Resultantes de tensão em um elemento infinitesimal de chapa.

Se a equação (2.15) for levada na equação de equilíbrio (2.16), a equação de Navier para o problemas de chapas pode ser escrita:

$$
\frac{1}{1-2 v_{p}} u_{i, i j}+u_{i, j j}+\frac{b_{i}}{t G}=0, \quad i, j=1,2
$$

Na equação (2.17), há necessidade de correção do $v_{p}$ analogamente ao procedimento empregado em (2.15). Com isso, finaliza-se a análise do efeito de chapas das lâminas, restando ainda outro a ser abordado: o estado de flexão mobilizado pelas ações aplicadas perpendicularmente ao plano médio das lâminas planas, caracterizando-se com isso as categorias das placas.

\subsection{4)Teoria clássica de placas}

O problema das placas está inserido na categoria dos corpos bidimensionais limitados por duas superfícies planas, isto é, um subconjunto das lâminas. Difere das chapas principalmente pela direção de aplicação das ações, conforme descrito no item (2.2). Na literatura existem diversas teorias para abordar o comportamento das placas submetidas à flexão simples, uma das primeiras é a teoria clássica de placas. O desenvolvimento dessa teoria é descrito em KIRCHHOF(1850), e é baseada em algumas hipóteses, a saber: 
a) A placa é constituída de material elástico linear, homogêneo e isótropo.

b) Os deslocamentos transversais são pequenos em relação à espessura da placa, isto é, a deformação é descrita a partir das hipóteses de pequenos deslocamentos.

c) As tensões normais na direção transversal são desprezadas, assim como as tensões tangenciais nas faces da placa, isto é, a análise é tomada segundo o EPT.

d)Seções planas, inicialmente normais ao plano médio da placa, após a flexão, permanecem planas e perpendiculares ao plano médio deformado, ou seja, a teoria clássica despreza a influência da deformação devido à força cortante.

e) A superfície média é assumida rígida nas direções do plano que a contém.

A partir das hipóteses descritas anteriormente, as equações governantes da teoria de placas de Kirchhoff podem ser determinadas. As componentes de deslocamento de um ponto pertencente à placa são representadas por $u_{1}, u_{2}, u_{3}$ nas direções dos eixos cartesianos $x_{1}, x_{2}, x_{3}$, mostrados na figura 2.1. O deslocamento vertical do plano médio $u_{3}$ é representado por $w$. Os deslocamentos $u_{1}$ e $u_{2}$ podem ser obtidos por relações geométricas, figura 2.4, a partir das rotações do plano médio, uma vez que ele é admitido como indeformável.

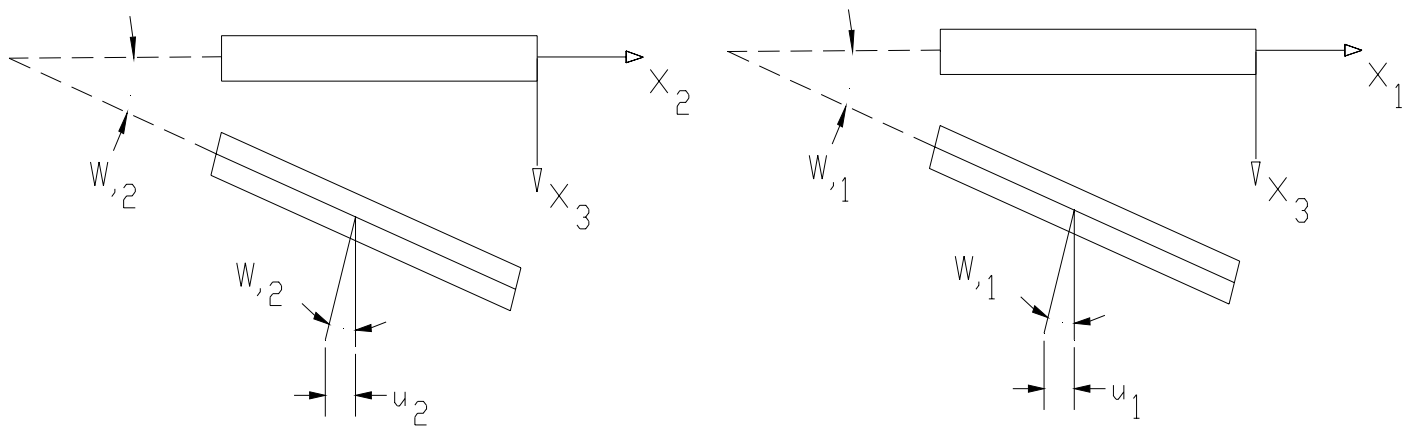

Figura 2.4- deslocamento vertical e rotações presentes na placa.

Indicialmente, tais relações geométricas dos deslocamentos podem ser apresentadas na forma, a saber: 


$$
u_{i}=-x_{3} w_{i} ; \quad i=1,2
$$

As deformações podem ser obtidas pela diferenciação de (2.18) e do tensor de Cauchy (2.1):

$$
\varepsilon_{i j}=\frac{1}{2}\left(u_{i, j}+u_{i, j}\right)=-x_{3} w_{i j} ; \quad i=1,2
$$

As hipóteses de inalterabilidade das seções planas nos estados iniciais e finais de flexão e das relações constitutivas elastolineares conduzem a uma distribuição linear das deformações ao longo da espessura. Com isso, as tensões ficam submetidas a mesma variação, conforme pode ser observado nas equações para o campo das tensões obtidas, levando a equação (2.19) na lei de Hooke para EPT (2.9), isto é:

$$
\sigma_{i j}=-x_{3} \frac{E}{1-v^{2}}\left[(1-v) w,_{i j}+v w{ }_{k k} \delta_{i j}\right] ; \quad i, j, k=1,2
$$

Os esforços, isto é, os momentos fletores, os momentos volventes e as forças cortantes são resultantes do campo das tensões atuantes ao longo de uma dada seção e podem ser representados, respectivamente, por:

$$
\begin{array}{ll}
m_{i j}=\int_{-t / 2}^{t / 2} \sigma_{i j} x_{3} d x_{3} ; & i, j=1,2 \\
q_{i}=\int_{-t / 2}^{t / 2} \sigma_{i 3} d x_{3} ; & i=1,2
\end{array}
$$

Outra alternativa para expressar os momentos é escrevê-los em função das curvaturas da placa a partir da substituição de (2.20) em (2.21), isto é:

$$
m_{i j}=K_{i j k l} w_{, k l} ; \quad i, j, k, l=1,2
$$

onde D é o módulo de rigidez à flexão e $K_{i j k l}$ é a componente do tensor momentocurvatura, cujos valores são dados por: 


$$
D=\frac{E t^{3}}{12\left(1-v^{2}\right)} ; \quad K_{i j k l}=-D\left[v \delta_{i j} \delta_{k l}+\frac{1-v}{2}\left(\delta_{i k} \delta_{j l}+\delta_{i l} \delta_{j k}\right)\right]
$$

As forças cortantes também podem ser escritas em função da derivada do laplaciano do deslocamento transversal da placa:

$$
q_{i}=-D w_{i k k} ; \quad i, k=1,2
$$

A imposição de equilíbrio dos esforços e ações atuantes no elemento infinitesimal de placa, mostrado na figura 2.6, permite escrever as seguintes relações:

$$
\begin{array}{cc}
q_{i, i}+g=0 ; & i=1,2 \\
m_{i j, j}-q_{i}=0 ; & i, j=1,2
\end{array}
$$

onde $g$ é o carregamento externo distribuído.

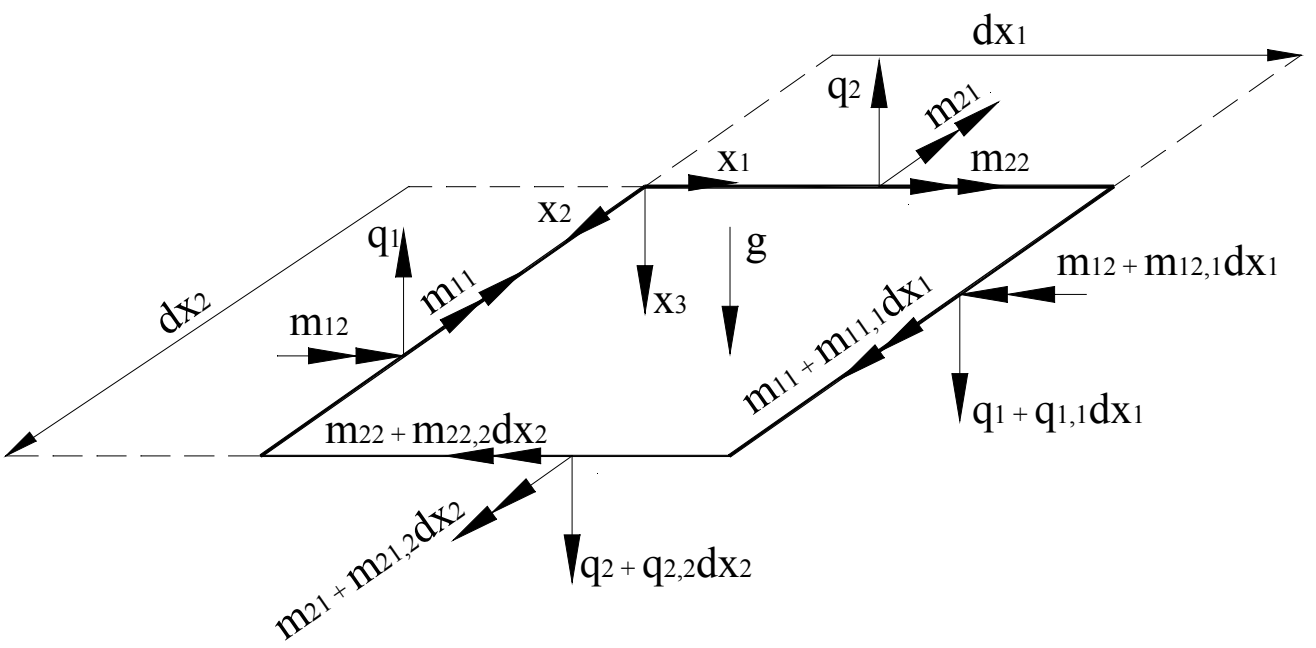

Figura 2.6- Esforços presentes em um elemento infinitesimal de placa.

Diferenciando-se (2.26) em relação a $i$, seguida da substituição em (2.25), obtém-se a equação diferencial de placas em função dos momentos, a saber:

$$
m_{i j, i j}+g=0 ; \quad i, j=1,2
$$

A equação diferencial de placas delgadas, em função do deslocamento transversal do plano médio- conhecida por equação de Lagrange, é obtida pela substituição de (2.23) em (2.28): 


$$
w_{i i j j}=\frac{g}{D} ; \quad i, j=1,2
$$

Nem sempre é vantajoso expressar as variáveis da placa no sistema global $\left(x_{1}, x_{2}\right)$. Um dos exemplos clássicos é a imposição das condições contorno em bordos inclinados em relação aos eixos globais. Uma alternativa mais eficaz é escrever as variáveis em relação a um sistema de coordenadas que contemple as direções normais e tangenciais a este bordo. Além disso, outro caso que pode ser citado é a presença de outras categorias de elementos estruturais conectados à placa, por exemplo, um pilar em um pavimento de edifício. Nem sempre os eixos desse elemento coincidem com o sistema global da placa, gerando, com isso, um trabalho adicional para promover o acoplamento de ambos. Assim, descrevem-se em seguida os procedimentos necessários para o ajuste das variáveis da placa em outros sistemas de referências distintos do inicial. Uma componente de tensão pode ser representada segundo as direções e sentidos de um sistema de coordenadas genérico a partir de um sistema de referência de coordenadas inicial. Seja tal componente tomada segundo a direção $m$ e sentido $p$ a partir do campo de tensões escrito em função do sistema $\left(x_{1}, x_{2}\right)$, então, a expressão para esta transformação pode ser escrita como:

$$
\sigma_{m p}=\sigma_{i j} m_{i} p_{j} ; \quad i, j=1,2
$$

onde $m_{i}, p_{i}$ são os co-senos diretores das direções $m$ e $p$ em relação ao sistema $x_{1}, x_{2}$.

Tomando-se as direções $(m, p)$ coincidentes com o sistema de coordenadas $(n, s)$ associadas ao contorno da placa, as tensões normais e tangenciais podem escritas a partir de (2.26) como:

$$
\begin{array}{ll}
\sigma_{n}=\sigma_{i j} n_{i} n_{j} ; & i, j=1,2 \\
\sigma_{n s}=\sigma_{i j} n_{i} s_{j} ; & i, j=1,2
\end{array}
$$

Uma transformação análoga à anterior pode ser aplicada aos momentos a partir de (2.21), (2.31) e (2.32), isto é: 


$$
\begin{array}{ll}
m_{n}=m_{i j} n_{i} n_{j} ; & i, j=1,2 \\
m_{n s}=m_{i j} n_{i} s_{j} ; & i, j=1,2
\end{array}
$$

A transformação das forças cortantes do sistema $\left(x_{1}, x_{2}\right)$ para o $(n, s)$ pode ser representado por:

$$
q_{n}=q_{i} n_{i} ; \quad i=1,2
$$

Faz-se necessário, para a resolução da equação diferencial de placas, a prescrição das condições de contorno. A solução para a equação diferencial de quarta ordem das placas requer que duas condições de contorno sejam satisfeitas em cada ponto do contorno da placa. Estas condições são escritas em relação ao sistema $(n, s)$ e podem ser uma combinação do deslocamento w, rotação normal $\theta_{p}$, força cortante $q_{n}$, momento fletor $m_{n}$ e momento volvente $m_{n s}$.

KIRCHHOFF(1850) mostrou que em placas cuja deformação por cortante é desprezada, as condições de contorno relativas aos esforços $q_{n} e m_{n s}$ podem ser agrupadas em uma única condição chamada de cortante equivalente, isto é:

$$
V_{n}=q_{n}+\frac{\partial m_{n s}}{\partial s}
$$

Com isso, as três condições de contorno para os esforços existentes em cada ponto do contorno analisado ficam reduzidas a apenas duas, possibilitando a resolução da equação diferencial de quarta ordem da teoria clássica.

\section{4) Representação de Papkovitch-Neuber}

Uma das dificuldades encontradas na análise de problemas elásticos está relacionada com a solução das equações diferenciais parciais (EDPs) governantes do problema. Examinando-se o caso da elastostática linear, uma interdependência entre as componentes de deslocamento pode ser verificada nas EDPs apresentadas em (2.8), e.g., as componentes de deslocamentos na direção $x_{l}$ : 


$$
u_{1,11}+u_{1,22}+u_{1,33}+\frac{1}{1-2 v}\left(u_{1,11}+u_{2,21}+u_{3,31}\right)=\frac{b_{1}}{G}
$$

Pode-se evidenciar que as EDPs (2.37) não só são dependentes das derivadas de $u_{1}$, mas também derivadas das componentes de deslocamentos nas demais direções, isto é, não existe apenas um único argumento caracterizando a variável das EDPs, conduzindo-se com isso a algumas complexidades para a obtenção da solução das equações diferenciais parciais do problema elástico.

GALERKIN(1930) apresentou uma técnica em que as componentes de tensão em um sólido elástico, isótropo, homogêneo são escritas em termos de derivadas parciais de funções $\varphi_{i}$ :

$$
\sigma_{i j}=(1-v)\left(\varphi_{i, j k k}+\varphi_{j, k k k}\right)-\varphi_{k, k i j}+v \varphi_{k, k m m} \delta_{i j} ; \quad i, \mathrm{j}, \mathrm{k}, \mathrm{m}=1,2,3
$$

Além disso, é admitido que as funções $\varphi_{i}$ satisfazem equações diferenciais de quarta ordem:

$$
\varphi_{i, k k m m}=C_{i} ; \quad i, k, m=1,2,3
$$

onde $C_{i}$ é uma constante arbitrária.

Ainda no desacoplamento das variáveis, tem-se os trabalhos de PAPKОVITCH(1932a, b) em que é verificado que os deslocamentos podem ser associados a algumas funções, que ao serem submetidas a operadores diferenciais pertencentes a uma mesma família das equações de Navier(2.8), podem desacoplar as variáveis dessas EDP, isto é:

$$
u_{i}=w_{i, k k}+\alpha w_{j, j i} ; \quad i, j, k=1,2,3
$$

Ao substituir-se (2.40) em (2.8), tem-se, então, a EDP equivalente à de Navier:

$$
\frac{1}{1-2 v}[1+2(1-v) \alpha] w_{j, j i k k}+w_{i, j j k k}+\frac{b_{i}}{G}=0 ; \quad i, j, k=1,2,3
$$

Um valor que pode ser atribuído à constante $\alpha$ e que reduz a equação (2.41) a um operador biarmônico é dado por: 


$$
\alpha=-\frac{1}{2(1-v)}
$$

Com isso, o desacoplamento das EDP é obtido, ficando apenas escrita em termo das derivadas da função $w$ na direção $i$, isto é:

$$
w_{i, k k m m}=-\frac{b_{i}}{G} ; \quad i, k, m=1,2,3
$$

Uma solução geral para (2.43) pode ser tomada como:

$$
w_{i}=w_{i}^{0}+t_{i}+z_{i} ; \quad i=1,2,3
$$

onde $w_{i}^{0}$ é uma solução particular de (2.43). O laplaciano de $t_{i}$ é dado por uma equação do tipo:

$$
t_{i, k k}=d_{i} ; \quad i, k=1,2,3
$$

onde $d_{i}, z_{i}$ são funções harmônicas, isto é, são regidas por:

$$
d_{i, k k}=0 ; \quad z_{i, k k}=0 ; \quad i, k=1,2,3
$$

A partir de (2.40) e (2.44), as componentes de deslocamento podem ser escritas como:

$$
u_{i}=u_{i}^{0}+d_{i}-\frac{1}{2(1-v)}\left[t_{j, j i}+z_{j, j i}\right] ; \quad i, j=1,2,3
$$

Com:

$$
u_{i}^{0}=w_{i, j j}^{0}-\frac{1}{2(1-v)} w_{j, j i}^{0} ; \quad i, j=1,2,3
$$

Admitindo-se ainda que uma função escalar $\psi$ é a divergência de $t_{i}$, isto é: $\psi=t_{i, i}$. Então, a partir de (2.45) e da propriedade harmônica de $d_{i}$ dada em (2.46), a seguinte identidade pode ser escrita:

$$
\psi_{, j j}=t_{i, i j j}=d_{i, i} ; \quad i, j=1,2,3
$$

Uma solução possível para (2.49) pode ser escrita como: 


$$
\psi=\frac{1}{2} x_{i} d_{i} ; \quad i=1,2,3
$$

Tem-se também que a divergência de $z_{i}$ pode ser escrita em termos de uma função harmônica $g$, isto é:

$$
z_{i, i}=\frac{1}{2} g ; \quad i=1,2,3
$$

Substituindo-se (2.50), (2.51) em (2.47), tem-se que:

$$
u_{i}=u_{i}^{0}+d_{i}-\frac{1}{4(1-v)}\left(\psi_{, i}+g_{, i}\right) ; \quad i=1,2,3
$$

As componentes de tensão podem ser obtidas a partir da substituição de (2.1), (2.2), (2.48) e (2.49) em (2.52), resultando em:

$$
\begin{gathered}
\sigma_{i j}=\frac{E}{1+v}\left\{\left[\frac{1}{2}\left(w_{i, j k k}^{0}+w_{j, k k k}^{0}\right)-\frac{1}{2(1-v)}\left(w_{k, k i j}^{0}-v w_{k, k m m}^{0} \delta_{i j}\right)\right]+\right. \\
\left.\left[\frac{1}{2}\left(d_{i, j k k}+d_{j, i k k}\right)-\frac{1}{4(1-v)}\left(t_{k, k i j}-v t_{k, k m m} \delta_{i j}\right)\right]\right\} ; \quad i, \mathrm{j}, \mathrm{k}, \mathrm{m}=1,2,3
\end{gathered}
$$

Papkovitch também apontou que as constantes arbitrárias $C_{i}$ indicadas (2.39), podem ser escritas como:

$$
C_{i}=-\frac{b_{i}}{G} ; \quad i=1,2,3
$$

Em NEUBER(1934), é investigado o caso de problemas elásticos livres de forças volumétricas em que as componentes de deslocamentos são escritas em termos de duas funções, a saber:

$$
2 G u_{i}=-F_{, i}+\beta \Theta_{i} ; \quad i=1,2,3
$$

onde $\Theta_{i}$ são funções harmônicas, $F$ é uma função escalar e $\beta$ uma constante arbitrária a ser determinada.

Aplicando-se o operador laplaciano em (2.55), obtém-se a identidade: 


$$
2 G u_{i, k k}=-F_{, i k k}+\beta \Theta_{i, k k} ; \quad i, k=1,2,3
$$

Lembrando-se que $\Theta_{i}$ é harmônica $\left(\Theta_{i, k k}=0\right)$ e que o corpo não está submetido a forças volumétricas $\left(b_{i}=0\right)$, a partir de (2.8) e (2.56) uma equação pode ser escrita como:

$$
\frac{\partial}{\partial x_{i}}\left(-F_{, k k}+\frac{1}{1-2 v} u_{k, k}\right)=0 ; \quad i, k=1,2,3
$$

Se a expressão diferenciada em (2.57) conduz a um valor nulo, então concluise que a mesma independe de $x_{i}$, i.e., é igual a uma constante:

$$
-F_{, k k}+\frac{1}{1-2 v} u_{k, k}=\xi ; \quad k=1,2,3
$$

Arbitrando-se $\xi=1$ e substituindo-se (2.58) na derivada de (2.55) em relação à direção $i$, logo, uma equação pode ser escrita como:

$$
2(1-v) F_{, k k}=\beta \Theta_{i, i} ; \quad i, k=1,2,3
$$

Tomando-se uma função $F$ escrita em termos de uma função harmônica $h$ e do produto interno entre as funções vetoriais $\boldsymbol{x}$ e $\Theta$.

$$
F=x_{i} \Theta_{i}+h ; \quad i=1,2,3
$$

Ao substituir-se (2.60) em (2.59), a constante $\beta$ é determinada, isto é, $\beta=4(1-v)$.

Aplicando-se o operador laplaciano em (2.59), e lembrando-se que $\Theta_{i}$ é harmônica, logo uma equação biarmônica, que representa o desacoplamento das componentes de deslocamento, pode ser escrita como:

$$
F_{, k k m m}=0 ; \quad k, m=1,2,3
$$

Em WESTERGAARD(1935), são investigadas as EDPs de Galerkin (2.38) para um espaço n-dimensional. Foi proposto nesse trabalho que as funções de desacoplamento podem ser interpretadas como componentes de um vetor então 
chamado de vetor de Galerkin L. As componentes de deslocamentos e desse vetor relacionam-se segundo:

$$
u_{i}=\frac{1}{2 G}\left\{\frac{2[1-(n-2) v]}{1-(n-3) v} L_{i, k k}-L_{k, k i}\right\} ; \begin{array}{cc}
\text { se } n=2 ; & i, k=1,2 \\
\text { se } n=3 ; & i, k=1,2,3
\end{array}
$$

onde $n$ é a dimensão do problema. No caso bidimensional, o estado em questão é o EPT.

Em MINDLIN (1936, b), as funções $w_{i}$ passaram a ser chamadas de componentes do vetor de Papkovitch. Uma relação entre as componentes dos vetores de Papkovitch e de Galerkin foi então escrita, o que pode ser verificado comparandose (2.40) e (2.62), isto é:

$$
w_{i}=\frac{1-v}{G} L_{i} ; \quad i=1,2,3
$$

Nos capítulos subseqüentes serão discutidas algumas representações integrais e suas respectivas discretizações para a modelagem de estruturas poliédricas. Essas equações integrais podem ser escritas de tal forma que dois tipos de problemas distintos ficam correlacionados: O primeiro é o próprio problema real, e o segundo é um virtual, que sob algumas condições ad hoc, é denominado problema fundamental. Na seqüência, serão expostos alguns problemas fundamentais associados à elastostática tri e bidimensional(chapas e placas de Kirchhoff).

\section{5)Problemas elásticos fundamentais}

Os problemas elásticos fundamentais caracterizam-se por atender duas condições básicas: a primeira está associada a EDP de equilíbrio. A segunda condição está vinculada ao campo de tensões mobilizado em um ponto de interesse devido à aplicação de uma fonte em outro ponto do corpo. As EDPs de equilíbrio dos problemas elastolineares submetidos a pequenas deformações são representadas pelas equações de Navier (2.8). Quanto ao campo de tensões mobilizado, deve satisfazer duas condições:

a)Quando a distância entre ponto de aplicação da fonte e aquele onde é observado o seu efeito tender ao infinito, as tensões nesse ponto devem tender a zero. 
b)As tensões devem ser infinitas quando houver coincidência dos pontos de aplicação e observação.

\subsubsection{Problema de Kelvin tridimensional}

\subsubsection{1) Deslocamentos via vetor de Papkovitch}

O problema de Kelvin tridimensional pode ser representado como um corpo esférico elastolinear de raio infinito envolvendo o ponto de aplicação da fonte. Para caracterizar esse problema como fundamental, as condições básicas mostradas na seção 2.5 deverão necessariamente ser satisfeitas. As equações governantes de equilíbrio - para uma fonte $b_{i j}(p, s)$ aplicada em um ponto $p$, denominado de pontofonte, segundo uma direção $i$, e com seu efeito observado em um ponto $s$, denominado de ponto-campo, segundo uma direção $j$ - podem ser escritas a partir de (2.8) como:

$$
u_{i j, k k}(p, s)+\frac{1}{1-2 v} u_{i k, k j}(p, s)+\frac{1}{G} b_{i j}(p, s)=0 ; \quad i, j, k=1,2,
$$

Conforme descrito na seção 2.4, há uma interdependência de variáveis nas famílias de EDP a que (2.64) pertence; logo, é mister utilizar uma técnica de desacoplamento. Assim, as componentes de deslocamentos em termos das componentes do vetor de Papkovitch podem ser escritas a partir de (2.52):

$$
u_{i j}=d_{i j}-\frac{1}{4(1-v)}\left[\frac{\partial}{x_{j}}\left(x_{j} d_{i j}+g\right)\right] ; \quad i, \mathrm{j}=1,2,3
$$

onde $d_{i j}$ são funções vetoriais harmônicas de Papkovitch.

Um passo importante agora é a escolha de uma função para $d_{i j}$ e outra para $g$ que atendam individualmente às equações de Laplace e que satisfaçam, a partir de (2.65), as condições do campo de tensões para o problema fundamental, conforme descrito na seção 2.5. Arbitrando-se $g=0$, uma função simples que verifica todas as condições citadas anteriormente é dada por:

$$
d_{i j}=\frac{\delta_{i j}}{r} ; \quad i, j=1,2,3
$$


onde $r$ é a distância entre os pontos campo e fonte.

Substituindo-se (2.66) em (2.65), uma outra representação para as componentes de deslocamentos pode ser escrita como:

$$
u_{i j}=\frac{1}{r}\left[(1-\kappa) \delta_{i j}+\kappa r_{, i} r_{, j}\right] ; \quad i, j=1,2,3
$$

onde $\kappa=-1 / 4(1-v) ; r_{, m}=\left[x_{m}(s)-x_{m}(p)\right] / r$.

Se for aplicado no interior de uma esfera representativa do problema uma carga concentrada de intensidade $P$, segundo uma direção $i$ e com seu efeito observado na direção $j, \quad b_{i j}=P \delta(p, s) \delta_{i j}$, pode-se calcular as resultantes mobilizadas no corpo a partir das condições de equilíbrio. Tal procedimento pode ser explicitado pela integração da equação de Navier (2.64) sobre o domínio $\Omega_{\varepsilon}$ da esfera. Assim, tem-se:

$$
\int_{\Omega_{\varepsilon}}\left[u_{i j, k k}(p, s)+\frac{1}{1-2 v} u_{i k, k j}(p, s)\right] d \Omega_{\varepsilon}=\int_{\Omega_{\varepsilon}} \frac{-P}{G} \delta(p, s) \delta_{i j} d \Omega_{\varepsilon} ; i, j, k=1,2,3
$$

Utilizando-se as propriedades da distribuição de Dirac $\delta(p, s)$, a equação (2.68) passa a ser escrita como:

$$
\int_{\Omega_{\varepsilon}}\left[u_{i j, k k}(p, s)+\frac{1}{1-2 v} u_{i k, k j}(p, s)\right] d \Omega_{\varepsilon}=-\frac{P}{G} \delta_{i j} ; \quad i, j, k=1,2,3
$$

Lembrando-se que o teorema da divergência para um campo vetorial $\chi$ é dado por:

$$
\int_{\Omega_{\varepsilon}} \operatorname{div} \chi d \Omega_{\varepsilon}=\int_{\Gamma_{\varepsilon}}(\chi \circ n) d \Gamma_{\varepsilon}
$$

onde $\Gamma_{\varepsilon}$ e $\mathrm{n}$ são o contorno e a normal a ele; o símbolo (o) indica produto escalar.

O teorema do gradiente é um corolário de (2.70) e pode ser escrito como:

$$
\int_{\Omega_{\varepsilon}} \nabla \chi d \Omega_{\varepsilon}=\int_{\Gamma_{\varepsilon}}(n \otimes \chi) d \Gamma_{\varepsilon}
$$

onde o símbolo $(\otimes)$ denota produto tensorial. 
As relações (2.70) e (2.71) podem ser expressas alternativamente em função das componentes, respectivamente, por:

$$
\begin{gathered}
\int_{\Omega_{\varepsilon}} \chi_{i, i} d \Omega_{\varepsilon}=\int_{\Gamma_{\varepsilon}} \chi_{i} n_{i} d \Gamma_{\varepsilon} \\
\int_{\Omega_{\varepsilon}}(\nabla \chi)_{i} d \Omega_{\varepsilon}=\int_{\Gamma_{\varepsilon}} n_{i} \chi d \Gamma_{\varepsilon}
\end{gathered}
$$

Aplicando-se as relações (2.73) e (2.72) em (2.69), tem-se uma expressão envolvendo apenas integrais sobre o contorno da esfera:

$$
\int_{\Gamma_{\varepsilon}}\left[\frac{1}{1-2 v} u_{i k, k}(p, s) n_{j}(s)+u_{i j, k}(p, s) n_{k}(s)\right] d \Gamma_{\varepsilon}=-\frac{P}{G} \delta_{i j} ; \quad i, j, k=1,2,3
$$

Fazendo-se as devidas derivadas das componentes de deslocamentos requeridas em (2.74), essas podem ser expressas como:

$$
\begin{gathered}
u_{i j, k}=\frac{1}{r^{2}}\left[-(1-\kappa) \delta_{i j} r_{, k}+k\left(\delta_{i k} r_{, j}+\delta_{j k} r_{, i}-3 r_{, i} r_{, j} r_{, k}\right)\right] ; \quad i, j, k=1,2,3 \\
u_{i k, k}=-\frac{(1-2 \kappa)}{r^{2}} r_{, i} ; \quad i, \mathrm{k}=1,2,3
\end{gathered}
$$

$\mathrm{Na}$ esfera pode ser observada uma coincidência entre as direções do raio vetor e da normal à superfície de contorno:

$$
r_{, i}=n_{i} ; \quad i=1,2,3
$$

Substituindo-se (2.77), (2.76) e (2.75) em (2.74), tem-se que:

$$
\int_{\Gamma_{\varepsilon}}\left\{-\frac{(1-2 \kappa)}{1-2 v} \frac{1}{r^{2}} r_{, i} r_{, j}-\frac{1}{r^{2}}\left[(1-\kappa) \delta_{i j}+r_{, i} r_{, j}\right]\right\} d \Gamma_{\varepsilon}=-\frac{P}{G} \delta_{i j} ; \quad i, j, k=1,2,3
$$

Escrevendo-se (2.78) em coordenadas esféricas $(\varepsilon, \theta, \phi)$ e sabendo-se que a relação de transformação entre os diferenciais é dada por $d \Gamma_{\varepsilon}=\varepsilon^{2} d \theta d \phi$, essa integral para a superfície da esfera de raio $\varepsilon$ pode ser escrita como: 


$$
\int_{0}^{2 \pi} \int_{0}^{\pi}\left\{-\frac{(1-2 \kappa)}{1-2 v} \frac{1}{\varepsilon^{2}} r_{, i} r_{, j}-\frac{1}{\varepsilon^{2}}\left[(1-\kappa) \delta_{i j}+r_{, i} r_{, j}\right]\right\} \mathcal{E}^{2} d \theta d \phi_{\varepsilon}=-\frac{P}{G} \delta_{i j} ; i, j, k=1,2,3
$$

onde o co-seno diretor $\quad r_{, i}$ em coordenadas esféricas é dado por $r_{, 1}=\operatorname{sen} \theta \cos \phi ; r_{, 2}=\operatorname{sen} \theta \operatorname{sen} \phi ; r_{, 3}=\cos \theta$.

Fazendo-se a integração indicada em (2.79) para as três direções envolvidas e lembrando-se que $\kappa=-1 / 4(1-v)$, uma identidade pode ser escrita como:

$$
4 \pi=\frac{P}{G}
$$

Se por ventura o equilíbrio fosse verificado para um carga concentrada unitária aplicada no lugar de $P$, bastaria simplificar a equação (2.68) pelo valor dado por $P=4 \pi G$ :

$$
u_{i j}^{*}=\frac{1}{4 \pi G r}\left[(1-\kappa) \delta_{i j}+\kappa r_{, i} r_{, j}\right] ; \quad i, j=1,2,3
$$

Ao substituir-se o valor de $\kappa$ utilizado em (2.67), obtém-se o kernel de deslocamento usualmente mencionado na literatura:

$$
u_{i j}^{*}=\frac{1}{16 \pi G(1-v) r}\left[(3-4 v) \delta_{i j}+r_{, i} r_{, j}\right] ; \quad i, j=1,2,3
$$

\subsubsection{2) Deslocamentos via transformadas de Fourier}

Uma outra técnica que pode ser aplicada à resolução da EDP de Navier (2.64) é a transformada integral de Fourier $\hat{g}[f(r)]$ para a função $f(r)$-que tende a um valor nulo quando $r \rightarrow \infty$ ou $r \rightarrow-\infty$ - é escrita como:

$$
\hat{g}[f(r)]=F(\varsigma)=\int_{-\infty-\infty}^{\infty} \int_{-\infty}^{\infty} \int^{\infty} f(r) e^{-2 \pi i r_{j} \varsigma_{j}} d r_{1} d r_{2} d r_{3} ; \quad j=1,2,3
$$

onde $\varsigma$ é o domínio transformado de $r ; i$ é o número imaginário igual a $\sqrt{-1}$.

Se a função $f(r)=\delta(p, s)$, a transformada de Fourier é dada por: 


$$
\hat{g}[\delta(p, s)]=F(\varsigma)=\int_{-\infty-\infty}^{\infty} \int_{-\infty}^{\infty} \int_{\infty}^{\infty} \delta(p, s) e^{-2 \pi i r_{j} \varsigma_{j}} d r_{1} d r_{2} d r_{3}=1 ; \quad j=1,2,3
$$

Além disso, a transformada da derivada de $f(r)$ em uma direção genérica $k$ pode ser obtida pela integração por partes de (2.84), de forma que pode ser expressa como:

$$
\hat{g}\left[\frac{\partial}{\partial x_{k}} f(r)\right]=\int_{-\infty-\infty}^{\infty} \int_{-\infty}^{\infty} \int_{0}^{\infty} \frac{\partial}{\partial x_{k}}[f(r)] e^{-2 \pi i r_{j} \varsigma_{j}} d r_{1} d r_{2} d r_{3}=i \varsigma_{k} F(\varsigma) ; \quad j=1,2, .
$$

Desde que as derivadas de ordens inferiores da função $f(r)$ atendam a condição de existência da transformada de Fourier, as derivadas de ordens superiores podem ser obtidas empregando-se recursivamente a estratégia de integrações por partes:

$$
\int_{-\infty-\infty-\infty}^{\infty} \int_{0}^{\infty}\left(\frac{\partial}{\partial x_{k}} \frac{\partial}{\partial x_{l}} \cdots \frac{\partial}{\partial x_{n}}\right)[f(r)] e^{-2 \pi i r_{j} \varsigma_{j}} d r_{l} d r_{2} d r_{3}=(-2 \pi i)^{p} \varsigma_{k} \varsigma_{l} \cdots \varsigma_{n} F(\varsigma) ; j=1,2,3
$$

onde $p$ é a ordem da maior diferenciação.

Tomando-se as componentes do deslocamento fundamental $u_{i j}^{*}$ como $f(r)$, o campo transformado para seu laplaciano e seu div grad pode ser escrito a partir de (2.86), respectivamente, como:

$$
\begin{gathered}
\Delta u_{i j}^{*}=u_{i j, k k}^{*}(r)=-4 \pi^{2} \varsigma_{k} \varsigma_{k} U_{i j}^{*}(\varsigma)=-4 \pi^{2} \varsigma^{2} U_{i j}^{*}(\varsigma) ; \quad i, j, k=1,2,3 \\
\operatorname{div} \operatorname{grad}\left(u_{i k}^{*}\right)=u_{i k, k j}^{*}(r)=-4 \pi^{2} \varsigma_{j} \varsigma_{k} U_{i k}^{*}(\varsigma) ; i, j, k=1,2,3
\end{gathered}
$$

Substituindo-se (2.87), (2.88) e (2.84) em (2.64), e ainda sabendo-se que $b_{i j}=\delta(p, s) \delta_{i j}$, a equação de Navier pode ser escrita no espaço transformado como:

$$
\varsigma^{2} U_{i j}^{*}(\varsigma)+\frac{1}{1-2 v} \varsigma_{j} \varsigma_{k} U_{i k}^{*}(\varsigma)-\frac{\delta_{i j}}{4 \pi^{2} G}=0 ; \quad i, j, k=1,2,3
$$

Multiplicando-se a $\operatorname{EDP}(2.89)$ pela componente $\varsigma_{j}$ do espaço transformado, uma relação pode ser reescrita como: 


$$
\varsigma_{k} U_{i k}^{*}(\varsigma)=\frac{(1-2 v) \varsigma_{i}}{8 \pi^{2}(1-v) G \varsigma^{2}} ; \quad i, k=1,2,3
$$

Levando-se (2.90) em (2.89), tem-se o deslocamento fundamental escrito no espaço transformado, isto é:

$$
U_{i j}^{*}(\varsigma)=\frac{1}{4 \pi^{2} G}\left[\frac{\delta_{i j}}{\varsigma^{2}}-\frac{\varsigma_{i} \varsigma_{j}}{2(1-v) \varsigma^{4}}\right] ; \quad i, j=1,2,3
$$

A solução da EDP de Navier (2.91) no espaço transformado não é suficiente para representar os campos físicos da elasticidade no sistema real primitivo, de forma que há necessidade de fazer-se o retorno do espaço transformado para o primitivo. Essa operação é feita por meio da transformada inversa de Fourier, $\hat{g}^{-1}[F(\varsigma)]$, que pode ser escrita para problemas tridimensionais como:

$$
\hat{g}^{-1}[F(\varsigma)]=f(r)=\frac{1}{(2 \pi)^{3}} \int_{-\infty-\infty}^{\infty} \int_{-\infty}^{\infty} \int_{\infty}^{\infty} F(\varsigma) e^{i r_{j} \varsigma_{j}} d \varsigma_{1} d \varsigma_{2} d \varsigma_{3} ; \quad j=1,2,3
$$

Assim, para a obtenção do kernel dos deslocamentos no espaço primitivo é resolver a integral formada da substituição de (2.91) em (2.92):

$$
u_{i j}^{*}(p, s)=\frac{1}{4 \pi^{2} G}\left\{\hat{g}^{-1}\left[\frac{1}{\varsigma^{2}}\right]-\frac{1}{2(1-v)} \hat{g}^{-1}\left[\frac{\varsigma_{i} \varsigma_{j}}{\varsigma^{4}}\right]\right\} ; i, j=1,2,3
$$

Se essa integração for efetuada diretamente no sistema de coordenada esférica, chegar-se-á a uma integral imprópria, cuja solução não é trivial. Assim - em FOLLAND(1992), CHEN \& ZHOU(1992), etc.- estão descritas algumas técnicas tais como as identidades de Bessel-Parseval, funções Gama, que são empregadas no integrando de (2.91) em (2.92). Por meio das técnicas citadas nos trabalhos anteriores, a transformada de Fourier de $f(r)=\frac{1}{r^{n}}$ para um espaço tridimensional pode ser escrita como:

$$
\hat{g}\left[\frac{1}{r^{n}}\right]=F(\varsigma)=\alpha \varsigma^{n-3} ; \quad i, j=1,2,3
$$

Com 


$$
\alpha=\pi^{n-\frac{3}{2}} \frac{\Gamma\left[\frac{1}{2}(3-n)\right]}{\Gamma\left(\frac{1}{2} n\right)} ; \quad i, j=1,2,3
$$

onde a função gama é definida como $\Gamma(z)=\int_{0}^{\infty} t^{z-1} e^{-t} d t$. Se ao argumento $z$ for acrescido um valor $p$ tem-se que: $\Gamma(z+p)=z(z+1) \cdots(z+p-1) \Gamma(z)$; para $z=1$, $\Gamma(1+p)=1.2 \cdots p \Gamma(1)=p ! ; z=\frac{1}{2}, \Gamma\left(\frac{1}{2}+p\right)=\frac{1}{2} \cdot \frac{3}{2} \cdots\left(p-\frac{1}{2}\right) \sqrt{\pi}$.

Utilizando-se a propriedade $f(r)=\hat{g}^{-1} F(\varsigma)$ e tomando-se $f(r)=\frac{1}{\alpha r^{n}}$ temse $\hat{g}^{-1}\left[\frac{1}{\varsigma^{-n+3}}\right]$ dada a partir de (2.94) por:

$$
\hat{g}^{-1}\left[\frac{1}{\varsigma^{-n+3}}\right]=\frac{r^{-n}}{\alpha} ; \quad i, j=1,2,3
$$

Em (2.93), uma das transformadas de interesse é dada por (2.94) e (2.95) com $n=1$, isto é:

$$
\hat{g}^{-1}\left[\frac{1}{\varsigma^{2}}\right]=\frac{\pi}{r} ; \quad i, j=1,2,3
$$

Já a transformada inversa da segunda parcela em $(2.93), \hat{g}^{-1}\left[\frac{\varsigma_{i} \varsigma_{k}}{\varsigma^{4}}\right]$, pode ser obtida pela propriedades da diferenciação $\hat{g}^{-1}\left[\frac{\partial}{\partial x_{i}} \frac{\partial}{\partial x_{k}} F(\varsigma)\right]=-4 \pi^{2} \varsigma_{i} \varsigma_{k} \hat{g}^{-1}[F(\varsigma)]$ onde $F(\varsigma)$ é obtida atribuindo-se $n=-1$ em (2.95) e (2.96). Assim, vem que:

$$
\hat{g}^{-1}\left[\frac{\varsigma_{i} \varsigma_{j}}{\varsigma^{4}}\right]=\frac{\partial^{2}}{\partial x_{i} \partial x_{j}}\left(-2 \pi^{3} r\right)=\frac{\partial}{\partial x_{i}}\left(-2 \pi r_{, j}\right)=\frac{-2 \pi^{3}}{r}\left(\delta_{i j}-r_{, i} r_{, j}\right) ; i, j=1,2,3
$$

Substituindo-se (2.98), (2.97) em (2.93), tem-se as componentes do kernel dos deslocamentos tal qual expresso em(2.82). 


\subsubsection{3) Tensões, deformações e forças de superfície}

O campo das deformações pode ser obtido a partir de (2.1) e (2.82):

$$
\varepsilon_{i j k}^{*}=-\frac{1}{16 \pi(1-v) r^{2} G}\left[(1-2 v)\left(\delta_{i k} r_{, j}+\delta_{j k} r_{, i}\right)-\delta_{i j} r_{, k}+3 r_{, i} r_{, j} r_{, k}\right] ; i, j, k=1,2,3
$$

Outro campo de interesse para completar a análise do corpo é o das tensões, que pode ser obtido a partir da lei de Hooke (2.2) e (2.99):

$$
\sigma_{i j k}^{*}=-\frac{1}{8 \pi(1-v) r^{2}}\left[(1-2 v)\left(\delta_{i k} r_{, j}+\delta_{j k} r_{, i}-\delta_{i j} r_{, k}\right)+3 r_{, i} r_{, j} r_{, k}\right] ; i, j, k=1,2,3
$$

Além da caracterização dos campos no domínio do corpo, forças de superfície podem ser determinadas pela fórmula de tensão de Cauchy (2.6) em (2.100):

$$
p_{i j}^{*}=-\frac{1}{8 \pi(1-v) r^{2}}\left\{r_{, n}\left[(1-2 v) \delta_{i j}+3 r_{, i} r_{, j}\right]+(1-2 v)\left(n_{j} r_{, i}-n_{i} r_{, j}\right)\right\} ; i, j, k=1,2,3
$$

\subsubsection{Problema de Kelvin bidimensional}

\subsubsection{1) Deslocamentos via vetor de Papkovitch}

O problema de Kelvin para o caso bidimensional pode ser associado a um disco de espessura $t$ e com raio infinito envolvendo o ponto de aplicação da fonte. Para que esse problema seja configurado como fundamental ele deve satisfazer as condições básicas discutidas na seção 2.5.2.

Embora a representação de Papkovich (2.65) tenha sido originalmente desenvolvida para contemplar os problemas tridimensionais, ela pode ser aplicada aos bidimensionais utilizando-se o conceito de coeficiente de Poisson aparente discutido na seção 2.2.3. Assim as componentes de deslocamentos podem ser expressas por:

$$
u_{i j}=d_{i j}-\kappa\left[\frac{\partial}{x_{j}}\left(x_{j} d_{i j}+g\right)\right] ; \quad i, \mathrm{j}=1,2
$$

onde $\kappa$ para o problema bidimensional é dada pela expressão:

$$
\kappa=-1 / 4\left(1-v_{p}\right)
$$

$\operatorname{com} v_{p}$ denotando o coeficiente de Poisson aparente dado em (2.15). 
Uma função vetorial harmônica candidata para representar os deslocamentos, que atende as condições fundamentais para as tensões quando diferenciada, pode ser escrita como:

$$
d_{i j}=(\ln r) \delta_{i j} ; \quad i, j=1,2
$$

Além disso, se for arbitrado $g=0$, e substituindo-se (2.104) em (2.102), tem-se:

$$
u_{i j}=(1-\kappa) \ln r \delta_{i j}-k r_{, i} r,{ }_{j} ; \quad i, j=1,2
$$

Substituindo-se (2.105) na equação de Navier bidimensional (2.17), tem-se que:

$$
\frac{1}{1-2 v_{p}} u_{i k, k j}+u_{i j, k k}+\frac{b_{i j}}{t G}=0, \quad i, \mathrm{j}, \mathrm{k}=1,2
$$

Aplicando-se no interior do disco uma carga concentrada $b_{i k}=P \delta(p, s) \delta_{i j}$, conforme discutido na seção 2.5.2, o equilíbrio em termos das resultantes deve ser verificado. Com isso, uma identidade pode ser escrita:

$$
\int_{\Omega_{\varepsilon}}\left[u_{i j, k k}(p, s)+\frac{1}{1-2 v_{p}} u_{i k, k j}(p, s)\right] d \Omega_{\varepsilon}=\int_{\Omega_{\varepsilon}} \frac{-P}{t G} \delta(p, s) \delta_{i j} d \Omega_{\varepsilon} ; i, j, k=1,2
$$

Utilizando-se as propriedades do delta de Dirac, os teoremas da divergência e do gradiente, a equação (2.107) pode ser expressa no contorno do disco como:

$$
\int_{\Gamma_{\varepsilon}}\left[\frac{1}{1-2 v_{p}} u_{i k, k}(p, s) n_{j}(s)+u_{i j, k}(p, s) n_{k}(s)\right] d \Gamma_{\varepsilon}=-\frac{P}{t G} \delta_{i j} ; \quad i, j, k=1,2
$$

As derivadas e o divergente das componentes de deslocamento presentes em (2.108) podem ser expressos, respectivamente, por

$$
u_{i j, k}=\frac{1}{r}\left[(1-\kappa) \delta_{i j} r_{, k}-\kappa\left(\delta_{i k} r_{, j}+\delta_{j k} r_{, i}-2 r_{, i} r_{, j} r_{, k}\right)\right] ; \quad i, j, k=1,2
$$




$$
u_{i k, k}=\frac{(1-2 \kappa)}{r} r_{, i} ; \quad i, \mathrm{k}=1,2
$$

Como as direções do raio vetor e da normal são coincidentes, então:

$$
r_{, i}=n_{i} ; \quad i=1,2
$$

Substituindo-se (2.109), (2.110) e (2.111) em (2.108), uma expressão pode ser expressa por:

$$
\int_{\Gamma_{\varepsilon}}\left[\frac{(1-2 \kappa)}{1-2 v_{p}} \frac{1}{r} r_{, i} r_{, j}+\frac{(1-\kappa)}{r} \delta_{i j}\right] d \Gamma_{\varepsilon}=-\frac{P}{t G} \delta_{i j} ; \quad i, \mathrm{j}=1,2
$$

Escrevendo-se (2.105) em coordenadas polares $(\varepsilon, \theta)$ e sabendo-se que a relação de transformação entre os diferenciais é dada por $d \Gamma_{\varepsilon}=\varepsilon d \theta$, essa integral para o contorno do disco de raio $\varepsilon$ pode ser escrita como:

$$
\int_{0}^{2 \pi}\left[\frac{(1-2 \kappa)}{1-2 v_{p}} \frac{1}{\varepsilon} r_{, i} r_{, j}+\frac{(1-\kappa)}{\varepsilon} \delta_{i j}\right] \varepsilon d \theta=-\frac{P}{t G} \delta_{i j} ; \quad i, j=1,2
$$

onde os co-senos diretores $r_{, i}$ em coordenadas esféricas são dados por $r_{, 1}=\cos \theta ; r_{, 2}=\operatorname{sen} \theta$.

Efetuando-se o cálculo da integral presente em (2.113), tem-se que:

$$
2 \pi=-\frac{P}{t G}
$$

Se o corpo for submetido a uma carga concentrada unitária, logo, a equação (2.107) deve reduzida por um fator igual ao inverso $P$ :

$$
u_{i j}^{*}=-\frac{1}{2 \pi G t}\left[(1-\kappa) \ln r \delta_{i j}+k r_{, i} r,{ }_{j}\right] ; \quad i, j=1,2
$$

Substituindo-se o valor da constante $k(2.103)$ em (2.115) tem-se:

$$
u_{i j}^{*}=-\frac{1}{8 \pi\left(1-v_{p}\right) G t}\left[\left(3-4 v_{p}\right) \ln r \delta_{i j}+r_{, i} r_{j}\right] ; \quad i, j=1,2
$$




\subsubsection{2) Deslocamentos via transformadas de Fourier.}

Para os problemas bidimensionais podem ser aplicadas estratégias similares às dos tridimensionais. Assim, a EDP de Navier no espaço transformado pode ser obtida a partir de (2.106), (2.84) e (2.85), isto é:

$$
\varsigma^{2} U_{i j}^{*}(\varsigma)+\frac{1}{1-2 \nu_{p}} \varsigma_{j} \varsigma_{k} U_{i k}^{*}(\varsigma)-\frac{\delta_{i j}}{4 \pi^{2} G t}=0 ; \quad i, j, k=1,2
$$

Se (2.117) for multiplicada pela componente $\varsigma_{j}$ do espaço transformado, a $\operatorname{EDP}(2.117)$ pode ser reescrita como:

$$
\varsigma_{k} U_{i k}^{*}(\varsigma)=\frac{(1-2 v) \varsigma_{i}}{8 \pi^{2}(1-v) G t \varsigma^{2}} ; \quad i, k=1,2
$$

Se (2.118) for levada em (2.117), tem-se as componentes do kernel dos deslocamentos no espaço transformado:

$$
U_{i j}^{*}(\varsigma)=\frac{1}{4 \pi^{2} G t}\left[\frac{\delta_{i j}}{\varsigma^{2}}-\frac{\varsigma_{i} \varsigma_{j}}{2\left(1-v_{p}\right) \varsigma^{4}}\right] ; \quad i, \mathrm{j}=1,2
$$

Tal qual no problema tridimensional, nos problemas planos há necessidade de calcular as transformadas inversas de Fourier das parcelas de (2.119) para se obter as componentes do kernel no espaço real primitivo. Em CHEN \& ZHOU(1992), relações análogas a (2.94) para o problema bidimensional podem ser escritas como:

$$
\hat{g}[\ln r+1]=F(\varsigma)=\beta \varsigma^{-2}
$$

onde

$$
\beta=\frac{1}{2}
$$

e

$$
\begin{gathered}
\hat{g}\left[r^{2} \ln r\right]=F(\varsigma)=\beta_{1} \varsigma^{-4} \\
\beta_{1}=\frac{1}{2 \pi^{2}}
\end{gathered}
$$


Ao fazer-se as transformadas inversas em (2.120) e (2.122), tem-se que:

$$
\begin{gathered}
\hat{g}^{-1}\left[\varsigma^{-2}\right]=\frac{\ln r}{\beta} \\
\hat{g}^{-1}\left[\varsigma^{-4}\right]=2 \pi^{2} r^{2} \ln r
\end{gathered}
$$

Para o cálculo da transformada inversa da segunda parcela em (2.119) podese utilizar a propriedade da derivada $\hat{g}^{-1}\left[\frac{\partial}{\partial x_{i}} \frac{\partial}{\partial x_{k}} F(\varsigma)\right]=-4 \pi^{2} \varsigma_{i} \varsigma_{k} \hat{g}^{-1}[F(\varsigma)]$, isto é:

$$
\hat{g}^{-1}\left[\frac{\varsigma^{-4} \varsigma_{i} \varsigma_{j} 4 \pi^{2} i^{2}}{-4 \pi^{2}}\right]=-\frac{1}{4 \pi^{2}} \frac{\partial}{\partial x_{i}} \frac{\partial}{\partial x_{j}}\left(r^{2} \ln r\right)=-\frac{1}{2 \pi^{2}}\left[\left(\ln r+\frac{1}{2}\right) \delta_{i j}-r_{, i} r_{, j}\right] ; i, j=1,2
$$

Substituindo-se (2.126), (2.125) em (2.119), tem-se as componentes dos kernels de deslocamentos expressos no campo real primitivo e dadas pela expressão (2.116).

\subsubsection{3) Tensões, deformações e forças de superfície.}

Além dos deslocamentos, uma expressão para seus gradientes pode ser escrita a partir da diferenciação de (2.116):

$$
u_{i j k}^{*}(p, s)=\frac{\partial}{\partial x_{k}(p)} u_{i j}^{*}=\frac{1}{8 \pi\left(1-v_{p}\right) G t r}\left[\left(3-4 v_{p}\right) \delta_{i k} r_{, j}-\delta_{i j} r_{, k}-\delta_{j k} r_{, i}+2 r_{, i} r_{, j} r_{, k}\right] ; i, j, k=1,2
$$

Já o campo das deformações pode ser obtido a partir das relações do tensor de Cauchy (2.1) e (2.127):

$$
\varepsilon_{i j k}^{*}=-\frac{1}{8 \pi\left(1-v_{p}\right) G t r}\left[\left(1-2 v_{p}\right)\left(\delta_{i k} r_{, j}+\delta_{j k} r_{, i}\right)-\delta_{i j} r_{, k}+2 r_{, i} r_{, j} r_{, k}\right]
$$

Para finalizar o problema fundamental de Kelvin para os estados planos, o campo das tensões pode ser obtido a partir da lei de Hooke (2.15) e (2.128), de forma que uma expressão pode ser escrita como: 


$$
N_{i j k}^{*}=t C_{i j m h} \varepsilon_{m h}^{*}=-\frac{1}{4 \pi\left(1-v_{p}\right) r}\left[\left(1-2 v_{p}\right)\left(\delta_{i k} r_{, j}+\delta_{j k} r_{, i}-\delta_{i j} r_{, k}\right)+2 r_{, i} r_{, j} r_{, k}\right]
$$

$$
i, j, m, h, k=1,2
$$

Além da caracterização dos campos no domínio do corpo, forças de superfície podem ser determinadas pela fórmula de tensão de Cauchy (2.14) em (2.129):

$$
\begin{gathered}
f_{i j}^{*}=N_{i k j}^{*} n_{k}=-\frac{1}{4 \pi\left(1-v_{p}\right) r}\left\{\left(1-2 v_{p}\right)\left(n_{j} r_{, i}-n_{i} r_{, j}\right)+r_{, m} n_{m}\left[\left(1-2 v_{p}\right) \delta_{i j}+2 r_{, i} r_{, j}\right]\right. \\
i, j, k, m=1,2
\end{gathered}
$$

\section{6) Problema fundamental de placas delgadas}

\subsection{1) Deslocamentos via solução direta}

O problema fundamental do regime de flexão pode ser associado a uma placa circular de raio infinito cujo ponto-fonte está colocado em seu centro e cuja EDP pode ser escrita a partir de (2.29):

$$
w_{, i i j j}^{*}=\frac{\delta(p, s)}{D} ; \quad i, j=1,2
$$

Utilizando-se as propriedades do delta de Dirac $\delta(p, s)$, para pontos-fonte e campos distintos, (2.131) torna-se uma EDP biarmônica:

$$
w_{, i i j j}^{*}=0 ; \quad i, j=1,2
$$

Assim, para facilitar as manipulações matemáticas da EDP (2.132), pode-se escrevê-la segundo o sistema polar de coordenadas. Dentre as relações clássicas entre operadores escritos no sistema de coordenadas retangulares e polares, tem-se que o laplaciano dado por:

$$
\nabla^{2}=\frac{d^{2}}{d r^{2}}+\frac{1}{r} \frac{d}{d r}
$$

A partir de (2.133) e (2.132), a EDP biarmônica pode ser reescrita em coordenadas polares como: 


$$
\nabla^{2} \nabla^{2}\left(w^{*}\right)=\left[\frac{d^{4}}{d r^{4}}+\frac{2}{r} \frac{d^{3}}{d r^{3}}-\frac{1}{r^{2}} \frac{d^{2}}{d r^{2}}+\frac{1}{r^{3}} \frac{d}{d r}\right]\left(w^{*}\right)=0
$$

Uma família de soluções analíticas diretas para (2.134) pode ser escrita genericamente como:

$$
w^{*}=\frac{C_{1}}{4} r^{2} \ln r+\frac{r^{2}}{8}\left(C_{2}-C_{1}\right)+C_{3} \ln r+C_{4}
$$

onde $C_{1}, C_{2}, C_{3}$ e $C_{4}$ são constantes.

A partir da condição de simetria, a rotação no ponto sob o carregamento aplicado deve ser nula, i. e., $\left.\frac{d w^{*}}{d r}\right|_{r=0}=0 . \quad \mathrm{O}$ coeficiente $C_{3}$ deve ser, obrigatoriamente, igualado a zero; caso contrário, a rotação em $r=0$ é conduzida a um valor infinito.

Para a determinação do coeficiente $C_{1}$, é utilizada a condição de equilíbrio das forças verticais atuantes em um círculo auxiliar de raio $r$, cujo centro é o ponto de aplicação da carga unitária(vide figura 2.7) o que conduz a seguinte relação:

$$
2 \pi V_{n} r-1=0
$$

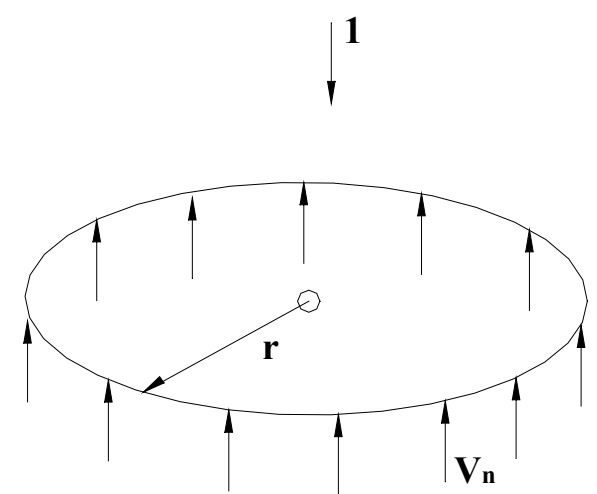

Figura 2.7- Equilíbrio no círculo auxiliar.

A força equivalente de Kirchhoff no contorno do círculo auxiliar pode ser escrita a partir de (2.24), (2.34) e (2.133), isto é: 


$$
V_{n}=-D r_{, i} n_{i}\left\{\frac{d}{d r}\left[\frac{d^{2}}{d r^{2}}+\frac{1}{r} \frac{d}{d r}\right]\right\}\left(w^{*}\right)
$$

Substituindo-se (2.136), (2.137) em (2.134), o valor do coeficiente $C_{1}$ pode ser escrito como:

$$
C_{1}=\frac{1}{2 \pi D}
$$

Assim, substituindo-se (2.137) em (2.134), tem-se o kernel dos deslocamentos:

$$
w^{*}=\frac{1}{8 \pi D} r^{2} \ln r+\frac{r^{2}}{8}\left(C_{2}-\frac{1}{2 \pi D}\right)+C 4
$$

onde $C_{1}, C_{2}$ são constantes oriundas da integração indefinida da equação diferencial fundamental. A esses coeficientes podem ser atribuídos valores arbitrários, porém STERN(1979) e BEZINI(1978) adotam $C_{1}=\frac{1}{4 \pi D}$ e $C_{2}=0$. Com isso, o deslocamento transversal fundamental (2.139) pode ser escrito como:

$$
w^{*}=\frac{1}{8 \pi D} r^{2} \ln r
$$

Alternativamente, DANSON(1979) apresentou os seguintes valores às constantes $C_{1}=0$ e $C_{2}=0$, de forma que o kernel (2.140) também pode ser apresentado como:

$$
w^{*}=\frac{1}{8 \pi D} r^{2}\left(\ln r-\frac{1}{2}\right)
$$

Convém notar que tanto (2.140) como (2.141) pertencem à família de soluções fundamentais para os deslocamentos transversais de placas de Kirchhoff. Assim, ambas podem ser utilizadas na implementação da teoria clássica de placas via MEC. 


\subsection{2) Deslocamentos via transformada de Fourier}

A derivada de ordem quatro de um função $f(r)$, que atende às condições das transformadas, pode ser dada a partir de (2.86), isto é:

$$
\int_{-\infty}^{\infty} \int_{-\infty}^{\infty}\left(\frac{\partial}{\partial x_{k}} \frac{\partial}{\partial x_{l}} \frac{\partial}{\partial x_{m}} \frac{\partial}{\partial x_{n}}\right)[f(r)] e^{-2 \pi i r_{j} \varsigma_{j}} d r_{l} d r_{2}=(-2 \pi i)^{4} \varsigma_{k} \varsigma_{l} \varsigma_{m} \varsigma_{n} F(\varsigma) ; j, l, m, n=1,2
$$

Se (2.142) for substituída em (2.131), a EDP de placas no espaço transformado pode ser escrita como:

$$
W(\varsigma)=\frac{1}{16 \pi^{4} \varsigma^{4} D}
$$

Utilizando-se a transformada inversa (2.125) em (2.143), tem-se o kernel dos deslocamentos transversais no campo real primitivo expresso tal qual em (2.140).

\subsection{3) Derivadas dos deslocamentos, esforços}

Além dos deslocamentos transversais, existem outros campos do problema que podem ter condições de contorno associadas à teoria clássica de placas. Assim, na seqüência são apresentados esses campos para o problema fundamental.

O kernel da rotação normal $\theta_{p}^{*}$ pode ser escrito a partir da diferenciação de (2.140), isto é:

$$
\theta_{p}^{*}=w_{, i}^{*} n_{i}=\frac{\partial}{\partial x_{i}(s)}\left\{w^{*}(p, s)\right\} n_{i}=\frac{r_{i} n_{i}}{4 \pi D} r \ln r ; i=1,2
$$

Os kernels dos momentos podem ser obtidos a partir da diferenciação dupla em (2.140) e da lei constitutiva de placa(2.23), isto é:

$$
\begin{aligned}
& m_{n}^{*}=K_{i j k l} w_{k l}^{*} n_{i} n_{j}=K_{i j k} n_{i} n_{j} \frac{\partial^{2}}{\partial x_{k}(s) \partial x_{l}(s)}\left\{w^{*}\right\}=-\frac{1}{4 \pi}\left[(1+v) \ln r+(1-v)\left(n_{i} r_{, i}\right)^{2}+v\right] ; \\
& m_{n s}^{*}=K_{i j k l} w_{, k l}^{*} n_{i} t_{j}=K_{i j k l} n_{i} t_{j} \frac{\partial^{2}}{\partial x_{k}(s) \partial x_{l}(s)}\left\{w^{*}\right\}=-\frac{1-v}{4 \pi}\left(t_{i} r_{, i}\right)\left(n_{j} r_{, j}\right) ; i, j, k, l=1,2
\end{aligned}
$$

Já o kernel da cortante pode ser obtido a partir da diferenciação do laplaciano de (2.140) e da relação (2.25): 


$$
q_{n}^{*}=-D w_{, i k}^{*} n_{k}=\frac{\partial^{3}}{\partial x_{i}(s) \partial x_{i}(s) \partial x_{k}(s)}\left\{w^{*}\right\}=-\frac{r_{, k} n_{k}}{2 \pi r} ; i, k=1,2
$$

O kernel da força equivalente de Kirchhoff pode ser escrito a partir da forca cortante(2.146) e da derivada direcional tangencial do momento volvente (2.146):

$$
V_{n}^{*}=q_{n}^{*}+\frac{\partial m_{n s}^{*}}{\partial x_{i}(s)} t_{i}=-\frac{n_{j} r_{, j}}{4 \pi r}\left[2(1-v)\left(t_{i} r_{, i}\right)^{2}-3+v\right]+\frac{1-v}{2 \pi R}\left(t_{i} r_{, i}\right)\left(n_{j} r_{, j}\right) ; i, j=1,2
$$

onde $1 / R$ é a curvatura do contorno; $t_{i}, n_{i}$ são os co-senos diretores das direções tangencial e normal no contorno; $r_{, i}$ é o co-seno diretor da direção do raio vetor $\vec{r}$. 


\section{REPRESENTAÇÕES INTEGRAIS PARA PROBLEMAS ELASTOSTÁTICOS PLANOS}

\section{1) Introdução}

No capítulo anterior, foram descritas tanto as relações básicas da teoria da elasticidade bidimensional e da teoria clássica de placas como algumas soluções usuais para seus respectivos problemas fundamentais.

Neste capítulo, as equações diferenciais parciais de equilíbrio dos estados planos e do regime de flexão são transformadas em representações integrais mediante a aplicação de algumas estratégias, dentre as quais, constam a Técnica do Resíduo Ponderado(TRP) e o Teorema da Reciprocidade de Betti(TRB).

Assim, com intuito de descrever a aplicação de ambas estratégias, neste trabalho optou-se por empregar a TRP para o regime de flexão e o TRB para os problemas planos de tensão ou de deformação.

\section{2)Equações integrais de contorno de chapas}

\subsection{1)Pontos no domínio}

As representações integrais para os estados planos podem ser obtidas por meio da aplicação direta do TRB nos campos tensoriais dos problemas real e fundamental:

$$
\int_{\Omega} N_{i k}(S) \varepsilon_{i j k}^{*}(p, S) d \Omega=\int_{\Omega} \varepsilon_{i k}(S) N_{i j k}^{*}(p, S) d \Omega ; \quad i, j, k=1,2
$$

onde os kernels $\varepsilon_{i j k}^{*}$ e $N_{i j k}^{*}$ estão expressos em (2.128) e (2.129).

Tomando-se ainda as identidades $N_{i j} \varepsilon_{i j k}^{*}=N_{i j} u_{i j, k}^{*}, \quad u_{i, j} N_{i j k}^{*}=\varepsilon_{i j} N_{i j k}^{*} \quad \mathrm{e}$ substituindo-as em (3.1), pode-se escrever a seguinte equação:

$$
\int_{\Omega} N_{i j}(S) u_{i j, k}^{*}(p, S) d \Omega=\int_{\Omega} u_{i, j}(S) N_{i j k}^{*}(p, S) d \Omega ; \quad i, j, k=1,2
$$

onde o kernel $u_{i j, k}^{*}$ está indicado em (2.127).

Ao integrar-se por partes (3.2), tem-se a seguinte relação: 


$$
\begin{gathered}
\oint_{\Gamma} N_{i k}(s) n_{k} u_{i j}^{*}(p, s) d \Gamma-\int_{\Omega} N_{i k, k}(S) u_{i j}^{*}(p, s) d \Omega=\oint_{\Gamma} u_{i}(s) N_{i j k}^{*}(p, s) n_{k} d \Gamma+ \\
-\int_{\Omega} N_{i j k, k}^{*}(p, S) u_{i}(S) d \Omega ; \quad i, j, k=1,2
\end{gathered}
$$

Além disso, a EDP de equilíbrio do problema fundamental, que está submetido a um carregamento concentrado unitário $\delta(p, s) \delta_{i j}$, pode ser escrita como:

$$
N_{i j k, k}^{*}+\delta(p, s) \delta_{i k}=0 ; \quad i, j, k=1,2
$$

Substituindo-se as relações de Cauchy (2.14), a EDP de equilíbrio do problema real (2.16), e aquela do problema fundamental (3.4) em (3.3), tem-se outra representação integral que pode ser escrita como:

$$
\begin{gathered}
\oint_{\Gamma} f_{j}(s) u_{i j}^{*}(p, s) d \Gamma-\int_{\Omega} b_{j}(S) u_{i j}^{*}(p, s) d \Omega=\oint_{\Gamma} u_{j}(s) f_{i j}^{*}(p, s) d \Gamma+ \\
-\int_{\Omega} u_{i}(S) \delta(p, s) \delta_{i j} d \Omega ; i, j=1,2
\end{gathered}
$$

Sabendo-se que as propriedades da distribuição de Dirac são dadas por :

$$
\int_{\Omega} \delta(p, S) \delta_{i j} u_{j}(S) d \Omega=\delta_{i j} u_{i}(p)=u_{i}(p) ; \quad i, j=1,2
$$

e com a substituição de (3.6) em (3.5), tem-se a identidade de Somigliana para problemas elásticos bidimensionais, isto é:

$$
u_{i}(p)+\oint_{\Gamma} f_{i j}^{*}(p, s) u_{j}(s) d \Gamma=\oint_{\Gamma} u_{i j}^{*}(p, s) f_{j}(s) d \Gamma+\int_{\Omega} u_{i j}^{*}(p, S) b_{j}(S) d \Omega ; i, j=1,2
$$

onde $f_{i j}^{*}$ e $u_{i j}^{*}$ representam os kernels relativos às forças de superfície e aos deslocamentos que estão expressos respectivamente em (2.130) e (2.116).

Outra equação integral a ser escrita é dos gradientes de deslocamentos, que pode ser obtida a partir da diferenciação da representação integral dos deslocamentos(3.7):

$$
u_{i, j}(p)+\oint_{\Gamma} f_{i j k}^{*}(p, s) u_{k}(s) d \Gamma=\oint_{\Gamma} u_{i j k}^{*}(p, s) f_{k}(s) d \Gamma+\int_{\Omega} u_{i j k}^{*}(p, S) b_{k}(S) d \Omega ; i, j=1,2
$$


onde $f_{i j k}^{*}$ e $u_{i j k}^{*}$ são os kernels relativos às derivadas das forças de superfície e deslocamentos e podem ser expressos por:

$$
\begin{aligned}
& f_{i j k}^{*}(p, s)=\frac{\partial}{\partial x_{k}(p)} p_{i j}^{*}=\frac{1}{4 \pi(1-v) r^{2}}\left\{(1-2 v)\left[\delta_{i k} n_{j}+\delta_{j k} n_{i}-\delta_{i j} n_{k}-2 r_{, j}\left(r_{, k} n_{i}-r_{, i} n_{k}\right)\right]+\right. \\
& \left.\left.+2 r_{, i} r_{, k} n_{j}+2 r_{, n} \mid \delta_{j k} r_{, i}+\delta_{i j} r_{, k}-(1-2 v) \delta_{i k} r_{, j}-4 r_{, i} r_{, j} r_{, k}\right]\right\} ; i, j=1,2 k \\
& u_{i j k}^{*}(p, s)=\frac{\partial}{\partial x_{k}(p)} u_{i j}^{*}=\frac{1}{8 \pi\left(1-v_{p}\right) G t r}\left[\left(3-4 v_{p}\right) \delta_{i k} r_{, j}-\delta_{i j} r_{, k}-\delta_{j k} r_{, i}+2 r_{, i} r_{, j} r_{, k}\right] ; i, j, k=1,2
\end{aligned}
$$

Além das representações integrais para os deslocamentos e seus gradientes, as equações integrais para as tensões podem ser obtidas a partir da substituição de (3.8) no tensor de Cauchy (2.1) e na lei de Hooke(2.15), isto é:

$$
N_{i j}(p)+\oint_{\Gamma} s_{i j k}^{*}(p, s) u_{k}(s) d \Gamma=\oint_{\Gamma} d_{i j k}^{*}(p, s) f_{k}(s) d \Gamma+\int_{\Omega} d_{i j k}^{*}(p, S) b_{k}(S) d \Omega ; i, j, k=1,2
$$

onde os kernels $s_{i j k}^{*}$ e $d_{i j k}^{*}$ são dados por:

$$
\begin{aligned}
& s_{i j k}^{*}(p, s)=t C_{i j m l} f_{m l k}^{*}=\frac{G t}{2 \pi\left(1-v_{p}\right) r^{2}}\left\{2 r_{, n}\left[\left(1-2 v_{p}\right) \delta_{i j} r_{, k}+v_{p}\left(\delta_{i k} r_{, j}+\delta_{j k} r_{, i}\right)-4 r_{, i} r_{, j} r_{, k}\right]+\right. \\
& \left.+2 v_{p}\left(n_{i} r_{, j} r_{, k}+n_{j} r_{, i} r_{, k}\right)+\left(1-2 v_{p}\right)\left(2 n_{k} r_{, i} r_{, j}+\delta_{i k} n_{j}+\delta_{j k} n_{i}\right)-\left(1-4 v_{p}\right) \delta_{i j} n_{k}\right\} ; \mathrm{i}, \mathrm{j} \mathrm{k}=1,2 \\
& d_{i j k}^{*}(p, s)=t C_{i j m l} u_{m l k}^{*}=\frac{1}{4 \pi\left(1-2 v_{p}\right) r}\left[\left(1-2 v_{p}\right)\left(\delta_{i k} r_{, j}+\delta_{k j} r_{, i}-\delta_{i j} r_{, k}\right)+2 r_{, i} r_{, j} r_{, k}\right] ; \mathrm{i}, \mathrm{j}, \mathrm{k}=1,2
\end{aligned}
$$

\subsection{2) Pontos no contorno}

A identidade de Somigliana é válida para pontos do domínio. Quando o ponto fonte é colocado em um ponto $i$ do contorno, há necessidade de um artifício matemático para equacionar-se tal ponto. Uma estratégia que tem sido empregada por diversos pesquisadores - BREBBIA(1978), BREBBIA \& WALKER(1980), VENTURINI(1982) e outros- é adicionar um setor de círculo no ponto $i$, e com isso, o contorno passa a ser $\Gamma_{c}=\Gamma-\bar{\Gamma}-\Gamma_{\varepsilon}$, como mostrado na figura 3.1. Com essa modificação, o ponto $i$ passa a pertencer ao domínio $\bar{\Omega}$, portanto, equação (3.7) pode ser utilizada:

$$
u_{i}(p)=\int_{\Gamma-\bar{\Gamma}+\Gamma_{\varepsilon}} u_{i j}^{*}(p, s) f_{j}(s) d \Gamma-\int_{\Gamma-\bar{\Gamma}+\Gamma_{\varepsilon}} f_{i j}^{*}(p, s) u_{j}(s) d \Gamma+\int_{\Omega-\bar{\Omega}+\Omega_{\varepsilon}} u_{i j}^{*}(p, S) b_{j}(S) d \Omega ; i, j=1,2
$$


A fim de retornar ao contorno primitivo basta $\Gamma_{\varepsilon} \rightarrow 0$, e ainda subdividindose os intervalos de integração em $\Gamma-\bar{\Gamma}$ e $\Gamma_{\varepsilon}$, o cálculo das integrais desses intervalos pode ser escrito, respectivamente, como:

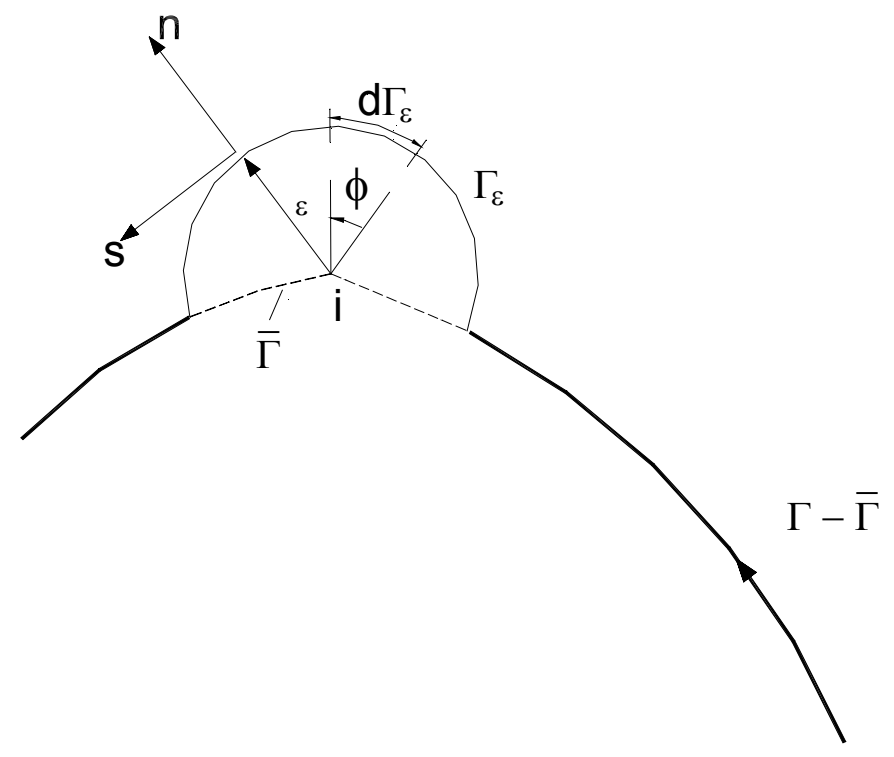

Figura 3.1 - Ponto fonte situado no contorno.

$$
\begin{aligned}
& i_{c 1}=\lim _{\bar{\Gamma}_{\varepsilon} \rightarrow 0}\left[\int_{\Gamma-\bar{\Gamma}} u_{i j}^{*}(p, s) f_{j}(s) d \Gamma-\int_{\Gamma-\bar{\Gamma}} f_{i j}^{*}(p, s) u_{j}(s) d \Gamma+\int_{\Omega-\Omega} u_{i j}^{*}(p, S) b_{j}(S) d \Omega\right] ; i, j=1,2 \\
& i_{c 2}=\lim _{\varepsilon \rightarrow 0}\left[\int_{\Gamma_{\varepsilon}} u_{i j}^{*}(p, s) f_{j} d \Gamma-\int_{\Gamma_{\varepsilon}} f_{i j}^{*}(p, s) u_{j} d \Gamma+\int_{\Omega_{\varepsilon}} u_{i j}^{*}(p, S) b_{j}(S) d \Omega\right] ; i, j=1,2
\end{aligned}
$$

Utilizando-se o conceito do valor principal de Cauchy em (3.15), essa equação pode ser reduzida a:

$$
i_{c l}=\oint_{\Gamma} u_{i j}^{*}(p, s) f_{j}(s) d \Gamma-\oint_{\Gamma} f_{i j}^{*}(p, s) u_{j}(s) d \Gamma+\int_{\Omega} u_{i j}^{*}(p, S) b_{j}(S) d \Omega ; i, j=1,2
$$

Já a identidade indicada em (3.16) pode ser dividida em duas partes, consistindo na presença ou não de singularidades fortes. As parcelas com singularidades fracas têm os valores nulos para seus limites, quando o raio tende a zero:

$$
\lim _{\varepsilon \rightarrow 0} \int_{\Gamma_{\varepsilon}} u_{i j}^{*}(p, s) f_{j}(s) d \Gamma=0 ; i, j=1,2
$$




$$
\lim _{\varepsilon \rightarrow 0} \int_{\Omega_{\varepsilon}} u_{i j}^{*}(p, S) b_{j}(S) d \Omega=0 ; i, j=1,2
$$

A parcela que tem o kernel das forças de superfície $f_{i j}^{*}$ apresenta uma singularidade forte. Assim, para superar essa descontinuidade na integração, pode ser utilizado um artifício de somar e subtrair o mesmo termo auxiliar:

$$
\lim _{\varepsilon \rightarrow 0} \int_{\Gamma_{\varepsilon}} f_{i j}^{*}(p, s)\left[u_{j}(s)-u_{j}(p)\right] d \Gamma+\lim _{\varepsilon \rightarrow 0} \int_{\Gamma_{\varepsilon}} f_{i j}^{*}(p, s) u_{j}(p) d \Gamma ; i, j=1,2
$$

Assumindo-se válida a condição de Hölder para os deslocamentos, isto é:

$$
\left|u_{j}(s)-u_{j}(p)\right| \leq B \varepsilon^{\alpha} ; i, j=1,2
$$

onde $\mathrm{B}$ e $\alpha$ são números positivos.

E substituindo-se (3.21) no primeiro termo de (3.20), tem-se o valor nulo para o limite quando o raio tende a zero:

$$
\lim _{\varepsilon \rightarrow 0} \int_{\Gamma_{\varepsilon}} f_{i j}^{*}(p, s) B \varepsilon^{\alpha} d \Gamma=0 ; i, j=1,2
$$

Já a segunda parcela de (3.20) pode ser calculada por meio de:

$$
\lim _{\varepsilon \rightarrow 0}\left\{-\int_{\theta_{1}}^{\theta_{2}} \frac{\left(1-2 v_{p}\right) \delta_{i j}+2 r_{, i} r_{, j}}{4\left(1-v_{p}\right)} d \phi\right\} u_{i}(p)=\bar{C}_{i j} u_{i}(p) ; i, j=1,2
$$

Com a substituição de (3.23), (3.17) em (3.14), a identidade de Somigliana pode ser representada por:

$$
C_{i j} u_{j}(p)+\oint_{\Gamma} f_{i j}^{*}(p, s) u_{j}(s) d \Gamma=\oint_{\Gamma} u_{i j}^{*}(p, s) f_{j}(s) d \Gamma+\int_{\Omega} u_{i j}^{*}(p, S) b_{j}(S) d \Omega ; i, j=1,2
$$

onde o termo livre $C_{i j}$ é expresso tal qual em HARTMANN(1980): 


$$
C_{i j}=\left[\begin{array}{cc}
\frac{\alpha_{1}-\alpha_{2}}{2 \pi}+\frac{\operatorname{sen} 2 \alpha_{1}-\operatorname{sen} 2 \alpha_{2}}{8 \pi\left(1-v_{p}\right)} & \frac{1}{4 \pi\left(1-v_{p}\right)}\left(\operatorname{sen}^{2} \alpha_{1}-\operatorname{sen}^{2} \alpha_{2}\right) \\
\frac{1}{4 \pi\left(1-v_{p}\right)}\left(\operatorname{sen}^{2} \alpha_{1}-\operatorname{sen}^{2} \alpha_{2}\right) & \frac{\alpha_{1}-\alpha_{2}}{2 \pi}+\frac{\operatorname{sen} 2 \alpha_{1}-\operatorname{sen} 2 \alpha_{2}}{8 \pi\left(1-v_{p}\right)}
\end{array}\right]
$$

onde $\left(\alpha_{1}, \alpha_{2}\right)$ representam os ângulos das direções tangenciais do contorno anterior e posterior à angulosidade indicados na figura 3.2.

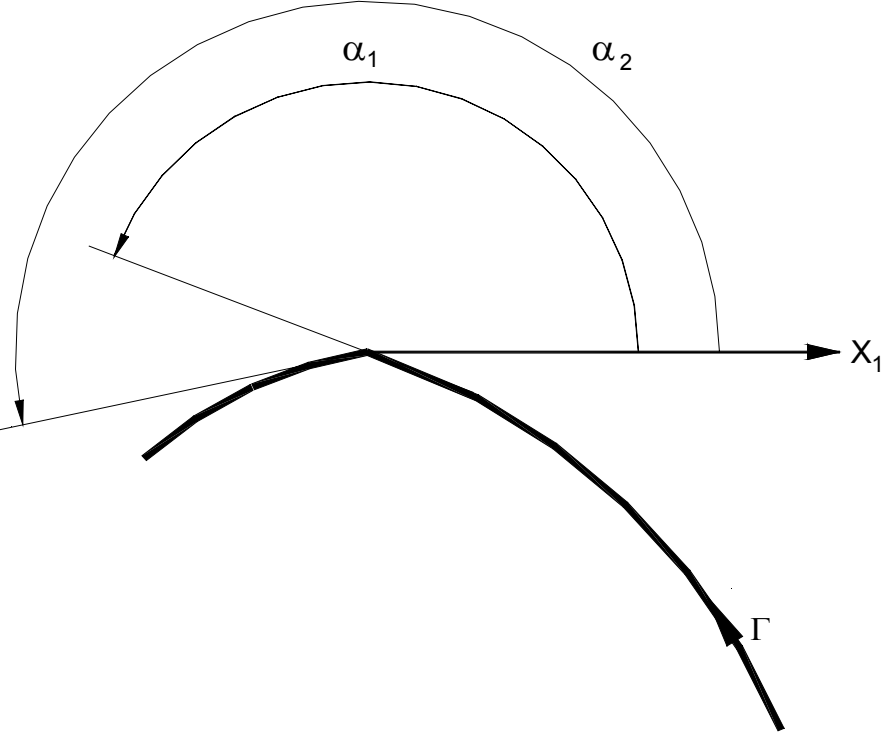

Figura 3.2-Ângulos presentes em $C_{i j}$

Tal qual para a representação integral dos deslocamentos, ao levar-se o ponto fonte para o contorno ocorrem singularidades nos kernels das equações integrais dos gradientes dos deslocamentos. Assim, utilizando-se técnica análoga àquela descrita para os deslocamentos, isto é, após a subdivisão dos intervalos de integração em $\Gamma-\bar{\Gamma}$ e $\Gamma_{\varepsilon}$, uma relação pode ser escrita como:

$$
\delta_{i k} \delta_{j l} u_{k, l}(p)-i_{3 c}-i_{4 c}=0 ; i, j k l=1,2
$$

onde

$$
\begin{aligned}
& i_{3 c}=\int_{\Gamma-\bar{\Gamma}} f_{i j k}^{*}(p, s) u_{k}(s) d \Gamma-\int_{\Gamma-\bar{\Gamma}} u_{i j k}^{*}(p, s) f_{k}(s) d \Gamma+\int_{\Omega-\bar{\Omega}} u_{i j k}^{*}(p, S) b_{k}(S) d \Omega ; i, j k=1,2 \\
& i_{4 c}=\int_{\Gamma_{\varepsilon}} f_{i j k}^{*}(p, s) u_{k}(s) d \Gamma-\int_{\Gamma_{\varepsilon}} u_{i j k}^{*}(p, s) f_{k}(s) d \Gamma+\int_{\Omega_{\varepsilon}} u_{i j k}^{*}(p, S) b_{k}(S) d \Omega ; i, j k=1,2
\end{aligned}
$$


Ao ser tomado o limite do raio $\varepsilon \rightarrow 0$, a fim de recuperar-se o contorno primitivo, e ainda utilizando-se o conceito de valor principal de Cauchy(v.p.c.) e de Hadamard (v.p.h.)em (3.27), pode-se escrever a seguinte relação:

$$
\begin{aligned}
& i_{3 c}=\lim _{\Gamma \rightarrow 0}\left[\int_{\Gamma-\bar{\Gamma}} f_{i j k}^{*}(p, s) u_{k}(s) d \Gamma-\int_{\Gamma-\bar{\Gamma}} u_{i j k}^{*}(p, s) f_{k}(s) d \Gamma\right]+\underset{\Omega \rightarrow 0}{\lim } \int_{\Omega-\Omega} u_{i j k}^{*}(p, S) b_{k}(S) d \Omega \\
& =\oint_{\Gamma} f_{i j k}^{*}(p, s) u_{k}(s) d \Gamma+\oint_{\Gamma} u_{i j k}^{*}(p, s) f_{k}(s) d \Gamma+\int_{\Omega} u_{i j k}^{*}(p, S) b_{k}(S) d \Omega ; i, j k=1,2
\end{aligned}
$$

Incorporando-se em (3.28) um movimento de corpo rígido de valor $-u_{k}(p)$, essa equação pode ser reescrita como:

$$
i_{4 c}=\lim _{\Gamma \rightarrow 0}\left\{\int_{\Gamma_{\varepsilon}} f_{i j k}^{*}(p, s)\left[u_{k}(s)-u_{k}(p)\right] d \Gamma-\int_{\Gamma_{\varepsilon}} u_{i j k}^{*}(p, s) f_{k}(s) d \Gamma\right\} ; i, j k=1,2
$$

Admitindo-se válidas as condições de Hölder para os deslocamentos e forças de superfície, as seguintes expansões na vizinhança do ponto-fonte podem ser expressas por, GUIGGIANI(1998):

$$
\begin{gathered}
u_{k}(s)=u_{k}(p)+u_{k, l}(p)\left[x_{l}(s)-x_{l}(p)\right]+O\left(r^{\alpha}\right) ; k l=1,2 \\
f_{m}(s)=t C_{m h k l} n_{h} u_{k, l}(s)=t C_{m h k l} n_{h} u_{k, l}(p)+O\left(r^{\alpha-1}\right) ; m h k l=1,2
\end{gathered}
$$

Se (3.31), com $r_{, l}=\left[x_{l}(p)-x_{l}(p)\right] / r$, e (3.32) forem substituídas em (3.30), uma relação pode ser expressa por:

$$
i_{4 c}=\lim _{\Gamma \rightarrow 0}\left\{\int_{\Gamma_{\varepsilon}} f_{i j k}^{*}(p, s) r r_{, l} u_{k, l}(p) d \Gamma-\int_{\Gamma_{\varepsilon}} u_{i j m}^{*}(p, s) t C_{m h k l} n_{h} u_{k, l}(p) d \Gamma\right\} ; m h k, l=1,2
$$

ou

$$
i_{4 c}=\lim _{\Gamma \rightarrow 0}\left\{\int_{\Gamma_{\varepsilon}} X_{i j k l}^{*}(p, s) u_{k, l}(p) d \Gamma\right\} ; i, j, k, l=1,2
$$

onde o kernel $X_{i j k l}^{*}$ é expresso em DONG \& GEA(1998) como: 


$$
\begin{gathered}
X_{i j k l}^{*}(p, s)=r r_{, l} f_{i j k}^{*}(p, s)-t C_{m h k l} n_{h} u_{i j m}^{*}(p, s)=\frac{1}{8 \pi\left(1-v_{p}\right) r}\left\{\left(5-8 v_{p}\right) \delta_{i k} r_{, j} r_{, l}+\right. \\
\left(3-4 v_{p}\right) \delta_{i l} r_{, j} r_{, k}-2\left(2+2 v_{p}\right) \delta_{i j} r_{, k} r_{, l}-\left(7-4 v_{p}\right) \delta_{j k} r_{, i} r_{, l}-\delta_{j l} r_{, j} r_{, k}+ \\
\left.16 r_{, i} r_{, j} r_{, k} r_{, l}+\frac{2 v_{p}}{1-2 v_{p}}\left[4\left(1-v_{p}\right) \delta_{k l} r_{, i} r_{, j}-\delta_{i j} \delta_{k l}\right]\right\} ; i, j, k, l=1,2
\end{gathered}
$$

Calculando-se as integrais em (3.34) para um contorno suave, tem-se que:

$$
i_{4 c}=\lim _{\varepsilon \rightarrow 0} \int_{0}^{\pi} \frac{X_{i j k l}^{*}}{\varepsilon}(\phi) \varepsilon d \phi u_{k, l}(p)=\frac{1}{2} \delta_{i k} \delta_{j l} u_{k, l}(p) ; i, j, k, l=1,2
$$

onde $X_{i j k l}^{*}(\phi)=r X_{i j k l}^{*}(p, s)$.

Com isso, a partir de (3.36), (3.29) em (3.26), tem-se a representação integral para pontos colocados sobre contornos suaves, isto é:

$$
\begin{aligned}
D_{i j k l} u_{k, l}+\oint_{\Gamma} f_{i j k}^{*}(p, s) u_{k}(s) d \Gamma= & \oint_{\Gamma} u_{i j k}^{*}(p, s) f_{k}(s) d \Gamma+ \\
& \int_{\Omega} u_{i j k}^{*}(p, S) b_{k}(s) d \Omega ; i, j, k l=1,2
\end{aligned}
$$

onde as componentes do tensor $D_{i j k l}$ são dadas por:

$$
D_{i j k l}=\frac{1}{2} \delta_{i k} \delta_{j l} ; i, j, k, l=1,2
$$

As representações integrais das resultantes de tensão no contorno requerem um tratamento análogo ao aplicado ao caso dos gradientes de deslocamentos, uma vez que as ordens das singularidades presentes têm as mesmas características. Assim, (3.11) pode ser expressa similarmente à (3.26):

$$
\delta_{i k} \delta_{j l} N_{k l}(p)-i_{3 t}-i_{4 t}=0 ; i, j, k, l=1,2
$$

Assim, a partir da relação constitutiva (2.15), as componentes dos kernels dos gradientes de deslocamentos devem ser ajustadas para o campo das tensões:

$$
\begin{aligned}
i_{3 t}=\lim _{\Gamma \rightarrow 0}\left[\int_{\Gamma-\bar{\Gamma}} s_{i j k}^{*}(p, s) u_{k}(s) d \Gamma-\int_{\Gamma-\bar{\Gamma}} d_{i j k}^{*}(p, s) f_{k}(s) d \Gamma\right]+\underset{\Omega \rightarrow 0}{\lim } \int_{\Omega-\Omega} d_{i j k}^{*}(p, S) b_{k}(S) d \Omega \\
=\oint_{\Gamma} s_{i j k}^{*}(p, s) u_{k}(s) d \Gamma+\oint_{\Gamma} d_{i j k}^{*}(p, s) f_{k}(s) d \Gamma ; i, j, k l=1,2
\end{aligned}
$$


O termo $i_{4 t}$ para os casos de contorno suave, equivalente ao $i_{4 c}$, pode ser escrito como:

$$
\begin{gathered}
i_{4 t}=\lim _{\Gamma \rightarrow 0}\left\{\int_{\Gamma_{\varepsilon}} s_{i j k}^{*}(p, s) u_{k}(s) d \Gamma-\int_{\Gamma_{\varepsilon}} d_{i j k}^{*}(p, s) f_{k}(s) d \Gamma\right\}= \\
\lim _{\Gamma \rightarrow 0}\left\{\int_{\Gamma_{\varepsilon}} f_{i j k}^{*}(p, s) r r_{, l} N_{k l}(p) d \Gamma-\int_{\Gamma_{\varepsilon}} u_{i j m}^{*}(p, s) t C_{m h k l} n_{h} N_{k l}(s) d \Gamma\right\} ; i, j, k l=1,2
\end{gathered}
$$

A partir da comparação de (3.42) com (3.33), pode-se concluir que as parcelas da integração de $i_{4 t}$ são similares às de $i_{4 c}$. Desta forma, substituindo-se (3.42), (3.41) em (3.40), tem-se a representação integral de tensões para pontos-fonte em contorno suave dada por:

$$
D_{i j k l} N_{k l}(p)+\oint_{\Gamma} s_{i j k}^{*}(p, s) u_{k}(s) d \Gamma=\oint_{\Gamma} d_{i j k}^{*}(p, s) f_{k}(s) d \Gamma+\int_{\Omega} d_{i j k}^{*}(p, S) b_{k}(S) d \Omega ; \quad i, j, k, l=1,2
$$

onde $D_{i j k l}$ pode ser escrito como em (3.39).

\subsection{3)Carregamentos externos distribuídos em linha e concentrados (estados planos).}

Além das ações externas aplicadas distribuídas no domínio bidimensional da chapa, outras modalidades de carregamentos podem estar presentes no problema, tais como os unidimensionalmente distribuídos e os discretamente aplicados (carregamentos concentrados). A fim de estender as representações integrais (3.24), (3.38) e (3.43) para contemplar esses casos, é necessário que apenas o termo de domínio seja ajustado à ação externa em questão. Assim, a força volumétrica $b_{j}$, referida nas equações integrais discutidas nas seções anteriores deste capítulo, pode ser subdividida conforme a dimensão de seus respectivos domínios de aplicação:

$$
b_{j}(S)=\left\{\begin{array}{cc}
b_{j} & \text { se } S \in \Omega_{b} \text { (Bidimens.) } \\
\int_{\Omega_{l}} \delta(S, l) b_{L j}(l) d \Omega_{l}(l) & \left., \text { se } l \in \Omega_{l} \text { (Uni dimens. }\right) \\
\delta(S, c) F_{j}(c) & , \text { se } c \text { for um ponto }
\end{array}\right.
$$


Em (3.44), utilizando-se as propriedades do delta de Dirac para o carregamento aplicado em linha, tem-se: $b_{j}(S)=\int_{\Omega_{l}} \delta(S, l) b_{L j}(l) d \Omega_{l}=b_{L j}(S)$.

Substituindo-se (3.44) no termo de domínio de (3.24), tem-se a seguinte relação:

$$
\begin{gathered}
\int_{\Omega} u_{i j}^{*}(p, S) b_{j}(S) d \Omega=\int_{\Omega_{b}} u_{i j}^{*}(p, S) b_{j}(S) d \Omega+\int_{\Omega_{l}} u_{i j}^{*}(p, S) b_{L j}(S) d \Omega+ \\
\int_{\Omega} u_{i j}^{*}(p, S) \delta(S, c) F_{j}(c) d \Omega ; i, j=1,2
\end{gathered}
$$

Como $F_{j}(c)$ é uma variável independente no último termo de (3.45), essa parcela pode ser reescrita como:

$$
\int_{\Omega} u_{i j}^{*}(p, S) \delta(S, c) F_{j}(c) d \Omega=F_{j}(c) \int_{\Omega} u_{i j}^{*}(p, S) \delta(S, c) d \Omega(S) ; i, j=1,2
$$

Aplicando-se as propriedades do delta de Dirac no último termo de (3.46), e sendo em seguida substituído em (3.45), tem-se a integral de domínio contemplando os três tipos de carregamentos em suas respectivas regiões de aplicação, isto é:

$$
\int_{\Omega} u_{i j}^{*}(p, S) b_{j}(S) d \Omega=\int_{\Omega_{b}} u_{i j}^{*}(p, S) b_{j}(S) d \Omega+\int_{\Omega_{l}} u_{i j}^{*}(p, S) b_{L j}(S) d \Omega+u_{i j}^{*}(p, c) F_{j}(c) ; i, j=1,2
$$

Para as representações integrais dos gradientes de deslocamentos(3.38) e das resultantes de tensão(3.43) pode ser aplicado um procedimento análogo, de forma que o termo de domínio dessas pode ser escrito respectivamente como:

$$
\begin{gathered}
\int_{\Omega} u_{i j k}^{*}(p, S) b_{k}(S) d \Omega=\int_{\Omega_{b}} u_{i j k}^{*}(p, S) b_{k}(S) d \Omega+\int_{\Omega_{l}} u_{i j k}^{*}(p, S) b_{L k}(S) d \Omega+ \\
u_{i j k}^{*}(p, c) F_{k}(c) ; \quad i, j, k=1,2 \\
\int_{\Omega} d_{i j k}^{*}(p, S) b_{k}(S) d \Omega=\int_{\Omega_{b}} d_{i j k}^{*}(p, S) b_{k}(S) d \Omega+\int_{\Omega_{l}} d_{i j k}^{*}(p, S) b_{L k}(S) d \Omega+ \\
d_{i j k}^{*}(p, c) F_{k}(c) ; \quad i, j, k=1,2
\end{gathered}
$$




\subsection{4)Representações integrais dos estados planos no sistema de referência local.}

$\mathrm{Na}$ literatura, as representações integrais para os problemas planos e tridimensionais, em geral, são apresentados utilizando-se um sistema de referência global $\left(x_{1}, x_{2}\right)$. Contudo, em algumas situações, pode ser mais atrativo adotar-se sistemas distintos para expressar as componentes dos campos (de deslocamentos, de deformações e das resultantes de tensão) associadas ao ponto-fonte e para as variáveis ao contorno. Assim, nesta presente formulação optou-se escrever as representações integrais para os estados planos de tal forma que no ponto-fonte os deslocamentos são escritos segundo uma direção genérica $q$ e as variáveis do problema são expressas segundo às direções tangencial $\tau$ e normal $\eta$ ao contorno.

Substituindo-se (3.47) em (3.24), a representação integral dos deslocamentos pode ser escrita como:

$$
\begin{gathered}
\lambda u_{q}(p)+q_{i}(p) \oint_{\Gamma} f_{i j}^{*}(p, s) Q_{j k}(s) v_{k}(s) d \Gamma=q_{i}(p) \oint_{\Gamma} u_{i j}^{*}(p, s) Q_{j k}(s) t_{k}(s) d \Gamma+ \\
q_{i}(p) \int_{\Omega} u_{i j}^{*}(p, S) b_{j}(S) d \Omega+q_{i}(p) \int_{\Omega_{L}} u_{i j}^{*}(p, S) g_{j}(S) d \Omega_{L}+\sum_{k=l}^{N f_{c}} q_{i}(p) u_{i j}^{*}(p, S) F_{j}^{K}(S) ; i, j, k=1,2
\end{gathered}
$$

onde $\lambda$ é o coeficiente livre de integral com valores dependentes da região de colocação do ponto-fonte $(\lambda=1$, ponto no interior; $\lambda=0$, ponto no exterior; $\lambda=1 / 2$ para ponto sobre contorno suave); $v_{i}$ e $t_{i}$ são os deslocamentos e as forças de superfície escritos nas direções do sistema $(\tau, \eta) ; u_{q}(p)$ é o deslocamento do ponto-fonte segundo a direção $q$, que pode ser representado por $u_{q}=u_{i}(p) q_{i}(p)$ em que $q_{i}(p)$ está associado ao co-seno diretor de $q$. Vide figura 3.3.

Em (3.50), $Q(s)$ é a matriz de transformação, entre os sistemas $\left(x_{1}, x_{2}\right) \mathrm{e}$ $(\tau, \eta)$, que pode ser escrita como:

$$
\begin{array}{ll}
Q_{1 j}(s)=\tau_{j}(s) ; & j=1,2 \\
Q_{2 j}(s)=\eta_{j}(s) ; & j=1,2
\end{array}
$$

Já as rotações no plano da chapa, i.e., a derivada direcional segundo uma direção $m$, de uma componente de deslocamento na direção $q$, pode ser escrita como:

$$
u_{q, m}(p)=u_{i, m}(p) q_{i}(p)=u_{i, j}(p) q_{i}(p) m_{j}(p) ; \quad i, j=1,2
$$




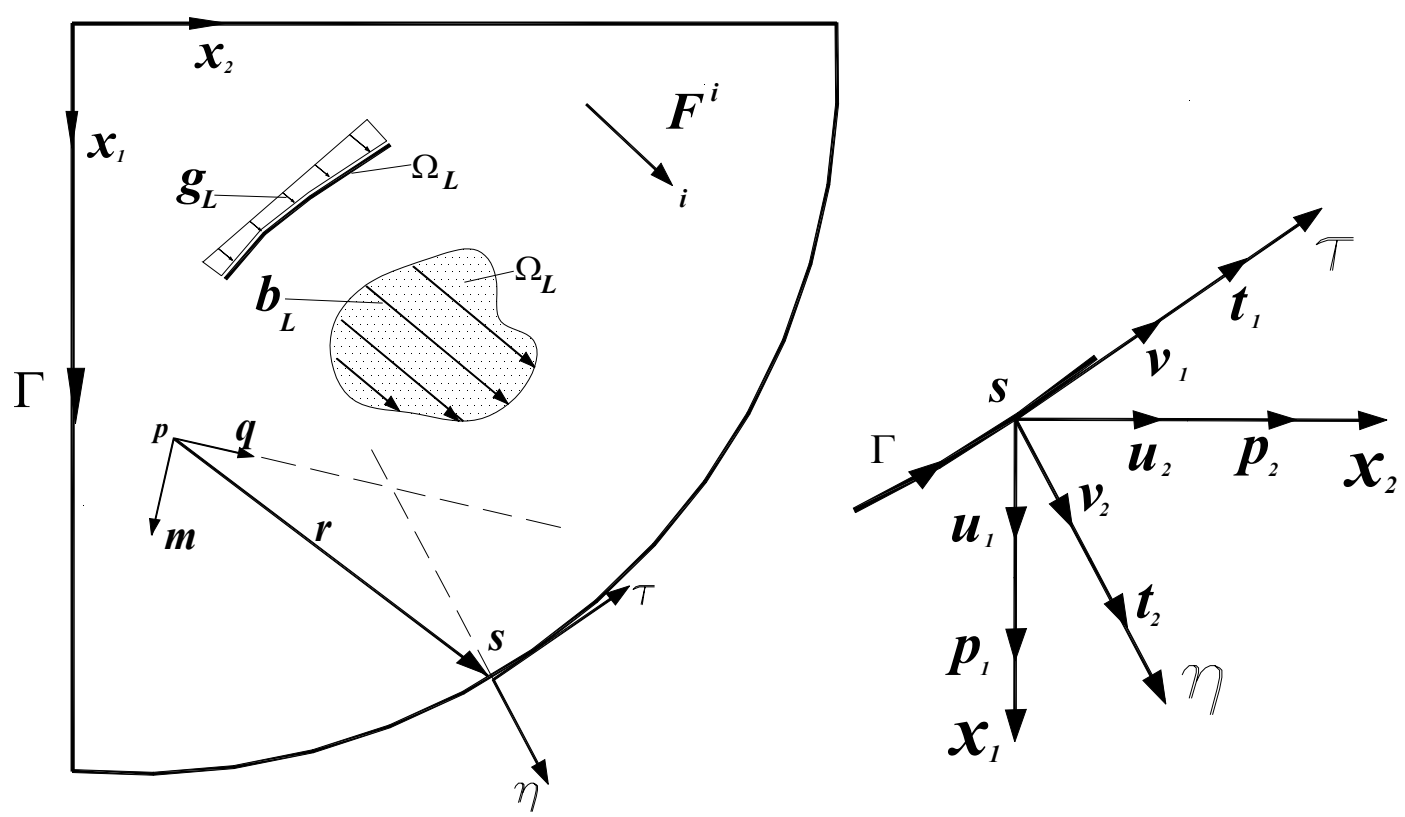

Figura 3.3- Esquema representativo da chapa.

A partir de (3.53), (3.38) e de (3.48), a representação integral das rotações no plano da chapa em que as variáveis do contorno estão no sistema local de coordenadas pode ser escrita como:

$$
\begin{gathered}
\lambda_{\theta} u_{q, m}(p)+q_{i}(p) \oint_{\Gamma} f_{i j k}^{*}(p, s) m_{j}(p) Q_{k r}(s) v_{r}(s) d \Gamma= \\
q_{i}(p) \oint_{\Gamma} u_{i j k}^{*}(p, s) m_{k}(p) Q_{k r}(s) t_{r}(s) d \Gamma+q_{i}(p) \int_{\Omega} u_{i j k}^{*}(p, S) m_{j} b_{k}(S) d \Omega+ \\
q_{i}(p) \int_{\Omega_{L}} u_{i j k}^{*}(p, S) m_{j}(p) g_{k}(S) d \Omega_{L}+q_{i}(p) u_{i j k}^{*}(p, K) m_{j}(p) F_{k}(K) ; i, j, k, r=1,2
\end{gathered}
$$

onde $q_{i}$ e $m_{i}$ são co-senos diretores de $q$ e $m$ em relação a $\left(x_{1}, x_{2}\right) . \lambda_{\theta}=1 / 2$ é o termo livre de integral para ponto de colocação em contorno suave.

\section{3)Equações integrais de placas delgadas}

\subsection{1)Pontos de domínio}

De uma maneira sucinta, a técnica do resíduo ponderado pode ser descrita como uma estratégia de impor um valor nulo para o resíduo ponderado médio global do problema causado pela admissão de soluções aproximadas para as equações diferenciais do problema em cada ponto do problema. 
Se o domínio de um problema (por exemplo, um corpo elástico) for composto de $n$ partes discretas e $R(i)$ for o resíduo devido à admissão de uma solução aproximada da EDP em cada ponto. Além disso, se $U(i)$ for tomada com a função ponderadora desse ponto e ainda se as condições essenciais(deslocamentos) e as naturais(forças) forem plenamente satisfeitas em suas respectivas regiões definidas sobre o contorno do corpo, o resíduo ponderado médio global $R_{m}$ do problema pode ser calculado como:

$$
R_{m}=\frac{\sum_{i=1}^{n} R(i) U(i)}{\sum_{i=1}^{n} U(i)}
$$

Se o resíduo médio ponderado global for imposto nulo em (3.55), tem-se a equação da TRP deste problema:

$$
\sum_{i=1}^{n} R(i) U(i)=0
$$

Analogamente ao caso anterior, a equação da TRP para problemas de domínios contínuos $\boldsymbol{x}$ pode ser escrita como:

$$
\int_{x} R(x) U(x) d x=0
$$

No entanto, se for admitido que as condições essenciais e naturais não são satisfeitas, isto conduzirá a resíduos no contorno do corpo. Assim, os resíduos do contorno deverão ser introduzidos na expressão (3.57), resultando em:

$$
\int_{x} R(x) U(x) d x=\int_{\partial x_{1}} r_{1} f(\partial x) d \partial x+\int_{\partial x_{2}} r_{2} u(\partial x) d \partial x
$$

onde $x, \partial x$ são as regiões relativas ao domínio e ao contorno do corpo; a expressão do resíduo das condições essenciais é dada por $r_{l}=u-\bar{u}$, sendo definida em $\partial x_{1} \mathrm{e}$ $\bar{u}$ denota deslocamento prescrito e $f(\partial x)$ é a função de ponderação de $r_{l}$. Analogamente, Já $r_{2}=t-\bar{t}$ é a expressão para as condições naturais definidas em $\partial x_{2}, \bar{t}$ denotando força prescrita e $u(\partial x)$ é a função de ponderação de $r_{2}$.

Tomando-se a EDP do problema real de placas delgadas(2.29) e a função ponderadora representada pelo kernel de deslocamento(2.141); as variáveis de contorno $w, \theta_{p}, m_{n}, V_{n} e R_{c}$ são ponderadas respectivamente pelos seus campos 
fundamentais duais, isto é $V_{n}^{*}, m_{n}^{*}, \theta_{p}^{*}, w^{*} e w_{c}^{*}$. Assim, tem-se a equação da TRP análoga à (3.58) escrita como:

$$
\begin{gathered}
\int_{\Omega}\left[D w_{, i i j j}(S)-g(S)\right] w^{*}(p, S) d \Omega=\int_{\Gamma_{1}}[w(s)-\bar{w}]\left[q_{n}^{*}(p, s)+m_{n s, t}^{*}(p, s)\right] d \Gamma- \\
\int_{\Gamma_{1}}\left[\theta_{p}(s)-\bar{\theta}_{p}\right] m_{n}^{*}(p, s) d \Gamma-\int_{\Gamma_{2}}\left[V_{n}(s)-\bar{V}_{n}\right] w^{*}(p, s) d \Gamma+ \\
R_{c}^{*}(p, s)\left(w_{c}-\bar{w}_{c}\right)+\int_{\Gamma_{2}}\left[m_{n}(s)-\bar{m}_{n}\right]_{p}^{*}(p, s) d \Gamma+w_{c}^{*}(p, s)\left(R_{c}-\bar{R}_{c}\right) ; \\
i, j=1,2 \text { e } c=1, \ldots, N_{c}
\end{gathered}
$$

onde $\Gamma_{l}$ é a região do contorno $\Gamma$ onde as condições essenciais $\left(w=\bar{w}, \theta_{p}=\bar{\theta}_{p}\right)$ são conhecidas; $\Gamma_{2}$ denota a região em que as condições naturais $\left(V_{n}=\bar{V}_{n}, m_{n}=\bar{m}_{n}\right)$ são conhecidas. A cortante de Kirchhoff, como discutida no capítulo 2, pode ser expressa como $V_{n}=q_{n}+m_{n s, t}$.

Fazendo-se a integração por partes na primeira parcela de (3.59), tem-se a identidade:

$$
\begin{gathered}
D \int_{\Gamma} w_{, i j}(s) n_{j} w^{*}(p, s) d \Gamma-D \int_{\Omega} w_{i i j}(p) w_{, j}^{*}(p, S) d \Omega=\int_{\Omega} g(s) w^{*}(p, s) d \Omega+ \\
\int_{\Gamma_{l}}[w(s)-\bar{w}]\left[q_{n}^{*}(p, s)+m_{n s, t}^{*}(p, s)\right] d \Gamma- \\
\int_{\Gamma_{1}}\left[\theta_{p}(s)-\bar{\theta}_{p}\right] m_{n}^{*}(p, s) d \Gamma-\int_{\Gamma_{2}}\left[V_{n}(s)-\bar{V}_{n}\right] w^{*}(p, s) d \Gamma+ \\
R_{c}^{*}(p, s)\left(w_{c}-\bar{w}_{c}\right)+w_{c}^{*}(p, s)\left(R_{c}-\bar{R}_{c}\right)+ \\
\int_{\Gamma_{2}}\left[m_{n}(s)-\bar{m}_{n}\right] \theta_{p}^{*}(p, s) d \Gamma ; i, j=1,2
\end{gathered}
$$

A equação (3.60) pode ser expressa de uma maneira mais concisa como:

$$
D \int_{\Gamma} w_{, i j}(s) n_{j} w^{*}(p, s) d \Gamma-D \int_{\Omega} w_{, i j}(p) w_{, j}^{*}(p, S) d \Omega=I_{p}
$$

com: 


$$
\begin{gathered}
I_{p}=\int_{\Omega} g(s) w^{*}(p, s) d \Omega+\int_{\Gamma_{1}}[w(s)-\bar{w}]\left[q_{n}^{*}(p, s)+m_{n s, t}^{*}(p, s)\right] d \Gamma- \\
\int_{\Gamma_{1}}\left[\theta_{p}(s)-\bar{\theta}_{p}\right] m_{n}^{*}(p, s) d \Gamma-\int_{\Gamma_{2}}\left[V_{n}(s)-\bar{V}_{n}\right] w^{*}(p, s) d \Gamma+ \\
\int_{\Gamma_{2}}\left[m_{n}(s)-\bar{m}_{n}\right] \theta_{p}^{*}(p, s) d \Gamma ; i, j=1,2
\end{gathered}
$$

Substituindo-se (2.25) e (2.27) em (3.61), tem-se que:

$$
-\oint_{\Gamma} q_{n}(s) w^{*}(p, s) d \Gamma+\int_{\Omega} m_{i j, i}(p) w_{, j}^{*}(p, S) d \Omega=I_{p} ; i, j=1,2
$$

Integrando-se por partes a integral de domínio do lado esquerdo de (3.63), uma nova identidade pode ser escrita como:

$$
\begin{gathered}
-\oint_{\Gamma} q_{n}(s) w^{*}(p, s) d \Gamma+\oint_{\Gamma} m_{i j}(s) n_{i} w_{, j}^{*}(p, s) d \Gamma-\int_{\Omega} m_{i j}(p) w_{i j}^{*}(p, S) d \Omega=I_{p} ; \\
i, j=1,2
\end{gathered}
$$

A partir das relações (2.19) e (2.20) em (3.1), o teorema da reciprocidade de Betti para placas delgadas pode ser escrito como:

$$
\int_{\Omega} m_{i j}(S) w_{, i j}^{*}(p, S) d \Omega=\int_{\Omega} m_{i j}^{*}(p, S) w_{, i j}(S) d \Omega ; i, j=1,2
$$

Levando-se (3.65) em (3.64), vem que:

$$
\begin{gathered}
-\oint_{\Gamma} q_{n}(s) w^{*}(p, s) d \Gamma+\oint_{\Gamma} m_{i j}(s) n_{i} w_{, j}^{*}(p, s) d \Gamma= \\
I_{p}+\oint_{\Omega} m_{i j}^{*}(p, S) w_{i j}(S) d \Omega ; i, j=1,2
\end{gathered}
$$

Aplicando-se convenientemente duas integrações por partes na parcela da integral de domínio do lado direito de (3.66), uma relação pode ser escrita como:

$$
\begin{gathered}
-\oint_{\Gamma} q_{n}(s) w^{*}(p, s) d \Gamma+\oint_{\Gamma} m_{i j}(s) n_{i} w_{, j}^{*}(p, s) d \Gamma=I_{p}- \\
\oint_{\Gamma} w(s) q_{n}^{*}(p, s) w(s) d \Gamma+\oint_{\Gamma} n_{i} w_{, j}(s) m_{i j}^{*}(p, s) d \Gamma+\int_{\Omega} m_{i j, i j}^{*}(p, s) w(S) d \Omega ; i, j=1,2
\end{gathered}
$$

Com o auxílio de relações trigonométricas, a seguinte identidade pode ser escrita:

$$
n_{i} n_{j}+s_{i} s_{j}=\delta_{i j} ; i, j=1,2
$$

A soma dos pares(momento-rotação) no sistema de referências do contorno $(s, n)$ pode ser expressa no sistema global $\left(x_{1}, x_{2}\right)$ a partir da relação: 


$$
m_{n} \theta_{p}+m_{n s} \theta_{t}=m_{i j} w_{, k} n_{i}\left(n_{j} n_{k}+s_{j} s_{k}\right) ; i, j, k=1,2
$$

Se (3.68) for substituída em (3.69), uma outra identidade pode ser escrita:

$$
m_{n} \theta_{p}+m_{n s} \theta_{t}=m_{i j} w_{, j} n_{i} ; i, j=1,2
$$

Substituindo-se (3.70) em (3.67), uma representação integral envolvendo esforços, deslocamentos e rotações no contorno, além dos carregamentos real e fundamental no domínio, pode ser escrita como:

$$
\begin{gathered}
\oint_{\Gamma}\left[w(s) q_{n}^{*}(p, s)-\theta_{p}(s) m_{n}^{*}(p, s)-\theta_{t}(s) m_{n s}^{*}(p, s)\right] d \Gamma=\int_{\Omega} w(S) m_{i j, i j}^{*}(p, S) d \Omega+ \\
\oint_{\Gamma}\left[q_{n}(s) w^{*}(p, s)-m_{n}(s) \theta_{p}^{*}(p, s) m_{n}-m_{n s}(s) \theta_{t}^{*}(p, s)\right] d \Gamma+I_{p}
\end{gathered}
$$

Conforme discutido no capítulo 2 , os esforços $q_{n}^{*}$ e $m_{n s}^{*}$ não podem ser determinados simultaneamente nas hipóteses da teoria clássica de placas. Assim foi proposto por Kirchhoff o conceito de força cortante equivalente em que esses dois esforços são escritos em função de um único, que está indicada na expressão (2.36).

Aplicando-se a integração por partes na terceira parcela da primeira integral do lado direito de (3.71), tem-se que:

$$
\int_{\Gamma} m_{n s}(s) \theta_{t}^{*}(p, s) d \Gamma=\left[m_{n s}(s) w^{*}(p, s)\right]_{\beta_{1}}^{\beta_{2}}-\int_{\Gamma} w^{*}(p, s) \frac{\partial}{\partial t} m_{n s}(s) d \Gamma
$$

onde $\left(\beta_{1}, \beta_{2}\right)$ são as coordenadas das extremidades dos contornos contíguos a um canto da placa.

Substituindo-se (2.36) em (3.72), tem-se que:

$$
\int_{\Gamma} m_{n s}(s) \theta_{t}^{*}(p, s) d \Gamma=\left[m_{n s}(s) w^{*}(p, s)\right]_{\beta_{1}}^{\beta_{2}}-\int_{\Gamma} w^{*}(p, s)\left[V_{n}(s)-q_{n}(s)\right] d \Gamma
$$

Levando-se (3.73) em (3.71), obtém-se:

$$
\begin{gathered}
\oint_{\Gamma}\left[w(s) q_{n}^{*}(p, s)-\theta_{p}(s) m_{n}^{*}(p, s)-\theta_{t}(s) m_{n s}^{*}(p, s)\right] d \Gamma=\int_{\Omega} w(S) m_{i j, i j}^{*}(p, S) d \Omega+ \\
R_{c}(S) w_{c}^{*}(p, s)+\oint_{\Gamma}\left[V_{n}(s) w^{*}(p, s)-m_{n}(s) \theta_{p}^{*}(p, s) m_{n}\right] d \Gamma+I_{p}
\end{gathered}
$$

onde $R_{c}(s)=-\left[m_{n s}(s)\right]_{\beta_{1}}^{\beta_{2}}$.

Se a segunda parcela de (3.62) for integrada por partes, a identidade $I_{p}$ pode ser reescrita como: 


$$
\begin{gathered}
I_{p}=\int_{\Omega} g(s) w^{*}(p, s) d \Omega+\int_{\Gamma_{1}}[w(s)-\bar{w}] q_{n}^{*}(p, s) d \Gamma \\
-\int_{\Gamma_{1}}\left[\theta_{t}(s)-\bar{\theta}_{t}\right] m_{n s}^{*}(p, s) d \Gamma+\left.[w(s)-\bar{w}] m_{n s}^{*}\right|_{\beta_{1}} ^{\beta_{2}}- \\
\int_{\Gamma_{1}}\left[\theta_{p}(s)-\bar{\theta}_{p}\right] m_{n}^{*}(p, s) d \Gamma-\int_{\Gamma_{2}}\left[V_{n}(s)-\bar{V}_{n}\right] w^{*}(p, s) d \Gamma+ \\
\int_{\Gamma_{2}}\left[m_{n}(s)-\bar{m}_{n}\right] \theta_{p}^{*}(p, s) d \Gamma ; i, j=1,2
\end{gathered}
$$

Ao substituir-se (3.75) em (3.74), tem-se que:

$$
\begin{gathered}
-\int_{\Omega} w(S) m_{i j, i j}^{*}(p, S) d \Omega+\int_{\Gamma_{I}}\left[\bar{w} q_{n}^{*}(p, s)-\bar{\theta}_{p} m_{n}^{*}(p, s)-\bar{\theta}_{t} m_{n s}^{*}(p, s)\right] d \Gamma+ \\
\int_{\Gamma_{2}}\left[w(s) q_{n}^{*}(p, s)-\theta_{p}(s) m_{n}^{*}(p, s)-\theta_{t}(s) m_{n s}^{*}(p, s)\right] d \Gamma= \\
\bar{R}_{c}(S) w_{c}^{*}(p, S)+\int_{\Gamma_{l}}\left[V_{n}(s) w^{*}(p, s)-m_{n}(s) \theta_{p}^{*}(p, s)\right] d \Gamma- \\
\int_{\Gamma 2}\left[\bar{V}_{n} w^{*}(p, s)-\bar{m}_{n} \theta_{p}^{*}(p, s)\right] d \Gamma+\int_{\Omega} g(p, S) w^{*}(p, S) d \Omega
\end{gathered}
$$

Sabendo-se que as condições essenciais em $\Gamma_{l}$ e que as condições naturais em $\Gamma_{2}$ são conhecidas, a equação (3.76) pode ser escrita em uma forma genérica uma vez que $\Gamma=\Gamma_{1}+\Gamma_{2}$. Assim, vem que:

$$
\begin{gathered}
\oint_{\Gamma}\left[w(s) q_{n}^{*}(p, s)-\theta_{p}(s) m_{n}^{*}(p, s)-\theta_{t}(s) m_{n s}^{*}(p, s)\right] d \Gamma=\int_{\Omega} w(S) m_{i j, i j}^{*}(p, S) d \Omega+ \\
R_{c}(S) w_{c}^{*}(p, S)+\oint_{\Gamma}\left[V_{n}(s) w^{*}(p, s)-m_{n}(s) \theta_{p}^{*}(p, s)\right] d \Gamma+\int_{\Omega} g(S) w^{*}(p, S) d \Omega \\
c=1, \ldots, N_{c}
\end{gathered}
$$

A equação de equilíbrio do problema fundamental de placas - analogamente à (2.28) - é dada por $m_{i j, i j}^{*}+g^{*}=0, \operatorname{com} \delta(s, p)=g^{*}$ representando o carregamento do problema fundamental. Substituindo-se essas relações em (3.77) e ainda utilizando-se as propriedades da distribuição de Dirac, a equação integral dos deslocamentos para pontos do domínio pode ser escrita como: 


$$
\begin{gathered}
w(p)+\oint_{\Gamma}\left[w(s) q_{n}^{*}(p, s)-\theta_{p}(s) m_{n}^{*}(p, s)-\theta_{t}(s) m_{n s}^{*}(p, s)\right] d \Gamma= \\
R_{c}(s) w_{c}^{*}(p, s)+\oint_{\Gamma}\left[V_{n}(s) w^{*}(p, s)-m_{n}(s) \theta_{p}^{*}(p, s)\right] d \Gamma+ \\
\int_{\Omega} g(S) w^{*}(p, S) d \Omega ; c=1, \ldots, N c
\end{gathered}
$$

Além disso, se para o termo $\int_{\Gamma} m_{n s}^{*} \theta_{t} d \Gamma$ forem aplicados procedimentos análogos aos descritos nas equações (3.72) e (3.73) para a integral $\int_{\Gamma} m_{n s} \theta_{t}^{*} d \Gamma$, uma relação pode ser escrita como:

$$
\int_{\Gamma} m_{n s}^{*}(p, s) \theta_{t}(s) d \Gamma=\left[m_{n s}^{*}(p, s) w(s)\right]_{\beta_{I}}^{\beta_{2}}-\int_{\Gamma} w(s)\left[V_{n}^{*}(p, s)-q_{n}^{*}(p, s)\right] d \Gamma
$$

Se (3.79) for substituída em (3.78), tem-se a representação integral conhecida como identidade de Rayleigh-Green:

$$
\begin{gathered}
w(p)+\oint_{\Gamma}\left[w(s) V_{n}^{*}(p, s)-\theta_{p}(s) m_{n}^{*}(p, s)\right] d \Gamma+w_{c}(s) R_{c}^{*}(p, s)= \\
R_{c}(s) w_{c}^{*}(p, s)+\oint_{\Gamma}\left[V_{n}(s) w^{*}(p, s)-m_{n}(s) \theta_{p}^{*}(p, s)\right] d \Gamma+ \\
\int_{\Omega} g(S) w^{*}(p, S) d \Omega ; c=1, \ldots, N c
\end{gathered}
$$

Tanto a equação(3.78), neste trabalho denominada de identidade triparamétrica, quanto a identidade de Rayleigh-Green(3.80) podem ser escritas em uma representação integral comum:

$$
\begin{gathered}
w(p)+\oint_{\Gamma}\left[w(s) \alpha_{n}^{*}(p, s)-\theta_{p}(s) m_{n}^{*}(p, s)-\theta_{t}(s) \beta_{n}^{*}(p, s)\right] d \Gamma+w_{c}(s) \gamma_{c}^{*}(p, s)= \\
R_{c}(s) w_{c}^{*}(p, s)+\oint_{\Gamma}\left[V_{n}(s) w^{*}(p, s)-m_{n}(s) \theta_{p}^{*}(p, s)\right] d \Gamma+ \\
\int_{\Omega} g(S) w^{*}(p, S) d \Omega ; c=1, \ldots, N c
\end{gathered}
$$

onde $\left(\begin{array}{lll}\alpha_{n}^{*} & \beta_{n}^{*} & \gamma_{c}^{*}\end{array}\right)=\left(\begin{array}{lll}q_{n}^{*} & m_{n s}^{*} & 0\end{array}\right), \quad$ para $\operatorname{Representação~triparamétrica(RTP);~}$ $\left(\begin{array}{lll}\alpha_{n}^{*} & \beta_{n}^{*} & \gamma_{c}^{*}\end{array}\right)=\left(\begin{array}{lll}V_{n}^{*} & 0 & R_{c}^{*}\end{array}\right)$, para Representação de Rayleigh-Green(RRG) Além disso, $p$ está associado ao ponte-fonte; $s$ e $S$ são os pontos-campo associados ao contorno e ao domínio, respectivamente; $V_{n}, q_{n}, m_{n}$ e $m_{n s}$ são os esforços do contorno associados à força equivalente de Kirchhoff, força cortante, momento fletor e momento volvente, respectivamente; $R_{c}$ é a reação de canto; $w, \theta_{p}$ e $\theta_{t}$ são os 
respectivos deslocamentos transversais, rotações normais e tangenciais ao contorno; $N c, R_{c}$ indicam o número de cantos e as reações sobre eles, vide figura 3.4.

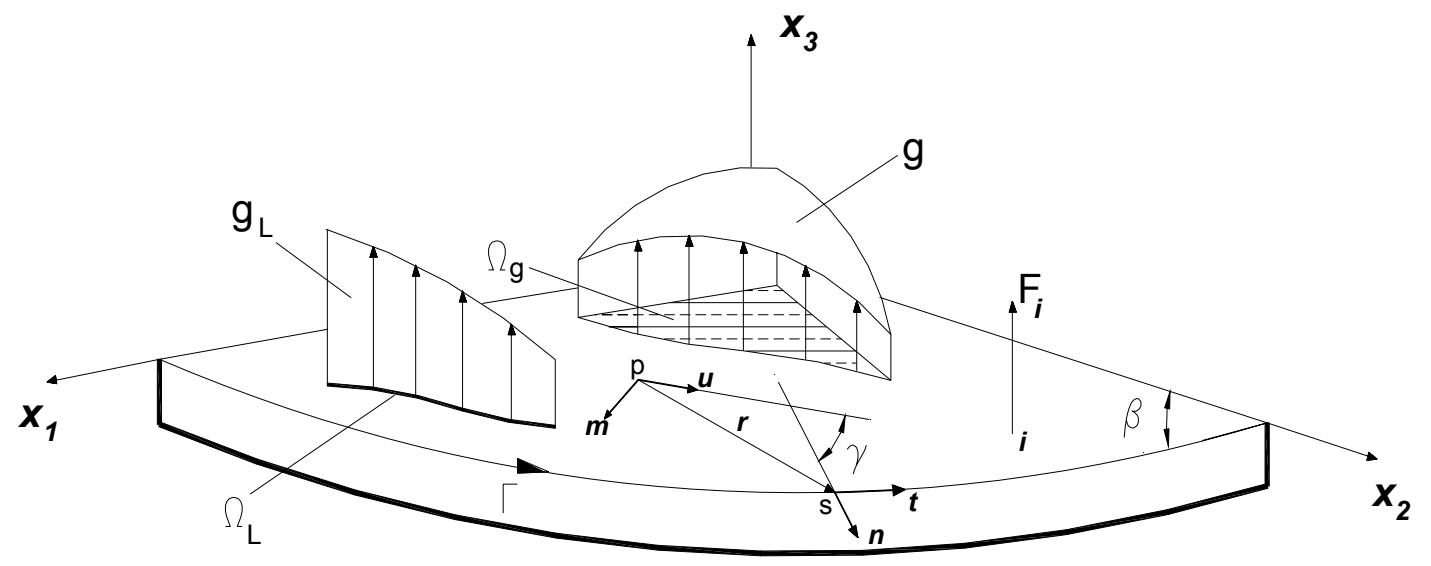

Figura 3.4- Carregamentos presentes na placa

Diferenciando-se a equação integral dos deslocamentos transversais(3.81) segundo uma direção genérica $m$, a representação integral para as derivadas direcionais dos deslocamentos pode ser escrita como:

$$
\begin{gathered}
w_{, m}(p)+\oint_{\Gamma}\left[w(s) \alpha_{n, m}^{*}(p, s)-\theta_{p}(s) m_{n, m}^{*}(p, s)-\theta_{t}(s) \beta_{n, m}^{*}(p, s)\right] d \Gamma+ \\
w_{c}(s) \mu_{c}^{*}(p, s)=\oint_{\Gamma}\left[V_{n}(s) w_{, m}^{*}(p, s)-m_{n}(s) \theta_{p, m}^{*}(p, s)\right] d \Gamma+ \\
R_{c}(s) w_{c, m}^{*}(p, s)+\int_{\Omega} g(s) w_{, m}^{*}(p, s) d \Omega ; c=1, \ldots, N c
\end{gathered}
$$

onde $\left(\begin{array}{lll}\alpha_{n, m}^{*} & \beta_{n, m}^{*} & \mu_{c}^{*}\end{array}\right)=\left(\begin{array}{lll}q_{n, m}^{*} & m_{n, m}^{*} & 0\end{array}\right), \operatorname{RTP} ;\left(\begin{array}{lll}\alpha_{n, m}^{*} & \beta_{n, m}^{*} & \mu_{c}^{*}\end{array}\right)=\left(\begin{array}{lll}V_{n, m}^{*} & 0 & R_{c, m}^{*}\end{array}\right)$, RRG.

Em (3.82), um dos procedimentos para a obtenção das derivadas direcionais em uma direção genérica $m$ dos kernels de (3.81) pode descrito tomando-se, por exemplo, a diferenciação de $q_{n}^{*}$ :

$$
q_{n, m}^{*}(p, s)=\frac{1}{2 \pi r^{2}}\left(m_{k} n_{k}-2 r_{, n} r_{, m}\right) ; k, n, m=1,2
$$

Assim, os demais kernels podem ser obtidos de forma análoga ao da derivada direcional da força cortante $q_{n, m}^{*}(3.83)$ e seus valores podem ser escritos como:

$$
w_{, m}^{*}(p, s)=-\frac{r_{, i} m_{i}}{4 \pi D} r \ln r ; \quad \mathrm{i}=1,2
$$




$$
\begin{gathered}
\theta_{p, m}^{*}(p, s)=\frac{-1}{4 \pi D}\left[\left(m_{i} r_{, i}\right)\left(n_{j} r_{, j}\right)+\left(m_{k} n_{k}\right) \ln r\right] ; \quad i, j, k=1,2 \\
m_{n, m}^{*}(p, s)=\frac{1}{4 \pi r}\left\{(1+v)\left(m_{i} r_{, i}\right)+2(1-v)\left(n_{j} r_{, j}\right)\left[\left(m_{i} n_{i}\right)-\left(m_{i} r_{, i}\right)\left(n_{k} r_{, k}\right)\right]\right\} ; i, j, k,=1,2 \\
m_{n t, m}^{*}(p, s)=\frac{1-v}{4 \pi r}\left\{\left(m_{i} n_{i}\right)\left(t_{j} r_{, j}\right)+\left(m_{k} t_{k}\right)\left(n_{i} r_{, i}\right)-2\left(m_{i} r_{, i}\right)\left(n_{j} r_{, j}\right)\left(t_{k} r_{, k}\right)\right\} ; i, j, k=1,2 \\
V_{n, m}^{*}(p, s)=\frac{1}{4 \pi r^{2}}\left\{2 ( 1 - v ) ( s _ { q } r _ { , q } ) \left[4\left(m_{i} r_{, \mathrm{i}}\right)\left(n_{j} r_{, \mathrm{j}}\right)\left(s_{t} r_{, \mathrm{t}}\right)-2\left(m_{i} s_{i}\right)\left(n_{j} r_{, \mathrm{j}}\right)\right.\right. \\
\left.+(3-v)\left(\left(n_{j} m_{j}\right)-2\left(m_{i} r_{, i}\right)\left(n_{j} r_{, j}\right)\right]\right\}+\frac{1-v}{\pi R r}\left(s_{i} r_{, i}\right)\left[\left(m_{t} r_{, t}\right)-2\left(m_{q} r_{, q}\right)\left(s_{j} r_{, j}\right)\right] ; i, j, q, t=1,2
\end{gathered}
$$

onde $D$ é o módulo de flexão da placa; $r$ é a distância entre o ponto fonte $p$ e o ponto campo $s ; 1 / R$ é a curvatura do contorno; $r_{, i}$ é o co-seno do raio vetor $r$; $n_{i}$ e $t_{i}$ são as componentes da direção normal e tangencial ao contorno no ponto $s$.

Além das representações integrais dos deslocamentos transversais e seus gradientes, uma outra equação integral que pode ser escrita é para as curvaturas, a partir da diferenciação em uma direção genérica $q$ da equação (3.82), isto é:

$$
\begin{gathered}
w_{, m q}(p)+\oint_{\Gamma}\left[w(s) \alpha_{n, m q}^{*}(p, s)-\theta_{p}(s) m_{n, m q}^{*}(p, s)-\theta_{t}(s) \beta_{n, m q}^{*}(p, s)\right] d \Gamma+ \\
\varsigma_{c}^{*}(p, S) w_{c}(S)=\oint_{\Gamma}\left[V_{n}(s) w_{, m q}{ }^{*}(p, s)-m_{n}(s) \theta_{p, m q}^{*}(p, s)\right] d \Gamma+\int_{\Omega} g(S) w_{, m q}{ }^{*}(p, S) d \Omega
\end{gathered}
$$

$$
c=1,2, \ldots, N c
$$

onde $\left(\begin{array}{lll}\alpha_{n, m q}^{*} & \beta_{n, m q}^{*} & S_{c}^{*}\end{array}\right)=\left(\begin{array}{lll}q_{n, m q}^{*} & m_{n s, m q}^{*} & 0\end{array}\right), \operatorname{RTP} ;\left(\begin{array}{lll}\alpha_{n, m q}^{*} & \beta_{n, m q}^{*} & S_{c}^{*}\end{array}\right)=\left(\begin{array}{lll}V_{n, m q}^{*} & 0 & R_{c, m q}^{*}\end{array}\right), \mathrm{RRG}$ os kernels são dados por:

$$
\begin{gathered}
q_{n, m q}^{*}(p, s)=\frac{1}{\pi r^{3}}\left[m_{k} n_{k} r_{, i} q_{i}+m_{i} r_{, i} q_{j} n_{j}+r_{, k} m_{k}\left(m_{i} q_{i}-4 r_{, i} m_{i} r_{, j} q_{j}\right)\right] ; i, j, k=1,2 \\
m_{n, m q}^{*}(p, s)=-\frac{1}{4 \pi r^{2}}\left\{(1+v)\left(m_{k} q_{k}-2 r_{, i} m_{i} r_{, j} q_{j}\right)+2(1-v)\left[m_{, k} n_{k} q_{j} n_{j}\right.\right. \\
\left.\left.-\left(m_{k} q_{k}-2 r_{, i} m_{i} r_{, j} q_{j}\right)\left(r_{, \alpha} n_{\alpha}\right)^{2}-2 r_{, \alpha} m_{\alpha} r_{, \beta} n_{\beta}\left(m_{k} n_{k}-r_{, i} q_{i} r_{, j} n_{j}\right)\right]\right\} ; i, j, k, \alpha, \beta=1,2 \\
m_{n s, m q}^{*}(p, s)=\frac{1-v}{4 \pi r^{2}}\left\{2 \left[r_{, \gamma} t_{\gamma}\left(r_{, i} m_{i} q_{k} n_{k}+r_{, j} q_{j} m_{k} n_{k}\right)+r_{, \beta} n_{\beta}\left(r_{, i} m_{i} q_{k} t_{k}+r_{, j} q_{j} m_{\alpha} t_{\alpha}\right)+\right.\right. \\
\left.\left.r_{, \alpha} n_{\alpha} r_{, \beta} t_{\beta}\left(m_{k} q_{k}-4 r_{, i} m_{i} r_{, j} q_{j}\right)\right]-\left(m_{k} n_{k} q_{\alpha} t_{\alpha}+q_{k} n_{k} m_{\alpha} t_{\alpha}\right)\right\} ; i, j, k, \alpha, \beta, \gamma=1,2 \\
w_{, m q}^{*}(p, s)=\frac{1}{4 \pi D}\left\{r_{, i} m_{i} r_{, j} q_{j}+m_{k} q_{k} \ln r\right\} ; i, j, k=1,2
\end{gathered}
$$




$$
\begin{gathered}
\theta_{p, m q}^{*}(p, s)=\frac{1}{4 \pi r D}\left\{\left[2 r_{, i} m_{i} r_{, j} q_{j}-m_{j} q_{j}\right] r_{, k} n_{k}-r_{, j} m_{j} q_{\tau} n_{\tau}-r_{, \beta} q_{\beta} m_{\gamma} n_{\gamma}\right\} \\
i, j, k, \alpha, \beta, \gamma, \tau=1,2 \\
V_{n, m q}^{*}(p, s)=\frac{1}{4 \pi r^{3}}\left\{2 ( 1 - v ) ( s _ { k } r _ { , k } ) ^ { 2 } \left[24 m_{i} r_{, i} q_{j} r_{, j} n_{l} r_{, l}-\right.\right. \\
\left.-4\left(m_{i} r_{, i} n_{j} q_{j}+m_{i} r_{, j} n_{i} q_{j}+m_{i} q_{i}\right)\right]+4(1-v) r_{, k} s_{k}\left\lfloor\left(m_{i} n_{i} s_{j} q_{j}+m_{i} n_{j} s_{i} q_{j}\right)-\right. \\
\left.4 r_{, k} n_{k}\left(m_{i} r_{, i} s_{j} q_{j}+m_{i} r_{, j} s_{i} q_{j}\right)\right]+4(1-v) r_{, k} n_{k} m_{i} s_{i} s_{j} q_{j}+ \\
\left.\left.2(3-v) \mid r_{, k} n_{k}\left(m_{i} q_{i}-4 m_{i} r_{, i} r_{, j} q_{j}\right)+m_{i} r_{, i} n_{j} q_{j}+m_{i} r_{, j} n_{i} q_{j}\right]\right\}+ \\
\frac{1-v}{\pi R r^{2}} s_{k} r_{, k} r_{, j} q_{j}\left(m_{i} s_{i}-m_{i} r_{, i} s_{l} r_{, l}\right) ; i, j, k, l=1,2
\end{gathered}
$$

A representação integral dos momentos fletores e volventes, associados aos eixos de referência arbitrários $(m, q)$, pode ser obtida utilizando-se as relações constitutivas da teoria clássicas de placas(2.24) e a equação (3.89):

$$
\begin{gathered}
m_{m q}(p)+q_{i}(p) m_{j}(p)\left\{\oint_{\Gamma}\left[w(s) \mu \alpha_{n, i j}^{*}(p, s)-\theta_{p}(s) \mu m_{n, i j}^{*}(p, s)\right] d \Gamma-\right. \\
\left.\oint_{\Gamma}\left[\theta_{t}(s) \mu \beta_{n, i j}^{*}(p, s)\right] d \Gamma\right\}+q_{i}(p) t_{j}(p) \mu \varsigma_{c}^{*}(p, S) R_{c}(S)= \\
q_{i}(p) t_{j}(p) \oint_{\Gamma}\left[V_{n}(s) \mu w_{i j}^{*}(p, s)-m_{n}(s) \mu \theta_{p, i j}^{*}(p, s)\right] d \Gamma+
\end{gathered}
$$

$q_{i}(p) t_{j}(p) R_{c}(S) \mu w_{c, i j}^{*}(p, S)+q_{i}(p) t_{j}(p) \int_{\Omega} g(S) \mu w w_{, i j}(p, S) d \Omega ; c=1,2, \ldots, N c$

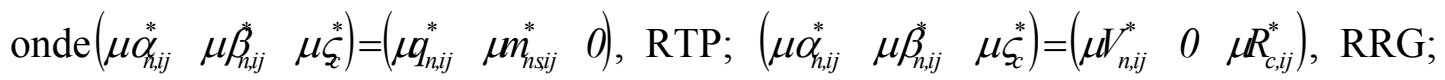
os kernels são dados por:

$$
\begin{gathered}
\mu w_{, i j}^{*}=-\frac{(1+v)}{4 \pi}\left\{\left[\ln r-\frac{v}{(1+v)}\right] \delta_{i j}-r_{, i} r_{, j}\right\} ; i, j=1,2 \\
\mu \theta_{p, i j}^{*}=-\frac{1}{4 \pi r}\left\{(1+v) \delta_{i j} r_{, k} n_{k}+(1-v)\left[r_{, i} n_{j}+r_{, j} n_{i}-2 r_{, i} r_{, j}\right]_{, j}\right\} ; i, j, k=1,2 \\
\mu m_{n, i j}^{*}=\frac{D(1-v)}{4 \pi r^{2}}\left\{(1+3 v) \delta_{i j}-2(1+v) r_{, i} r_{, j}-2(1-v)\left[-n_{i} n_{j}+2 r_{, k} n_{k}\left(r_{, j} n_{i}+\right.\right.\right. \\
\left.\left.\left.r_{, i} n_{j}-2 r_{, i} r_{, j} r_{, k} n_{k}\right]-2(1+v) \delta_{i j}\left(r_{, k} n_{k}\right)^{2}\right]\right\} ; i, j, k=1,2
\end{gathered}
$$




$$
\begin{gathered}
\mu m_{i j, \alpha k}^{*}=\frac{D(1-v)}{4 \pi r^{2}}\left\{(1+3 v) \delta_{i j} \delta_{\alpha k}-2(1+v) \delta_{i j} r_{, \alpha} r_{, k}\right]-2(1-v)\left[\delta_{j k} r_{, \alpha} r_{, i}+\right. \\
\left.\left.\delta_{j \alpha} r_{, i} r_{, k}+\delta_{i \alpha} r_{, j} r_{, k}-4 r_{, i} r_{, j} r_{, k} r_{, \alpha}\right]+(1-v)\left(\delta_{i k} \delta_{j \alpha}+\delta_{i \alpha} \delta_{j k}\right)-2(1+v) \delta_{\alpha k} r_{, i} r_{, j}\right\} \\
; i, j, k, \alpha=1,2 \\
\mu q_{n, i j}^{*}=\frac{-D}{\pi r^{3}}\left\{(1-v)\left[r_{, j} n_{i}+r_{, i} n_{j}-r_{, k} n_{k} r_{, i} r_{, j}\right]+(1+2 v) \delta_{i j} r_{, k} n_{k}\right\} ; i, j, k=1,2 \\
\mu V_{n, i j}^{*}(p, s)=\frac{-D}{4 \pi r^{3}}\left\{2 ( 1 - v ) ( s _ { k } r _ { , k } ) ^ { 2 } \left[24 n_{l} r_{, l}\left\{\delta_{i j} v-(1+v) r_{, i} r_{, j}\right\}-\right.\right. \\
\left.-4\left\{(1-v)\left(r_{, i} n_{j}+r_{, j} n_{i}\right)+(1+3 v) r_{,} n_{l} \delta_{i j}\right\}\right]+ \\
4(1-v) r_{, k} s_{k} \mid(1+v) n_{i} s_{j}+(1-v) n_{j} s_{i}- \\
\left.4 r_{, k} n_{k}\left\{(1+v) r_{, i} s_{j}+(1-v) r_{, j} s_{i}\right\}\right]+4(1-v) r_{, k} n_{k}\left\lfloor(1-v) s_{i} s_{j}+v \delta_{i j}\right]+ \\
\left.2(3-v)\left[r_{, k} n_{k}\left\{(1-3 v) \delta_{i j}-4(1-v) r_{, i} r_{, j}\right\}+(1+v) r_{, i} n_{j}+(1-v) r_{, j} n_{i}\right]\right\}+ \\
\frac{1-v}{\pi R r^{2}} s_{k} r_{, k}\left\{s_{i} r_{, j}-\left[\delta_{i j} v+(1-v) r_{, i} r_{, j}\right]\left(s_{l} r_{l}\right)\right\} ; i, j, k, l=1,2
\end{gathered}
$$

A força cortante segundo a direção $m$ pode ser obtida pela derivação do Laplaciano dos deslocamentos em relação à direção $m$ :

$$
q_{m}=-D w_{, i t t} m_{i} ; \quad i, t=1,2
$$

onde a representação integral para a derivada do laplaciano dos deslocamentos pode ser obtida da diferenciação de (3.89):

$$
\begin{gathered}
w_{, m t t}(p)+\oint_{\Gamma}\left[w(s) \alpha_{n, m t t}^{*}(p, s)-\theta_{p}(s) m_{n, m t t}^{*}(p, s)\right] d \Gamma- \\
\oint_{\Gamma}\left[\theta_{t}(s) \beta_{n, m t t}^{*}(p, s)\right] d \Gamma+\varsigma_{, t t c}^{*}(p, S) R_{c}(S)= \\
\oint_{\Gamma}\left[V_{n}(s) w_{, m t t}{ }^{*}(p, s)-m_{n}(s) \theta_{p, t t}^{*}(p, s)\right] d \Gamma+ \\
R_{c, m t t}^{*}(p, i) w_{c}(S)+\int_{\Omega} g(S) w_{, m t t}{ }^{*}(p, S) d \Omega ; c=1,2, \ldots, N c ;
\end{gathered}
$$

$\operatorname{onde}\left(\alpha_{n, m t t}^{*} \beta_{n, m t t}^{*} S_{c, t t}^{*}\right)=\left(\begin{array}{lll}q_{n, m t t}^{*} & m_{n s, t t}^{*} & 0\end{array}\right), \mathrm{RTP} ;\left(\begin{array}{lll}\alpha_{n, m t t}^{*} & \beta_{n, m t t}^{*} & \varsigma_{, t t c}^{*}\end{array}\right)=\left(\begin{array}{lll}V_{n, m t t}^{*} & 0 & R_{c, m t t}^{*}\end{array}\right), \mathrm{RRG}$ os kernels são dados por:

$$
\begin{gathered}
q_{n, m t t}^{*}(p, s)=0 ; t=1,2 \\
m_{n, m t t}^{*}(p, s)=-\frac{1-v}{\pi r^{3}}\left[r_{, i} m_{i}+2 m_{k} n_{k} r_{, j} n_{j}-4 r_{, \alpha} m_{\alpha}\left(r_{, \beta} n_{\beta}\right)^{2}\right] ; i, j, k, \alpha, \beta=1,2
\end{gathered}
$$




$$
\begin{gathered}
m_{n s, m t t}^{*}(p, s)=\frac{1-v}{\pi r^{3}}\left[4 r_{, i} m_{i} r_{, j} t_{j} r_{, k} n_{k}-m_{i} n_{i} r_{, j} t_{j}-m_{i} t_{i} r_{, j} n_{j}\right] ; i, j, k, t=1,2 \\
\theta_{p, m t t}^{*}(p, s)=-\frac{1}{2 \pi D r^{2}}\left(2 r_{, i} m_{i} r_{, j} n_{j}-m_{j} n_{j}\right) ; \quad i, j, t=1,2 \\
w_{, m t t}^{*}(p, s)=-\frac{m_{i} r_{, i}}{2 \pi D} \frac{1}{r} ; \quad i, t=1,2 \\
V_{n, m t t}^{*}(p, s)=-\frac{1-v}{\pi r^{4}}\left\{4\left(r_{, k} s_{k}\right)^{2}\left(6 r_{, i} m_{i} r_{, j} n_{j}-n_{i} m_{i}\right)-4 r_{, l} n_{l}\left(2 s_{i} m_{i} s_{j} r_{, j}+m_{i} r_{, i}\right)+\right. \\
\left.n_{i} m_{i}\right\}+\frac{1-v}{\pi R r^{3}}\left(r_{, i} m_{i}\right)^{2} s_{k} r_{, k}\left\{m_{j} s_{j}-m_{j} r_{, j} s_{l} r_{, l}\right\} ; i, j, k, l, t=1,2
\end{gathered}
$$

\subsection{2)Pontos no contorno}

Se o ponto-fonte for levado para o contorno, ocorrem singularidades nos kernels. Com isso, algumas técnicas são necessárias para superar este inconveniente analogamente àquelas utilizadas nos problemas de chapas. Uma das técnicas, descrita em PAIVA(1987) e OLIVEIRA NETO(1998), consiste em escrever a representação integral de placas sobre um novo contorno definido como $\Gamma_{n}=\Gamma-\bar{\Gamma}+\Gamma_{\varepsilon}$ indicados na figura 3.5. Assim, a equação (3.78) pode ser alterada para:

$$
\begin{gathered}
w(p)+\int_{\Gamma-\bar{\Gamma}}\left[w(s) \alpha_{n}^{*}(p, s)-\theta_{p}(s) m_{n}^{*}(p, s)-\theta_{t}(s) \beta_{n}^{*}(p, s)\right] d \Gamma+ \\
\int_{\Gamma_{\varepsilon}}\left[w(s) \alpha_{n}^{*}(p, s)-\theta_{p}(s) m_{n}^{*}(p, s)-\theta_{t}(s) \beta_{n}^{*}(p, s)\right] d \Gamma \\
+\gamma_{c e}^{*}(p, S) w_{E}(S)+\gamma_{c d}^{*}(p, S) w_{D}(S)= \\
\int_{\Gamma-\bar{\Gamma}}\left[V_{n}(s) w^{*}(p, s)-m_{n}(s) \theta_{p}^{*}(p, s)\right] d \Gamma+ \\
\int_{\Gamma_{\varepsilon}}\left[V_{n}(s) w^{*}(p, s)-m_{n}(s) \theta_{p}^{*}(p, s)\right] d \Gamma+R_{k}(S) w_{k}^{*}(p, S)+ \\
R_{c e}(S) w_{E}^{*}(p, S)+R_{c d}(S) w_{D}^{*}(p, S) \\
+\int_{\Omega-\bar{\Omega}} g(S) w^{*}(p, S) d \Omega+\int_{\Omega_{\varepsilon}} g(S) w^{*}(p, S) d \Omega ; k=1, \ldots, n-1
\end{gathered}
$$


onde $R_{c e}, R_{c d}$ representam as reações de canto anterior e posterior à angulosidade; $w_{E}^{*}, w_{D}^{*}$ são os seus respectivos kernels; da mesma forma $\gamma_{E}^{*}, \gamma_{D}^{*}$ estão associados ao kernel $\gamma_{c}^{*}$.

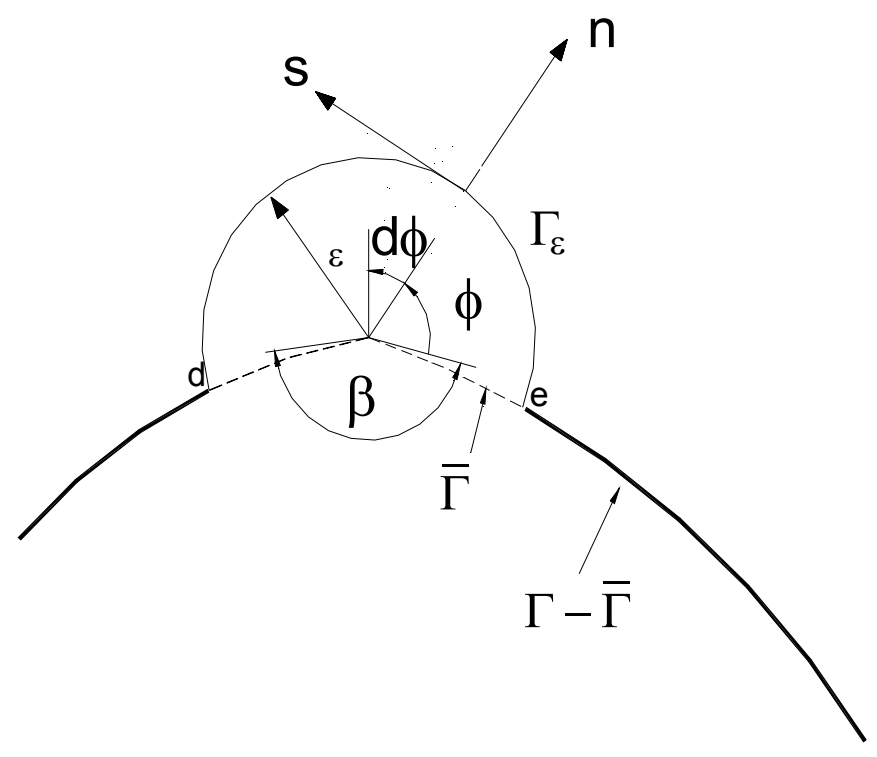

Figura 3.5-Contorno auxiliar

Quando o raio $\varepsilon$ de $\Gamma_{\varepsilon}$ tende a zero, tem-se que $\bar{\Gamma}$ e $\bar{\Omega} \rightarrow 0$. Com isso, (3.111) no limite pode ser escrita como:

$$
\begin{gathered}
w(p)+\lim _{\Gamma \rightarrow 0} \int_{\Gamma-\bar{\Gamma}}\left[w(s) \alpha_{n}^{*}(p, s)-\theta_{p}(s) m_{n}^{*}(p, s)-\theta_{t}(s) \beta_{n}^{*}(p, s)\right] d \Gamma+ \\
\lim _{\Gamma_{\varepsilon} \rightarrow 0} \int_{\Gamma_{\varepsilon}}\left[w(s) \alpha_{n}^{*}(p, s)-\theta_{p}(s) m_{n}^{*}(p, s)-\theta_{t}(s) \beta_{n}^{*}(p, s)\right] d \Gamma+ \\
\lim _{\Gamma_{e} \rightarrow 0}\left[R_{c e}^{*}(p, S) w_{E}(S)+R_{d e}^{*}(p, S) w_{D}(S)\right]= \\
\frac{\lim _{\Gamma \rightarrow 0}}{\int_{\Gamma-\bar{\Gamma}}}\left[V_{n}(s) w^{*}(p, s)-m_{n}(s) \theta_{p}^{*}(p, s)\right] d \Gamma+ \\
\lim _{\Gamma_{\varepsilon} \rightarrow 0} \int_{\Gamma_{\varepsilon}}\left[V_{n}(s) w^{*}(p, s)-m_{n}(s) \theta_{p}^{*}(p, s)\right] d \Gamma+ \\
+R_{k}(S) w_{k}^{*}(p, S)+\lim _{\Gamma_{e} \rightarrow 0}\left[R_{c e}(S) w_{E}^{*}(p, S)+R_{c d}(S) w_{D}^{*}(p, S)\right] \\
+\lim _{\Omega \rightarrow 0} \int_{\Omega-\bar{\Omega}} g(S) w^{*}(p, S) d \Omega+\lim _{\Omega_{\varepsilon} \rightarrow 0} \int_{\Omega_{\varepsilon}} g(S) w^{*}(p, S) d \Omega ; k=1, \ldots, n-1
\end{gathered}
$$


O cálculo dos limites envolvendo as integrais definidas sobre o contorno $\Gamma-\bar{\Gamma}$, na equação (3.112), conduz a resultados equivalentes aos valores das próprias integrais definidas sobre o contorno $\Gamma$, isto é:

$$
\begin{gathered}
i_{1}=\lim _{\Gamma \rightarrow 0} \int_{\Gamma-\bar{\Gamma}}\left[w(s) \alpha_{n}^{*}(p, s)-\theta_{p}(s) m_{n}^{*}(p, s)-\theta_{t}(s) \beta_{n}^{*}(p, s)\right] d \Gamma- \\
\frac{\lim }{\Gamma \rightarrow 0} \int_{\Gamma-\bar{\Gamma}}\left[V_{n}(s) w^{*}(p, s)-m_{n}(s) \theta_{p}^{*}(p, s)\right] d \Gamma-\lim _{\Omega \rightarrow 0} \int_{\Omega-\bar{\Omega}} g(s) w^{*}(p, S) d \Omega= \\
\int_{\Gamma}\left[w(s) q_{n}^{*}(p, s)-\theta_{p}(s) m_{n}^{*}(p, s)-\theta_{t}(s) m_{n s}^{*}(p, s)\right] d \Gamma-\int_{\Omega} g(S) w^{*}(p, S) d \Omega
\end{gathered}
$$

Assim, restam os limites das integrais definidas sobre o contorno auxiliar $\Gamma_{\varepsilon}$. Utilizando-se o artifício de adicionar e subtrair o deslocamento transversal $w(p)$ e as rotações $\left[\frac{\partial}{\partial n} w(p), \frac{\partial}{\partial s} w(p)\right]$ às suas equivalentes no ponto campo $w, \frac{\partial}{\partial n} w=\theta_{p}, \frac{\partial}{\partial s} w=\theta_{t}$; uma identidade sobre o contorno auxiliar pode ser apresentada como:

$$
\begin{gathered}
i_{2}=\lim _{\Gamma_{\varepsilon} \rightarrow 0} \int_{\Gamma_{\varepsilon}}\left\{\{w(s)-w(p)] \alpha_{n}^{*}(p, s)-\left[\theta_{p}(s)-\frac{\partial}{\partial n} w(p)\right] m_{n}^{*}(p, s)\right\} d \Gamma- \\
\lim _{\Gamma_{\varepsilon} \rightarrow 0} \int_{\Gamma_{\varepsilon}}\left\{\left[\theta_{t}(s)-\frac{\partial}{\partial s} w(p)\right] \beta_{n}^{*}(p, s)+w(p) \alpha_{n}^{*}(p, s)\right\} d \Gamma- \\
\lim _{\Gamma_{\varepsilon} \rightarrow 0} \int_{\Gamma_{\varepsilon}}\left[m_{n}^{*}(p, s) \frac{\partial}{\partial_{n}} w(p)+\beta_{n}^{*}(p, s) \frac{\partial}{\partial s} w(p)\right] d \Gamma
\end{gathered}
$$

Admitido-se válida as condições de Hölder, os limites das três primeiras integrais em (3.114) tornam-se nulos. Assim, essa equação passa a ser escrita como:

$$
i_{2}=\int_{\Gamma_{\varepsilon}}\left\{w(p) \alpha_{n}^{*}(p, s)-m_{n}^{*}(p, s) \frac{\partial}{\partial s} w(p)-\beta_{n}^{*}(p, s) \frac{\partial}{\partial s} w(p)\right\} d \Gamma
$$

As rotações normal e tangencial podem ser escritas em função de direções genéricas $\left(m_{q}, u_{q}\right)$ indicadas na figura 3.4 como: 


$$
\left\{\begin{array}{l}
\frac{\partial}{\partial n} w(p) \\
\frac{\partial}{\partial s} w(p)
\end{array}\right\}=\left[\begin{array}{cc}
\operatorname{sen}(\phi-\gamma) & -\cos (\phi-\gamma) \\
\cos (\phi-\gamma) & \operatorname{sen}(\phi-\gamma)
\end{array}\right]\left\{\begin{array}{c}
\frac{\partial}{\partial m} w(p) \\
\frac{\partial}{\partial u} w(p)
\end{array}\right\}
$$

Substituindo-se (3.116) em (3.115), tem-se que:

$$
\begin{gathered}
\left.i_{2}=-\lim _{\varepsilon \rightarrow 0} \int_{\Gamma_{\varepsilon}}-\frac{1}{4 \pi}\left[(1+v) \ln \varepsilon+(1-v) r_{, n}^{2}+v\right] \operatorname{sen}(\phi-\gamma) \frac{\partial w(p)}{\partial m_{q}}-\cos (\phi-\gamma) \frac{\partial w(p)}{\partial m_{u}}\right] d \Gamma_{\varepsilon} \\
-\lim _{\varepsilon \rightarrow 0} \int_{\Gamma_{\varepsilon}}-\frac{1-v}{4 \pi} r_{, n} s_{, n}\left[\cos (\phi-\gamma) \frac{\partial w(p)}{\partial m_{q}}+\operatorname{sen}(\phi-\gamma) \frac{\partial w(p)}{\partial m_{u}}\right] d \Gamma_{\varepsilon}+\lim _{\varepsilon \rightarrow 0} \int_{\Gamma_{\varepsilon}} \alpha_{n}^{*} w(p) d \Gamma_{\varepsilon}
\end{gathered}
$$

A partir de relações geométricas indicadas na figura 3.5, pode-se concluir que $r_{, n}=1$ e $r_{, s}=0$. Com isso, $V_{n}^{*}=q_{n}^{*}$, de forma que a última parcela em (3.117) pode ser escrita como $\lim _{\varepsilon \rightarrow 0} \int_{\Gamma_{\varepsilon}}\left(\frac{-r_{, n}}{2 \pi \varepsilon}\right) w(p) d \Gamma_{\varepsilon}$. E, ainda, utilizando-se da relação $d \Gamma_{\varepsilon}=\varepsilon d \phi$, a identidade $i_{2}$ em (3.117) passa a ser escrita como:

$$
i_{2}=\frac{2 \pi-\beta}{2 \pi} w(p)
$$

Substituindo-se (3.118), (3.113) em (3.112), a representação integral geral para o deslocamento transversal pode ser expressa por:

$$
\begin{aligned}
& k w(p)+\oint_{\Gamma}\left[w(s) \alpha_{n}^{*}(p, s)-\theta_{p}(s) m_{n}^{*}(p, s)-\theta_{t}(s) \beta_{n}^{*}(p, s)\right] d \Gamma+\gamma_{c}^{*}(p, S) w_{c}(S)= \\
& R_{c}(S) w_{c}^{*}(p, S)+\oint_{\Gamma}\left[V_{n}(s) w^{*}(p, s)-m_{n}(s) \theta_{p}^{*}(p, s)\right] d \Gamma+\int_{\Omega} g(S) w^{*}(p, S) d \Omega ; c=1, \ldots, N c
\end{aligned}
$$

onde o termo livre de integral é dado por $k=\frac{\beta}{2 \pi}$.

Tal qual a representação integral do deslocamento transversal, há necessidade de investigar-se as singularidades que ocorrem na representação integral das derivadas direcionais do deslocamento transversal, ao levar-se o ponto-fonte para o contorno. Assim, pode-se utilizar de um procedimento análogo ao empregado na representação integral dos deslocamentos, isto é, após o acoplamento de um setor circular auxiliar com centro no ponto singular do contorno primitivo e a divisão desse contorno em $\left(\Gamma-\bar{\Gamma}, \Gamma_{\varepsilon}\right)$, as integrações podem ser estudadas individualmente em cada uma dessas regiões. 
O cálculo dos limites das integrais(3.82) sobre $\Gamma-\bar{\Gamma}$ pode ser tomado como os valores principais das integrais definidas sobre o contorno $\Gamma$, isto é:

$$
\begin{gathered}
w_{, m}(p)+\oint_{\Gamma}\left[w(s) \alpha_{n, m}^{*}(p, s)-\theta_{p}(s) m_{n, m}^{*}(p, s)-\theta_{t}(s) \beta_{n, m}^{*}(p, s)\right] d \Gamma+ \\
\lim _{\Gamma_{\varepsilon} \rightarrow 0} \int\left[w(s) \alpha_{\Gamma_{\varepsilon}}^{*}(p, s)-\theta_{p}(s) m_{n, m}^{*}(p, s)-\theta_{t}(s) \beta_{n, m}^{*}(p, s)\right] d \Gamma+ \\
\lim _{\Gamma_{\varepsilon} \rightarrow 0}\left[R_{c e}^{*}(p, S) w_{E}(S)+R_{c d}^{*}(p, S) w_{D}(S)\right]= \\
\oint_{\Gamma}\left[V_{n}(s) w_{, m}^{*}(p, s)-m_{n}(s) \theta_{p, m}^{*}(p, s)\right] d \Gamma+ \\
\lim _{\Gamma_{\varepsilon} \rightarrow 0} \int_{\Gamma_{\varepsilon}}\left[V_{n}(s) w_{, m}^{*}(p, s)-m_{n}(s) \theta_{p, m}^{*}(p, s)\right] d \Gamma+ \\
\lim _{\Gamma_{\varepsilon} \rightarrow 0}\left[R_{c e}(S) w_{-}^{*}(p, S)+R_{c d}(S) w_{+}^{*}(p, S)\right]+ \\
\int_{\Omega} g(S) w_{, m}^{*}(p, S) d \Omega ; \quad c=1, \ldots, N c
\end{gathered}
$$

Submetendo-se a placa a um movimento de corpo rígido de valor igual a $-w(p)$, vide figura 3.6, a equação (3.120) pode ser reapresentada como:

$$
\begin{gathered}
w_{, m}(p)+\oint_{\Gamma}\left\{[w(s)-w(p)] \alpha_{n, m}^{*}(p, s)-\theta_{p}(s) m_{n, m}^{*}(p, s)-\theta_{t}(s) \beta_{n, m}^{*}(p, s)\right\} d \Gamma+ \\
\lim _{\Gamma_{\varepsilon} \rightarrow 0} \int_{\Gamma_{\varepsilon}}\left\{[w(s)-w(p)] \alpha_{n, m}^{*}(p, s)-\theta_{p}(s) m_{n, m}^{*}(p, s)-\theta_{t}(s) \beta_{n, m}^{*}(p, s)\right\} d \Gamma+ \\
\lim _{\Gamma_{\varepsilon} \rightarrow 0}\left\{\gamma_{c e}^{*}(p, S)\left[w_{E}(S)-w(p)\right]+\gamma_{c d}^{*}(p, S)\left[w_{D}(S)-w(p)\right]\right\}+\gamma_{c}^{*}(p, S) w_{c}(S)+ \\
R_{c}(S) w_{c, m}^{*}(p, S)=\oint_{\Gamma}\left[V_{n}(s) w_{, m}^{*}(p, s)-m_{n}(s) \theta_{p, m}^{*}(p, s)\right] d \Gamma+ \\
\lim _{\Gamma_{\varepsilon} \rightarrow 0}\left[R_{c e}(S) w_{E}^{*}(p, S)+R_{c d}(S) w_{D}^{*}(p, S)\right]+\int_{\Omega} g(s) w_{, m}^{*}(p, s) d \Omega ; c=1, \ldots, N_{c}-1
\end{gathered}
$$

Os limites não-nulos das integrais definidas sobre o contorno auxiliar $\Gamma_{\varepsilon} \mathrm{em}$ (3.121) podem ser expressos como:

$$
\begin{aligned}
& i_{3}=\lim _{\Gamma_{\varepsilon} \rightarrow 0} \int_{\Gamma_{\varepsilon}}\left\{[w(s)-w(p)] \alpha_{n, m}^{*}(p, s)-\left[\theta_{p}(s)-\frac{\partial}{\partial n} w(p)\right] m_{n, m}^{*}(p, s)\right\} d \Gamma- \\
& \lim _{\Gamma_{\varepsilon} \rightarrow 0} \int_{\Gamma_{\varepsilon}}\left\{\left[\theta_{t}(s)-\frac{\partial}{\partial s} w(p)\right] \beta_{n, m}^{*}(p, s)-\left[m_{n, m}^{*}(p, s) \frac{\partial}{\partial h} w(p)+\beta_{n, m}^{*}(p, s) \frac{\partial}{\partial s} w(p)\right]\right\} d \Gamma+ \\
& \lim _{\Gamma_{\varepsilon \rightarrow 0}}\left\{\gamma_{c e}^{*}(p, S)\left[w_{E}(S)-w(p)\right]+\gamma_{c d}^{*}(p, S)\left[w_{D}(S)-w(p)\right]\right\}
\end{aligned}
$$


Admitindo-se como válidas as condições de Hölder, a segunda e a terceira parcela de (3.122) tornam-se nulas, de forma que passa a ser escrita como:

$$
\begin{gathered}
i_{3}=\lim _{\Gamma_{\varepsilon} \rightarrow 0} \int_{\Gamma_{\varepsilon}}\left\{\left\{[(s)-w(p)] \alpha_{n, m}^{*}(p, s)-\left[m_{n, m}^{*}(p, s) \frac{\partial}{\partial n} w(p)+\beta_{n, m}^{*}(p, s) \frac{\partial}{\partial} w(p)\right]\right\} d \Gamma+\right. \\
\lim _{\Gamma_{\varepsilon \rightarrow 0}}\left\{\gamma_{c e}^{*}(p, S)\left[w_{E}(S)-w(p)\right]+\gamma_{c d}^{*}(p, S)\left[w_{D}(S)-w(p)\right]\right\}
\end{gathered}
$$

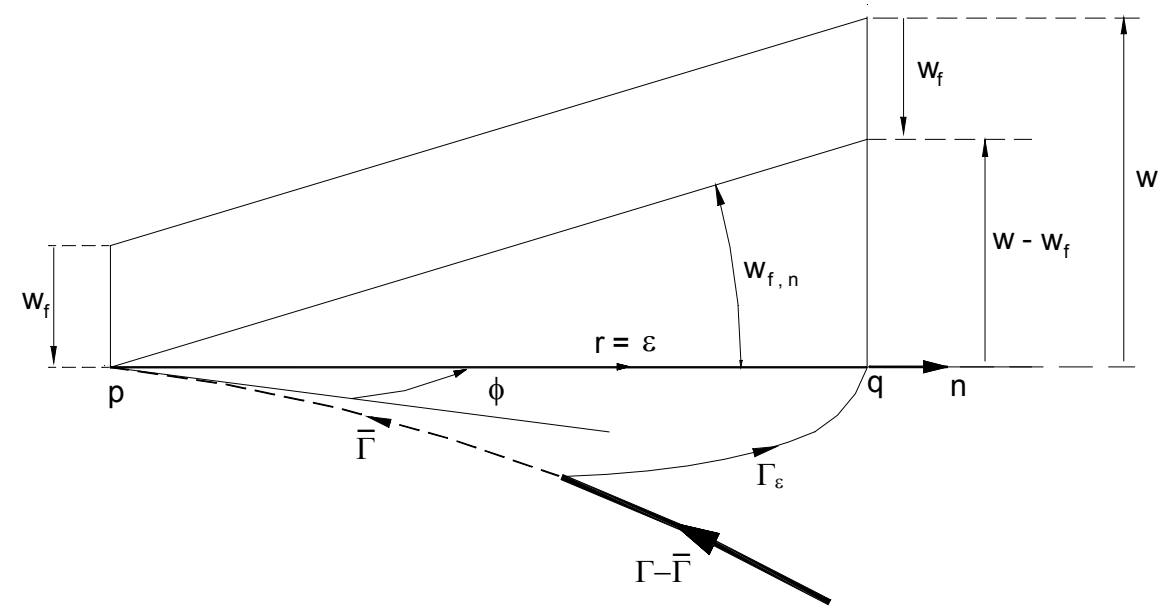

Figura 3.6-Movimento de corpo rígido para a obtenção do termo livre.

Ou a partir da figura 3.6 ou através da expansão de Taylor, é possível escrever a seguinte relação geométrica no contorno auxiliar:

$$
w(s)-w(p)=\varepsilon w_{, n}(p)
$$

Substituindo-se (3.124) em (3.123) e ainda com $r=\varepsilon, r_{, n}=1$ e $s_{, n}=0$, os termos envolvidos pela integral resultante podem ser rescritos como:

$$
\begin{gathered}
\overline{i_{3}}=\lim _{\Gamma_{\varepsilon} \rightarrow 0} \int\left[\frac{-a r_{, m}}{4 \pi \varepsilon^{2}} \varepsilon w_{, n}(p)-\frac{1}{4 \pi \varepsilon}(1+v) r_{, m} w_{, n}(p)\right] d \Gamma_{\varepsilon}- \\
\lim _{\Gamma_{\varepsilon} \rightarrow 0} \int \frac{b}{4 \pi \varepsilon}(1-v) m_{k} s_{k} \frac{\partial}{\partial s} w(p) d \Gamma_{\varepsilon}
\end{gathered}
$$

onde $(a, b)=(2,1)$, RTP; $(a, b)=(3-v, 0), \mathrm{RRG}$.

A partir da figura 3.5, pode-se deduzir que $r_{, i} m_{i}=\operatorname{sen}(\phi-\gamma) \mathrm{e}$ $s_{i} m_{i}=\cos (\phi-\gamma)$; o diferencial do contorno $d \Gamma_{e}=\varepsilon d \phi$ e substituindo-se essas relações e (3.116) em(3.125), tem-se que: 


$$
\begin{gathered}
\bar{i}_{3}=\frac{-(a+1+v)}{4 \pi} \lim _{\varepsilon \rightarrow 0} \int_{0}^{2 \pi-\beta}\left[\operatorname{sen}^{2}(\phi-\gamma) w_{, m}-\operatorname{sen}(\phi-\gamma) \cos (\phi-\gamma) w_{, u}\right] d \phi- \\
\frac{b}{4 \pi}(1-v) \lim _{\Gamma_{\varepsilon} \rightarrow 0} \int_{0}^{2 \pi-\beta}\left[\cos ^{2}(\phi-\gamma) w_{, m}+\operatorname{sen}(\phi-\gamma)\right] d \phi
\end{gathered}
$$

Após o cálculo das integrais presentes em (3.126), tem-se que:

$$
\begin{gathered}
\bar{i}_{3}=-\frac{[a+1+v+(1-v) b]}{8 \pi}(2 \pi-\beta) w_{, m}(p)- \\
\frac{[a+1+v-(1-v) b]}{16 \pi}\left\{[\operatorname{sen} 2(\beta+\gamma)-\operatorname{sen} 2 \gamma] w_{, m}(p)-\cos 2 \gamma \cos 2(\beta+\gamma) w_{, u}(p)\right\}
\end{gathered}
$$

Na identidade descrita em (3.123) ainda restam as parcelas livres de integral:

$$
\overline{\bar{i}}_{3}=\lim _{\Gamma_{\varepsilon \rightarrow 0}}\left\{\gamma_{c e}^{*}(p, S)\left[w_{E}(S)-w(p)\right]+\gamma_{c d}^{*}(p, S)\left[w_{D}(S)-w(p)\right]\right\}
$$

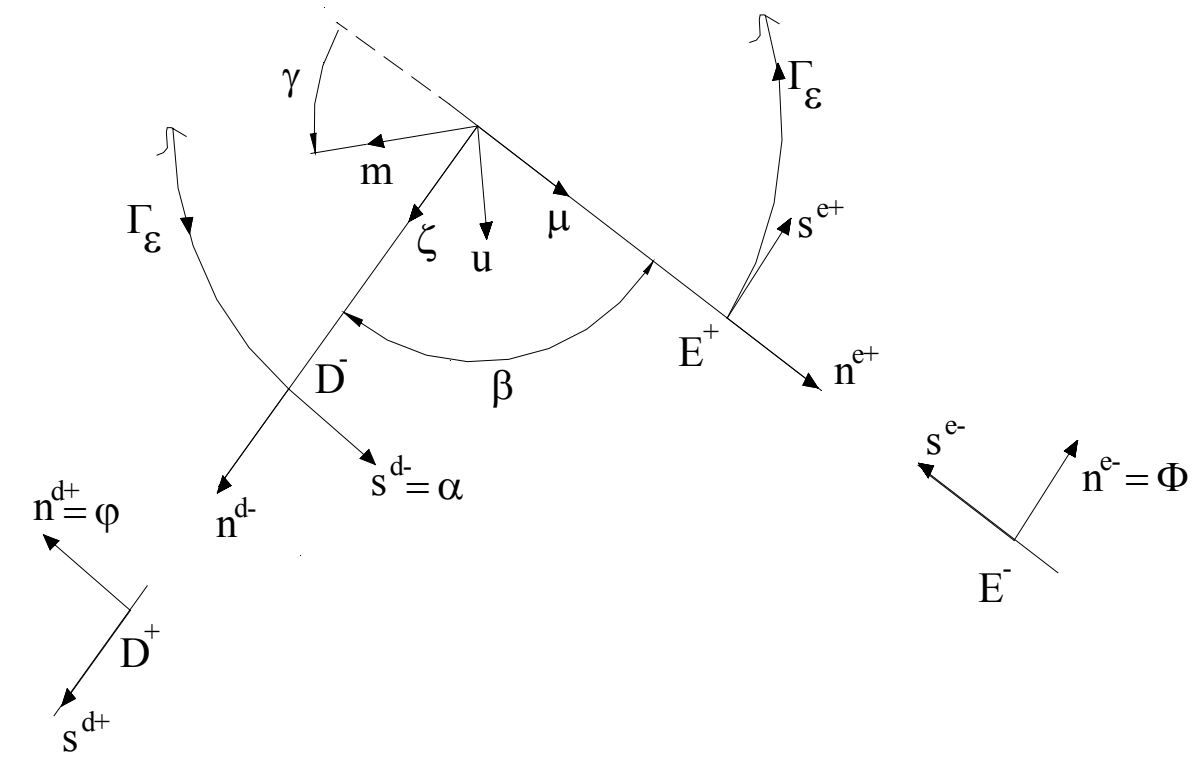

Figura 3.7-Pontos anteriores e posteriores aos cantos.

Assim, passa-se agora a examinar os dois cantos definidos pela interseção do setor de círculo com o contorno primitivo, vide figura 3.7. A primeira parcela associada ao primeiro canto pode ser escrita como:

$$
\gamma_{c e}^{*}(p, S)\left[w_{E}(S)-w(p)\right]=\left[m_{n s, m}^{*_{e+}}(p, S)-m_{n s, m}^{*_{e-}}(p, S)\right] \varepsilon w_{, \mu}(p)
$$


onde $m_{n s}^{*_{e+}}, m_{n s}^{*_{e-}}$ são os kernels das derivadas dos momentos volventes posterior e anterior ao canto E. Para o ponto anterior ao primeiro canto, a partir da figura 3.6, tem-se que $\mu_{i} n_{i}^{e-}=0$ e $\mu_{i} s_{i}^{e-}=-1$, que, se substituídos na expressão (3.87), esse kernel pode escrito como:

$$
m_{n s, m}^{*^{*}-}(p, S)=-\frac{(1-v)}{4 \pi \varepsilon} m_{k} \Phi_{k} ; k=1,2
$$

onde $\Phi_{i}$ é o co-seno diretor da normal ao contorno no ponto anterior ao canto $E$, vide figura 3.7 .

Para o ponto posterior ao canto $E$, tem-se as relações $\mu_{i} s_{i}^{e+}=0$ e $\mu_{i} n_{i}^{e+}=1$, que, quando levados em (3.87), tem-se que:

$$
m_{n s, m}^{*_{e+}}(p, S)=\frac{(1-v)}{4 \pi \varepsilon} m_{k} \Phi_{k} ; k=1,2
$$

Assim, outra relação pode ser escrita para o primeiro canto, substituindo-se (3.131) e (3.130) em (3.129):

$$
\gamma_{c e}^{*}(p, S)\left[w_{E}(S)-w(p)\right]=\frac{1-v}{2 \pi} m_{k} \Phi_{k} w_{, \mu}(p) ; k=1,2
$$

Analogamente ao tratamento do canto $E$, as relações geométricas para os pontos anterior e posterior ao canto $D$ podem ser escritas como $\left(\xi_{i} s_{i}^{d-}=0\right.$, $\left.\xi_{i} n_{i}^{d-}=1\right)$. Se essas relações forem substituídas em (3.87), tem-se os kernels anterior e posterior ao segundo canto- escritos como:

$$
\begin{aligned}
& \frac{m_{n s, m}^{* d-}(p, S)=-\frac{(1-v)}{4 \pi \varepsilon} m_{k} \alpha_{k}}{{ }^{*}} ; k=1,2 \\
& m_{n s, m}^{* d+}(p, S)=-\frac{(1-v)}{4 \pi \varepsilon} m_{k} \varphi_{k} ; k=1,2
\end{aligned}
$$

onde $\varphi_{i}$ é o co-seno diretor da nornal ao contorno no ponto posterior ao canto $D$. A partir da figura 3.7, pode ser notado que $\alpha_{i}$ tem orientação oposta à de $\varphi_{i}$, de forma que uma relação entre esses co-senos pode ser escrita como $\alpha_{i}=-\varphi_{i}$.

Assim, a segunda parcela de (3.128) pode ser expressa a partir da substituição de (3.134), (3.133) em (3.87) por: 


$$
\gamma_{c d}^{*}(p, S)\left[w_{D}(S)-w(p)\right]=\left[m_{n s, m}^{* d+}(p, S)-m_{n s, m}^{* d-}(p, S)\right] \varepsilon w_{, \xi}=-\frac{1-v}{2 \pi} m_{i} \varphi_{i} w_{, \xi}
$$

Além disso, as derivadas direcionais $w_{, \mu}$ e $w_{, \xi}$ podem ser escritas em função do sistema $(m, u)$ a partir de relações geométricas como, vide figura 3.7.

$$
\left\{\begin{array}{l}
w_{, \mu}(p) \\
w_{, \xi}(p)
\end{array}\right\}=-\left[\begin{array}{cc}
\operatorname{sen} \gamma & \cos \gamma \\
\operatorname{sen}(\gamma+\beta) & \cos (\gamma+\beta)
\end{array}\right]\left\{\begin{array}{l}
w_{, m}(p) \\
w_{, u}(p)
\end{array}\right\}
$$

Com o auxílio de (3.136) e das relações $m_{k} \Phi_{k}=\cos \gamma \quad \mathrm{e}$ $m_{i} \varphi_{i}=-\cos (\gamma+\beta)$, a relação (3.118) pode ser reescrita como:

$$
\overline{\bar{i}}_{3}=\frac{1}{4 \pi}\left\{[\operatorname{sen} 2(\gamma+\beta)-\operatorname{sen} 2 \gamma] w_{, m}(p)+[\cos 2 \gamma-\cos 2(\gamma+\beta)] w_{, u}(p)\right\}
$$

Ao substituir-se (3.137), (3.127) em (3.124), tem-se que:

$$
\begin{gathered}
i_{3}=-\frac{[a+1+v+(1-v) b]}{8 \pi}(2 \pi-\beta) w_{, m}(p)- \\
\frac{[a+1+v-(1-v) b-4 d]}{16 \pi}\left\{[\operatorname{sen} 2(\beta+\gamma)-\operatorname{sen} 2 \gamma] w_{, m}(p)-\cos 2 \gamma \cos 2(\beta+\gamma) w_{, u}(p)\right\}
\end{gathered}
$$

onde $(a, b, d)=(2,1,0)$, RTP; $(a, b, d)=(3-v, 0,1), \mathrm{RRG}$.

Se a expressão (3.138) for levada em (3.122), a representação integral da derivada direcional dos deslocamentos pode ser escrita como:

$$
\begin{gathered}
k_{3} w_{, m}(p)+k_{4} w_{, u}(p)+ \\
\oint_{\Gamma}\left[w(s) \alpha_{n, n_{q}}^{*}(p, s)-\theta_{p}(s) m_{n, m}^{*}(p, s)-\theta_{t}(s) \beta_{n, m}^{*}(p, s)\right] d \Gamma+\gamma_{c}^{*}(p, s) R_{c}(s)= \\
\oint_{\Gamma}\left[V_{n}(s) w_{, m}^{*}(p, s)-m_{n}(s) \theta_{p, m}^{*}(p, s)\right] d \Gamma+R_{c}(s) w_{c, m}^{*}(p, s)+\int_{\Omega} g(S) w_{, m}^{*}(p, s) d \Omega ; c=1, \ldots, N_{c}
\end{gathered}
$$

onde os termos livres de integral para a representação triparamétrica(RTP) podem ser escritos como:

$$
\begin{gathered}
k_{3}=\frac{\beta}{2 \pi}+\frac{(1+v)}{8 \pi}[\operatorname{sen} 2 \gamma-\operatorname{sen} 2(\gamma+\beta)] \\
k_{4}=\frac{(1+v)}{8 \pi}[\cos 2 \gamma-\cos 2(\gamma+\beta)]
\end{gathered}
$$


Se a representação integral for a de Rayleigh-Green(RRG), esses termos livres passam a ser expressos por:

$$
\begin{gathered}
k_{3}=\frac{\beta}{2 \pi}+\frac{(1+v)}{4 \pi}[\operatorname{sen} 2 \gamma-\operatorname{sen} 2(\gamma+\beta)] \\
k_{4}=\frac{(1+v)}{4 \pi}[\cos 2 \gamma-\cos 2(\gamma+\beta)]
\end{gathered}
$$

Quando a direção genérica $m$ é particularizada para a direção normal $n_{1}$ na região do contorno onde o ponto-fonte está locado, a RRG para a derivada dos deslocamentos pode ser escrita como:

$$
\begin{gathered}
k_{3} w_{, n_{I}}(p)+k_{4} w_{, s_{I}}(p)+\oint_{\Gamma}\left[w(s) V_{n, n_{I}}^{*}(p, s)-\theta_{p}(s) m_{n, n_{I}}^{*}(p, s)\right] d \Gamma+ \\
R_{c, m}^{*}(p, s) w_{c}(s)=\oint_{\Gamma}\left[V_{n}(s) w_{, n I}^{*}(p, s)-m_{n}(s) \theta_{p, n_{I}}^{*}(p, s)\right] d \Gamma+R_{c}(s) w_{c, n_{I}}^{*}(p, s)+ \\
\int_{\Omega} g(s) w_{, n I}^{*}(p, s) d \Omega, c=1, \ldots, N c
\end{gathered}
$$

onde $k_{3}$ e $k_{4}$ estão indicados em (3.142) e (3.143).

Se a representação integral for a triparamétrica, as derivadas segundo as direções normal e tangencial $\left(n_{1}, s_{1}\right)$ ao contorno onde o ponto-fonte está colocado podem ser expressas respectivamente por:

$$
\begin{gathered}
k_{3} w_{, n_{I}}(p)+k_{4} w_{, s_{I}}(p)+\oint_{\Gamma}\left[w(s) q_{n, n_{I}}^{*}(p, s)-\theta_{p}(s) m_{n, n_{I}}^{*}(p, s)-\theta_{t}(s) m_{n s, n_{I}}^{*}(p, s)\right] d \Gamma= \\
\oint_{\Gamma}\left[V_{n}(s) w_{, n I}^{*}(p, s)-m_{n}(s) \theta_{p, n_{I}}^{*}(p, s)\right] d \Gamma+R_{c}(s) w_{c, n_{I}}^{*}(p, s)+ \\
\int_{\Omega} g(s) w_{, n I}^{*}(p, s) d \Omega, c=1, \ldots, N c \\
k_{3} w_{, s_{I}}(p)+k_{4} w_{, n_{I}}(p)+\oint_{\Gamma}\left[w(s) q_{n, s_{I}}^{*}(p, s)-\theta_{p}(s) m_{n, s_{I}}^{*}(p, s)-\theta_{t}(s) m_{n s, s_{I}}^{*}(p, s)\right] d \Gamma= \\
\oint_{\Gamma}\left[V_{n}(s) w_{, s I}^{*}(p, s)-m_{n}(s) \theta_{p, s_{I}}^{*}(p, s)\right] d \Gamma+R_{c}(s) w_{c, s_{I}}^{*}(p, s)+\int_{\Omega} g(s) w_{, s I}^{*}(p, s) d \Omega ; c=1, \ldots, N c
\end{gathered}
$$

onde $k_{3}$ e $k_{4}$ estão indicados em (3.140) e (3.141).

Assim como nas representações dos deslocamentos e nas suas derivadas direcionais, quando o ponto-fonte é colocado no contorno, ocorrem singularidades nos kernels das representações integrais das curvaturas, dos momentos e da força cortante. Conforme discutido anteriormente, após a utilização de algumas estratégias, 
os termos livres de integral podem ser finitamente obtidos para as representações integrais de contorno para os deslocamentos e suas derivadas direcionais. Todavia para os campos das curvaturas e dos esforços, as ordens das singularidades tornam-se mais severas.

$\mathrm{Na}$ literatura, certos pesquisadores têm descrito algumas estratégias alternativas para explicitar as representações integrais de contorno desses campos utilizando-se principalmente as técnicas conhecidas como regularização numérica e analítica.

Embora tais técnicas sejam eficientes no abrandamento das singularidades mais críticas, em geral elas introduzem modificações nas variáveis primitivas do problema. Assim, neste trabalho, optou-se pela não utilização das representações integrais de contorno dos esforços no problema de placas; em contrapartida utilizaram-se outras estratégias conhecidas para escrever a representação algébrica do problema, que estão descritas no capítulo 4.

\subsection{3) Ações aplicadas linearmente distribuídas e concentradas(placas)}

As integrais de domínio para carregamentos externos aplicados e distribuídos em linha ou concentrados para placas delgadas podem ser escritas de maneira análoga ao apresentado na seção 3.2.3. Assim, o carregamento externo $g(S)$ pode ser subdivididos nas três regiões de aplicação, vide figura 3.4:

$$
g(S)=\left\{\begin{array}{cc}
g(S) & \text {, se } \left.S \in \Omega_{b} \text { (Bidimens. }\right) \\
\int_{\Omega_{l}} \delta(S, l) g_{L}(l) d \Omega_{l}(l)=g_{L}(S) & , \text { se } l \in \Omega_{l}(\text { Unidimens. }) \\
\delta(S, c) F(c) & , \text { se } c \text { for um ponto }
\end{array}\right.
$$

A partir de (3.119) e (3.147), o termo de domínio da representação integral de deslocamentos contemplando essas ações pode ser escrito como:

$$
\int_{\Omega} w^{*}(p, S) g(S) d \Omega=\int_{\Omega_{b}} w^{*}(p, S) g(S) d \Omega+\int_{\Omega_{l}} u_{i j}^{*}(p, S) b_{L j}(S) d \Omega+F(c) \int_{\Omega_{l}} u_{i j}^{*}(p, S) \delta(S, c) d \Omega
$$

Utilizando-se as propriedades do delta de Dirac em (3.148), tem-se que: 


$$
\int_{\Omega} w^{*}(p, S) g(S) d \Omega=\int_{\Omega_{b}} w^{*}(p, S) g(S) d \Omega+\int_{\Omega_{l}} u_{i j}^{*}(p, S) b_{L j}(S) d \Omega+w^{*}(p, c) F(c)
$$

Por meio de um procedimento análogo ao aplicado no termo de domínio de (3.119), os respectivos termos das representações integrais da derivada direcional dos deslocamentos(3.139), das curvaturas(3.89), dos momentos(3.96) e da derivada direcional do laplaciano de deslocamentos(3.104) podem ser expressos por:

$$
\begin{aligned}
& \int_{\Omega} w_{, m}^{*}(p, S) g(S) d \Omega=\int_{\Omega_{b}} w_{, m}^{*}(p, S) g(S) d \Omega+\int_{\Omega_{l}} w_{, m}^{*}(p, S) g_{L}(S) d \Omega+w_{, m}^{*}(p, c) F(c) \\
& \int_{\Omega} w_{, m q}^{*}(p, S) g(S) d \Omega=\int_{\Omega_{b}} w_{, m q}^{*}(p, S) g(S) d \Omega+\int_{\Omega_{l}} w_{, m q}^{*}(p, S) g_{L}(S) d \Omega+w_{, m q}^{*}(p, c) F(c) \\
& \int_{\Omega} \mu w^{*}(p, S) g(S) d \Omega=\int_{\Omega_{b}} \mu w^{*}(p, S) g(S) d \Omega+\int_{\Omega_{l}} \mu w^{*}(p, S) g_{L}(S) d \Omega+\mu w w^{*}(p, c) F(c) \\
& \int_{\Omega} w_{, m t t}^{*}(p, S) g(S) d \Omega=\int_{\Omega_{b}} w_{, m t t}^{*}(p, S) g(S) d \Omega+\int_{\Omega_{l}} w_{, m t t}^{*}(p, S) g_{L}(S) d \Omega+w_{, m t t}^{*}(p, c) F(c)
\end{aligned}
$$




\section{REPRESENTAÇÕES ALGÉBRICAS DOS PROBLEMAS ELÁSTICOS}

\section{1)Introdução}

Neste capítulo, as representações integrais para os estados planos e para placas delgadas descritas no capítulo 3 são discretizadas. E após o cálculo das integrações presentes, as representações algébricas são inicialmente escritas separadamente para os estados planos e o regime de flexão. Também são discutidas algumas abordagens aplicadas às aproximações das variáveis. Em seguida, as representações algébricas são adaptadas para incorporar problemas laminares mais simples compostos por elementos-base coplanares de rigidezes distintas. A partir de então, a técnica de acoplamento é estendida para estruturas não-coplanares. Esses procedimentos são descritos para a formulação tetraparamétrica(TP) e para a hexaparamétrica(HP).

\section{2) Representações integrais discretizadas}

\subsection{1) Discretização}

As soluções analíticas para as equações integrais (3.50), (3.54), (3.119) e (3.139) estão disponíveis para poucos casos particulares. Assim, parte-se para soluções numéricas. Entretanto, essas requerem que o contorno $\Gamma$ do problema seja discretizado, isto é, dividido em um número finito de regiões menores, que são denominadas de elementos de contorno. Em geral, quando há presença de termos contendo integrais de domínio, uma das técnicas que pode ser aplicada é a discretização do domínio $\Omega$ em regiões menores, células, vide fig. 4.1.

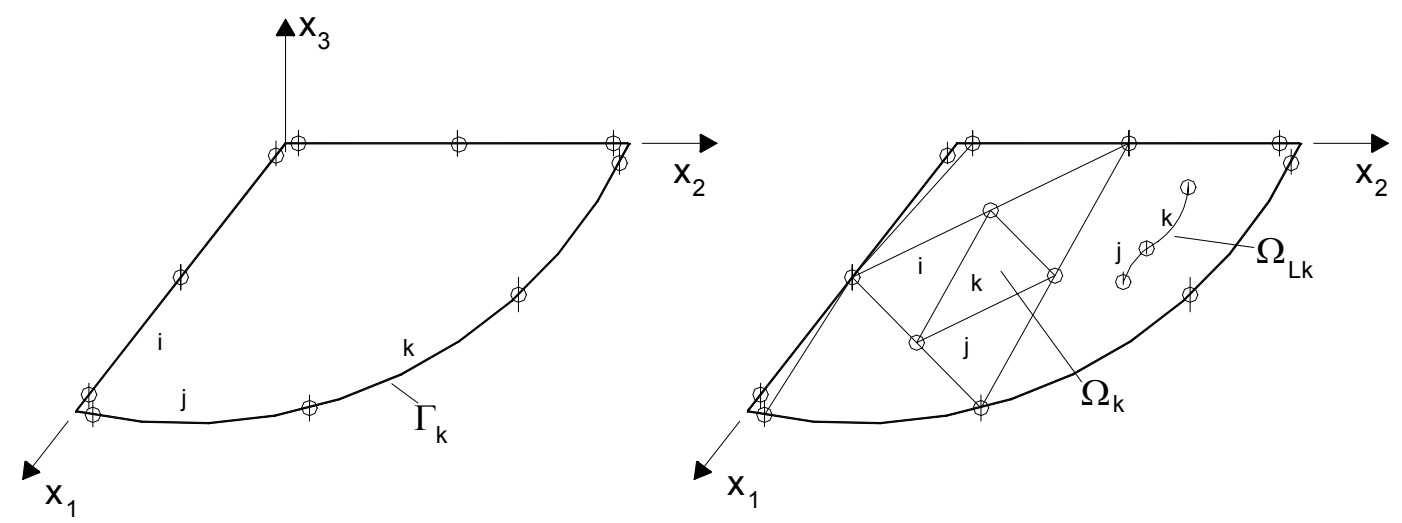

Figura 4.1- Discretização de contorno e de domínio. 
Assim, as representações integrais discretizadas de chapas associadas às equações (3.50) e (3.54) (de acordo com a formulação adotada) podem ser apresentadas como:

$$
\begin{aligned}
& \underset{\sim}{C} \underset{\sim}{(p)} \underset{\sim}{U}(p)+\sum_{k=1}^{N e l}\left[\int_{\Gamma_{k}} F_{\sim}^{*} \underset{\sim}{\Phi^{T}} \mathrm{~d} \Gamma_{k}\right] U_{k}^{n}(s)=\sum_{k=1}^{N e l}\left[\int_{\Gamma_{k}} U_{\sim}^{*}{\underset{\sim}{T}}^{T} \mathrm{~d} \Gamma_{k}\right] P_{k}^{n}(s)+ \\
& +\sum_{k=1}^{N c e l}\left[\int_{\Omega_{k}} U_{\sim}^{*} \Psi_{\sim}^{T} \mathrm{~d} \Omega_{\mathrm{k}}\right] B_{k}^{c}(S)+\sum_{k=1}^{N c e l l}\left[\int_{\Omega_{l k}} U_{\sim}^{*} \underset{\sim}{\Theta^{T}} \mathrm{~d} \Omega_{\mathrm{Lk}}\right] B_{L k}^{c c}(S)+\sum_{k=1}^{N f_{C}} U_{\sim}^{*} F_{k}(S)
\end{aligned}
$$

onde $n$ é o número de nós do elemento $k$; c e cc são os respectivos números de nós da célula $k$ com carregamentos aplicados em área e em linha; Nel, Ncel e Ncell são os respectivos números de elementos de contorno, de células das regiões submetidas a carregamentos aplicados em área e em linha; $\Phi^{\mathrm{T}}, \quad \Psi^{\mathrm{T}}$ e $\Theta^{\mathrm{T}}$ são as respectivas matrizes compostas por funções interpoladoras das variáveis de contorno e das forças volumétricas aplicadas em área e em linha.

$\mathrm{Na}$ representação (4.1), os vetores $k$-ésimos $P_{k}^{n}$ e $U_{k}^{n}$ estão associados às variáveis do contorno(forças e deslocamentos, respectivamente.); os vetores $k$-ésimos $B_{k}^{c}$ e $B_{L k}^{c c}$ estão associados às ações externas aplicadas distribuídas em área e linearmente, respectivamente; as matrizes $F^{*}$ e $U^{*}$ estão associadas aos conjuntos de kernels de forças e deslocamentos, respectivamente.

Já as representações integrais discretizadas de placas, (3.119) e (3.139), podem ser apresentadas como:

$$
\begin{aligned}
& \underset{\sim}{k}(p) \underset{\sim}{W}(p)+\sum_{k=1}^{N e l}\left[\int_{\Gamma_{k}} c_{\sim}^{*} \Phi_{\sim}^{T} d \Gamma_{k}\right] W_{\sim}^{n}(s)=\sum_{j=1}^{N e l}\left[\int_{\Gamma_{k}} d_{\sim}^{*} \Phi^{T} d \Gamma_{k}\right] V_{\sim}^{n}(s)+\sum_{g=1}^{N c} r_{g}(s) w_{g}^{*}+ \\
& \sum_{k=1}^{n c e l}\left[\int_{\Omega_{k}} w_{g}^{*} \Psi_{\sim}^{T} d \Omega_{k}\right] \underset{\sim}{G_{k}^{c}}(S)+\sum_{\substack{n=1 \\
\sim}}^{n c e l l}\left[\int_{\Omega_{L k}} w_{g}^{*} \Theta_{\sim}^{T} d \Omega_{L k}\right] \underset{\sim}{G_{L k}^{c}}(S)+\sum_{k=1}^{N F C} F_{k}(k) w_{\sim}^{*}
\end{aligned}
$$

Em (4.2), os vetores $k$-ésimos $V_{k}^{n}$ e $W_{k}^{n}$ estão associados às variáveis do contorno(esforços e deslocamentos, respectivamente); os vetores $k$-ésimos $G_{k}^{c}$ e $G_{L k}^{c c}$ estão associados às ações externas aplicadas e distribuídas em área e linearmente, 
respectivamente; as matrizes $c^{*}$ e $d^{*}$ estão associadas aos conjuntos de kernels de esforços e deslocamentos, respectivamente; $W_{g}^{*}$ é o vetor associado ao kernels dos deslocamentos dos cantos.

\subsection{2) Aproximação das variáveis do problema}

Neste trabalho, optou-se por duas abordagens para a interpolação das variáveis na formulação HP: a primeira consiste em aplicar-se as mesmas funções de forma tanto para os deslocamentos e rotações quanto para os esforços e forças de superfície. Na segunda abordagem são empregadas interpolações análogas para esses últimos, contudo, as funções aproximadoras para os deslocamentos e rotações são escritas de tal maneira que contemplem também ordens superiores nas interpolações. Já na formulação TP será empregada apenas a primeira técnica do modelo de HP.

\subsubsection{1) Interpolações na formulação Hexaparamétrica}

Na seqüência, são descritas as técnicas empregadas na abordagem HP para a obtenção da representação algébrica utilizando-se uma mesma função interpoladora para as variáveis dos problemas de chapas e placas.

Admitindo-se uma função interpoladora linear para a geometria do problema, resulta em:

$$
\left\{\begin{array}{l}
x_{1} \\
x_{2}
\end{array}\right\}=\left[\begin{array}{cc}
\varphi_{1} & 0 \\
0 & \varphi_{1}
\end{array}\right]\left\{\begin{array}{l}
x_{1}^{1} \\
x_{2}^{1}
\end{array}\right\}+\left[\begin{array}{cc}
\varphi_{2} & 0 \\
0 & \varphi_{2}
\end{array}\right]\left\{\begin{array}{l}
x_{1}^{2} \\
x_{2}^{2}
\end{array}\right\}
$$

onde $x_{i}^{1}, x_{i}^{2}$ são as respectivas coordenadas das extremidades iniciais e finais do elemento .

Adotando-se uma interpolação é isoparamétrica para o problema de placas, i.e., as variáveis são aproximadas pelas mesmas funções utilizadas para a geometria:

$$
\begin{gathered}
\left\{\begin{array}{c}
w \\
\theta_{p} \\
\theta_{t}
\end{array}\right\}=\left[\begin{array}{ccc}
\varphi_{1} & 0 & 0 \\
0 & \varphi_{1} & 0 \\
0 & 0 & \varphi_{1}
\end{array}\right]\left\{\begin{array}{c}
w^{l} \\
\theta_{p}^{1} \\
\theta_{t}^{l}
\end{array}\right\}+\left[\begin{array}{ccc}
\varphi_{2} & 0 & 0 \\
0 & \varphi_{2} & 0 \\
0 & 0 & \varphi_{2}
\end{array}\right]\left\{\begin{array}{c}
w^{2} \\
\theta_{p}^{2} \\
\theta_{t}^{2}
\end{array}\right\} \\
\left\{\begin{array}{l}
V_{n} \\
m_{n}
\end{array}\right\}=\left[\begin{array}{cc}
\varphi_{1} & 0 \\
0 & \varphi_{1}
\end{array}\right]\left\{\begin{array}{l}
V_{n}^{l} \\
m_{n}^{1}
\end{array}\right\}+\left[\begin{array}{cc}
\varphi_{2} & 0 \\
0 & \varphi_{2}
\end{array}\right]\left\{\begin{array}{l}
V_{n}^{2} \\
m_{n}^{2}
\end{array}\right\}
\end{gathered}
$$


Note que no modelo HP, o vetor dos deslocamentos de placas é formado por um deslocamento e duas rotações (normal e tangencial ao contorno).

Assim, substituindo-se (4.4) e (4.5) em (4.2), as representações integrais discretizadas de placas podem ser escritas como:

$$
\begin{gathered}
c I\left[\begin{array}{c}
w(p) \\
w_{, \mu}(p) \\
w_{, \mu}(p)
\end{array}\right]+\sum_{k=1}^{N e l} \int_{\Gamma_{k}}\left[\begin{array}{ccc}
q_{n}^{*} & -m_{n}^{*} & -m_{n s}^{*} \\
q_{n, \mu}^{*} & -m_{n, \mu}^{*} & -m_{n s, \mu}^{*} \\
q_{n, \xi}^{*} & -m_{n, \xi}^{*} & -m_{n s, \xi}^{*}
\end{array}\right]\left(\begin{array}{cccccc}
\varphi_{1} & 0 & 0 & \varphi_{2} & 0 & 0 \\
0 & \varphi_{1} & 0 & 0 & \varphi_{2} & 0 \\
0 & 0 & \varphi_{1} & 0 & 0 & \varphi_{2}
\end{array}\right) d \Gamma_{k}\left\{W_{k}^{2}\right\}= \\
\sum_{k=1}^{N e l} \int_{\Gamma_{k}}\left[\begin{array}{ccc}
w^{*} & -\theta_{p}^{*} & 0 \\
w_{, \mu}^{*} & -\theta_{p, \mu}^{*} & 0 \\
w_{, \xi}^{*} & -\theta_{p, \xi}^{*} & 0
\end{array}\right]\left(\begin{array}{cccccc}
\varphi_{1} & 0 & 0 & \varphi_{2} & 0 & 0 \\
0 & \varphi_{1} & 0 & 0 & \varphi_{2} & 0 \\
0 & 0 & \varphi_{1} & 0 & 0 & \varphi_{2}
\end{array}\right) d \Gamma_{k}\left\{V_{k}^{2}\right\}+\sum_{k=1}^{N_{c}}\left(\begin{array}{c}
w^{*} \\
w_{, \mu}^{*} \\
w_{, \xi}^{*}
\end{array}\right) R_{c k}+\left(\begin{array}{l}
g_{1} \\
g_{2} \\
g_{3}
\end{array}\right)
\end{gathered}
$$

onde $I$ é a matriz identidade; $c$ é o termo livre de integral que recebe o valor unitário para pontos-fonte no domínio; Em contornos suaves seu valor é $c=1 / 2$ e em formulações regulares recebe valor nulo. Os demais vetores têm em (4.6) podem ser representados como:

$$
\begin{gathered}
\left\{w_{k}^{2}\right\}^{T}=\left(\begin{array}{llllll}
w^{1} & \theta_{p}^{1} & \theta_{t}^{1} & w^{2} & \theta_{p}^{2} & \theta_{t}^{2}
\end{array}\right) \\
\left\{V_{k}^{2}\right\}^{T}=\left(\begin{array}{llllll}
V_{n}^{1} & m_{n}^{l} & \alpha^{1} & V_{n}^{2} & m_{n}^{2} & \alpha^{2}
\end{array}\right) \\
\varphi_{1}=\frac{1}{2}(1-\varsigma) ; \varphi_{2}=\frac{1}{2}(1+\varsigma)
\end{gathered}
$$

As funções interpoladoras $\varphi_{i}$ indicadas em (4.9) são definidas a partir de coordenadas adimensionais, conforme indicadas na figura 4.2 .
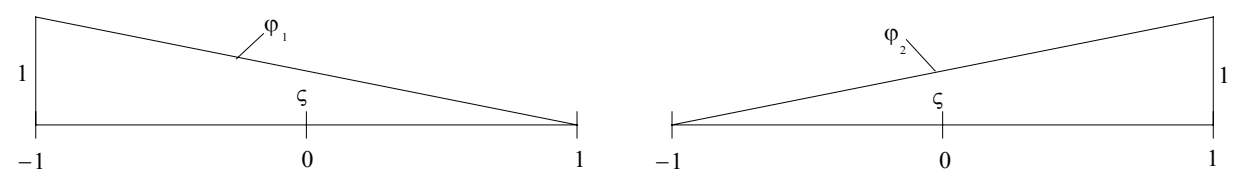

Figura 4.2- Funções interpoladoras lineares.

Os graus de liberdade remanescentes da lâmina plana associados ao problema de chapas podem ser interpolados de maneira análoga aos de placas: 


$$
\begin{gathered}
\left\{\begin{array}{l}
v_{1} \\
v_{2} \\
\theta_{z}
\end{array}\right\}=\left[\begin{array}{ccc}
\varphi_{1} & 0 & 0 \\
0 & \varphi_{1} & 0 \\
0 & 0 & \varphi_{1}
\end{array}\right]\left\{\begin{array}{l}
v_{1}^{1} \\
v_{2}^{1} \\
\theta_{z}^{1}
\end{array}\right\}+\left[\begin{array}{ccc}
\varphi_{2} & 0 & 0 \\
0 & \varphi_{2} & 0 \\
0 & 0 & \varphi_{2}
\end{array}\right]\left\{\begin{array}{l}
v_{1}^{2} \\
v_{2}^{2} \\
\theta_{z}^{2}
\end{array}\right\} ; \\
\left\{\begin{array}{l}
t_{1} \\
t_{2}
\end{array}\right\}=\left[\begin{array}{cc}
\varphi_{1} & 0 \\
0 & \varphi_{1}
\end{array}\right]\left\{\begin{array}{l}
t_{1}^{1} \\
t_{2}^{1}
\end{array}\right\}+\left[\begin{array}{cc}
\varphi_{2} & 0 \\
0 & \varphi_{2}
\end{array}\right]\left\{\begin{array}{l}
t_{1}^{2} \\
t_{2}^{2}
\end{array}\right\}
\end{gathered}
$$

Convém notar que o vetor de deslocamentos deslocamento em chapas é composto por dois deslocamentos (tangencial e normal ao contorno) e por uma rotação normal ao plano médio, neste trabalho chamada de rotação zenital.

Substituindo-se (4.10), (4.11) em (4.1), as representações integrais de chapas podem ser escritas como:

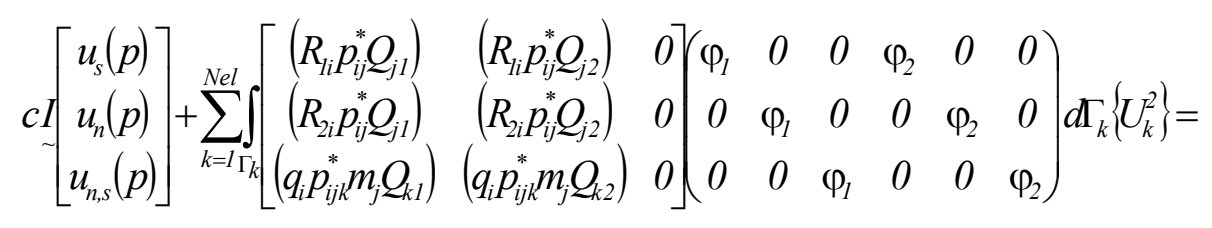

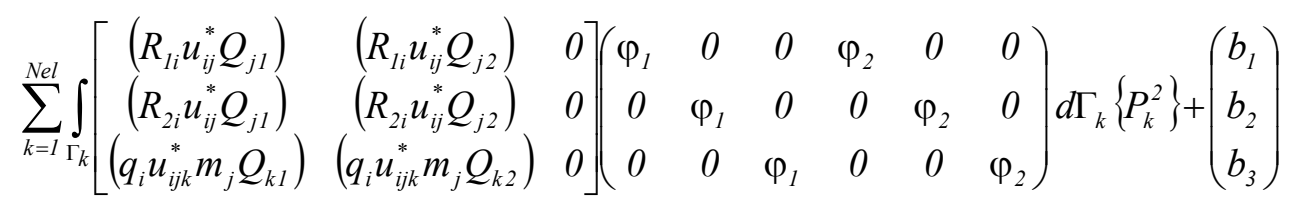

onde:

$$
\begin{gathered}
\left\{U_{k}^{2}\right\}^{T}=\left(\begin{array}{llllll}
v_{1}^{1} & v_{2}^{l} & \theta_{z}^{l} & v_{1}^{2} & v_{2}^{2} & \theta_{z}^{2}
\end{array}\right) \\
\left\{P_{k}^{2}\right\}^{T}=\left(\begin{array}{llllll}
t_{1}^{1} & t_{2}^{1} & \beta^{1} & t_{1}^{2} & t_{2}^{2} & \beta^{2}
\end{array}\right)
\end{gathered}
$$

Além da análise isoparamétrica, é discutido o emprego de funções aproximadoras distintas para a obtenção das matrizes de influência do problema no modelo HP. Os deslocamentos normais da chapa são aproximados por meio de uma interpolação cúbica envolvendo os valores nodais de deslocamentos e de suas derivadas tangenciais:

$$
u_{n}=\phi_{1} v_{1}^{1}+\phi_{2} \theta_{z}^{1}+\phi_{3} v_{2}^{2}+\phi_{4} \theta_{z}^{2}
$$

onde as funções de forma $\phi_{i}$ estão indicadas na figura 4.3 e podem ser escritas como:

$$
\begin{gathered}
\phi_{1}=2 \varsigma^{3}-3 \varsigma^{2}+1 ; \phi_{2}=L \varsigma\left(\varsigma^{2}-2 \varsigma+1\right) ; \\
\phi_{3}=-2 \varsigma^{3}+3 \varsigma^{2} ; \phi_{4}=L \varsigma^{2}(\varsigma-1)
\end{gathered}
$$

onde $L$ é o comprimento do elemento de contorno. 

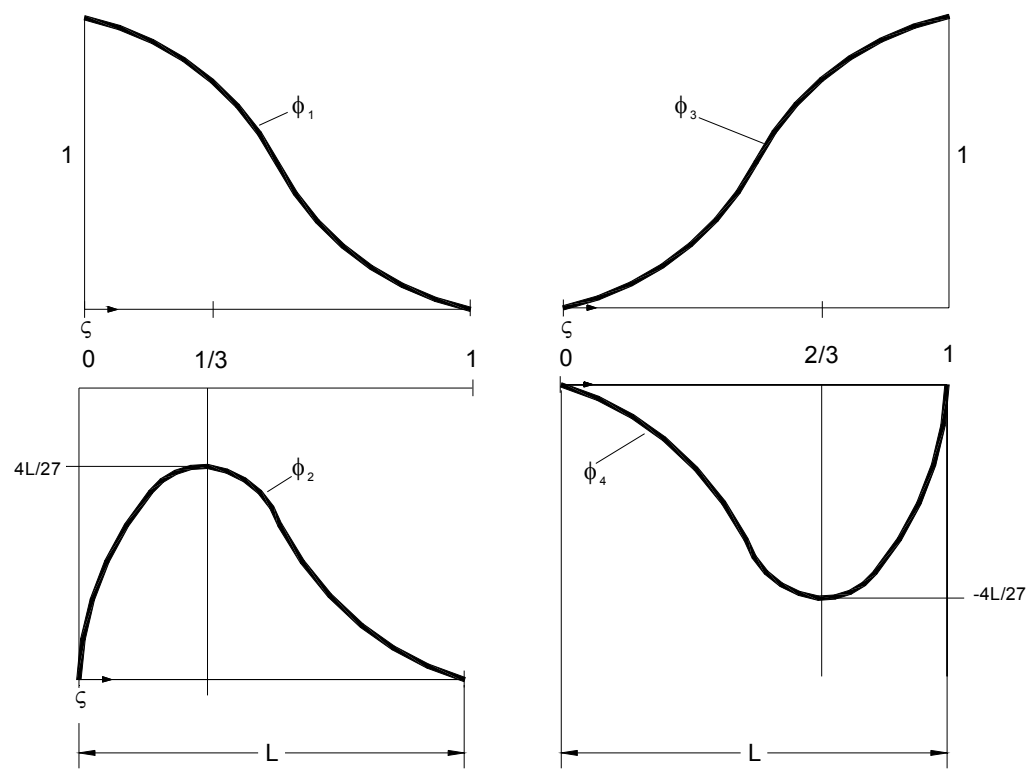

Figura 4.3- Funções Interpoladoras $\phi_{i}$.

Já os deslocamentos tangenciais são escritos com a mesma interpolação empregada na análise isoparamétrica linear:

$$
u_{s}=\varphi_{1} v_{1}^{1}+\varphi_{2} v_{1}^{2}
$$

As rotações no plano da chapa podem ser expressas a partir da diferenciação de (4.17):

$$
u_{n, s}=\phi_{1}^{\prime} v_{2}^{1}+\phi_{2}^{\prime} \theta_{z}^{1}+\phi_{3}^{\prime} v_{2}^{2}+\phi_{4}^{\prime} \theta_{z}^{2}
$$

onde as funções de forma $\phi_{i}^{\prime}$, indicadas na figura 4.4, podem ser escritas como:

$$
\begin{gathered}
\phi_{1}^{\prime}=\frac{6}{\mathrm{~L}} \varsigma(\varsigma-1) ; \phi_{2}^{\prime}=3 \varsigma^{2}-4 \varsigma+1 ; \\
\phi_{3}^{\prime}=-\frac{6}{\mathrm{~L}} \varsigma(\varsigma-1) ; \phi_{4}^{\prime}=\varsigma(3 \varsigma-2)
\end{gathered}
$$

Ressaltando-se que as interpolações para as forças de superfície são análogas a da abordagem isoparamétrica linear.

A partir da substituição de (4.16), (4.17), (4.18) e (4.19) em (4.1), a representação integral discretizada de chapas passa a ser escrita como: 


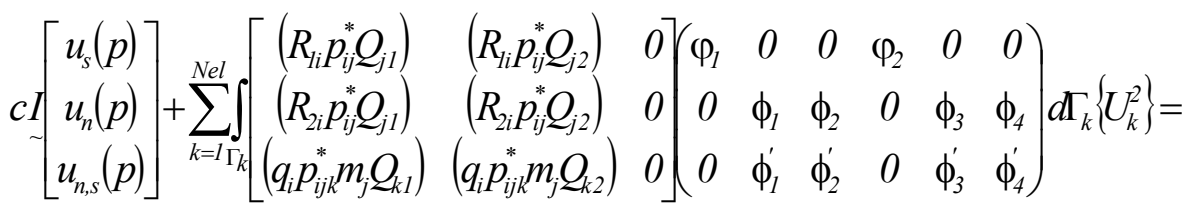

$$
\begin{aligned}
& \sum_{k=1}^{N e l} \int_{\Gamma_{k}}\left[\begin{array}{ccc}
\left(R_{l i} u_{i j}^{*} Q_{j 1}\right) & \left(R_{1 i} u_{i j}^{*} Q_{j 2}\right) & 0 \\
\left(R_{2 i} u_{i j}^{*} Q_{j 1}\right) & \left(R_{2 i} u_{i j}^{*} Q_{j 2}\right) & 0 \\
\left(q_{i} u_{i j k}^{*} m_{j} Q_{k 1}\right) & \left(q_{i} u_{i j k}^{*} m_{j} Q_{k 2}\right) & 0
\end{array}\right]\left(\begin{array}{cccccc}
\varphi_{1} & 0 & 0 & \varphi_{2} & 0 & 0 \\
0 & \varphi_{1} & 0 & 0 & \varphi_{2} & 0 \\
0 & 0 & \varphi_{1} & 0 & 0 & \varphi_{2}
\end{array}\right) d \Gamma_{k}\left\{P_{k}^{2}\right\}+\left(\begin{array}{l}
b_{1} \\
b_{2} \\
b_{3}
\end{array}\right)
\end{aligned}
$$
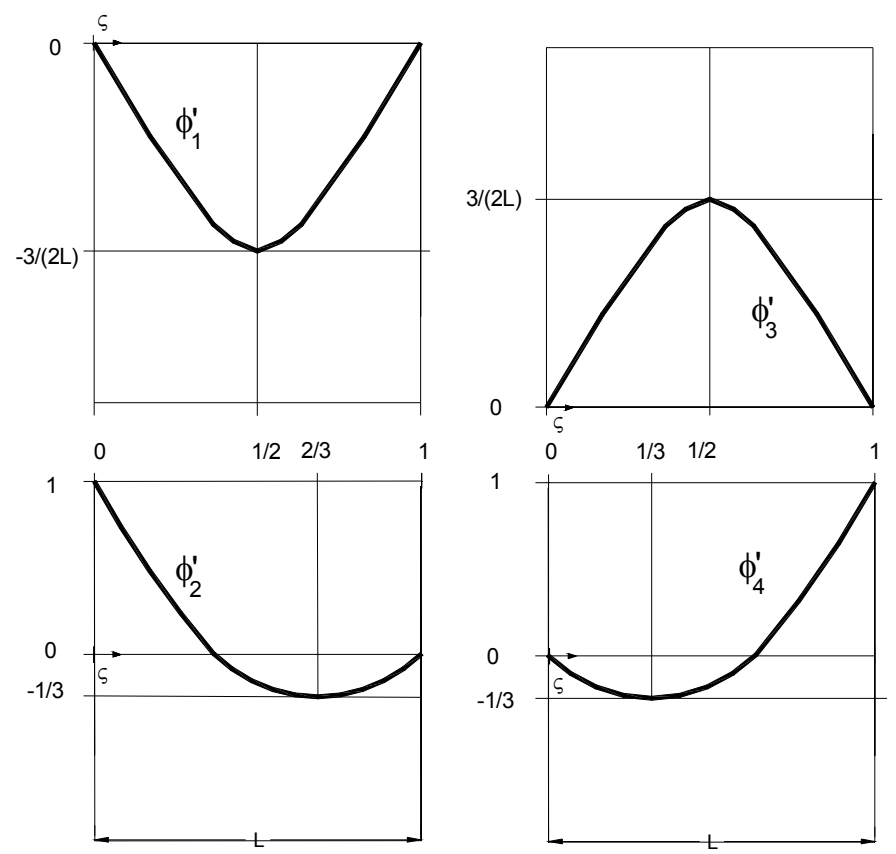

Figura 4.4-Funções interpoladoras $\phi_{i}^{\prime}$.

Uma interpolação análoga ao problema de chapas pode ser aplicada aos deslocamentos e rotações da placa, isto é:

$$
\begin{gathered}
w=\phi_{1} w^{1}+\phi_{2} \theta_{t}^{1}+\phi_{3} w^{2}+\phi_{4} \theta_{t}^{2} \\
\theta_{p}=\varphi_{1} \theta_{p}^{1}+\varphi_{2} \theta_{p}^{2} \\
\theta_{t}=\phi_{1}^{\prime} w^{1}+\phi_{2}^{\prime} \theta_{t}^{1}+\phi_{3}^{\prime} w^{2}+\phi_{4}^{\prime} \theta_{t}^{2}
\end{gathered}
$$

As interpolações para os esforços são análogas ao caso isoparamétrico linear. Assim, substituindo-se (4.5), (4.21)-(4.23) em (4.2), a representação integral discretizada de placas passa a ser expressa como: 


$$
\begin{aligned}
& c \underset{\sim}{\sim}\left[\begin{array}{c}
w(p) \\
w_{, \mu}(p) \\
w_{, \xi}(p)
\end{array}\right]+\sum_{k=1}^{N e l} \int_{\Gamma_{k}}\left[\begin{array}{ccc}
q_{n}^{*} & -m_{n}^{*} & -m_{n s}^{*} \\
q_{n, \mu}^{*} & -m_{n, \mu}^{*} & -m_{n s, \mu}^{*} \\
q_{n, \xi}^{*} & -m_{n, \xi}^{*} & -m_{n s, \xi}^{*}
\end{array}\right]\left(\begin{array}{cccccc}
\phi_{1} & 0 & \phi_{2} & \phi_{3} & 0 & \phi_{4} \\
0 & \varphi_{1} & 0 & 0 & \varphi_{2} & 0 \\
\phi_{1}^{\prime} & 0 & \phi_{2}^{\prime} & \phi_{3}^{\prime} & 0 & \phi_{4}^{\prime}
\end{array}\right] d \Gamma_{k}\left\{W_{k}^{2}\right\}= \\
& \sum_{k=1}^{N e l} \int_{\Gamma_{k}}\left[\begin{array}{ccc}
w^{*} & -\theta_{p}^{*} & 0 \\
w_{, \mu}^{*} & -\theta_{p, \mu}^{*} & 0 \\
w_{, \xi}^{*} & -\theta_{p, \xi}^{*} & 0
\end{array}\right]\left(\begin{array}{cccccc}
\varphi_{1} & 0 & 0 & \varphi_{2} & 0 & 0 \\
0 & \varphi_{1} & 0 & 0 & \varphi_{2} & 0 \\
0 & 0 & \varphi_{1} & 0 & 0 & \varphi_{2}
\end{array}\right) d \Gamma_{k}\left\{V_{k}^{2}\right\}+\sum_{k=1}^{N_{c}}\left(\begin{array}{c}
w^{*} \\
w_{, \mu}^{*} \\
w_{, \xi}^{*}
\end{array}\right) R_{c k}+\left(\begin{array}{l}
g_{1} \\
g_{2} \\
g_{3}
\end{array}\right)
\end{aligned}
$$

onde $w_{, \mu}(p)=\theta_{p}(p)$ e $w_{, \xi}(p)=\theta_{t}(p)$.

Os vetores independentes, $\left(\begin{array}{llllllll}g_{1} & g_{2} & g_{3}\end{array}\right)^{T}$ em (4.24) e $\left(\begin{array}{llll}b_{1} & b_{2} & b_{3}\end{array}\right)^{T}$ em (4.20), são obtidos pela integração dos carregamentos externos distribuídos em área e em linha sobre suas respectivas regiões de aplicação. Em placas, esse vetor pode ser escrito como:

$$
\left(\begin{array}{l}
g_{1} \\
g_{2} \\
g_{3}
\end{array}\right)=\sum_{k=1}^{N c e l} \int_{\Omega_{k}}\left(\begin{array}{c}
w^{*} \\
w_{, \mu}^{*} \\
w_{, \xi}^{*}
\end{array}\right) g_{k}(S) d \Omega_{k}+\sum_{k=1}^{N c e l l} \int_{\Omega_{k}}\left(\begin{array}{c}
w^{*} \\
w_{, \mu}^{*} \\
w_{, \xi}^{*}
\end{array}\right) g_{L k}(S) d \Omega_{k}+\sum_{k=1}^{N F c}\left(\begin{array}{c}
w^{*} \\
w_{, \mu}^{*} \\
w_{, \xi}^{*}
\end{array}\right) F_{k}
$$

\subsubsection{2) Interpolações na formulação Tetraparamétrica}

$\mathrm{Na}$ aproximação das variáveis no modelo TP é utilizada a interpolação isoparamétrica linear. Assim, empregando-se uma representação similar do vetor dos esforços (4.11) para seu respectivo vetor dos deslocamentos, a representação integral discretizada de chapas(3.50) pode ser escrita como:

$$
\begin{aligned}
& c I\left[\begin{array}{l}
u_{s}(p) \\
u_{n}(p)
\end{array}\right]+\sum_{k=1}^{N e l} \int_{\Gamma_{k}}\left[\begin{array}{ll}
\left(R_{l i} p_{i j}^{*} Q_{j 1}\right) & \left(R_{l i} p_{i j}^{*} Q_{j 2}\right) \\
\left(R_{2 i} p_{i j}^{*} Q_{j 1}\right) & \left(R_{2 i} p_{i j}^{*} Q_{j 2}\right)
\end{array}\right) \underset{\sim}{\varphi d \Gamma_{k}}\left\{U_{k}^{n}\right\}= \\
& \sum_{k=1}^{N e l} \int_{\Gamma_{k}}\left[\begin{array}{ll}
\left(R_{1 i} u_{i j}^{*} Q_{j 1}\right) & \left(R_{1 i} u_{i j}^{*} Q_{j 2}\right) \\
\left(R_{2 i} u_{i j}^{*} Q_{j 1}\right) & \left(R_{2 i} u_{i j}^{*} Q_{j 2}\right)
\end{array}\right] \underset{\sim}{\varphi} d \Gamma_{k}\left\{P_{k}^{n}\right\}+\left\{\begin{array}{l}
b_{1} \\
b_{2}
\end{array}\right\}
\end{aligned}
$$

onde os vetores em (4.26) são dados por:

$$
\begin{gathered}
\left\{U_{k}^{n}\right\}^{T}=\left(\begin{array}{llll}
v_{1}^{l} & v_{2}^{1} \cdots & v_{1}^{n} & v_{2}^{n}
\end{array}\right) \\
\left\{P_{k}^{n}\right\}^{T}=\left(\begin{array}{llll}
t_{1}^{1} & t_{2}^{1} \cdots & t_{1}^{n} & t_{2}^{n}
\end{array}\right)
\end{gathered}
$$

Analogamente, as equações integrais discretizadas de placas, (3.119) e (3.139), podem expressas a partir da aplicação de interpolação similar em(4.5) para seus respectivos deslocamentos: 


$$
\begin{aligned}
& c I\left[\begin{array}{c}
w(p) \\
w_{, \mu}(p)
\end{array}\right]+\sum_{k=1}^{N e l} \int_{\Gamma_{k}}\left[\begin{array}{cc}
V_{n}^{*} & -m_{n}^{*} \\
V_{n, \mu}^{*} & -m_{n, \mu}^{*}
\end{array}\right] \varphi d \Gamma_{k}\left\{W_{k}^{n}\right\}+\sum_{k=1}^{N c}\left[\begin{array}{c}
R_{c k}^{*} \\
R_{c k, \mu}^{*}
\end{array}\right] W_{k}= \\
& \sum_{k=1}^{N e l} \int_{\Gamma_{k}}\left[\begin{array}{cc}
w^{*} & -\theta_{p}^{*} \\
w_{, \mu}^{*} & -\theta_{p, \mu}^{*}
\end{array}\right] \varphi d \Gamma_{k}\left\{V_{k}^{n}\right\}+\sum_{k=1}^{N_{c}}\left[\begin{array}{c}
w^{*} \\
w_{, \mu}^{*}
\end{array}\right] R_{c k}+\left\{\begin{array}{c}
g_{1} \\
g_{2}
\end{array}\right\}
\end{aligned}
$$

onde $I$ e $c$ têm as mesmas definições indicadas na seção (4.2.2.1). Os vetores em (4.29) são expressos como:

$$
\begin{aligned}
& \left\{w_{k}^{n}\right\}^{T}=\left(\begin{array}{llll}
w^{l} & \theta_{p}^{1} \cdots & w^{n} & \theta_{p}^{n}
\end{array}\right) \\
& \left\{V_{k}^{n}\right\}^{T}=\left(\begin{array}{llll}
V_{n}^{1} & m_{n}^{1} \cdots & V_{n}^{2} & m_{n}^{2}
\end{array}\right)
\end{aligned}
$$

\subsection{3) Transformação das integrais de domínio para o carregamento}

Algumas integrais definidas sobre o domínio $\Omega_{d}$ de uma região associada a uma célula $d$ podem ser transformadas em outras equivalentes que envolvem apenas integrações ao longo de seus contornos $\Gamma_{d c e l}$. Em PAIVA(1987), foi proposta uma técnica para o problema de placas em que o domínio foi discretizado em células triangulares devido à grande adaptabilidade às geometrias poligonais; além disso, foi admitido que um carregamento externo linearmente distribuído atuava sobre o domínio de cada célula. Na seqüência, são mostradas as etapas utilizadas na transformação das integrais de placas e de chapas empregando-se os procedimentos descritos no trabalho de Paiva publicado em 1987.

A partir das hipóteses descritas anteriormente, a integral de domínio e o carregamento podem ser expressos respectivamente por:

$$
\begin{gathered}
h_{d}=\int_{\Omega_{d}} g \underset{\sim g}{W_{g}^{*} d \Omega_{d}} \\
g(S)=A_{i} x_{1 s}(S)+B_{i} x_{2 s}(S)+C_{i}(S)
\end{gathered}
$$

onde $x_{1 s}, x_{2 s}$ são as coordenadas do ponto $S$ no sistema $\left(x_{1}, x_{2}\right)$ e o vetor dos kernels dados por $\underset{\sim g}{W_{g}^{*}}=\left(\begin{array}{lll}w^{*} & w_{, \sigma}^{*} & w_{, \varepsilon}^{*}\end{array}\right)^{T}$.

Através de uma translação de sistemas de referência, as coordenadas do ponto $s$ podem ser escritas em relação a um sistema $\left(\bar{x}_{1}, \bar{x}_{2}\right)$, e em seguida, submetendo-se 
uma transformação desse último para o sistema polar $(r, \theta)$, o carregamento pode ser escrito como:

$$
g(p)=A_{i} r \cos \theta+B_{i} r \operatorname{sen} \theta+D_{i}(p)
$$

onde:

$$
D_{i}(p)=A_{i} x_{1 s}(S)+B_{i} x_{2 s}(S)+C_{i}(S)
$$

Por meio do Jacobiano de transformação, a relação entre os diferenciais em coordenadas cartesianas e polares é dada por:

$$
d \Omega_{d}=r d r d \theta
$$

A partir de (4.32)-(4.36), a contribuição da integral envolvendo o carregamento distribuído em área pode ser dada como:

$$
h_{\sim}=\iint_{\theta} w_{\rho} w_{g}^{*}\left(A_{i} r \cos \theta+B_{i} r \operatorname{sen} \theta+D_{i}\right) r d r d \theta
$$

Como o vetor $w_{g}^{*}$ é uma função de $\boldsymbol{r}$, a equação (4.37) pode ser integrada, resultando em:

$$
\underset{\sim}{h_{d}}=\int_{\theta} \underset{\sim}{\lambda}(\rho) d \theta
$$

onde $\rho$ é o valor de $\boldsymbol{r}$ no contorno da célula.

A partir de relações geométricas, vide Figura 4.5, pode-se escrever que:

$$
d \theta=\frac{\gamma_{i} r_{i}}{\rho} d \Gamma_{d c e l} ; \quad i=1,2
$$

onde $\gamma$ é o versor normal ao contorno de $\Omega_{d}$.

A partir de (4.38) e (4.39), obtém-se a integral no contorno da célula:

$$
h_{d}=\int_{\Gamma_{d c e l}} \lambda(\rho) \frac{\gamma_{i} r_{, i}}{\rho} d \Gamma_{d c e l} ; i=1,2
$$

Um dos valores de $\lambda_{p}=\left(\begin{array}{lll}\lambda_{p 1} & \lambda_{p 2} & \lambda_{p 3}\end{array}\right)^{T}$ envolvendo a equação integral dos deslocamentos transversais para o problema de placas é dado por:

$$
\lambda_{p 1}=\frac{\rho^{4}}{400 \pi D} r_{, i} p_{i}\left(A_{3} r_{, 1}+B_{3} r_{, 2}\right)(10 \ln \rho-7)+\frac{D_{3} \rho^{3}}{128 \pi D} r_{, i} p_{i}(4 \ln \rho-3) ; i=1,2
$$

onde $\rho_{, i}=r_{, i}$. 


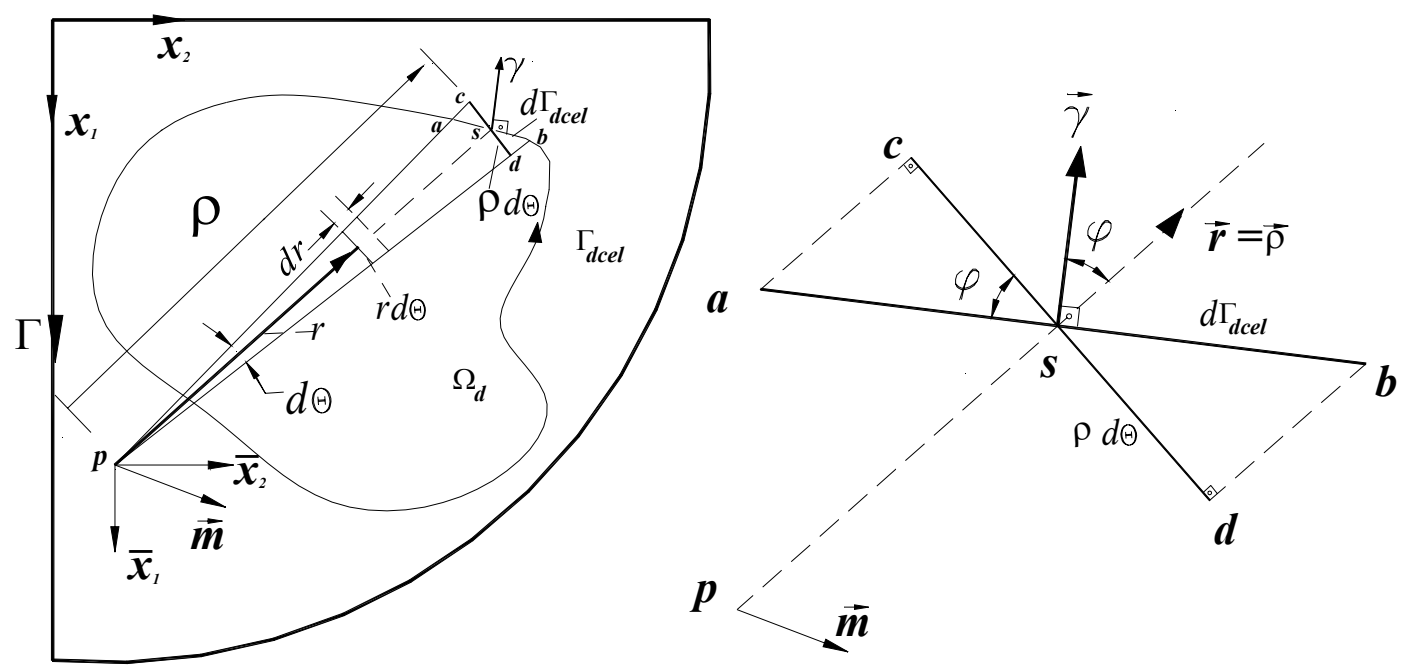

Figura 4.5- Esquema representativo da integração sobre a célula.

Já os valores associados às equações integrais das derivadas direcionais podem ser escritos em função de:

$$
\begin{gathered}
a(m)=-\frac{\rho^{3}}{64 \pi D} r_{, i} p_{i} r_{, j} m_{j}\left(A_{3} r_{, l}+B_{3} r_{, 2}\right)(4 \ln \rho-1)-\frac{D_{3} \rho^{2}}{36 \pi D} r_{, i} p_{i} r_{, j} m_{j}(3 \ln \rho-1) ; \\
i, j=1,2
\end{gathered}
$$

Assim, os valores $\lambda_{p 2}, \lambda_{p 3}$ ficam determinados a partir do momento que uma direção específica é atribuída a $\mathrm{m}$-no caso de ponto-fonte no contorno essas direções são $\mu, \xi$ respectivamente :

$$
\lambda_{p 2}=a(\mu) ; \quad \lambda_{p 3}=a(\xi)
$$

Em chapas, as integrais de domínio podem ser tratadas de maneira similar à técnica descrita anteriormente. Apenas um fato deve ser ressaltado: é quanto à presença do vetor $w_{g}^{*}$ em (4.32), que deve ser substituído pelo vetor equivalente do problema de chapa $u_{g}^{*}$. Assim, as componentes de $\lambda_{c}$ podem ser escritas como:

$$
\lambda_{c k}=R_{j i} g_{1 i}+R_{i j} g_{2 i} ; i, j, k=1,2
$$

onde:

$$
\begin{gathered}
g_{i j}=\frac{r_{, k} p_{k} \rho}{8 \pi\left(1-v_{p}\right) G t}\left[\left(3-4 v_{p}\right) \delta_{i j}\left(\frac{1}{2}-\ln \rho\right)+r_{, i} r_{, j}\right]\left[\frac{\rho}{3}\left(A_{j} r_{, 1}+B_{j} r_{, 2}\right)+\frac{1}{2} D_{j}\right] ; \\
i, j=1,2
\end{gathered}
$$




$$
\begin{gathered}
\lambda_{c 3}=\frac{q_{i} m_{j} r_{, \alpha} p_{\alpha}}{8 \pi\left(1-v_{p}\right) G t}\left[\left(3-4 v_{p}\right) \delta_{i k} r_{, j}-\delta_{i j} r_{, k}-\delta_{j k} r_{, i}+2 r_{, i} r_{, j} r_{, k}\left[D_{k}+\frac{1}{2} \rho\left(A_{k} r_{, 1}+B_{k} r_{, 2}\right)\right]\right. \\
i, j, k, \alpha=1,2
\end{gathered}
$$

As contribuições, devido ao carregamento externo aplicado em linha, para os vetores independentes podem ser calculadas de forma análoga às técnicas empregadas na obtenção das matrizes de influência, isto é, divide-se a curva representativa da linha de carga em segmentos de retas ou arcos menores, associando-se a eles uma quantidade de pontos nodais compatível à função representativa do carregamento aplicado. Neste trabalho, são analisados casos em que o carregamento em linha seja, no máximo, linearmente distribuído e a geometria da curva de aplicação será interpolada por células unidimensionais retas. Assim, a contribuição da integração de uma célula $k$ pode ser escrita como:

$$
h_{L k}=\int_{\Omega_{L k}}\left(\begin{array}{c}
w^{*} \\
w_{, \mu}^{*} \\
w_{, \xi}^{*}
\end{array}\right)\left(\begin{array}{ll}
\varphi_{1} & \varphi_{2}
\end{array}\right) d \Omega_{L k}\left(\begin{array}{l}
G_{L k}^{1} \\
G_{L k}^{2}
\end{array}\right)
$$

onde as funções interpoladoras $\varphi_{i}$ estão expressas em (4.9).

\section{3) Representações Algébricas}

\subsection{1) Cálculo das integrais}

Ao fazer-se a transição da representação integral para a algébrica, as integrais presentes no problema discretizado devem ser calculadas, em geral, utilizando-se uma técnica numérica.

\subsubsection{1) Integração singular}

Quando o ponto-fonte estiver contido no elemento em que a integração está sendo realizada, ocorrem singularidades. Assim, uma alternativa utilizada para o cálculo das integrais nesses casos é o procedimento analítico que é descrito a seguir.

As funções interpoladoras $\varphi_{i}$, vide figura 4.7, são dadas por:

$$
\varphi_{1}=\frac{1}{L}(b-\varsigma) ; \varphi_{2}=\frac{1}{L}(b+\varsigma)
$$


O cálculo ao longo do elemento singular pode ser subdivido em dois intervalos para os limites de integração:

$$
\int_{\Gamma_{k}} q_{n, m}^{*} \varphi_{l} d \Gamma_{k}=\int_{-a}^{-\varsigma} \frac{1}{2 \pi r^{2} L}\left(m_{i} n_{i}\right)(b-\varsigma) d \varsigma+\int_{\varsigma}^{b} \frac{1}{2 \pi r^{2} L}\left(m_{i} n_{i}\right)(b-\varsigma) d \varsigma ; i=1,2
$$

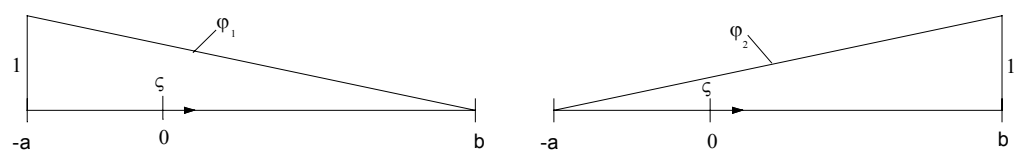

Figura 4.7-Funções interpoladoras lineares para o elemento singular

A partir da orientação da variável $\varsigma$, tem-se que $\varsigma=-r$ na parte negativa do eixo associado a $\varsigma$, e $\varsigma=r$ na parte positiva. Fazendo-se uma mudança de variável para parte negativa $\kappa=-\varsigma$, a expressão(4.49) pode ser escrita como:

$$
\int_{\Gamma_{k}} q_{n, m}^{*} \varphi_{1} d \Gamma_{k}=-\int_{a}^{\kappa} \frac{1}{2 \pi \kappa^{2} L}\left(m_{i} n_{i}\right)(b+\kappa) d \kappa+\int_{\varsigma}^{b} \frac{1}{2 \pi r^{2} L}\left(m_{i} n_{i}\right)(b-\varsigma) d \varsigma
$$

Em (4.50), existem dois integrandos contendo singularidades do tipo fraca e forte, as quais serão calculadas utilizando-se o conceito de Parte Finita de Hadamard(PFH), que será mostrado a seguir:

$$
\int_{t}^{\alpha} \frac{d y}{(y-t)^{n+1}}=\lim _{\beta \rightarrow t}\left[\int_{\beta}^{\alpha} \frac{d y}{(y-t)^{n+1}}-\frac{1}{n(\beta-t)^{n}}\right]=-\frac{1}{n}(\alpha-t)^{-n}
$$

onde $n>0$.

Para os casos em que $n=0$, a parte finita de Hadamard passa a ser expressa por:

$$
\int_{t}^{\alpha} \frac{d y}{(y-t)}=\lim \left[\int_{\beta}^{\alpha} \frac{d y}{(y-t)}+\ln (\beta-t)\right]=\ln (\alpha-t)
$$

onde $t<\alpha$. 
Nas integrações dos kernels tem-se integrandos similares a (PFH) onde $t=0$. Com isso, pode-se fazer uma mudança de variáveis $y_{1}=y / \alpha$ conduzindo as integrações (4.51) e (4.52) a:

$$
\begin{gathered}
\int_{0}^{\alpha} \frac{1}{(y)^{n+1}} d y=\int_{0}^{1} \frac{\alpha}{\left(\alpha y_{1}\right)^{n+1}} d y_{1}=-\left.\frac{1}{n} \alpha^{-2 n}\right|_{\alpha=1}=-\frac{1}{n} \\
\int_{0}^{\alpha} \frac{d y}{y}=\int_{0}^{1} \frac{\alpha}{\alpha y_{1}} d y_{1}=\left.\ln (\alpha)\right|_{\alpha=1}=0
\end{gathered}
$$

Para normalizar os limites de integração na parte negativa de $\varsigma$, faz-se $\kappa_{1}=\kappa / a$ e $\varsigma_{1}=\varsigma / b$ para a parte positiva. Com isso, a expressão (4.50) passa a ser escrita como:

$$
\int_{\Gamma_{k}} q_{n, m}^{*} \varphi_{l} d \Gamma_{k}=-\frac{1}{2 \pi L}(1+b / a)
$$

Procedendo-se analogamente à técnica para a obtenção de (4.55), o cálculo da integração do mesmo kernel ponderado por $\varphi_{2}$ pode ser escrita como:

$$
\int_{I_{k}} q_{n, m}^{*} \varphi_{2} d \Gamma_{k}=-\frac{1}{2 \pi L}(1+a / b)
$$

Em seguida, estão descritas as integrações singulares envolvendo as derivadas direcionais dos kernels dos momentos fletores e volventes, isto é:

$$
\int_{I_{k}} m_{n, m}^{*} \varphi_{l} d \Gamma_{k}=\int_{-a}^{-c} \frac{r_{r}}{4 \pi r L}(b-\varsigma) d \varsigma+\int_{\varsigma}^{b} \frac{r_{, m}}{4 \pi r L}(b-\varsigma) d \varsigma
$$

Através das mudanças de variáveis e do conceito de $\mathrm{PFH}$, a integração pode ser escrita como:

$$
\int_{\Gamma_{k}} m_{n, m}^{*} \varphi_{1} d \Gamma_{k}=-\frac{1+v}{4 \pi} r_{m}
$$

Para as demais integrais singulares dos kernels de placas, vide anexo I. As integrações para o elemento singular envolvendo os kernels da chapa são descritas na seqüência. Também são empregadas técnicas análogas àquelas aplicadas no problema de placas, de forma que as integrações singulares de chapas estão descritas no anexo II. 
Conforme discutido anteriormente, uma outra técnica empregada na formulação HP para obtenção das matrizes de influência é aplicar duas funções interpoladoras distintas para (deslocamentos, rotações) e (esforços, forças de superfície). Assim, na seqüência, é apresentado o cálculo das integrações para o elemento singular, envolvendo a matriz de influência dos deslocamentos e rotações.

As funções de forma indicadas na figura 4.8 podem ser escritas como:

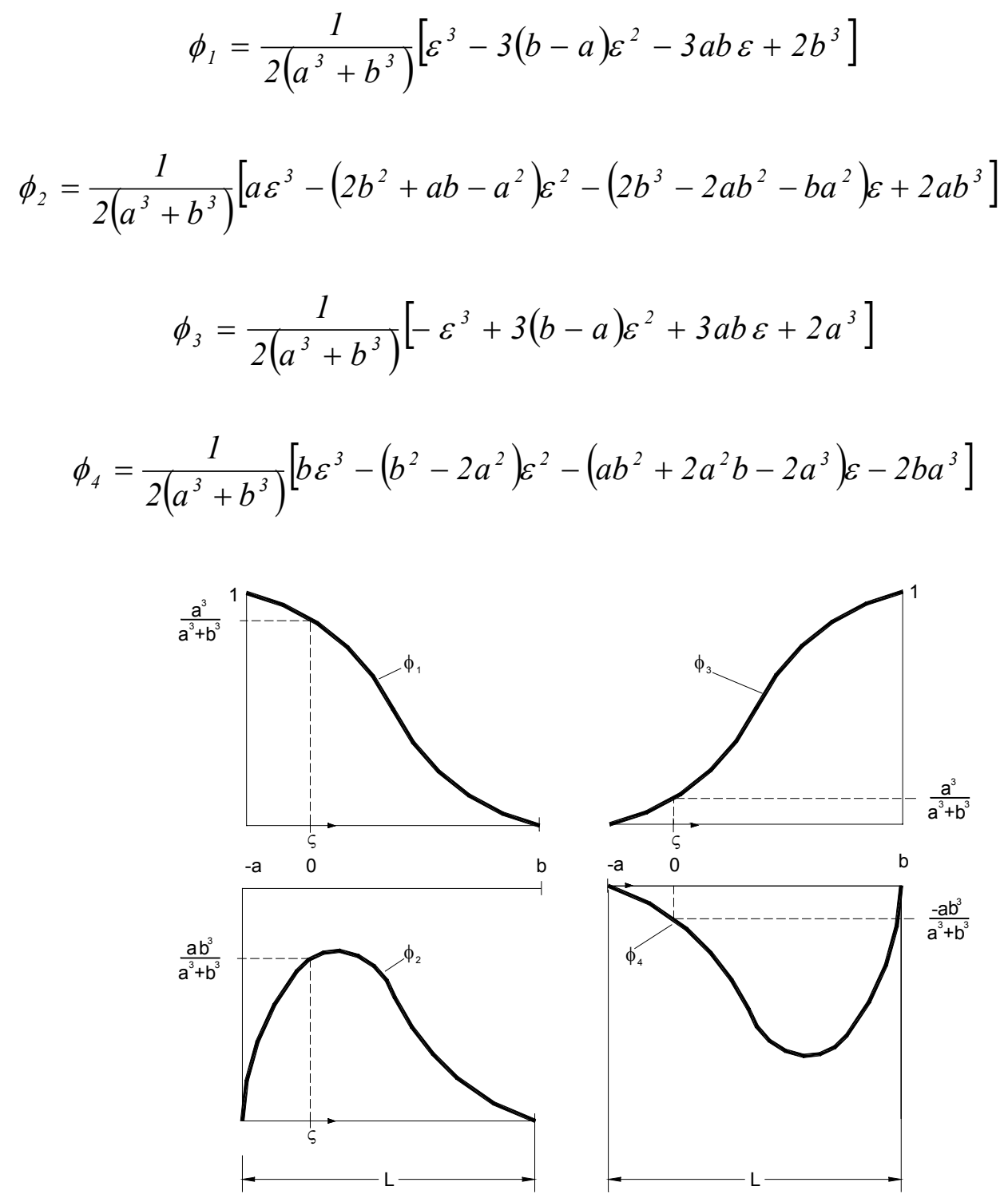

Figura 4.8- Funções $\phi_{i}$ no Elemento Singular.

As funções $\phi_{i}^{\prime}$, indicadas na figura 4.9, podem ser escritas como:

$$
\phi_{1}^{\prime}=\frac{1}{2\left(a^{3}+b^{3}\right)}\left[3 \varepsilon^{2}-6(b-a) \varepsilon-3 a b\right]
$$




$$
\begin{gathered}
\phi_{2}^{\prime}=\frac{1}{2\left(a^{3}+b^{3}\right)}\left[3 \varepsilon^{2}-2\left(2 b^{2}+a b-a^{2}\right) \varepsilon+2 b^{3}-2 a b^{2}-b a^{2}\right] \\
\phi_{3}^{\prime}=\frac{1}{2\left(a^{3}+b^{3}\right)}\left[-3 \varepsilon^{2}-6(-b+a) \varepsilon+3 a b\right] \\
\phi_{4}^{\prime}=\frac{1}{2\left(a^{3}+b^{3}\right)}\left[3 b \varepsilon^{2}-2\left(b^{2}-2 a^{2}\right) \varepsilon-a b^{2}-2 a^{2} b+2 a^{3}\right]
\end{gathered}
$$

No elemento singular, a matriz ponderada dos kernels pode ser escrita como:

$$
H_{i j}^{p K}=\int_{\Gamma_{k}}\left[\begin{array}{ccc}
0 & -m_{n}^{*} & 0 \\
q_{n, \mu}^{*} & 0 & -m_{n s, \mu}^{*} \\
0 & -m_{n, \xi}^{*} & 0
\end{array}\right]\left(\begin{array}{cccccc}
\varphi_{1} & 0 & 0 & \varphi_{2} & 0 & 0 \\
0 & \phi_{1} & \phi_{2} & 0 & \phi_{3} & \phi_{4} \\
0 & \phi_{1}^{\prime} & \phi_{2}^{\prime} & 0 & \phi_{3}^{\prime} & \phi_{4}^{\prime}
\end{array}\right) d \Gamma_{k}
$$

ou

$$
H_{i j}^{p k}=\int_{\Gamma_{k}}\left(\begin{array}{cccccc}
0 & -m_{n}^{*} \varphi_{1} & 0 & 0 & -m_{n}^{*} \varphi_{2} & 0 \\
f_{11} & 0 & f_{13} & f_{14} & 0 & f_{16} \\
0 & -m_{n, \xi}^{*} \varphi_{1} & 0 & 0 & -m_{n, \xi}^{*} \varphi_{2} & 0
\end{array}\right) d \Gamma_{k}
$$

onde:

$$
\begin{array}{ll}
f_{11}=q_{n, \mu}^{*} \phi_{1}-m_{n s, \mu}^{*} \phi_{1}^{\prime} ; & f_{13}=q_{n, \mu}^{*} \phi_{2}-m_{n s, \mu}^{*} \phi_{2}^{\prime} \\
f_{14}=q_{n, \mu}^{*} \phi_{3}-m_{n s, \mu}^{*} \phi_{3}^{\prime} ; & f_{16}=q_{n, \mu}^{*} \phi_{4}-m_{n s, \mu}^{*} \phi_{4}^{\prime}
\end{array}
$$

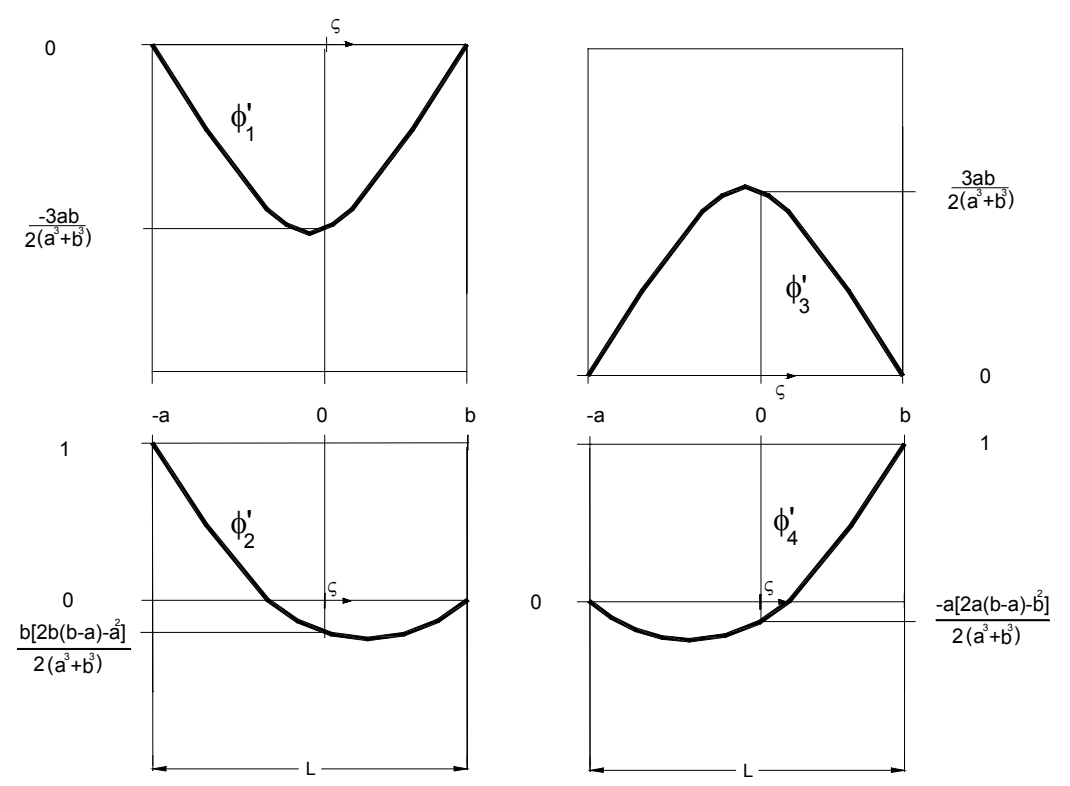

Figura 4.9-Funções Interpoladoras $\phi_{i}^{\prime}$ no Elemento Singular. 
As integrações singulares sobre cada um dos elementos da matriz(4.68) estão descritas no anexo III. Analogamente, as integrações para os kernels dos deslocamentos e rotações da chapa podem ser escritas como:

$$
\begin{aligned}
& H_{i j}^{c k}=\int_{\Gamma_{k}}\left[\begin{array}{ccc}
\left(R_{1 i} p_{i j}^{*} Q_{j 1}\right) & \left(R_{1 i} p_{i j}^{*} Q_{j 2}\right) & 0 \\
\left(R_{2 i} p_{i j}^{*} Q_{j 1}\right) & \left(R_{2 i} p_{i j}^{*} Q_{j 2}\right) & 0 \\
\left(q_{i} p_{i j k}^{*} m_{j} Q_{k 1}\right) & \left(q_{i} p_{i j k}^{*} m_{j} Q_{k 2}\right) & 0
\end{array}\right]\left(\begin{array}{cccccc}
\varphi_{1} & 0 & 0 & \varphi_{2} & 0 & 0 \\
0 & \phi_{1} & \phi_{2} & 0 & \phi_{3} & \phi_{4} \\
0 & \phi_{1}^{\prime} & \phi_{2}^{\prime} & 0 & \phi_{3}^{\prime} & \phi_{4}^{\prime}
\end{array}\right) d \Gamma_{k} \\
& {\left[\begin{array}{ccc}
\left(R_{1 i} p_{i j}^{*} Q_{j 1}\right) & \left(R_{1 i} p_{i j}^{*} Q_{j 2}\right) & 0 \\
\left(R_{2 i} p_{i j}^{*} Q_{j 1}\right) & \left(R_{2 i} p_{i j}^{*} Q_{j 2}\right) & 0 \\
\left(q_{i} p_{i j k}^{*} m_{j} Q_{k 1}\right) & \left(q_{i} p_{i j k}^{*} m_{j} Q_{k 2}\right) & 0
\end{array}\right]=\left(\begin{array}{lll}
a_{11} & a_{12} & 0 \\
a_{21} & a_{22} & 0 \\
a_{31} & a_{32} & 0
\end{array}\right)} \\
& H_{i j}^{c k}=\int_{\Gamma_{k}}\left(\begin{array}{cccccc}
a_{11} \varphi_{1} & a_{12} \phi_{1} & a_{12} \phi_{2} & a_{11} \varphi_{2} & a_{12} \phi_{3} & a_{12} \phi_{4} \\
a_{21} \varphi_{1} & a_{22} \phi_{1} & a_{22} \phi_{2} & a_{21} \varphi_{2} & a_{22} \phi_{3} & a_{22} \phi_{4} \\
a_{31} \varphi_{1} & a_{32} \phi_{1} & a_{32} \phi_{2} & a_{31} \varphi_{2} & a_{32} \phi_{3} & a_{32} \phi_{4}
\end{array}\right) d \Gamma_{k}
\end{aligned}
$$

Tal qual em (4.68), as integrações dos elementos da matriz (4.73) estão descritas no anexo IV.

\subsubsection{2) Integração não-singular}

$\mathrm{Na}$ literatura podem ser encontrados alguns trabalhos -ARISTIDEMO \& TURCO(1994), FOLTRAN(1999) e outros- em que são empregados métodos analíticos para o cálculo das integrações pontos fonte e campo não coincidentes. Contudo, de um modo geral, a estratégia mais usual é o cálculo numérico utilizandose quadraturas tais como Gauss-Legendre, Gauss-logarítmica, etc.

Assim, na seqüência são descritos os procedimentos básicos que devem ser observados para o emprego das técnicas mencionadas anteriormente. Em geral, essas quadraturas são apresentadas adimensionalizadas e escritas em função de um par de variáveis, isto é, a coordenada $\varepsilon_{i}$ e seu valor ponderado associado $w_{i}$. Tomando-se um kernel genérico $K^{*}(p, s)$, a integral desse deve ser escrita em função deste sistema de referência adimensional:

$$
\int_{\Gamma} K(p, s) d \Gamma=\int_{-1}^{l} K(\varepsilon)|J| d \varepsilon=\sum_{i=1}^{N q} K\left(\varepsilon_{i}\right) w_{i}
$$

onde $J$ é o Jacobiano do sistema $\left(x_{1}, x_{2}\right)$ para o adimensional $\varepsilon ; N_{q}$ é o número de pontos escolhidos na quadratura. 
À medida que o ponto-fonte é aproximado do ponto-campo, podem ocorrer imprecisões no cálculo das integrais. Assim, diversos pesquisadores propuseram técnicas auxiliares para melhorar o desempenho dessas quadraturas nos casos de quase-singularidades. Uma das primeiras abordagens para esse tema é a técnica $\boldsymbol{d a}$ subelementação descrita em LACHAT \& WATSON(1976,1977), JUN et al. (1985) e outros. Nessa técnica, no momento em que a colocação do ponto-fonte é admitida crítica, o elemento de contorno é fragmentado em regiões menores, e o número de pontos de integração é gradualmente concentrado no sentido do subelemento mais próximo do ponto-fonte. Dentre outras técnicas existentes para o aprimoramento do cálculo numérico, tem-se as transformações exponenciais HIGASHIMACHI et al.(1983), transformações cúbicas TELLES(1987), transformações de coordenadas HAYAMI \& BREBBIA(1987).

\subsection{2) Sistema de equações}

Após o cálculo das integrações das parcelas das equações integrais discretizadas, tem-se a representação algébrica do problema utilizando-se as formulações tetra e hexaparamétrica. Na seqüência são apresentados sistemas algébricos para a segunda abordagem: inicialmente, os problemas de chapas e placas são representados independentemente para problemas simplesmente conectados. Em seguida, esses sistemas são estendidos para casos coplanares compostos por regiões com rigidezes distintas. Concluindo-se a exposição da formulação HP, é escrita a representação algébrica de estruturas laminares não-coplanares. Na seção de fechamento do capítulo, a formulação HP é ajustada para contemplar apenas quatro equações por nó (formulação TP) para os problemas simplesmente conectados, problemas coplanares multi-conectados e problemas não-coplanares.

\subsubsection{1) Formulação Hexaparamétrica}

Ao longo dessa seção é discutida a obtenção das representações algébricasem que são utilizadas ( 3 equações, chapas; 3 equações, placas) - para o modelo HP.

\subsubsection{1)Problemas simplesmente conectados}

Por simplicidade, as contribuições do j-ésimo nó de uma representação algébrica hexaparamétrica genérica, correspondentes à equação (4.1) de chapas e (4.2) do regime de flexão, podem ser escritas respectivamente como: 


$$
\begin{aligned}
& h_{\sim} u_{\sim}^{j}=\underset{\sim}{g_{c}} p_{\sim}^{j}+b_{\sim}^{j} \\
& h_{p} w_{\sim}^{j}=g_{p}{\underset{\sim}{v}+g^{j}}_{\sim}^{j}
\end{aligned}
$$

Ou expressas matricialmente respectivamente por:

$$
\begin{gathered}
{\left[\begin{array}{lll}
h_{11} & h_{12} & h_{13} \\
h_{21} & h_{22} & h_{23} \\
h_{31} & h_{32} & h_{33}
\end{array}\right]\left(\begin{array}{l}
v_{1} \\
v_{2} \\
\theta_{z}
\end{array}\right)=\left[\begin{array}{ll}
g_{11} & g_{12} \\
g_{21} & g_{22} \\
g_{31} & g_{32}
\end{array}\right]\left(\begin{array}{l}
t_{1} \\
t_{2}
\end{array}\right)+\left(\begin{array}{l}
b_{1} \\
b_{2} \\
b_{3}
\end{array}\right)} \\
{\left[\begin{array}{lll}
\bar{h}_{11} & \bar{h}_{12} & \bar{h}_{13} \\
\bar{h}_{21} & \bar{h}_{22} & \bar{h}_{23} \\
\bar{h}_{31} & \bar{h}_{32} & \bar{h}_{33}
\end{array}\right]\left(\begin{array}{c}
w \\
\theta_{p} \\
\theta_{t}
\end{array}\right)=\left[\begin{array}{ll}
\bar{g}_{11} & \bar{g}_{12} \\
\bar{g}_{21} & \bar{g}_{22} \\
\bar{g}_{31} & \bar{g}_{32}
\end{array}\right]\left(\begin{array}{l}
V_{n} \\
m_{n}
\end{array}\right)+\left(\begin{array}{l}
g_{1} \\
g_{2} \\
g_{3}
\end{array}\right)}
\end{gathered}
$$

Inserindo-se valores nulos tanto em $g_{p}$ e $g_{c}$ assim como variáveis arbitrárias $\chi_{1}, \chi_{2}$ respectivamente em $v^{j}$ e $p^{j}$, as matrizes e vetores presentes em (4.77) e (4.78) têm suas dimensões compatibilizadas, isto é:

$$
\begin{aligned}
& {\left[\begin{array}{lll}
h_{11} & h_{12} & h_{13} \\
h_{21} & h_{22} & h_{23} \\
h_{31} & h_{32} & h_{33}
\end{array}\right]\left(\begin{array}{l}
v_{1} \\
v_{2} \\
\theta_{z}
\end{array}\right)=\left[\begin{array}{lll}
g_{11} & g_{12} & 0 \\
g_{21} & g_{22} & 0 \\
g_{31} & g_{32} & 0
\end{array}\right]\left(\begin{array}{l}
t_{1} \\
t_{2} \\
\chi_{1}
\end{array}\right)+\left(\begin{array}{l}
b_{1} \\
b_{2} \\
b_{3}
\end{array}\right)} \\
& {\left[\begin{array}{lll}
\bar{h}_{11} & \bar{h}_{12} & \bar{h}_{13} \\
\bar{h}_{21} & \bar{h}_{22} & \bar{h}_{23} \\
\bar{h}_{31} & \bar{h}_{32} & \bar{h}_{33}
\end{array}\right]\left(\begin{array}{l}
w \\
\theta_{p} \\
\theta_{t}
\end{array}\right)=\left[\begin{array}{lll}
\bar{g}_{11} & \bar{g}_{12} & 0 \\
\bar{g}_{21} & \bar{g}_{22} & 0 \\
\bar{g}_{31} & \bar{g}_{32} & 0
\end{array}\right]\left\{\begin{array}{l}
V_{n} \\
m_{n} \\
\chi_{2}
\end{array}\right\}+\left(\begin{array}{l}
g_{1} \\
g_{2} \\
g_{3}
\end{array}\right)}
\end{aligned}
$$

Alternativamente (4.79) e (4.80) podem ser reunidas em uma única representação algébrica para a lâmina plana:

$$
\left[\begin{array}{cccccc}
h_{11} & h_{12} & 0 & 0 & 0 & 0 \\
h_{21} & h_{22} & 0 & 0 & 0 & 0 \\
0 & 0 & h_{33} & h_{34} & h_{35} & 0 \\
0 & 0 & h_{43} & h_{44} & h_{45} & 0 \\
0 & 0 & h_{53} & h_{54} & h_{55} & 0 \\
h_{61} & h_{62} & 0 & 0 & 0 & h_{66}
\end{array}\right]\left\{\begin{array}{c}
v_{1} \\
v_{2} \\
w \\
\theta_{p} \\
\theta_{t} \\
\theta_{z}
\end{array}\right\}=\left[\begin{array}{cccccc}
g_{11} & g_{12} & 0 & 0 & 0 & 0 \\
g_{21} & g_{22} & 0 & 0 & 0 & 0 \\
0 & 0 & g_{33} & g_{34} & 0 & 0 \\
0 & 0 & g_{43} & g_{44} & 0 & 0 \\
0 & 0 & g_{53} & g_{54} & 0 & 0 \\
g_{61} & g_{62} & 0 & 0 & 0 & 0
\end{array}\right]\left\{\begin{array}{c}
t_{1} \\
t_{2} \\
v_{n} \\
m_{n} \\
\chi_{1} \\
\chi_{2}
\end{array}\right\}+\left\{\begin{array}{l}
z_{1} \\
z_{2} \\
z_{3} \\
z_{4} \\
z_{5} \\
z_{6}
\end{array}\right\}
$$

Na representação algébrica (4.81), algumas precauções são requeridas a fim de se evitar uma inconsistência na resolução desse sistema de equações. A prescrição das condições de contorno para os graus de liberdade associados à rotação tangencial 
$\theta_{t}$ na placa ou ligados à rotação zenital $\theta_{z}$ na chapa conduz a matriz das incógnitas a ser preenchida por linhas completamente nulas, uma vez que as variáveis fictícias possuem apenas valores nulos na matriz de influência dos esforços $G$.

Uma técnica que pode ser utilizada para evitar a singularidade da solução do sistema algébrico é atribuir valores nulos a todos os elementos localizados nas linhas e colunas associadas às variáveis fictícias, exceto os da diagonal principal da matriz de influência dos deslocamentos $H$. O vetor independente $T$ também deve ter os valores igualados a zero nas posições equivalentes ao graus de liberdade em questão.

Além disso, mesmo com a equação adicional das representações integrais para os gradientes de deslocamentos na chapa, a rotação é calculada apenas no ponto-fonte, de sorte que esse grau de liberdade não aparece no ponto-campo. Com isso, a única maneira pela qual esse parâmetro recebe influência da matriz $\bar{Q}_{p}$ é pelas componentes do tensor $D_{i j k l}$. Assim, a primeira restrição dessa formulação é que ela exclui a aplicabilidade do MEC regular, já que os posicionamentos do pontofonte nesse último conduzem a valores nulos de todas as componentes de $D_{i j k l}$, e portanto conduzindo à inconsistência na resolução do sistema algébrico.

A segunda restrição é a exclusão de posicionamento do ponto-fonte nas angulosidades, já que apenas os contornos suaves reduzem as componentes não-nulas de $D_{i j k l}$ à diagonal principal, o que, nessas condições, conduz ao desacoplamento pleno dos gradientes $u_{i, j}$.

\subsubsection{2) Problemas coplanares com multirregiões.}

Nas seções anteriores foram apresentadas as representações integrais e algébricas para os problemas de placa e chapa, em que tanto as propriedades físicas quanto as geométricas não sofriam alterações ao longo de toda a região onde esses problemas estavam definidos. Todavia, a presença dessas "não-uniformidades" é freqüentemente observada em diversos problemas de estruturas laminares.

Além disso, foi discutido o caso envolvendo uma região simples em que, na formulação HP, é observada uma diferença no número de graus de liberdade associados aos deslocamentos e às rotações com aquele que representa os esforços e 
as forças de superfície. Essa incompatibilidade do número de variáveis é problemática para os nós em que os deslocamentos ou as rotações estão prescritos; todavia, nesses casos as equações integrais de rotações- tangencial (placa) e zenital (chapa)- são removidas sem perturbar o sistema algébrico do problema.

Ao estender-se a formulação para modelar corpos com duas ou mais regiões, a disparidade entre os graus de liberdade não é alterada, contudo, nas interfaces das respectivas regiões os valores dos graus de liberdade são quase sempre desconhecidos, requerendo-se, portanto, outras técnicas para a solução do problema.

$\mathrm{Na}$ seqüência, é discutida a montagem do sistema algébrico de um caso especial em que a estrutura é coplanar e formada por regiões com propriedades físicas e/ou geométricas distintas. Para este fim, pode ser utilizada uma estratégia conhecida como técnica da subregião que foi descrita em diversos trabalhos, dentre eles tem-se BREBBIA \& WALKER(1980).

Assim passa-se agora para as etapas da técnica da subregião: discretização de cada uma das regiões; imposição das condições de compatibilidade (deslocamentos) e de equilíbrio nos pontos nodais pertencentes às interfaces das regiões. Na figura 4.10 é mostrado um problema contendo duas regiões: a primeira tendo associada a ela um domínio $\Omega_{1}$ assim como contornos $\Gamma_{1}$ e $\Gamma_{12}$; já a segunda está representada por entidades análogas $\Omega_{2}, \Gamma_{2}$ e $\Gamma_{21}$. Geometricamente, os contornos $\Gamma_{12}$ e $\Gamma_{21}$ estão definidos em uma mesma região de interface, contudo, suas orientações são opostas.

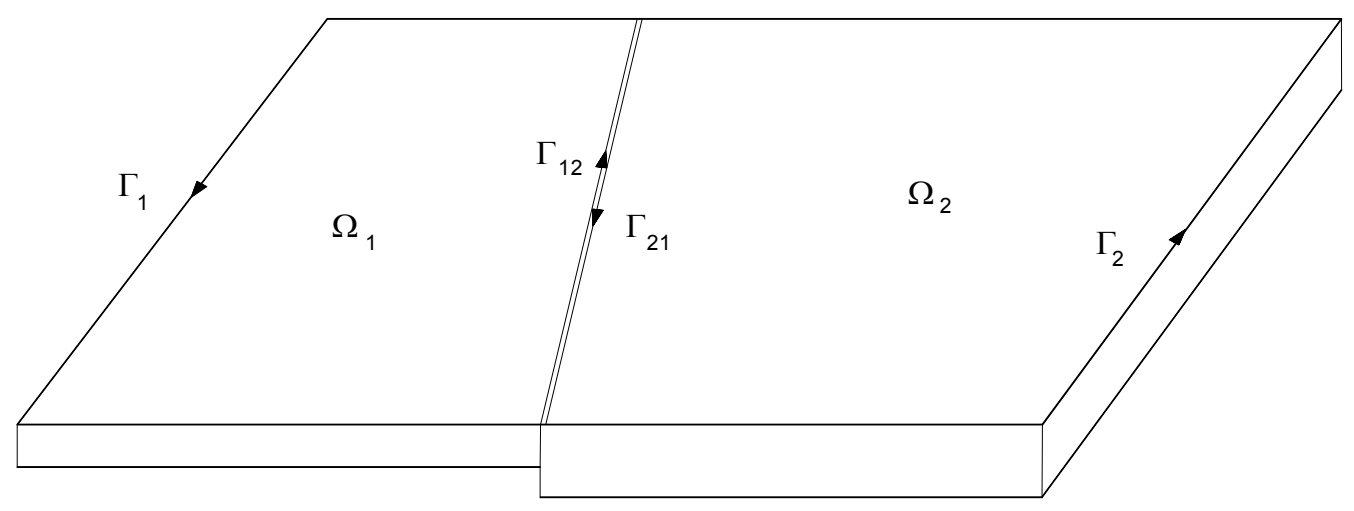

Figura 4.10- Duas regiões coplanares

Redefinindo-se os contornos de interface como $\Gamma_{12}=\Gamma_{p}$ e $\Gamma_{21}=\Gamma_{p^{\prime}}$, a representação algébrica da primeira região pode ser escrita como: 


$$
\left[\begin{array}{cc}
H_{11} & H_{1 p} \\
\tilde{H}_{p 1} & \tilde{H}_{p p}^{\sim}
\end{array}\right]\left\{\begin{array}{c}
U_{1} \\
\tilde{U}_{p} \\
\sim \sim
\end{array}\right\}=\left[\begin{array}{cc}
G_{11} & G_{1 p} \\
\tilde{\sim} & \tilde{\sim} \\
G_{p l} & G_{p p}
\end{array}\right]\left\{\begin{array}{c}
P_{l} \\
\tilde{\sim} \\
P_{p} \\
\sim
\end{array}\right\}+\left(\begin{array}{c}
Z_{1} \\
\tilde{Z_{p}} \\
\sim
\end{array}\right)
$$

onde os vetores genéricos $U_{i}, U_{j}$ estão associados respectivamente aos nós definidos sobre os contornos $\Gamma_{i}, \Gamma_{j}$. As matrizes de influência genéricas $H_{i j}$ e $G_{i j}$ são obtidas com pontos-fonte sobre o contorno $\Gamma_{i}$ e os pontos-campo sobre o contorno $\Gamma_{j}$.

A segunda região tem sua representação escrita como:

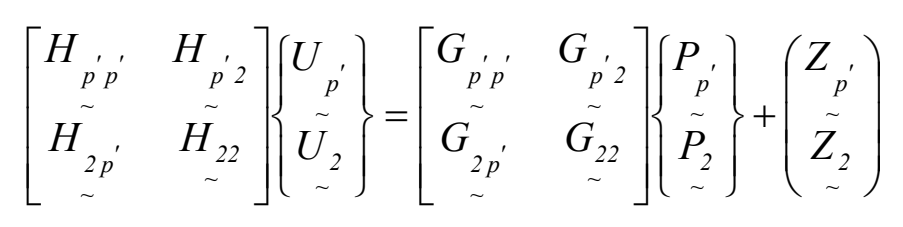

Há necessidade de equações adicionais para a solução do sistema algébrico (4.82) e (4.83), uma vez que o número de incógnitas supera as relações obtidas pelas equações integrais. $\mathrm{Na}$ interface, tais equações suplementares podem ser obtidas a partir das relações de compatibilidade e das equações de equilíbrio, isto é:

$$
\begin{aligned}
& \left(\begin{array}{c}
v_{1}^{p} \\
v_{2}^{p} \\
w^{p} \\
\theta_{p}^{p} \\
\theta_{t}^{p} \\
\theta_{z}^{p}
\end{array}\right)=\left(\begin{array}{c}
v_{1}^{p^{\prime}} \\
v_{2}^{p^{\prime}} \\
w^{p^{\prime}} \\
-\theta_{p}^{p^{\prime}} \\
-\theta_{t}^{p^{\prime}} \\
\theta_{z}^{p^{\prime}}
\end{array}\right) \\
& \left(\begin{array}{c}
t_{1}^{p} \\
t_{2}^{p} \\
V_{n}^{p} \\
m_{n}^{p}
\end{array}\right)=-\left(\begin{array}{c}
t_{1}^{p^{\prime}} \\
t_{2}^{p^{\prime}} \\
V_{n}^{p^{\prime}} \\
m_{n}^{p^{\prime}}
\end{array}\right)
\end{aligned}
$$

Note que entre as variáveis fictícias, o 'equilíbrio' também deve ser verificado; contudo os sentidos de aplicação são arbitrários. Portanto, as seguintes relações podem ser escritas:

$$
\chi_{1}^{p}+\chi_{1}^{p^{\prime}}=0 ; \quad \chi_{2}^{p}+\chi_{2}^{p^{\prime}}=0
$$


A partir de (4.84), (4.85) e (4.86), o sistema algébrico para ambas as regiões pode ser escrito como:

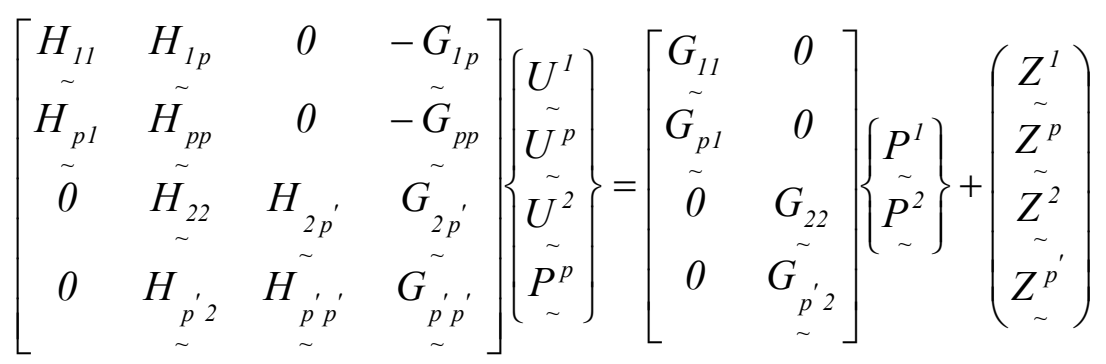

No sistema algébrico (4.87), tem-se um número superior de equações em relação às variáveis reais. Nos contornos que não pertençam a uma interface, pode ser utilizada uma técnica análoga àquela empregada em regiões simples. Nas interfaces, devem ser atribuídos zeros aos respectivos valores dos elementos da matriz de influência das incógnitas associados aos esforços fíctícios $\chi_{1}$ e $\chi_{2}$ do vetor $P^{P}$ - exceto aos da diagonal principal, que recebem a unidade. Aos valores do vetor independente na posição de $\chi_{1}$ e $\chi_{2}$ também devem ser atribuídos zeros. Com isso, as variáveis fictícias passam a ter apenas uma função auxiliar na montagem e resolução do sistema de equações, já que seus valores são sempre impostos como iguais a zero, uma vez que elas não fazem parte das variáveis efetivas do problema.

\subsubsection{3) Problemas não-coplanares}

Nesta seção, as técnicas discutidas na seção anterior são estendidas para corpos formados por uma disposição não-coplanar de lâminas. Inicialmente, é necessário eleger um sistema de referência em que as representações algébricas associadas a suas respectivas lâminas sejam acopladas em um único sistema de equações global. Um sistema que tem sido amplamente empregado para essa função, especialmente no Método dos Elementos Finitos, é adotar o sistema dextrógiro $\left(x_{1}, x_{2}, x_{3}\right)$ com origem em um ponto arbitrário. E, a partir desse sistema de referência, matrizes de rotações são escritas para todas as lâminas contribuintes da estrutura poliédrica envolvendo o sistema global e os associados a cada sistema local $\left(\bar{x}_{1}, \bar{x}_{2}, \bar{x}_{3}\right)$ das lâminas, conforme está indicado na figura 4.11, ZIENKIEWICZ(1991), NAVARRA(1995) e outros. 


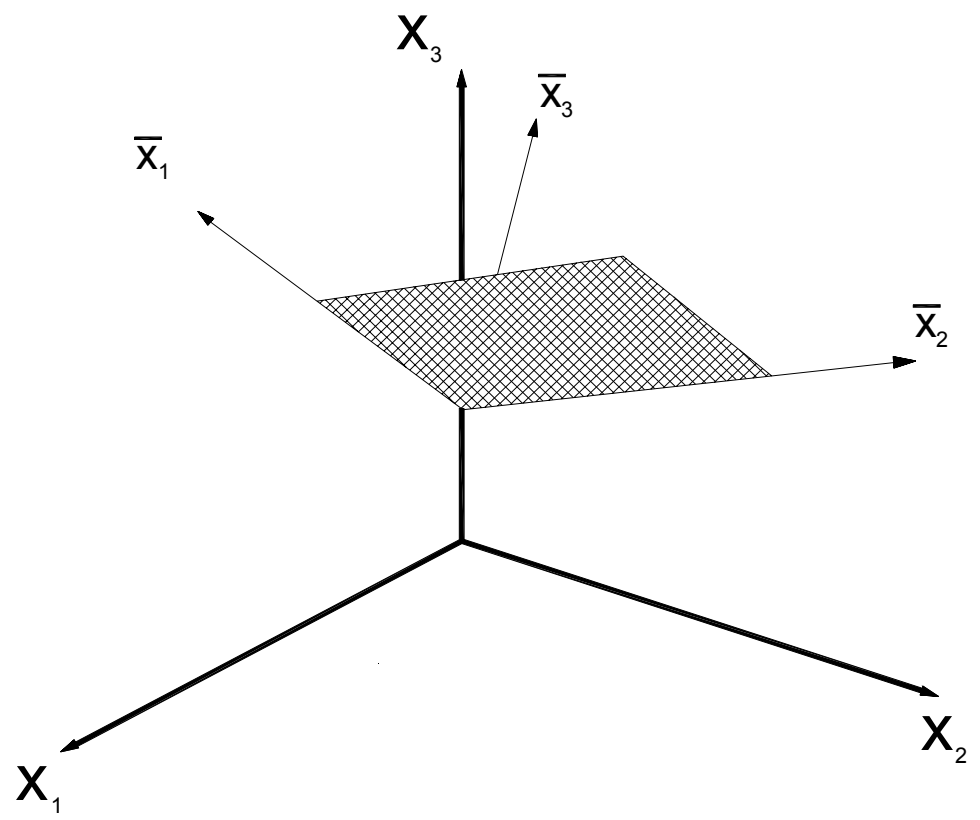

Figura 4.11- Sistemas de referências.

Além da utilização do MEF para modelagem de estruturas poliédricas, em algumas abordagens foram empregadas técnicas - envolvendo o acoplamento do MEC com outros métodos - apresentadas por diversos pesquisadores, dentre eles, KOMATSU \& NAGAI(1982),CODA(1993), GALUTA \& CHEUNG(1995), TANAKA \& BERCIN(1998), CARMO(2001). Nesses trabalhos foram utilizados sistemas de referências apropriados e compatíveis com cada um dos métodos, a fim de possibilitar o acoplamento entre eles.

Outros pesquisadores utilizaram apenas o método dos elementos de contorno para analisar estruturas poliédricas tais como: PALERMO JUNIOR(1989), OHGA et al.(1991), KRAMIN \& KRAMIN (1997). Nesses trabalhos foram utilizados basicamente dois tipos de sistemas de referências. No primeiro, as componentes dos deslocamentos e forças são escritas (compatibilizadas e equilibradas) em relação a um sistema global fixado em direções particulares de certas estruturas poliédricas. Já o segundo está associado a um sistema local de referência utilizado para escrever o equilíbrio de momentos fletores.

$\mathrm{Na}$ presente formulação optou-se desenvolver uma técnica alternativa, que utiliza uma conveniente hierarquia de sistemas de referência. Em linhas gerais, a técnica consiste em adotar sistemas globais independentes locados em cada interface 
e associados a apenas uma das lâminas, arbitrariamente eleitas como mestres, que concorrem a essas interfaces. As matrizes de rotações das variáveis do problema são calculadas a partir dos sistemas de referência das lâminas pertencentes às suas respectivas interfaces para o respectivo sistema de referência fixado nas suas respectivas lâminas-mestre.

Para elucidar esse procedimento, toma-se, por simplicidade, uma estrutura poliédrica cuja lâmina vertical possui duas interfaces em que feixes de lâminas estão ligadas a ela, conforme indicado na figura 4.12.

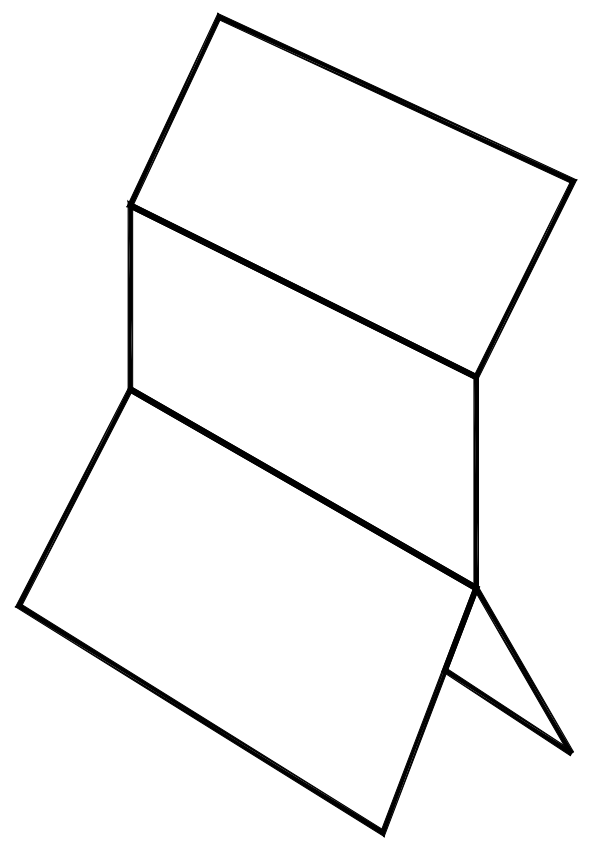

Figura 4.12-Geometria da estrutura poliédrica.

A primeira etapa para o acoplamento dos eixos de referência requer uma definição de uma hierarquia entre eles. Arbitrariamente são eleitos como mestres os contornos pertencentes à lâmina vertical, isto é, $\Gamma_{13}$, e os eixos associados aos contornos $\Gamma_{31}$ e $\Gamma_{41}$ como os seus respectivos escravos. Analogamente, o contorno $\Gamma_{21}$ está subjugado ao eixo mestre $\Gamma_{12}$, vide figura 4.13.

Note que os eixos-mestre pertencentes aos respectivos contornos de uma mesma sub-região são independentes, por exemplo, $\Gamma_{12}$ e $\Gamma_{13}$. As matrizes de rotação entre os contornos $\Gamma_{31}$ e $\Gamma_{41}$ e seus mestres comuns $\Gamma_{13}$ são dados por: 


$$
\begin{aligned}
& \left\{\begin{array}{l}
s_{31} \\
n_{31} \\
z_{31}
\end{array}\right\}=\left[\begin{array}{ccc}
-1 & 0 & 0 \\
0 & \cos \left(n_{31}, n_{13}\right) & \cos \left(n_{31}, z_{13}\right) \\
0 & \cos \left(z_{31}, n_{13}\right) & \cos \left(z_{31}, z_{13}\right)
\end{array}\right]\left\{\begin{array}{l}
s_{13} \\
n_{13} \\
z_{13}
\end{array}\right\} \\
& \left\{\begin{array}{l}
s_{41} \\
n_{41} \\
z_{41}
\end{array}\right\}=\left[\begin{array}{ccc}
-1 & 0 & 0 \\
0 & \cos \left(n_{41}, n_{13}\right) & \cos \left(n_{41}, z_{13}\right) \\
0 & \cos \left(z_{41}, n_{13}\right) & \cos \left(z_{41}, z_{13}\right)
\end{array}\right]\left\{\begin{array}{l}
s_{13} \\
n_{13} \\
z_{13}
\end{array}\right\}
\end{aligned}
$$

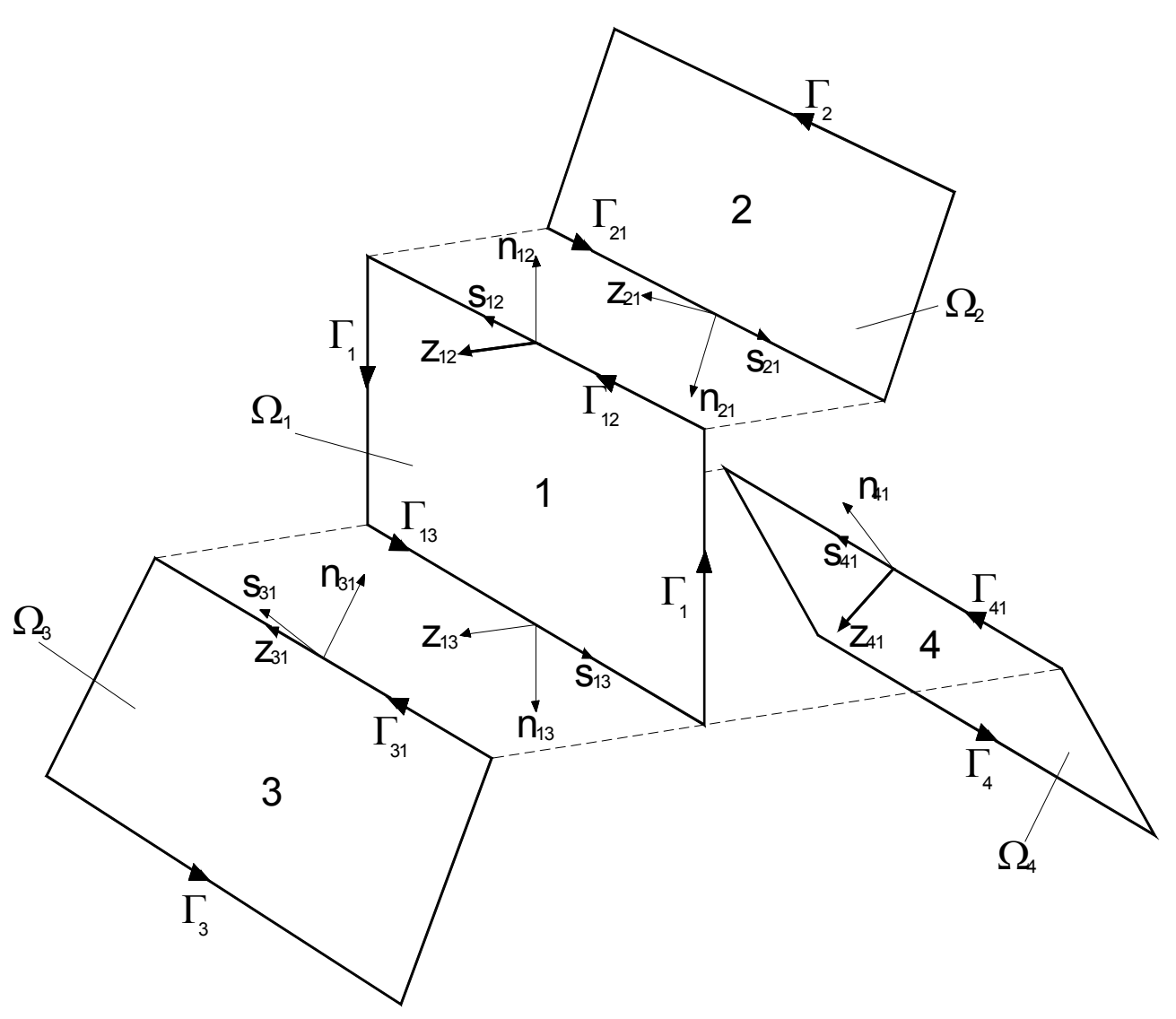

Figura 4.13- Orientação das lâminas na estrutura poliédrica.

Já a matriz de rotação entre os sistemas associados ao contorno $\Gamma_{21}$ e seu mestre $\Gamma_{12}$ pode ser escrita como:

$$
\left\{\begin{array}{l}
s_{21} \\
n_{21} \\
z_{21}
\end{array}\right\}=\left[\begin{array}{ccc}
-1 & 0 & 0 \\
0 & \cos \left(n_{21,} n_{12}\right) & \cos \left(n_{21}, z_{12}\right) \\
0 & \cos \left(z_{21,} n_{12}\right) & \cos \left(z_{21}, z_{12}\right)
\end{array}\right]\left\{\begin{array}{l}
s_{12} \\
n_{12} \\
z_{12}
\end{array}\right\}
$$

Outra etapa importante para o cálculo das matrizes de rotações indicadas em (4.88), (4.89) e (4.90) é a definição das orientações dos eixos normais $z_{i j}$ ao plano 
da lâmina, normais $n_{i j}$ e tangenciais $s_{i j}$ ao contorno. O sentido da normal ao plano de cada lâmina pode ser determinado a partir da então conhecida regra da mão direita uma vez conhecidos os sentidos de percurso dos seus respectivos contornos. Assim, os co-senos diretores de $n_{i j}$ podem ser determinados a partir das coordenadas, que estão associadas a um sistema global da estrutura, de três pontos arbitrários contidos nesse plano, conforme indicado na figura 4.14:

$$
\mathrm{z}_{\mathrm{ij}}=\left(\begin{array}{lll}
\mathrm{z}_{\mathrm{ij} 1} & \mathrm{z}_{\mathrm{ij} 2} & \mathrm{z}_{\mathrm{ij} 3}
\end{array}\right)
$$

onde:

$$
\mathrm{z}_{\mathrm{ijk}}=\frac{\lambda_{\mathrm{k}}}{\rho_{\mathrm{s}}} ; \mathrm{k}=1,2,3
$$

com:

$$
\begin{gathered}
\lambda_{1}=\left(\mathrm{x}_{2}^{\beta}-\mathrm{x}_{2}^{\alpha}\right)\left(\mathrm{x}_{3}^{\gamma}-\mathrm{x}_{3}^{\alpha}\right)-\left(\mathrm{x}_{2}^{\gamma}-\mathrm{x}_{2}^{\alpha}\right)\left(\mathrm{x}_{3}^{\beta}-\mathrm{x}_{3}^{\alpha}\right) \\
\lambda_{2}=\left(\mathrm{x}_{1}^{\gamma}-\mathrm{x}_{1}^{\alpha}\right)\left(\mathrm{x}_{3}^{\beta}-\mathrm{x}_{3}^{\alpha}\right)-\left(\mathrm{x}_{1}^{\beta}-\mathrm{x}_{1}^{\alpha}\right)\left(\mathrm{x}_{3}^{\gamma}-\mathrm{x}_{3}^{\alpha}\right) \\
\lambda_{3}=\left(\mathrm{x}_{1}^{\beta}-\mathrm{x}_{1}^{\alpha}\right)\left(\mathrm{x}_{2}^{\gamma}-\mathrm{x}_{2}^{\alpha}\right)-\left(\mathrm{x}_{1}^{\gamma}-\mathrm{x}_{1}^{\alpha}\right)\left(\mathrm{x}_{2}^{\beta}-\mathrm{x}_{2}^{\alpha}\right) \\
\rho=2 \sqrt{\lambda_{k} \lambda_{k}} ; \mathrm{k}=1,2,3
\end{gathered}
$$

onde $x_{i}^{\tau}$ são as coordenadas de um ponto $\tau$ em relação ao sistema global do estrutura.

Já os versores associados aos contornos podem ser obtidos quando a geometria é interpolada por elementos lineares a partir de dois nós pertencentes a esses:

$$
\begin{aligned}
\underset{\sim}{\mathrm{s}_{\mathrm{ij}}} & =\left(\begin{array}{lll}
\mathrm{s}_{\mathrm{ij} 1} & \mathrm{~s}_{\mathrm{ij} 2} & \mathrm{~s}_{\mathrm{ij} 3}
\end{array}\right) \\
\mathrm{s}_{\mathrm{ijk}} & =\frac{\zeta_{\mathrm{k}}}{\rho_{\mathrm{s}}} ; \mathrm{k}=1,2,3
\end{aligned}
$$

com:

$$
\xi_{\mathrm{i}}=\mathrm{x}_{\mathrm{i}}^{\varepsilon}-\mathrm{x}_{\mathrm{i}}^{\varsigma} ; \quad \mathrm{i}=1,2,3
$$




$$
\rho_{s}=\sqrt{\zeta_{k} \zeta_{k}} ; \mathrm{k}=1,2,3
$$

Os versores da direção normal ao contorno $\Gamma_{i j}$ podem ser obtidos pelo produto vetorial entre $\mathrm{S}_{\mathrm{ij}}$ e $\mathrm{Z}_{\mathrm{ij}}$, isto é :

$$
\mathrm{n}_{\mathrm{ij}}=\mathrm{s}_{\mathrm{ij}} \times \mathrm{Z}_{\mathrm{ij}}
$$

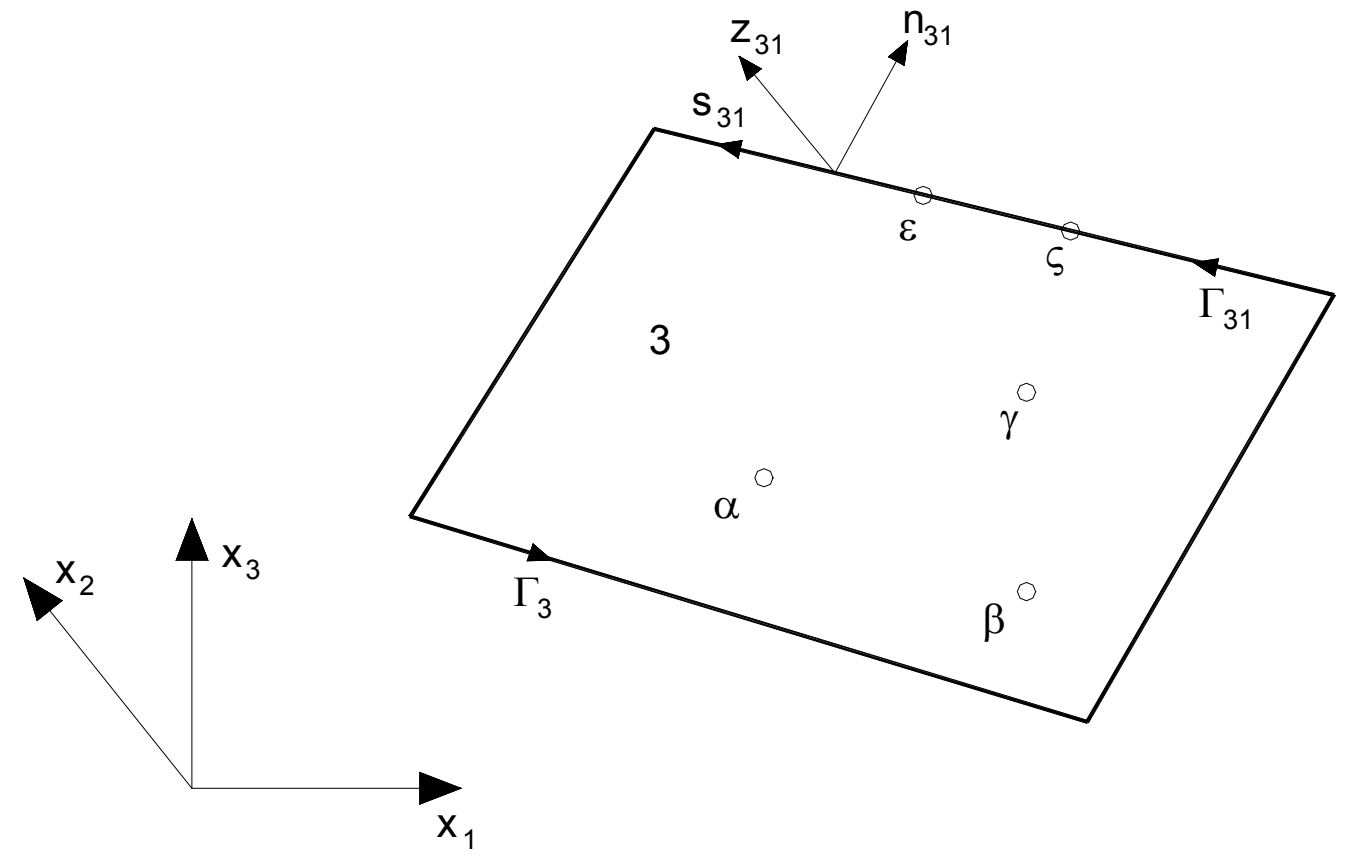

Figura 4.14- Orientação da lâmina $i$ em relação ao sist. global da estrutura.

O ângulo $\bar{\gamma}$, vide figura 4.15 , formado entre as normais de dois planos pode ser expresso por:

$$
\bar{\gamma}= \begin{cases}2 \pi-\gamma, & \text { se } \bar{\gamma}>\pi \\ \gamma, & \text { se } \bar{\gamma} \leq \pi\end{cases}
$$

Em(4.96), o seno do ângulo $\gamma$ é dado pela relação da álgebra de vetores:

$$
\operatorname{sen} \gamma=\frac{\left|n_{i j} \times n_{k l}\right|}{\left\|n_{i j}\right\|\left\|n_{k l}\right\|}
$$

Lembre-se que $\gamma$ é o menor ângulo formado entre as normais, isto é, seu intervalo de variação está situado em $[0, \pi]$, uma vez que o módulo do produto vetorial está presente na expressão (4.103). Todavia, para permitir um 
posicionamento arbitrário das lâminas escravas em relação às mestres, o intervalo desse ângulo $\gamma$ medido apenas no sentido anti-horário passa a ser $[0,2 \pi]$. É devido a esse fato que correções em $\gamma$, indicadas na expressão (4.102), devem ser aplicadas quando o ângulo real $\bar{\gamma}$ entre as normais for maior que $\pi$. Definindo-se $\operatorname{como} \alpha$ o ângulo do diedro, medido no sentido anti-horário, formado pelos planos do mestre e do escravo, as seguintes relações podem ser escritas:

$$
\bar{\gamma}+\alpha=2 \pi
$$

Assim, a matriz de rotação pode ser escrita como:

$$
\left\{\begin{array}{l}
\mathrm{s}_{31} \\
\mathrm{n}_{31} \\
\mathrm{z}_{31}
\end{array}\right\}=\left[\begin{array}{ccc}
-1 & 0 & 0 \\
0 & \cos \alpha & \operatorname{sen} \alpha \\
0 & \operatorname{sen} \alpha & \cos \bar{\gamma}
\end{array}\right]\left\{\begin{array}{l}
\mathrm{s}_{13} \\
\mathrm{n}_{13} \\
\mathrm{z}_{13}
\end{array}\right\}
$$

Outra maneira de obter-se as matrizes de rotação é escrever cada sistema local em relação a um sistema global da estrutura, isto é:

$$
\left\{\begin{array}{l}
\mathrm{s}_{31} \\
\mathrm{n}_{31} \\
\mathrm{z}_{31}
\end{array}\right\}=\underset{\sim}{\mathrm{A}}\left\{\begin{array}{l}
\mathrm{x}_{1} \\
\mathrm{x}_{2} \\
\mathrm{x}_{3}
\end{array}\right\}
$$

onde

$$
\begin{gathered}
\underset{\sim}{\mathrm{A}}=\left[\begin{array}{ccc}
\cos \left(\mathrm{s}_{31}, \mathrm{x}_{1}\right) & \cos \left(\mathrm{s}_{31}, \mathrm{x}_{2}\right) & \cos \left(\mathrm{s}_{31}, \mathrm{x}_{3}\right) \\
\cos \left(\mathrm{n}_{31}, \mathrm{x}_{1}\right) & \cos \left(\mathrm{n}_{31}, \mathrm{x}_{2}\right) & \cos \left(\mathrm{n}_{31}, \mathrm{x}_{3}\right) \\
\cos \left(\mathrm{z}_{31}, \mathrm{x}_{1}\right) & \cos \left(\mathrm{z}_{31}, \mathrm{x}_{2}\right) & \cos \left(\mathrm{z}_{31}, \mathrm{x}_{3}\right)
\end{array}\right]\left\{\begin{array}{l}
\mathrm{x}_{1} \\
\mathrm{x}_{2} \\
\mathrm{x}_{3}
\end{array}\right\} \\
\left\{\begin{array}{l}
\mathrm{s}_{13} \\
\mathrm{n}_{13} \\
\mathrm{z}_{13}
\end{array}\right\}=\underset{\sim}{\mathrm{B}}\left\{\begin{array}{l}
\mathrm{x}_{1} \\
\mathrm{x}_{2} \\
\mathrm{x}_{3}
\end{array}\right\}
\end{gathered}
$$

onde

$$
\underset{\sim}{\mathrm{B}}=\left[\begin{array}{ccc}
\cos \left(\mathrm{s}_{13}, \mathrm{x}_{1}\right) & \cos \left(\mathrm{s}_{13}, \mathrm{x}_{2}\right) & \cos \left(\mathrm{s}_{13}, \mathrm{x}_{3}\right) \\
\cos \left(\mathrm{n}_{13}, \mathrm{x}_{1}\right) & \cos \left(\mathrm{n}_{13}, \mathrm{x}_{2}\right) & \cos \left(\mathrm{n}_{13}, \mathrm{x}_{3}\right) \\
\cos \left(\mathrm{z}_{13}, \mathrm{x}_{1}\right) & \cos \left(\mathrm{z}_{13}, \mathrm{x}_{2}\right) & \cos \left(\mathrm{z}_{13}, \mathrm{x}_{3}\right)
\end{array}\right]\left\{\begin{array}{l}
\mathrm{x}_{1} \\
\mathrm{x}_{2} \\
\mathrm{x}_{3}
\end{array}\right\}
$$



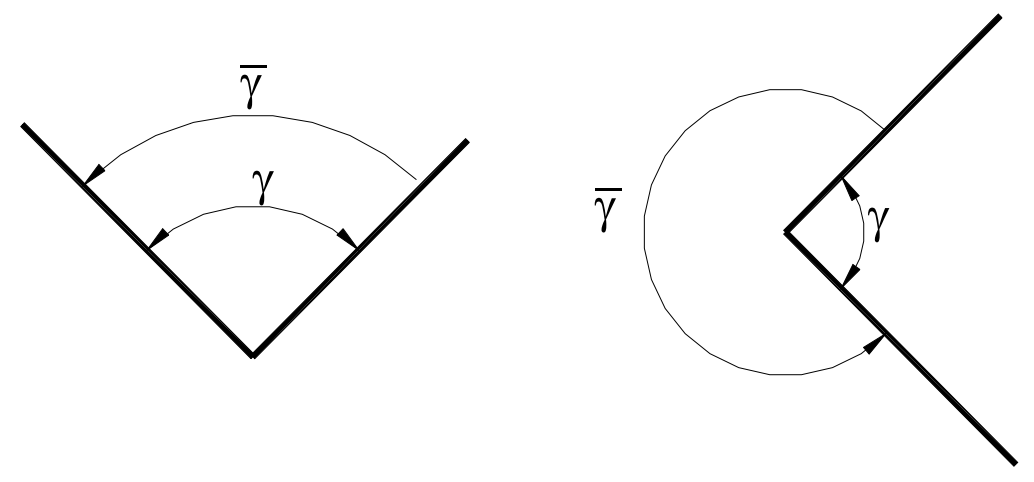

Figura 4.15- Definição do ângulo $\bar{\gamma}$.

Invertendo-se B e substituindo-se em (4.106), tem-se a relação:

$$
\left\{\begin{array}{l}
\mathrm{s}_{31} \\
\mathrm{n}_{31} \\
\mathrm{z}_{31}
\end{array}\right\}=\underset{\sim}{\mathrm{AB}_{\sim}^{-1}}\left\{\begin{array}{l}
\mathrm{s}_{13} \\
\mathrm{n}_{13} \\
\mathrm{z}_{13}
\end{array}\right\}
$$

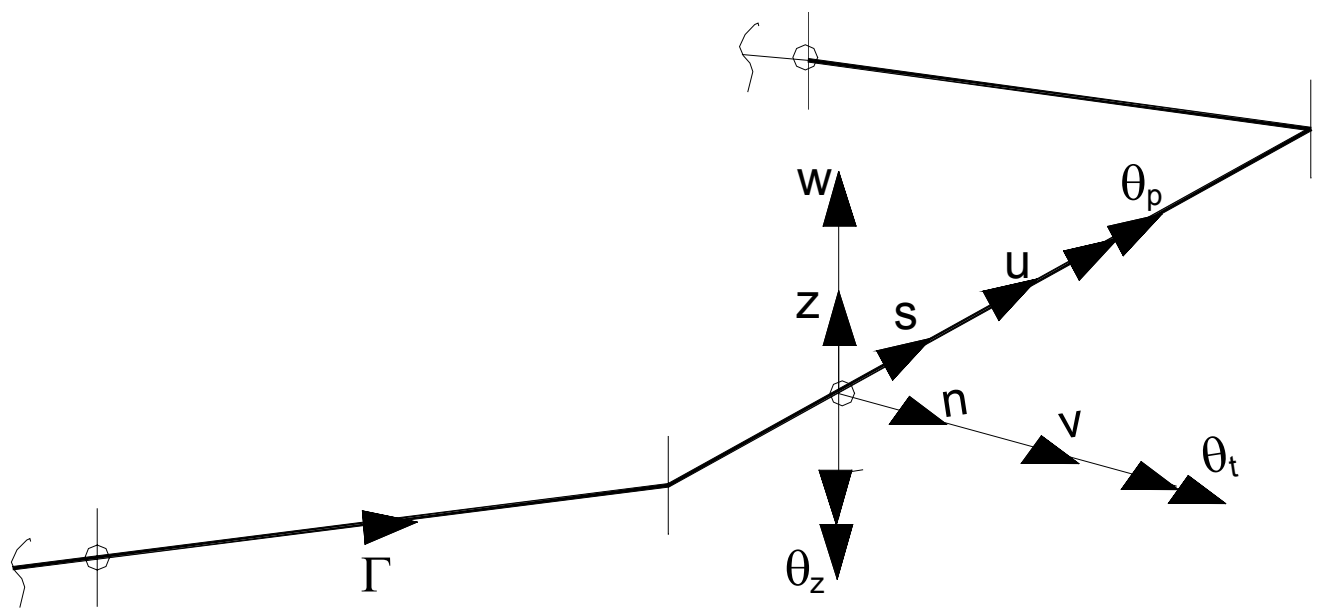

Figura 4.16- Orientação dos graus de liberdade versus sistema local.

Conforme indicado na figura 4.16, os deslocamentos, as forças de superfície de membrana e a força equivalente de Kirchhoff seguem a mesma orientação do sistema de coordenadas local:

$$
\begin{aligned}
& \left\{\begin{array}{c}
v_{1}^{31} \\
v_{2}^{31} \\
w^{31}
\end{array}\right\}=\underset{\sim}{A}{\underset{\sim}{\sim}}^{-1}\left\{\begin{array}{c}
v_{1}^{13} \\
v_{2}^{13} \\
w^{13}
\end{array}\right\} \\
& \left\{\begin{array}{c}
t_{1}^{31} \\
t_{2}^{31} \\
V_{n}^{31}
\end{array}\right\}=\underset{\sim}{A} B_{\sim}^{-1}\left\{\begin{array}{c}
t_{1}^{13} \\
t_{2}^{13} \\
V_{n}^{13}
\end{array}\right\}
\end{aligned}
$$


onde:

$$
\underset{\sim}{A}{\underset{\sim}{-1}}^{-1}=\left[\begin{array}{ccc}
-1 & 0 & 0 \\
0 & a_{22} & a_{23} \\
0 & a_{32} & a_{33}
\end{array}\right]
$$

Todavia, as rotações e os momentos fletores não seguem plenamente esse sistema, isto é:

$$
\begin{gathered}
\left\{\begin{array}{l}
\theta_{p}^{31} \\
\theta_{t}^{31} \\
\theta_{z}^{31}
\end{array}\right\}=\left[\begin{array}{ccc}
-1 & 0 & 0 \\
0 & a_{22} & -a_{23} \\
0 & -a_{32} & a_{33}
\end{array}\right]\left\{\begin{array}{c}
\theta_{p}^{13} \\
\theta_{t}^{13} \\
\theta_{z}^{13}
\end{array}\right\} \\
m_{n}^{31}=-m_{n}^{13}
\end{gathered}
$$

Nos problemas não-coplanares, surgem forças interativas distribuídas continuamente nas interfaces devido ao acoplamento dos campos dos regimes de membrana e flexão. Quando as hipóteses de Kirchhoff são admitidas para o problema de flexão, forças interativas concentradas são mobilizadas no problema da lâmina plana em virtude das reações de canto de placa conforme ilustrado - por simplicidade em uma estrutura composta por duas lâminas - na figura 4.17 .

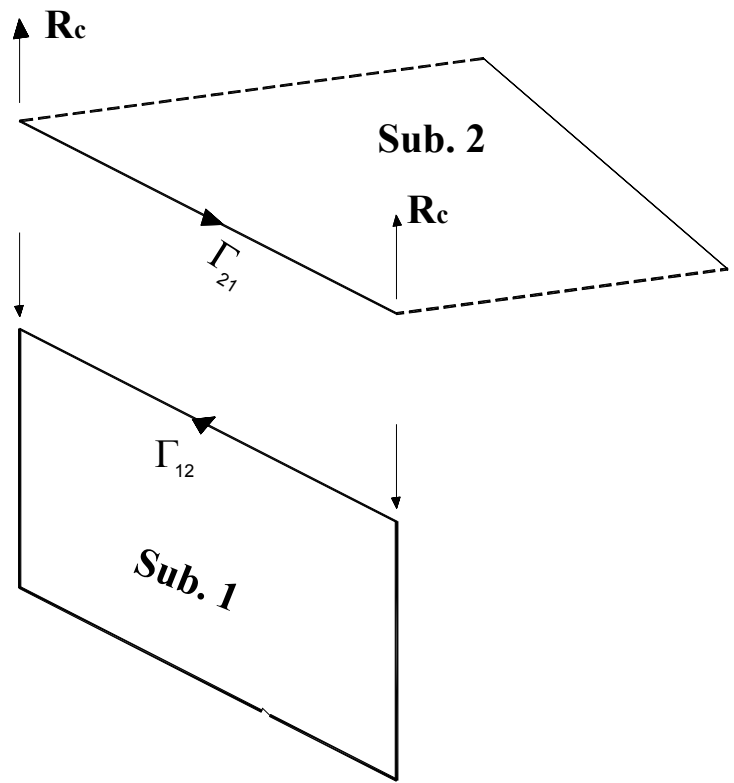

Figura 4.17- Forças interativas discretas.

Neste trabalho, as forças de interação discretas são desprezadas. 
Procedendo-se analogamente ao caso de duas lâminas coplanares, redefinindo-se os contornos de interface $\Gamma_{12}=\Gamma_{\alpha}, \quad \Gamma_{21}=\Gamma_{\alpha^{\prime}}, \Gamma_{13}=\Gamma_{\gamma}$, $\Gamma_{31}=\Gamma_{\gamma^{\prime}}$ e $\Gamma_{4 l}=\Gamma_{\tau^{\prime}} \quad$ as representações algébricas da primeira à quarta subregião podem ser escritas respectivamente como:

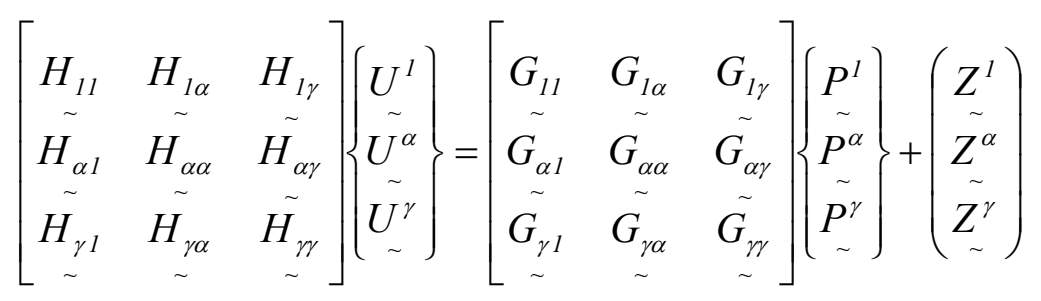

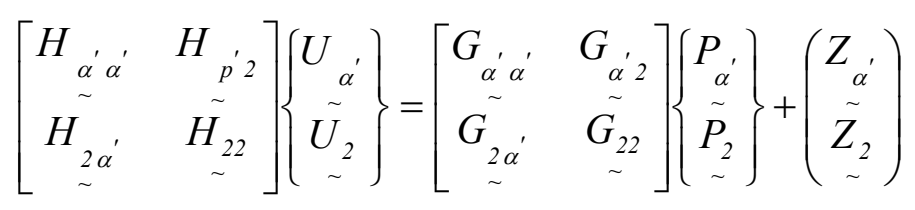

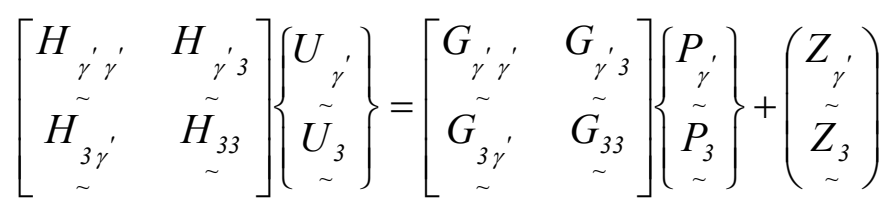

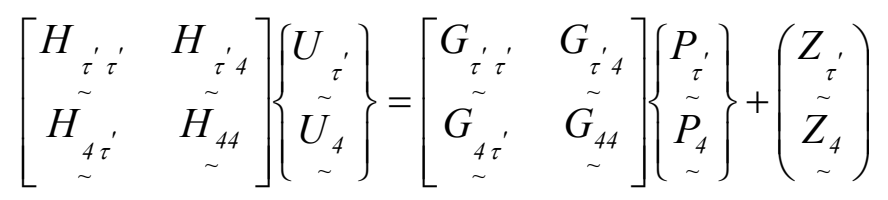

Em cada interface, as condições de compatibilidade são impostas segundo o sistema de referência do contorno-mestre. Assim, a partir das matrizes de rotação do escravo para o mestre, as relações suplementares podem ser determinadas. $\mathrm{Na}$ interface pertencente ao mestre $\Gamma_{13}$ essas relações podem ser obtidas a partir de (4.88) a (4.90). Na sub-região 4, relações análogas podem ser obtidas para as rotações: 


$$
\left(\begin{array}{c}
v_{1}^{13} \\
v_{2}^{13} \\
w^{13} \\
\theta_{, p}^{13} \\
\theta_{t}^{13} \\
\theta_{z}^{13}
\end{array}\right)=\underset{\sim t}{R_{t}^{31}}\left(\begin{array}{c}
v_{1}^{31} \\
v_{2}^{31} \\
w^{31} \\
\theta_{p}^{31} \\
\theta_{t}^{31} \\
\theta_{z}^{31}
\end{array}\right)=\underset{\sim t}{R^{41}}\left(\begin{array}{c}
v_{1}^{41} \\
v_{2}^{41} \\
w^{41} \\
\theta_{p}^{41} \\
\theta_{t}^{41} \\
\theta_{z}^{41}
\end{array}\right)
$$

onde:

$$
\underset{\sim t}{R_{j i}^{j i}}=\left[\begin{array}{cccccc}
-1 & 0 & 0 & 0 & 0 & 0 \\
0 & \cos \left(n_{i j}, n_{j i}\right) & \cos \left(n_{i j}, z_{j i}\right) & 0 & 0 & 0 \\
0 & \cos \left(z_{i j}, n_{j i}\right) & \cos \left(z_{i j}, z_{j i}\right) & 0 & 0 & 0 \\
0 & 0 & 0 & -1 & 0 & 0 \\
0 & 0 & 0 & 0 & \cos \left(n_{i j}, n_{j i}\right) & -\cos \left(n_{i j}, z_{j i}\right) \\
0 & 0 & 0 & 0 & -\cos \left(z_{i j}, n_{j i}\right) & \cos \left(z_{i j}, z_{j i}\right)
\end{array}\right]
$$

Outra relação pode ser obtida pelas equações de equilíbrio em cada interface:

$$
\left(\begin{array}{l}
t_{1}^{13} \\
t_{2}^{13} \\
V_{n}^{13} \\
m_{n}^{13}
\end{array}\right)+\underset{\sim t}{\bar{R}_{t}^{31}}\left(\begin{array}{c}
t_{1}^{31} \\
t_{2}^{31} \\
V_{n}^{31} \\
m_{n}^{31}
\end{array}\right)+\underset{\sim t}{\bar{R}_{t}^{41}}\left(\begin{array}{c}
t_{1}^{41} \\
t_{2}^{41} \\
V_{n}^{41} \\
m_{n}^{41}
\end{array}\right)=\left(\begin{array}{l}
0 \\
0 \\
0 \\
0
\end{array}\right)
$$

onde:

$$
\bar{R}_{t}^{j i}\left[\begin{array}{cccc}
-1 & 0 & 0 & 0 \\
0 & \cos \left(n_{i j}, n_{j i}\right) & \cos \left(n_{i j}, z_{j i}\right) & 0 \\
0 & \cos \left(z_{i j}, n_{j i}\right) & \cos \left(z_{i j}, z_{j i}\right) & 0 \\
0 & 0 & 0 & -1
\end{array}\right]
$$

A partir das equações (4.116)-(4.123), a representação algébrica global da estrutura poliédrica pode ser escrita como: 


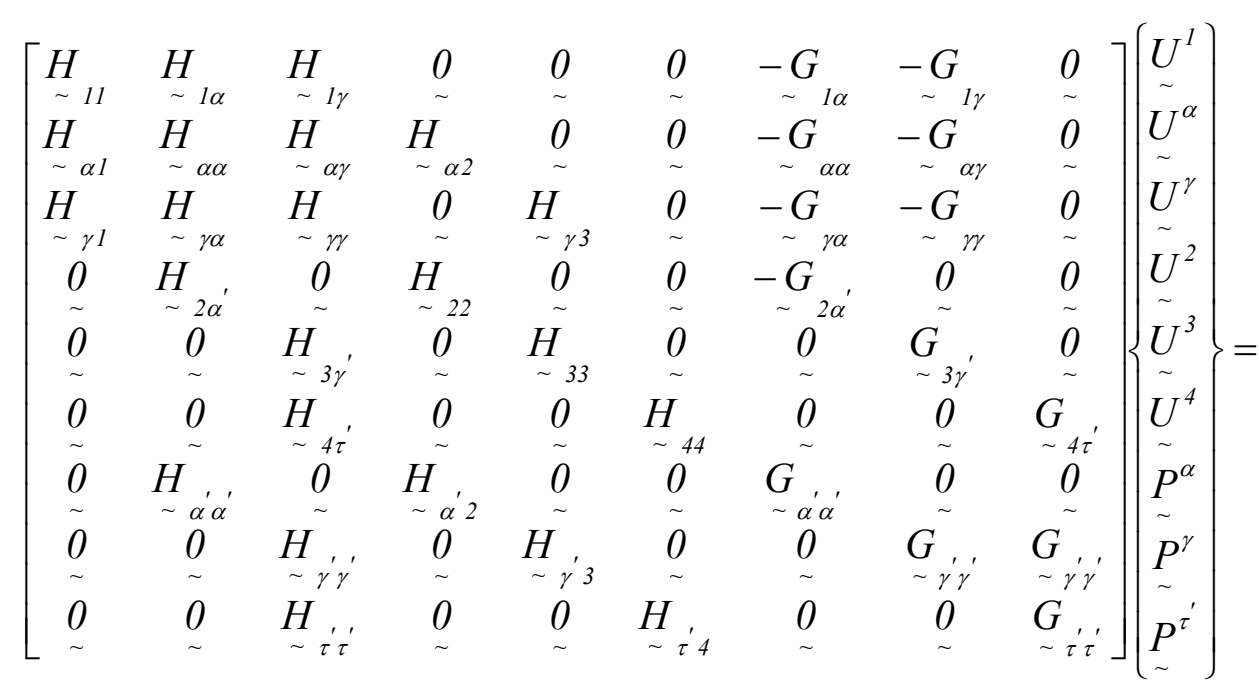

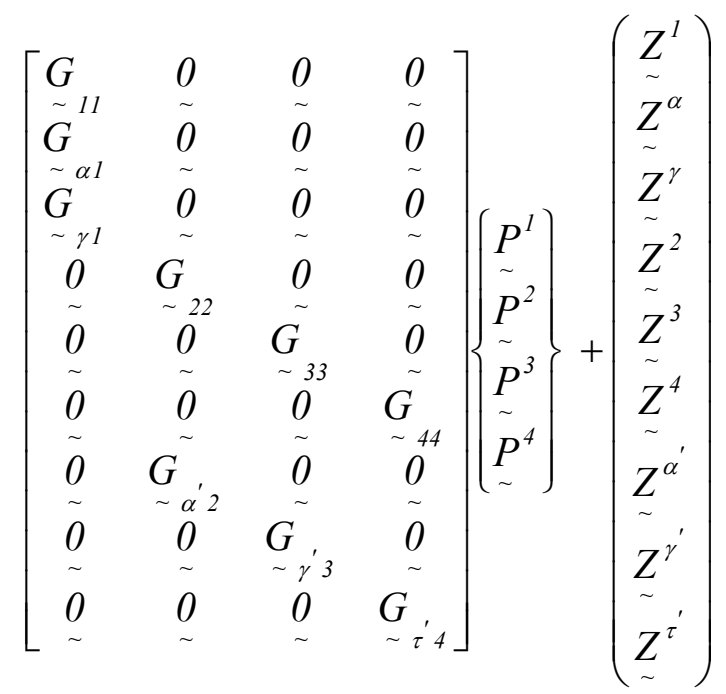

Nas interfaces podem estar convergindo diversas lâminas. Observando-se (4.120) e (4.122), pode-se notar que as variáveis pertencentes ao contorno de uma sub-região escrava em cada interface podem ser eliminadas da representação algébrica, isto é, os vetores $U^{31}$ e $P^{31}$ em $\Gamma_{31}$ e analogamente $U^{21}$ e $P_{\sim}^{21}$ em $\Gamma_{21}$. As variáveis fictícias presentes em $P^{12}$ e $P^{41}$ podem ser removidas da análise analogamente ao discutido no caso de duas lâminas coplanares.

\subsubsection{2) Formulação Tetraparamétrica}

Nesta seção são apresentadas algumas adaptações na formulação hexaparamétrica ( 3 equações: chapas; 3 equações: placas) a fim de reduzi-la para a representação do modelo TP (2 equações: chapas; 2 equações: placas). 


\subsubsection{1) Problemas com regiões simples.}

Tomando por simplicidade, a representação algébrica da lâmina plana para o modelo tetraparamétrico- obtida a partir da discretização das equações (3.50), (3.113) e (3.133)- pode ser apresentada de forma reduzida como:

$$
\left[\begin{array}{cccc}
h_{11} & h_{12} & 0 & 0 \\
h_{21} & h_{22} & 0 & 0 \\
0 & 0 & h_{33} & h_{34} \\
0 & 0 & h_{43} & h_{44}
\end{array}\right]\left\{\begin{array}{c}
v_{1} \\
v_{2} \\
w \\
\theta_{p}
\end{array}\right\}=\left[\begin{array}{cccc}
g_{11} & g_{12} & 0 & 0 \\
g_{21} & g_{22} & 0 & 0 \\
0 & 0 & g_{33} & g_{34} \\
0 & 0 & g_{43} & g_{44}
\end{array}\right]\left\{\begin{array}{l}
t_{1} \\
t_{2} \\
V_{n} \\
m_{n}
\end{array}\right\}+\left\{\begin{array}{l}
z_{1} \\
z_{2} \\
z_{3} \\
z_{4}
\end{array}\right\}
$$

Conforme pode ser observado em (4.125), os números de graus de liberdade associados aos deslocamentos e às forças são idênticos, dispensando, portanto a técnica de inserção de variáveis fictícias empregada na formulação hexaparamétrica. Com isso, a solução do sistema algébrico pode ser obtida impondo-se diretamente as condições de contorno.

\subsubsection{2) Estruturas coplanares}

Para as estruturas coplanares, as relações de compatibilidade na formulação tetraparamétrica podem ser expressas pela supressão das rotações zenitais e tangenciais em (4.84), resultando em:

$$
\left(\begin{array}{c}
v_{1}^{p} \\
v_{2}^{p} \\
w^{p} \\
\theta_{p}^{p}
\end{array}\right)=\left(\begin{array}{c}
v_{1}^{p^{\prime}} \\
v_{2}^{p^{\prime}} \\
w^{p^{\prime}} \\
-\theta_{p}^{p^{\prime}}
\end{array}\right)
$$

Já as equações de equilíbrio podem ser escritas tais quais em (4.85). Assim, substituindo-se essas relações nas representações algébricas de cada uma das subregiões (4.82) e (4.83), uma representação algébrica similar a (4.87) pode ser escrita para o problema coplanar.

\subsubsection{3) Estruturas não-coplanares}

A adaptação da abordagem hexa para a tetraparamétrica também pode ser efetuada com os devidos ajustes nas relações de equilíbrio e compatibilidade em uma interface que tem um feixe de lâminas convergentes. Tais relações podem ser obtidas pela supressão das rotações tangenciais e zenitais dadas em (4.120): 


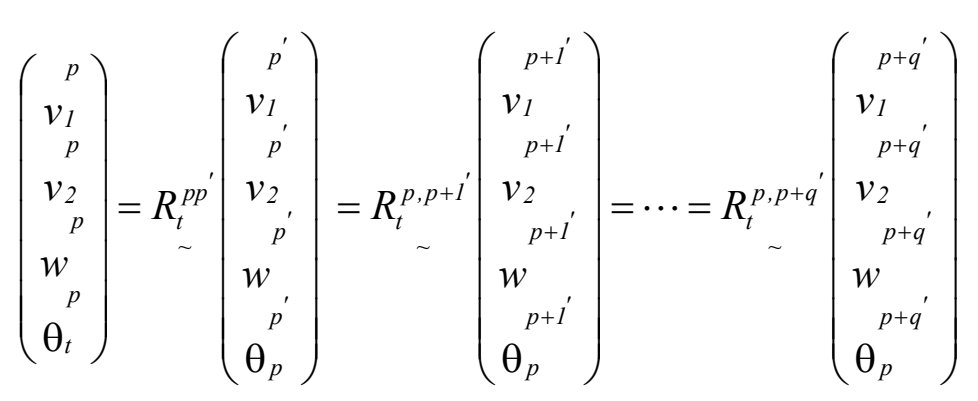

onde:

$$
\underset{\sim t}{R^{j i}}=\left[\begin{array}{cccc}
-1 & 0 & 0 & 0 \\
0 & \cos \left(n_{i j}, n_{j i}\right) & \cos \left(n_{i j}, z_{j i}\right) & 0 \\
0 & \cos \left(z_{i j}, n_{j i}\right) & \cos \left(z_{i j}, z_{j i}\right) & 0 \\
0 & 0 & 0 & -1
\end{array}\right]
$$

As condições de equilíbrio podem ser escritas similarmente às descritas em (4.122).

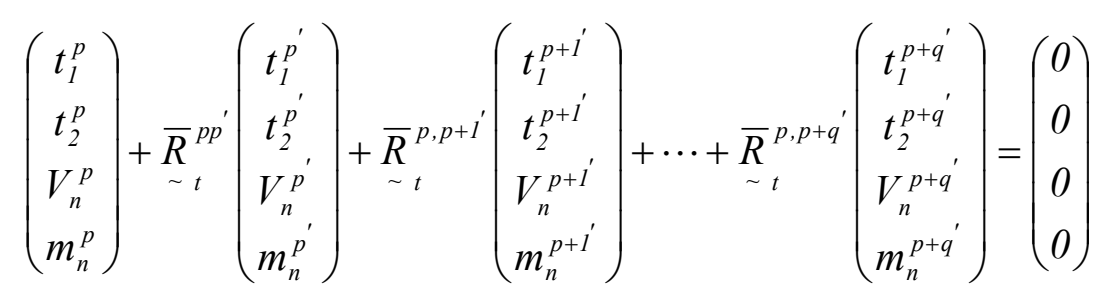

onde $R_{t}^{j i}=\bar{R}_{t}^{j i}$ para o modelo TP. Em (4.127) e (4.129), $q=n-1$ e $n$ é o número de interfaces escravas convergentes à interface-mestre.

Com isso, substituindo-se (4.127) e (4.129) nas representações (4.116)(4.123), tem-se um sistema de equações similar à (4.124) para o problema de lâminas não-coplanares via formulação tetraparamétrica. Contudo, ao contrário de (4.124), a resolução do sistema pode ser efetuada diretamente, dispensando inserção de variáveis fictícia uma vez que o número de variáveis do vetor de deslocamentos é igual ao do vetor de forças.

\section{3)Determinação dos deslocamentos e esforços no domínio}

Após a imposição das condições contorno no sistema final de equações, as incógnitas do problema são determinadas. Assim, as matrizes de rotações (4.110)(4.115) necessitam ser novamente empregadas para que os resultados da análise sejam expressos segundo cada sistema local de cada sub-região. Apenas os deslocamentos, rotações, esforços e forças de superfície no contorno de cada funículo 
não tornam a análise do problema completa; ainda restam determinar os campos de deslocamentos, tensões, esforços dos pontos internos. O cálculo dos esforços $q_{i}$ e $m_{i j}$ de pontos internos pode ser efetuado a partir das curvaturas da placa e de suas derivadas. Assim, os momentos fletores e volventes, associados aos eixos de referência arbitrários $(m, q)$, podem ser obtidos a partir da representação integral dos momentos descrita em (3.96); a força cortante segundo a direção $m$ pode ser obtida substituindo-se (3.104) em (3.103):

$$
\begin{aligned}
& q_{m}(p)-D \oint_{\Gamma}\left[w(s) \alpha_{n, m t t}^{*}(p, s)-\theta_{p}(s) m_{n, m t t}^{*}(p, s)\right] d \Gamma+ \\
& D \oint_{\Gamma}\left[\theta_{t}(s) \beta_{n, m t t}(p, s)\right] d \Gamma-D \varsigma_{c, t t}^{*}(p, S) R_{c}(S)= \\
& -D \oint_{\Gamma}\left[V_{n}(s) w_{, m t t}(p, s)-m_{n}(s) \theta_{p, m t t}(p, s)\right] d \Gamma- \\
& D R_{c, m t t}^{*}(p, i) w_{c}(S)-D \int_{\Omega} g(S) w_{, \text {, tt }}{ }^{*}(p, S) d \Omega ; c=1,2, \ldots, N c \text {; }
\end{aligned}
$$

Já as tensões $\sigma_{m q}^{f}$ mobilizadas pelo estado de flexão também podem ser determinadas a partir substituição das representações integral das curvaturas da placa(3.89)em (2.20). Além do estado de flexão, a lâmina também pode estar submetida ao estado de membrana. A resultante do campo das tensões $N_{m q}$ mobilizado nesse estado pode ser escrita a partir da representação integral do campo das resultantes de tensão (3.43); se expressa em coordenadas locais, tem-se que:

$$
\begin{gathered}
N_{m q}(p)+\oint_{\Gamma} q_{i}(p) s_{i j k}^{*}(p, s) m_{j}(p) Q_{k s}(s) v_{s}(s) d \Gamma=\oint_{\Gamma} q_{i}(p) d_{i j k}^{*}(p, s) m_{j}(p) Q_{k s}(s) t_{s}(s) d \Gamma+ \\
\int_{\Omega} q_{i}(p) s_{i j k}^{*}(p, S) m_{j}(p) b_{k}(S) d \Omega+\int_{\Omega_{L}} q_{i}(p) s_{i j k}^{*}(p, S) m_{j}(p) b_{L k}(S) d \Omega_{L}+ \\
\sum_{t=l}^{N_{f c}} q_{i}(p) s_{i j k}^{*}(p, S) m_{j}(p) F_{k t}(S) ; \quad i, j=1,2
\end{gathered}
$$


Em um ponto p (que está localizado ao longo da espessura de uma seção transversal qualquer) tem seu campo das tensões mobilizado obtido pela superposição dos efeitos de flexão $\sigma_{m q}^{f}$ e de membrana $\sigma_{m q}^{m}$ a partir de seus respectivos esforços por unidade de comprimento:

$$
\sigma_{m q}(p)=\sigma_{m q}^{m}(p)+\sigma_{m q}^{f}(p)
$$

onde:

$$
\begin{gathered}
\sigma_{m q}^{m}(p)=\frac{N_{m q}(p)}{t} \\
\sigma_{m q}^{f}(p)=12 \frac{m_{m q}(p)}{t^{3}} \varsigma
\end{gathered}
$$

Em (4.134), a coordenada $\varsigma$ tem intervalo $[-t / 2 \quad t / 2]$ e mesma orientação da normal ao plano médio de cada lâmina; $t$ é a espessura da lâmina. 


\section{REPRESENTAÇÕES INTEGRAIS E ALGÉBRICAS PARA PROBLEMAS INELÁSTICOS}

\section{1) Introdução}

Nos capítulos anteriores foram discutidas as representações integrais e algébricas para estruturas compostas por folhas poliédricas em regime elástico linear. Existem, porém, alguns problemas em que campos iniciais podem ser utilizados para representar o comportamento de regimes termoelástico, viscoelástico, elastoplástico e outros. Assim, nesse capítulo são discutidas as representações integrais de problemas inelásticos genéricos e, no próximo, a formulação será aplicada ao regime elastoplástico. Convém ressaltar que os problemas inelásticos podem ser divididos de uma maneira geral em dois grandes grupos: o primeiro pode ser associado àqueles materiais cuja reologia é dependente do tempo, em geral associada a um comportamento viscoso. A outra modalidade de problema pode ser reunida naqueles em que tais efeitos são desprezados, tais como os abordados pela teoria da plasticidade. Neste trabalho, as equações são descritas para um problema inelástico genérico, de forma que tanto os campos dependentes do tempo quanto os independentes são representados de uma única maneira. Assim, nos casos em que há presença de efeitos viscosos, o símbolo $(\cdot)$ representa o estado atual do campo. Nos demais casos, tal símbolo representa acréscimos do campo.

\section{2)Equações integrais para problemas com campos iniciais}

\subsection{1)Equações básicas}

As deformações totais podem ser escritas a partir da diferenciação dos deslocamentos:

$$
\dot{\varepsilon}_{i j}=\frac{1}{2}\left(\dot{u}_{i, j}+\dot{u}_{j, i}\right), i, j=1,2,3
$$

Essas mesmas deformações podem ser escritas em duas parcelas contribuintes

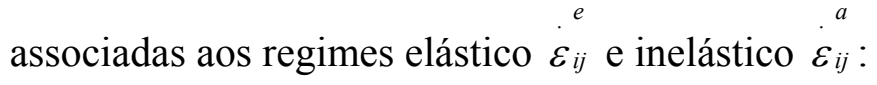

$$
\dot{\varepsilon}_{i j}=\dot{\varepsilon}_{i j}^{e}+\dot{\varepsilon}_{i j}^{a} ; \quad i, j=1,2,3
$$

As equações de equilíbrio podem ser escritas como: 


$$
\dot{\sigma}_{i j, j}+\dot{b}_{i}=0 ; \quad i, j=1,2,3
$$

Em um ponto na superfície do corpo, sujeito a um campo de tensões, uma relação entre as componentes de forças de superfície $\dot{p}_{i}$ e de tensões $\dot{\sigma}_{i j}$ pode ser escrita a partir de equações conhecidas como fórmula de tensão de Cauchy:

$$
\dot{p}_{i}=\dot{\sigma}_{i j} n_{j} ; \quad i, j=1,2,3
$$

onde $n_{i}$ são os co-senos diretores da normal à superfície no ponto.

Se as deformações inelásticas são tomadas como campo inicial, as relações Tensão-Deformação - com auxílio de relações geométricas indicadas na figura $5.1 \mathrm{~b}$ e da lei de Hooke - podem ser escritas como:

$$
\dot{\sigma}_{i j}=2 G\left(\dot{\varepsilon}_{i j}-\dot{\varepsilon}_{i j}^{a}\right)+\frac{2 G v}{1-2 v}\left(\dot{\varepsilon}_{k k}-\dot{\varepsilon}_{k k}^{a}\right) \delta_{i j} ; \quad i, j, k=1,2,3
$$

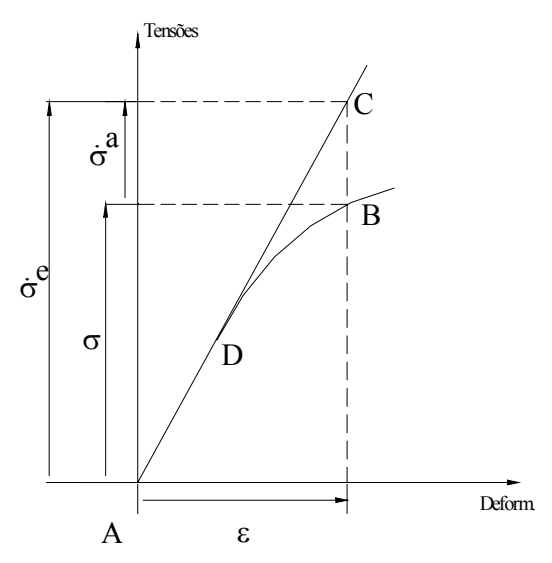

(a)

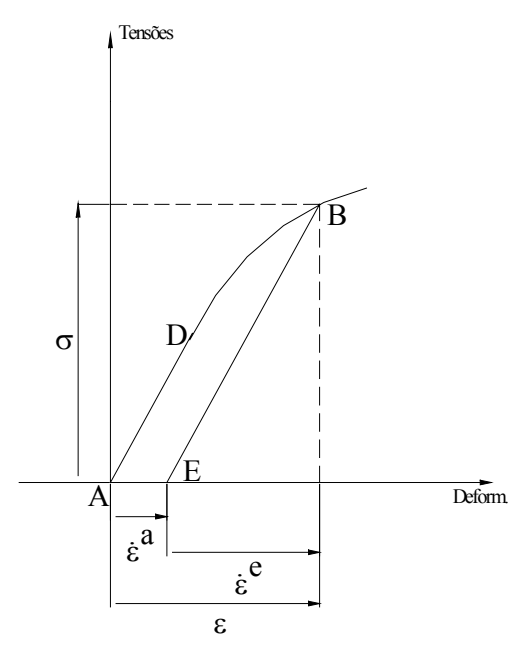

(b)

Figura 5.1- Diagramas tensão-deformação em problemas uniaxiais.

Se o problema inelástico for analisado tomando-se as tensões inelásticas como campo inicial, uma estratégia alternativa à anterior pode ser empregada. Para uma determinada deformação total, um campo de tensões elásticas fictícias $\dot{\sigma}_{i j}^{e}$, vide figura 5.1(a), pode ser obtido por intermédio da lei de Hooke: 


$$
\dot{\sigma}_{i j}^{e}=2 G \dot{\varepsilon}_{i j}+\frac{2 G v}{1-2 v} \dot{\varepsilon}_{k k} \delta_{i j} ; \quad i, j, k=1,2,3
$$

Essas tensões fictícias podem também ser representadas pela soma de parcelas de tensões verdadeiras $\dot{\sigma}_{i j}$ e inelásticas $\dot{\sigma}_{i j}^{a}$ :

$$
\dot{e}_{i j}^{e}=\dot{\sigma}_{i j}+\dot{\sigma}_{i j}^{a} ; \quad i, j=1,2,3
$$

Substituindo-se (5.6) em (5.7), tem-se a relação constitutiva em tensões iniciais:

$$
\dot{\sigma}_{i j}=2 G \dot{\varepsilon}_{i j}+\frac{2 G v}{1-2 v} \dot{\varepsilon}_{k k} \delta_{i j}-\dot{\sigma}_{i j}^{a} ; \quad i, j, k=1,2,3
$$

onde as tensões inelásticas em (5.8) são escritas em função das deformações inelásticas, substituindo-se (5.8) em (5.5):

$$
\stackrel{a}{\sigma_{i j}}=2 G \stackrel{a}{\varepsilon_{i j}}+\frac{2 G v}{1-2 v} \stackrel{a}{\varepsilon}_{k k} \delta_{i j} ; \quad i, j, k=1,2,3
$$

As relações apresentadas anteriormente neste capítulo são válidas para problemas tridimensionais, de forma que para casos bidimensionais elas devem ser adaptadas ao estado plano de interesse.

Tomando-se um problema de chapas, com espessura finita $t$, submetido a um carregamento externo e a campos iniciais. Fazendo-se o equilíbrio do corpo em um elemento infinitesimal, a equação diferencial governante do problema- em função das resultantes de tensão- pode ser escrita como:

$$
\dot{N}_{i j, j}+\dot{b}_{i}=0 ; \quad i, j=1,2
$$

Se as deformações inelásticas forem tomadas como campos iniciais e forem adotadas as hipóteses do estado plano de tensão(EPT) e de deformação(EPD) em (5.5), as relações tensão-deformação para esses casos podem ser escritas como: 


$$
\left\{\begin{array}{l}
\dot{N}_{i j}=t C_{i j m q}\left(\dot{\varepsilon}_{m q}-\dot{\varepsilon}_{m q}^{a}\right.
\end{array}\right), \quad E P T \quad r, j, m, q=1,2
$$

onde $\quad \mathrm{o}$ tensor $C_{i j m q}=\frac{2 G v_{p}}{1-2 v_{p}} \delta_{i j} \delta_{m q}+G\left(\delta_{i m} \delta_{j q}+\delta_{i q} \delta_{j m}\right) \quad$ é dado em $v_{p}=v$ para EPD e $v_{p}=\frac{v}{1-v}$ para EPT.

No entanto, se o campo inelástico for tomado em tensões iniciais e forem impostas as hipóteses dos estados planos em (5.8), as relações tensão-deformação devem ser escritas como:

$$
\dot{N}_{i j}=t C_{i j m q} \dot{\varepsilon}_{m q}-\dot{N}_{i j}^{a} ; \text { EPT ou EPD; } \quad i, j, m, q=1,2
$$

Como no regime elástico, as representações integrais para problemas inelásticos podem ser obtidas tanto com a aplicação do Teorema da Reciprocidade de Betti(TRB) quanto com a Técnica do Resíduo Ponderado(TRP). No capítulo 3, foi aplicada para o regime elástico a primeira estratégia para os estados planos e a segunda para o regime de flexão. Neste capítulo, para exemplificar mais uma vez a transformação das EDPs em equações integrais, os problemas e a ordem dos procedimentos empregados serão invertidos, isto é: TRB para placas, e TRP para os estados planos.

\subsection{2)Equações integrais}

Uma expressão do resíduo ponderado de chapas, envolvendo a ponderação de (5.10) no domínio e das condições essenciais $\dot{\bar{u}}_{j}-\dot{u}_{j}(s)=0$ e naturais $\dot{\bar{f}}_{j}-\dot{f}_{j}=0$ no contorno, pode ser escrita como:

$$
\begin{gathered}
\int_{\Omega}\left[\dot{N}_{j k, k}(s)+\dot{b}_{j}(s)\right] u_{i j}^{*}(p, S) d \Omega=-\int_{\Gamma_{1}}\left[\dot{\bar{f}}_{j}-\dot{f}_{j}(s)\right] u_{i j}^{*}(p, s) d \Gamma+ \\
\int_{\Gamma_{2}}\left[\dot{\bar{u}}_{j}-\dot{u}_{j}(s)\right] f_{i j}^{*}(p, s) d \Gamma i, j, k=1,2
\end{gathered}
$$


onde os kernels $u_{i j}^{*}, f_{i j}^{*}$ estão indicados em (2.116) e (2.130); $\Gamma_{1}, \Gamma_{2}$ são as regiões do contorno onde as condições essenciais e naturais são prescritas, respectivamente; $\Gamma=\Gamma_{1}+\Gamma_{2}$.

Aplicando-se a técnica de integração por partes na primeira parcela de (5.10), uma identidade pode ser escrita como:

$$
\begin{gathered}
\int_{\Omega} \dot{b}_{j}(S) u_{i j}^{*}(p, S) d \Omega+\int_{\Gamma} \dot{f}_{j}(s) u_{i j}^{*}(p, s) d \Gamma=\int_{\Omega} \dot{N}_{j k}(S) u_{i j, k}^{*}(p, S) d \Omega- \\
\int_{\Gamma_{1}}\left[\dot{\bar{f}}_{j}-\dot{f}_{j}(s)\right] u_{i j}^{*}(p, s) d \Gamma+\int_{\Gamma_{2}}\left[\dot{\bar{u}}_{j}-\dot{u}_{j}(s)\right] f_{i j}^{*}(p, s) d \Gamma ; \quad i, j, k=1,2
\end{gathered}
$$

Se o regime em questão fosse apenas elástico, um provável passo seguinte para a obtenção da identidade de Somigliana seria a aplicação do teorema da reciprocidade de Betti na integral de domínio do lado direito de (5.14). Em se tratando do regime inelástico, uma etapa intermediária ainda é requerida, isto é, a generalização desse teorema para problemas inelásticos.

Inicialmente, é discutida a aplicação do teorema da reciprocidade em problemas uniaxiais, uma vez que a representação gráfica do diagrama tensãodeformação pode ser obtida de maneira bem simples. O teorema de Betti pode ser aplicado nas retas do diagrama tensão-deformação, por exemplo no segmento EB indicado na figura 5.1b. Assim, a partir dessa figura, estendendo-se uma analogia para o caso tridimensional, em que as deformações são tomadas como campos iniciais, esse teorema pode ser escrito como:

$$
\int_{\Omega} \sigma_{i j k}^{*}(p, S)\left[\dot{u}_{j, k}(S)-\dot{u}_{j, k}^{a}(S)\right] d \Omega=\int_{\Omega} \dot{\sigma}_{j k}(S) u_{i j, k}^{*}(p, S) d \Omega ; i, j, k=1,2,3
$$

Uma outra discussão é a adequação da identidade descrita em (5.15) para os problemas bidimensionais- Estados Planos de Deformação (EPD) e de Tensão (EPT).

No EPD, as componentes de deformações totais $\dot{\varepsilon}_{33}$ e as componentes do tensor fundamental $\varepsilon_{i 33}^{*}$ são nulas, de forma que a equação integral (5.15), pode ser escrita como: 


$$
\begin{gathered}
\int_{\Omega} N_{i j k}^{*}(p, S)\left[\dot{u}_{j, k}(S)-\dot{u}_{j, k}^{a}(S)\right] d \Omega-\int_{\Omega} N_{i 33}^{*}(p, S) \dot{\varepsilon}_{33}^{a}(S) d \Omega=\int_{\Omega} \dot{N}_{j k}(S) u_{i j, k}^{*}(p, S) \\
i, j, k=1,2
\end{gathered}
$$

onde os kernels $N_{i j k}^{*}$ e $u_{i j, k}^{*}$ estão indicados nas expressões (2.129) e (2.127); convém ressaltar que $\dot{N}_{i j}$ é a resultante do campo das tensões ao longo da espessura, isto é, $\dot{N}_{i j}=t \dot{\sigma}_{i j}$ e o kernel $N_{i j k}^{*}$ tem uma representação análoga expressa por $N_{i j k}^{*}=t \sigma_{i j k}^{*}$.

No EPT, $\dot{\sigma}_{33}$ e $\sigma_{i 33}$ são admitidas como nulas. Assim, a generalização do teorema de Betti, para problemas em que as deformações inelásticas são tomadas como campo inicial, pode ser escrita como:

$$
\int_{\Omega} N_{i j k}^{*}(p, S)\left[\dot{u}_{j, k}(S)-\dot{u}_{j, k}^{a}(S)\right] d \Omega=\int_{\Omega} \dot{N}_{j k}(S) u_{i j, k}^{*}(p, S) d \Omega ; i, j, k=1,2
$$

Uma estratégia análoga à relação dada em (5.15) pode ser aplicada na generalização do teorema de Betti para problemas bidimensionais em que as tensões inelásticas são tomadas como campo inicial:

$$
\int_{\Omega} N_{i j k}^{*}(p, S) \dot{u}_{j, k}(S) d \Omega=\int_{\Omega} u_{i j, k}^{*}(p, S)\left[\dot{N}_{j k}^{e}(S)+\dot{N}_{j k}^{a}(S)\right] d \Omega ; i, j, k=1,2
$$

Com o teorema generalizado de Betti para problemas do EPD com deformações inelásticas tomadas como campo inicial, outras identidades podem ser escritas a partir da substituição de (5.16) em (5.14). Se nessas identidades forem aplicadas as técnicas de integração por partes, a seguinte expressão pode ser escrita:

$$
\begin{gathered}
-\int_{\Omega} \dot{b}_{j}(S) u_{i j}^{*}(p, S) d \Omega=\oint_{\Gamma} f_{j}(s) u_{i j}^{*}(p, s) d \Gamma-\oint_{\Gamma} \dot{u}_{j}(s) f_{i j}^{*}(p, s) d \Gamma+ \\
\int_{\Gamma_{1}}\left[\dot{\bar{f}}_{j}-\dot{f}_{j}(s)\right] u_{i j}^{*}(p, s) d \Gamma-\int_{\Gamma_{2}}\left[\dot{\bar{u}}_{j}-\dot{u}_{j}(s)\right] f_{i j}^{*}(p, s) d \Gamma+\int_{\Omega} N_{i j k}^{*}(p, S) \dot{u}_{j, k}^{a}(S) d \Omega+ \\
\int_{\Omega} N_{i 33}^{*}(p, S) \dot{\varepsilon}_{33}^{a}(S) d \Omega+\int_{\Omega} N_{i j k, k}^{*}(p, S) \dot{u}_{j}(S) d \Omega ; i, j, k=1,2
\end{gathered}
$$


Convém ressaltar que a equação diferencial de equilíbrio do problema elástico fundamental é dada por:

$$
N_{i j k, k}^{*}(p, S)+\delta(p, S) \delta_{i k}=0 ; i, j, k=1,2
$$

Substituindo-se (5.20) em (5.19), tem-se a identidade de Somigliana para o EPD para problemas em que as deformações inelásticas são tomadas como campo inicial:

$$
\begin{aligned}
& \dot{u}_{i}(p)+\oint_{\Gamma} \dot{u}_{j}(s) f_{i j}^{*}(p, s) d \Gamma=\oint_{\Gamma} \dot{f}_{j}(s) u_{i j}^{*}(p, s) d \Gamma+\int_{\Omega} N_{i j k}^{*}(p, S) \dot{u}_{j, k}^{a}(S) d \Omega+ \\
& \int_{\Omega} N_{i 33}^{*}(p, S) \dot{\varepsilon}_{33}^{a}(S) d \Omega+\int_{\Omega} u_{i j}^{*}(p, S) b_{j}(S) d \Omega ; i, j, k=1,2
\end{aligned}
$$

A representação integral equivalente à equação (5.21) para o EPT pode ser escrita como:

$$
\begin{gathered}
\dot{u}_{i}(p)+\oint_{\Gamma} \dot{u}_{j}(s) f_{i j}^{*}(p, s) d \Gamma=\oint_{\Gamma} f_{j}(s) u_{i j}^{*}(p, s) d \Gamma+\int_{\Omega} N_{i j k}^{*}(p, S) \dot{u}_{j, k}^{a}(S) d \Omega+ \\
+\int_{\Omega} \dot{b}_{j}(S) u_{i j}^{*}(p, S) d \Omega ; i, j, k=1,2
\end{gathered}
$$

As representações integrais anteriormente mostradas são escritas em termos de um sistema de referência global $\left(x_{1}, x_{2}\right)$. Conforme apresentada no capítulo 3 , uma técnica alternativa consiste em escrever as representações dos estados planos em um sistema local equivalente àquele do problema de flexão, (vide figura 5.2).

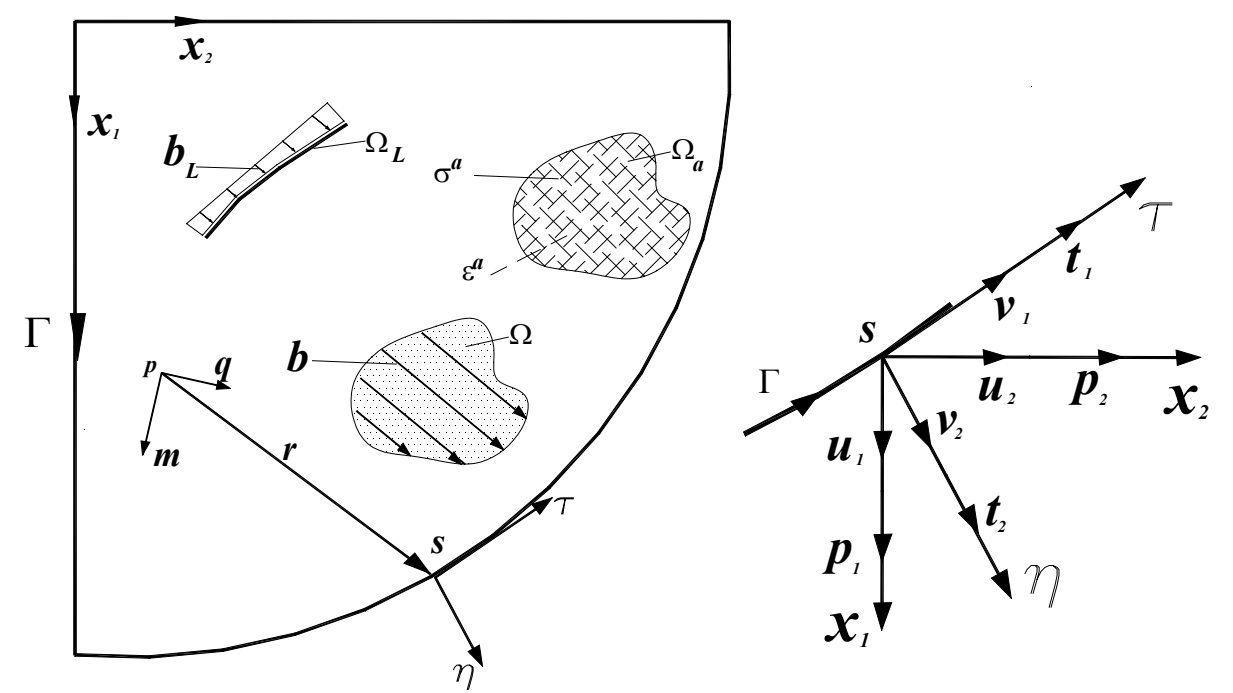

Figura 5.2- Esquema representativo do problema de membrana. 
Assim, substituindo-se a identidade $N_{i j k}^{*} \dot{u}_{j, k}^{a}=N_{i j k}^{*} \stackrel{a}{\varepsilon}_{j k}$ nas equações (5.21) ou (5.22), a representação integral paras os deslocamentos em deformações iniciais pode ser expressa por:

$$
\begin{gathered}
u_{q}(p)+q_{i}(p) \oint_{\Gamma} f_{i j}^{*}(p, s) Q_{j r}(s) \dot{v}_{r}(s) d \Gamma=q_{i}(p) \oint_{\Gamma} u_{i j}^{*}(p, s) Q_{j r}(s) \dot{t}_{r}(s) d \Gamma+ \\
+q_{i}(p) \int_{\Omega} u_{i j}^{*}(p, S) \dot{b}_{j}(S) d \Omega+q_{i}(p) \int_{\Omega_{L}} u_{i j}^{*}(p, S) \dot{b}_{L j}(S) d \Omega_{L}+I_{u}\left(\varepsilon^{a}\right) ; i, j, r=1,2
\end{gathered}
$$

onde $\dot{u}_{q}(p)=\dot{u}_{i}(p) q_{i}(p)$; o termo inelástico $I_{u}\left(\varepsilon^{a}\right)$ é dado por:

$$
I_{u}\left(\varepsilon^{a}\right)=\left\{\begin{array}{cc}
q_{i}(p) \int_{\Omega} N_{i j k}^{*}(p, S) \stackrel{\dot{\varepsilon}_{j k}}{a}(S) d \Omega ; & E P T \\
q_{i}(p) \int_{\Omega} N_{i j k}^{*}(p, S) \dot{\varepsilon}_{j k}^{a}(S) d \Omega+q_{i}(p) \int_{\Omega} N_{i 33}^{*}(p, S) \dot{\varepsilon}_{33}^{a}(S) d \Omega ; E P D & \\
i, j, k=1,2 &
\end{array}\right.
$$

Se as tensões inelásticas forem tomadas como campo inicial, a representação integral em deslocamentos pode ser obtida pela substituição de $I_{u}\left(\varepsilon^{a}\right)$ por $I_{u}\left(N^{a}\right)$ em (5.23). Essa última parcela inelástica pode ser escrita para ambos estados planos como:

$$
I_{u}\left(N^{a}\right)=q_{i}(p) \int_{\Omega} \varepsilon_{i j k}^{*}(p, S) \dot{N}_{j k}^{a}(S) d \Omega ; E P D \text { ou EPT.; } \quad i, j, k=1,2
$$

Na obtenção da representação integral dos gradientes de deslocamentos, a diferenciação do termo plástico da equação dos deslocamentos (5.23) pode ser efetuada utilizando-se o conceito de derivação de integrais singulares de MIKHLIN(1962), conforme sugerido e aplicado em problemas tridimensionais por BUI(1978). Na seqüência, serão mostradas as representações completas dos estados planos e para o regime de flexão utilizando-se esses conceitos.

A diferenciação da integral de domínio das tensões inelásticas em (5.23) pode ser escrita como:

$$
\dot{V}_{i}=\frac{\partial}{\partial x_{m}(p)} \int_{\Omega} \varepsilon_{i j k}^{*}(p, S) \dot{N}_{j k}^{a}(S) d \Omega ; i, j, k=1,2
$$

Nos trabalhos de Mikhlin, as equações integrais singulares foram amplamente discutidas e um dos tópicos está associado às diferenciações dessas equações com 
singularidades fracas. Em MIKHLIN(1965), pode ser encontrada uma expressão para a diferenciação de equações integrais para problemas multidimensionais -a partir do trabalho de TRICOMI(1928) para o espaço bidimensional- expressa como:

$$
\frac{\partial}{\partial x_{k}} \int u(y) \frac{\varphi(x, \theta)}{r^{m-1}} d y=\int u(y) \frac{\partial}{\partial x_{k}}\left[\frac{\varphi(x, \theta)}{r^{m-1}}\right] d y-u(x) \int_{T} \varphi(x, \theta) \cos \left(r, x_{m}\right) d y
$$

onde $T$ é o contorno de raio unitário; $m$ é a dimensão do espaço.

Adaptando-se (5.27) ao problema inelástico bidimensional, em que as tensões são tomadas campo inicial, uma relação pode ser escrita como:

$$
\begin{gathered}
\frac{\partial}{\partial x_{m}(p)} \int_{\Omega} \dot{N}_{j k}^{a}(s) \frac{\psi_{i j k}^{*}(\theta)}{r} d \Omega=\int_{\Omega} \dot{N}_{j k}^{a}(s) \frac{\partial}{\partial x_{m}(p)}\left[\frac{\psi_{i j k}^{*}(\theta)}{r}\right] d \Omega-\dot{N}_{j k}^{a}(p) \int_{T} \psi_{i j k}^{*}(\theta) r_{, m} d \Gamma \\
i, j, k, m=1,2
\end{gathered}
$$

onde $\varepsilon_{i j k}^{*}(p, s)=\frac{1}{r} \psi_{i j k}^{*}(\theta)$.

Uma maneira alternativa para expressar (5.28) é:

$$
\begin{gathered}
\frac{\partial}{\partial x_{m}(p)} \int_{\Omega} \dot{N}_{j k}^{a}(S) \varepsilon_{i j k}^{*}(p, S) d \Omega=\int_{\Omega} \dot{N}_{j k}^{a}(S) \kappa_{i j k m}^{*}(p, S) d \Omega-\dot{N}_{j k}^{a}(p) \int_{T} \varepsilon_{i j k}^{*}(p, S) r_{, m} d \Gamma ; \\
i, j, k, m=1,2
\end{gathered}
$$

onde a derivada das componentes do kernel das deformações é dada por:

$$
\begin{gathered}
\kappa_{i j k m}^{*}=\frac{\partial}{\partial x_{m}(p)} \varepsilon_{i j k}^{*}=\frac{1}{8 \pi\left(1-v_{p}\right) r^{2} G t}\left\{\left(1-2 v_{p}\right)\left(\delta_{i j} \delta_{k m}+\delta_{j m} \delta_{i k}\right)-\delta_{i m} \delta_{j k}+\right. \\
2\left[r_{, i}\left(\delta_{j k} r_{, m}+\delta_{j m} r_{, k}\right)+r_{, j}\left(\delta_{k m} r_{, i}+\delta_{i m} r_{, k}\right)+r_{, m}\left(\delta_{i j} r_{, k}+\delta_{i k} r_{, j}\right)-\right. \\
\left.\left.2 v_{p}\left(\delta_{i j} r_{, k} r_{, m}+\delta_{i k} r_{, j} r_{, m}\right)-4 r_{, i} r_{, j} r_{, k} r_{, m}\right]\right\} ; i, j, k, m=1,2
\end{gathered}
$$

Convém ressaltar que a convergência da identidade (5.29) depende fortemente da segunda integral TELLES (1981). Em alguns casos, para os quais essa integral converge, está associada a colocação dos pontos-fonte no domínio ou em contorno sem angulosidade.

A terceira integral da identidade (5.29) pode ser calculada analiticamente no domínio circular de raio unitário com a utilização do kernel descrito em (2.128) e com o auxílio de coordenadas polares. Por simplicidade, o cálculo dessa integração 
será efetuado para aqueles casos descritos anteriormente que conduzem à convergência de (5.29).

Ao transformar o sistema de coordenadas cartesiano para o polar, a integração do último termo de (5.29) pode ser dividido em duas parcelas, a primeira das quais pode ser escrita como:

$$
\int_{0}^{\theta} r_{, \alpha} r_{, \beta} d \theta=c \pi \delta_{\alpha \beta} ; \alpha, \beta=1,2
$$

onde o coeficiente $c$ está associado a:

$$
c=\left\{\begin{array}{c}
1, \text { se } \theta=2 \pi, \text { i.e. } p \in \Omega \\
1 / 2, \text { se } \theta=\pi, \text { i.e. } p \in \Gamma \text { (suave) }
\end{array}\right.
$$

A parcela remanescente da última parcela de (5.28) pode ser escrita como:

$$
\int_{0}^{\theta} r_{, \alpha} r_{, \beta} r_{, \gamma} r_{\varsigma} d \theta=c \frac{\pi}{4}\left(\delta_{\alpha \beta} \delta_{\gamma_{\zeta}}+\delta_{\alpha \varsigma} \delta_{\beta \gamma}+\delta_{\alpha \gamma} \delta_{\beta \zeta}\right) ; \alpha, \beta, \gamma, \varsigma=1,2
$$

Substituindo-se (5.31), (5.33) na última parcela de (5.29), uma expressão para o coeficiente do termo livre de integrais inelásticas pode ser apresentada assim:

$$
\begin{gathered}
-N_{j k}^{a}(p) \int_{\Gamma_{l}} \varepsilon_{i j k}^{*}(p, S) r_{, \alpha} d \Gamma=q_{i}(p) m_{\alpha}(p) D_{i j k \alpha} \dot{N}_{j k}^{a}(p)= \\
-\frac{c q_{i}(p) m_{\alpha}(p)}{8\left(1-v_{p}\right) G t}\left[\left(3-4 v_{p}\right) \dot{N}_{i \alpha}^{a}(p)-\frac{1}{2} \dot{N}_{t t}^{a}(p) \delta_{i \alpha}\right] ; i, j, k, m, t, \alpha=1,2
\end{gathered}
$$

onde:

$$
D_{i j k \alpha}=-\frac{c}{16\left(1-v_{p}\right) G t}\left[\left(3-4 v_{p}\right)\left(\delta_{i j} \delta_{k \alpha}+\delta_{i k} \delta_{j \alpha}\right)-\delta_{i \alpha} \delta_{j k}\right] ; i, j, k, r=1,2
$$

Substituindo-se (5.34) e (5.28) na equação resultante da diferenciação da equação integral dos deslocamentos(5.23), tem-se a representação integral para os gradientes de deslocamentos em que as tensões inelásticas são tomadas como campo inicial:

$$
\begin{gathered}
\dot{u}_{q, m}(p)+q_{i}(p) \oint_{\Gamma} f_{i j k}^{*}(p, s) m_{j}(p) Q_{k r}(s) \dot{v}_{r}(s) d \Gamma=q_{i}(p) \oint_{\Gamma} u_{i j k}^{*}(p, s) m_{j}(p) Q_{k r}(s) \dot{t}_{r}(s) d \Gamma+ \\
+q_{i}(p) \int_{\Omega} u_{i j k}^{*}(p, S) m_{j}(p) \dot{b}_{k}(S) d \Omega+q_{i}(p) \int_{\Omega_{L}} u_{i j k}^{*}(p, S) m_{j}(p) \dot{b}_{L k}(S) d \Omega_{L}+I_{\theta_{z}}\left(N^{\cdot a}\right) \\
; i, j, k, \alpha=1,2
\end{gathered}
$$


onde o termo inelástico $I_{\theta_{z}}\left(N^{\cdot a}\right)$ pode ser escrito como:

$$
\begin{gathered}
I_{\theta_{z}}\left(N^{a}\right)=q_{i}(p) \int_{\Omega_{a}} \kappa_{i j k r}^{*}(p, S) m_{j}(p) N_{k r}^{a}(S) d \Omega_{a}+q_{i}(p) m_{j}(p) D_{i j k r} \dot{N}_{k r}^{a}(k) ; \\
i, j, k, r=1,2
\end{gathered}
$$

A representação integral dos gradientes de deslocamentos em deformações iniciais pode ser obtida pela substituição de $I_{\theta_{z}}\left(N^{a}\right)$ por $I_{\theta_{z}}\left(\varepsilon^{a}\right)$ em (5.36). Essa última parcela inelástica para o EPT pode ser escrita como:

$$
I_{\theta_{z}}\left(\varepsilon^{a}\right)=q_{i}(p) \int_{\Omega_{a}} \lambda_{i j k r}^{*}(p, S) m_{j}(p) \dot{\varepsilon}_{k r}^{a}(S) d \Omega_{a}+q_{i}(p) m_{j}(p) E_{i j k r} \stackrel{a}{\varepsilon_{k r}}(k) ; i, j, k=1,2
$$

onde $\lambda_{i j k r}^{*}$ e $E_{i j k r}$ são dados por:

$$
\begin{gathered}
\lambda_{i j k r}^{*}=\frac{\partial}{\partial x_{r}(p)} N_{i j k}^{*}=\frac{1}{8 \pi\left(1-v_{p}\right) r^{2}}\left\{2 ( 1 - 2 v _ { p } ) \left[\delta_{i j} \delta_{k r}+\delta_{j r} \delta_{i k}-\delta_{i r} \delta_{j k}+\right.\right. \\
\left.\left.-r_{, r}\left(\delta_{i j} r_{, k}+\delta_{i k} r_{, j}-\delta_{j k} r_{, i}\right)\right]+\delta_{i j} r_{, i} r_{, k}+\delta_{k r} r_{, i} r_{, j}+\delta_{i r} r_{, j} r_{, k}-4 r_{, i} r_{, j} r_{, k} r_{, r}\right\} ; \\
i, j, k, r=1,2 \\
E_{i j k r}=\frac{c}{16\left(1-v_{p}\right)}\left[\left(3-4 v_{p}\right)\left(\delta_{i j} \delta_{k r}+\delta_{i k} \delta_{j r}\right)-\left(1+4 v_{p}\right) \delta_{i r} \delta_{j k}\right] ; i, j, k, r=1,2
\end{gathered}
$$

onde o valor de $c$ é dado em (5.32).

Além das representações integrais dos deslocamentos e de seus gradientes, uma outra equação integral que pode ser expressa é para o campo das tensões e que pode ser escrita a partir das representações integrais dos gradientes dos deslocamentos(5.36) e da relação tensão-deformação do problema em questão. Assim, para os casos em que as tensões inelásticas são tomadas como um campo inicial, uma 'identidade de Somigliana' para as tensões pode ser escrita como:

$$
\begin{gathered}
\dot{N}_{q m}(p)+q_{i}(p) \oint_{\Gamma} s_{i j k}^{*}(p, s) m_{j}(p) Q_{k r}(s) \dot{v}_{r}(s) d \Gamma=q_{i}(p) \oint_{\Gamma} d_{i j k}^{*}(p, s) m_{j}(p) Q_{k r}(s) \dot{t}_{r}(s) d \Gamma+ \\
+q_{i}(p) \int_{\Omega} d_{i j k}^{*}(p, S) m_{j}(p) \dot{b}_{k}(S) d \Omega+q_{i}(p) \int_{\Omega_{L}} d_{i j k}^{*}(p, S) m_{j}(p) \dot{b}_{L k}(S) d \Omega_{L}+I_{\sigma}\left(N^{a}\right) \\
i, j, k, r=1,2
\end{gathered}
$$


onde termo inelástico $I_{\sigma}\left(N^{a}\right)$ para ambos estados é dado por:

$$
I_{\sigma}\left(N^{a}\right)=q_{i}(p) m_{j}(p) Z_{i j k r}(p, S) \dot{N}_{k r}^{a}(p)+q_{i}(p) \int_{\Omega} \varepsilon_{i j k l}^{*}(p, S) m_{j}(p) \stackrel{a}{N_{k l}}(S) d \Omega ; \quad i, j, k r=1,2
$$

$\operatorname{com} \varepsilon_{i j k l}^{*}$ e $Z_{i j k r}$ dados por:

$$
\begin{gathered}
\varepsilon_{i j k l}^{*}=2 G t\left[\frac{1}{2}\left(\frac{\partial}{\partial x_{l}} \varepsilon_{i j k}^{*}+\frac{\partial}{\partial x_{x}} \varepsilon_{i j l}^{*}\right)\right]+\frac{2 G v_{p} t}{1-2 v_{p}} \frac{\partial}{\partial x_{x}} \varepsilon_{i j k}^{*} \delta_{k l}= \\
\frac{1}{2 \pi\left(1-v_{p}\right) r^{2}}\left\{\frac{1}{2}\left(1-2 v_{p}\right)\left[\delta_{i k} \delta_{j l}+\delta_{j k} \delta_{i l}-\delta_{i j} \delta_{k l}+2 \delta_{i j} r_{, k} r_{l}\right]+\right. \\
\left.v_{p}\left(\delta_{i l} r_{, j} r_{, k}+\delta_{j k} r_{, i} r_{, l}+\delta_{i k} r_{, j} r_{, l}+\delta_{j l} r_{, i} r_{, k}\right)+\delta_{k l} r_{, i} r_{, j}-4 r_{, i} r_{, j} r_{, k} r_{l}\right\} ; i, j, k, l=1,2 \\
Z_{i j k r}=\frac{1}{8\left(1-v_{p}\right)}\left\{\left[4 v_{p}(2-c)-5\right] \delta_{i k} \delta_{j r}+\left(3-4 v_{p}\right) \delta_{j k} \delta_{i r}-\left(1-4 v_{p}\right) \delta_{i j} \delta_{k r}\right\} ; i, j, k, r=1,2
\end{gathered}
$$

onde o valor de $c$ é dado em (5.32).

A representação integral das tensões em deformações iniciais pode ser obtida pela substituição de $I_{\sigma}\left(N^{a}\right)$ por $I_{\sigma}\left(\varepsilon^{a}\right)$ em (5.41). A parcela inelástica tomada como campo inicial de deformações para o EPT pode ser escrita como:

$$
I_{\sigma}\left(\varepsilon^{a}\right)=q_{i}(p) \int_{\Omega} N_{i j k r}^{*}(p, S) m_{j}(p) \stackrel{\dot{a}_{k r}^{a}}{\varepsilon_{k}}(S) d \Omega+q_{i}(p) m_{j}(p) L_{i j k r}(p, S) \stackrel{a}{\dot{\varepsilon}_{k r}}(p) ; i, j, k, r=1,2
$$

onde $N_{i j k r}^{*}$ e $L_{i j k r}$ são dados por:

$$
\begin{gathered}
N_{i j k r}^{*}=2 G t\left[\frac{1}{2}\left(\frac{\partial}{\partial x_{r}} N_{i j k}^{*}+\frac{\partial}{\partial x_{k}} N_{i j r}^{*}\right)\right]+\frac{2 G v_{p} t}{1-2 v_{p}} \frac{\partial}{\partial x_{l}}\left(N_{l j k}^{*}\right) \delta_{i r}= \\
\frac{G t}{2 \pi\left(1-v_{p}\right) r^{2}}\left\{\left(1-2 v_{p}\right)\left[2\left(\delta_{i j} r_{, k} r_{, r}+\delta_{k r} r_{, i} r_{, j}\right)+\left(\delta_{i k} \delta_{j r}+\delta_{j k} \delta_{i r}\right)\right]-\left(1-4 v_{p}\right) \delta_{i j} \delta_{k r}+\right. \\
\left.+2 v_{p}\left(\delta_{i r} r_{, j} r_{, k}+\delta_{j k} r_{, i} r_{, r}+\delta_{i k} r_{, j} r_{, r}+\delta_{j r} r_{, i} r_{, k}\right)-8 r_{, i} r_{, j} r_{, k} r_{, r}\right\} ; i, j, k, r=1,2
\end{gathered}
$$




$$
\begin{gathered}
L_{i j k r}=\frac{G t}{4\left(1-v_{p}\right)}\left\{\left[v_{p}(2-c)+3 c-8\right] \delta_{i r} \delta_{j k}+\left(3-4 v_{p}\right) c \delta_{i k} \delta_{j r}+\right. \\
\left.\frac{1}{1-2 v_{p}}\left[8 v_{p}^{2}(1-c)+(9 c-8) v_{p}-c\right] \delta_{i j} \delta_{k j}\right\} ; \quad i, j, k, r=1,2
\end{gathered}
$$

onde o valor de $c$ é dado em (5.32).

No problema de lâmina plana, além dos estados planos, o corpo pode estar submetido aos campos associados ao estado de flexão. Assim, na seqüência serão mostradas as representações integrais de placas submetidas a campos iniciais de momentos e de curvaturas.

Alternativamente ao método dos resíduos ponderados que foi aplicado aos problemas dos estados planos, as equações diferenciais de equilíbrio de placas serão transformadas em representações integrais, partindo-se diretamente do teorema de reciprocidade para o regime de flexão.

Utilizando-se as hipóteses de KIRCHHOFF(1850), o regime de flexão pode ser obtido a partir do estado de membrana empregando-se (2.19) e (2.20) em (5.5), e tem-se as relações constitutivas para placas com curvaturas inelásticas tomadas como campo inicial:

$$
m_{i j}=-D\left[v\left(\dot{w}_{, k k}-\dot{w}_{, k k}^{a}\right) \delta_{i j}+(1-v)\left(\dot{w}_{, i j}-\dot{w}_{, i j}^{a}\right)\right] ; \quad i, j, k=1,2
$$

Se as equações (2.19) e (2.20) forem substituídas em (5.15), tem-se o teorema da reciprocidade para placas em curvaturas iniciais:

$$
\int_{\Omega} m_{i j}^{*}(p, S)\left[\dot{w}_{, i j}(S)-\dot{w}_{, i j}^{a}(S)\right] d \Omega=\int_{\Omega} \dot{m}_{i j}(S) w_{, i j}^{*}(p, S) d \Omega i, j=1,2
$$

onde $w_{, i j}^{*}$ e $m_{i j}^{*}$ são dados por:

$$
\begin{gathered}
w_{, i j}^{*}(p, s)=\frac{1}{4 \pi D}\left\{r_{, i} r_{, j}+\delta_{i j} \ln r\right\} ; i, j=1,2 \\
m_{i j}^{*}=-\frac{1}{4 \pi}\left\{[(1+v) \ln r-v] \delta_{i j}+(1-v) r_{, i} r_{, j}\right\} ; i, j=1,2
\end{gathered}
$$


A partir da conveniente aplicação sucessiva (duas vezes) das técnicas de integração por partes - nas integrais de domínio em ambos lados da equação (5.49) e da identidade(3.70) - obtém-se a representação integral dos deslocamentos transversais de placas para problemas inelásticos, cujo campo inicial está associado às curvaturas:

$$
\begin{gathered}
k \dot{w}(p)+\oint_{\Gamma}\left[\dot{w}(s) \alpha_{n}^{*}(p, s)-\dot{\theta}_{p}(s) m_{n}^{*}(p, s)-\dot{\theta}_{t}(s) \beta_{n}^{*}(p, s)\right] d \Gamma+ \\
\gamma_{c}^{*}(p, S) \dot{w}_{c}(S)=R_{c}(s) w_{c}^{*}(p, s)+\oint_{\Gamma}\left[\dot{V}_{n}(s) w^{*}(p, s)-\theta_{p}^{*}(p, s) \dot{m}_{n}(s)\right] d \Gamma+ \\
\int_{\Omega} g(S) w^{*}(p, S) d \Omega-I_{w}\left(\dot{w}^{a}, i j\right) ; c=1,2, \ldots, N c ;
\end{gathered}
$$

onde $\left(\begin{array}{lll}\alpha_{n}^{*} & \beta_{n}^{*} & \gamma_{c}^{*}\end{array}\right)=\left(\begin{array}{lll}q_{n}^{*} & m_{n s}^{*} & 0\end{array}\right), \quad$ para $\operatorname{Representação~triparamétrica(RTP);~}$ $\left(\begin{array}{lll}\alpha_{n}^{*} & \beta_{n}^{*} & \gamma_{c}^{*}\end{array}\right)=\left(\begin{array}{lll}V_{n}^{*} & 0 & R_{c}^{*}\end{array}\right)$, para Representação de Rayleigh-Green(RRG)

As contribuições inelásticas são representadas por:

$$
I_{w}\left(\dot{w}^{a}, i j\right)=\int_{\Omega} \dot{w}^{a}(S) m_{i j}^{*}(p, S) d \Omega ; \quad i, j=1,2
$$

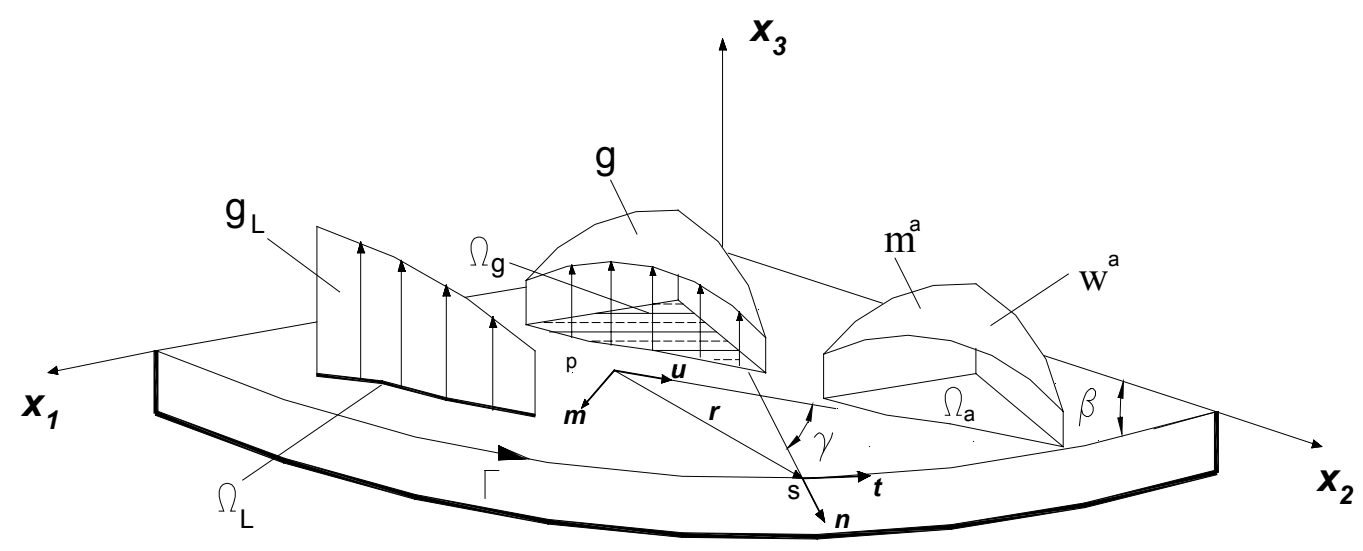

Figura 5.3-Esquema representativo do problema de flexão.

Além das equações integrais dos deslocamentos, as rotações também podem ter um papel na estrutura do sistema de equações do problema. Assim, as derivadas direcionais, segundo uma direção genérica $m$, podem ser obtidas diferenciando-se a equação (5.52). 
Aplicando-se a fórmula de Leibnitz na diferenciação da parcela inelástica de (5.53), e utilizando-se uma representação análoga àquela descrita em TELLES(1981), tem-se que:

$$
\begin{gathered}
\frac{\partial}{\partial x_{m}(p)} \int_{\varepsilon}^{R}\left[a \ln r+\psi_{i j}(\theta)\right] \dot{w}_{, i j}^{a}(s) \bar{r} d \bar{r}=\int_{\varepsilon}^{R} \frac{\partial}{\partial x_{m}(p)}\left[a \ln r+\psi_{i j}(\theta)\right] \dot{w}_{, i j}^{a}(s) \bar{r} d \bar{r}- \\
a \ln r(\bar{\varepsilon}, \bar{\theta}) \bar{\varepsilon} \frac{\partial \bar{\varepsilon}}{\partial x_{m}} ; \quad i, j, m=1,2
\end{gathered}
$$

onde $(\bar{r}, \theta)$ são os eixos de referência do sistema polar, vide figura 5.4.

Em (5.54), o kernel dos momentos escrito no sistema polar tem a forma de:

$$
\begin{gathered}
m_{i j}^{*}=a \ln r+\psi_{i j}(\theta) ; i, j=1,2 \\
a=-\frac{1+v}{4 \pi} \delta_{i j} ; \psi_{i j}(\theta)=-\frac{1}{4 \pi}\left[(1-v) r_{, i} r_{, j}-v \delta_{i j}\right] ; i, j=1,2
\end{gathered}
$$

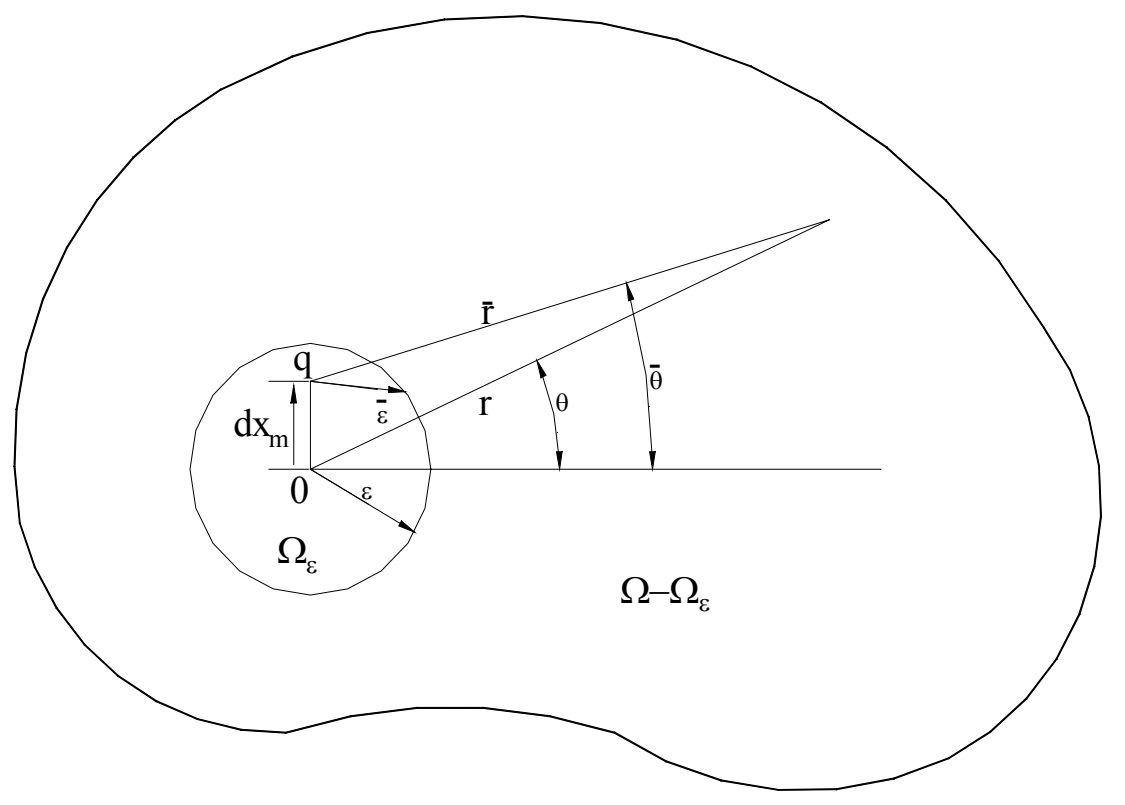

Figura 5.4- Sistema de referências utilizado na diferenciação de Leibnitz.

Após a diferenciação de (5.54), quando o ponto-fonte é tomado na origem 0 de sistema $(r, \theta)$, isto é, $O \equiv q$, tem-se que $\bar{\theta}=\theta$ e $\varepsilon(\bar{r}, \bar{\theta})=\varepsilon$. Assim, (5.54) pode ser alternativamente expressa como: 


$$
\begin{gathered}
\frac{\partial}{\partial x_{m}(p)} \int_{\varepsilon}^{R}\left[a \ln r+\psi_{i j}(\theta)\right] \dot{w}_{, i j}^{a}(s) r d r=\int_{\varepsilon}^{R} \frac{\partial}{\partial x_{m}(p)}\left[a \ln r+\psi_{i j}(\theta)\right] \dot{w}, i j^{a}(s) r d r- \\
(a \ln \varepsilon) \varepsilon \frac{\partial \varepsilon}{\partial x_{m}} ; \quad i, j, m=1,2
\end{gathered}
$$

Fazendo-se o limite da expressão (5.57) com $\varepsilon \rightarrow 0$, tem-se a convergência das integrais, e o limite do último termo conduz a um valor nulo, isto é, $\lim _{\varepsilon \rightarrow 0}(\varepsilon \ln \varepsilon)=0$. Assim, as representações integrais das rotações com curvaturas inelásticas, tomadas como campo inicial, podem ser escritas como:

$$
\begin{gathered}
k_{3} w_{, m}(p)+k_{4} w_{, u}(p)+ \\
m_{k}(p) \oint_{\Gamma}\left[\dot{w}(s) \alpha_{n, k}^{*}(p, s)-\dot{\theta}_{p}(s) m_{n k}^{*}(p, s)-\dot{\theta}_{t}(s) \beta_{n, k}^{*}(p, s)\right] d \Gamma+ \\
w_{c}(s) \mu_{c}^{*}(p, s)=m_{k}(p) \oint_{\Gamma}\left[\dot{V}_{n}(s) w_{, k}^{*}(p, s)-\dot{m}_{n}(s) \theta_{p, k}^{*}(p, s)\right] d \Gamma+ \\
m_{k}(p) \dot{R}_{c} w_{c, k}^{*}(p, c)+m_{k}(p) \int_{\Omega} g(S) w_{, k}^{*}(p, S) d \Omega-I_{\theta}\left(w_{, i j}^{a}\right) ; c=1,2, \ldots, N c ; k=1,2
\end{gathered}
$$

onde os coeficientes dos termos livres de integral $\left(k_{3}, k_{4}\right)$ valem, respectivamente, $(1,0)$ para pontos-fonte no domínio, e $\left(\frac{1}{2}, 0\right)$ para pontos de colocação em contorno suaves. $m_{k}$ é o co-seno diretor da direção de diferenciação; os kernels estão associados $\left(\begin{array}{lll}\alpha_{n, k}^{*} & \beta_{n, k}^{*} & \mu_{c}^{*}\end{array}\right)=\left(\begin{array}{lll}q_{n, k}^{*} & m_{n, k}^{*} & 0\end{array}\right), \mathrm{RTP} ;\left(\begin{array}{lll}\alpha_{n, k}^{*} & \beta_{n, k}^{*} & \mu_{c}^{*}\end{array}\right)=\left(\begin{array}{lll}V_{n, k}^{*} & 0 & R_{c, k}^{*}\end{array}\right), \mathrm{RRG}$.

As contribuições do termo inelástico em (5.58) são dadas por:

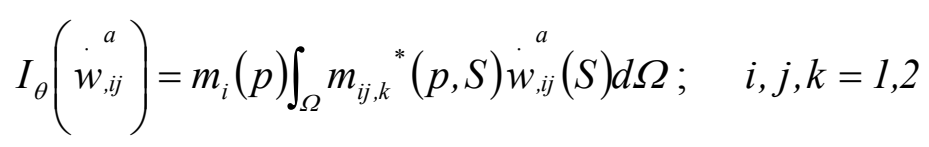

com:

$$
m_{i j, k}^{*}=\frac{1}{4 \pi r}\left[(1+v) \delta_{i j} r_{, k}+(1-v)\left(\delta_{j k} r_{, i}+\delta_{i k} r_{, j}-2 r_{, i} r_{, j} r_{, k}\right)\right] ; \quad i, j, k=1,2
$$

Os momentos são escritos a partir das curvaturas, de forma que para sua representação por equações integrais é necessário que seja efetuada o estudo da convergência das equações integrais das curvaturas; essas por sua vez podem ser escritas aplicando-se uma diferenciação dupla em (5.52), resultando em: 


$$
\begin{gathered}
\dot{w}_{, t q}(p)+q_{i}(p) t_{j}(p) \oint_{\Gamma}\left[\dot{w}(s) \alpha_{n, i j}^{*}(p, s)-\dot{\theta}_{p}(s) m_{n, i j}^{*}(p, s)-\dot{\theta}_{t}(s) \beta_{n, i j}^{*}(p, s)\right] d \Gamma+ \\
S_{c}^{*}(P, S) \dot{w}_{c}(S)=q_{i}(p) t_{j}(p) \oint_{\Gamma}\left[\dot{V}_{n}(s) w_{, i j}^{*}(p, s)-\dot{m}_{n}(s) \theta_{p, i j}^{*}(p, s)\right] d \Gamma+ \\
q_{i}(p) t_{j}(p) \dot{R}_{c}(S) w_{c, i j}^{*}(p, S)+q_{i}(p) t_{j}(p) \int_{\Omega} g(S) w_{, i j}{ }^{*}(p, S) d \Omega- \\
q_{k}(p) t_{r}(p) \frac{\partial^{2}}{\partial x_{k}(p) \partial x_{r}(p)} \int_{\Omega} m_{i j}^{*}(p, S) \dot{w}_{, i j}^{a}(S) d \Omega ; c=1,2, \ldots, N c ; i, j=1,2 ;
\end{gathered}
$$

onde $q_{i}, t_{j}$ são os co-senos diretores associados às direções $q e t$. $\left(\begin{array}{lll}\alpha_{n, t q}^{*} & \beta_{n, t q}^{*} & \zeta_{c}^{*}\end{array}\right)=\left(\begin{array}{lll}q_{n, t q}^{*} & m_{n s, t q}^{*} & 0\end{array}\right), \mathrm{RTP} ;\left(\begin{array}{lll}\alpha_{n, t q}^{*} & \beta_{n, t q}^{*} & \zeta_{c}^{*}\end{array}\right)=\left(\begin{array}{lll}V_{n, t q}^{*} & 0 & R_{c, t q}^{*}\end{array}\right), \mathrm{RRG}$.

A diferenciação do termo plástico em (5.61) pode ser escrita como:

$$
\begin{gathered}
J_{I}\left(w_{, i j}^{a}\right)=\int_{0}^{\alpha}\left\{\frac{\partial}{\partial x_{m}(p)}\left[\int_{\varepsilon}^{R} \frac{\hat{m}_{i j, k}^{*}(\theta)}{r} w_{i j}^{a}(s) \bar{r} d \bar{r}\right]\right\} d \theta=\int_{0}^{\alpha}\left\{\int_{\varepsilon}^{R} \frac{\partial}{\partial x_{m}(p)}\left(\frac{\hat{m}_{i j, k}^{*}(\theta)}{r}\right) w_{, i j}^{a}(s) \bar{r} d \bar{r}\right\} d \theta- \\
\int_{0}^{\alpha}\left[\frac{\left.\hat{m}_{i j, k}^{*} \cdot \dot{w}_{, i j}^{a}(p) \bar{\varepsilon} \frac{\partial \bar{\varepsilon}}{\partial x_{m}}\right] d \theta ; \quad i, j, k=1,2}{r(\varepsilon, \theta)}\right.
\end{gathered}
$$

onde

$$
\hat{m}_{i j, k}^{*}=m_{i j, k}^{*} r ; \quad i, j, k=1,2
$$

Analogamente à (5.57), feita a diferenciação de (5.62), tomando-se $O \equiv q$ e ainda fazendo-se o limite $\varepsilon \rightarrow 0$ para representar a integral de domínio original, temse que:

$$
\begin{gathered}
J_{l}\left(w_{, i j}^{a}\right)=\int_{0}^{\alpha} \lim _{\varepsilon \rightarrow 0}\left\{\int_{\varepsilon}^{R} \frac{\partial}{\partial x_{m}(p)}\left(\frac{\hat{m}_{i j, k}^{*}(\theta)}{r}\right) w_{, i j}^{a}(s) r d r\right\} d \theta-\int_{0}^{\alpha} \lim _{\varepsilon \rightarrow 0}\left\{\frac{\left.\hat{m}_{i j, k}^{*} \dot{w}_{, i j}^{a}(p) \varepsilon \frac{\partial \bar{\varepsilon}}{\partial x_{m}}\right\} d \theta ;}{i, j, k, m=1,2}\right.
\end{gathered}
$$

$\mathrm{Na}$ identidade (5.64), a última integral converge diretamente, contudo a penúltima converge condicionalmente. A fim de elucidar esse tópico, essa parcela pode ser escrita como: 


$$
\begin{gathered}
J_{l}\left(w_{, i j}^{a}\right)=\int_{0}^{\alpha} \lim _{\varepsilon \rightarrow 0}\left\{\int_{\varepsilon}^{R} \frac{\partial}{\partial x_{m}(p)}\left(\frac{\hat{m}_{i j, k}^{*}(\theta)}{r}\right) w_{, i j}^{a}(s) \bar{r} d \bar{r}\right\} d \theta=\int_{0}^{\alpha} \lim _{\varepsilon \rightarrow 0}\left\{\int_{\varepsilon}^{R} \frac{\hat{m}_{i j, k m}^{*}(\theta)}{r} w_{, i j}^{a}(s) d \bar{r}\right\} d \theta \\
=\lim _{\varepsilon \rightarrow 0}\left\{w_{, i j}^{a}(s)[\ln R-\ln \varepsilon] \int_{0}^{\alpha} \hat{m}_{i j, k m}^{*}(\theta) d \theta ; \quad i, j, k, m=1,2\right.
\end{gathered}
$$

onde os kernels são dados por:

$$
\begin{gathered}
\hat{m}_{i j, k m}^{*}(\theta)=r^{2} m_{i j, k m}^{*} ; \quad i, j, k, m=1,2 \\
m_{i j, k m}^{*}=-\frac{1}{4 \pi r^{2}}\left\{(1+v)\left(\delta_{i j} \delta_{k m}-2 \delta_{i j} r_{, m} r_{, k}\right)+(1-v)\left(\delta_{i k} \delta_{j m}+\delta_{i m} \delta_{j k}\right)-\right. \\
\left.\left.2(1-v)\left(\delta_{j k} r_{, i} r_{, m}+\delta_{i k} r_{, j} r_{, m}+\delta_{m k} r_{, i} r_{, j}+\delta_{j m} r_{, i} r_{, k}+\delta_{i m} r_{, j} r_{, k}-4 r_{, i} r_{, j} r_{, k} r_{, m}\right)\right]\right\} ; \\
i, j, k, \alpha=1,2
\end{gathered}
$$

A não-convergência da integral é causada quando $\varepsilon \rightarrow 0 \mathrm{em} \ln \varepsilon$. Assim, uma condição para garantir a convergência do problema é fazer que a última integral em (5.67) seja nula:

$$
\int_{0}^{\alpha} \hat{m}_{i j, k m}^{*}(\theta) d \theta=0 ; i, j, k, m=1,2
$$

Algumas das raízes da equação (5.68) podem ser expressas por ângulos $\alpha=\pi$ (ponto-fonte colocado em um contorno suave) e $\alpha=2 \pi$ (ponto-fonte no domínio). Além disso, o cálculo da última parcela de (5.64) pode ser escrito como:

$$
\int_{0}^{\alpha} \lim _{\varepsilon \rightarrow 0}\left\{\hat{m}_{i j, k}^{*}(\theta) \dot{w}, i j^{a}(p) \frac{\partial \varepsilon}{\partial x_{m}}\right\} d \theta=J_{i j k m} w_{, i j}^{*}(p) ; i, j, k, m=1,2
$$

onde

$$
j_{i j k m}=\frac{c}{8}\left[(1+2 v) \delta_{i j} \delta_{m k}+(1-2 v)\left(\delta_{i k} \delta_{j m}+\delta_{i m} \delta_{j k}\right)\right] ; i, j, k, m=1,2
$$

onde o valor de $c$ é dado em (5.32).

Substituindo-se (5.68) e (5.69) em (5.61), tem-se a representação integral das curvaturas com campo inicial em curvaturas: 


$$
\begin{gathered}
\dot{w}_{, t q}(p)+q_{i}(p) t_{j}(p) \oint_{\Gamma}\left[\dot{w}(s) \alpha_{n, i j}^{*}(p, s)-\dot{\theta}_{p}(s) m_{n, i j}^{*}(p, s)-\dot{\theta}_{t}(s) \beta_{n, i j}^{*}(p, s)\right] d \Gamma+ \\
S_{c}^{*}(P, S) \dot{w}_{c}(S)=q_{i}(p) t_{j}(p) \oint_{\Gamma}\left[\dot{V}_{n}(s) w_{, i j}{ }^{*}(p, s)-\dot{m}_{n}(s) \theta_{p, i j}^{*}(p, s)\right] d \Gamma+ \\
q_{i}(p) t_{j}(p) \dot{R}_{c}(S) w_{c, i j}^{*}(p, S)+q_{i}(p) t_{j}(p) \int_{\Omega} g(S) w_{, i j}^{*}(p, S) d \Omega+I_{\chi}\left(w_{, i j}^{a}\right) \\
c=1,2, \ldots, N c ; \quad i, j=1,2 ;
\end{gathered}
$$

onde:

$$
I_{\chi}\left(w_{, i j}^{a}\right)=-q_{i}(p) t_{j}(p) \int_{\Omega} m_{i j, k r}^{*}(p, S) \stackrel{a}{\dot{w}_{i j}}(S) d \Omega+q_{i}(p) t_{j}(p) J_{i j k r} \stackrel{a}{\dot{w}_{k, k r}}(p) ; i, j, k, r=1,2
$$

com $m_{i j, k r}^{*}$ expresso em (5.67).

A representação integral dos momentos pode ser obtida por meio da substituição de (5.71) em (5.48):

$$
\begin{gathered}
\dot{m}_{t q}(p)+q_{i}(p) t_{j}(p) \oint_{\Gamma}\left[\dot{w}(s) \mu \alpha_{n, i j}^{*}(p, s)-\dot{\theta}_{p}(s) \mu m_{n, i j}^{*}(p, s)-\dot{\theta}_{t}(s) \mu \beta_{n, i j}^{*}(p, s)\right] d \Gamma+ \\
q_{i}(p) t_{j}(p) \mu \epsilon_{c}^{*}(p, S) R_{c}(S)=q_{i}(p) t_{j}(p) \oint_{\Gamma}\left[\dot{V}_{n}(s) \mu w_{, i j}^{*}(p, s)-\dot{m}_{n}(s) \mu \theta_{p, i j}^{*}(p, s)\right] d \Gamma+ \\
q_{i}(p) t_{j}(p) \int_{\Omega} g(S) \mu w_{i j}^{*}(p, S) d \Omega+q_{i}(p) t_{j}(p) \dot{R}_{c}(S) \mu w_{c, i j}^{*}(p, S)+I_{\mu}\left(w_{, i j}^{a}\right) ; \\
c=1,2, \ldots, N c ; \quad i, j=1,2 ;
\end{gathered}
$$

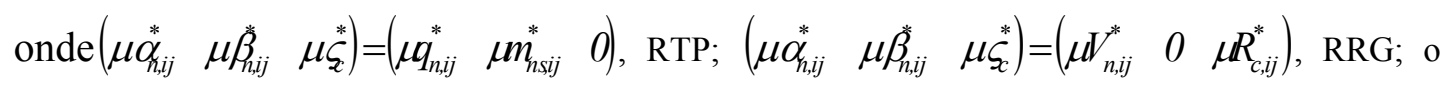
termo inelástico em (5.70) é dado por:

$$
\begin{gathered}
I_{\mu}\left(w_{, i j}^{a}\right)=-q_{i}(p) s_{j}(p) \int_{\Omega} \mu m_{i j, k r}{ }^{*}(p, S) \dot{w}, k r^{a}(S) d \Omega+q_{i}(p) s_{j}(p) \mu J_{i j k r} \stackrel{a}{w}, k r^{a}(p) \\
i, j, k, r=1,2
\end{gathered}
$$

com :

$$
\begin{gathered}
\mu m_{i j, k m}^{*}=-\frac{D}{4 \pi r^{2}}\left\{(1+v)\left[(1-2 v) \delta_{i j} \delta_{k m}-2(1-v) \delta_{i j} r_{, m} r_{, k}\right]+(1-v)^{2} \delta_{i m} \delta_{j k}-\right. \\
\left.\left.2(1-v)^{2}\left(\delta_{j k} r_{, i} r_{, m}+\delta_{i k} r_{, j} r_{, m}+\delta_{m k} r_{, i} r_{, j}+\delta_{j m} r_{, i} r_{, k}+\delta_{i m} r_{, j} r_{, k}-4 r_{, i} r_{, j} r_{, k} r_{, m}\right)\right]\right\} ; \\
i, j, k, \alpha=1,2
\end{gathered}
$$




$$
\mu j_{i j k m}=\frac{c D}{8}\left\{(1+2 v)(1+v) \delta_{i j} \delta_{m k}+(1-2 v)\left[(1+v) \delta_{i k} \delta_{j m}+(1-v) \delta_{i m} \delta_{j k}\right]\right\} ;
$$

$$
i, j, k, m=1,2 \text {; }
$$

onde $c$ é dado em (5.32).

A força cortante é obtida a partir da diferenciação do Laplaciano dos deslocamentos(3.103). Assim, é necessário escrever a representação integral para a derivada direcional das curvaturas:

$$
\begin{gathered}
\dot{w}_{, m t t}(p)+m_{i}(p) \oint_{\Gamma}\left[\dot{w}(s) \alpha_{n, i t t}^{*}(p, s)-\dot{\theta}_{p}(s) m_{n, i t t}^{*}(p, s)-\dot{\theta}_{t}(s) \beta_{n, i t t}^{*}(p, s)\right] d \Gamma+ \\
m_{i}(p) \zeta_{c, i t t}^{*}(p, S) \dot{w}_{c}(S)=m_{i}(p) \oint_{\Gamma}\left[\dot{V}_{n}(s) w_{, i t t}^{*}(p, s)-\dot{m}_{n}(s) \theta_{p, i t t}^{*}(p, s)\right] d \Gamma+ \\
m_{i}(p) \dot{R}_{c}(S) w_{c, i t t}^{*}(p, S)+m_{i}(p) \int_{\Omega} g(S) w_{, i t t}^{*}(p, S) d \Omega- \\
m_{k}(p) \frac{\partial^{3}}{\partial x_{r} \partial x_{r} \partial x_{k}} \int_{\Omega} m_{i j}^{*}(p, S) \dot{w}_{, i j}^{a}(S) d \Omega ; c=1,2, \ldots, N c ; \quad i, r, j=1,2
\end{gathered}
$$

$\operatorname{onde}\left(\begin{array}{lll}\alpha_{n, i t t}^{*} & \beta_{n, i t t}^{*} & \varsigma_{c, i t t}^{*}\end{array}\right)=\left(\begin{array}{lll}q_{n, i t t}^{*} & m_{n, i t t}^{*} & 0\end{array}\right), \mathrm{RTP} ;\left(\begin{array}{lll}\alpha_{n, i t t}^{*} & \beta_{n, i t}^{*} & \varsigma_{, t i t}^{*}\end{array}\right)=\left(\begin{array}{lll}V_{n, i t t}^{*} & 0 & R_{c, i t t}^{*}\end{array}\right), \mathrm{RRG}$.

Conforme discutido nos casos anteriores, uma etapa importante para a obtenção das equações integrais está associada ao estudo da convergência de suas integrais. Assim, um procedimento para tal fim pode ser executado a partir da diferenciação das equações das curvaturas indicadas em (5.77):

$$
\begin{gathered}
J_{2}\left(w_{, i j}^{a}\right)=\int_{0}^{\alpha} \lim _{\varepsilon \rightarrow 0}\left\{\frac{\partial}{\partial x_{\beta}(p)}\left[\frac{\partial}{\partial x_{m}(p)} \int_{\varepsilon}^{R} \frac{\hat{m}_{i j, k}^{*}(\theta)}{r} w_{, i j}^{a}(s) \bar{r} d \bar{r}\right]\right\} d \theta= \\
\int_{0}^{\alpha} \lim _{\varepsilon \rightarrow 0}\left\{\frac{\partial}{\partial x_{\beta}(p)}\left[\int_{\varepsilon}^{R} \frac{\partial}{\partial x_{m}(p)}\left(\frac{\hat{m}_{i j, k}^{*}(\theta)}{r}\right) w_{, i j}^{a}(s) \bar{r} d \bar{r}\right\} d \theta-\right. \\
\int_{0}^{\alpha} \lim _{\varepsilon \rightarrow 0} \frac{\partial}{x_{\beta}(p)}\left[\dot{w}_{, i j}^{a}(p) \bar{\varepsilon} \frac{\partial \bar{\varepsilon}}{\partial x_{m}}\right] d \theta ; \quad i, j, k=1,2
\end{gathered}
$$

Após o cálculo das derivadas presentes em (5.78) e ao tomar-se $O \equiv q$, uma outra forma para a identidade pode ser escrita deste modo: 


$$
\begin{gathered}
J_{2}\left(w_{, i j}^{a}\right)=\int_{0}^{\alpha} \lim _{\varepsilon \rightarrow 0}\left\{\int_{\varepsilon}^{R} \frac{\partial^{2}}{\partial x_{m}(p) \partial x_{\beta}(p)}\left(\frac{\hat{m}_{i j, k}^{*}(\theta)}{r}\right) w_{, i j}^{a}(s) r d r\right\} d \theta- \\
\left.\int_{0}^{\alpha}\left\{\dot{w}_{, i j}^{a}(p)\left[\hat{m}_{i j, k}^{*}\left(-\delta_{\beta m}+2 r_{, k} r_{, \beta}\right)-\hat{m}_{i j, k m}^{*} r_{, \beta}-\hat{m}_{i j, k \beta}^{*} r_{, m}\right]\right]_{\varepsilon \rightarrow 0}\left(\frac{1}{\varepsilon}\right)\right\} d \theta- \\
\int_{0}^{\alpha} \lim _{\varepsilon \rightarrow 0}\left[\hat{m}_{i j, k}^{*} r_{, m} \dot{w}_{, i j \beta}^{a}(p)\right] ; \quad i, j, k, m, \beta=1,2
\end{gathered}
$$

Ajustando-se (5.79) à derivada do Laplaciano dos deslocamentos e fazendose o limite da expressão com $\varepsilon \rightarrow 0$, tem-se:

$$
\begin{gathered}
J_{2}\left(w_{, i j}^{a}\right)=\int_{0}^{\alpha} \lim _{\varepsilon \rightarrow 0}\left[\int_{\varepsilon}^{R}\left(\frac{\hat{m}_{i j, k k \beta}^{*}(\theta)}{r^{2}}\right) w_{, i j}^{a}(s) d r\right] d \theta- \\
\int_{0}^{\alpha} \lim _{\varepsilon \rightarrow 0}\left\{\frac{1}{\varepsilon}\left[\hat{m}_{i j, k}^{*}\left(-\delta_{\beta k}+2 r_{, k} r_{, \beta}\right)-\hat{m}_{i j, k k}^{*} r_{, \beta}-\hat{m}_{i j, k \beta}^{*} r_{, k}\right] \dot{w}_{, i j}^{a}(p)\right\} d \theta+ \\
\int_{0}^{\alpha} \lim _{\varepsilon \rightarrow 0}\left[\hat{m}_{i j, k}^{*} r_{, k} \dot{w}_{, i j \alpha}^{a}(p)\right] d \theta ; \quad i, j, k, \alpha, \beta=1,2
\end{gathered}
$$

onde o kernel do laplaciano dos momentos é dado por:

$$
\begin{gathered}
m_{i j, k \beta \beta} *(\theta)=r^{2} \frac{\partial}{\partial x_{k}(p)}\left[\frac{\partial^{2}}{\partial x_{\beta}^{2}(p)} m_{i j}^{*}\right]=r^{2}\left(m_{i j, k \beta \beta} *\right)= \\
r^{2}\left\{-\frac{1}{\pi r^{3}}\left[2 r_{, k}+5(1-v)\left(\delta_{j k} r_{, i}+\delta_{i k} r_{, j}\right)-20(1-v) r_{, i} r_{, j} r_{, k}\right]\right\} ; i, j, k, \beta=1,2
\end{gathered}
$$

Examinando-se a identidade (5.80), verifica-se que o último termo é diretamente convergente, contudo a segunda e a terceira parcela têm convergências condicionadas. O segundo termo pode ser reescrito como:

$$
\int_{0}^{\alpha} \lim \left[\int_{\varepsilon \rightarrow 0}^{R}\left(\frac{\hat{m}_{i j, k k \beta}^{*}(\theta)}{r^{2}}\right) w_{, i j}^{a}(s) d \bar{r}\right] d \theta=\lim _{\varepsilon \rightarrow 0}\left(-\frac{1}{R}+\frac{1}{\varepsilon}\right) w_{, i j}^{a}(s) \int_{0}^{\alpha} m_{i j, k k \beta}^{*}(\theta) d \theta ; i, j, k, \alpha=1,2
$$

Assim a convergência de (5.81) está condicionada à imposição de valor nulo para a última integral:

$$
\int_{0}^{\alpha} \hat{m}_{i j, k k \beta}^{*}(\theta) d \theta=0 ; i, j, k, \beta=1,2
$$

Um dos valores que satisfazem essa equação é $\alpha=2 \pi$ ( ponto-fonte no domínio). Convém ressaltar que para pontos-fonte posicionados em contorno suave 
$(\alpha=\pi)$, a equação (5.83) não é satisfeita conduzindo (5.81), portanto, à nãoconvergência.

O terceiro termo em (5.80) pode ser expresso mais simplesmente por:

$$
\begin{gathered}
\int_{0}^{\alpha} \lim _{\varepsilon \rightarrow 0}\left\{\frac{1}{\varepsilon}\left[\hat{m}_{i j, k}^{*}\left(-\delta_{\beta k}+2 r_{, k} r_{, \beta}\right)-\hat{m}_{i j, k k}^{*} r_{, \beta}-\hat{m}_{i j, k}^{*} r_{, k}\right] \dot{w}_{, i j}^{a}(p)\right\} d \theta= \\
\frac{1-v}{2 \pi} \lim _{\varepsilon \rightarrow 0}\left(\frac{1}{\varepsilon}\right) w_{, i j}^{a}(p) \int_{0}^{\alpha}\left(\delta_{i j} r_{, \beta}+2 \delta_{i \beta} r_{, j}\right) d \theta ; i, j, k, \beta=1,2
\end{gathered}
$$

Assim, a convergência é condicionada à imposição $\int_{0}^{\alpha}\left(\delta_{i j} r_{, \alpha}+2 \delta_{i \alpha} r_{, j}\right) d \theta=0$, em que uma das raízes pode ser obtida para $\alpha=2 \pi$; o valor da integração do último termo de (5.80) pode ser dado por:

$$
\int_{0}^{\alpha} \lim _{\varepsilon \rightarrow 0}\left[\hat{m}_{i j, k}^{*} r_{, k} \dot{w}_{, i j \beta}^{a}(p)\right] d \theta=\left.\frac{(1+v) \alpha}{4 \pi}\right|_{\alpha=2 \pi} \dot{w}_{, i j \beta}^{a}(p)=\frac{(1+v)}{2} \dot{w}_{, i j \beta}^{a}(p) ; i, j, k, \beta=1,2
$$

Com isso, substituindo-se as expressões (5.85), (5.84) e (5.79) em (5.77), obtém-se a representação da derivada direcional do Laplaciano dos deslocamentos tomando-se as curvaturas inelásticas como campo inicial:

$$
\begin{gathered}
\dot{w}_{, \text {mtt }}(p)+m_{i}(p) \oint_{\Gamma}\left[\dot{w}(s) \alpha_{n, i t t}^{*}(p, s)-\dot{\theta}_{p}(s) m_{n, i t t}^{*}(p, s)-\dot{\theta}_{t}(s) \beta_{n, i t t}^{*}(p, s)\right] d \Gamma+ \\
m_{i}(p) \varsigma_{c, i t t}^{*}(p, S) \dot{w}_{c}(S)=m_{i}(p) \oint_{\Gamma}\left[\dot{V}_{n}(s) w_{, i t t}^{*}(p, s)-\dot{m}_{n}(s) \theta_{p, i t t}^{*}(p, s)\right] d \Gamma+ \\
m_{i}(p) \dot{R}_{c}(S) w_{c, i t t}^{*}(p, S)+m_{i}(p) \int_{\Omega} g(S) w_{, i t t}^{*}(p, S) d \Omega-I_{q}\left(w_{, i j}^{a}\right) ; \\
c=1,2, \ldots, N c ; \quad i, r, j=1,2
\end{gathered}
$$

onde:

$$
I_{q}\left(w_{, i j}^{a}\right)=-m_{k}(p) \int_{\Omega} m_{i j, k t t}^{*}(p, S) \dot{w}_{i j}^{a}(S) d \Omega+m_{k}(p) \dot{w}^{a}, k t t(p) ; i, j, k=1,2
$$

Equivalentemente ao problema de membrana, uma outra alternativa de tratar o regime inelástico em placas é tomá-lo como campo de momentos iniciais. Assim, as relações constitutivas para esses casos podem ser obtidas a partir da substituição de (2.19) e (2.20) em (5.8), vem que: 


$$
m_{i j}=-D\left[v \dot{w}_{, k k} \delta_{i j}+(1-v) \dot{w}, i j\right]-\dot{m}_{i j}^{a} ; \quad i, j, k=1,2
$$

Além disso, o teorema da reciprocidade generalizado para placas, em que os momentos inelásticos são tomados como campo inicial, pode ser obtido a partir da substituição de (2.19) e (2.20) em (5.18):

$$
\int_{\Omega} m_{i j}^{*}(p, S) \dot{w}_{, i j}(S) d \Omega=\int_{\Omega}\left[\dot{m}_{i j}(S)+\dot{m}_{i j}^{a}(S)\right] w_{, i j}^{*}(p, S) d \Omega ; i, j=1,2
$$

Aplicando-se duas vezes a técnica de integração por partes em (5.89), as equações integrais dos deslocamentos podem ser apresentadas tal qual em (5.18), bastando que a parcela $I_{w}\left(w_{, i j}^{a}\right)$ seja substituída por $I_{w}\left(m_{i j}^{a}\right)$. Esse termo pode ser escrito como:

$$
I_{w}\left(m_{i j}^{a}\right)=\int_{\Omega} \dot{m}_{i j}^{a}(S) w_{i j}^{*}(p, S) d \Omega ; \quad i, j=1,2
$$

As representações integrais para as derivadas dos deslocamentos para o campo de momentos iniciais - após um tratamento análogo ao dado à diferenciação da integral inelástica no caso do campo de curvatura inicial - podem ser escritas como (5.58), requerendo apenas a troca do termo inelástico de $I_{\theta}\left(w_{, i j}^{a}\right)$ por $I_{\theta}\left(m_{i j}^{a}\right)$. Esse último pode ser expresso por:

$$
I_{\theta}\left(m_{i j}^{a}\right)=m_{k}(p) \int_{\Omega} w_{i j k}^{*}(p, S) \dot{m}_{i j}^{a}(S) d \Omega ; \quad i, j, k=1,2
$$

onde:

$$
w_{i j k}^{*}=-\frac{1}{4 \pi D r}\left(\delta_{i j} r_{, k}+\delta_{j k} r_{, i}+\delta_{i k} r_{, j}-2 r_{, i} r_{, j} r_{, k}\right) ; \quad i, j, k=1,2
$$

As representações integrais das curvaturas para os campos iniciais em momentos também podem ser escritas utilizando-se estratégias similares às equações integrais descritas anteriormente, isto é, adequando-se o termo inelástico ao seu respectivo campo inicial, portanto, trocando-se $I_{\chi}\left(w_{, i j}^{a}\right)$ por $I_{\chi}\left(m_{i j}^{a}\right)$ em (5.71). Esse termo pode ser escrito como:

$$
I_{\chi}\left(m_{i j}^{a}\right)=-q_{k}(p) t_{\alpha}(p) \int_{\Omega} w_{, i j k \alpha}^{*}(p, S) \stackrel{a}{m_{i j}}(S) d \Omega+q_{i}(p) t_{j}(p) Y_{i j k \alpha} \stackrel{a}{m_{k \alpha}}(p) ; i, j, k, \alpha=1,2
$$

onde: 


$$
\begin{gathered}
w_{, i j k \alpha}^{*}=\frac{1}{4 \pi D r^{2}}\left\{\delta_{i j} \delta_{k \alpha}+\delta_{j k} \delta_{i \alpha}+\delta_{i k} \delta_{j \alpha}-2\left[\left(\delta_{i j} r_{, k}+\delta_{j k} r_{, i}+\delta_{i k} r_{, j}\right) r_{, \alpha}+\right.\right. \\
\left.\left.+\delta_{j \alpha} r_{, i} r_{, k}+\delta_{k \alpha} r_{, i} r_{, j}+\delta_{i \alpha} r_{, j} r_{, k}-4 r_{, i} r_{, j} r_{, k} r_{, \alpha}\right]\right\} ; i, j, k, \alpha=1,2 \\
Y_{i j k \alpha}=\frac{c}{8 D}\left(\delta_{i j} \delta_{\alpha k}+\delta_{i k} \delta_{\alpha j}+\delta_{i \alpha} \delta_{j k}\right) ; i, j, k, \alpha=1,2
\end{gathered}
$$

onde $c$ é dado em (5.32).

A partir das representações integrais das curvaturas em momentos iniciais, as equações integrais para os momentos podem ser escritas utilizando-se em (5.73) a troca do termo $I_{\mu}\left(w_{, i j}^{a}\right)$ pelo $I_{\mu}\left(m_{i j}^{a}\right)$. Esse último termo pode ser escrito como:

$$
\begin{gathered}
I_{\mu}\left(m_{i j}^{a}\right)=-q_{k}(p) t_{\alpha}(p) \int_{\Omega} \mu w_{, j k \alpha \alpha}^{*}(p, S) \dot{m}_{i j}^{a}(S) d \Omega+q_{k}(p) t_{\alpha}(p) \mu Y_{i j k \alpha} \dot{m}_{i j}^{a}(p) ; \\
i, j, k, \alpha=1,2
\end{gathered}
$$

onde:

$$
\begin{gathered}
\mu Y_{i j k \alpha}=\frac{c}{8}\left\{(1+3 v) \delta_{i j} \delta_{\alpha k}+[(1-v)+8 / c] \delta_{i k} \delta_{\alpha j}+(1-v) \delta_{j k} \delta_{\alpha i}\right\} ; i, j, k=1,2 \\
\mu w_{, i j k \alpha}^{*}=\frac{-1}{4 \pi r^{2}}\left\{(1+v) \delta_{i j} \delta_{k \alpha}+(1-v)\left(\delta_{j k} \delta_{i \alpha}+\delta_{i k} \delta_{j \alpha}\right)-\right. \\
2\left[(1-3 v) \delta_{i j} r_{, k} r_{, \alpha}+(1-v)\left(\delta_{j k} r_{, i}+\delta_{i k} r_{, j}\right) r_{, \alpha}+\right. \\
\left.\left.(1-v)\left(\delta_{j \alpha} r_{, i} r_{, k}+\delta_{k \alpha} r_{, i} r_{, j}+\delta_{i \alpha} r_{, j} r_{, k}-8 r_{, i} r_{, j} r_{, k} r_{, \alpha}\right)\right]\right\} \quad i, j, k, \alpha=1,2
\end{gathered}
$$

onde $c$ é dado em (5.32).

Finalizando-se as representações integrais dos esforços em momentos iniciais, tem-se as equações integrais dos esforços em momentos iniciais, tem-se a força cortante que pode ser escrita a partir de uma modificação nas equações integrais das derivadas direcionais das curvaturas em (5.86), isto é, trocando-se $I_{q}\left(w_{, i j}^{a}\right)$ por $I_{q}\left(m_{i j}^{a}\right)$. Para a obtenção desse termo pode ser empregada uma técnica análoga ao caso do problema inelástico tomado como campo de curvatura inicial:

$$
I_{q}\left(m_{i j}^{a}\right)=m_{k}(p) \frac{\partial^{3}}{\partial x_{r}(p) \partial x_{r}(p) \partial x_{k}(p)} \int_{\Omega} w_{i j}^{*}(p, S) \dot{m}_{i j}^{a}(S) d \Omega ; i, j, k, r=1,2
$$

Para o cálculo das diferenciações e o estudo das integrais resultantes, uma estratégia análoga ao caso de campo inicial em curvaturas é utilizada: 


$$
\begin{gathered}
J_{2}\left(m_{i j}^{a}\right)=\int_{0}^{\alpha} \lim _{\varepsilon \rightarrow 0}\left[\int_{\varepsilon}^{R}\left(\frac{\hat{w}_{, j i k k \beta}^{*}(\theta)}{r^{2}}\right) \dot{m}_{i j}^{a}(s)\right] d \theta- \\
\int_{0}^{\alpha} \lim _{\varepsilon \rightarrow 0}\left\{\frac{1}{\varepsilon}\left[\hat{w}_{, j i k}^{*}\left(-\delta_{\beta k}+2 r_{, k} r_{, \beta}\right)-\hat{w}_{i j, k k}^{*} r_{, \beta}-\hat{w}_{i j, k \beta}^{*} r_{, k}\right] \dot{m}_{i j}^{a}(p)\right\} d \theta+ \\
\int_{0}^{\alpha} \lim _{\varepsilon \rightarrow 0}\left[\hat{w}_{, i j k}^{*} r_{, k} \dot{m}_{i j, \beta}^{a}(p)\right] d \theta ; \quad i, j, k=1,2
\end{gathered}
$$

Em (5.100), a última parcela converge incondicionalmente, contudo as demais são dependentes dos valores do ângulo $\alpha$ :

$$
\begin{gathered}
\int_{0}^{\alpha} \lim _{\varepsilon \rightarrow 0}\left\{\frac{1}{\varepsilon}\left[\hat{w}_{, i j k}^{*}\left(-\delta_{\beta k}+2 r_{, k} r_{, \beta}\right)-\hat{w}_{i j, k k}^{*} r_{, \beta}-\hat{w}_{, j i k}^{*} r_{, k}\right] \dot{m}_{i j}^{a}(p)\right\} d \theta= \\
\frac{1-v}{2 \pi} \lim _{\varepsilon \rightarrow 0}\left(\frac{1}{\varepsilon}\right) \dot{m}_{i j}^{a}(p) \int_{0}^{\alpha}\left(\delta_{i j} r_{, \beta}+2 \delta_{i \beta} r_{, j}\right) d \theta ; i, j, k, \beta=1,2
\end{gathered}
$$

Assim, a convergência é condicionada à imposição $\int_{0}^{\alpha}\left(\delta_{i j} r_{, \alpha}+2 \delta_{i \alpha} r_{, j}\right) d \theta=0$, em que uma das raízes pode ser obtida para $\alpha=2 \pi$ e o valor da integração do último termo pode ser dado por:

$$
\int_{0}^{\alpha} \lim _{\varepsilon \rightarrow 0}\left[\hat{w}_{, i j k}^{*} r_{, \beta} \dot{m}_{i j, \beta}^{a}(p)\right] d \theta=-\left.\frac{\alpha}{8 \pi} \delta_{i j}\right|_{\alpha=2 \pi} \dot{m}_{i j, \beta}^{a}(p)=-\frac{1}{4} \dot{m}_{i i, \beta}^{a}(p) ; i, j, \beta=1,2
$$

Assim, substituindo-se (5.102), (5.101) em (5.99), obtém-se a parcela inelástica da representação integral da derivada direcional das curvaturas, isto é:

$$
I_{q}\left(m_{i j}^{a}\right)=-m_{k}(p) \int_{\Omega} w_{, k t t}^{*}(p, S) \dot{m}_{i j}^{a}(S) d \Omega+m_{k}(p) \Xi_{i j} \dot{m}_{i j, k}^{a}(p) ; i, j, k=1,2
$$

onde:

$$
\begin{gathered}
w_{, k t t}^{*}=\frac{1}{\pi D r^{3}}\left(\delta_{i j} r_{, k}+\delta_{j k} r_{, i}+\delta_{i k} r_{, j}-4 r_{, i} r_{, j} r_{, k}\right) ; i, j, k, t=1,2 \\
\Xi_{i j}=\frac{1}{4 D}\left(\delta_{i j}+4\right) ; i, j=1,2
\end{gathered}
$$




\subsection{3)Representações Integrais Discretizadas}

\subsubsection{1) Discretização}

As soluções analíticas para as equações integrais dos problemas inelásticos, em geral, não estão disponíveis; assim, parte-se para soluções numéricas. Dessa forma, analogamente ao descrito no capítulo 3, essas soluções requerem que o contorno $\Gamma$ do problema seja discretizado em elementos de contorno. Em geral, para os termos que contêm integrais de domínio, uma das técnicas que podem ser aplicadas é a discretização $\Omega$ em células, vide figura 5.5.

Assim representações integrais discretizadas de chapas(5.23/5.25), em deformações iniciais, podem ser apresentadas como:

$$
\begin{aligned}
& C \underset{\sim}{(p)} \underset{\sim}{U}(p)+\sum_{k=1}^{N e l}\left[\int_{\Gamma_{k}} P_{\sim}^{*} \underset{\sim}{Q} \underset{\sim}{\Phi^{T}} \mathrm{~d} \Gamma_{k}\right] U_{k}^{n}(s)=\sum_{k=1}^{N e l}\left[\int_{\Gamma_{k}}^{U_{\sim}^{*}} \underset{\sim}{Q} \underset{\sim}{\Phi^{T}} \mathrm{~d} \Gamma_{k}\right] P_{k}^{n}(s)+
\end{aligned}
$$

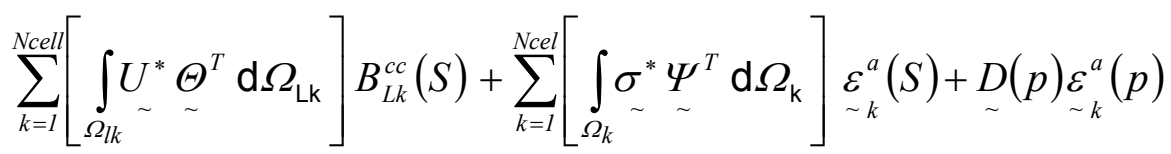

onde $n$ é o número de nós do elemento $k$; c e cc são os respectivos números de nós da célula $k$ com carregamentos aplicados em área e em linha; Nel, Ncel e Ncell são os respectivos números de elementos de contorno, de células das regiões submetidas a carregamentos aplicados em área e em linha; $\Phi^{\mathrm{T}}, \quad \Psi^{\mathrm{T}}$ e $\Theta^{\mathrm{T}}$ são as respectivas matrizes compostas por funções interpoladoras das variáveis de contorno e das deformações inelásticas .
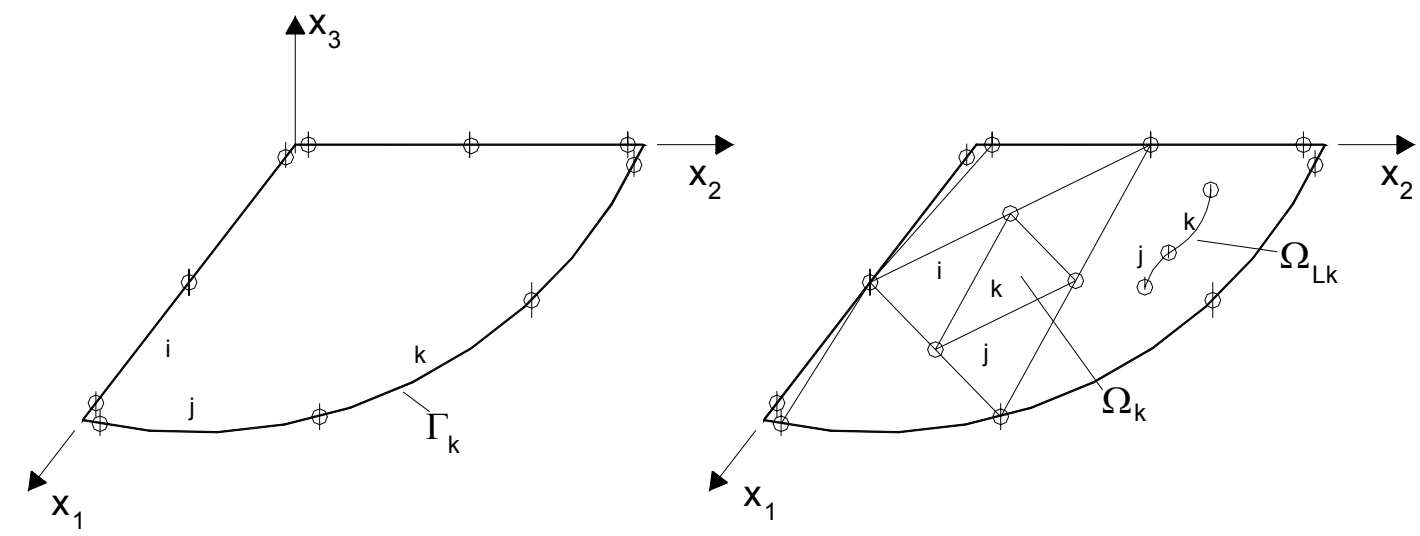

Figura 5.5- Discretização de contorno e de domínio. 
Na equação (5.106), os vetores $k$-ésimos associados às variáveis de contorno e aos valores de domínio dados tal qual em (4.1); o vetor que contém as contribuições inelásticas em deformações iniciais pode ser escrito como:

$$
\varepsilon_{k}^{T}=\left(\begin{array}{lllllll}
\varepsilon_{11}^{a 1} & 2 \varepsilon_{12}^{a 1} & \varepsilon_{22}^{a 2} & \cdots & \varepsilon_{11}^{a c} & 2 \varepsilon_{12}^{a c} & \varepsilon_{22}^{a c}
\end{array}\right)^{T}
$$

Já as representações integrais discretizadas de placas,(5.52/5.58) em curvaturas iniciais, podem ser apresentadas como:

$$
\begin{aligned}
& \underset{\sim}{k}(p) \underset{\sim}{W}(p)+\sum_{k=1}^{N e l}\left[\int_{\Gamma_{k}} c_{\sim}^{*} \Phi_{\sim}^{T} d \Gamma_{k}\right] W_{\sim}^{n}(s)=\sum_{j=l}^{N e l}\left[\int_{\Gamma_{k}} d_{\sim}^{*} \Phi^{T} d \Gamma_{k}\right] V_{\sim}^{n}(s)+\sum_{g=1}^{N c} r_{g}(s) w_{\sim}^{*}+ \\
& \sum_{k=1}^{n c e l l}\left[\int_{\Omega_{L k}} w_{g}^{*} \Theta_{\sim}^{T} d \Omega_{L k}\right] G_{\sim k}^{c}(S)+\sum_{k=1}^{N c e l}\left[\int_{\Omega_{k}} m^{*} \Psi_{\sim}^{T} d \Omega_{k}\right] \underset{\sim}{\chi_{k}^{a}}(S)
\end{aligned}
$$

Em (5.106), os vetores $k$-ésimos associados às variáveis de contorno e os valores de domínio são dados tal qual em (4.2); os vetores das contribuições inelásticas em curvaturas iniciais podem ser escritos como:

$$
\chi_{k}^{T}=\left(\begin{array}{lllllll}
w_{, 11}^{a l} & 2 w_{, 12}^{a l} & w_{, 22}^{a l} & \cdots & w_{, 11}^{a c} & 2 w_{, 12}^{a c} & w_{, 22}^{a c}
\end{array}\right)^{T}
$$

Convém ressaltar que as representações integrais discretizadas, em tensões (chapas) e momentos (placa) iniciais, podem ser escritas analogamente às equações (5.108), bastando unicamente fazer as trocas convenientes das matrizes de influência associadas às deformações/curvaturas iniciais por aquelas das tensões/momentos iniciais.

Além das representações integrais discretizadas dos deslocamentos, para viabilizar a solução do sistema algébrico dos problemas inelásticos, em geral, são utilizadas as representações dos esforços, por exemplo, tensões para os problemas de chapas e momentos para o regime de flexão. Neste trabalho, as representações integrais discretizadas desses campos tensoriais serão escritas apenas para pontosfonte colocados no domínio, de forma que elas podem ser expressas respectivamente a partir de (5.41) e (5.73): 


$$
\begin{aligned}
& \underset{\sim}{\sigma}(p)+\sum_{k=1}^{N e l}\left[\int_{\Gamma_{k}} \sigma_{\sim}^{*} \underset{\sim}{Q} \underset{\sim}{\Phi^{T}} \mathrm{~d} \Gamma_{k}\right] U_{k}^{n}(s)=\sum_{k=1}^{N e l}\left[\int_{\Gamma_{k}} \sigma_{\sim}{ }_{\sim}^{*} \underset{\sim}{Q} \underset{\sim}{\Phi^{T}} \mathrm{~d} \Gamma_{k}\right] P_{k}^{n}(s)+
\end{aligned}
$$

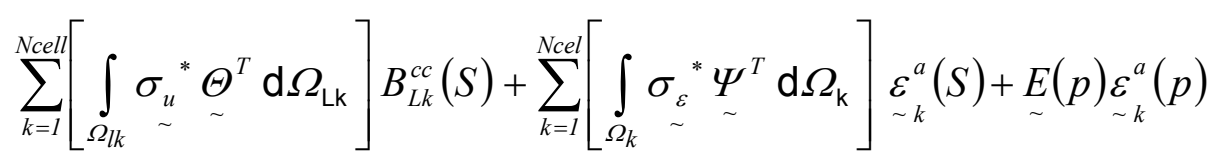

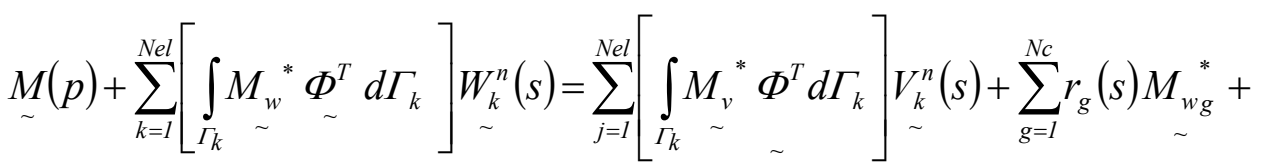

$$
\begin{aligned}
& \sum_{k=1}^{n c e l l}\left[\int_{\Omega_{L k}} M_{\sim g}^{*} \Theta_{\sim}^{T} d \Omega_{L k}\right] G_{\sim}^{c}(S)+\sum_{\sim=1}^{N c e l}\left[\int_{\Omega_{k}} M_{\sim}^{*} \Psi_{\sim}^{T} d \Omega_{k}\right] \underset{\sim}{\chi_{\sim}^{a}}(S)+\underset{\sim}{\Lambda} \underset{\sim}{\underset{\sim}{u}(p)}
\end{aligned}
$$

onde os vetores $\Theta, \Psi, \Phi$ são dados em (4.1), (4.2). Os demais vetores em (5.110) são dados por:

$$
\begin{aligned}
& \underset{\sim}{\sigma_{p}^{*}}=\left[\begin{array}{cc}
q_{i} d_{i j 1}^{*} q_{j} & q_{i} d_{i j 2}^{*} q_{j} \\
q_{i} d_{i j 1}^{*} m_{j} & q_{i} d_{i j 2}^{*} m_{j} \\
m_{i} d_{i j 1}^{*} m_{j} & m_{i} d_{i j 2}^{*} m_{j}
\end{array}\right] ; i, j=1,2 \\
& \underset{\sim}{\sigma_{u}^{*}}=\left[\begin{array}{cc}
q_{i} s_{i j}^{*} q_{j} & q_{i} s_{i j 2}^{*} q_{j} \\
q_{i} s_{i j 1}^{*} m_{j} & q_{i} s_{i j 2}^{*} m_{j} \\
m_{i} s_{i j 1}^{*} m_{j} & m_{i} s_{i j 2}^{*} m_{j}
\end{array}\right] ; i, j=1,2 \\
& \underset{\sim}{\sigma_{\varepsilon}^{*}}=\left[\begin{array}{ccc}
q_{i} N_{i j 11}^{*} q_{j} & 2 q_{i} N_{i j 12}^{*} q_{j} & q_{i} N_{i j 22}^{*} q_{j} \\
q_{i} N_{i j 11}^{*} m_{j} & 2 q_{i} N_{i j 12}^{*} m_{j} & q_{i} N_{i j 22}^{*} m_{j} \\
m_{i} N_{i j 11}^{*} m_{j} & 2 m_{i} N_{i j 12}^{*} m_{j} & m_{i} N_{i j 22}^{*} m_{j}
\end{array}\right] ; i, j=1,2 \\
& \underset{\sim}{E}=\left[\begin{array}{ccc}
q_{i} L_{i j 11} q_{j} & 2 q_{i} L_{i j 12} q_{j} & q_{i} L_{i j 22} q_{j} \\
q_{i} L_{i j 11} m_{j} & 2 q_{i} L_{i j 12} m_{j} & q_{i} L_{i j 22} m_{j} \\
m_{i} L_{i j 11} m_{j} & 2 m_{i} L_{i j 12} m_{j} & m_{i} L_{i j 22} m_{j}
\end{array}\right] ; i, j=1,2
\end{aligned}
$$

onde os kernels em (5.112) a (5.115) são dados respectivamente em (3.12), (3.13) e (5.46). Já os termos livres de integral em (5.115) estão indicados em (5.47).

Além dos vetores $\Theta, \Psi, \Phi$, os demais presentes em (5.108) são dados por: 


$$
\begin{aligned}
& M_{\sim}^{*}=\left[\begin{array}{ccc}
q_{i} \mu \alpha_{n, i j}^{*} q_{j} & q_{i} \mu m_{n, i j}^{*} q_{j} & q_{i} \mu \beta_{n, i j}^{*} q_{j} \\
q_{i} \mu \alpha_{n, i j}^{*} m_{j} & q_{i} \mu m_{n, i j}^{*} m_{j} & q_{i} \mu \beta_{n, i j}^{*} m_{j} \\
m_{i} \mu \alpha_{n, i j}^{*} m_{j} & m_{i} \mu m_{n, i j}^{*} m_{j} & m_{i} \mu \beta_{n, i j}^{*} m_{j}
\end{array}\right] ; i, j=1,2 \\
& M_{\sim}^{*}=\left[\begin{array}{ccc}
q_{i} \mu w_{, i j}^{*} q_{j} & q_{i} \mu \theta_{p, i j}^{*} q_{j} & 0 \\
q_{i} \mu w_{, i j}^{*} m_{j} & q_{i} \mu \theta_{p, i j}^{*} m_{j} & 0 \\
m_{i} \mu w_{, i j}^{*} m_{j} & m_{i} \mu \theta_{p, i j}^{*} m_{j} & 0
\end{array}\right] ; i, j=1,2 \\
& \underset{\sim}{M_{\chi}}=\left[\begin{array}{ccc}
q_{i} \mu m_{i j 11}^{*} q_{j} & 2 q_{i} \mu m_{i j 12}^{*} q_{j} & q_{i} \mu m_{i j 22}^{*} q_{j} \\
q_{i} \mu m_{i j 11}^{*} m_{j} & 2 q_{i} \mu m_{i j 12}^{*} m_{j} & q_{i} \mu m_{i j 22}^{*} m_{j} \\
m_{i} \mu m_{i j 11}^{*} m_{j} & 2 m_{i} \mu m_{i j 12}^{*} m_{j} & m_{i} \mu m_{i j 22}^{*} m_{j}
\end{array}\right] ; i, j=1,2 \\
& \underset{\sim}{\Lambda}=\left[\begin{array}{ccc}
q_{i} \mu J_{i j 11} q_{j} & 2 q_{i} \mu J_{i j 12} q_{j} & q_{i} \mu J_{i j 22} q_{j} \\
q_{i} \mu J_{i j 11} m_{j} & 2 q_{i} \mu J_{i j 12} m_{j} & q_{i} \mu J_{i j 22} m_{j} \\
m_{i} \mu J_{i j 11} m_{j} & 2 m_{i} \mu J_{i j 12} m_{j} & m_{i} \mu J_{i j 22} m_{j}
\end{array}\right] ; i, j=1,2
\end{aligned}
$$

Os kernels presentes em (5.116) e (5.117) estão indicados nas expressões de (3.97) a (3.102). O vetor indicado em (5.118) é composto pelo kernel expresso em (5.75). Já os termos livres de integral reunidos em (5.119) estão indicados em (5.76).

Caso as representações integrais para os problemas de chapas e flexão sejam escritas em tensões/momentos iniciais, os vetores $\varepsilon_{k}^{T}$ (5.107) e $\chi_{k}^{T}$ (5.109) devem ser trocados respectivamente para $\sigma_{k}^{T}$ e $m_{k}^{T}$ que são expressos por:

$$
\begin{gathered}
\underset{\sim}{\sigma_{k}^{T}}=\left(\begin{array}{lllllll}
N_{11}^{a 1} & 2 N_{12}^{a 1} & N_{22}^{a 2} & \cdots & N_{11}^{a c} & 2 N_{12}^{a c} & N_{22}^{a c}
\end{array}\right)^{T} \\
m_{k}^{T}=\left(\begin{array}{llllllll}
m_{11}^{a 1} & 2 m_{12}^{a 1} & m_{22}^{a 1} & \cdots & m_{11}^{a c} & 2 m_{12}^{a c} & m_{22}^{a c}
\end{array}\right)^{T}
\end{gathered}
$$

Além disso, as matrizes $\sigma_{\varepsilon}^{*} \underset{\sim}{E}, M_{\chi}$ e $\underset{\sim}{\Lambda}$ em (5.110) e (5.111) devem ser substituídas respectivamente por $\sigma_{\sigma}^{*}, F, M_{m}$ e $\Xi$. Essas são expressas por:

$$
\underset{\sim}{\sigma_{\sigma}^{*}}=\left[\begin{array}{ccc}
q_{i} \varepsilon_{i j 11}^{*} q_{j} & 2 q_{i} \varepsilon_{i j 12}^{*} q_{j} & q_{i} \varepsilon_{i j 22}^{*} q_{j} \\
q_{i} \varepsilon_{i j 11}^{*} m_{j} & 2 q_{i} \varepsilon_{i j 12}^{*} m_{j} & q_{i} \varepsilon_{i j 22}^{*} m_{j} \\
m_{i} \varepsilon_{i j 11}^{*} m_{j} & 2 m_{i} \varepsilon_{i j 12}^{*} m_{j} & m_{i} \varepsilon_{i j 22}^{*} m_{j}
\end{array}\right] ; i, j=1,2
$$




$$
\underset{\sim}{F}=\left[\begin{array}{ccc}
q_{i} Z_{i j 11} q_{j} & 2 q_{i} Z_{i j 12} q_{j} & q_{i} Z_{i j 22} q_{j} \\
q_{i} Z_{i j 11} m_{j} & 2 q_{i} Z_{i j 12} m_{j} & q_{i} Z_{i j 22} m_{j} \\
m_{i} Z_{i j 11} m_{j} & 2 m_{i} Z_{i j 12} m_{j} & m_{i} Z_{i j 22} m_{j}
\end{array}\right] ; i, j=1,2
$$

onde os kernels presentes (5.122) são dados em (5.43). Já os termos livres de integral em (5.123) estão indicados em (5.44).

$$
\begin{aligned}
\underset{\sim}{M_{m}} & =\left[\begin{array}{ccc}
q_{i} \mu w_{, i j 11}^{*} q_{j} & 2 q_{i} \mu w_{, i j 12}^{*} q_{j} & q_{i} \mu w_{, i j 22}^{*} q_{j} \\
q_{i} \mu w_{, i j 11}^{*} m_{j} & 2 q_{i} \mu w_{, i j 12}^{*} m_{j} & q_{i} \mu w_{, i j 22}^{*} m_{j} \\
m_{i} \mu w_{, i j 11}^{*} m_{j} & 2 m_{i} \mu w_{, i j 12}^{*} m_{j} & m_{i} \mu w_{, i j 22}^{*} m_{j}
\end{array}\right] ; i, j=1,2 \\
& \underset{\sim}{\Xi}=\left[\begin{array}{lll}
q_{i} \mu Y_{i j 11} m_{j} & 2 q_{i} \mu Y_{i j 12} m_{j} & q_{i} \mu Y_{i j 22} m_{j} \\
q_{i} \mu Y_{i j 11} m_{j} & 2 q_{i} \mu Y_{i j 12} m_{j} & q_{i} \mu Y_{i j 22} m_{j} \\
m_{i} \mu Y_{i j 11} m_{j} & 2 m_{i} \mu Y_{i j 12} m_{j} & m_{i} \mu Y_{i j 22} m_{j}
\end{array}\right] ; i, j=1,2
\end{aligned}
$$

Os kernels presentes em (5.124) estão indicados na expressão (5.98). Já os termos livres de integral reunidos em (5.125) estão indicados em (5.97).

\subsubsection{2) Aproximação das variáveis do problema}

Conforme descrito no capítulo 4, são utilizadas duas abordagens no modelo hexaparamétrico para interpolação das variáveis do contorno: a primeira é a isoparamétrica linear e a outra é a interpolação cúbica para os deslocamentos normais e transversais ao contorno da lâmina. Já na formulação tetraparamétrica apenas a interpolação isoparamétrica linear é utilizada. $\mathrm{O}$ assunto da aproximação das variáveis no contorno já foi abordado no capítulo 4. Assim, optou-se descrever nesta seção apenas as técnicas empregadas na interpolação dos campos iniciais nas células.

Os termos inelásticos são linearmente interpolados no domínio de cada célula, vide figura 5.6.

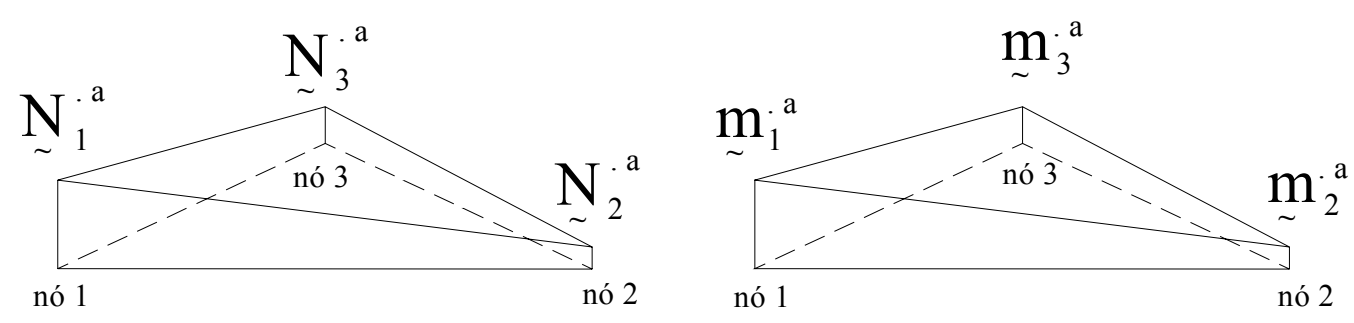

Figura 5.6- Interpolação dos Campos Inelásticos. 
Empregando-se a interpolação isoparamétrica linear, a representação integral discretizadas de chapas, em que as deformações são tomadas como campo inicial, pode ser escrita tal qual em (5.106); os vetores k-ésimos $P_{k}^{n}, U_{k}^{n}, B_{k}^{c}, P_{\sim}^{*}, U^{*}$ denotam o mesmo que em (4.1); os demais vetores podem ser expressos como:

$$
\begin{aligned}
\underset{\sim}{\Psi} & =\left(\begin{array}{ccccccccc}
\psi_{1} & 0 & 0 & \psi_{2} & 0 & 0 & \psi_{3} & 0 & 0 \\
0 & \psi_{1} & 0 & 0 & \psi_{2} & 0 & 0 & \psi_{3} & 0 \\
0 & 0 & \psi_{1} & 0 & 0 & \psi_{2} & 0 & 0 & \psi_{3}
\end{array}\right) \\
\dot{\sim}_{\sim}^{T} & =\left(\begin{array}{lllllllll}
\varepsilon_{11}^{1} & \varepsilon_{12}^{1} & \varepsilon_{22}^{1} & \varepsilon_{11}^{2} & \varepsilon_{12}^{2} & \varepsilon_{22}^{2} & \varepsilon_{11}^{3} & \varepsilon_{21}^{3} & \varepsilon_{22}^{3}
\end{array}\right)
\end{aligned}
$$

Já para o problema de flexão e com a interpolação isoparamétrica linear, os vetores $k$-ésimos $V_{k}^{n}, W_{k}^{n}, G_{k}^{c}, G_{L k}^{c c}, c^{*}, d^{*}$ e $W_{g}^{*}$ podem ser expressos tais quais em (4.2). O vetor $\Psi$ é dado tal qual em (5.126) e os demais vetores presentes em (5.108) podem escritos como:

$$
\chi^{T}=\left(\begin{array}{lllllllll}
w_{, 11}^{1} & w_{, 12}^{1} & w_{, 22}^{1} & w_{, 11}^{2} & w_{, 12}^{2} & w_{, 22}^{2} & w_{, 11}^{3} & w_{, 21}^{3} & w_{, 22}^{3}
\end{array}\right)
$$

\section{3) Representação Algébrica}

\subsection{1) Cálculo das integrais para os campos iniciais}

Devido à presença de singularidades mais severas, uma alternativa para calcular as integrais inelásticas é empregar técnicas numéricas(quadraturas) no domínio. Uma dessas técnicas é o procedimento proposto em TELLES(1981), em que o domínio é escrito em função de coordenadas polares e, em seguida, os kernels são integrados analiticamente em função do raio. Por fim, é aplicada uma quadratura unidimensional nos termos resultantes da primeira integração, que são dependentes da variável angular do sistema polar. $\mathrm{Na}$ seqüência, são descritos esses procedimentos.

Conforme discutido na seção 5.2.3.2, as parcelas tensoriais inelásticas são interpoladas linearmente no domínio. Assim, esses termos associados tanto com os estados planos quanto como o regime de flexão para campos iniciais em tensão/momento podem ser escritos como: 


$$
\begin{aligned}
& N_{\sim}^{N^{a}}=\psi_{1}{\underset{\sim}{N^{a}}+\psi_{2}}_{\sim}^{N_{2}^{a}+\psi_{3}} \underset{\sim 3}{N^{a}} \\
& m_{\sim}^{m^{a}}=\psi_{1} \underset{\sim 1}{m^{a}}+\psi_{2} \underset{\sim}{m_{2}^{a}}+\psi_{3} \underset{\sim 3}{m^{a}}
\end{aligned}
$$

onde $\psi_{i}, N^{i}$ e $m^{i}$ são respectivamente a função interpoladora; os vetores que contêm as componentes da tensão e momento inelástico; ambos estão associados aos nós 1, 2 ou 3 da célula, vide figura 5.6.

Em (5.126), as funções interpoladoras podem ser escritas utilizando-se equações de planos, de forma que podem ser expressas como:

$$
\psi_{i}=A_{i} x_{1}(S)+B_{i} x_{2}(S)+C_{i}
$$

onde os coeficientes $A_{i}, B_{i}, C_{i}$ podem ser expressos por:

$$
\begin{gathered}
A_{1}=\left(x_{2 j}-x_{2 k}\right) / D_{t} ; B_{1}=\left(x_{1 k}-x_{2 j}\right) / D_{t} ; C_{1}=\left(x_{1 j} x_{2 k}-x_{1 k} x_{2 j}\right) / D_{t} ; \\
A_{2}=\left(x_{2 k}-x_{2 i}\right) / D_{t} ; B_{2}=\left(x_{1 i}-x_{2 k}\right) / D_{t} ; C_{2}=\left(x_{1 k} x_{2 i}-x_{1 i} x_{2 k}\right) / D_{t} ; \\
A_{3}=\left(x_{2 i}-x_{2 j}\right) / D_{t} ; B_{3}=\left(x_{1 j}-x_{1 i}\right) / D_{t} ; C_{3}=\left(x_{1 i} x_{2 j}-x_{1 j} x_{2 i}\right) / D_{t}
\end{gathered}
$$

com:

$$
D_{t}=x_{1 i}\left(x_{2 j}-x_{2 k}\right)+x_{1 j}\left(x_{2 k}-x_{2 i}\right)+x_{1 k}\left(x_{2 i}-x_{2 j}\right)
$$

Alternativamente, (5.132) pode ser escrita segundo o sistema polar, isto é:

$$
\psi_{i}=r\left(A_{i} \cos \theta+B_{i} \operatorname{sen} \theta\right)+C_{i}
$$

A parcela de integral inelástica da representação dos gradientes de deslocamentos em chapas(5.36) pode escrita no sistema polar de coordenadas, vide figura 5.7, por:

$$
\begin{gathered}
\int_{\Omega} q_{i}(p) \kappa_{i j k r}^{*}(p, s) m_{j}(p) N_{k r}^{a}(S) d \Omega=\sum_{n=1}^{3}\left(c_{11}^{h} N_{11}^{a h}+2 c_{12}^{h} N_{12}^{a h}+c_{22}^{h} N_{22}^{a h}\right) ; \\
i, j, k, r=1,2
\end{gathered}
$$

onde

$$
c_{k r}^{h}=\int_{\theta}^{R_{2}(\theta)} \int_{R_{I}(\theta)} q_{i}(p) \frac{\hat{\kappa}_{i j k r}^{*}}{r^{2}}(\theta) m_{j}(p)\left[r\left(A^{h} \cos \theta+B^{h} \operatorname{sen} \theta\right)+C^{h}\right] r d r d \theta
$$

$\operatorname{com} \hat{\kappa}_{i j k r}^{*}(\theta)$ é a parte independente do raio $r$ no kernel dado em (5.30):

$$
\hat{\kappa}_{i j k r}^{*}(\theta)=r^{2} \kappa_{i j k r}^{*} ; i, j, k, r=1,2
$$




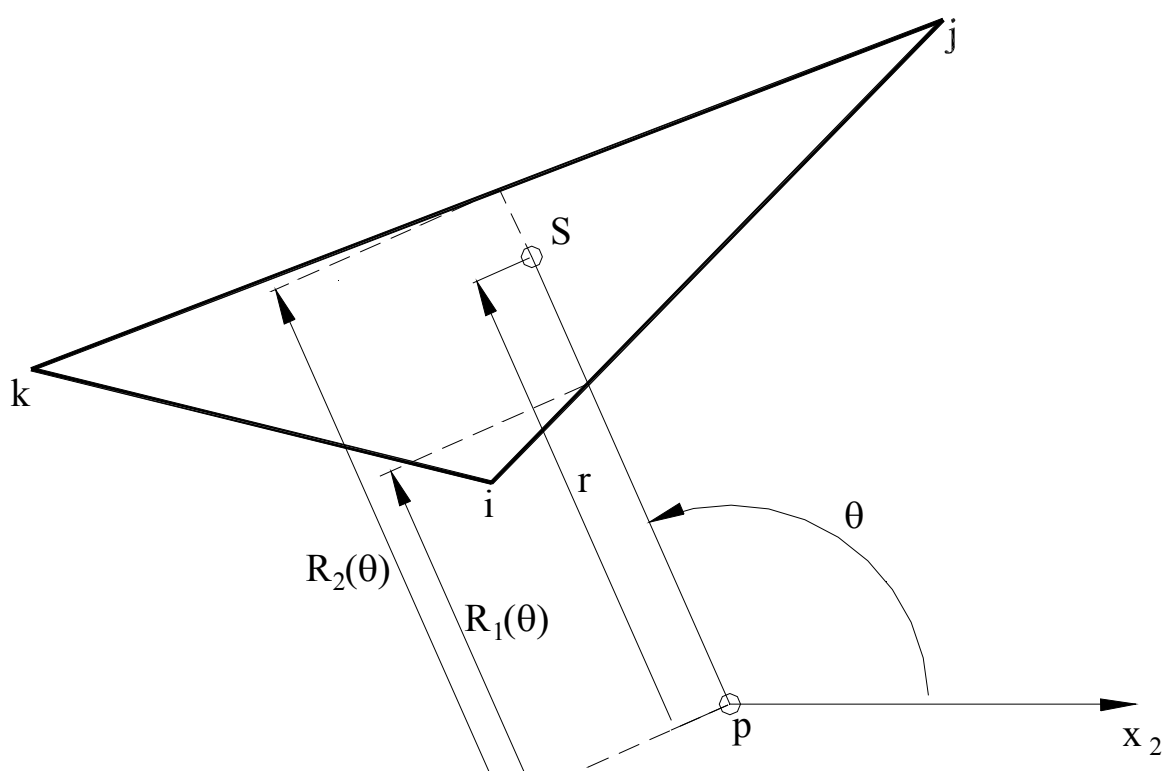

Figura 5.7- Integração na célula.

Após o cálculo da integração na direção radial, (5.135) pode ser escrita como:

$$
\begin{gathered}
c_{k r}^{h}=\int_{\theta} q_{i}(p) \hat{\kappa}_{i j k r}^{*}(\theta) m_{j}(p)\left\{\left(A^{h} \cos \theta+B^{h} \operatorname{sen} \theta\right) \ln \left[\frac{R_{2}(\theta)}{R_{l}(\theta)}\right]+\right. \\
\left.C^{h}\left[R_{2}(\theta)-R_{l}(\theta)\right]\right\} d \theta ; i, j, k, r=1,2
\end{gathered}
$$

Analogamente à representação (5.135), o termo inelástico da representação integral dos deslocamentos transversais de placa (5.90) pode ser escrito como:

$$
\begin{gathered}
\int_{\Omega} m_{i} m_{j} w_{, k r}^{*}(p, s) m_{k r}^{a}(S) d \Omega=\sum_{n=1}^{3}\left(p_{11}^{h} m_{11}^{. a h}+2 p_{12}^{h} m_{12}^{. a h}+p_{22}^{h} m_{22}^{. a h}\right) ; \\
i, j, k, r=1,2
\end{gathered}
$$

onde:

$$
p_{k r}^{h}=\int_{\theta}^{R_{R_{I}}(\theta)} \int_{(\theta)}\left[\frac{m_{i} m_{j}}{4 \pi D}\left(\delta_{k r} \ln r+r_{, k} r_{, r}\right)\right]\left[r\left(A^{h} \cos \theta+B^{h} \operatorname{sen} \theta\right)+C^{h}\right] r d r d \theta
$$

Após o cálculo da integração na direção radial, (5.139) pode ser escrita como:

$$
\begin{gathered}
p_{k r}^{h}=\frac{m_{i} m_{j}}{4 \pi D} \int_{\theta} C^{h}\left\{\left[R_{l}(\theta)\left\{1-\ln R_{l}(\theta)\right\}-R_{2}(\theta)\left\{1-\ln R_{2}(\theta)\right\}\right] \delta_{k r}+\right. \\
\left.\left[R_{2}(\theta)-R_{l}(\theta)\right] r_{, k} r_{, r}\right\} d \theta+\frac{m_{i} m_{j}}{8 \pi D} \int_{\theta}\left(A^{h} \cos \theta+B^{h} \operatorname{sen} \theta\right)\left\{\left[R_{l}^{2}(\theta)-R_{2}^{2}(\theta)\right] r_{, k} r_{, r}+\right. \\
\left.\left[R_{l}^{2}(\theta)\left(\frac{1}{2}-\ln R_{l}(\theta)\right)-R_{2}^{2}(\theta)\left(\frac{1}{2}-\ln R_{2}(\theta)\right)\right] \delta_{k r}\right\} d \theta ; i, j, k, r=1,2
\end{gathered}
$$


O cálculo dos termos das integrais inelásticas da representação integral das resultantes de tensões (5.41) pode ser efetuado tal qual em (5.134), bastando-se trocar $\kappa_{i j k r}^{*}$ por $\varepsilon_{i j k r}^{*}$, uma vez que a ordem das singularidades nesses kernels é a mesma. Assim, tem-se que:

$$
\int_{\Omega} q_{i}(p) \varepsilon_{i j k r}^{*}(p, s) m_{j}(p) N_{k r}^{a}(S) d \Omega=\sum_{n=1}^{3}\left(t_{11}^{h} N_{11}^{. a h}+2 t_{12}^{h} N_{12}^{. a h}+t_{22}^{h} N_{22}^{. a h}\right)
$$

com:

$$
\begin{gathered}
t_{k r}^{h}=\int_{\theta} q_{i}(p) \hat{\varepsilon}_{i j k r}^{*}(\theta) m_{j}(p)\left\{\left(A^{h} \cos \theta+B^{h} \operatorname{sen} \theta\right) \ln \left[\frac{R_{2}(\theta)}{R_{l}(\theta)}\right]+\right. \\
\left.C^{h}\left[R_{2}(\theta)-R_{l}(\theta)\right]\right\} d \theta ; i, j, k, r=1,2
\end{gathered}
$$

onde $\hat{\varepsilon}_{i j k r}^{*}(\theta)$ é a parte independente do raio $r$ no kernel em (5.43):

$$
\hat{\varepsilon}_{i j k r}^{*}(\theta)=r^{2} \varepsilon_{i j k r}^{*} ; i, j, k, r=1,2
$$

O kernel da integral inelástica para a representação integral dos momentos (5.73) pode ser trabalhado no sistema polar de coordenadas de maneira similar ao da parcela inelástica da representação integral dos gradientes (5.136). Assim, o cálculo da integral de domínio de (5.96) pode apresentado como:

$$
\int_{\Omega} q_{i}(p) \mu w_{, i j k r}^{*}(p, s) m_{j}(p) m_{k r}^{a}(S) d \Omega=\sum_{n=1}^{3}\left(e_{11}^{h} m_{11}^{a h}+2 e_{12}^{h} m_{12}^{a h}+e_{22}^{h} m_{22}^{a h}\right) ; i, j, k, r=1,2
$$

com:

$$
\begin{gathered}
e_{k r}^{h}=\int_{\theta} q_{i}(p) \mu \hat{w}_{, i j k r}^{*}(\theta) m_{j}(p)\left\{\left(A^{h} \cos \theta+B^{h} \operatorname{sen} \theta\right) \ln \left[\frac{R_{2}(\theta)}{R_{l}(\theta)}\right]+\right. \\
\left.C^{h}\left[R_{2}(\theta)-R_{l}(\theta)\right]\right\} d \theta ; i, j, k, r=1,2
\end{gathered}
$$

onde $\mu \hat{w}_{, j k r}^{*}(\theta)$ é a parte independente do raio $r$ no kernel dado em (5.98):

$$
\mu \hat{w}_{, i j k r}^{*}(\theta)=r^{2} \mu w_{, i j k r}^{*} ; i, j, k, r=1,2
$$

As integrações anteriormente apresentadas foram escritas para campos inelásticos em tensões/momentos iniciais. Conforme discutido nas seções anteriores deste capítulo, uma outra maneira que os problemas inelásticos podem ser abordados é por meio de campos iniciais em deformações/curvaturas. Adotando-se uma 
interpolação linear para esses campos no domínio de cada célula, o cálculo das integrações do termo inelástico pode ser efetuado um procedimento similar ao dos campos iniciais em deformações/curvaturas. Assim, as representações dos gradientes dos deslocamentos em chapas são obtidas trocando-se $\hat{\kappa}_{i j k r}^{*}(\theta)$ por $\hat{\lambda}_{i j k r}^{*}(\theta)$ em (5.135); já em placas, a troca deve ser $w_{, k r}{ }^{*}$ por $m_{k r}^{*}$ em (5.140):

$$
\int_{\Omega} q_{i}(p) \lambda_{i j k r}^{*}(p, s) m_{j}(p) \varepsilon_{k r}^{a}(S) d \Omega=\sum_{n=1}^{3}\left(c_{11}^{h} \varepsilon_{11}^{a h}+2 c_{12}^{h} \varepsilon_{12}^{a h}+c_{22}^{h} \varepsilon_{22}^{a h}\right) ; i, j, k, r=1,2
$$

onde

$$
\begin{gathered}
c_{k r}^{h}=\int_{\theta} q_{i}(p) \hat{\lambda}_{i j k r}^{*}(\theta) m_{j}(p)\left\{\left(A^{h} \cos \theta+B^{h} \operatorname{sen} \theta\right) \ln \left[\frac{R_{2}(\theta)}{R_{l}(\theta)}\right]+\right. \\
\left.C^{h}\left[R_{2}(\theta)-R_{l}(\theta)\right]\right\} d \theta ; \quad i, j, k, r=1,2
\end{gathered}
$$

com $\hat{\lambda}_{i j k r}^{*}(\theta)$ é a parte independente do raio $r$ no kernel dado em (5.39):

$$
\begin{aligned}
& \hat{\lambda}_{i j k r}^{*}(\theta)=r^{2} \lambda_{i j k r}^{*} ; i, j, k, r=1,2 \\
& \int_{\Omega} m_{i} m_{j} m_{k r}^{*}(p, S) w_{, k r}^{a}(S) d \Omega=\sum_{n=1}^{3}\left(p_{11}^{\chi h} w_{, 11}^{a h}+2 p_{12}^{\chi h} w_{, 12}^{a h}+p_{22}^{\chi h} w_{, 22}^{a h}\right) ; i, j, k, r=1,2 \\
& p_{k r}^{\chi}=\frac{(1+v)}{4 \pi} m_{i} m_{j} \int_{\theta} C^{h}\left\{\left[R_{l}(\theta)\left\{1-\ln R_{l}(\theta)\right\}-R_{2}(\theta)\left\{1-\ln R_{2}(\theta)\right\}\right] \delta_{k r}+\right. \\
& \left.\left[R_{2}(\theta)-R_{l}(\theta)\right]\left(\frac{r_{, k} r_{, r}}{1+v}-v \delta_{k r}\right)\right\} d \theta+ \\
& \frac{(1+v) m_{i} m_{j}}{8 \pi} \int_{\theta}\left(A^{h} \cos \theta+B^{h} \operatorname{sen} \theta\right)\left\{\left[R_{l}^{2}(\theta)-R_{2}^{2}(\theta)\right]\left(\frac{r_{, k} r_{r}}{1+v}-v \delta_{k r}\right)+\right. \\
& \left.\left[R_{l}^{2}(\theta)\left(\frac{1}{2}-\ln R_{l}(\theta)\right)-R_{2}^{2}(\theta)\left(\frac{1}{2}-\ln R_{2}(\theta)\right)\right] \delta_{k r}\right\} d \theta ; i, j, k, r=1,2
\end{aligned}
$$

Da mesma forma, o cálculo dos termos inelásticos das representações integrais das tensões e momentos para os campos iniciais em deformação/curvatura pode ser efetuado a partir do procedimento aplicado à abordagem tensão/momento inicial, bastando-se ajustar os respectivos kernels $\hat{\varepsilon}_{i j k r}^{*}(\theta)$ por $\hat{\sigma}_{i j k r}^{*}(\theta)$; $\mu \hat{w}_{, i j k r}^{*}(\theta)$ por $\mu \hat{m}_{i j, k r}^{*}(\theta)$. Assim, tem-se que: 


$$
\begin{gathered}
\int_{\Omega} q_{i}(p) \mu m_{i j, k r}^{*}(p, s) m_{j}(p) w_{, k r}^{a}(S) d \Omega=\sum_{n=1}^{3}\left(e_{11}^{\mu h} w_{, 11}^{a h}+2 e_{12}^{\mu h} w_{, 12}^{a h}+e_{22}^{\mu h} w,_{22}^{. a h}\right) ; \\
i, j, k, r=1,2
\end{gathered}
$$

com:

$$
\begin{gathered}
e_{k r}^{\mu h}=\int_{\theta} q_{i}(p) \mu \hat{m}_{i j, k r}^{*}(\theta) m_{j}(p)\left\{\left(A^{h} \cos \theta+B^{h} \operatorname{sen} \theta\right) \ln \left[\frac{R_{2}(\theta)}{R_{l}(\theta)}\right]+\right. \\
\left.C^{h}\left[R_{2}(\theta)-R_{l}(\theta)\right]\right\} d \theta ; \quad i, j, k, r=1,2
\end{gathered}
$$

onde com $\mu \hat{m}_{i j, k r}^{*}(\theta)$ é a parte independente do raio $r$ no kernel dado em (5.75):

$$
\mu \hat{m}_{i j, k r}^{*}(\theta)=r^{2} \mu m_{i j, k r}^{*} ; i, j, k, r=1,2
$$

\subsection{2)Sistema de equações}

Conforme discutido no capítulo 4, a representação algébrica é obtida por meio da integração das equações integrais discretizadas. Nesta seção são descritos os sistemas algébricos para as formulações tetra e hexaparamétrica.

\subsubsection{1)Formulação hexaparamétrica}

$\mathrm{Na}$ seqüência são apresentados os sistemas algébricos da formulação hexaparamétrica para domínios simplesmente conectados para os problemas independentes dos estados planos e do regime de flexão. Em seguida, esses sistemas são estendidos para domínios coplanares com regiões com rigidezes distintas.

\subsubsection{1)Problemas simplesmente conectados de chapas e placas}

Inicialmente, são discutidos os sistemas de equações obtidos das equações integrais dos deslocamentos e seus gradientes. Em seguida, o mesmo é feito para as equações integrais de tensões/momentos para pontos de domínio.

Conforme discutido no capítulo 4 , devido a uma diferença no número de graus de liberdade no vetor dos deslocamentos e no de forças em cada um dos problemas de chapas e placas são inseridos zeros nas respectivas posições associadas às variáveis fictícias introduzidas no vetor das forças. No problema de campos iniciais em tensões/momentos, as contribuições de um j-ésimo elemento da representação algébrica - deslocamentos e seus gradientes em chapas e 
deslocamentos transversais e suas derivadas direcionais em placas- podem ser escritas respectivamente como:

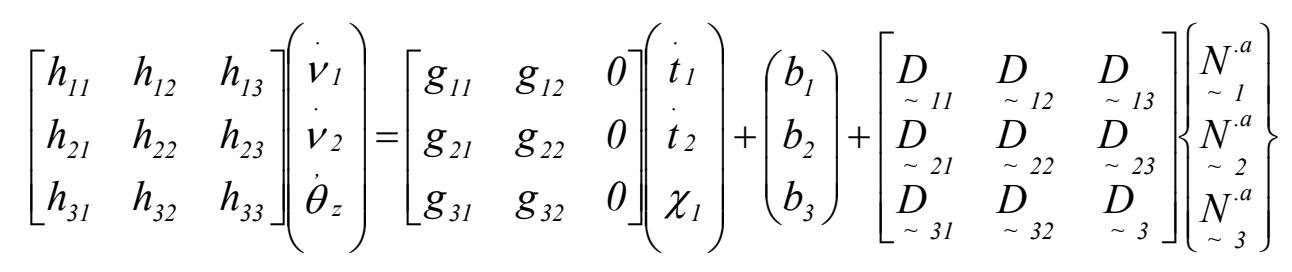

onde $D_{i j}$ são as submatrizes em que os índices $i, j$ estão associados respectivamente à linha da representação integral e o número do nó $j$ da célula; o vetor $N_{k}^{a}$ contém as componentes das tensões inelásticas do nó $k$ da célula.

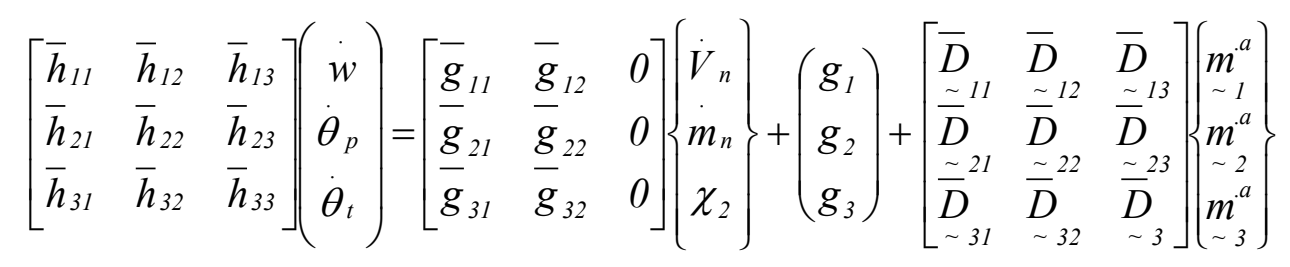

onde $\bar{D}_{i j}$ são submatrizes equivalentes à $D_{i j} ;$. o vetor $m_{k}^{a}$ contém as componentes dos momentos inelásticos do nó $k$ da célula.

Após a colocação do ponto-fonte nos pontos de domínio e a incorporação das contribuições de todos os elementos e células, as representações (5.152) ou (5.153) podem escritas genericamente como:

$$
\underset{\sim}{H \underset{\sim}{u}}=\underset{\sim}{G} \underset{\sim}{p}+(\underset{\sim}{D}+\underset{\sim}{\hat{D}}) \dot{T}_{\sim}^{a}
$$

onde $\underset{\sim}{D}$ é a matriz de influência da integral de domínio associada aos campos inelásticos(tensão ou momento inicial) $T^{a} . \hat{D}$ é a matriz dos coeficientes dos termos livres inelástico.

Aplicando-se um procedimento simular para as representações integrais de tensões/momentos para pontos-fonte no domínio, as contribuições de um j-ésimo elemento podem ser escritas respectivamente como: 


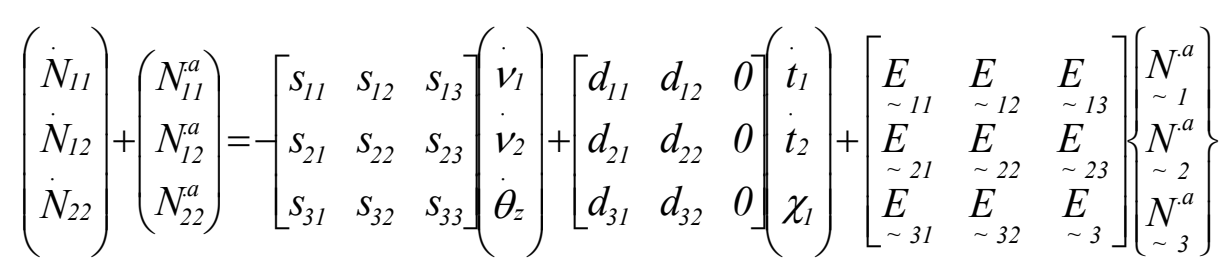

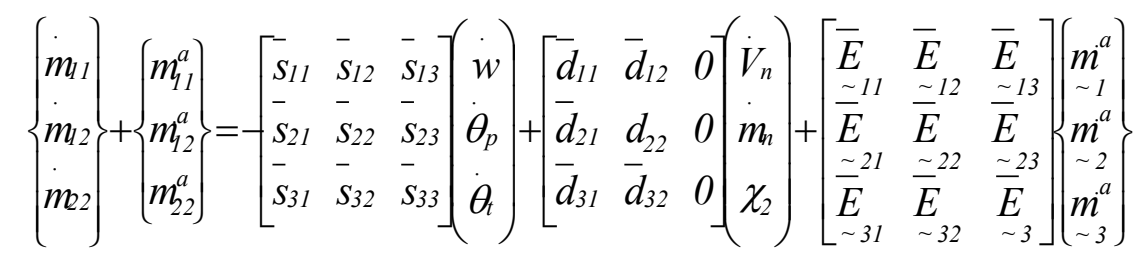

Após a colocação do ponto-fonte nos pontos de domínio e o cômputo das contribuições de todos os elementos e células, as representações (5.155) ou (5.156) podem escritas genericamente como:

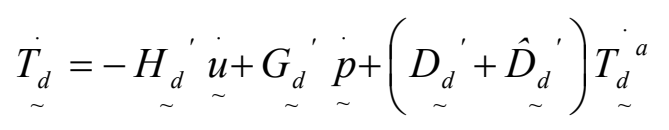

onde $D_{\sim}^{\prime}$ é a matriz de influência dos campos inelásticos(tensão e/ou momento inicial) das representações integrais dos esforços(tensão e/ou momento) respectivamente. $\hat{D}_{\sim}^{\prime}$ é matriz dos termos livres inelásticos. $H_{d}{ }^{\prime}, G_{d}{ }^{\prime}$ e $\dot{T}_{d}$, $T_{d}{ }^{a}$ são as matrizes de influência das variáveis de contorno e do vetor dos momentos/tensões reais e inelásticos para pontos-fonte no domínio, respectivamente.

Nesse trabalho, optou-se preterir as representações integrais de contorno para tensões e momentos devido à presença de algumas singularidades severas dos kernels. Assim, partiu-se para uma abordagem usual - BANERJEE et al.(1979), TELLES \& BREBBIA(1979), etc. - em que os tensões e momentos no contorno são determinados a partir de equações de equilíbrio de parte de suas componentes. As demais são obtidas por interpolações dos valores nodais dos deslocamentos e rotações. Na seqüência, essa técnica é discutida com mais detalhe.

Tomando-se um elemento de contorno genérico e o sistema de referência local $\left(\hat{x}_{1}, \hat{x}_{2}\right)$, conforme indicado na figura 5.8, os co-senos diretores $n_{1}=\cos \left(\hat{x}_{2}, \hat{x}_{2}\right)=1$ e $n_{2}=\cos \left(\hat{x}_{1}, \hat{x}_{2}\right)=0$, se levados nas relações de Cauchy (5.4), e as componentes de força de superfície podem ser escritas como: 


$$
\begin{aligned}
& \dot{\hat{\hat{N}}}_{11}=\dot{\hat{t}}_{1}=\dot{t}_{2} \\
& \dot{\hat{N}}_{12}=\dot{\hat{t}}_{2}=\dot{t}_{1}
\end{aligned}
$$

A componente remanescente de tensão $\hat{N}_{22}$ pode ser obtida por um algebrismo na lei constitutiva em tensões iniciais (5.8):

$$
\dot{\hat{N}}_{22}=\frac{v_{p}}{1-v_{p}} t\left(\dot{\hat{N}}_{11}+\hat{N}_{11}^{a}\right)+\frac{2 G t}{1-v_{p}} \dot{\hat{\varepsilon}}_{22}-\hat{N}_{22}^{a}
$$

Se (5.158) for substituída em (5.160), vem:

$$
\dot{\hat{N}}_{22}=\frac{v_{p}}{1-v_{p}} t\left(\dot{t}_{1}+\hat{N}_{11}^{a}\right)+\frac{2 G t}{1-v_{p}} \dot{\hat{\varepsilon}}_{22}-\hat{N}_{22}^{a}
$$

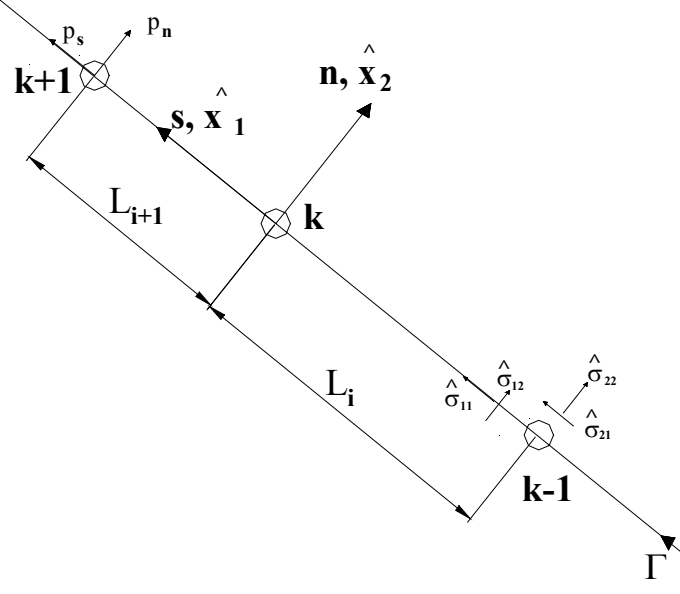

Figura 5.8- Sistema de referência (resultantes de tensão no contorno).

Já a deformação $\hat{\varepsilon}_{22}$ pode ser obtida empregando-se uma técnica bastante utilizada no Método dos Elementos Finitos (MEF), isto é, diferenciando-se as funções de forma dos deslocamentos. Assim, tem-se que:

$$
\hat{\boldsymbol{\varepsilon}}_{22}=\frac{\partial}{\partial t}\left[\phi_{1}(s)\right]{\dot{v_{1}}}^{1}+\frac{\partial}{\partial t}\left[\phi_{2}(s)\right]{\dot{v_{1}}}^{2}=\frac{1}{L}\left\{\frac{\partial}{\partial \xi}\left[\phi_{1}(\xi)\right] \dot{v}_{1}+\frac{\partial}{\partial \xi}\left[\phi_{2}(\xi)\right] \dot{v}_{1}^{2}\right\}
$$

Para o regime de flexão pode ser empregada uma estratégia similar ao problema de chapas, vide figura 5.9. Assim, a partir das relações (2.32), pode-se escrever que: 


$$
\dot{\hat{m}}_{11}=\dot{m}_{n}
$$

Após uma manipulação algébrica nas relações constitutivas para campos inelásticos tomados como momentos iniciais (5.88) e, ainda, utilizando-se (5.163), a componente $\dot{\hat{m}}_{22}$ dos momentos pode ser escrita como:

$$
\dot{\hat{m}}_{22}=v\left(\dot{m}_{n}+\hat{m}_{11}^{a}\right)-D\left(1-v^{2}\right) \dot{\hat{w}}_{, 22}-\hat{m}_{22}^{a}
$$

Já a componente $\dot{\hat{m}}_{12}$ pode ser expressa a partir de (5.88) como:

$$
\hat{m}_{12}=-D(1-v) \hat{w}_{, 12}-\hat{m}_{12}^{a}
$$

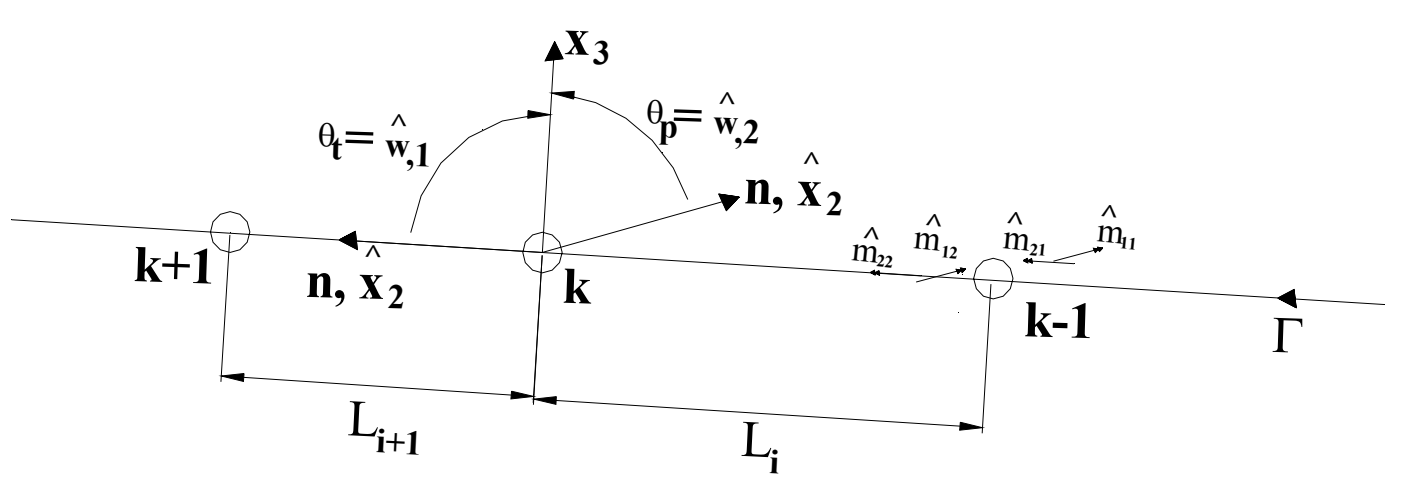

Figura 5.9- Sistema de referência (momentos no contorno).

A partir da figura 5.9, as derivadas direcionais no contorno podem escritas como:

$$
\dot{\hat{w}}_{, 2}=\dot{\theta}_{p} ; \dot{\hat{w}}_{, 1}=\dot{\theta}_{t}
$$

Tanto (5.165) e (5.166) estão escritas em função das unicamente em função das curvaturas nas direções e sentidos dos momentos em questão. Essas curvaturas podem ser aproximadas a partir da diferenciação das funções de forma das rotações tangenciais e normais ao contorno: 


$$
\begin{gathered}
\dot{\hat{\hat{w}}}_{, 21}=\frac{\partial}{\hat{x}_{1}} \dot{\theta}_{p}=\frac{\partial}{\partial \hat{x}_{1}}\left[\phi_{1}(s) \dot{\theta}_{p}^{l}+\phi_{2}(s) \dot{\theta}_{p}^{2}\right]=\frac{1}{L}\left[\dot{\theta}_{p}^{l} \frac{\partial}{\partial \xi} \phi_{1}(\xi)+\dot{\theta}_{p}^{2} \frac{\partial}{\partial \xi} \phi_{2}(\xi)\right] \\
\dot{\hat{\hat{w}}}_{, 11}=\frac{\partial}{\hat{x}_{1}} \dot{\theta}_{t}=\frac{\partial}{\partial \hat{x}_{2}}\left[\phi_{1}(s) \dot{\theta}_{t}^{l}+\phi_{2}(s) \dot{\theta}_{t}^{2}\right]=\frac{1}{L}\left[\dot{\theta}_{t}^{l} \frac{\partial}{\partial \xi} \phi_{1}(\xi)+\dot{\theta}_{t}^{2} \frac{\partial}{\partial \xi} \phi_{2}(\xi)\right]
\end{gathered}
$$

Convém enfatizar que para um nó pertencente a dois elementos contíguos, cujos comprimentos sejam $L_{i+1}, L_{i}$, as contribuições para ele podem ser aproximados, utilizando-se a média aritmética daquelas associadas aos dois elementos:

$$
\dot{\hat{w}}_{, 22}=\frac{1}{2}\left[\dot{\theta}_{p}^{l} \frac{\partial}{\partial \xi} \phi_{1}(\xi) \frac{1}{L_{i+1}}+\dot{\theta}_{p}^{2} \frac{\partial}{\partial \xi} \phi_{2}(\xi) \frac{1}{L_{i}}\right]
$$

Para as demais componentes dos campos aproximadas no contorno descritas em (5.168) e (5.162) pode ser empregada uma técnica similar.

As equações (5.158), (5.159), (5.161) e (5.162) podem ser reunidas em uma única representação algébrica das tensões de um ponto no contorno para os problemas de chapas:

$$
\begin{gathered}
\left\{\begin{array}{l}
\dot{\hat{N}}_{11} \\
\dot{\hat{N}}_{12} \\
\dot{\hat{N}}_{22}
\end{array}\right\}=\left[\begin{array}{ccc}
1 & 0 & 0 \\
0 & 1 & 0 \\
\frac{v_{p}}{1-v_{p}} t & 0 & 0
\end{array}\right]\left\{\begin{array}{l}
\dot{t}_{1} \\
\dot{t}_{2} \\
\chi_{1}
\end{array}\right\}+\left[\begin{array}{ccc}
0 & 0 & 0 \\
0 & 0 & 0 \\
\frac{v_{p}}{1-v_{p}} t & 0 & -1
\end{array}\right]\left\{\begin{array}{c}
\hat{N}_{11}^{a} \\
\hat{N}_{12}^{a} \\
\hat{N}_{22}^{a}
\end{array}\right\}+ \\
\frac{2 G t}{\left(1-v_{p}\right) L_{i}}\left[\begin{array}{ccccccc}
0 & 0 & 0 & 0 & 0 & 0 \\
0 & 0 & 0 & 0 & 0 & 0 \\
A_{1} & 0 & 0 & A_{2} & 0 & 0
\end{array}\right]\left\{\begin{array}{c}
1 \\
\dot{v}_{1} \\
\dot{v}_{2} \\
\dot{\theta}_{z} \\
\dot{v}_{1} \\
\dot{v}_{2} \\
\dot{\theta}_{z} \\
\dot{\theta}_{z}
\end{array}\right\}
\end{gathered}
$$

onde $A_{i}=\frac{\partial}{\partial \xi}\left[\phi_{i}(\xi)\right]$, em que $A_{i}=0,5$ para uma função $\phi_{i}$ linear. 
Se equação (5.170) for escrita para o ponto coincidente com o segundo nó do elemento de contorno, isto é, $\dot{v}_{i}=\dot{v}_{i}^{2}$ nó $k$ (figura 5.7), e ainda, se for empregada a técnica da média dos coeficientes de influência, discutida em (5.169), tem-se que:

$$
\begin{gathered}
\left\{\begin{array}{l}
\dot{\hat{N}}_{11} \\
\dot{\hat{N}}_{12} \\
\dot{\hat{N}}_{22}
\end{array}\right\}=\left[\begin{array}{ccc}
1 & 0 & 0 \\
0 & 1 & 0 \\
\frac{v_{p}}{1-v_{p}} t & 0 & 0
\end{array}\right]\left\{\begin{array}{l}
\dot{t}_{1}^{2} \\
\dot{t}_{2} \\
\chi_{1}^{2}
\end{array}\right\}+\left[\begin{array}{ccc}
0 & 0 & 0 \\
0 & 0 & 0 \\
\frac{v_{p}}{1-v_{p}} t & 0 & -1
\end{array}\right]\left\{\begin{array}{l}
\hat{N}_{11}^{a} \\
\hat{N}_{12}^{a} \\
\hat{N}_{22}^{a}
\end{array}\right\}+ \\
\frac{2 G t}{1-v_{p}}\left(\frac{1}{L_{i}}+\frac{1}{L_{i+1}}\right)\left[\begin{array}{ccc}
1 & 0 & 0 \\
0 & 0 & 0 \\
0 & 0 & 0
\end{array}\right]\left\{\begin{array}{l}
\dot{v}_{1}^{2} \\
\dot{v}_{2} \\
\dot{v}_{2} \\
\dot{\theta}_{z}
\end{array}\right\}
\end{gathered}
$$

Para o problema de flexão, pode ser utilizada uma estratégia similar para representar as resultantes de tensões nos pontos de contorno, de forma que a representação algébrica equivalente a (5.171) pode ser expressa por:

$$
\begin{gathered}
\left\{\begin{array}{l}
\dot{\hat{m}}_{11} \\
\dot{\hat{m}}_{12} \\
\dot{\hat{m}}_{22}
\end{array}\right\}=\left[\begin{array}{lll}
0 & 1 & 0 \\
0 & 0 & 0 \\
0 & v & 0
\end{array}\right]\left\{\begin{array}{l}
\dot{V}_{n}^{2} \\
\dot{m}_{n} \\
\chi_{2}^{2}
\end{array}\right\}+\left[\begin{array}{ccc}
0 & 0 & 0 \\
0 & 0 & -1 \\
v & 0 & -1
\end{array}\right]\left\{\begin{array}{l}
\hat{m}_{11}^{a} \\
\hat{m}_{12}^{a} \\
\hat{m}_{22}^{a}
\end{array}\right\}- \\
D(1-v)\left(\frac{1}{L_{i}}+\frac{1}{L_{i+1}}\right)\left[\begin{array}{ccc}
0 & 0 & 0 \\
0 & 1 & 0 \\
0 & 0 & 1
\end{array}\right]\left\{\begin{array}{c}
\dot{w}^{2} \\
\dot{\theta}_{p}^{2} \\
\dot{\theta}_{t} \\
\dot{\theta}^{2}
\end{array}\right\}
\end{gathered}
$$

Assim, após incorporação das contribuições de todos os nós do contorno, uma representação algébrica para as tensões dessa região pode ser escrita como:

$$
\underset{\sim}{T_{c}}=-H_{\sim}^{\prime} \underset{\sim}{\dot{u}}+G_{\sim}^{\prime} \underset{\sim}{p}+\left(\underset{\sim}{D_{c}^{\prime}}+\hat{D}_{\sim}^{\prime}\right) T_{\sim}^{T_{c}^{a}}
$$

Em (5.173), o índice c das matrizes de influência está associado aos pontosfonte no contorno. Assim, o sistema algébrico para pontos de domínio e de contorno pode ser expresso a partir de (5.157) e (5.173): 


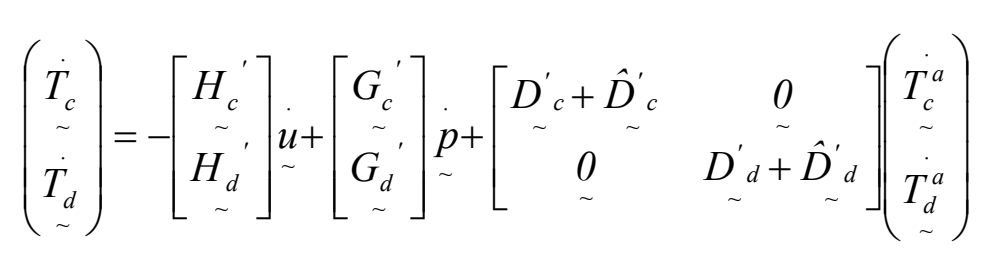

Ou ainda expressa na forma compacta como:

$$
\dot{T}=-H_{\sim}^{\prime} \underset{\sim}{u}+G_{\sim}^{\prime} \underset{\sim}{p}+\left(D_{\sim}^{\prime}+\hat{D}_{\sim}^{\prime}\right) T_{\sim}^{a}
$$

Uma das maneiras para se escrever o sistema algébrico do problema inelástico é representá-lo eliminando-se as incógnitas do contorno por meio da substituição da representação algébrica de contorno dos deslocamentos e suas derivadas (5.154) na representação das tensões/momentos (5.175). As incógnitas do contorno são reagrupadas nesses sistemas mediante a imposição das condições de contorno. Conforme discutido anteriormente, devido à presença de variáveis fictícias no vetor das forças, um procedimento especial, similar ao discutido na seção 4.3.1, pode ser empregado, caso os graus de liberdade(GL) $\theta_{z}$ e/ou $\theta_{t}$ forem prescritos. Nessa estratégia, às linhas do sistema associadas aos GL prescrito(s), $\theta_{z}$ e/ou $\theta_{t}$, devem ser atribuídos valores nulos, inclusive em $D_{\sim}^{\prime}$ e $\hat{D}_{\sim}^{\prime}$. Em seguida, às respectivas colunas das matrizes de influência associadas a esse(s) GL também devem ser impostos valores nulos. E finalizando-se o procedimento, atribui-se a unidade nos elementos da diagonal associado(s) às rotações $\operatorname{prescritas}\left(\theta_{z}\right.$ e/ou $\left.\theta_{t}\right)$.

Assim, após o procedimentos de imposição das condições de contorno em (5.175), as incógnitas podem ser regrupadas como:

$$
\begin{aligned}
& \underset{\sim}{A} \underset{\sim}{\dot{y}}=\underset{\sim}{f}+(\underset{\sim}{D}+\underset{\sim}{\hat{D}}) T_{\sim}^{a} \\
& \underset{\sim}{\dot{T}}=-\underset{\sim}{A^{\prime}} \underset{\sim}{\dot{y}}+f_{\sim}^{\prime}+\left(D_{\sim}^{\prime}+\hat{D}_{\sim}^{\prime}\right) T_{\sim}^{a}
\end{aligned}
$$

E, finalmente, as incógnitas do contorno podem ser eliminadas do sistema algébrico de placas com a substituição de (5.176) em (5.173):

$$
\dot{\sim}_{\sim}^{e}=\underset{\sim}{\dot{T}}+\underset{\sim}{\dot{T}^{a}}=\underset{\sim}{n}+\underset{\sim}{B \underset{\sim}{T}}
$$


onde:

$$
\begin{aligned}
& \underset{\sim}{B}=\underset{\sim}{D^{\prime}}+\underset{\sim}{E^{\prime}-} A_{\sim}^{\prime} A_{\sim}^{-1}(\underset{\sim}{D}+\underset{\sim}{D})\left(\underset{\sim}{D^{\prime}}+\hat{D}^{\prime}\right) \\
& \underset{\sim}{n}=\dot{f}^{\prime}-A_{\sim}^{\prime} A_{\sim}^{-1} \dot{f}
\end{aligned}
$$

Se o campo inicial for tomado em deformações/curvaturas, representações para deslocamento e tensões( domínio) podem ser escritas como:

$$
\begin{aligned}
& \underset{\sim}{H \underset{\sim}{u}}=\underset{\sim}{G} \dot{p}+(\underset{\sim}{R}+\underset{\sim}{R}) \chi^{a}
\end{aligned}
$$

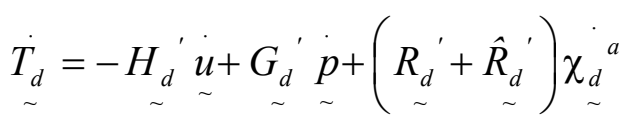

onde $R_{d}^{\prime}$ é a matriz de influência dos campos inelásticos (deformação e/ou curvatura inicial) das representações integrais dos esforços(tensão e/ou momento) respectivamente. $\quad \hat{R}_{d}{ }^{\prime}$ é a matriz dos termos livres inelásticos. $\chi_{d}{ }^{a}{ }^{a}$ é o vetor dos deformações/curvaturas iniciais para pontos-fonte no domínio, respectivamente.

Conforme discutido anteriormente, neste trabalho optou-se por não escrever as equações integrais das tensões/momentos em pontos do contorno. Assim, aplicando uma técnica similar ao caso dos campos iniciais em tensões/momentos, tem-se que no problema de chapas, em que o campo inelástico é tomado como deformações iniciais, uma expressão análoga a (5.161) pode ser escrita como:

$$
\dot{\hat{N}}_{22}=\frac{t}{1-v_{p}}\left(v_{p} \dot{\hat{N}}_{11}+\dot{\hat{\varepsilon}}_{22}+\hat{\varepsilon}_{22}^{a}\right)-\frac{4 G t v_{p}}{1-2 v_{p}} \hat{\varepsilon}_{11}^{a}
$$

onde $\hat{\varepsilon}_{22}$ pode ser escrita tal qual (5.162).

Para o problema de flexão em curvaturas iniciais, a componente dos momentos $\dot{\hat{m}}_{11}$ pode ser expressa tal qual em (5.163); as demais podem ser escritas a partir de (5.48):

$$
\dot{\hat{m}}_{12}=-D(1-v)\left(\dot{\hat{w}}_{, 12}-\hat{w}_{, 12}^{a}\right)
$$




$$
\dot{\hat{m}}_{12}=-D(1-v)\left(\dot{\hat{w}}_{, 22}-\hat{w}_{, 22}^{a}\right)
$$

onde as curvaturas $\dot{\hat{w}}_{, 12}$ e $\dot{\hat{w}}_{, 22}$ estão expressas respectivamente (5.167) e (5.169).

Se as expressões das componentes de $\dot{\hat{N}}_{i j}$ e $\dot{\hat{m}}_{i j}$ forem reagrupadas, um sistema análogo a (5.173) pode ser escrito como:

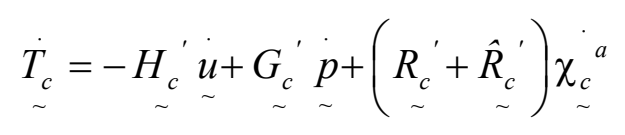

Assim, o sistema algébrico para pontos de domínio e de contorno pode ser expresso a partir de (5.182) e (5.186):

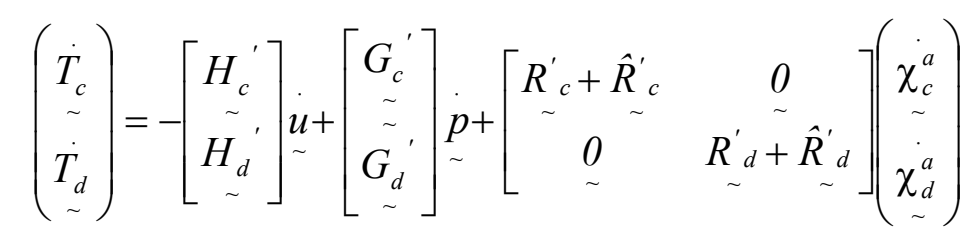

Ou ainda expressa na forma compacta como:

$$
\dot{T}=-H_{\sim}^{\prime} \underset{\sim}{u}+G_{\sim}^{\prime} \underset{\sim}{p}+\left(R_{\sim}^{\prime}+\hat{R}_{\sim}^{\prime}\right) \chi_{\sim}^{a}
$$

De forma análoga, as representações algébricas de chapas e placas com as parcelas inelásticas são tomadas como campos iniciais em deformações/curvaturas podem ser escritas como:

$$
\begin{aligned}
& \underset{\sim}{A \dot{y}}=\dot{f}+(\underset{\sim}{R+\hat{R}}) \dot{\chi}^{a} \\
& \underset{\sim}{\dot{T}}=-\boldsymbol{\sim}_{\sim}^{\prime} \underset{\sim}{\operatorname{y}}+f_{\sim}^{f^{\prime}}+\left(\underset{\sim}{R^{\prime}}+\hat{R}_{\sim}^{\prime}\right) \boldsymbol{\chi}_{\sim}^{a}
\end{aligned}
$$

Assim, os respectivos sistemas algébricos compactos das resultantes de tensões e momentos podem ser escritos substituindo-se (5.189) e (5.190):

$$
\dot{\sim}=\underset{\sim}{n}+\underset{\sim}{\underset{\sim}{\chi}{ }^{a}}
$$

onde:

$$
\underset{\sim}{Q}=\underset{\sim}{R^{\prime}}+j_{\sim}^{\prime}-A_{\sim}^{\prime} A_{\sim}^{-1}(\underset{\sim}{R}+\underset{\sim}{\hat{R}})\left(\underset{\sim}{R^{\prime}}+\underset{\sim}{\hat{R}^{\prime}}\right)
$$




\subsubsection{2) Problemas coplanares com multirregiões.}

Nas seções anteriores foram apresentadas as representações integrais e algébricas para os problemas de placa e chapa definidos em um domínio simples. Contudo, é muito freqüente o aparecimento de problemas compostos por várias regiões que possuem suas respectivas propriedades geométricas e/ou físicas. Adotando-se uma disposição de apresentação similar àquela utilizada para problemas simplesmente conectados; nas seções subseqüentes, são discutidos os sistemas resultantes das equações integrais dos deslocamentos e seus gradientes, das tensões/momentos em pontos de domínio.

Nesta seção é discutido um caso especial da estrutura coplanar formada por duas regiões com propriedades físicas e/ou geométricas distintas. $\mathrm{Na}$ figura 5.10, estão indicadas as duas regiões com seus respectivos domínios e contornos.

Utilizando-se a mesma estratégia discutida no capítulo anterior, de redefinir os contornos de interface como $\Gamma_{12}=\Gamma_{p}$ e $\Gamma_{2 l}=\Gamma_{p^{\prime}} \quad$ a representação algébrica da primeira região pode ser escrita como:

$$
\left[\begin{array}{cc}
H_{11} & H_{1 p} \\
\tilde{H}_{p 1} & \tilde{H}_{p p}^{\sim}
\end{array}\right]\left\{\begin{array}{c}
\dot{U}_{1} \\
\sim \\
\dot{U}_{p} \\
\sim
\end{array}\right\}=\left[\begin{array}{cc}
G_{11} & G_{1 p} \\
\sim & \sim \\
G_{p 1} & G_{p p} \\
\sim & \sim
\end{array}\right]\left\{\begin{array}{c}
\dot{P}_{1} \\
\sim \\
\dot{P}_{p} \\
\sim
\end{array}\right\}+\left[\begin{array}{cc}
D_{11} & D_{1 p} \\
\sim & \tilde{\sim} \\
D_{p 1} & D_{p p} \\
\sim & \sim
\end{array}\right]\left\{\begin{array}{c}
T_{1}^{a} \\
\sim \\
T_{p}^{. a} \\
\sim
\end{array}\right\}
$$

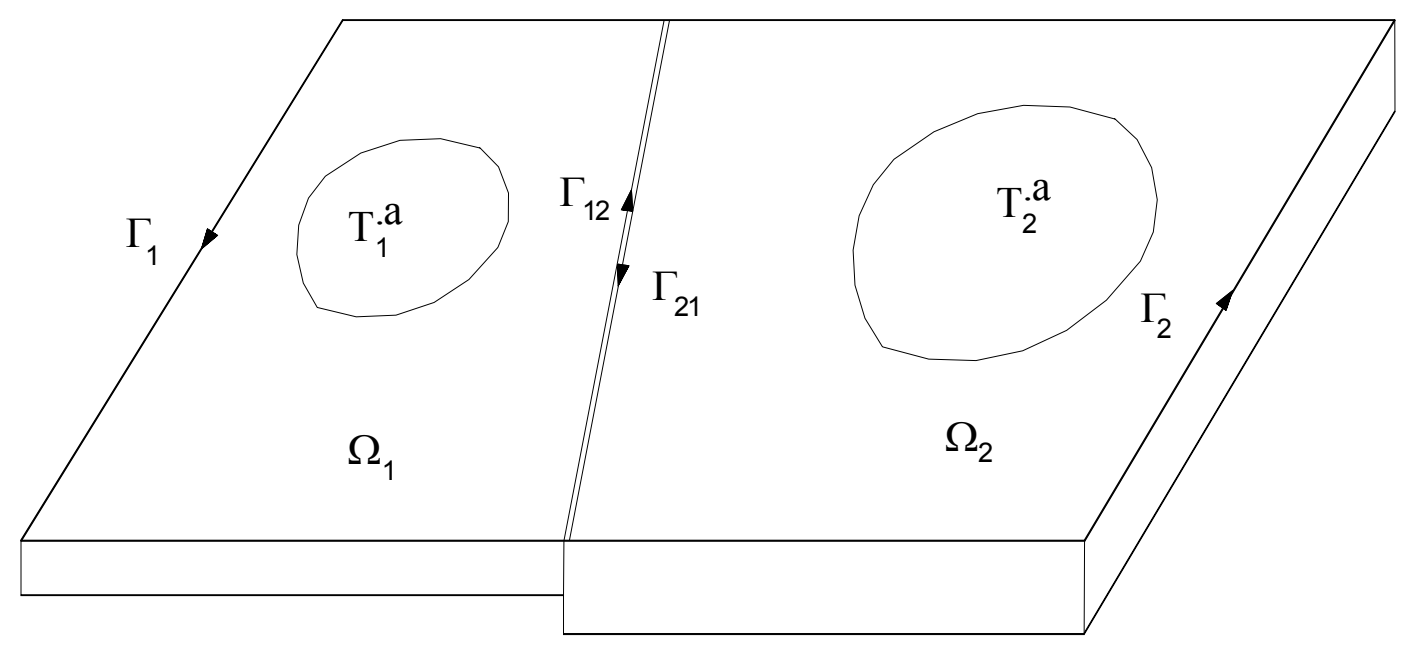

Figura 5.10- Duas regiões inelásticas coplanares. 
A segunda região tem sua representação escrita como:

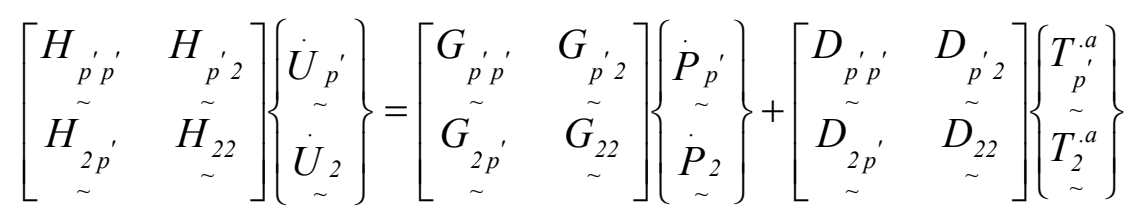

$\mathrm{Na}$ interface, tanto as equações de equilíbrio (forças e esforços verdadeiros) quanto as relações de compatibilidade (deslocamentos e rotações totais) fornecem uma relação adicional para as representações de ambas subregiões:

$$
\left(\begin{array}{c}
p \\
\dot{v}_{l} \\
\dot{v}_{2} \\
\dot{w}^{p} \\
\dot{\theta}_{p}^{p} \\
\dot{\theta}_{p} \\
\dot{\theta}_{t}^{p} \\
\dot{\theta}_{z}^{p}
\end{array}\right)=\left(\begin{array}{c}
p^{\prime} \\
\dot{v}_{1} \\
p^{\prime} \\
\dot{v}_{2} \\
p^{\prime} \\
w^{\prime} \\
\dot{\theta}_{p}^{p^{\prime}} \\
\dot{\theta}_{t}^{\prime} \\
\dot{\theta}^{\prime} \\
\dot{\theta}_{z}
\end{array}\right)
$$

$$
\begin{aligned}
& \left(\begin{array}{c}
{ }^{p} \\
t_{1} \\
p_{p} \\
t_{2} \\
\dot{V}_{n} \\
\dot{m}_{n} \\
m_{n}
\end{array}\right)=-\left(\begin{array}{c}
p^{\prime} \\
\dot{t}_{1} \\
p^{\prime} \\
t_{2} \\
p^{\prime} \\
\dot{V}_{n} \\
p^{\prime} \\
m_{n}
\end{array}\right) ; \\
& \left(\begin{array}{c}
\dot{p}^{p} \\
\chi_{1} \\
\dot{\chi}_{2}
\end{array}\right)=-\left(\begin{array}{c}
p^{\prime} \\
\chi_{1} \\
p^{\prime} \\
\chi_{2}
\end{array}\right)
\end{aligned}
$$

Assim, partir de (5.193) a (5.196), o sistema algébrico envolvendo ambas regiões pode ser escrito como: 


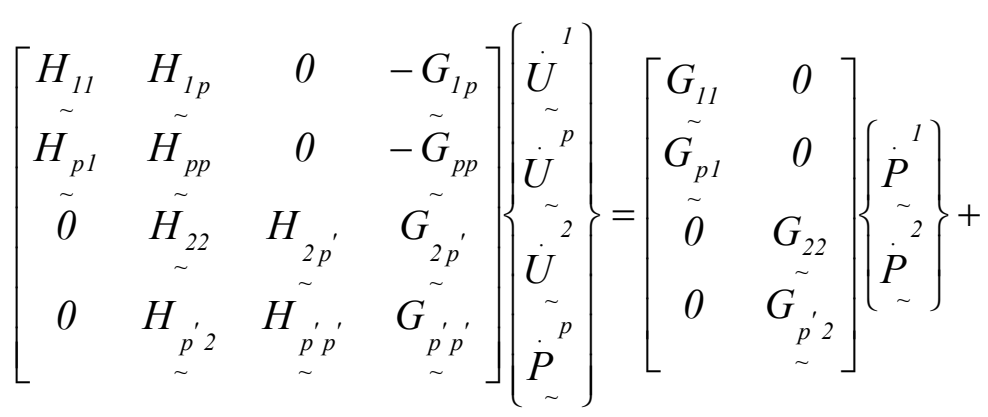

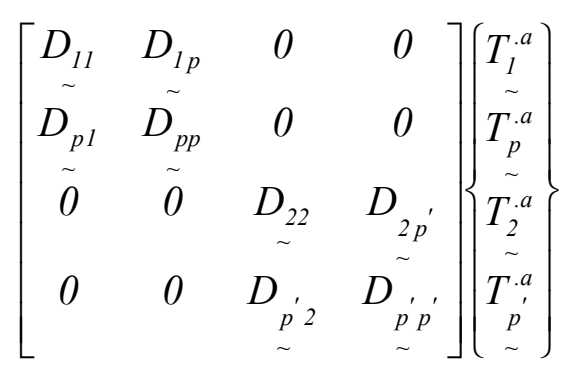

Ou ainda apresentada em forma compacta como:

$$
\overline{\bar{H}} \underset{\sim}{u}=\underset{\sim}{\bar{G}} \underset{\sim}{p}+(\underset{\sim}{\bar{D}}+\underset{\sim}{\overline{\hat{D}}}) \stackrel{\dot{\overline{T^{a}}}}{\sim}
$$

A representação algébrica para as tensões/momentos no domínio pode ser feita de maneira análoga ao caso do sistema algébrico para os deslocamentos e suas derivadas. Assim, após a imposição das condições de compatibilidade e de equilíbrio nas interfaces das regiões, o sistema algébrico pode ser escrito como:

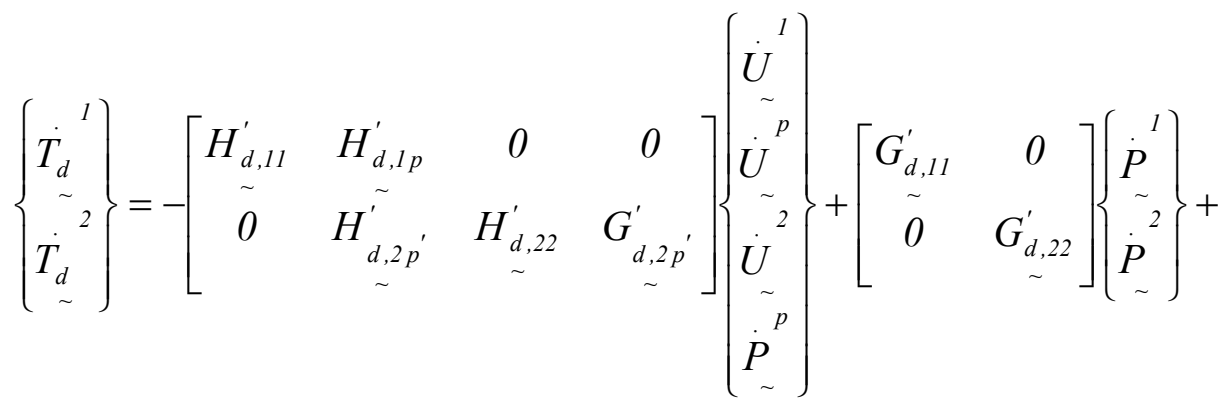

$$
\begin{aligned}
& {\left[\begin{array}{ccccc}
D_{d, 11}+\hat{D}_{d, 11} & D_{d, 1 p}+\hat{D}_{d, 1 p} & 0 & 0 \\
\sim & \sim & D_{d, 22}+\hat{D}_{d, 22} & D_{d, 2 p^{\prime}}+\hat{D}_{d, 2 p^{\prime}}
\end{array}\right]\left\{\begin{array}{c}
T_{d, 1}^{\cdot a} \\
\sim \\
T_{d, p}^{. a} \\
\sim \\
T_{d, 2}^{\cdot a} \\
\sim \\
T_{d, p^{\prime}}^{. a} \\
\sim
\end{array}\right\}}
\end{aligned}
$$


A representação algébrica para campos tensoriais no contorno pode ser expressa pelo acoplamento dos sistemas algébricos escritos independentemente para cada um dos contornos.

Inicialmente, para as representações dos campos tensoriais são empregadas as técnicas discutidas na seção 5.3.2.1.3, isto é: parte das componentes é obtida pela relações de Cauchy e as demais por intermédio da aplicação de diferenciações aos valores nodais dos graus de liberdade, isto é, representações algébricas similares às (5.158 a 5.169), para os pontos $p$ e $p^{\prime}$ de mesmas coordenadas da interface, vide figura 5.11 .

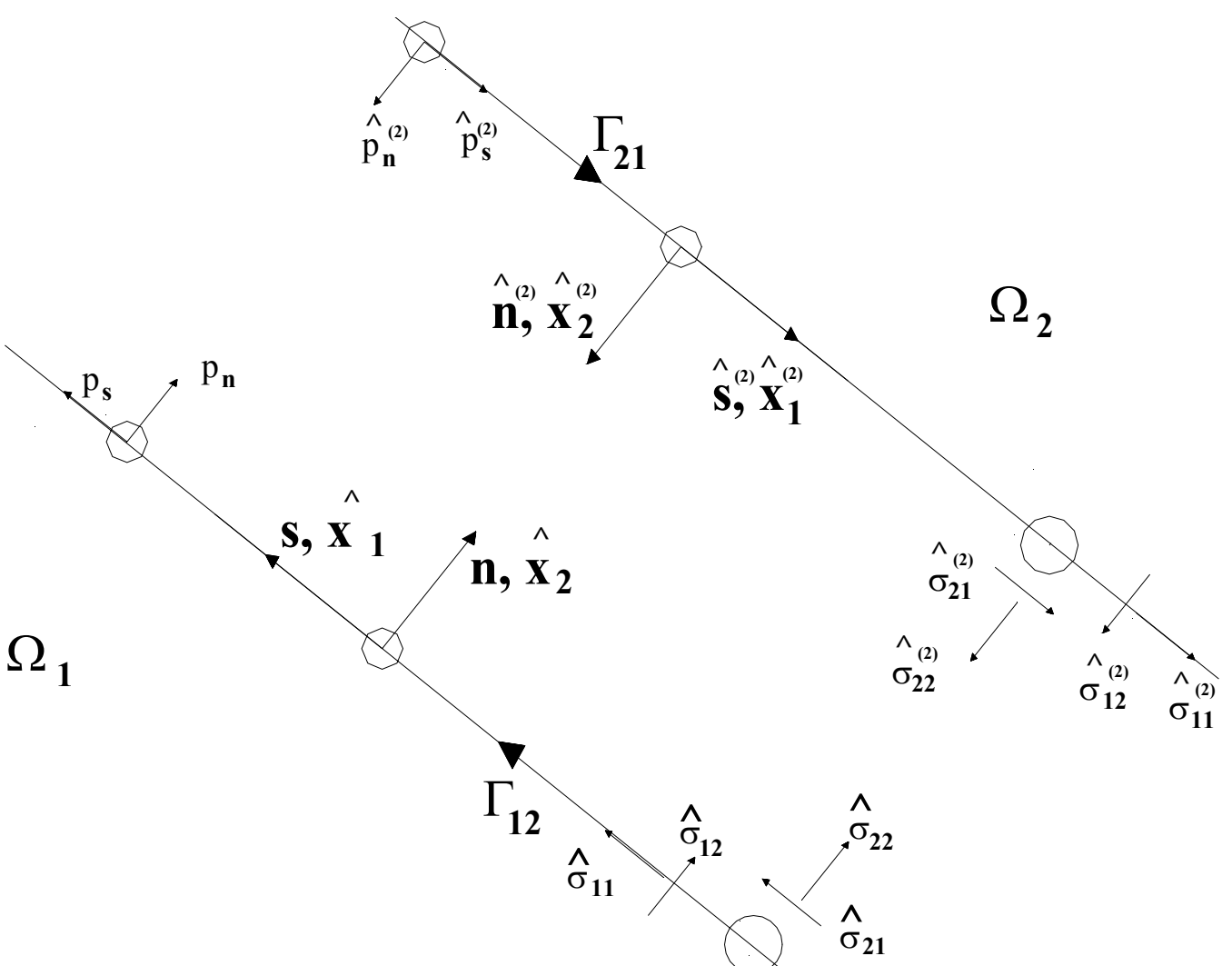

Figura 5.11- Sistemas locais em uma interface com duas regiões.

Em seguida, o acoplamento das regiões é feito utilizando-se as relações de equilíbrio e de compatibilidade nesses pontos. 


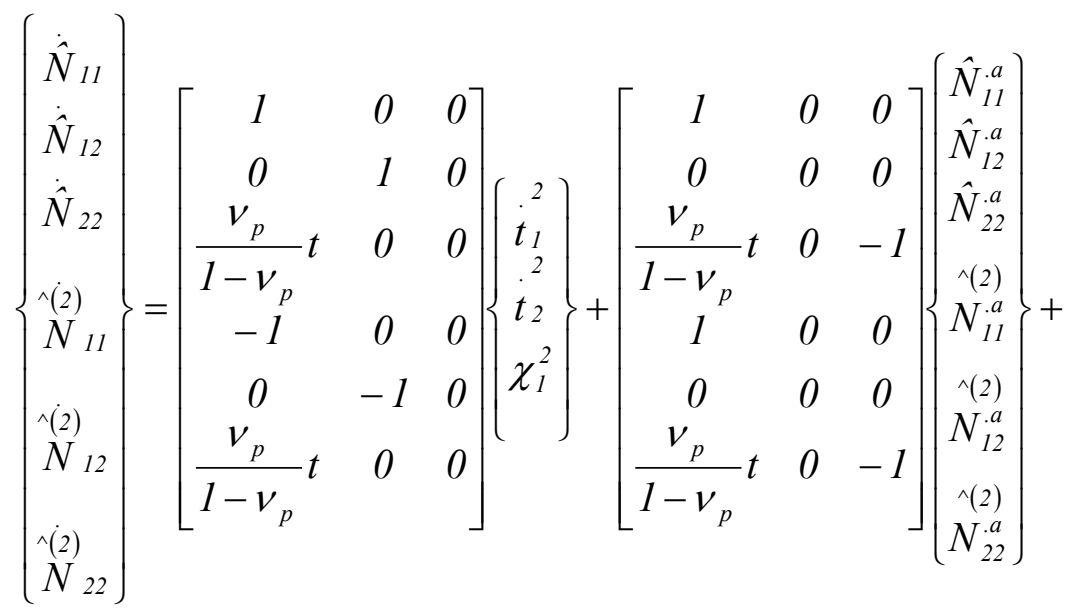

$$
\frac{2 G t}{1-v_{p}}\left(\frac{1}{L_{i}}+\frac{1}{L_{i+1}}\right)\left[\begin{array}{ccc}
1 & 0 & 0 \\
0 & 0 & 0 \\
0 & 0 & 0 \\
0 & 1 & 0 \\
0 & 0 & 0 \\
0 & 0 & 0
\end{array}\right]\left\{\begin{array}{c}
\dot{v}_{1}^{2} \\
\dot{v}_{2} \\
\dot{\theta}_{z} \\
v^{2}
\end{array}\right\}
$$

Analogamente, os momentos no contorno podem ser escritos como:

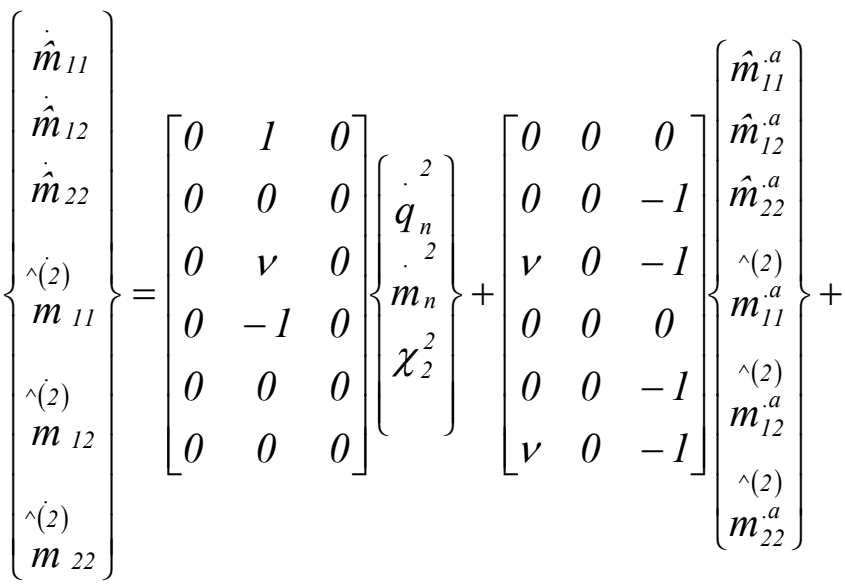

$$
\begin{aligned}
& D(1-v)\left(\frac{1}{L_{i}}+\frac{1}{L_{i+1}}\right)\left[\begin{array}{ccc}
0 & 0 & 0 \\
0 & 1 & 0 \\
0 & 0 & 1 \\
0 & 0 & 0 \\
0 & 1 & 0 \\
0 & 0 & 1
\end{array}\right]\left\{\begin{array}{l}
\dot{w}^{2} \\
\dot{\theta}_{p}^{2} \\
\dot{\theta}_{t}^{2}
\end{array}\right\}
\end{aligned}
$$

Após escrever as equações (5.200) e (5.201) para todos os nós do contorno, uma representação algébrica pode ser escrita como: 


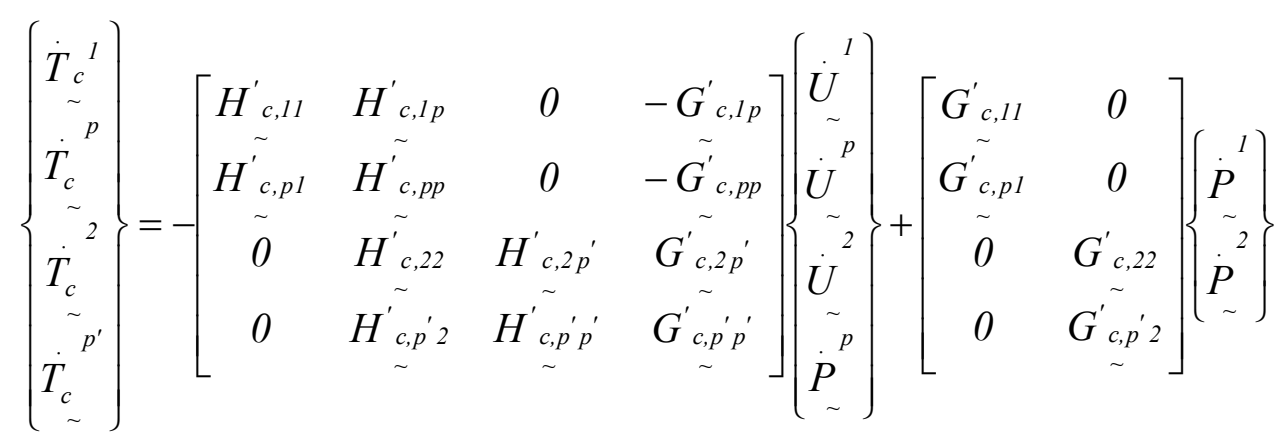

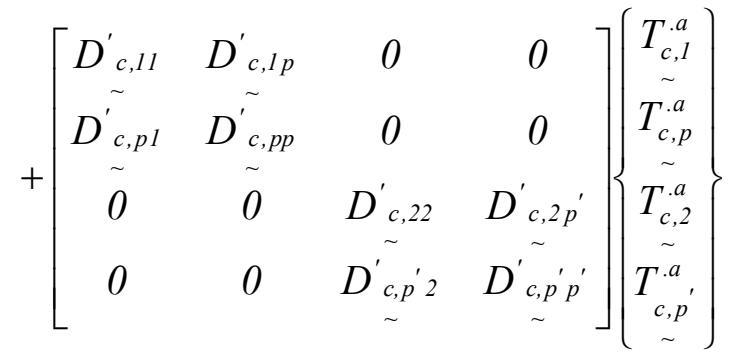

Ao reunir as representações das tensões/momentos do domínio e do contorno, uma forma compacta para elas pode ser escrita como:

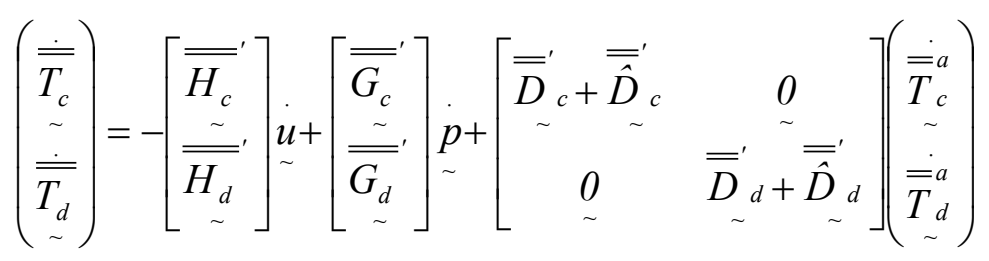

Ou ainda expressa na forma super compacta como:

$$
\underset{\sim}{\dot{\bar{T}}}=-\overline{\bar{H}}_{\sim} \underset{\sim}{u}+\overline{\bar{G}}_{\sim} \underset{\sim}{p}+\left(\overline{\bar{D}}_{\sim}+\overline{\hat{\bar{D}}}_{\sim}^{\prime}\right) \overline{\bar{T}}_{\sim}^{a}
$$

No sistema algébrico (5.204), devido ao número superior de equações em relação às variáveis reais, para os contornos simplesmente conectados, pode ser utilizada uma técnica análoga àquela discutida na seção 5.4.2 para as interfaces ligadas: a de inserção dos graus de liberdade fictícios $\chi_{1}$ e $\chi_{2}$ do vetor $P_{\sim}^{P}$. Com isso, após manipulações algébricas similares às mencionadas na seção anterior, o sistema algébrico dos deslocamentos de contorno pode ser expresso de maneira similar à (5.177), isto é:

$$
\stackrel{\overline{\bar{T}}}{=\overline{\bar{A}}^{\prime}} \dot{\mathrm{y}}+\dot{\mathrm{g}}+\overline{\bar{D}}_{\sim}^{\prime} \overline{\bar{\tau}}^{a}
$$


A partir da substituição de (5.198) em (5.205), tem-se a representação das tensões/momentos verdadeiros em função dos campos inelásticos analogamente à (5.178)

\subsubsection{2)Formulação Tetraparamétrica}

Nesta seção são apresentadas algumas adaptações na formulação hexaparamétrica (3 equações: chapas; 3 equações: placas) a fim de reduzi-la para quatro representações integrais por nó.

\subsubsection{1) Problemas com regiões simples}

Inicialmente, são discutidos os sistemas de equações obtidos das equações integrais dos deslocamentos e seus gradientes. Em seguida, o mesmo é feito para as equações integrais de tensões/momentos para pontos de domínio; finalizando-se a seção, tem-se a representação desses campos no contorno.

Assim, para representar os efeitos de chapa da formulação tetraparamétrica, são discretizadas apenas as equações integrais dos deslocamentos (5.23), (5.52) e (5.58), se o campo inelástico for tomado em tensões/momentos iniciais:

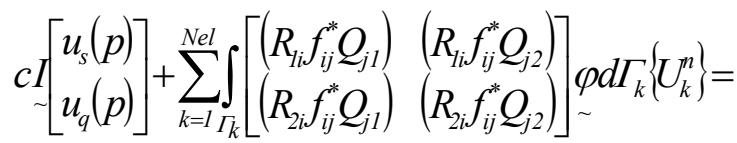

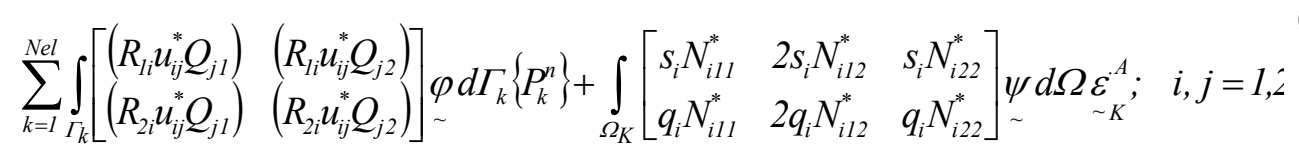

$$
\begin{gathered}
c I\left[\begin{array}{c}
w(p) \\
w_{, q}(p)
\end{array}\right]+\sum_{k=1}^{N e l} \int_{\Gamma_{k}}\left[\begin{array}{cc}
V_{n}^{*} & -m_{n}^{*} \\
V_{n, q}^{*} & -m_{n, q}^{*}
\end{array}\right] \varphi d \Gamma_{\sim}\left\{W_{k}^{n}\right\}+\sum_{k=1}^{N c}\left[\begin{array}{c}
R_{c k}^{*} \\
R_{c k, q}^{*}
\end{array}\right] W_{k}= \\
\sum_{k=1}^{N e l} \int_{\Gamma_{k}}\left[\begin{array}{cc}
w^{*} & -\theta_{p}^{*} \\
w_{, q}^{*} & -\theta_{p, q}^{*}
\end{array}\right] \varphi d \Gamma_{\sim}\left\{V_{k}^{n}\right\}+\sum_{k=1}^{N_{c}}\left[\begin{array}{c}
w^{*} \\
w_{, q}^{*}
\end{array}\right] R_{c k}+\int_{\Omega_{k}}\left[\begin{array}{ccc}
m_{11}^{*} & 2 m_{12}^{*} & m_{22}^{*} \\
q_{i} m_{11, i}^{*} & 2 q_{i} m_{11, i}^{*} & q_{i} m_{22, i}^{*}
\end{array}\right] \psi \sim \underset{\sim}{\sim} \chi_{i}
\end{gathered}
$$

onde $I$ é a matriz identidade; $c$ é o termo livre de integral que recebe o valor unitário para pontos-fonte no domínio. Em contornos suaves, seu valor é $c=1 / 2 \mathrm{e}$, em 
formulações regulares, recebe valor nulo. $s_{i}, q_{i}$ são os co-senos diretores das direções tangencial e normal ao contorno no ponto de colocação.

As representações integrais discretizadas para as resultantes de tensões e momentos no modelo TP podem ser escritas como em (5.110) e (5.111), bastando ajustar os valores dos kernels $\left(\mu \alpha_{n, i j}^{*}\right.$ e $\left.\mu \beta_{n, i j}^{*}\right)$ em (5.116) para a representação de Rayleigh-Green.

Assim, no problema de campos iniciais em tensões/momentos onde a colocação é feita no contorno, as contribuições de um j-ésimo elemento da representação algébrica - deslocamentos em chapas e deslocamentos transversais e suas derivadas direcionais em placas- podem ser escritas respectivamente como:

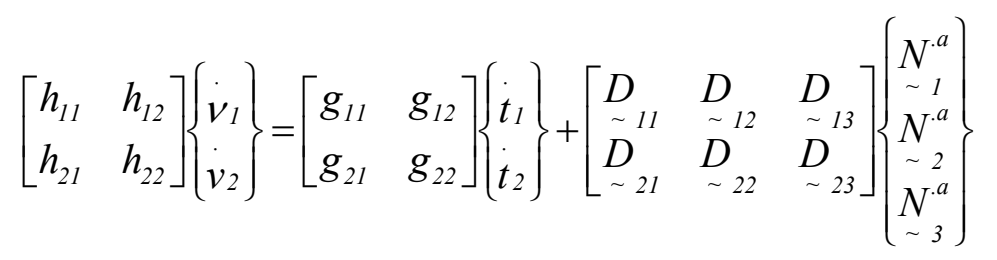

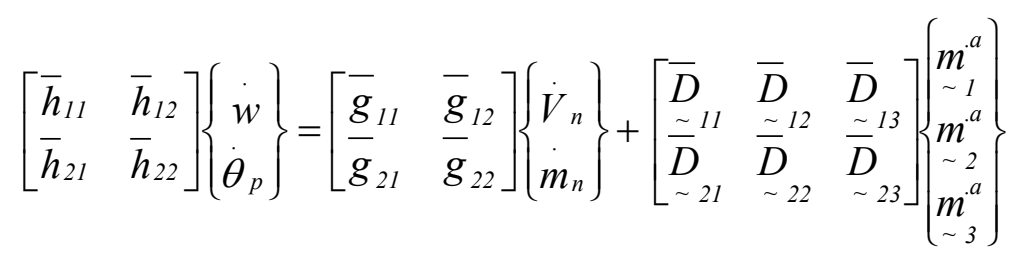

onde $D_{i j}, \bar{D}_{i j}$ são as submatrizes em que os índices $i, j$ estão associados respectivamente à linha da representação integral e ao número do nó $j$ da célula; os vetores $N_{k}^{a}, m_{k}^{a}$ contêm as componentes das tensões/momentos inelásticas do nó $k$ da célula.

As contribuições de um j-ésimo elemento das representações algébricas das tensões e momentos reais, em que o campo inelástico é tomado em tensão/momento inicial e a colocação dos pontos-fonte no domínio, para a formulação tetraparamétrica podem ser escritas a partir da discretização de (5.41) e (5.73):

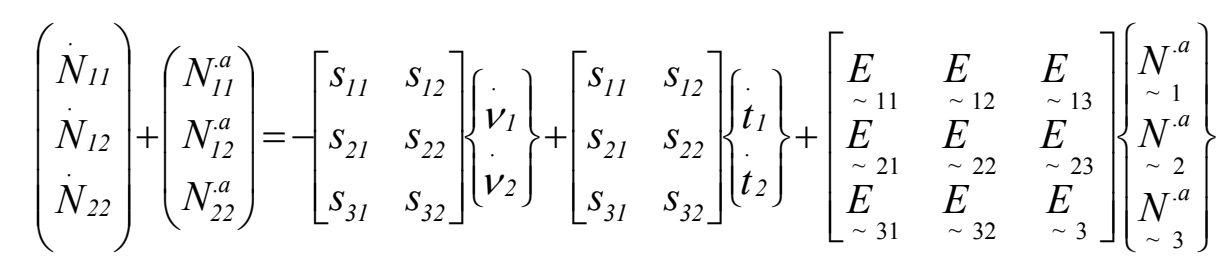




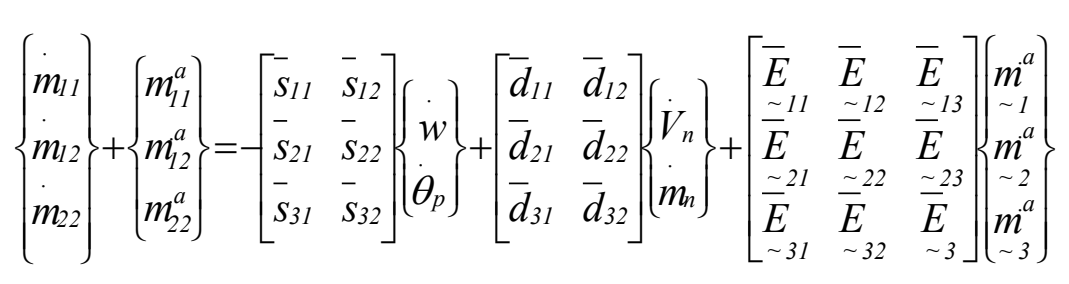

Após a colocação do ponto-fonte nos pontos de domínio e após a incorporação das contribuições de todos os elementos e células, tem-se uma representação análoga à (5.157). Para a determinação dos momentos no contorno pode ser utilizada uma técnica similar à discutida na seção (5.3.2.1.1). Assim, as componentes podem ser escritas tais quais em (5.163), (5.164) e (5.168). Contudo, para o cálculo de parte das rotações e curvaturas, há necessidade de fazer algumas adaptações no procedimento descrito em (5.166), (5.167) e (5.168). Assim, a definição das rotações pode ser escrita como:

$$
\dot{\hat{w}}_{, 2}=\dot{\theta}_{p}
$$

Convém ressaltar que (5.212) é idêntica a uma das relações descritas em (5.166) e com isso, a curvatura $\dot{\hat{w}}_{22}$ pode também ser escrita tal qual em (5.169). Contudo, para o cálculo da curvatura $\dot{\hat{w}}_{, 11}$ é necessário utilizar uma dupla diferenciação do valor nodal dos deslocamentos:

$$
\dot{\hat{w}}_{, 11}=\frac{\partial}{\partial \hat{x}_{1}}\left(\dot{\hat{w}}_{, 1}\right)=\frac{\partial}{\partial \hat{x}_{1}} \frac{\partial}{\partial \hat{x}_{1}} \dot{w}=\frac{\partial^{2}}{\partial \hat{x}_{1}^{2}}\left[\phi_{i} \dot{w}\right] ; i=1,2, \cdots, n
$$

Assim, a ordem mínima da função interpoladora a ser empregada é uma quadrática, isto é , $n=2$. Assim, é utilizada a aproximação de segundo grau para os deslocamentos transversais apenas para o cálculo por diferenças finitas dos momentos no contorno na formulação TP.

Desta forma, as representações (5.213) devem ser ajustadas para este caso:

$$
\dot{\hat{w}}_{, 11}=\frac{\partial^{2}}{\partial \hat{x}_{1}^{2}}\left[\phi_{1}(s) \dot{\theta}_{t}^{l}+\phi_{2}(s) \dot{\theta}_{t}^{2}+\phi_{3}(s) \dot{\theta}_{t}^{3}\right]
$$

Ou expressa em coordenadas adimensionais como:

$$
\dot{\hat{w}}_{, 11}=\frac{1}{L^{2}}\left[\dot{\theta}_{p}^{1} \frac{\partial^{2}}{\partial \xi^{2}} \phi_{1}(\xi)+\dot{\theta}_{p}^{2} \frac{\partial^{2}}{\partial \xi^{2}} \phi_{2}(\xi)+\dot{\theta}_{p}^{3} \frac{\partial^{2}}{\partial \xi^{2}} \phi_{3}(\xi)\right]
$$

onde as funções interpoladoras quadráticas podem ser expressas por: 


$$
\phi_{1}(\xi)=\frac{1}{2} \xi(\xi-1) ; \phi_{2}(\xi)=1-\xi^{2} ; \phi_{3}(\xi)=\frac{1}{2} \xi(\xi+1)
$$

Para o efeito de chapas, as tensões no contorno podem ser obtidas similarmente ao descrito na seção (5.3.2.1.1). Convém ressaltar que para componente $\dot{\hat{\varepsilon}}_{22}$, é utilizada uma interpolação linear para os deslocamentos pode ser de primeiro grau conduzindo a uma representação idêntica (5.171). Já para os momentos no contorno, a partir de (5.215) e (5.88) a seguinte relação pode ser escrita:

$$
\begin{gathered}
\left\{\begin{array}{l}
\dot{\hat{m}}_{11} \\
\dot{\hat{m}}_{12} \\
\dot{\hat{m}}_{22}
\end{array}\right\}=\left[\begin{array}{ll}
0 & 1 \\
0 & 0 \\
0 & v
\end{array}\right]\left\{\begin{array}{l}
\dot{V}_{n} \\
\dot{m}_{n}
\end{array}\right\}+\left[\begin{array}{ccc}
0 & 0 & 0 \\
0 & 0 & -1 \\
v & 0 & -1
\end{array}\right]\left\{\begin{array}{l}
\hat{m}_{11}^{a} \\
\hat{m}_{12}^{a} \\
\hat{m}_{22}^{\cdot a}
\end{array}\right\}+ \\
\frac{D(1-v)}{L_{i}}\left[\begin{array}{cccccc}
0 & 0 & 0 & 0 & 0 & 0 \\
0 & A_{1} & 0 & A_{2} & 0 & A_{3} \\
B_{1} & 0 & B_{2} & 0 & B_{3} & 0
\end{array}\right]\left\{\begin{array}{c}
\dot{w}^{1} \\
\dot{\theta}_{p}^{1} \\
\dot{w}_{2} \\
\dot{\theta}_{p} \\
3 \\
w_{3} \\
\dot{\theta}_{p}
\end{array}\right\}
\end{gathered}
$$

onde $A_{i}=\frac{\partial}{\partial \xi}\left[\phi_{i}(\xi)\right]$ e $B_{i}=\frac{\partial^{2}}{\partial \xi^{2}}\left[\phi_{i}(\xi)\right]$.

Conforme pode ser observado nas equações (5.208) a (5.211), os números de graus de liberdade associados aos deslocamentos e às forças são idênticos, dispensando, portanto, na abordagem tetraparamétrica, a técnica de inserção de variáveis fictícias empregada na formulação hexaparamétrica.

\subsubsection{2) Problemas coplanares multiconectados}

As adaptações utilizadas nos problemas de domínio simples podem ser estendidas para os casos coplanares multiconectados. 


\section{REPRESENTAÇÃO ALGÉBRICA PARA PROBLEMAS ELASTOPLÁSTICOS}

\section{1)Introdução}

As representações integrais para problemas inelásticos, discutidas no capítulo anterior, são direcionadas para o estudo de problemas elastoplásticos. Inicialmente, são apresentados os conceitos básicos da plasticidade clássica e, em seguida, parte-se para a obtenção da representação algébrica. E, por fim, é discutida a aplicação de um algoritmo incremental-iterativo para a resolução do sistema de equações não-lineares representativo do problema.

\section{2)Conceitos básicos da plasticidade}

Nesta seção, são introduzidas noções de alguns princípios básicos da teoria da plasticidade clássica, que serão utilizados na representação de alguns problemas com comportamento fisicamente não-linear.

As décadas de 1930 e 1950 foram alguns dos períodos mais intensivos, em que os conceitos e hipóteses básicas da então chamada teoria da plasticidade clássica de metais foram concebidos. A partir de observações experimentais, os pesquisadores admitiram algumas hipóteses para a deformação plástica, que podem ser descritas como:

a)a deformação plástica está associada com a dissipação de energia, de forma que o campo relativo a essa deformação é irreversível;

b)devido ao caráter dissipativo, o processo de deformação plástica é dependente da história do carregamento;

c)a deformação plástica é assumida como independente do tempo, isto é, os efeitos viscosos são desprezados durante a ocorrência do fluxo plástico.

No desenvolvimento das equações constitutivas da plasticidade clássica, têm sido usadas, principalmente, duas abordagens: a primeira é a então chamada teoria de deformação, cuja característica principal é a relação total entre as deformações e as tensões $f\left(\sigma_{i j}\right)=\varepsilon_{i j}^{p}$. Contudo essa teoria é restrita aos casos de carregamento proporcional. A segunda abordagem para a reologia do problema é a chamada teoria incremental, cujo conceito principal está fundamentado na relação dos incrementos de deformação plástica $d \varepsilon_{i j}^{p}$ com o estado de tensão $\sigma_{i j}$ e com seus incrementos 
$d \sigma_{i j}$. À teoria incremental da plasticidade, há um sistema algébrico constituído por equações não-lineares associado. Para esse sistema, uma das técnicas utilizadas na solução é subdividir o problema em vários estágios e resolver cada um deles como se fosse linear. Assim, na teoria incremental, o algoritmo de solução do sistema já é montado diretamente na filosofia incremental, e, em geral, envolvendo processos iterativos.

Um dos aspectos importantes na plasticidade é a descrição da então conhecida superfície de carregamento, que pode ser entendida como a superfície de escoamento subseqüente para um material deformado elastoplasticamente, que define o contorno da corrente região elástica. Se o valor da tensão estiver dentro do campo definido por essa região, nenhuma deformação plástica ocorrerá. Em contrapartida, se o estado de tensões estiver no contorno da região elástica e tender a mover-se para fora da corrente superfície de carregamento, deformações adicionais ocorrerão acompanhadas pela mudança de forma dessa superfície. Assim, a função para a superfície de escoamento pode ser escrita em termos de variáveis referentes ao corrente estado de tensões e a um parâmetro $\kappa$ da resposta pós-escoamento, isto é:

$$
f\left(\sigma_{i j}, \kappa\right)=0, i, j=1,2,3
$$

ou escrito de uma maneira alternativa como:

$$
f\left(\sigma_{i j}, \kappa\right)=F\left(\sigma_{i j}\right)-\kappa^{2}\left(\bar{\varepsilon}_{p}\right), i, j=1,2,3
$$

onde $F\left(\sigma_{i j}\right)$ e $\kappa^{2}\left(\bar{\varepsilon}_{p}\right)$ definem, respectivamente, a forma e o tamanho da superfície de carregamento. $\bar{\varepsilon}_{p}$ é a denominada deformação efetiva, que depende da história do carregamento.

Uma das tarefas árduas da plasticidade é modelar o comportamento da resposta pós-escoamento do material, chamada de lei de encruamento, em que é descrita a evolução das superfícies de carregamento. Diversas abordagens para esse problema já foram propostas por investigadores, contudo as mais difundidas na literatura são aqueles modelos conhecidos como: encruamento isótropo, encruamento cinemático e encruamento misto. Este último consiste na combinação dos dois primeiros. 
Inicialmente, será discutido o modelo do encruamento isótropo. A característica principal dessa abordagem é que a superfície expande igualmente em todas direções, contudo sem sofrer distorções e translações. Por simplicidade, a evolução das superfícies de problemas unidimensionais está ilustrada na figura 6.1.

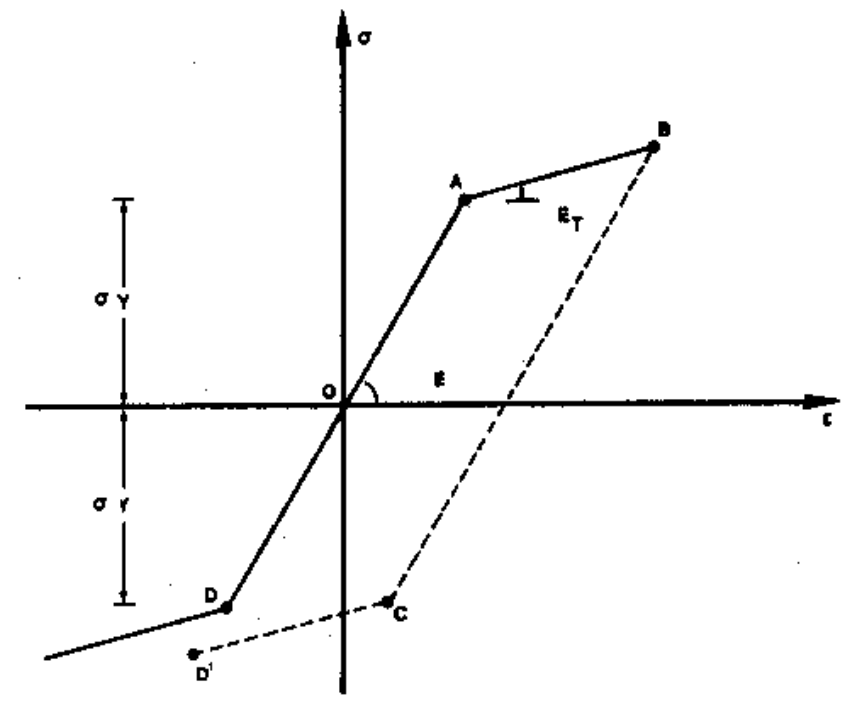

Figura 6.1- Modelo isótropo (caso uniaxial)- TELLES(1981).

Para o caso particular em que a superfície de carregamento sofre uma expansão uniforme, diz-se que o material é elastoplasticamente perfeito(figura 6.2), isto é:

$$
\kappa^{2}\left(\bar{\varepsilon}_{p}\right)=\rho
$$

onde $\rho$ é uma constante.

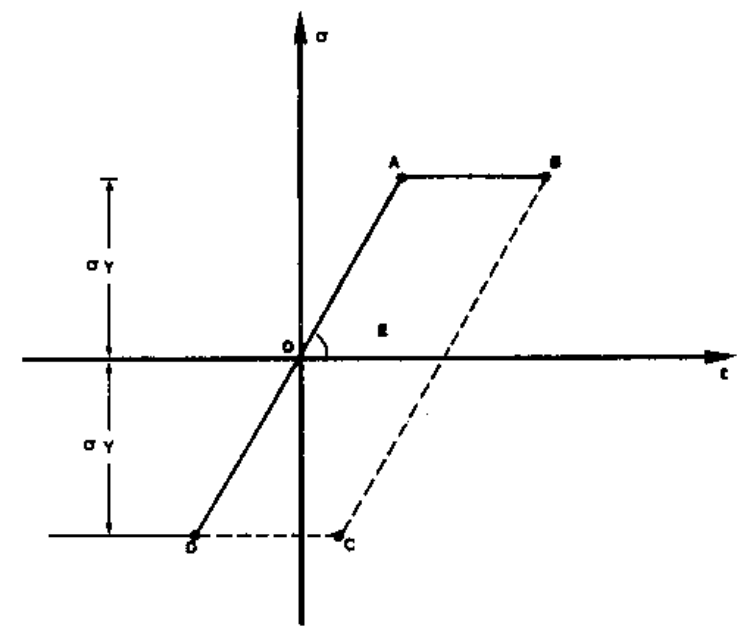

Figura 6.2- Modelo isótropo uniaxial (elastoplástico perfeito)-TELLES(1981). 
Embora o modelo de encruamento isótropo seja atraente devido à sua simplicidade, sua resposta é mais adequada para problemas submetidos a carregamentos monotônicos. Essa restrição foi explicada por meio de observações experimentais de materiais sob ações cíclicas, de forma que se verificou que as deformações plásticas induziam uma anisotropia direcional em materiais inicialmente isótropos, isto é, a deformação plástica inicial atuante em um determinado sentido reduzia a resistência do material em relação à deformação plástica subseqüente de sentido oposto. Em outras palavras, se a deformação plástica corrente for de tração, a superfície de carregamento posterior de compressão terá seu tamanho reduzido. Essa perturbação na reologia do material é chamada de efeito Bauschinger. Esse fenômeno não é contemplado pelo modelo isótropo, uma vez que ele prevê uma expansão das superfícies de tração e compressão de tamanhos equalitários.

Assim, outros modelos para a lei de encruamento foram propostos, dentre os quais, consta o encruamento cinemático. Nessa abordagem, é assumido que durante o processo de deformação plástica, a superfície de carregamento translada como corpo rígido no espaço das tensões, mantendo tamanho, forma e orientação da superfície de escoamento inicial, (vide figura 6.3).

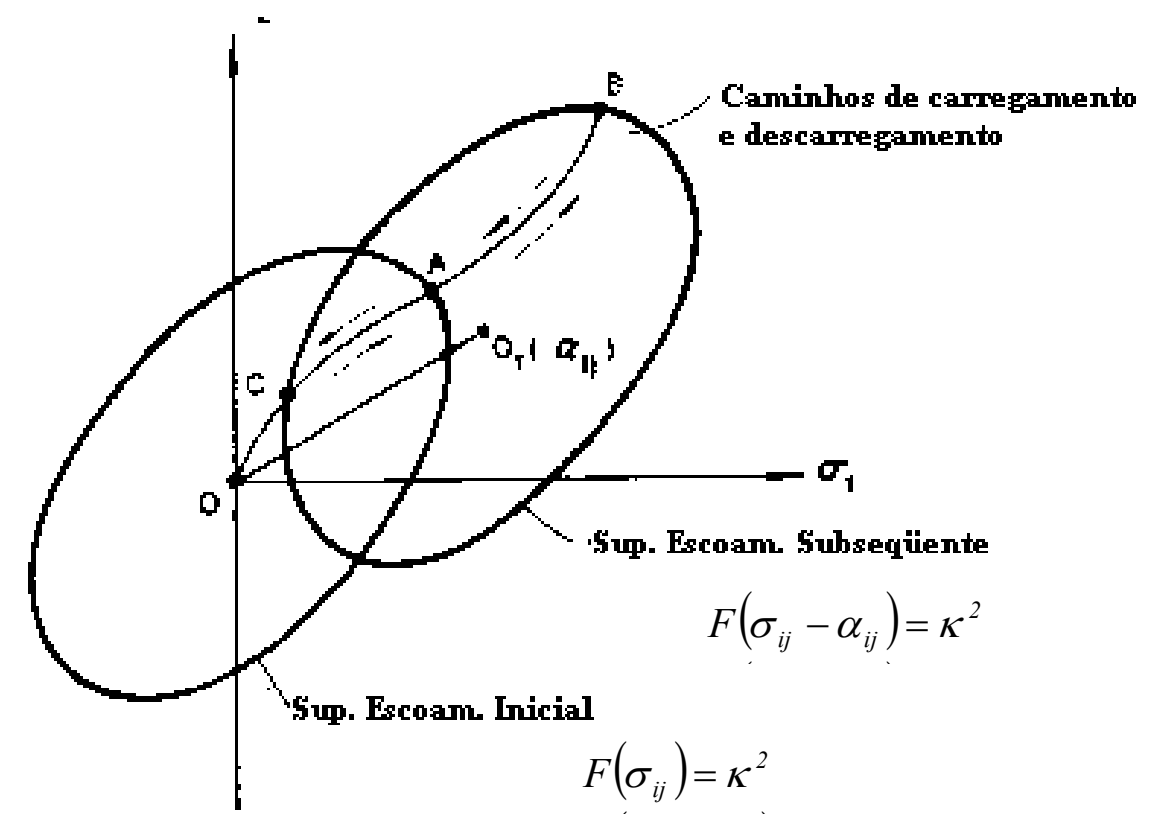

Figura 6.3- Modelo Cinemático -CHEN \& HAN(1988). 
Para o encruamento cinemático, a função da superfície de carregamento pode ser escrita como:

$$
f\left(\sigma_{i j}, \alpha_{i j}\right)=F\left(\sigma_{i j}-\alpha_{i j}\right)-\chi^{2}=0, i, j=1,2,3
$$

onde $\alpha_{i j}$ é a coordenada do centro da superfície de carregamento, que varia em termos da deformação plástica e $\chi$ é uma constante.

Assim, no modelo cinemático, uma etapa importante é a descrição da trajetória de $\alpha_{i j}$. Um dos modelos desenvolvidos para esse fim é a então conhecida lei de encruamento de Prager. Nessa abordagem, foi proposto que os acréscimos das coordenadas do centro da superfície de carregamento $d \alpha_{i j}$ são proporcionais aos acréscimos de deformação plástica, isto é:

$$
d \alpha_{i j}=c d \varepsilon_{i j}^{p}, i, j=1,2,3
$$

Contudo algumas inconsistências podem ser observadas no modelo de Prager, principalmente, quando usado no espaço das tensões. Por exemplo, seja o espaço das tensões composto por $\left(\sigma_{i j}^{\prime}+\sigma_{i j}^{\prime \prime}\right)$. Se parte das componentes das tensões é arbitrariamente tomada como nula $\sigma_{i j}^{\prime \prime}=0$ em (6.4), a nova superfície de carregamento pode ser escrita como:

$$
F\left(\sigma_{i j}^{\prime}-\alpha_{i j}^{\prime}-\alpha_{i j}^{\prime \prime}\right)-\chi^{2}=0, i, j=1,2,3
$$

Desde que $d \alpha_{i j}^{\prime \prime}=c d \varepsilon_{i j}^{p}$ não seja necessariamente nulo, a superfície indicada em (6.6) não está necessariamente restrita à translação pura, portanto não mais satisfazendo completamente as hipóteses do encruamento cinemático.

Assim, ZIEGLER(1959) propôs algumas modificações no modelo de Prager, de forma que se passou a admitir que a translação do centro da superfície de carregamento ocorreria segundo as direções de um vetor de tensão reduzida $\bar{\sigma}_{i j}=\sigma_{i j}-\alpha_{i j}$. Desse modo, a lei de encruamento modificada foi escrita na forma:

$$
d \alpha_{i j}=\left(\sigma_{i j}-\alpha_{i j}\right) d \mu, \quad i, j=1,2,3
$$

onde $d \mu$ é um coeficiente de proporcionalidade, que depende do histórico de deformação plástica. 
O terceiro modelo amplamente difundido na literatura é a abordagem de encruamento misto. Nesse modelo, a superfície translada e expande, isto é, há uma combinação do isótropo e do cinemático(figura 6.4).

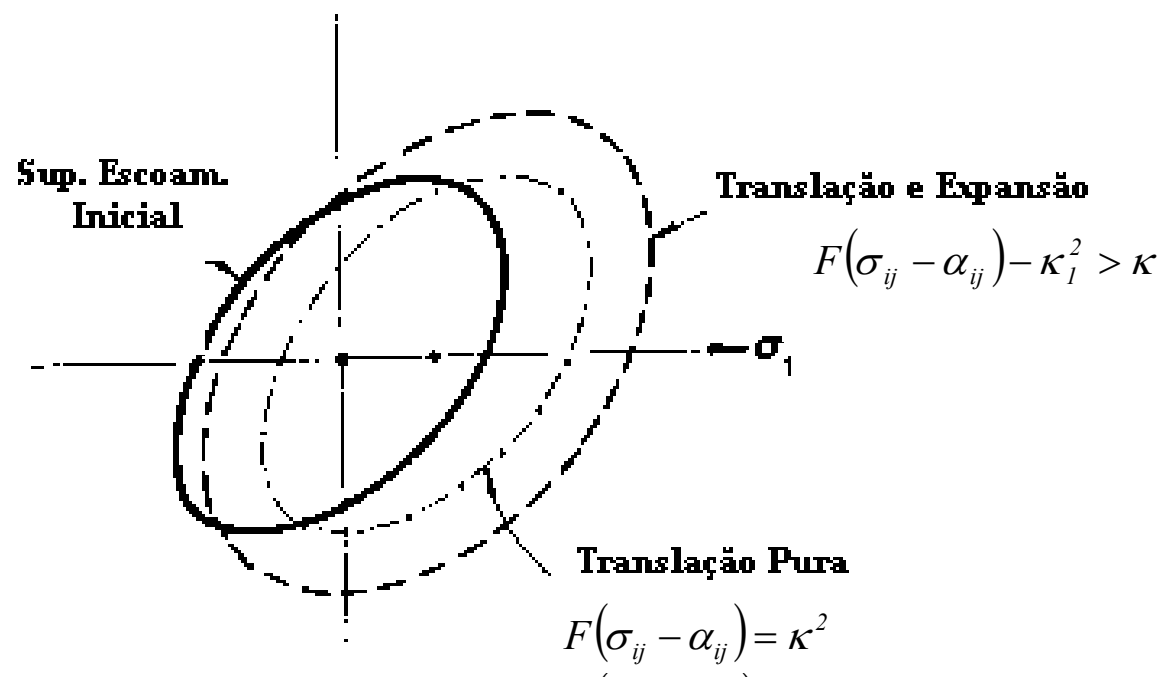

Figura 6.4- Modelo misto - CHEN \& HAN(1988).

Assim, a função da superfície de carregamento pode ser escrita como:

$$
f\left(\sigma_{i j}, k\right)=F\left(\sigma_{i j}-\alpha_{i j}\right)-\kappa^{2}\left(\bar{\varepsilon}_{p}\right)=0, i, j=1,2,3
$$

Outra etapa importante da teoria incremental na plasticidade é a definição da lei de fluxo. A energia potencial elástica $W$ e a deformação elástica $d \varepsilon_{i j}^{e}$ tem por definição a seguinte relação sob uma transformação isotérmica:

$$
d \varepsilon_{i j}^{e}=\frac{\partial}{\partial \sigma_{i j}}(W) d \sigma_{i j}, \quad i, j=1,2,3
$$

Em 1928, von Mises introduziu o conceito da lei de fluxo a partir de uma analogia de (6.9), de forma que as deformações plásticas podem ser obtidas a partir da energia potencial plástica $g$, isto é:

$$
d \varepsilon_{i j}^{p}=d \lambda \frac{\partial}{\partial \sigma_{i j}} g, \quad i, j=1,2,3
$$

onde $d \lambda$ é o então conhecido fator de proporcionalidade.

$\mathrm{Na}$ literatura, as leis de fluxo são apresentadas seguindo basicamente dois conceitos: os associativos e os não-associativos. Os primeiros são definidos de forma que a função da superfície de carregamento é tomada como a energia potencial plástica. 
A modelagem do estado de tensões multiaxiais não é uma tarefa fácil. Assim, em geral, parte-se para uma abordagem alternativa, em que os problemas definidos em espaços de dimensões superiores podem ser analisados a partir de ensaios uniaxiais. Assim, definiu-se um par de tensores conhecidos como deformação plástica efetiva $\bar{\varepsilon}_{p}$ e tensão efetiva $\bar{\sigma}_{e}$. O primeiro campo efetivo pode ser expresso por:

$$
d \bar{\varepsilon}_{p}=C \sqrt{d \varepsilon_{i j}^{p} d \varepsilon_{i j}^{p}}, i, j=1,2,3
$$

onde o parâmetro $C$ depende do modelo utilizado para a superfície de carregamento.

A tensão efetiva é definida, em geral, utilizando-se a função de forma da superfície de carregamento isto é:

$$
F\left(\sigma_{i j}\right)=C \bar{\sigma}_{e}, i, j=1,2,3
$$

Além disso, o trabalho plástico por unidade de volume é expresso por:

$$
d w_{p}=\bar{\sigma}_{e} d \bar{\varepsilon}_{p}
$$

e, por definição, o incremento de trabalho plástico é dado por:

$$
d w_{p}=\sigma_{i j} d \varepsilon_{i j}^{p}, \quad i, j=1,2,3
$$

A relação tensão-deformação efetiva é calibrada no ensaio de tensão uniaxial utilizando-se a expressão:

$$
d \bar{\sigma}_{e}=H d \bar{\varepsilon}_{p}
$$

ou

$$
\frac{d \bar{\sigma}_{e}}{d \bar{\varepsilon}_{p}}=H, i, j=1,2,3
$$

onde $H$ é a inclinação da curva do diagrama tensão-deformação uniaxial do valor corrente de $\bar{\sigma}_{e}$.

\subsection{1)Relações tensão-deformação incremental}

Inicialmente, serão discutidas as relações incrementais para materiais modelados segundo a abordagem do encruamento isótropo e também com as deformações plásticas tomadas como campo inicial. Assim, conforme discutido no 
capítulo anterior, as relações constitutivas para problemas com deformações iniciais podem ser escritas como:

$$
d \sigma_{i j}=C_{i j k l}\left(d \varepsilon_{k l}-d \varepsilon_{k l}^{p}\right), i, j, k, l=1,2,3
$$

Além disso, se for substituída a lei de fluxo(6.10) em (6.17), uma forma alternativa para relações constitutivas incrementais pode ser escrita como:

$$
d \sigma_{i j}=C_{i j k l}\left(d \varepsilon_{k l}-d \lambda a_{k l}\right), i, j, k, l=1,2,3
$$

onde $a_{k l}=\frac{\partial g}{\partial \sigma_{k l}}$.

A diferencial total da função da superfície de escoamento $f\left(\sigma_{i j}, \kappa\right)=0$ pode ser escrita como:

$$
d f=\frac{\partial f}{\partial \sigma_{i j}} d \sigma_{i j}+\frac{\partial f}{\partial \kappa} d \kappa=0, i, j=1,2,3
$$

A relação expressa em (6.19) é conhecida como condição de consistência, que assegura que no processo de carregamento, as tensões e os estados de deformações permanecem na superfície de escoamento subseqüente.

Dentre os modelos que relacionam as deformações plásticas com o parâmetro de encruamento, têm-se as abordagens então chamadas de encruamento por deformação e encruamento por trabalho. A relação da primeira é definida por :

$$
\kappa=\bar{\varepsilon}_{p}=\int d \bar{\varepsilon}_{p}
$$

Já o encruamento por trabalho tem sua lei, por definição, escrita como:

$$
\kappa=w_{p}=\int \sigma_{i j} d \varepsilon_{i j}^{p}, i, j=1,2,3
$$

Assim, o incremento de encruamento pode ser escrito a partir de (6.11), (6.20) e de (6.21), isto é:

$$
d \kappa=\beta d \lambda \sqrt{a_{i j} a_{i j}}, i, j=1,2,3
$$

com,

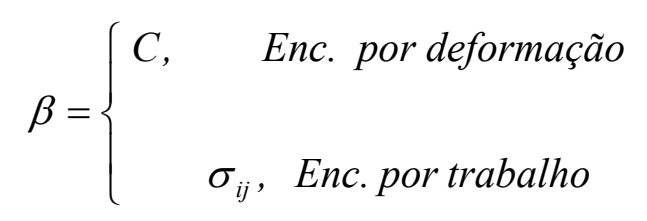


Substituindo-se a lei de fluxo(6.10), a relação constitutiva(6.18) na equação de consistência (6.19), vem:

$$
d f=b_{i j} C_{i j k l} d \varepsilon_{k l}-h d \lambda, i, j, k, l=1,2,3
$$

onde

$$
h=b_{i j} C_{i j k l} a_{k l}-\frac{\partial f}{\partial \kappa} \beta \sqrt{a_{i j} a_{i j}}, i, j, k, l=1,2,3
$$

$\mathrm{e}$

$$
b_{i j}=\frac{\partial f}{\partial \sigma_{i j}}, \quad i, j=1,2,3
$$

Assim, o escalar $d \lambda$ pode ser isolado na expressão (6.23), isto é:

$$
d \lambda=\frac{1}{h} b_{m n} C_{m n s t} d \varepsilon_{s t}, m, n, s, t=1,2,3
$$

Substituindo-se (6.24) na relação constitutiva(6.18), tem-se que:

$$
d \sigma_{i j}=C_{i j k l}\left(\delta_{i l} \delta_{s k}-\frac{1}{h} b_{m n} C_{m n s t} a_{k l}\right) d \varepsilon_{s t}, \quad m, n, s, t=1,2,3
$$

Para o caso em que as tensões inelásticas são tomadas como campo inicial, tem-se a seguinte relação constitutiva, conforme discutido no capítulo anterior:

$$
d \sigma_{i j}^{e}=d \sigma_{i j}^{p}+d \sigma_{i j}=C_{i j k l} d \varepsilon_{k l}, i, j, k, l=1,2,3
$$

Se a relação anterior for substituída em (6.24), tem-se a seguinte relação:

$$
d \sigma_{i j}=d \sigma_{i j}^{e}-\frac{1}{h} b_{m n} a_{k l} C_{i j k l} d \sigma_{m n}^{e}, i, j, k, l=1,2,3
$$

Ou ainda, pode-se escrever os incrementos de tensão plástica em função dos incrementos de tensões elásticas fictícias, isto é:

$$
d \sigma_{i j}^{p}=d \sigma_{i j}^{e}-d \sigma_{i j}=\frac{1}{h} b_{m n} a_{k l} C_{i j k l} d \sigma_{m n}^{e}, i, j, k, l, m, n=1,2,3
$$

Conforme descrito anteriormente, um outro modelo para o encruamento é o cinemático, cuja diferencial total pode ser escrita como:

$$
d f=\frac{\partial f}{\partial \sigma_{i j}} d \sigma_{i j}+\frac{\partial f}{\partial \alpha_{i j}} d \alpha_{i j}=0, i, j=1,2,3
$$

Se o coeficiente de proporcionalidade do modelo de Ziegler for assumido como dependente da deformação plástica efetiva, isto é, regido pela relação 
$d \mu=a d \varepsilon_{p}$, então os incrementos das coordenadas do centro da superfície de carregamento podem ser escritos como:

$$
d \alpha_{i j}=\varphi d \lambda, \quad i, j=1,2,3
$$

onde

$$
\varphi=\left\{\begin{array}{c}
c a_{i j}, \text { Prager } \\
a\left(\sigma_{i j}-\alpha_{i j}\right) C \sqrt{a_{s t} a_{s t}}, \text { Ziegler }
\end{array}, i, j=1,2,3\right.
$$

Substituindo-se a lei de fluxo(6.30) na equação da condição de consistência (6.29), a seguinte relação pode ser escrita:

$$
d \lambda=\frac{1}{\hat{h}} b_{m n} C_{m n s t} d \varepsilon_{s t}, m, n, s, t=1,2,3
$$

onde

$$
\hat{h}=C\left[a\left(\sigma_{m n}-\alpha_{m n}\right) \frac{\partial f}{\partial \alpha_{m n}}-C_{m n s t} \frac{\partial f}{\partial \sigma_{m n}}\right] \sqrt{a_{s t} a_{s t}}, m, n, s, t=1,2,3
$$

Substituindo-se (6.31) na relação constitutiva(6.26), tem-se os acréscimos de tensões em função dos acréscimos da deformação total, isto é :

$$
d \sigma_{i j}=C_{i j k l}\left(\delta_{i l} \delta_{s k}-\frac{1}{\hat{h}} b_{m n} C_{m n s t} a_{k l}\right) d \varepsilon_{s t}, i, j, k, l, m, n=1,2,3
$$

Para a obtenção da relação incremental governante do modelo cinemático, no caso em que as tensões plásticas são tomadas como campo inicial, é possível utilizar um procedimento análogo ao caso do encruamento isótropo, de forma que uma relação pode ser escrita como:

$$
d \sigma_{i j}^{p}=d \sigma_{i j}^{e}-d \sigma_{i j}=\frac{1}{\hat{h}} b_{m n} a_{k l} C_{i j k l} d \sigma_{m n}^{e}, i, j, k, l, m, n=1,2,3
$$

ou representada matricialmente como:

$$
d \sigma_{\sim}^{p}=\underset{\sim}{d} \sigma_{\sim}^{e}-d \sigma=\frac{1}{\hat{h}} d b_{\sim}^{T} d \sigma^{e}
$$

onde $d=C a$

Todas relações anteriormente nesta seção são válidas para corpos tridimensionais. Assim, para problemas analisados sob o modelo bidimensional 
algumas adaptações nas relações acima são necessárias. Introduzindo-se a condição do EPD em (6.34) tem-se, TELLES(1981):

$$
\underset{\sim}{d=2 G}\left(\begin{array}{c}
a_{11}+\frac{v}{1-2 v}\left(a_{11}+a_{22}+a_{33}\right) \\
a_{12} \\
a_{22}+\frac{v}{1-2 v}\left(a_{11}+a_{22}+a_{33}\right) \\
a_{33}+\frac{v}{1-2 v}\left(a_{11}+a_{22}+a_{33}\right)
\end{array}\right)
$$

$\operatorname{com} a^{T}=\left(\begin{array}{llll}a_{11} & a_{12} & a_{22} & a_{33}\end{array}\right)$.

Impondo as condições do EPT em (6.34), resulta -TELLES(1981):

$$
\underset{\sim}{\sim}=2 G\left(\begin{array}{c}
a_{11}+\frac{v}{1-v}\left(a_{11}+a_{22}\right) \\
a_{12} \\
a_{22}+\frac{v}{1-v}\left(a_{11}+a_{22}\right) \\
0
\end{array}\right)
$$

Com isso, a expressão (6.34) para os problemas bidimensionais pode ser escrita como- TELLES(1981):

$$
\left(\begin{array}{l}
d \sigma_{11} \\
d \sigma_{12} \\
d \sigma_{22} \\
d \sigma_{33}
\end{array}\right)=\left(\begin{array}{l}
d \sigma_{11}^{e} \\
d \sigma_{12}^{e} \\
d \sigma_{22}^{e} \\
d \sigma_{33}^{e}
\end{array}\right)-\frac{1}{\hat{h}} \underset{\sim}{d} b^{T}\left(\begin{array}{l}
d \sigma_{11}^{e} \\
d \sigma_{12}^{e} \\
d \sigma_{22}^{e} \\
d \sigma_{33}^{e}
\end{array}\right)
$$

$\left.d \sigma_{33}^{e}=0,(E P T) ; d \sigma_{33}^{e}=v \mid d \sigma_{11}^{e}+d \sigma_{22}^{e}\right\rfloor(E P D)$.

\subsubsection{1)Critérios de plastificação}

O critério de plastificação define o limite elástico de um material submetido a um determinado estado de tensões. Na literatura, são freqüentemente descritos alguns modelos clássicos para as superfícies de plastificação, que podem ser agrupados em duas classes: A primeira é representada por modelos que independem da pressão hidrostática e a segunda classe constitui-se de abordagens em que essa pressão é levada em conta. Assim, na seqüência, serão apresentadas as hipóteses básicas dos modelos clássicos do primeiro grupo. 


\subsubsection{1)Critério de Tresca}

Em TRESCA(1864), é proposto um modelo, a partir de observações experimentais feitas por ele e por outros pesquisadores, em que é admitido que o escoamento ocorrerá quando a tensão cisalhante atingir um valor crítico. Essa propriedade levou muitos pesquisadores a denominar o critério de modelo de máxima tensão de cisalhamento.

Assim, a função para o critério pode ser escrita como:

$$
\operatorname{Máx}\left(\frac{1}{2}\left|\sigma_{1}-\sigma_{2}\right|, \frac{1}{2}\left|\sigma_{2}-\sigma_{3}\right|, \frac{1}{2}\left|\sigma_{3}-\sigma_{1}\right|\right)=\kappa
$$

ou, de maneira mais concisa, como:

$$
\frac{1}{2}\left(\sigma_{\max }-\sigma_{\min }\right)=k
$$

Se a função do modelo for escrita em termos dos invariantes de tensão, ela pode ser apresentada como:

$$
\sqrt{3} J_{2}-2 \kappa=0
$$

onde

$$
J_{2}=\frac{1}{2} S_{i j} S_{i j}, S_{i j}=\sigma_{i j}-\frac{1}{3} \sigma_{k k} \delta_{i j} ; ; i, j=1,2,3
$$

\subsubsection{2)Critério de Maxwell-Huber- Mises}

Um outro critério que independe das pressões hidrostáticas amplamente conhecido é o modelo de Mises, devido ao trabalho publicado em MISES(1913). Contudo, em HUBER(1904) já haviam sido apresentadas hipóteses semelhantes, e ainda em BELL(1973) é comentado que esse critério foi mostrado por Maxwell em uma carta direcionada ao lorde Kelvin, no ano de 1856. Assim, em alguns trabalhos, o modelo passou a ser denominado de Maxwell-Huber-Mises.

Nesse critério é assumido que o escoamento ocorrerá somente quando o segundo invariante das tensões deviatóricas $J_{2}$ se aproximar de um valor crítico $\kappa^{2}$, isto é:

$$
J_{2}-\kappa^{2}=0
$$


Em HENCKY(1924), foi mostrado que o início da plastificação está relacionado com um valor crítico da energia de distorção, de forma que esse critério de escoamento é também conhecido como modelo da máxima energia de distorção.

Se se admite que a função do critério de Maxwell-Huber-Mises (6.42) é a energia potencial plástica $g$, isto é, $f=g$, a lei de fluxo (6.10) é denominada como equações Prandtl-Reuss, que podem ser escritas :

$$
\varepsilon_{i j}^{p}=\frac{\partial}{\sigma_{i j}}\left(J_{2}-\kappa^{2}\right) d \lambda=S_{i j} d \lambda . ; i, j=1,2,3
$$

A relação (6.43) foi obtida por PRANDTL(1924) para problemas bidimensionais a partir das equações de Levy-Mises aplicadas a materiais rígidoplásticos. Em REUSS(1930), foi estendido o modelo de Prandtl para problemas tridimensionais.

Tanto o critério de Tresca quanto o de Maxwell-Huber-Mises podem ser reunidos e representados graficamente no espaço das tensões principais conforme ilustrado na figura 6.5 .

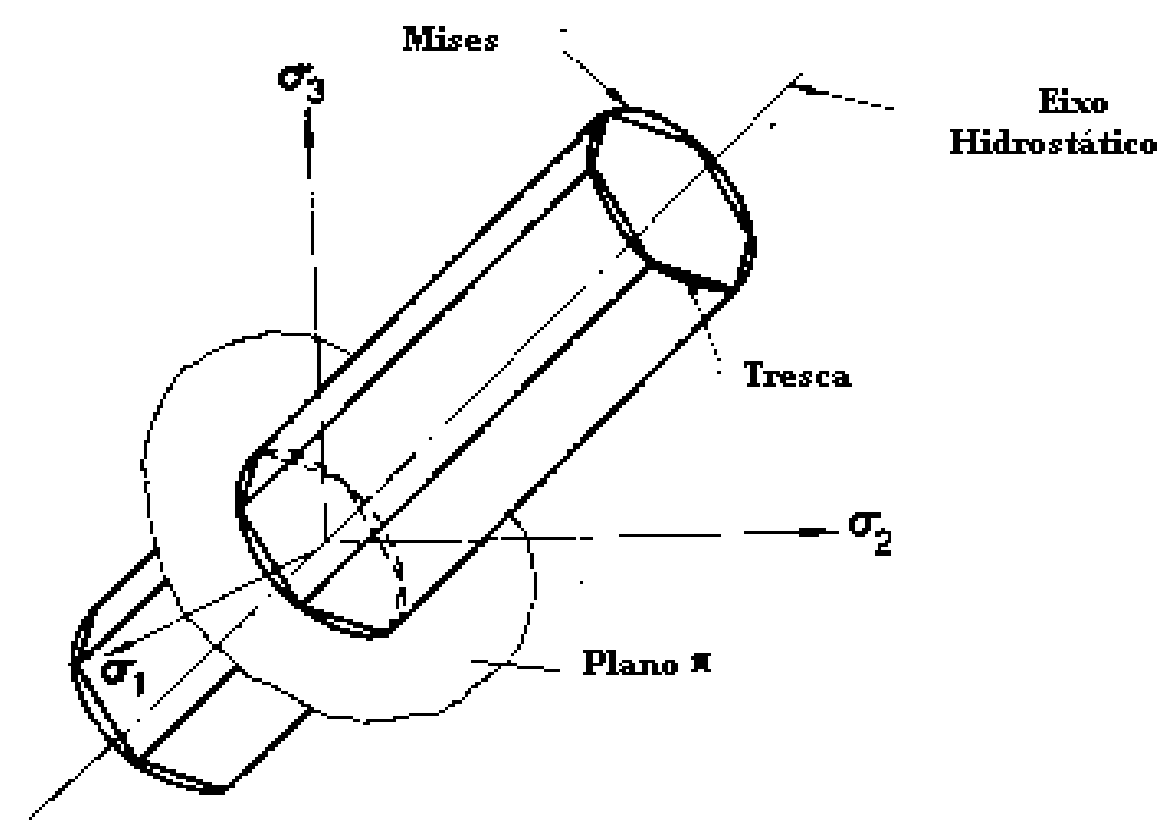

Figura 6.5- Tresca \& Mises em tensões principais- CHEN\&HAN(1988).

Conforme comentado anteriormente, além dos modelos que não incorporam a pressão hidrostática em suas estruturas, existem outras abordagens que contemplam esses casos. 


\subsubsection{3)Critério de Mohr-Coulomb}

Um dos primeiros modelos que incorporaram a influência da pressão foi apresentado em 1773 por Coulomb para descrever o problema de ruptura por fricção empregando-se a relação:

$$
\tau=\alpha-p \tan \phi
$$

onde $\alpha$ é a coesão ; $p$ é a tensão normal ao plano de deslizamento e $\phi$ é o ângulo de atrito interno. Em 1882, Mohr mostrou graficamente que a lei de fricção (6.44) representava a tensão cisalhante crítica dependendo tanto da tensão cisalhante máxima quanto da tensão normal ao plano de cisalhamento. Assim, se se admitir $\sigma_{1}>\sigma_{2}>\sigma_{3}$, uma maneira alternativa para (6.44) é escrevê-la como:

$$
\left(\sigma_{1}-\sigma_{3}\right)=2 \alpha \cos \phi-\left(\sigma_{1}+\sigma_{3}\right) \operatorname{sen} \phi
$$

$\mathrm{Ou}$

$$
\frac{1+\operatorname{sen} \phi}{1-\operatorname{sen} \phi} \sigma_{1}+\sigma_{3}=\frac{2 \alpha \cos \phi}{1-\operatorname{sen} \phi}
$$

ou ainda em função dos invariantes de tensão:

$$
I_{1} \operatorname{sen} \phi+J_{2} \alpha \cos \phi_{03}-\frac{J_{2}}{\sqrt{3}} \operatorname{sen} \phi \operatorname{sen} \phi_{0}-\alpha \cos \phi=0
$$

Convém ressaltar que para $\alpha=\kappa$ e $\phi=0$, o modelo de Tresca é recuperado.

\subsubsection{4)Critério de Drucker-Prager}

O modelo de Mohr-Coulomb e naturalmente seu caso particular(Tresca) possuem uma superfície de escoamento com angulosidades presentes, que, no caso da plasticidade associativa, podem causar alguns inconvenientes. Assim, DRUCKER \& PRAGER(1952) propuseram uma superfície cônica obtida pela adição de uma parcela contendo tensões hidrostáticas ao modelo de Maxwell-HuberMises, de forma que a lei do critério pode ser escrita como:

$$
f=\sqrt{J_{2}}+3 I_{1} \mu-\varphi=0
$$

onde $\mu=\frac{2 \operatorname{sen} \phi}{\sqrt{3}(3-\operatorname{sen} \phi)}$ e $\varphi=\frac{6 \alpha \cos \phi}{\sqrt{3}(3-\operatorname{sen} \phi)}$. 
Convém ressaltar que em YU(1994) é apresentada uma solução fechada para os modelos de Mohr-Coulomb e Tresca na obtenção da matriz de rigidez do método dos elementos finitos.

No espaço das tensões principais, os critérios de Mohr-Coulomb e DruckerPrager podem representados graficamente como na figura 6.6.

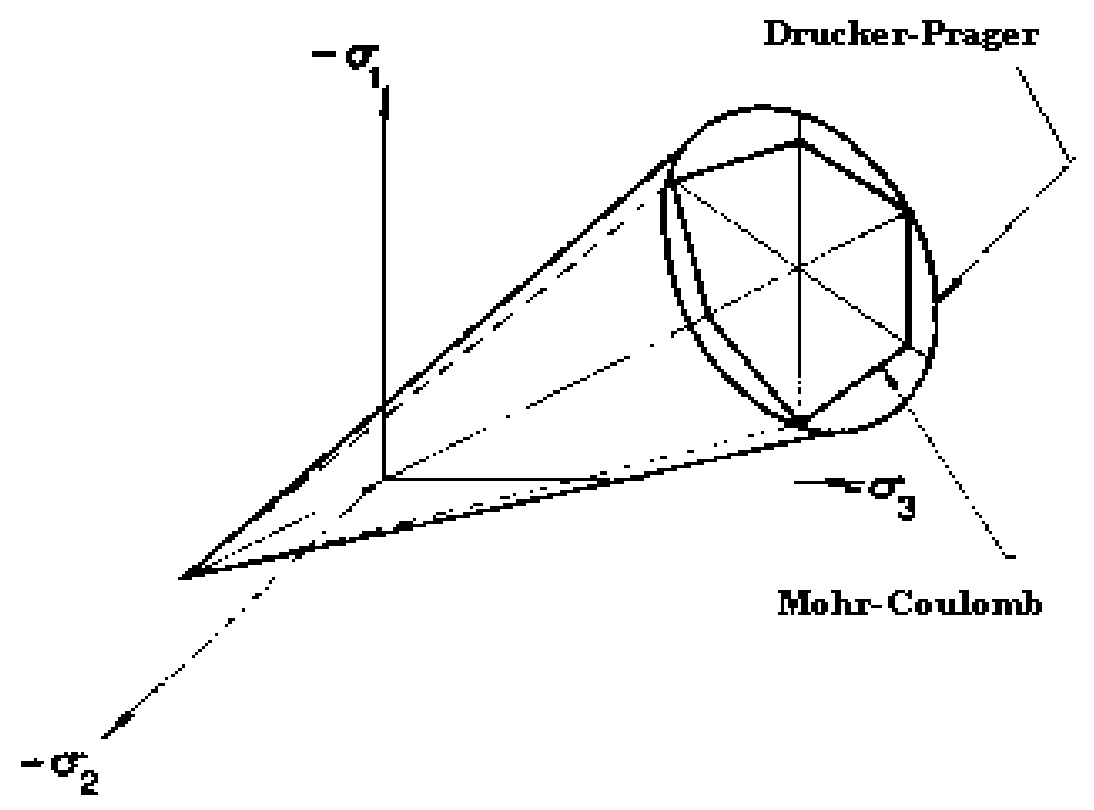

Figura 6.6- Drucker-Prager \& Mohr-Coulomb - CHEN \& HAN(1988).

\subsubsection{5)Critério de Rankine}

Um outro modelo que depende da pressão hidrostática foi proposto por Rankine em 1876. Esse critério é geralmente empregado para materiais frágeis e nele é admitido que a ruptura ocorre quando as tensões de tração atingem um valor crítico, de forma que esse critério também é conhecido como modelo das máximas tensões normais. Assim, as equações do critério podem ser escritas como:

$$
\sigma_{1}=\sigma_{0} ; \sigma_{2}=\sigma_{0}, \sigma_{3}=\sigma_{0}
$$

Esse critério pode ser representado graficamente como na figura 6.7. 


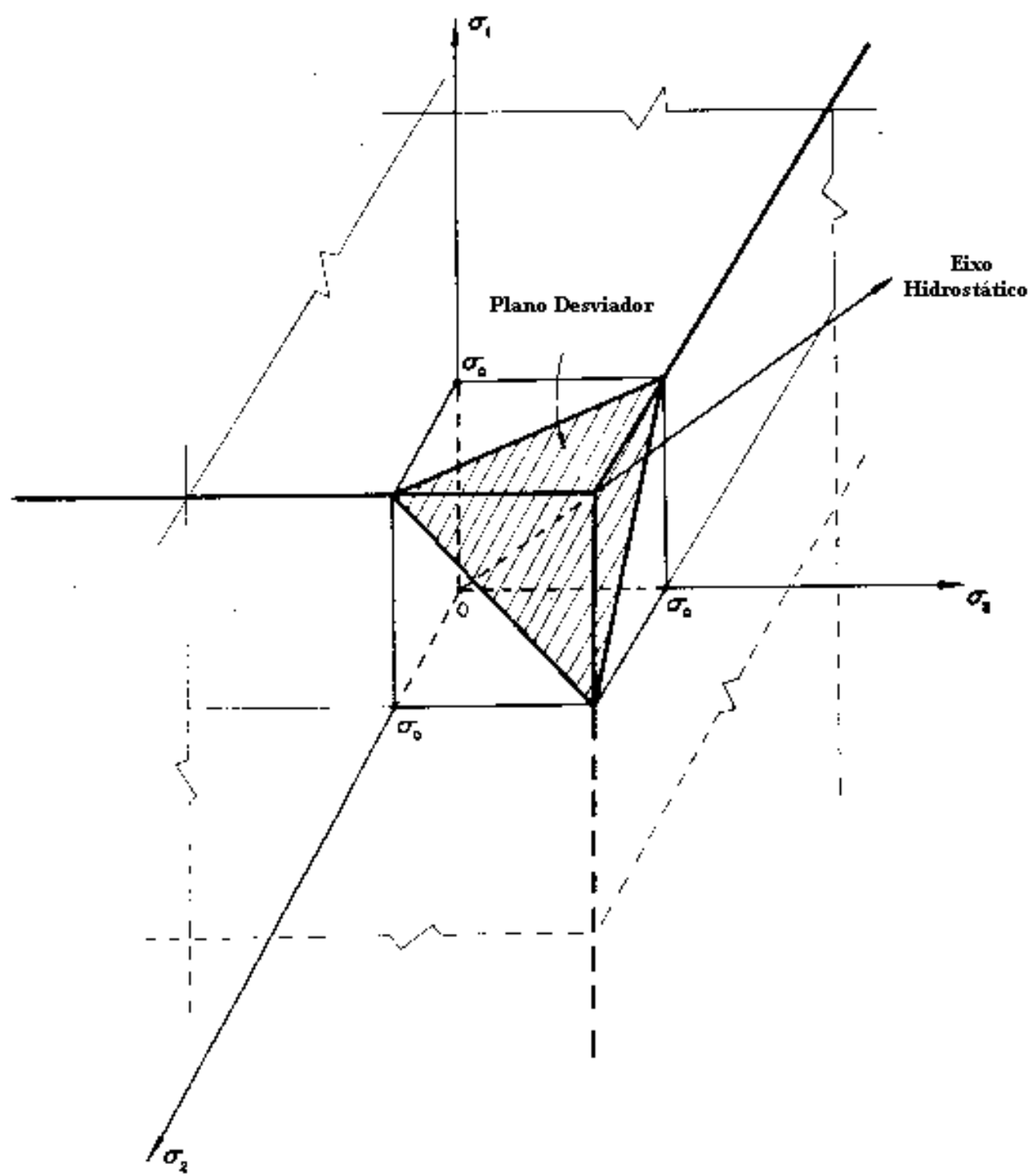

Figura 6.7-Modelo de Rankine- CHEN \& HAN(1988).

No artigo de NAYAK \& ZIENKIEWICZ(1972), é proposta uma técnica em que as derivadas das funções dos modelos clássicos (Tresca, Maxwell-Huber-Mises, Mohr-Coulomb e Drucker-Prager) podem ser reunidas em uma expressão genérica, que é estruturada a partir dos invariantes de tensão, isto é:

$$
\frac{\partial f}{\partial \sigma}=C_{1} \frac{\partial I_{1}}{\partial \sigma}+C_{2} \frac{\partial \sqrt{J_{2}}}{\partial \sigma}+C_{3} \frac{\partial J_{3}}{\partial \sigma}
$$

onde 


\begin{tabular}{|c|c|c|c|}
\hline Critério & $C_{1}$ & $C_{2}$ & $C_{3}$ \\
\hline Tresca & 0 & $2 \cos \phi_{0}\left(1+\tan \phi_{0} \tan 3 \phi_{0}\right)$ & $\frac{\sqrt{3} \operatorname{sen} \phi_{0}}{J_{2} \cos 3 \phi_{0}}$ \\
\hline $\begin{array}{c}\text { Max.-Huber- } \\
\text { Mises }\end{array}$ & 0 & $\sqrt{3}$ & 0 \\
\hline Mohr-Coulomb & $\operatorname{sen} \phi$ & $\cos \phi_{0}\left[\left(1+\tan \phi_{o} \tan 3 \phi_{0}\right)+\right.$ & $\frac{\sqrt{3} \operatorname{sen} \phi_{0}+\cos \phi \operatorname{sen} \phi}{2 J_{2} \cos 3 \phi_{0}}$ \\
& $\left.\frac{\operatorname{sen} \phi}{\sqrt{3}}\left(\tan 3 \phi_{0}-\tan \phi_{0}\right)\right]$ & \\
\hline Drucker-Prager & $3 \alpha$ & 1 & 0 \\
\hline
\end{tabular}

e os vetores em (6.50) são dados por:

a) caso tridimensional

$$
\begin{gathered}
\left\{\begin{array}{c}
\left.\frac{\partial I_{1}}{\partial \sigma}\right\}^{T}= \\
\sim
\end{array}\right\}^{T}(1,1,1,0,0,0) \\
\left\{\frac{\partial \sqrt{J_{2}}}{\partial \underset{\sim}{\sigma}}\right\}^{T}=\frac{1}{2 \sqrt{J_{2}}}\left(S_{11}, S_{22}, S_{33}, 2 \sigma_{12}, 2 \sigma_{23}, 2 \sigma_{13}\right) \\
\left\{\frac{\partial J_{3}}{\partial \underset{\sim}{\sigma}\}^{T}=} \frac{1}{3} J_{2}(1,1,1,0,0,0)+\left\{\left(S_{22} S_{33}-\sigma_{23}{ }^{2}\right),\left(S_{11} S_{33}-\sigma_{13}{ }^{2}\right),\left(S_{11} S_{22}-\sigma_{12}{ }^{2}\right),\right.\right. \\
\left.2\left(S_{23} S_{13}-S_{33} \sigma_{12}\right), 2\left(S_{13} S_{12}-S_{11} \sigma_{23}\right), 2\left(S_{12} S_{23}-S_{22} \sigma_{13}\right)\right\}
\end{gathered}
$$

b) caso bidimensional-OWEN \& HINTON(1980).

$$
\begin{aligned}
& \left\{\frac{\partial I_{1}}{\partial \sigma}\right\}_{\sim}^{T}=\frac{1}{3}(1,1,0,1) \\
& \left\{\frac{\partial \sqrt{J_{2}}}{\partial \underset{\sim}{\sigma}}\right\}^{T}=\frac{1}{2 \sqrt{J_{2}}}\left(S_{11}, S_{22}, 2 \sigma_{12}, S_{33}\right) \\
& \left\{\frac{\partial J_{3}}{\partial \sigma}\right\}^{T}=\frac{1}{3} J_{2}(1,1,0,1)+\left\{\left(S_{22} S_{33}-\sigma_{23}{ }^{2}\right),\left(S_{11} S_{33}-\sigma_{13}{ }^{2}\right),-2 S_{33} \sigma_{12},\left(S_{12} S_{23}-\sigma_{22} S_{12}\right)\right\}
\end{aligned}
$$




\section{3)Algoritmos Incrementais-iterativos do Sistema de Equações}

Devido ao caráter não-linear do sistema do problema elastoplástico, uma das alternativas para a resolução desse sistema é uma estratégia incremental e iterativa. Diversos pesquisadores já apresentaram técnicas voltadas para a solução incremental-iterativa de problemas inelásticos, dentre eles: RICCARDELLA(1973), BANERJEE et al.(1979), OWEN \& HINTON(1980), TELLES(1981) e outros. Na seqüência será apresentado um algoritmo descrito em CHUERI(1994), que mescla algumas técnicas utilizadas principalmente pelos dois últimos trabalhos citados anteriormente(Owen \& Hinton, Telles).

Inicialmente, serão descritas as etapas do procedimento que podem ser aplicadas no caso dos campos iniciais em tensões. Assim, a representação (5.175) pode ser reescrita na forma incremental como:

$$
T_{\sim}^{e}=\lambda_{k} \underset{\sim}{n}+\underset{\sim}{R}\left(T_{\sim k-1}^{p}+\Delta \underset{\sim k}{T^{p}}\right)
$$

Ou expressa nas relações puramente incrementais, isto é:

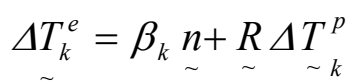

Para um incremento de carga genérico, admitindo-se comportamento elástico, pode-se determinar o incremento de tensões/momentos em cada ponto do problema, que são acumulados no campo de tensões/momentos atuais. Se algum ponto atinge o escoamento, o incremento de tensões/momentos verdadeiros deve ser calculado e o excesso de tensões/momentos ou incremento de tensões/momentos plásticos deve ser reaplicado ao sistema como um campo de tensões/momentos iniciais. Para a elucidação da sinopse do algoritmo apresentado acima, suas etapas serão discutidas mais detalhadamente na seqüência.

Inicialmente, é admitido que todos os pontos estejam em regime elástico linear devido a uma ação externa inicial, de forma que os campos de tensões/momentos atuais e os elásticos fíctícios sejam idênticos. E, ainda, tomandose esse nível de carregamento como referência, isto é, incrementos de carga $i=0$ e como o sistema do problema nesse patamar de carregamento é linear, podem-se dispensar operações iterativas, isto é, $r=0$, de forma que as tensões obtidas do sistema de equações podem ser escritas como: 


$$
T_{r, i}^{e}=T_{0,0}^{e}=N
$$

A partir do valor da tensão/momento elástica fictícia inicializada, sua variação, devido a um incremento de carga genérico, pode ser escrita como:

$$
\Delta T_{r, i}^{e}=\beta_{i} T_{0,0}^{e}
$$

De forma que, acumulando-se os valores de $\beta_{i}$, obtêm-se as respectivas somas dos acréscimos de tensões/momentos.

Em um incremento de carregamento genérico, a tensão/momento elástica fictícia pode estar fora da superfície de escoamento, de forma que a tensão excedente, a plástica, deve ser reaplicada utilizando-se, em geral, operações iterativas. Assim, sucintamente, cada passo, em um incremento de carga $j$, pode ser descrito como:

Etapa (a): Calcula-se o incremento de carga $\Delta T_{j, r}^{e}$, que pode ser obtido para a primeira iteração $r=1$ por meio da equação (6.54). Para as demais iterações desse incremento, $\underset{\sim}{\Delta T_{j}^{e}}$ é calculado a partir do excesso de tensões/momentos $\Delta T_{j, r-1}^{p}$, determinado na iteração anterior, que é aplicado como um campo inicial. Assim, a partir de (6.54), admitindo-se que todo incremento de carga tenha sido aplicado na primeira iteração, tem-se:

$$
\Delta T_{\sim \sim}^{e}=\underset{\sim}{R} \Delta T_{j, r-1}^{p}
$$

Se os regimes de membrana e flexão forem explicitados em (6.57), essa representação pode ser escrita como:

$$
\left\{\begin{array}{c}
\Delta N_{j, r}^{e} \\
\underset{\sim}{\Delta m_{j, r}^{e}}
\end{array}\right\}=\left[\begin{array}{cc}
R_{m} & 0 \\
\sim & \sim \\
\tilde{0} & R_{f} \\
\sim & \sim
\end{array}\right]\left\{\begin{array}{c}
\Delta N_{j, r}^{p} \\
\sim \\
\sim \\
m_{j, r}^{p} \\
\sim
\end{array}\right\}
$$

Em cada ponto nodal do problema, calcula-se o estado de tensões/momentos, supondo-se comportamento elástico, e, em seguida, soma-se o incremento $\Delta T_{i, r}^{e}$ às tensões verdadeiras da iteração anterior, isto é:

$$
\left\{\begin{array}{c}
N_{j, r}^{e} \\
\tilde{\sim} \\
m_{j, r}^{e} \\
\sim
\end{array}\right\}=\left\{\begin{array}{c}
N_{j, r-1} \\
\sim \\
m_{j, r-1} \\
\sim
\end{array}\right\}+\left\{\begin{array}{c}
\Delta N_{j, r}^{p} \\
\sim \sim \sim \\
\Delta m_{j, r}^{p} \\
\sim
\end{array}\right\}
$$


Antes de partir para o passo subseqüente, isto é, a verificação do campo das tensões elásticas fictícias no espaço da superfície de plastificação, é necessário compor essas tensões advindas dos regimes de membrana e flexão.

As tensões de flexão podem ser determinadas, ao longo da espessura de uma seção, partir de (2.19), ou ainda , como:

$$
\sigma^{f}=12 \frac{m}{t^{3}} x_{3}
$$

Neste trabalho, ao longo da espessura de uma seção, os pontos a serem escolhidos das tensões são coincidentes com aqueles dados pelas coordenadas das quadraturas de integração $\zeta_{i}$, vide figura 6.8 .

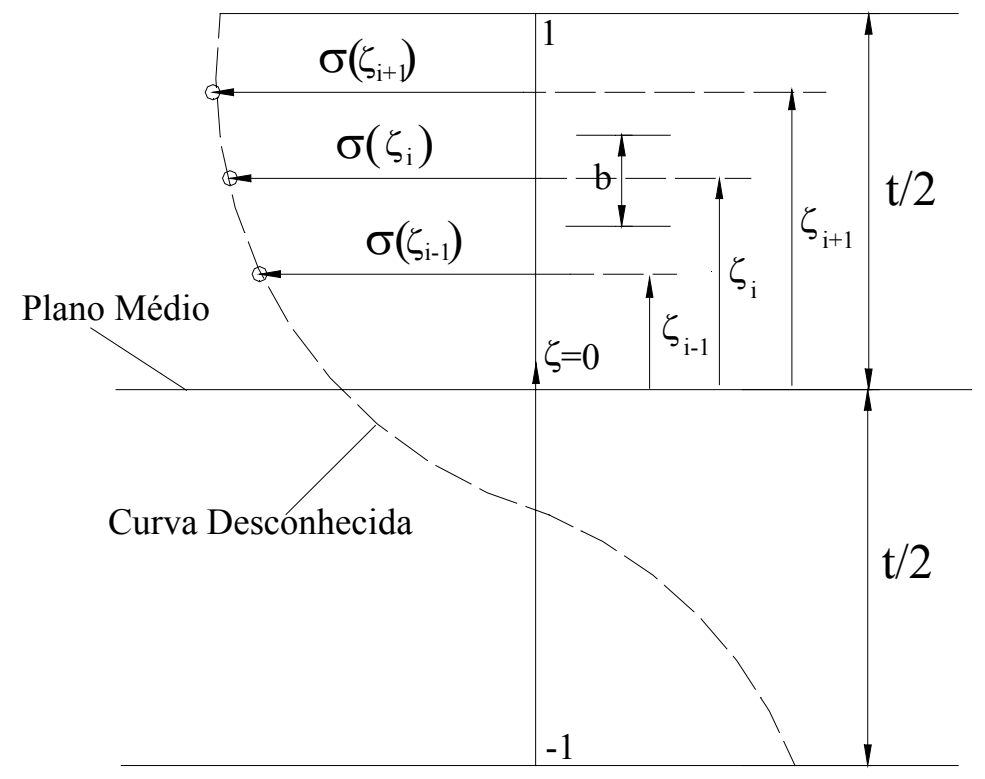

Figura 6.8- Tensões em pontos discretizados ao longo da seção.

Como a distribuição de tensões verdadeiras ao longo da seção transversal não é conhecida, quanto mais pontos de integração forem tomados, mais bem representado estará o campo das tensões. Desta forma, a tensão verdadeira, em um ponto $\zeta_{i}$, oriunda dos regimes membrana e flexão pode ser escrita como:

$$
\sigma^{e}\left(\zeta_{i}\right)=\sigma^{e c}\left(\zeta_{i}\right)+12 \frac{m^{e}}{t^{3}} \zeta_{i}
$$

Convém ressaltar que $\sigma^{e c}\left(\zeta_{i}\right)$ pertence a $\sigma^{e}$ e está associado ao ponto $i$ disposto em uma cota da espessura da seção, e $m^{e}$ está associado ao momento em relação um ponto localizado. 
Etapa (b): Nesse passo, é necessário verificar a existência do conjunto-imagem da função da superfície de carregamento $f\left[\sigma\left(\zeta_{i}\right), \kappa\right]=F\left[\sigma\left(\zeta_{i}\right)\right]-\sigma_{y}\left[\kappa\left(\zeta_{i}\right)\right] \leq 0$, cujo parâmetro de encruamento foi atualizado no final da iteração anterior, $\sigma_{y}\left[\kappa\left(\zeta_{i}\right)\right]=\sigma_{0}+H^{\prime} \bar{\varepsilon}_{j, r-l}^{p}\left(\zeta_{i}\right)$, para elementos pertencentes ao conjuntodomínio com valores estimados referentes à tensão elástica fictícia da corrente iteração $F\left[\sigma\left(\zeta_{i}\right)=\sigma_{j, r}^{e}\left(\zeta_{i}\right)\right]$. Assim, nas subetapas posteriores, pode-se partir para a investigação de dois casos possíveis.

$\operatorname{Etapa(c):~Se~} F\left[\sigma_{i, r}^{e}\left(\zeta_{i}\right)\right] \geq \sigma_{y}\left[\kappa\left(\zeta_{i}\right)\right]$, então esse ponto, na corrente iteração, não pertence ao conjunto imagem de $f$, o que conduz a um excesso de tensão, que deve ser reaplicado na próxima iteração. Contudo, ainda há necessidade de investigar-se qual parcela da previsão da corrente de tensão elástica fictícia deve ser reaplicada, uma vez que a parcela complementar pode ainda estar no regime elástico. Assim, parte-se para a análise do campo de tensões verdadeiras da iteração anterior.

$\operatorname{Etapa(c.1):~Se~} F\left[\sigma_{i, r-1}\left(\zeta_{i}\right)\right]=\sigma_{y}\left[\kappa\left(\zeta_{i}\right)\right]$, então o ponto já havia escoado na iteração anterior $(r-1)$ e com isso, tem-se os valores positivos na condição de Kühn-Tucker $\left(\sigma\left(\zeta_{i}\right) \Delta \lambda\left(\zeta_{i}\right)>0\right)$, indicando que as tensões nessa iteração estão sendo acrescidas.

Para esse caso, deve ser notado que todo o excesso de tensões deve ser reduzido à superfície de escoamento, de forma que os acréscimos de tensões verdadeiras podem ser escritos a partir dos acréscimos das tensões elásticas fictícias e das tensões plásticas:

$$
\Delta \sigma_{j, r}\left(\zeta_{i}\right)=\Delta \sigma_{\sim}^{e}\left(\zeta_{i}\right)-d \lambda\left(\zeta_{i}\right) \underset{\sim}{d}
$$

onde o incremento de tensões plásticas é igual ao último termo de (6.62), isto é:

$$
\Delta \sigma_{i, r}^{p}\left(\zeta_{i}\right)=d \lambda\left(\zeta_{i}\right) d
$$

Assim, as tensões verdadeiras da corrente iteração podem ser obtidas pela soma de seus respectivos acréscimos atuais nos valores das tensões verdadeiras da iteração anterior:

$$
\sigma_{\sim}^{j, r}\left(\zeta_{i}\right)=\sigma_{j, r-1}\left(\zeta_{i}\right)+\Delta \underset{\sim}{\sigma_{j, r}^{e}}\left(\zeta_{i}\right)-d \lambda\left(\zeta_{i}\right) \underset{\sim}{d}
$$

Em OWEN \& HINTON(1980) é discutida uma estratégia para melhorar o desempenho do algoritmo de retorno, isto é, da tensão elástica fictícia para a tensão 
verdadeira, que é descrita pela expressão (6.64). Nessa técnica, a tensão excedente à superfície de plastificação é dividida por um número de incrementos $k$. Em seguida, é utilizado um processo recursivo na atualização da tensão verdadeira:

O valor atualizado da tensão plástica é obtido pelo acúmulo dos seus respectivos acréscimos no valor de tensões plásticas da iteração anterior, isto é:

$$
\sigma_{i, r}^{p}\left(\zeta_{i}\right)=\Delta \sigma_{i, r-1}^{p}\left(\zeta_{i}\right)+\Delta \sigma_{i, r}^{p}\left(\xi_{i}\right)
$$

As contribuições dos acréscimos de tensões plásticas no ponto $\zeta_{i}$ para os acréscimos dos momentos plásticos na seção podem ser calculados utilizando-se:

$$
\Delta m_{j, r}^{p}=\Delta \sigma_{j, r}^{p}\left(\zeta_{i}\right) \frac{I}{\zeta_{i}}
$$

E analogamente às tensões, o valor atualizado dos momentos plásticos pode ser escrito como:

$$
m_{j, r}^{p}\left(\zeta_{i}\right)=\Delta m_{j, r-1}^{p}\left(\zeta_{i}\right)+\Delta m_{j, r}^{p}\left(\xi_{i}\right)
$$

Convém ressaltar que tanto a tensão quanto o momento plástico serão aplicados como campos iniciais na próxima iteração. Além disso, para finalizar as etapas da corrente iteração, é necessário calcular o valor das deformações plásticas efetivas, de forma a possibilitar a atualização da evolução isotrópica da superfície de escoamento. Conforme mostrado nas seções anteriores, a expansão da superfície de escoamento com os acréscimos de deformações plásticas pode ser descrita classicamente utilizando-se o modelo de encruamento por trabalho ou por deformação. A partir de $(6.13),(6,14)$ e $(6.21)$ para o primeiro modelo, os incrementos de deformação plástica efetiva podem ser expressos:

$$
\Delta \bar{\varepsilon}_{j, r}^{p}=d \lambda \frac{\stackrel{a^{T} \sigma_{i, r}}{\sim}}{\bar{\sigma}_{i, r}}
$$

onde tensão efetiva $\bar{\sigma}_{i, r}$ é dada por $\bar{\sigma}_{i, r}=F\left(\sigma_{i, r}\right)$.

Já a segunda abordagem a partir de (6.11) e (6.13) conduz a uma expressão dos incrementos de deformação plástica efetiva, que pode ser escrita como:

$$
\Delta \bar{\varepsilon}_{j, r}^{p}=d \lambda \sqrt{\underset{\sim}{a^{T} a}}
$$


Assim, o valor atualizado da deformação plástica efetiva pode ser obtido pelo acúmulo de seus acréscimos, dados por (6.70) ou (6.71), nos valores calculados na iteração anterior, de forma que esse procedimento pode ser expresso por:

$$
\bar{\varepsilon}_{i, r}^{p}\left(\zeta_{i}\right)=\bar{\varepsilon}_{i, r-1}^{p}\left(\zeta_{i}\right)+\Delta \bar{\varepsilon}_{i, r}^{p}\left(\zeta_{i}\right)
$$

Etapa(c.2): O caso da contrapartida da etapa (c.1), isto é, $F\left[\sigma_{i, r-1}\left(\zeta_{i}\right)\right]<\sigma_{y}\left[\kappa\left(\zeta_{i}\right)\right]$ significa que o ponto na iteração anterior $(r-1)$ estava no regime elástico e escoa no decorrer da corrente iteração. Assim, é necessário determina-se a parcela do acréscimo elástico fíctício, que conduz o estado de tensões à superfície de escoamento, e a parcela complementar das tensões fictícias deve ser reaplicada de forma análoga à etapa (c.1), isto é:

$$
\sigma_{j, r}\left(\zeta_{i}\right)=\sigma_{j, r-1}\left(\zeta_{i}\right)+(1-F a t) \Delta \sigma_{j, r}^{e}\left(\zeta_{i}\right)-F a t d \lambda\left(\zeta_{i}\right) d
$$

onde o coeficiente Fat é dado por:

$$
F a t=\frac{F\left[\sigma_{i, r}^{e}\left(\zeta_{i}\right)\right]-F\left[\sigma_{i, r-1}\left(\zeta_{i}\right)\right]}{F\left[\sigma_{i, r}^{e}\left(\zeta_{i}\right)\right]-\sigma_{i, r-1}^{y}\left(\zeta_{i}\right)}
$$

Assim, a atualização das tensões verdadeiras, das tensões plásticas, das deformações plásticas efetivas, e por fim, à atualização da evolução da superfície de escoamento podem ser efetuadas, analogamente ao descrito na etapa (c.1).

Etapa d: Ainda no mesmo incremento de carga e mesma iteração, para os demais pontos pertencentes à seção em questão, isto é, $\zeta_{i+1}, \zeta_{i+2}, \cdots, \zeta_{i+n}, \zeta_{i}$, os procedimentos descritos anteriormente para o ponto de coordenada $\zeta_{i}$ devem ser repetidos.

Etapa e: Neste passo, é verificada a convergência do problema na corrente iteração. Convém ressaltar que a convergência será atingida quando todas as coordenadas (pontos discretos) forem menores ou iguais ao valor de tolerância fornecido pelo critério de convergência adotado. Assim, caso não tenha ocorrido, passa-se para uma nova iteração, envolvendo cada um dos nós da seção, a partir da etapa $a$. Se a convergência for verificada, parte-se para um novo incremento de carga, repetindo-se todos os passos. Assim, esse processo incremental-iterativo é executado até que o carregamento total seja aplicado. 


\section{AVALIAÇÃO NUMÉRICA}

Neste capítulo são apresentados alguns exemplos numéricos a fim de investigar tanto o desempenho quanto a aplicabilidade da presente formulação. Os problemas foram divididos em três grupos: regime elástico, termoelástico e elastoplástico.

\section{1) Análise Elastolinear}

Nesta seção, são analisados problemas laminares com elementos-base isolados(chapa e placa), coplanarmente multiconectados e não-coplanamente acoplados sob regime elastolinear.

\subsection{1) Placa engastada sob carregamento uniformemente distribuído.}

Neste exemplo é analisada a placa quadrada de lado L, engastada ao longo de seu contorno e submetida a um carregamento uniformemente distribuído $\mathrm{q}$, vide figura 7.1. O valor do coeficiente de Poisson utilizado é 0,3 e a discretização do problema envolve um total de 32 elementos simetricamente distribuídos. Os resultados adimensionalizados estão indicados tabela 1 e são comparados com soluções analíticas TIMOSHENKO (1940). A abreviatura TP denota formulação dos três parâmetros nodais e BP representação biparamétrica.
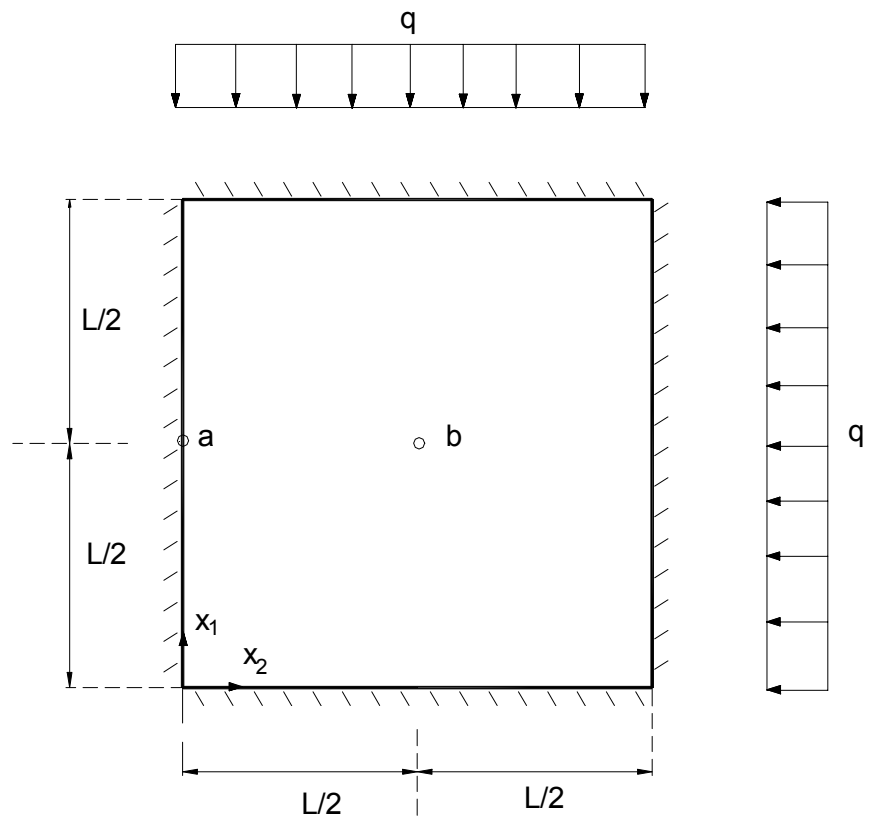

Figura 7.1-Placa engastada com carregamento uniformemente distribuído. 
Tabela 7.1-Deslocamentos e momentos adimensionalizados

\begin{tabular}{|c|c|c|c|c|}
\hline \multicolumn{2}{|c|}{} & BP & TP & $\begin{array}{c}\text { TIMOSHENKO } \\
\text { (1940) }\end{array}$ \\
\hline \multirow{2}{*}{$\mathrm{wD} /\left(\mathrm{qL}^{4}\right)$} & $\boldsymbol{b}$ & 0,001265 & 0,001266 & 0,00126 \\
\hline \multirow{2}{*}{$\mathrm{m}_{\mathrm{x}_{2}} /\left(\mathrm{qL}^{2}\right)$} & $\boldsymbol{a}$ & $-0,0521$ & $-0,0547$ & $-0,0513$ \\
\cline { 2 - 5 } & $\boldsymbol{b}$ & 0,0229 & 0,0229 & 0,0229 \\
\hline
\end{tabular}

A partir dos resultados da tabela 7.1, pode-se notar desempenhos excelentes, tanto da formulação biparamétrica(BP) quanto da triparamétrica(TP) em relação à solução analítica de Timoshenko, para deslocamentos de momentos fletores no centro da placa. Já os momentos fletores no ponto A(contorno) tiveram um razoável desempenho, porém mais modestos que os apresentos no ponto B.

\subsection{2) Placa engastada submetida a um carregamento hidrostático.}

Seguindo-se a análise de placas engastadas, neste exemplo esse elemento estrutural é modelado para o caso de um carregamento hidrostático aplicado conforme indicado na figura 7.2. As constantes elásticas, a geometria e a discretização são idênticas àquela de 7.1.1. Já os resultados adimensionalizados das análises estão indicados na tabela 7.2.
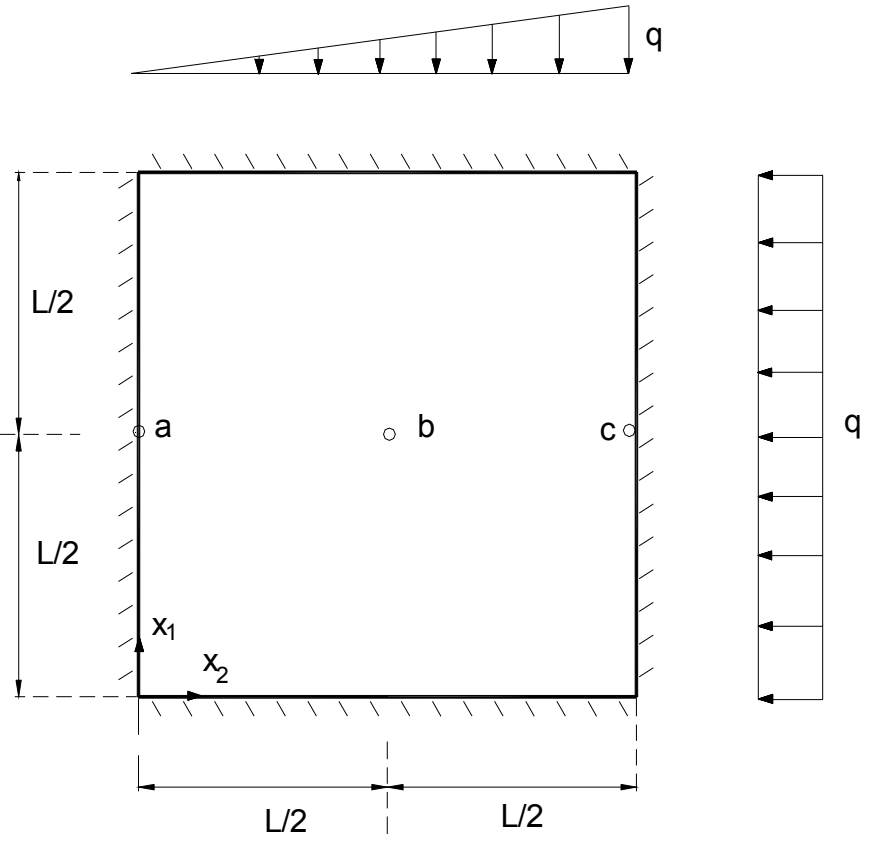

Figura 7.2- Carregamento linearmente distribuído aplicado. 
Tabela 7.2- Deslocamentos e momentos adimensionalizados.

\begin{tabular}{|c|c|c|c|c|}
\hline \multicolumn{2}{|c|}{} & BP & T P & $\begin{array}{c}\text { TIMOSHENKO } \\
\text { (1940) }\end{array}$ \\
\hline \multirow{2}{*}{$\mathrm{wD} /\left(\mathrm{qL}^{4}\right)$} & $\boldsymbol{b}$ & 0,00063 & 0,000634 & 0,00063 \\
\hline \multirow{2}{*}{$\mathrm{m}_{\mathrm{x}_{1}} /\left(\mathrm{qL}^{2}\right)$} & $\boldsymbol{b}$ & $-0,0181$ & $-0,0182$ & $-0,0179$ \\
\cline { 2 - 5 } & $\boldsymbol{c}$ & $-0,0115$ & 0,01145 & 0,0115 \\
\cline { 2 - 5 } & & $-0,00338$ & $-0,0039$ & $-0,0034$ \\
\hline
\end{tabular}

Neste exemplo pode-se notar na tabela 7.2 um bom desempenho das formulações BP e TP com as soluções analíticas dadas em TIMOSHENKO(1940).

\subsection{3) Placa apoiada sob carregamento uniformemente distribuído.}

Outra configuração de vinculação a ser analisada é aquela que permite que a placa gire livremente normalmente a seus bordos. Uma das classes que atente essas características é a placa simplesmente apoiada, indicada na figura 7.3. Tanto as constantes elásticas, geometria e a discretização permanecem inalteradas, isto é, são utilizados trinta e dois elementos lineares simetricamente posicionados no contorno, $v=0,3$. Os resultados adimensionalizados estão mostrados na tabela 7.3.

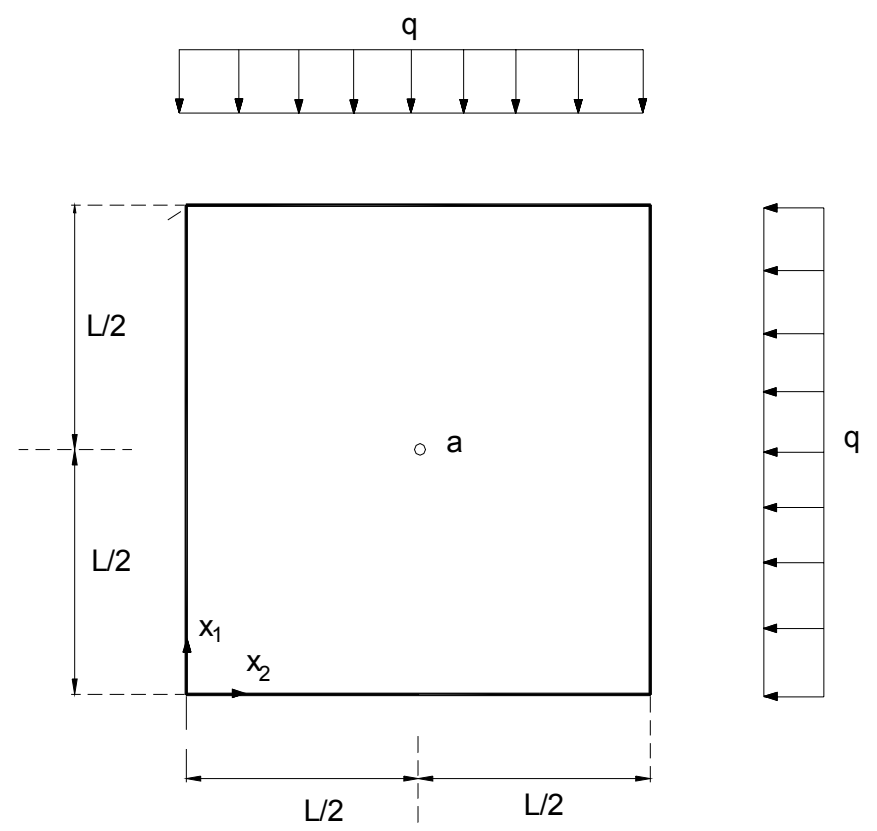

Figura 7.3- Placa simplesmente apoiada uniformemente carregada. 
Tabela 7.3-Deslocamentos e momentos adimensionalizados

\begin{tabular}{|c|c|c|c|}
\hline $\boldsymbol{a}$ & $\boldsymbol{B P}$ & T.P & $\begin{array}{c}\text { TIMOSHENKO } \\
\text { (1940) }\end{array}$ \\
\hline $\mathrm{wD} /\left(\mathrm{qL}^{4}\right)$ & 0,004045 & 0,004039 & 0,004062 \\
\hline $\mathrm{m}_{\mathrm{x}_{1}} /\left(\mathrm{qL}^{2}\right)$ & 0,04773 & 0,04765 & 0,0478 \\
\hline
\end{tabular}

Neste exemplo também pode ser observada na tabela 7.3 uma razoável concordância de resultados entre as soluções numéricas e a analítica disponível no trabalho de Timoshenko para o ponto central da placa.

\subsection{4) Placa apoiada sob carregamento hidrostático.}

Uma placa quadrada simplesmente apoiada é analisada para um carregamento hidrostático aplicado conforme indicada na figura 7.4. As constantes elásticas e a discretização são as mesmas dos problemas anteriores e os resultados adimensionalizados dessa análise, envolvendo apenas a formulação TP e a solução analítica, estão indicados na tabela 7.4.
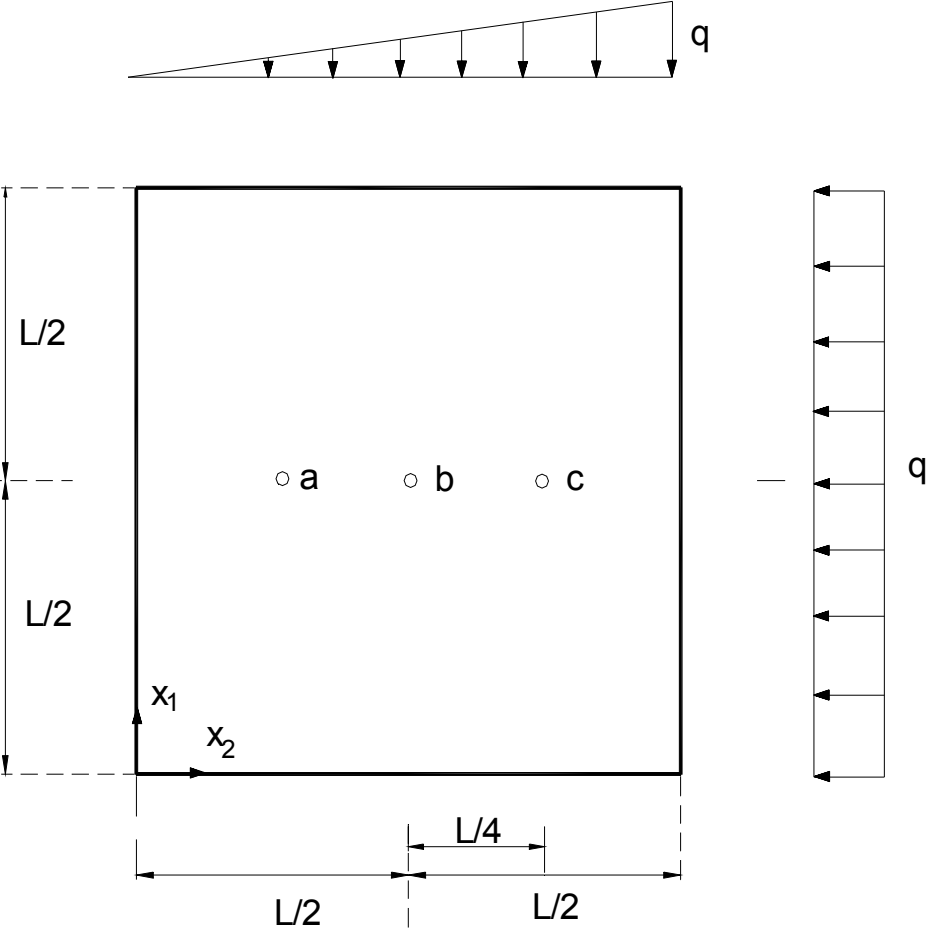

Figura 7.4- Carregamento hidrostático em placa simplesmente apoiada. 
Tabela 7.4- Deslocamentos e momentos adimensionalizados.

\begin{tabular}{|c|c|c|c|}
\hline \multicolumn{2}{|c|}{} & TP & TIMOSHENKO(1940) \\
\hline \multirow{3}{*}{$\mathrm{wD} /\left(\mathrm{qL}^{4}\right)$} & $\boldsymbol{C}$ & 0,001617 & 0,00162 \\
\cline { 2 - 4 } & $\boldsymbol{B}$ & 0,002019 & 0,00203 \\
\cline { 2 - 4 } & $\boldsymbol{A}$ & 0,001303 & 0,00131 \\
\hline \multirow{3}{*}{$\mathrm{m}_{\mathrm{x} 1} /\left(\mathrm{qL}^{2}\right)$} & $\boldsymbol{C}$ & 0,02563 & 0,0259 \\
\cline { 2 - 4 } & $\boldsymbol{B}$ & 0,02382 & 0,0239 \\
\cline { 2 - 4 } & $\boldsymbol{C}$ & 0,01301 & 0,0132 \\
\hline
\end{tabular}

Uma excelente concordância de resultados pode ser observada entre a formulação Triparamétrica (TP) e a solução analítica de Timoshenko para deslocamentos e momentos fletores.

\subsection{5) Placa apoiada sob carregamento concentrado.}

Dando continuidade na análise de placas simplesmente apoiadas dos problemas anteriores, neste exemplo tem-se uma configuração de carregamento consistindo-se de uma força concentrada $\boldsymbol{P}$ aplicada no centro de gravidade placa conforme indicada na figura 7.5. O deslocamento adimensionalizado no ponto $\boldsymbol{a}$, para diversas razões entre os lados $(1, \mathrm{~L})$ da placa, está indicado na tabela 7.5.

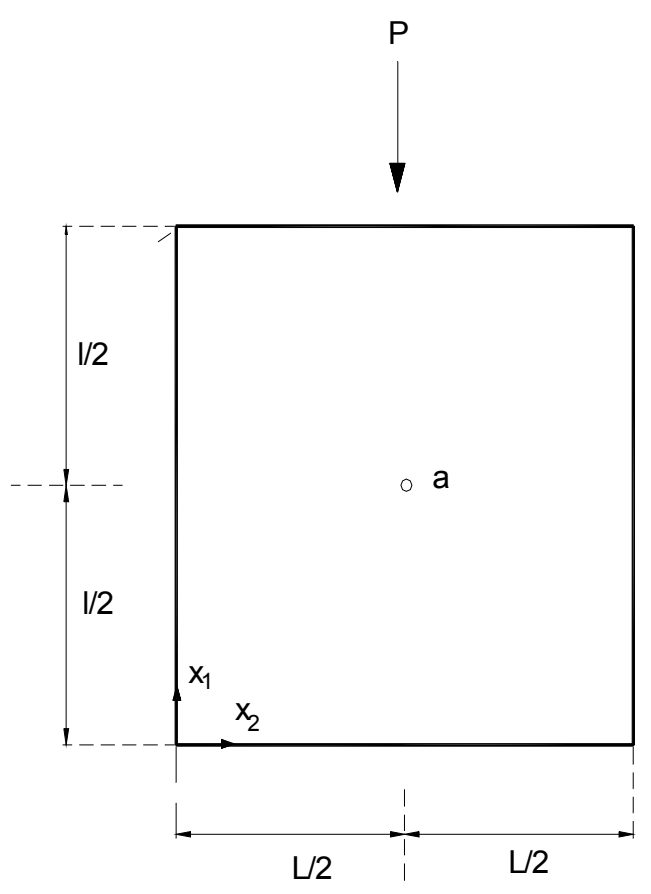

Figura 7.5- Placa simplesmente apoiada sob carregamento concentrado. 
Tabela 7.5- Deslocamentos adimensionalizados para diversas razões dos lados

\begin{tabular}{|c|c|c|c|}
\hline \multicolumn{2}{|c|}{ I/L } & TP & TIMOSHENKO(1940) \\
\hline \multirow{4}{*}{$\mathrm{w} D /\left(\mathrm{PL}^{2}\right)$} & 1,0 & 0,01155 & 0,01160 \\
\cline { 2 - 4 } & 1,1 & 0,01261 & 0,01265 \\
\cline { 2 - 4 } & 1,2 & 0,01349 & 0,01353 \\
\cline { 2 - 4 } & 1,4 & 0,01478 & 0,01484 \\
\cline { 2 - 4 } & 1,8 & 0,01614 & 0,01620 \\
\cline { 2 - 4 } & 2,0 & 0,01645 & 0,01651 \\
\cline { 2 - 4 } & 3,0 & 0,01684 & 0,01690 \\
\hline
\end{tabular}

Os resultados obtidos pela formulação Triparamétrica (TP) e a solução analítica de Timoshenko têm um bom nível de concordância para deslocamentos no centro da placa para diferentes razões entre as dimensões dos lados.

\subsection{6) Placa apoiada nos cantos e carregamento uniformemente distribuído.}

Finalizando-se a análise de placas retangulares, neste exemplo é modelado um problema com $v=0,3$, cuja vinculação que consiste em apoiar a placa exclusivamente nos cantos conforme indicado na figura 7.6. Nesta análise foram utilizadas duas discretizações simétricas: a primeira com 32 elementos, e a segunda com 40. Os resultados adimensionalizados estão mostrados na tabela 7.6.

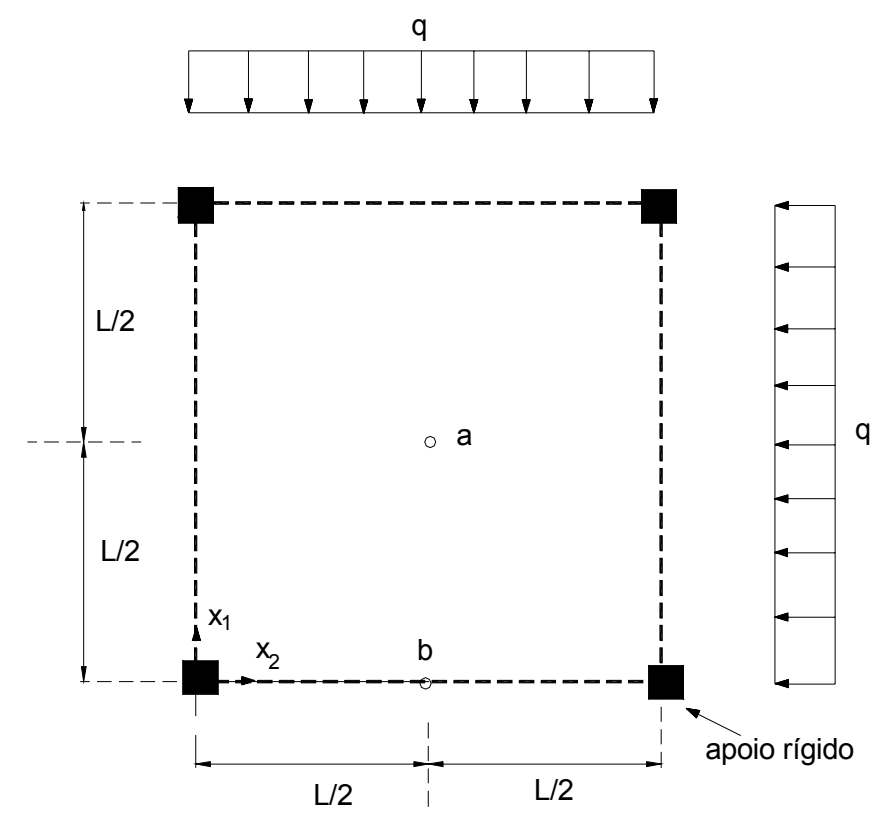

Figura 7.6- Placa apoiada exclusivamente sobre os apoios rígidos. 
Tabela 7.6 - Deslocamentos e momentos.

\begin{tabular}{|c|c|c|c|c|c|}
\hline \multicolumn{2}{|c|}{} & $\begin{array}{c}\text { BP } \\
\mathbf{N}=\mathbf{4 0}\end{array}$ & $\begin{array}{c}\text { TP } \\
\mathbf{N = 3 2}\end{array}$ & $\begin{array}{c}\text { TP } \\
\boldsymbol{N}=\mathbf{4 0}\end{array}$ & TIMOSHENKO(1940) \\
\hline \multirow{2}{*}{$\mathrm{wD} /\left(\mathrm{qL}^{4}\right)$} & $\boldsymbol{b}$ & 0,0163 & 0,0156 & 0,0160 & - \\
\cline { 2 - 6 } & $\boldsymbol{a}$ & 0,0246 & 0,0238 & 0,0240 & 0,0249 \\
\hline $\mathrm{m}_{\mathrm{x}_{1}} /\left(\mathrm{qL}^{2}\right)$ & $\boldsymbol{a}$ & 0,110 & 0,1109 & 0,1111 & 0,109 \\
\hline
\end{tabular}

Neste exemplo também se obteve um bom nível de desempenho de ambas formulações.

\subsection{7) Chapa simplesmente tracionada}

Neste exemplo inicia-se a análise numérica de chapas utilizando as equações integrais da elastostática bidimensional. A chapa modelada tem configuração geométrica quadrada, solicitada à tração unitária no topo e vinculações em uma das extremidades conforme indicado na figura 7.7. As constantes elásticas são $\mathrm{E}=1,0 \mathrm{kPa}, v=0,0$ e os resultados da formulação triparamétrica de chapas-TRC (dois deslocamentos e uma rotação como parâmetros nodais) e da solução analítica estão indicados na tabela 7.7.

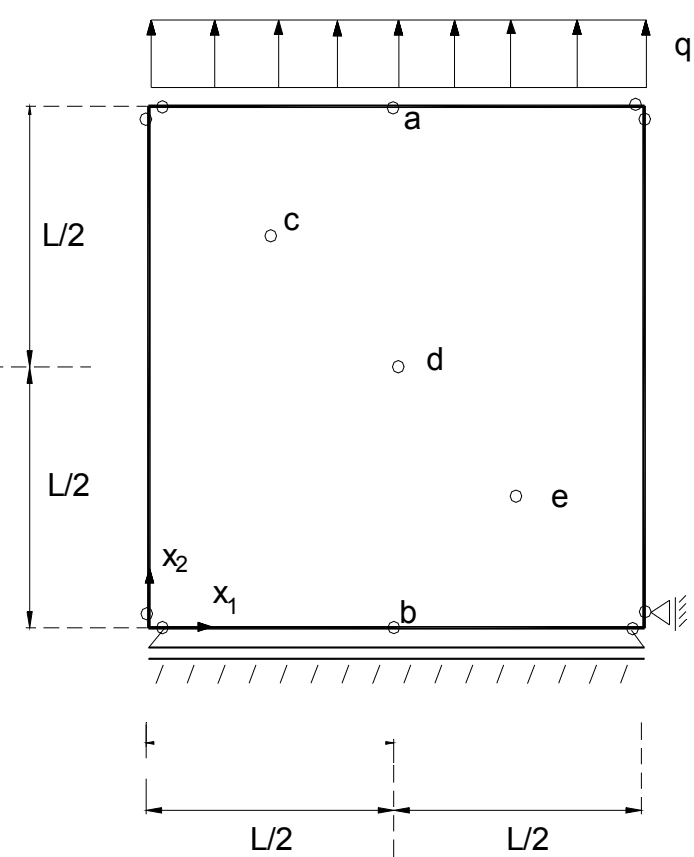

Figura 7.7- Chapa apoiada ao longo da base na direção $\mathrm{x}_{2}$. 
Tabela 7.7- Deslocamentos, forças de superfície e tensões.

\begin{tabular}{|c|c|c|c|}
\hline \multicolumn{2}{|c|}{} & TPC & $\begin{array}{c}\text { Solução } \\
\text { analítica }\end{array}$ \\
\hline \multirow{3}{*}{$\mathrm{W}(\mathrm{m})$} & $\boldsymbol{a}$ & $-1,0000$ & $-1,0000$ \\
\cline { 2 - 4 } & $\boldsymbol{c}$ & $-0,7500$ & $-0,7500$ \\
\cline { 2 - 4 } & $\boldsymbol{d}$ & $-0,5000$ & $-0,5000$ \\
\cline { 2 - 4 } & $\boldsymbol{e}$ & $-0,2500$ & $-0,2500$ \\
\hline \multirow{3}{*}{$\sigma_{22}(\mathrm{kPa})$} & $\boldsymbol{c}$ & $-1,0000$ & $-1,0000$ \\
\cline { 2 - 4 } & $\boldsymbol{d}$ & $-1,0000$ & $-1,0000$ \\
\cline { 2 - 4 } & $\boldsymbol{e}$ & $-1,0000$ & $-1,0000$ \\
\hline \multirow{2}{*}{$\mathrm{p}_{2}(\mathrm{kN} / \mathrm{m})$} & $\boldsymbol{b}$ & 1,0000 & 1,0000 \\
\hline
\end{tabular}

\subsection{8) Chapa submetida a binários nas extremidades}

Neste exemplo é analisada uma viga solicitada por binários nas extremidades. As constantes elásticas tem valores de 0,2 para o coeficiente de Poisson e $80000 \mathrm{MPa}$ para o módulo de elasticidade transversal. As dimensões e o carregamento aplicado estão indicados na figura 7.8 .

Os resultados numéricos - de DOMINGUEZ(1989), com aproximações constante e quadrática, e da formulação triparamétrica de chapas TRC com interpolação linear- estão indicados na tabela 7.8 .

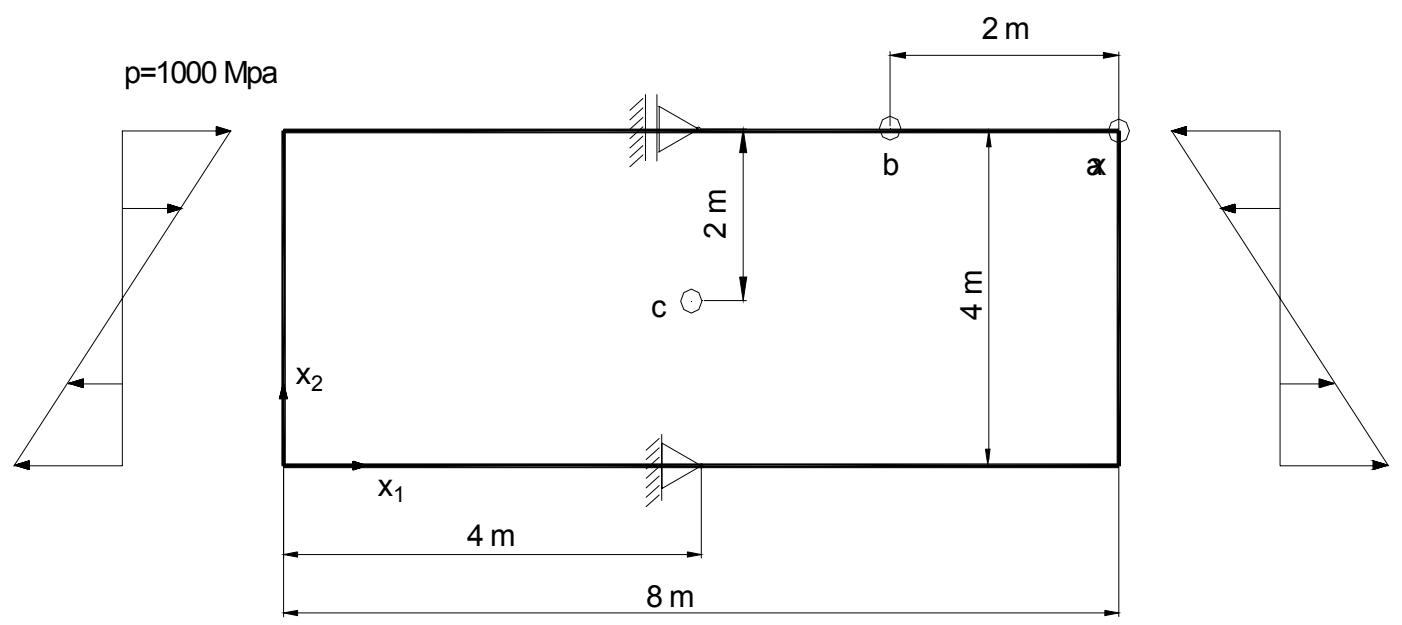

Figura 7.8- Chapa submetida à binários. 
Tabela 7.8- Deslocamentos e tensões.

\begin{tabular}{|l|c|c|c|c|}
\hline & & TRC & \multicolumn{2}{|l|}{ DOMINGUEZ(1989) } \\
\hline \multirow{2}{*}{$\mathrm{u}_{1}(\mathrm{~m})$} & $\boldsymbol{a}$ & $-0,01933$ & $-0,0157$ & $-0,019999$ \\
\cline { 2 - 5 } & $\boldsymbol{b}$ & 0,009626 & - & 0,009999 \\
\hline \multirow{2}{*}{$\mathrm{u}_{2}(\mathrm{~m})$} & $\boldsymbol{a}$ & 0,01875 & 0,0165 & 0,019999 \\
\cline { 2 - 5 } & $\boldsymbol{c}$ & $-0,001147$ & - & $-0,00125$ \\
\hline$\sigma_{11}(\mathrm{MPa})$ & $\boldsymbol{c}$ & $-0,8881 \mathrm{E}-14$ & - & $0,1640 \mathrm{E}-3$ \\
\hline$\sigma_{22}(\mathrm{MPa})$ & $\boldsymbol{c}$ & $0,9204 \mathrm{E}-12$ & - & $0,6484 \mathrm{E}-3$ \\
\hline
\end{tabular}

A partir da tabela 7.8 pode-se notar que os resultados da TRC utilizando-se interpolação linear têm respostas mais próximas das soluções numéricas com interpolação quadrática obtidas em Dominguez.

\subsection{9) Chapa submetida ao cisalhamento puro}

Neste exemplo é analisada uma chapa submetida ao cisalhamento devido a uma força $\mathrm{q}=1,0 \mathrm{kN} / \mathrm{m}$. A discretização é composta por 16 elementos simetricamente posicionados pelo contorno. A dimensão dos lado é $\mathrm{L}=1,0 \mathrm{~m}$ e está indicada na figura 7.9; as constantes elásticas são $\mathrm{G}=1,0 \mathrm{kPa}, v=0,0$. Os resultados estão indicados na tabela 7.9.

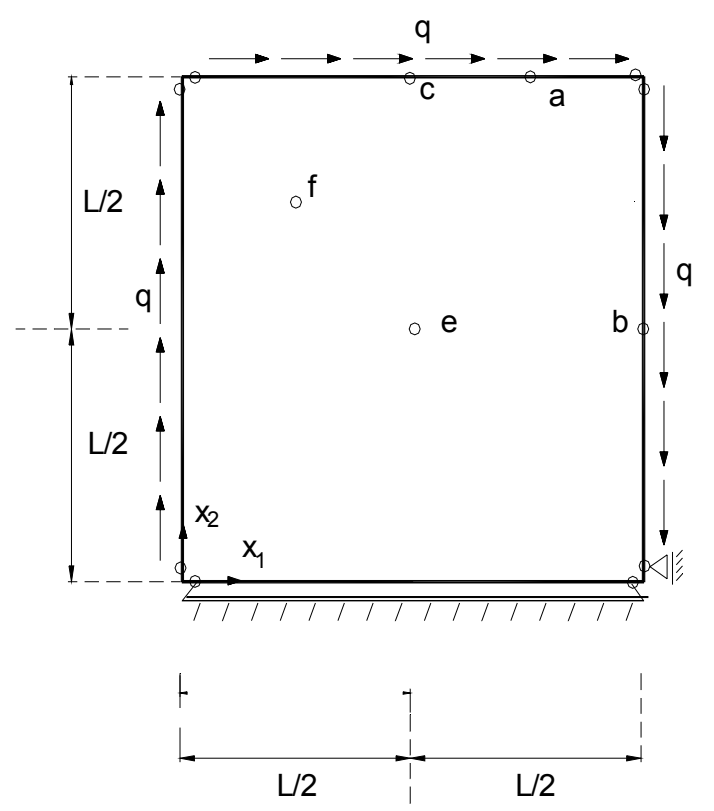

Figura 7.9- Chapa submetida ao cisalhamento 
Tabela 7.9- Deslocamentos e tensões.

\begin{tabular}{|l|c|c|c|c|}
\hline & $\mathrm{u}_{1}(\mathrm{~m})$ & $\mathrm{u}_{2}(\mathrm{~m})$ & $\mathrm{p}_{1}(\mathrm{kN} / \mathrm{m})$ & $\mathrm{p}_{2}(\mathrm{kN} / \mathrm{m})$ \\
\hline $\boldsymbol{a}$ & 0,500 & $0,15 \mathrm{E}-7$ & 0,000 & 1,000 \\
\hline $\boldsymbol{b}$ & 1,000 & $0,23 \mathrm{E}-7$ & 0,000 & 1,000 \\
\hline $\boldsymbol{c}$ & 2,000 & $0,11 \mathrm{E}-7$ & 1,000 & 0,000 \\
\hline $\boldsymbol{d}$ & 2,000 & $0,15 \mathrm{E}-15$ & 1,000 & 0,000 \\
\hline & $\mathrm{u}_{1}(\mathrm{~m})$ & $\mathrm{u}_{2}(\mathrm{~m})$ & $\sigma_{11}\left(k N / \mathrm{m}^{2}\right)$ & $\sigma_{12}\left(k N / \mathrm{m}^{2}\right)$ \\
\hline $\boldsymbol{e}$ & 1,000 & $0,20 \mathrm{e}-15$ & $0,62 \mathrm{e}-16$ & 1,000 \\
\hline $\boldsymbol{f}$ & 1,500 & $-1,08 \mathrm{e}-7$ & $0,40 \mathrm{e}-8$ & 1,000 \\
\hline
\end{tabular}

As respostas obtidas com a TRC são praticamente coincidentes com àquelas da solução analítica.

\subsubsection{0) Problema de Cook}

Neste exemplo é analisada uma membrana de espessura unitária engastada em uma das extremidades e livre nas demais com um carregamento tangencial unitário total na borda oposta à vinculada ${ }^{3}$, vide figura 7.10. As constantes elásticas da chapa são $E=1 \mathrm{kN} / \mathrm{cm}^{2}$ e $v=1 / 3$. O carregamento tangencial distribuído na extremidade não-vinculada tem resultante unitária.

Os resultados da análise estão indicados na tabela 7.10 onde as formulações triparamétrica cúbica(TPC) e biparamétrica linear de chapas(BPC) têm discretização (8X8), vide 7.10a. Além disso, também são mostrados os resultados obtidos por BERGAN \& FELIPPA(1985) via MEF utilizando uma formulação que incorpora um grau de liberdade de rotação, cujo vetor associado é normal plano médio da chapa.

Bergan utilizou diversas discretizações para o problema, na tabela 7.10 estão indicados apenas os resultados para a malha do MEF com o padrão de 32 partições por lado, rotulado como (32X32); um padrão mais pobre de discretização está indicado na figura 7.10b. Optou-se ilustrar o padrão (8X8) do MEF apenas com o intuito de atingir um melhor nível de clareza no desenho.

\footnotetext{
${ }^{3}$ Esse problema foi proposto originalmente por COOK(1974) para testar casos gerais de elementos finitos quadrilaterais.
} 


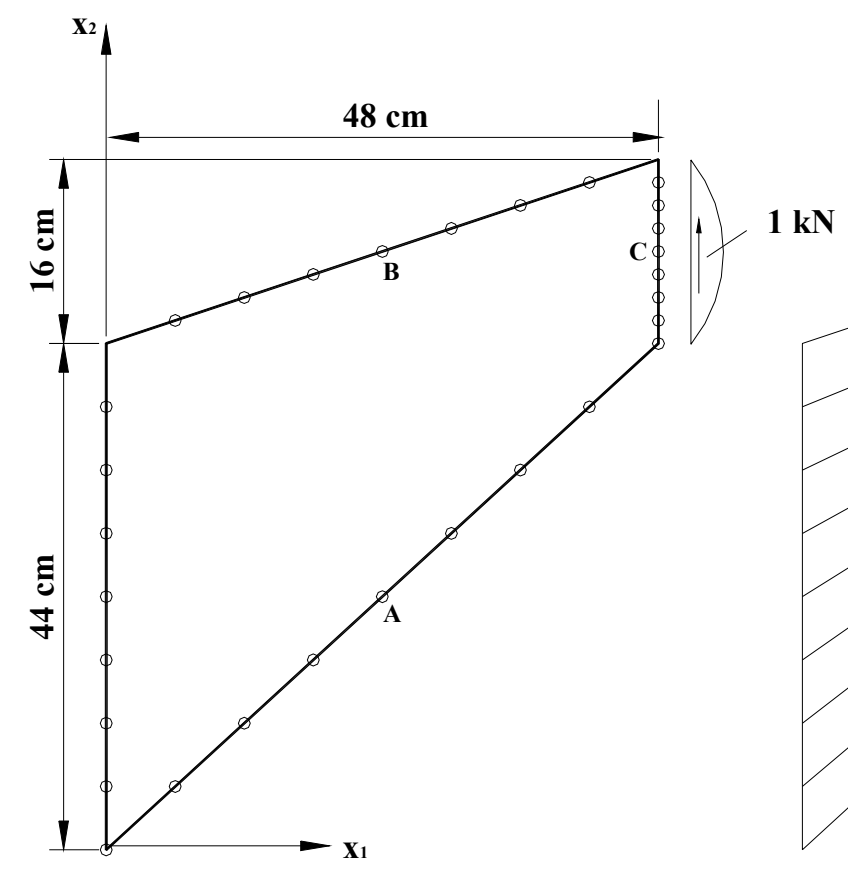

(a)

(b)

Figura 7.10- Esquema e discretização do problema de Cook.

Tabela 7.10- Deslocamentos e tensões principais no problema de Cook.

\begin{tabular}{|c|c|c|c|}
\hline & BERGAN \& F.(1985) & BPC & TPC \\
\hline Malha & $(32 \times 32):$ MEF & $(8 X 8): M E C$ & $(8 X 8): M E C$ \\
\hline \multicolumn{4}{|c|}{ Deslocamento vertical } \\
\hline Ponto & 23,91 & 22,94 \\
\hline \multicolumn{5}{|c|}{ Tensão principal mínima } \\
\hline C & $-0,2012$ & -0.2074 \\
\hline \multicolumn{5}{|c|}{ Tensão principal máxima } \\
\hline A & 0,2359 & 0,24939 & $-0,2024$ \\
\hline \multicolumn{5}{|c|}{} & 0,2308 \\
\hline B & &
\end{tabular}

A partir da tabela 7.10, pode-se observar um bom desempenho das formulações BPC e TPC com as respostas obtidas utilizando uma malha rica de elementos finitos. Convém notar que neste caso a TPC tem um melhor nível de concordância com a resposta admitida valor de referência: MEF publicada em BERGAN \& FELIPPA(1985). 


\subsubsection{1) Placa apoiada com duas regiões sob carregamento distribuído em linha.}

Uma placa quadrada de lado $a$, simplesmente apoiada está submetida a um carregamento em linha uniformemente distribuído $p$ conforme indicado na figura 7.11. Inicialmente, admite-se que seu plano médio esteja associado a duas regiões com regiões de rigidezes distintas $D_{1}$ e $D_{2}$, respectivamente. Modelando-se esse problema para cada subregião, e aplicando-se a técnica de subregiões, e com intuito de comparar o desempenho da formulação triparamétrica com valores analíticos disponíveis em TIMOSHENKO(1940), é atribuído via 'input' o mesmo valor para ambas rigidezes, isto é, $D_{1}=D_{2}=D$. Na análise do problema são utilizadas diferentes discretizações, para o MEC (tipo 1 a 4), vide figura 7.12, aplicadas igualmente em cada subregião. Convém notar que a malha do tipo 5 é para discretização do MEF que será utilizada em outras análises a partir do exemplo 7.1.12. Na figura 7.13, estão indicados os valores do coeficiente $\alpha$ em função do tipo de interpolação das variáveis e do tipo de discretização. O coeficiente $\alpha$ está associado ao deslocamento transversal máximo pela relação: $w=\alpha p a^{3} / D$. Além disso, os resultados da formulação triparamétrica de placas para as interpolações linear e cúbica estão indicados como 'TL e TC'.

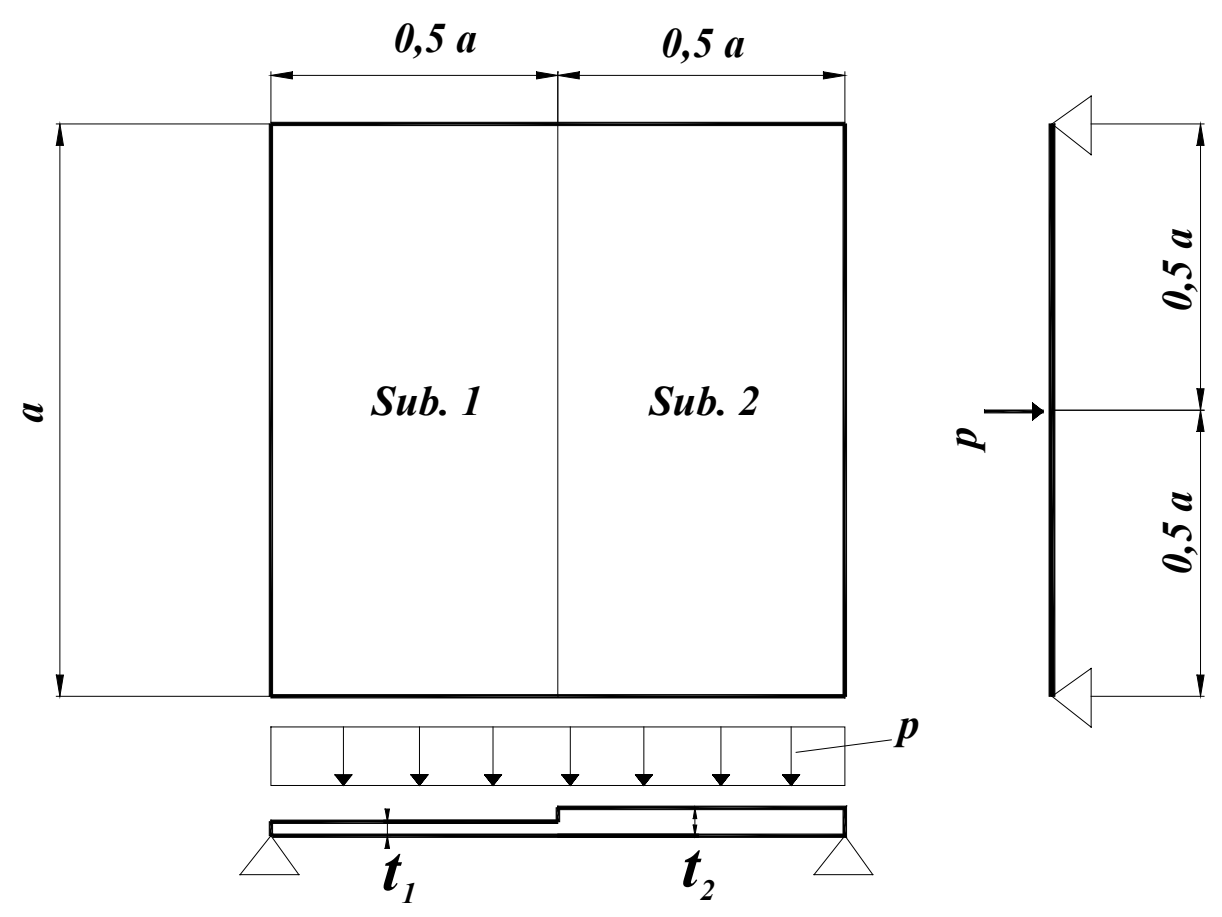

Figura 7.11- Placa simplesmente apoiada sob carregamento distribuído em linha. 


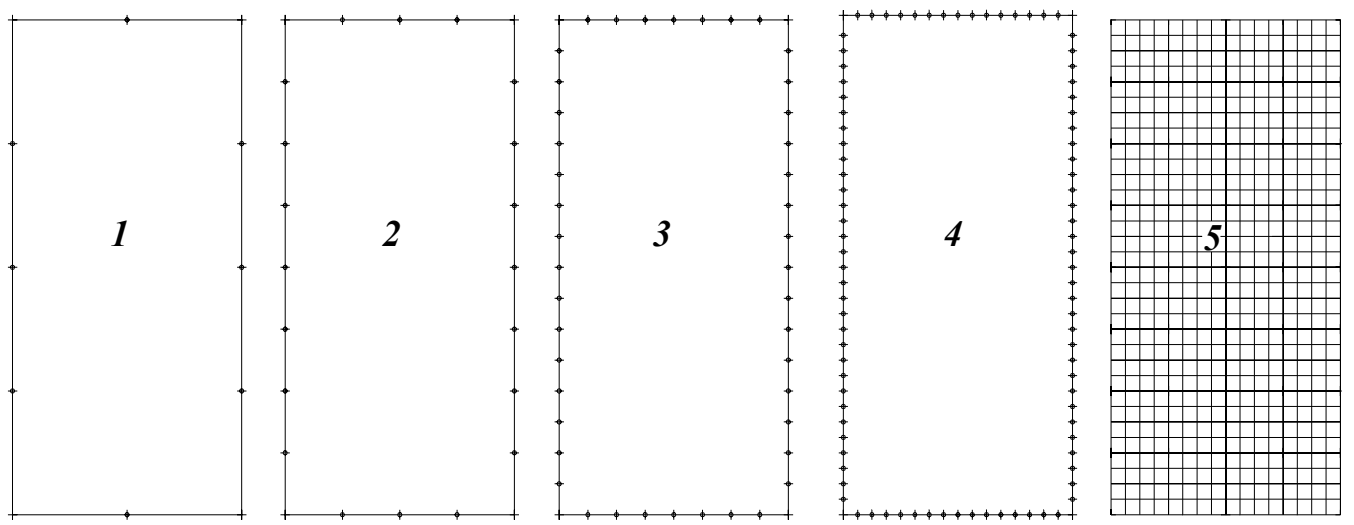

Figura 7.12-Tipos de Malhas

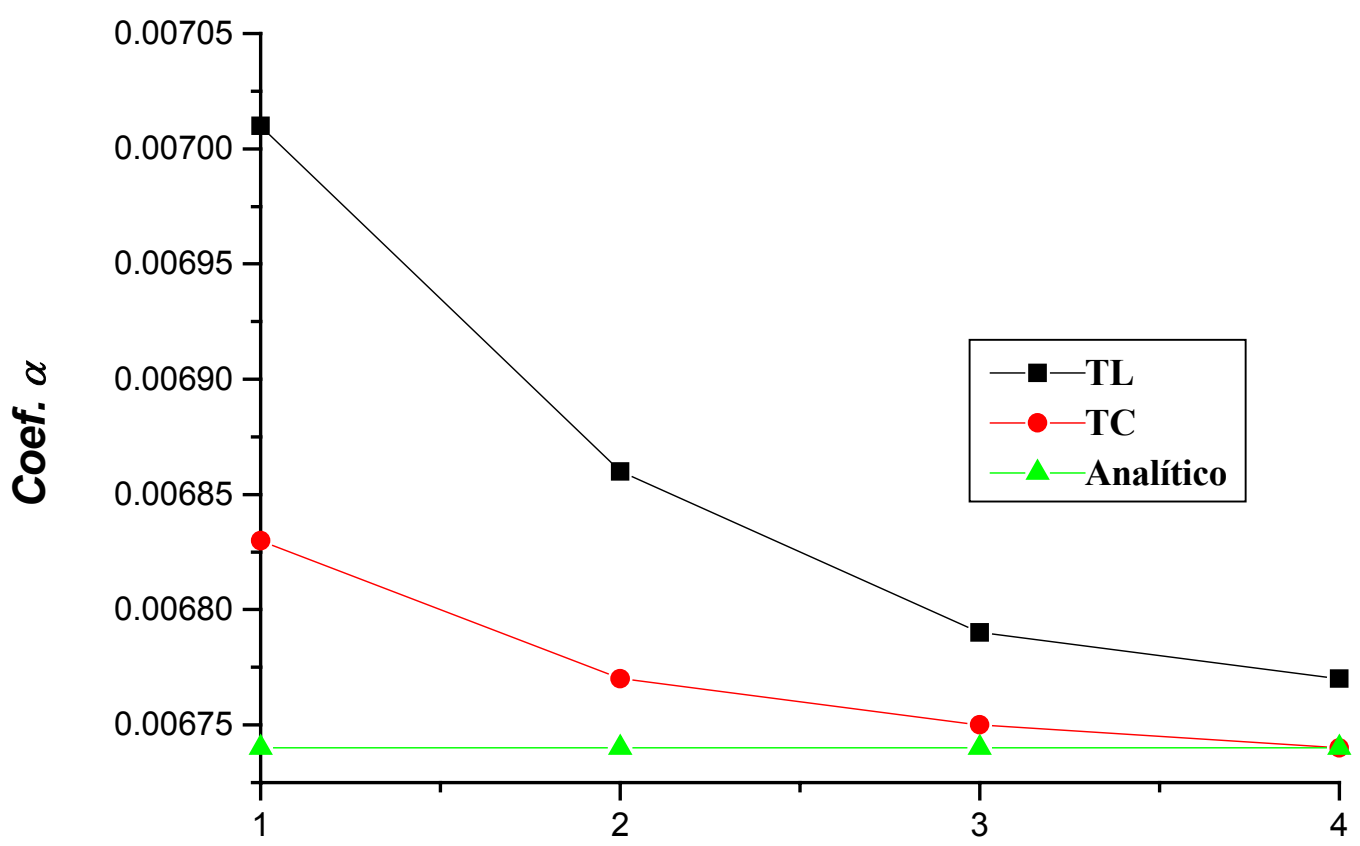

Tipo de Malha

Figura- 7.13- Coeficiente $\alpha$ Versus Tipo de Malha.

A partir da figura 7.13, pode-se notar que a convergência para a solução analítica é sensivelmente melhorada quando é utilizada a interpolação cúbica para os deslocamentos na formulação triparamétrica de placas(TC). 


\subsubsection{2) Placa de espessura variável em balanço.}

Uma placa quadrada com variação de espessura em uma direção é modelada admitindo-se quatro subregiões tendo suas respectivas rigidezes, vide figura 7.14. A placa está engastada na borda mais espessa e livre nas demais; também está submetida a um carregamento unitário, uniformemente distribuído ao longo de todo domínio. O lado da placa $a=100 \mathrm{~cm}$ e o módulo de elasticidade longitudinal $E=10^{8} \mathrm{kN} / \mathrm{cm}^{2}$. O coeficiente de Poisson $v=0,3$. Na figura 7.15, está indicado os valores do deslocamento transversal ao longo da linha A-B, definida pelos pontos médios das bordas (engastada e de sua oposta), em função da discretização (tipo 1 ou tipo 2, vide figura 7.12) e da interpolação das variáveis(linear ou cúbica). Os resultados do MEC são comparados com aqueles obtidos pelo MEF utilizando-se o elemento Shell 63 do Software ANSYS e cada subregião tendo uma discretização do tipo 5, vide figura 7.12 .
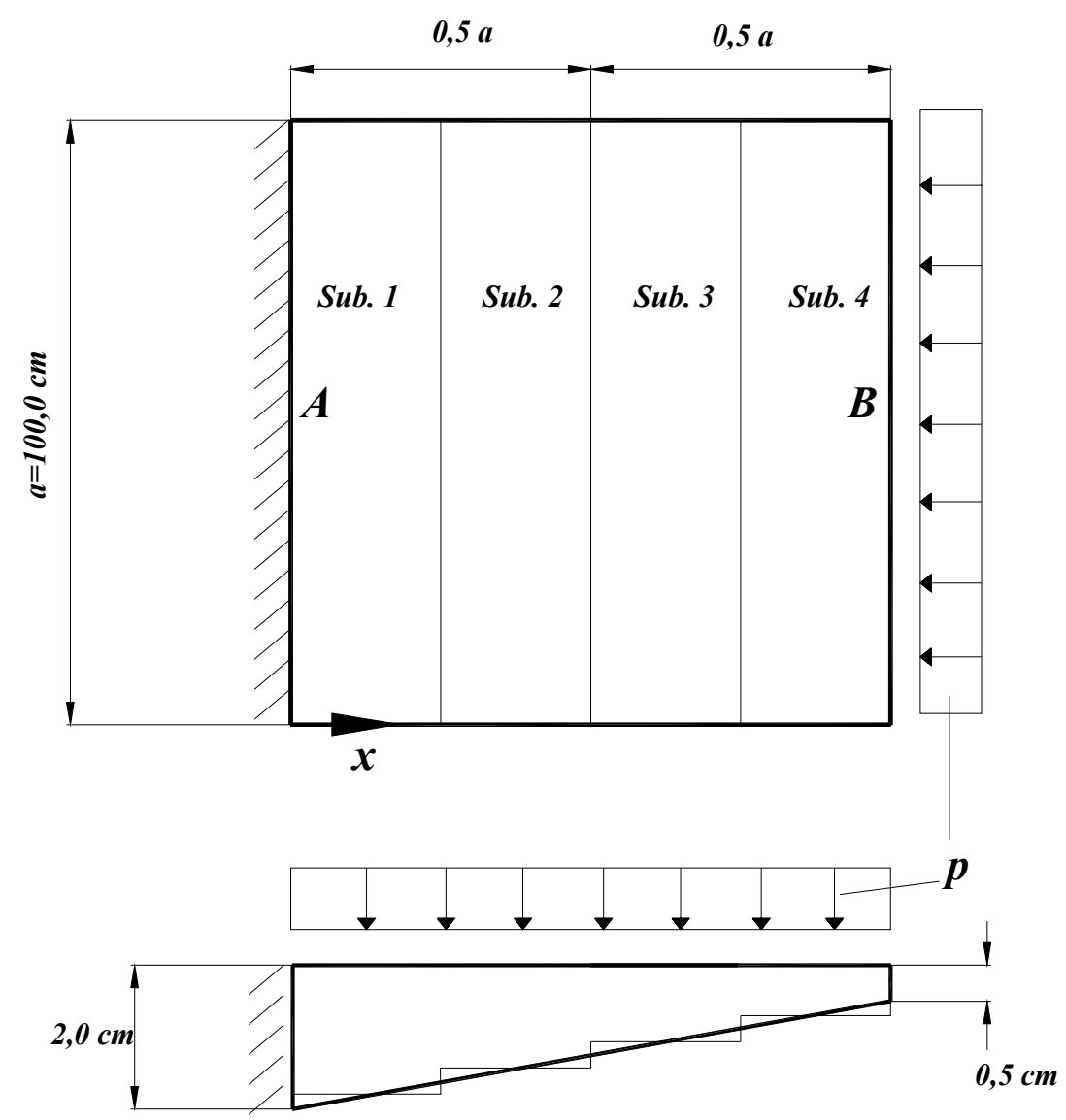

Figura 7.14- Placa engastada com variação de espessura. 


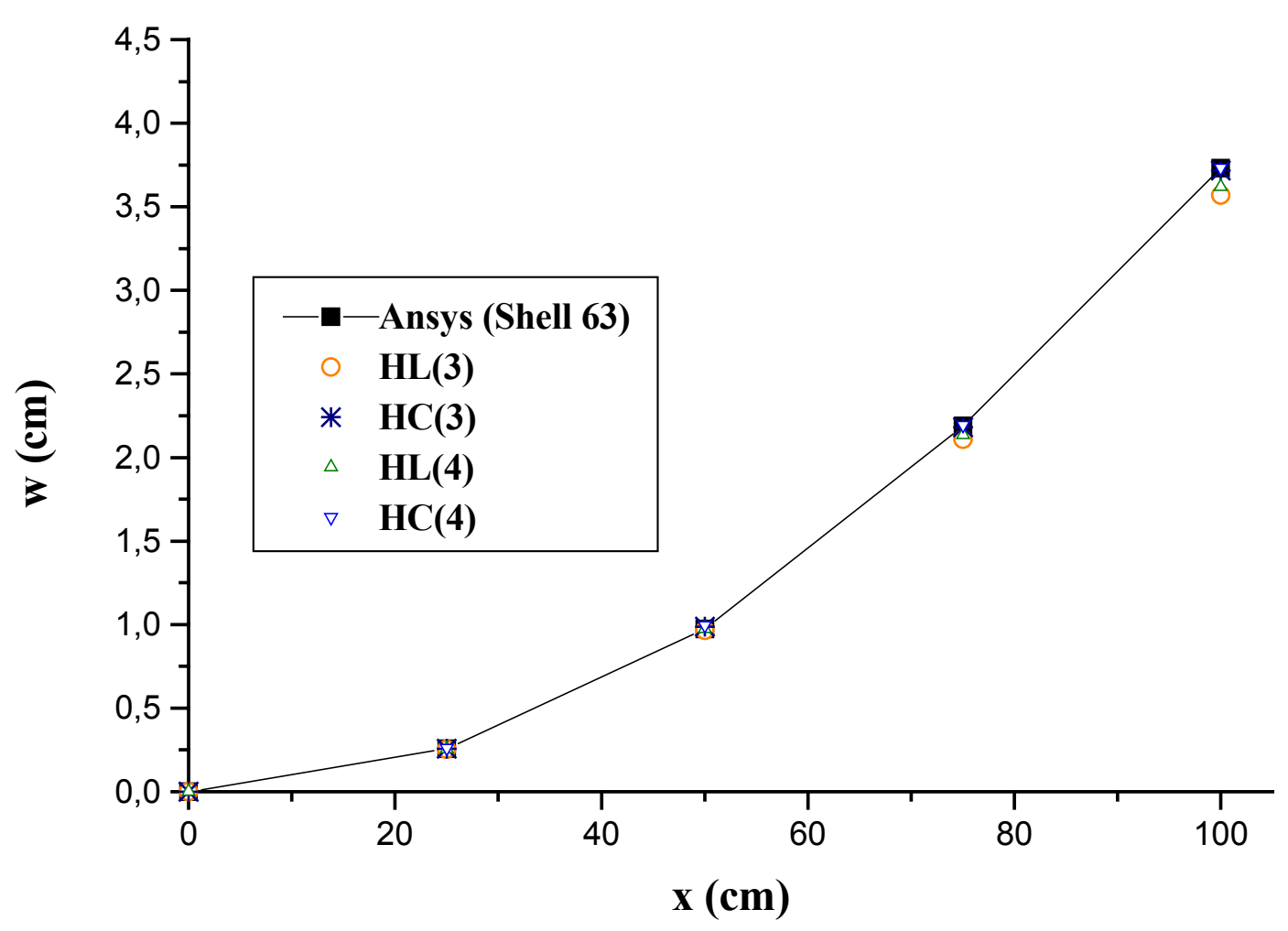

Figura 7.15- Deslocamento Transversal ao Longo de A-B.

Pode-se notar que para todas as malhas discretizadas, os resultados da formulação triparamétrica de placas ficaram muito próximos daqueles obtidos via MEF.

Nos exemplos a seguir as propriedades do material constituinte têm valores associados respectivamente ao módulo de elasticidade e ao coeficiente de Poisson por $E=1,09210^{3} \mathrm{kN} / \mathrm{m}^{2}$ e $v=0,3$. O vão livre e a espessura das lâminas recebem os respectivos valores de $L=10,0 \mathrm{~m}$ e $t=0,1 \mathrm{~m}$. As extremidades longitudinais das estruturas são engastadas.

Os resultados são indicados em figuras em que os desempenhos da formulação hexaparamétrica são abreviados por $H C(\beta)$ ou $H L(\beta)$, correspondendo respectivamente às interpolações cúbica e linear; $\beta$ denota o tipo de malha utilizada. Já os resultados da formulação tetraparamétrica linear são abreviados por $T L(\beta)$ e a discretização utilizada nas análises do MEC está associada aos tipos de malhas $\beta=3,4$. 
Além disso, os problemas também são modelados pelo MEF via ANSYS utilizando-se o elemento Shell 63 com a discretização do tipo 5, cuja indicação nas figuras é denotada por Ansys( shell63). É indicado em tabelas, a diferença relativa de MEC(HC, HL e TL) e o do MEF(Ansys: Shell 63) -quando os valores do Ansys são tomados como referência- dada por: $\operatorname{Drel}(\%)=100 \frac{\mid \text { valor }_{\text {Ansys }}-\text { valor }_{M E C} \mid}{\mid \text { valor }_{\text {Ansys }} \mid}$.

\subsubsection{3) Viga $\pi$ engastada nas extremidades.}

Neste exemplo analisa-se uma estrutura de seção aberta contendo duas interfaces com três lâminas convergentes a cada uma delas. Tal estrutura é uma viga pi submetida a um carregamento unitário uniformemente distribuído ao longo do domínio das lâminas da flange da viga, vide na figura 7.16.

Por simetria, são descritos os deslocamentos transversal, normal e tangencial associados aos nós discretizados entre a extremidade e o ponto médio da interface. Os resultados, indicados nas figuras 7.17-19, são expressos em função do triedro local $(s, n, w)$ da interface $\mathrm{AB}$ da subregião 2, conforme indicado na figura 7.16. Já nas figuras de 7.20-21 estão indicados os deslocamentos e momentos ao longo da linha $\mathrm{BC}$ ( pontos no domínio da lâmina central da flange da viga)

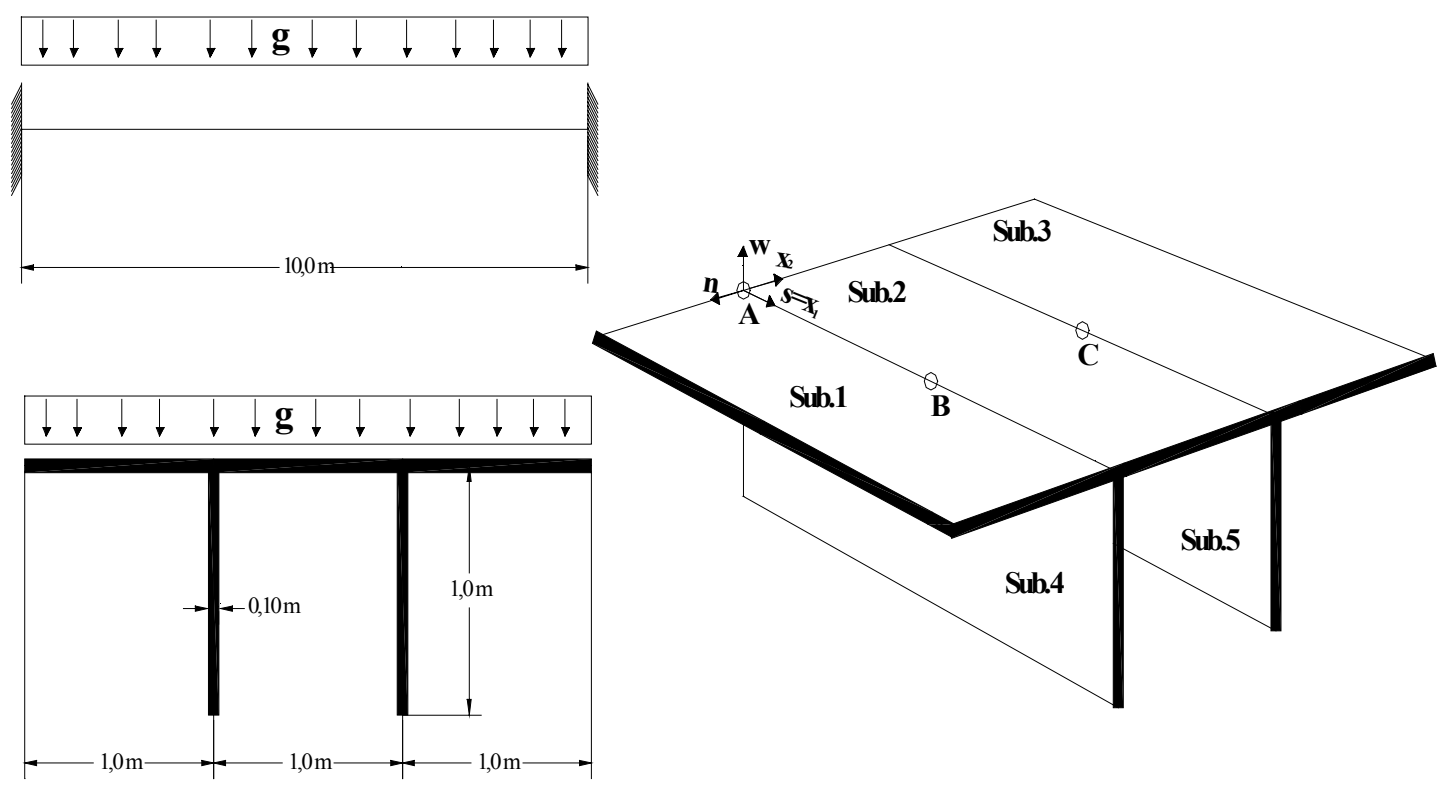

Figura 7.16- Esquema Representativo da Viga $\pi$. 


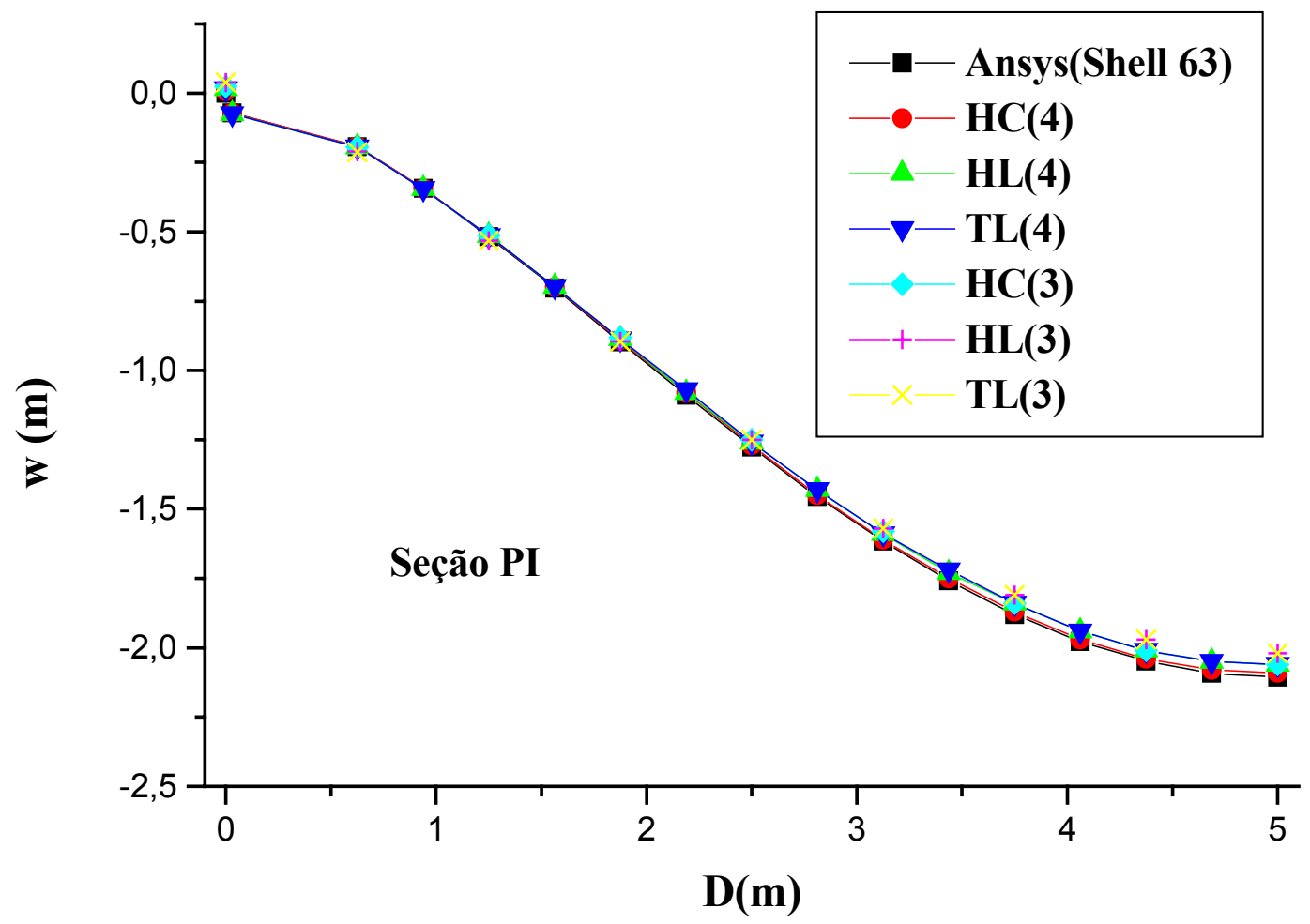

Figura 7.17- Deslocamento Transversal ao Longo da Interface AB da Viga $\pi$.

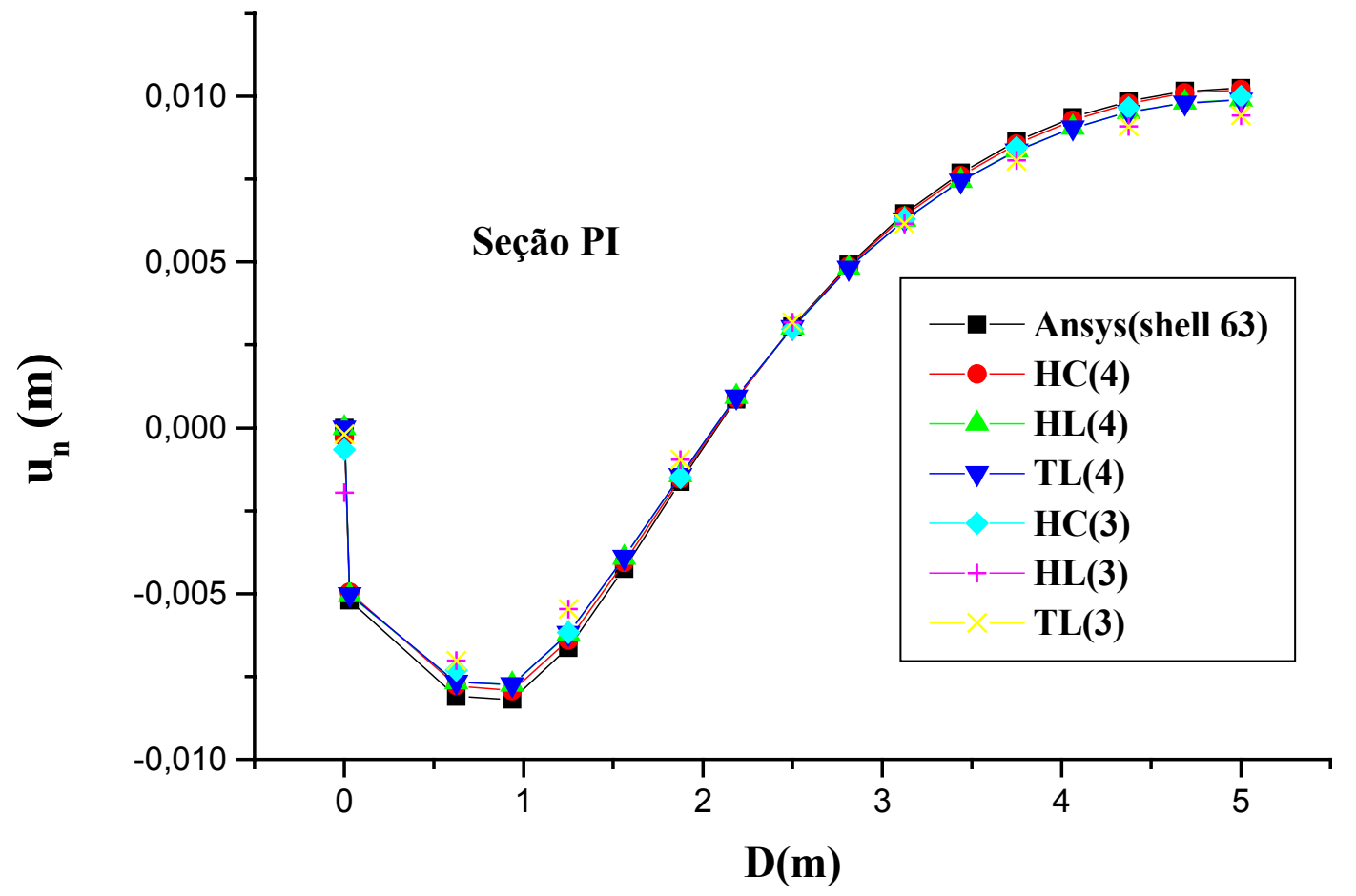

Figura 7.18- Deslocamento Normal ao Longo da Interface AB da Viga $\pi$. 


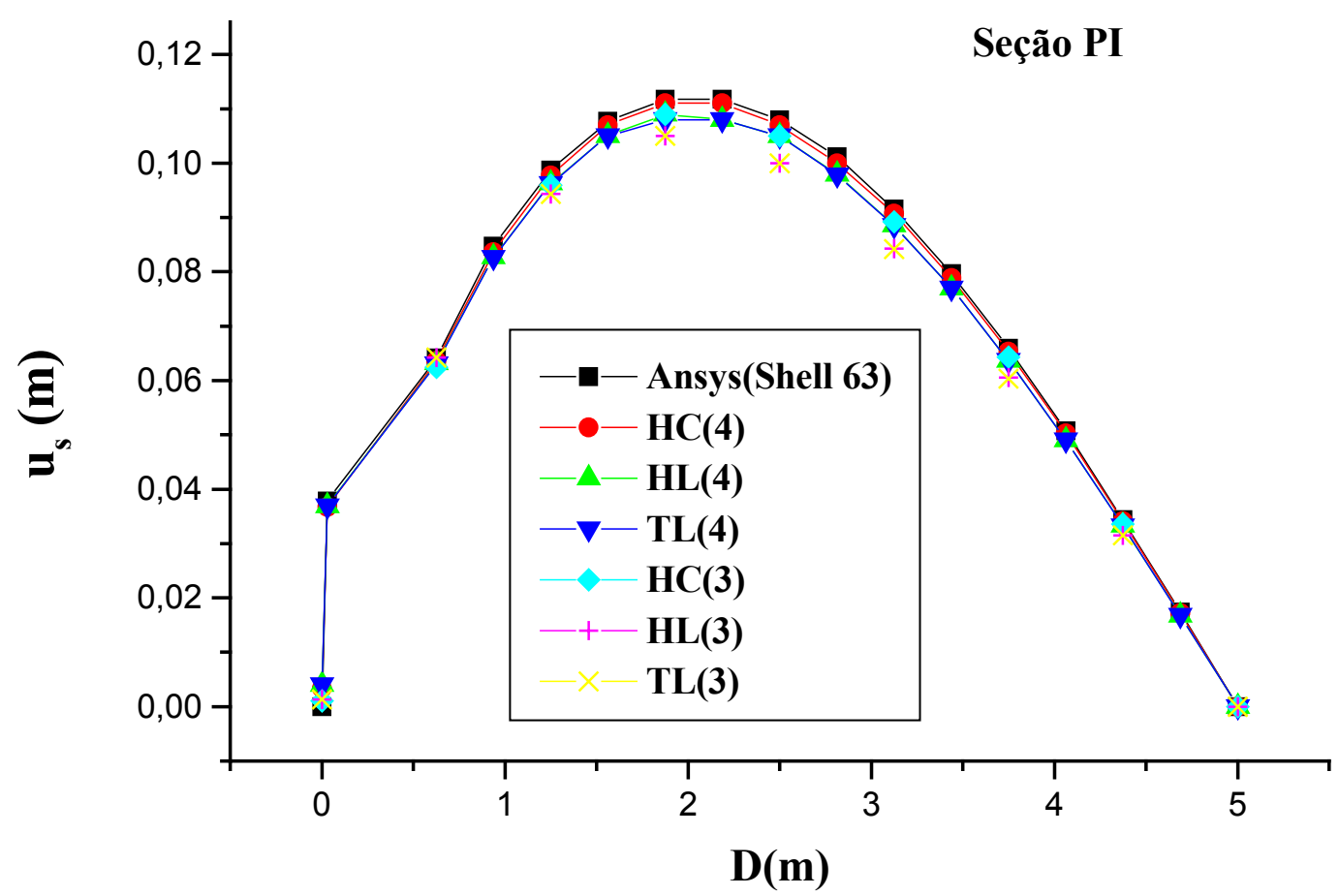

Figura 7.19- Deslocamento Tangencial ao Longo da Interface da Viga $\pi$.

$\mathrm{Na}$ tabela 7.11, estão indicados os valores das diferenças relativas para os deslocamentos tangencial, normal e transversal. Pode-se notar que $u_{s}$ e $u_{n}$ têm as maiores diferenças nos resultados HL e TL obtidas com a malha do tipo 3. Já a interpolação HP cúbica é menos afetada pela transição do tipo de malha 4 para 3 . Além disso, para os campos em questão, o modelo HC, com uma malha menos rica $\beta=3$, tem melhor desempenho que HL e TL discretizados com $\beta=4$. Para $w$ pode ser observado uma variação menor que os campos anteriores, e mais uma vez, o modelo HC(3) tem desempenho na mesma ordem de grandeza que HL(4) e TL(4).

Tabela 7.11- Diferença relativa para campos na interface AB.

\begin{tabular}{|c|c|c|c|c|c|c|}
\hline \multicolumn{7}{|c|}{ Drel $(\%)$} \\
\hline \multicolumn{7}{|c|}{ Heslocamento Tangencial $\left(u_{s}\right)$} \\
\hline D(m) & HC(4) & HL(4) & TL(4) & HC(3) & HL(3) & TL(3) \\
\hline 3,75 & 0,96 & 3,38 & 3,38 & 2,47 & 8,24 & 8,39 \\
\hline \multicolumn{7}{|c|}{ Deslocamento Normal $\left(u_{n}\right)$} \\
\hline 5,00 & 0,49 & 3,42 & 3,51 & 2,44 & 8,10 & 8,10 \\
\hline \multicolumn{7}{|c|}{ Deslocamento Transversal $(w)$} \\
\hline 5,00 & 0,76 & 2,19 & 2,19 & 2,19 & 4,09 & 4,09 \\
\hline
\end{tabular}




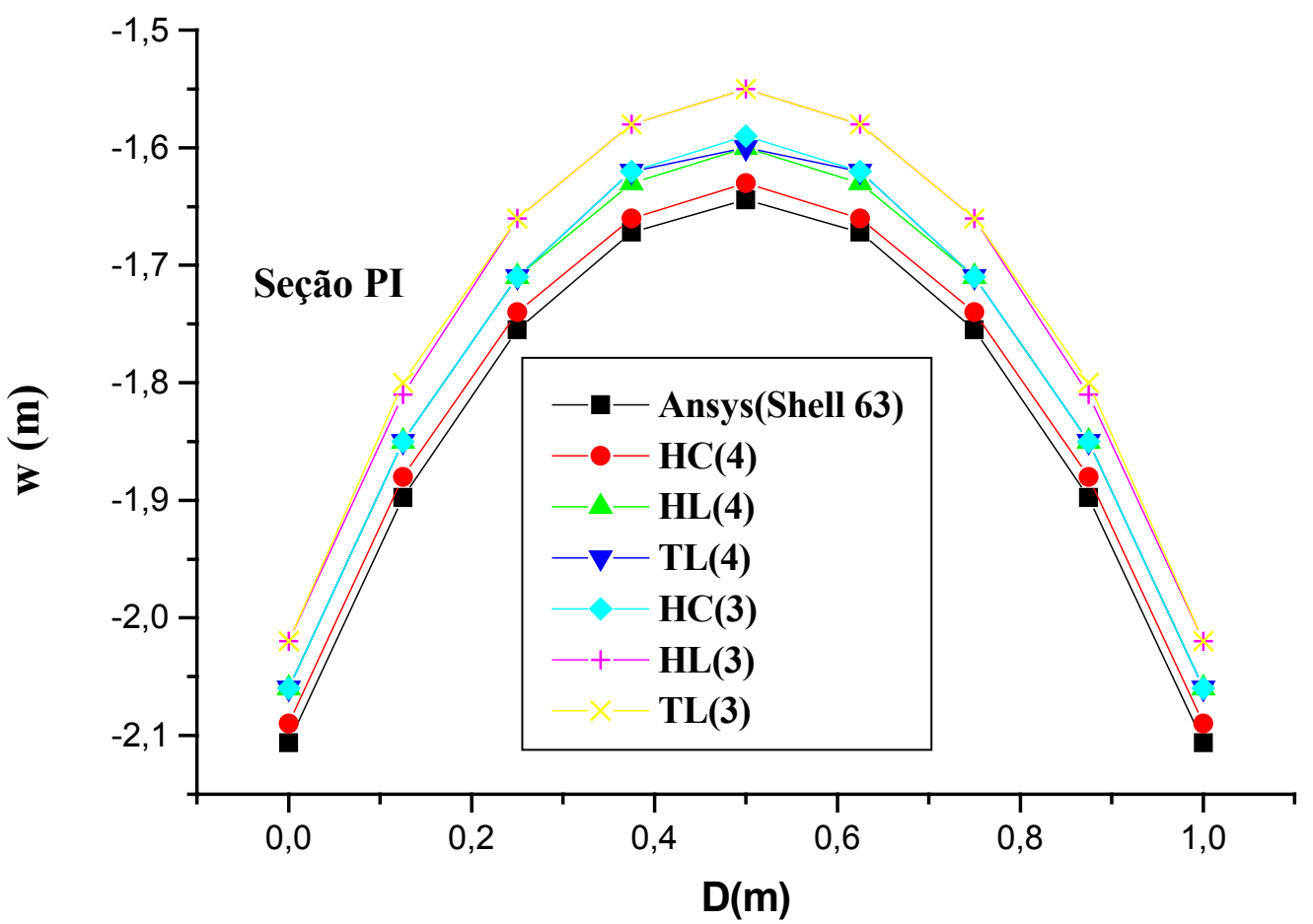

Figura 7.20- Deslocamento transversal ao Longo da linha BC da Viga $\pi$.

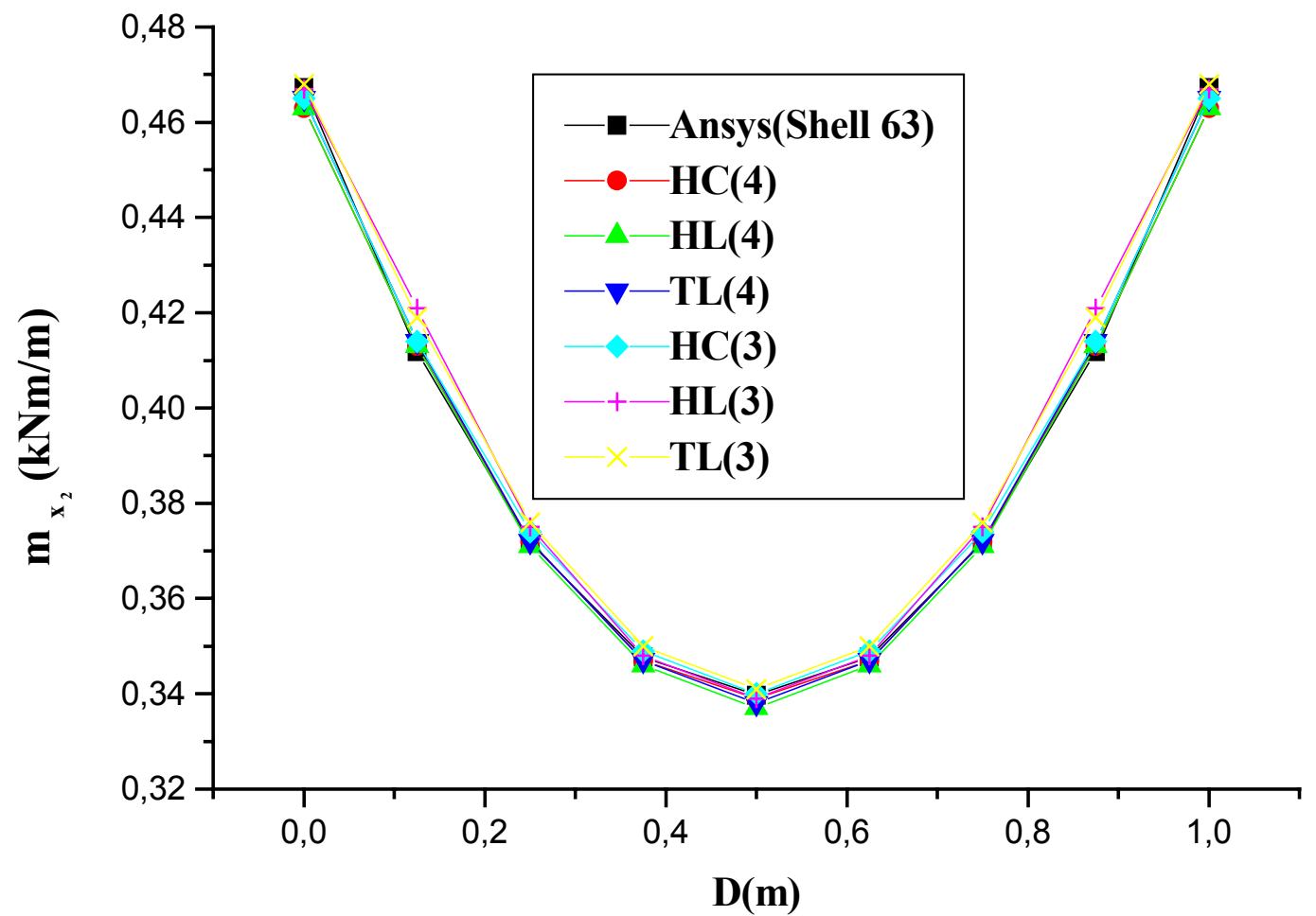

Figura 7.21- Momentos fletores $m_{x_{2}}$ ao Longo da linha BC da Viga $\pi$. 
$\mathrm{Na}$ tabela 7.12, estão indicadas as diferenças relativas para $w$ e $m_{x_{2}}$ em alguns pontos da linha $\mathrm{BC}$.

Tabela 7.12- Diferença relativa em deslocamentos e momentos na linha BC

\begin{tabular}{|c|c|c|c|c|c|c|}
\hline \multicolumn{7}{|c|}{$\operatorname{Drel}(\%)$} \\
\hline $\mathbf{D}(\mathbf{m})$ & HC(4) & HL(4) & TL(4) & HC(3) & HL(3) & TL(3) \\
\hline 0,50 & 0,88 & 2,70 & 2,70 & 3,31 & 5,74 & 5,74 \\
\hline \multicolumn{7}{|c|}{ Momento fletor $\left(m_{x_{2}}\right)$} \\
\hline 0,5 & 0,22 & 0,81 & 0,51 & 0,08 & 0,22 & 0,37 \\
\hline 1,00 & 0,91 & 0,90 & 0,48 & 0,48 & 0,05 & 0,16 \\
\hline
\end{tabular}

Note que $m_{x_{2}}$ é menos sensível à mudança do enriquecimento das malhas 3 para 4, que os campos de deslocamento, apresentando valores muito próximos aos do Ansys.

\subsubsection{4) Viga $V$ engastada nas extremidades.}

Neste exemplo tem-se uma estrutura em que a interface tem quatro lâminas conectadas a ela, vide figura 7.22. Um carregamento unitário está uniformemente aplicado nas lâminas horizontais. Os resultados, indicados nas figuras 7.23-26, são expressos em função do triedro local $(s, n, w)$ da interface $\mathrm{AB}$ da subregião 2 , vide figura 7.22. Na tabela 7.13, as diferenças relativas entre as respostas do MEC e do MEF(Ansys) são mostradas para pontos sobre as linha AB e BC, vide figura 7.22.

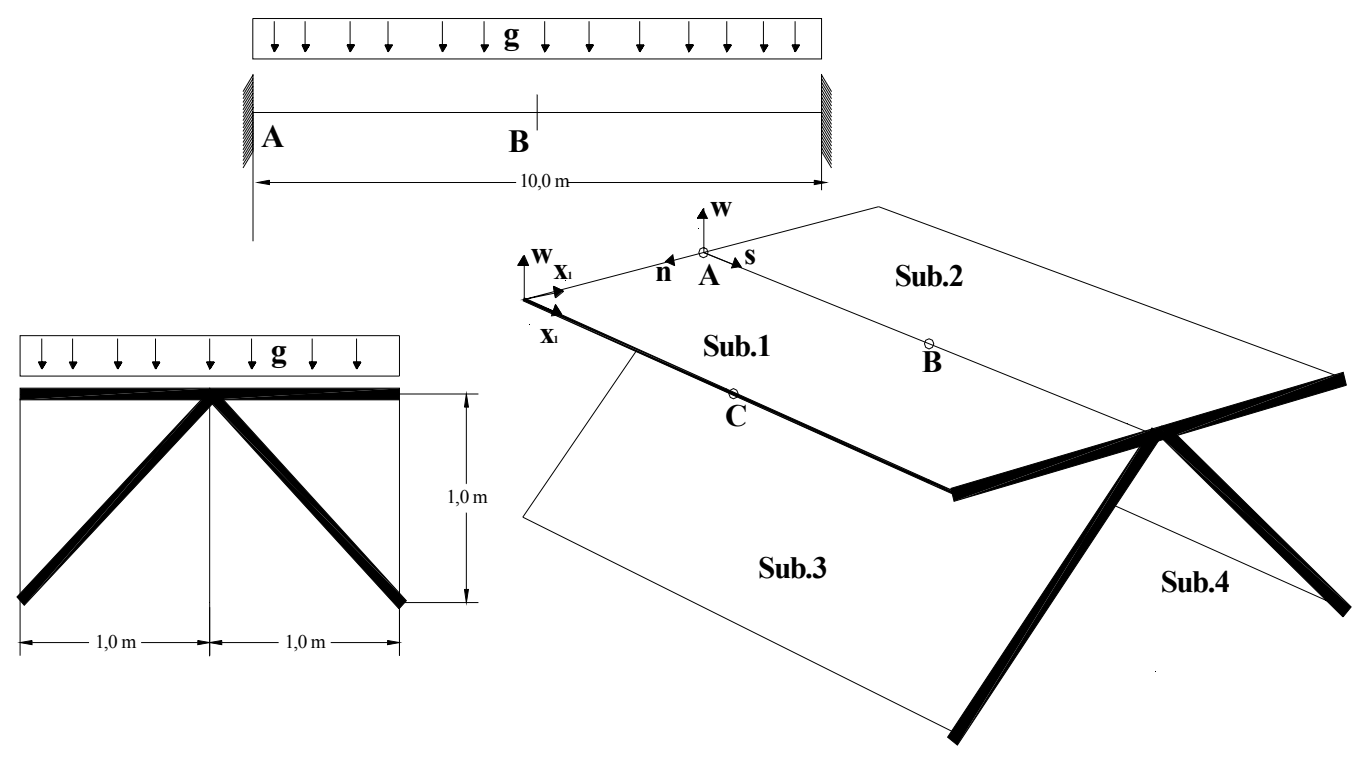

Figura 7.22- Esquema representativo da viga $V$. 


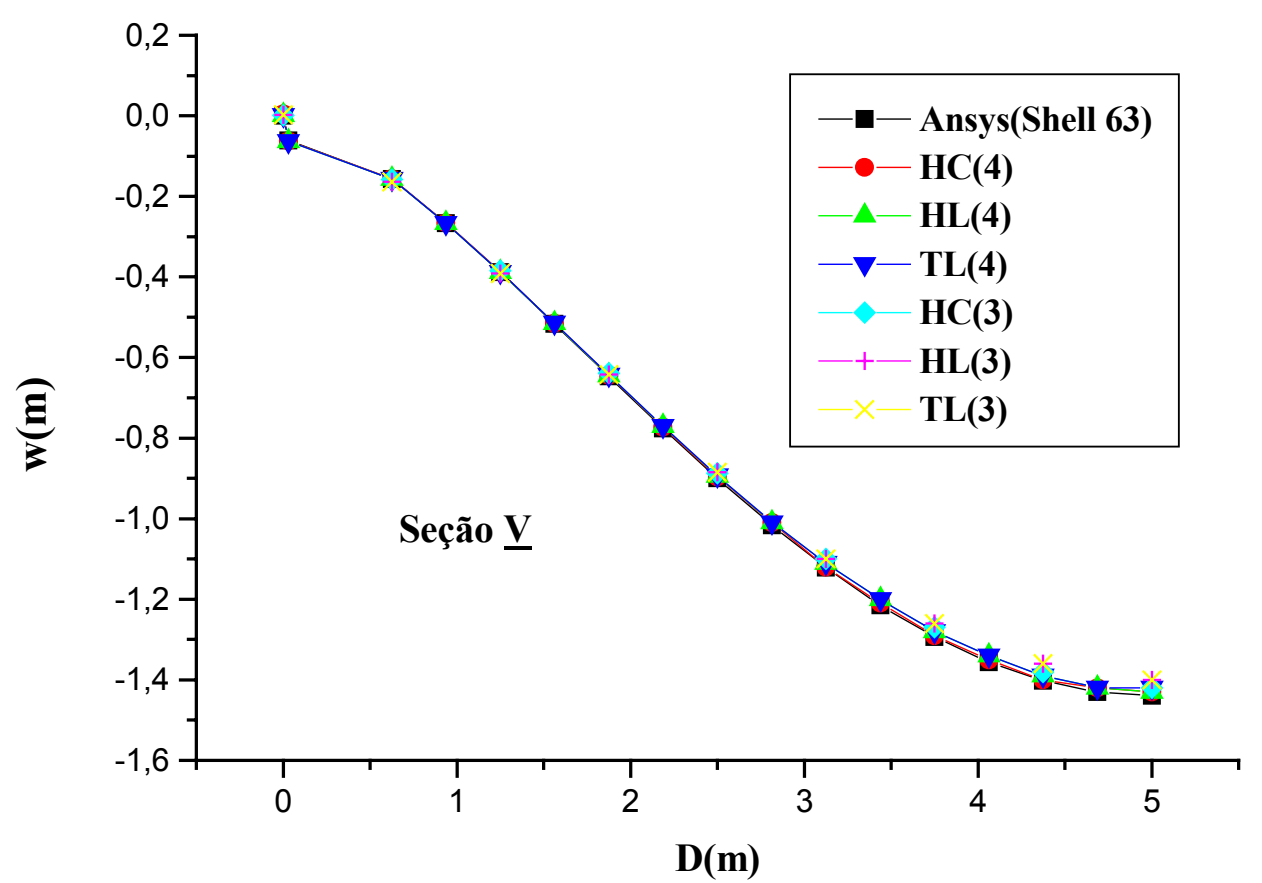

Figura 7.23- Deslocamento Transversal ao Longo da Interface AB da Viga $V$.

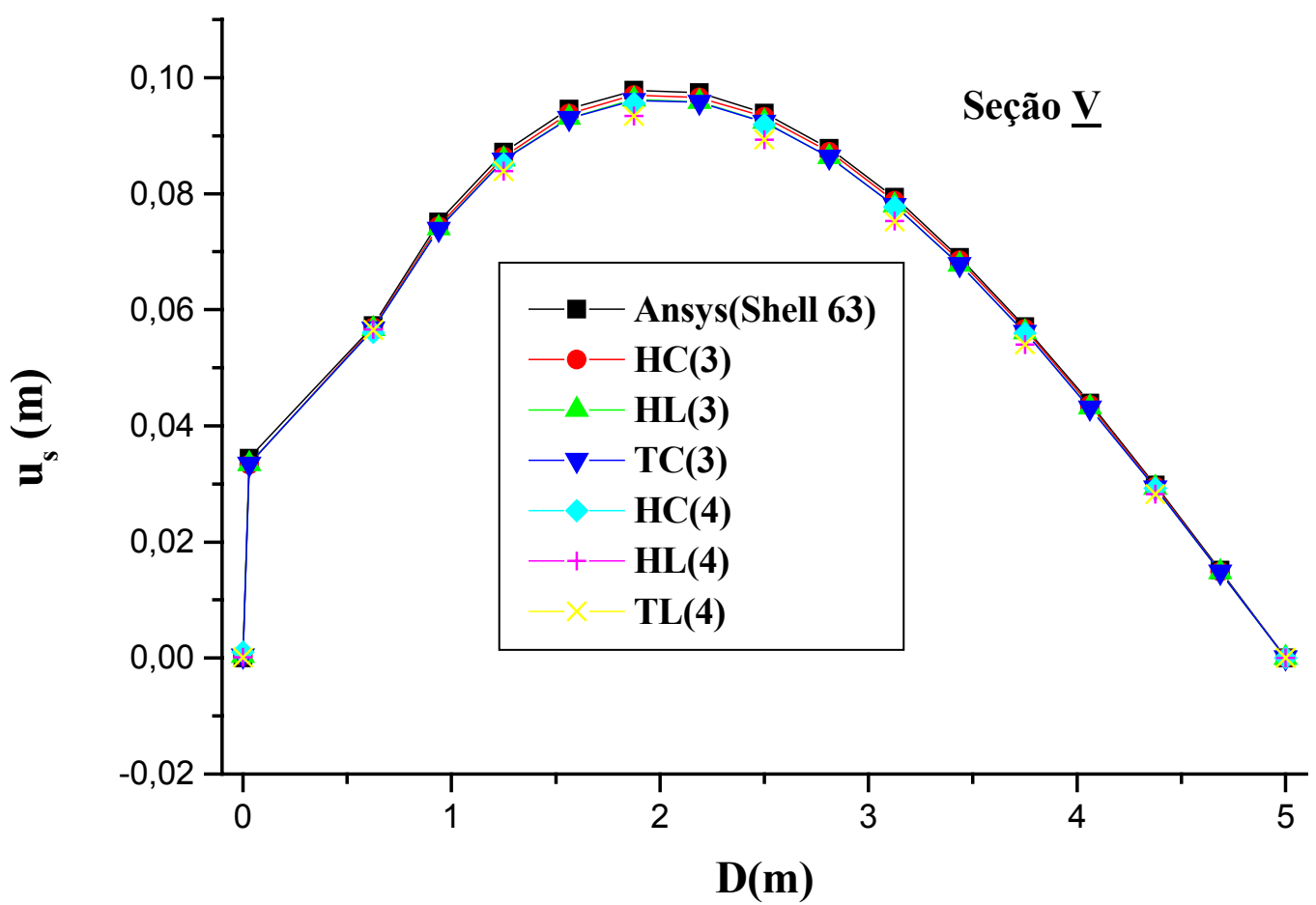

Figura 7.24- Deslocamento Tangencial ao Longo da Interface AB da Viga $V$. 


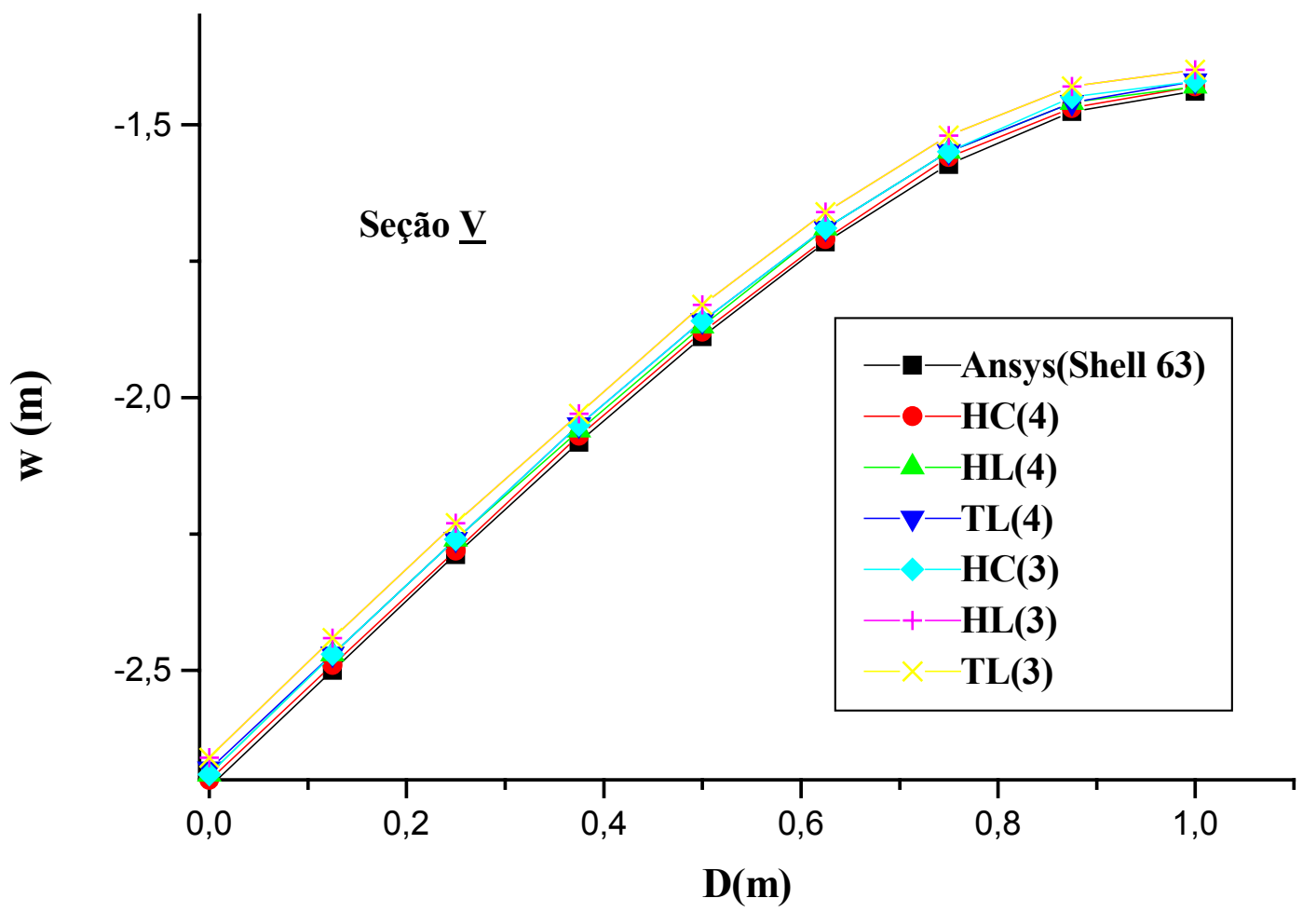

Figura 7.25- Deslocamento Transversal ao Longo da BC da Viga $V$.

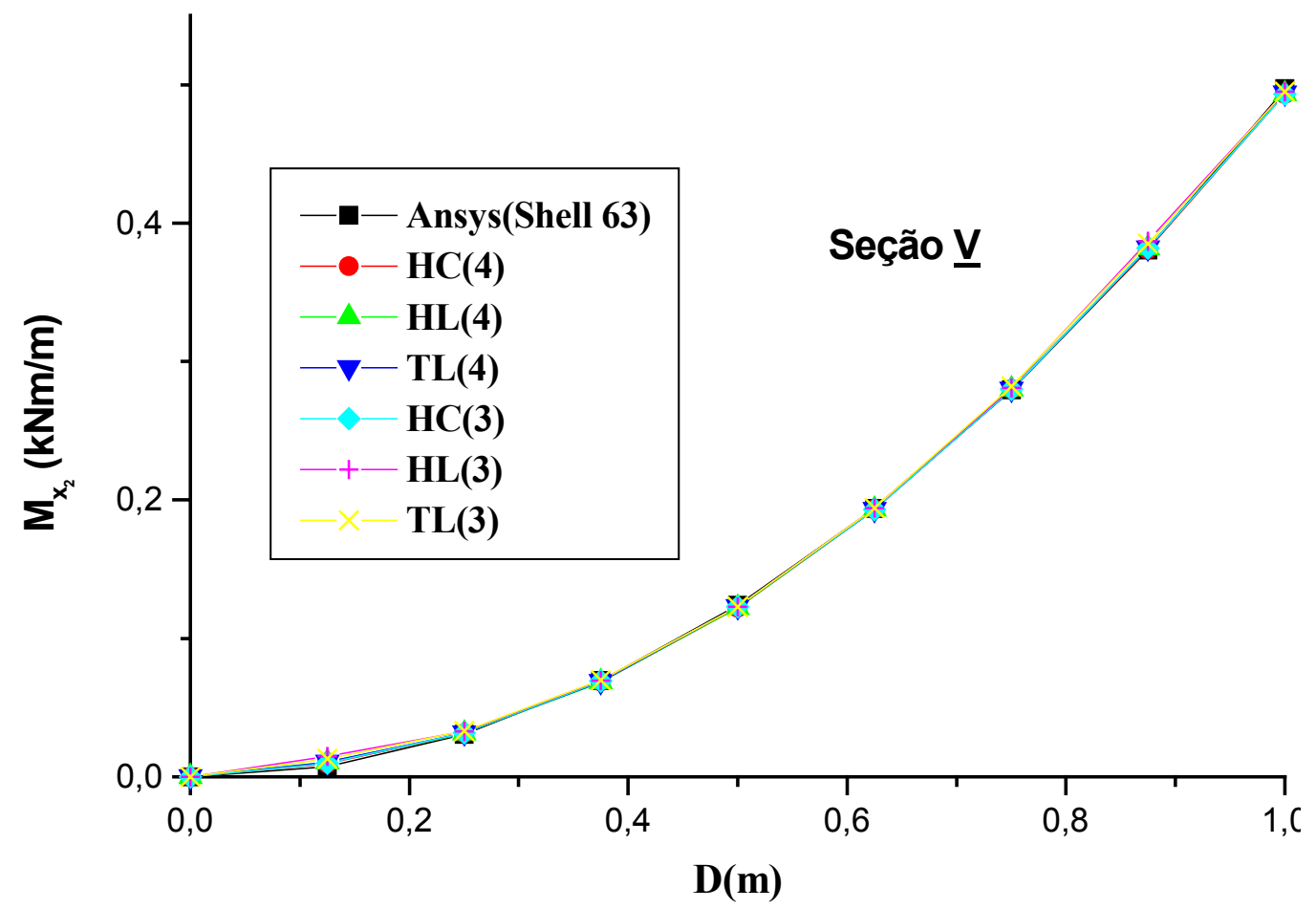

Figura 7.26- Momentos fletores $m_{x_{2}}$ ao Longo da linha BC da Viga $V$. 
Tabela 7.13- Diferença relativa para os campos de deslocamentos e momentos.

\begin{tabular}{|c|c|c|c|c|c|c|}
\hline \multicolumn{7}{|c|}{$\operatorname{Drel}(\%)$} \\
\hline $\mathbf{D}(\mathbf{m})$ & HC(4) & HL(4) & TL(4) & HC(3) & HL(3) & TL(3) \\
\hline \multicolumn{7}{|c|}{ Deslocamento Tangencial $\left(u_{s}\right)$, Interface $\mathrm{AB}$} \\
\hline 3,125 & 0,76 & 1,76 & 1,76 & 2,14 & 5,16 & 5,29 \\
\hline \multicolumn{7}{|c|}{ Deslocamento Transversal $(w)$, Interface $\mathrm{AB}$} \\
\hline 5,00 & 0,67 & 0,67 & 1,36 & 1,36 & 2,75 & 2,75 \\
\hline \multicolumn{7}{|c|}{ Deslocamento Transversal $(w)$, Linha BC } \\
\hline 0,75 & 0,85 & 1,48 & 1,48 & 1,48 & 3,39 & 3,39 \\
\hline \multicolumn{7}{|c|}{ Momento Fletor $\left(m_{x_{2}}\right)$, Linha BC } \\
\hline 0,5 & 1,44 & 1,44 & 0,63 & 0,63 & 0,63 & 0,63 \\
\hline
\end{tabular}

A partir das figuras 7.23-26, um bom nível de concordância entre as repostas do MEC (tetra e hexaparamétrica) e as do MEF(Ansys) pode ser observado. Na tabela 7.13, são explicitadas as coordenadas nas interfaces/linhas em que as diferenças relativas para os deslocamentos/momentos foram mais severas. Também nesses casos, as diferenças não foram tão sensíveis(5,29\% entre TL(3) e Ansys em $\left.u_{s}\right)$.

\subsubsection{5) Viga de seção monocelular engastada nas extremidades.}

Neste exemplo é analisada uma estrutura de seção fechada tendo lâminas acopladas na flange superior ao longo das interfaces longitudinais. $\mathrm{O}$ carregamento unitário está aplicado na flange superior e os resultados em deslocamentos, indicados nas figuras 7.28-30, são expressos segundo o triedro local $(s, n, w)$ da interface $\mathrm{AB}$ da subregião 2 , vide na figura 7.27 .

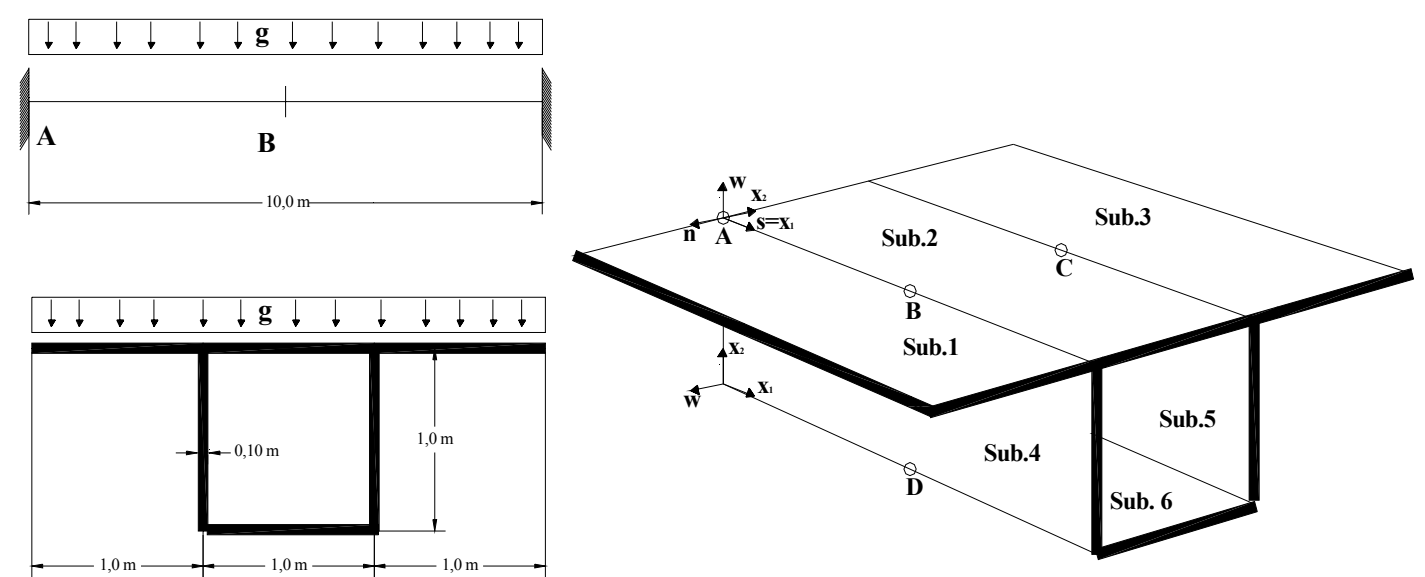

Figura 7.27- Esquema Representativo da Viga Monocelular. 


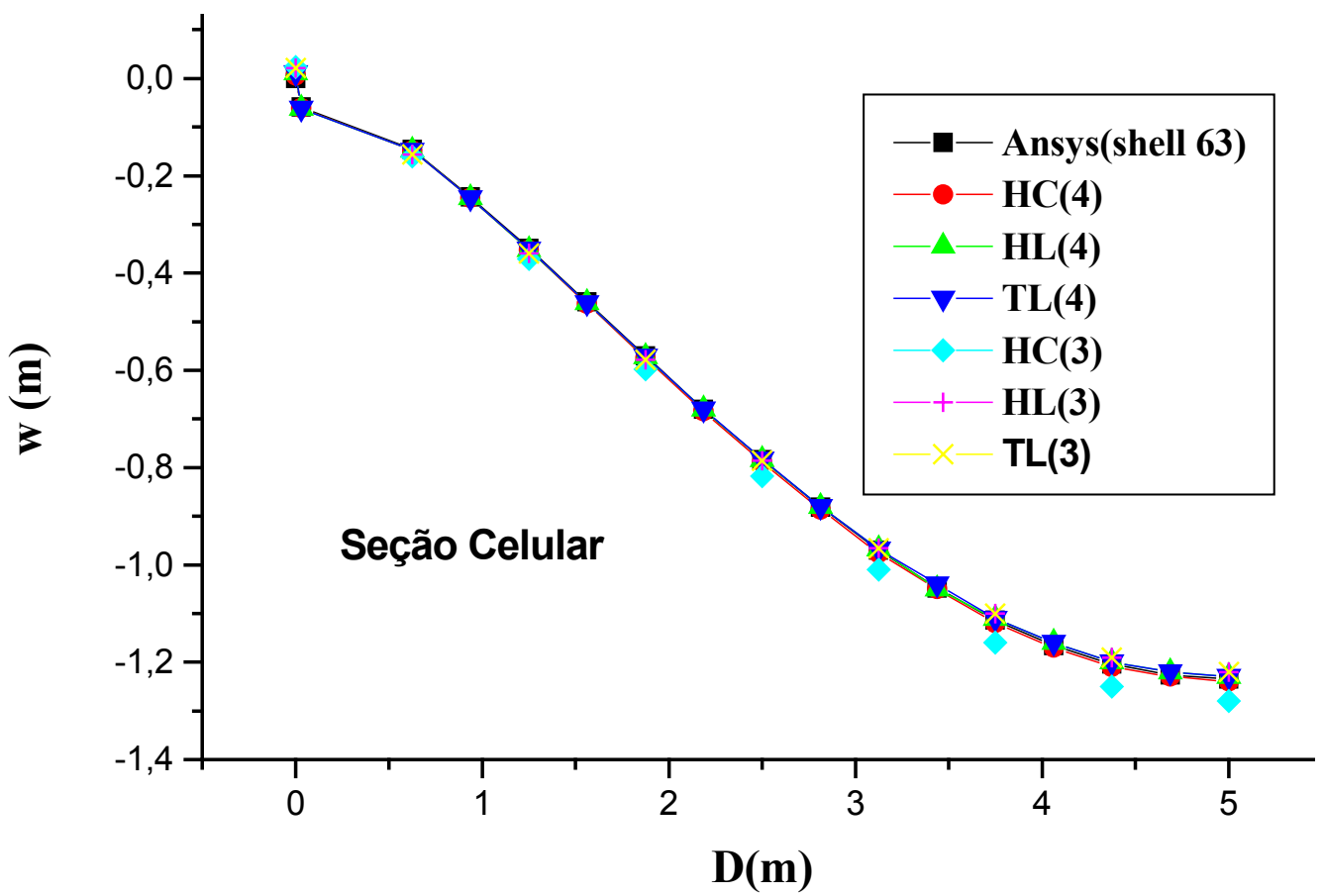

Figura 7.28- Deslocamento Transversal na Interface AB da Viga Monocelular.

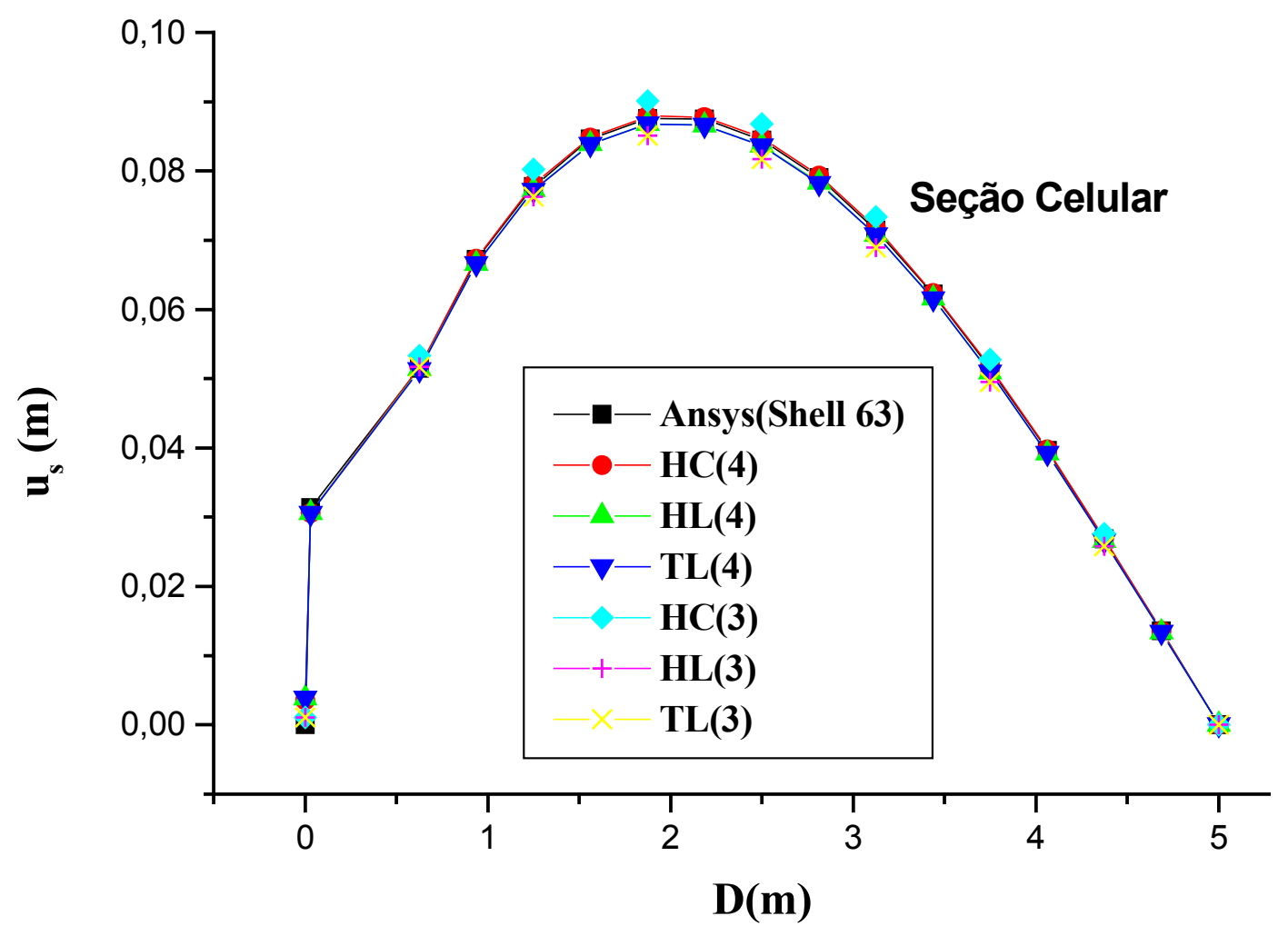

Figura 7.29- Deslocamento Tangencial na Interface AB da Viga Monocelular. 


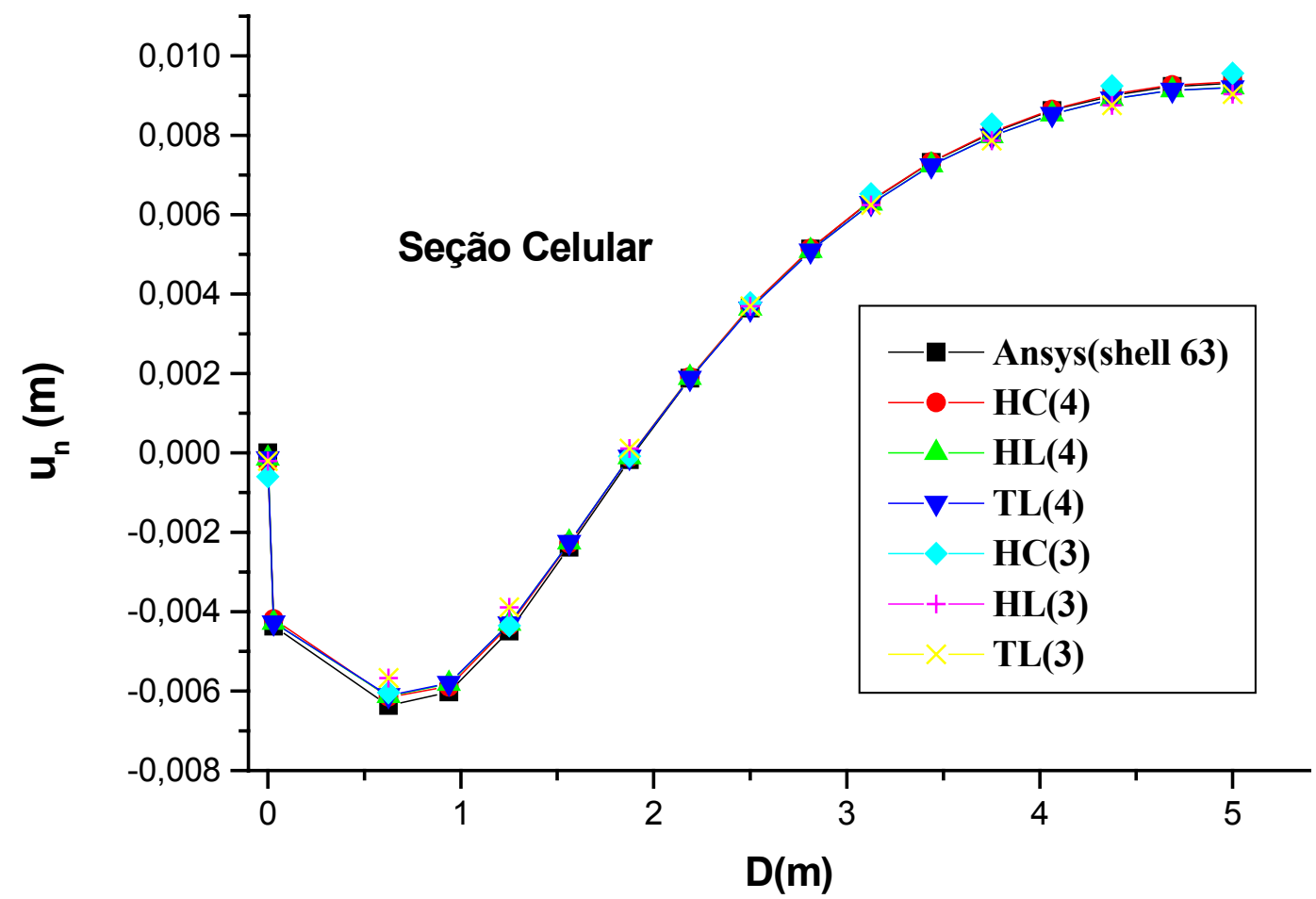

Figura 7.30- Deslocamento Normal na Interface AB da Viga Monocelular.

As diferenças relativas para os deslocamentos entre o MEC -hexa, tetraparamétrica- e o MEF(Ansys) estão indicadas na tabela 7.14.

Tabela 7.14- Diferença relativa para deslocamentos na interface AB.

\begin{tabular}{|c|c|c|c|c|c|c|}
\hline \multicolumn{7}{|c|}{ Drel $(\%)$} \\
\hline \multicolumn{7}{|c|}{ Deslocamento Tangencial $\left(u_{s}\right)$} \\
\hline D(m) & HC(4) & HL(4) & TL(4) & HC(3) & HL(3) & TL(3) \\
\hline 0,625 & 0,45 & 0,14 & 0,33 & 3,56 & 0,45 & 0,45 \\
\hline \multicolumn{7}{|c|}{ Deslocamento Normal $\left(u_{n}\right)$} \\
\hline 0,625 & 3,30 & 3,77 & 3,93 & 5,03 & 10,85 & 10,85 \\
\hline \multicolumn{7}{|c|}{ Deslocamento Transversal $(w)$} \\
\hline 1,25 & 0,92 & 0,63 & 0,35 & 6,07 & 2,92 & 2,92 \\
\hline
\end{tabular}

Os resultados indicados nas figuras 7.28-30 mostram, de um modo geral, um bom desempenho entre o MEC e o Ansys. Nas figuras 7.31 e 32, estão mostradas os valores dos momentos ao longo das linhas $\mathrm{BC}$ e $\mathrm{BD}$ segundo os respectivos eixos globais das subregiões 2 e 4, vide figura 7.27. 


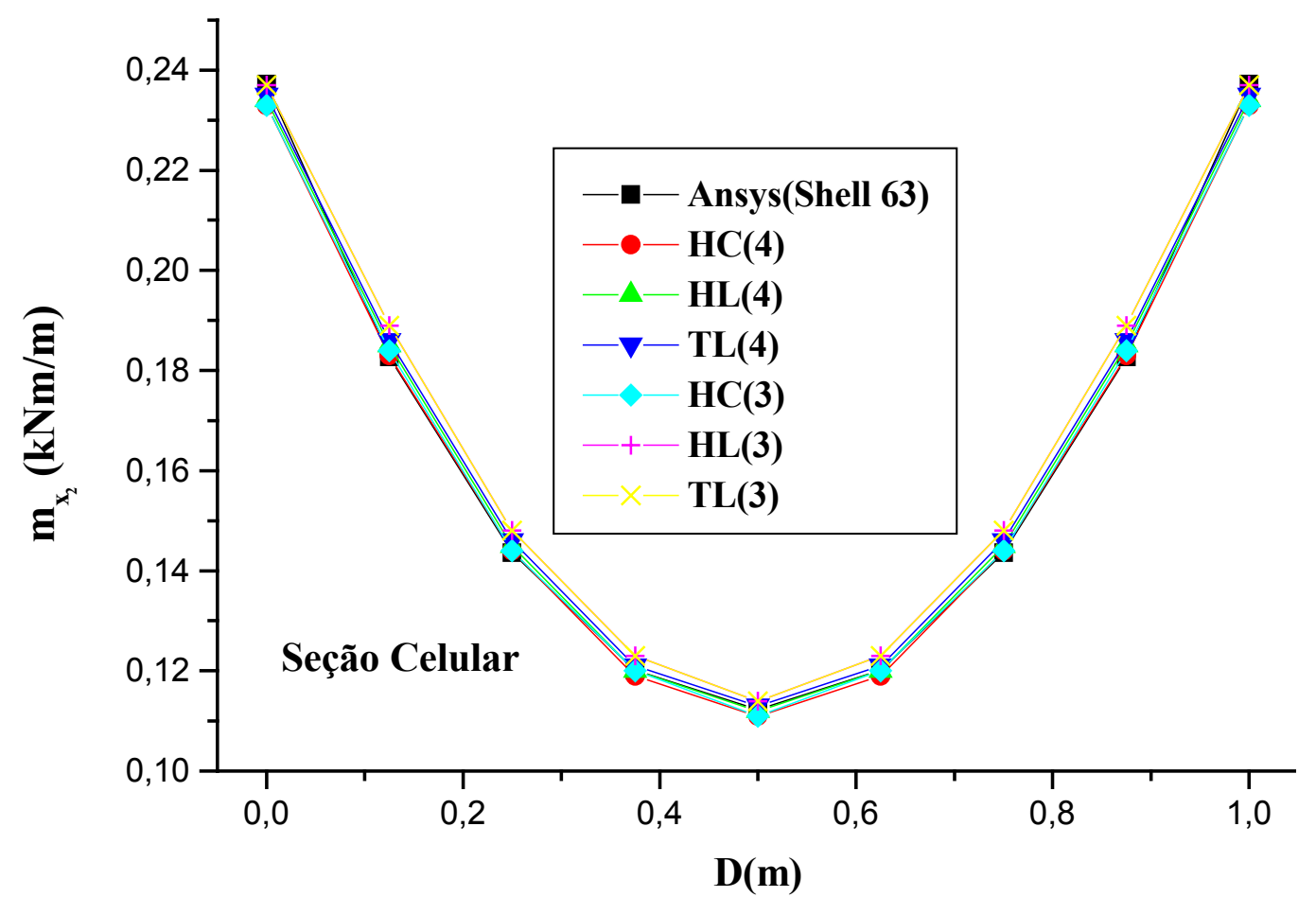

Figura 7.31- Momentos fletores $m_{x_{2}}$ ao longo de BC da Viga Monocelular.

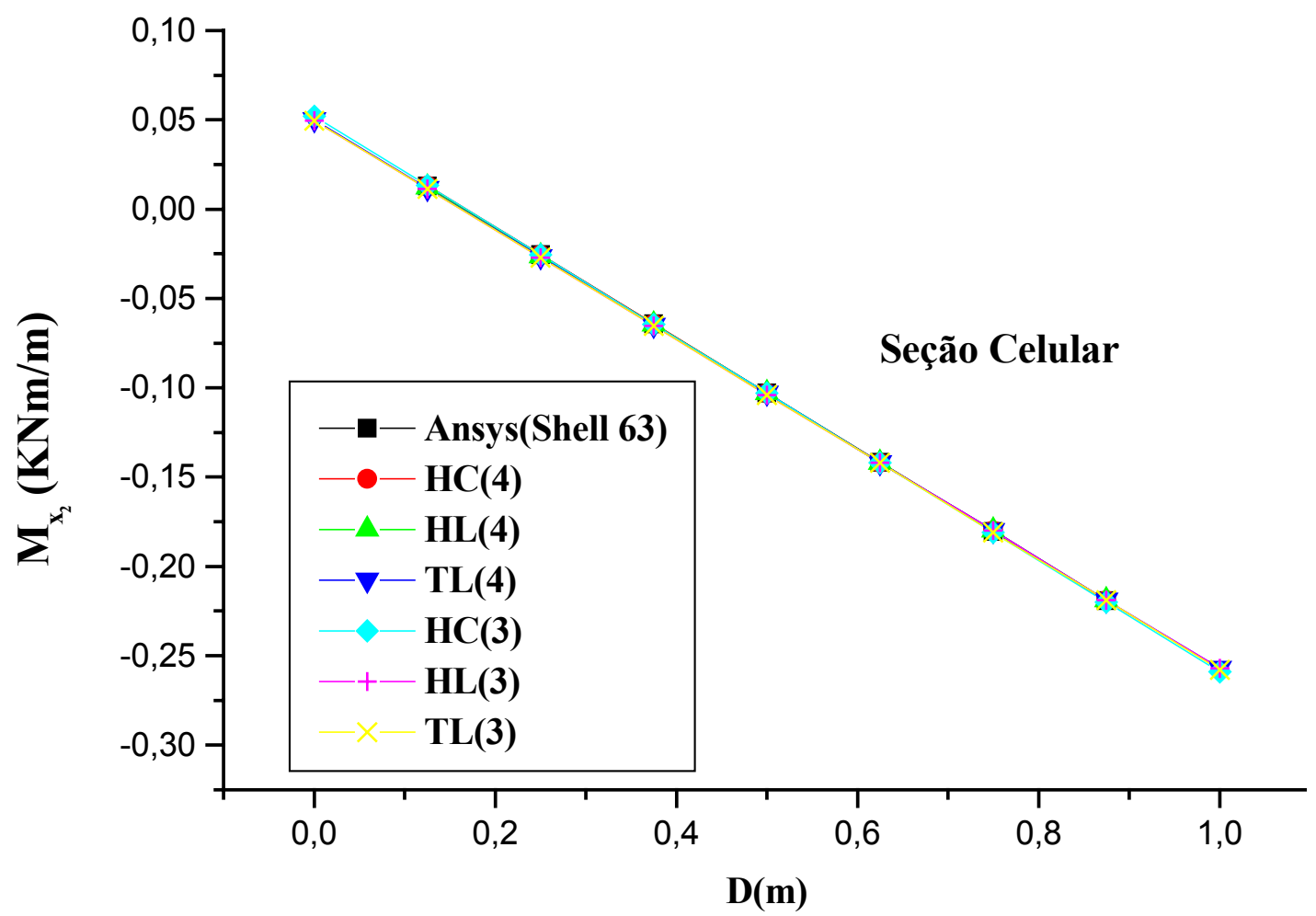

Figura 7.32- Momentos fletores $m_{x_{2}}$ ao longo de BD da Viga Monocelular.

Uma boa concordância pode ser observada entre as respostas numéricas para os momentos fletores ao longo de BC e BD. 
Os exemplos anteriores fazem parte de um conjunto de estruturas que pode ser classificado como tendo um eixo longitudinal, isto é, "uma geratriz", cujo plano que a contém é paralelo aos planos das lâminas constituintes da estrutura poliédrica. Tais exemplos podem ser analisados por algumas formulações mistas MEF/MEC GALUTA \& CHEUNG(1995) ou para casos especiais de seção tubular fechada via MSPF/MEC em KOMATSU \& NAGAI(1982). Alem disso, os exemplos anteriores podem ser analisados utilizando-se apenas o MEC de acordo com as formulações descritas em PALERMO JR (1989), OHGA et al.(1991) e TANAKA \& BERCIN(1998). A presente formulação além da possibilidade de aplicação nos problemas descritos anteriormente, ela também viabiliza análise via MEC de outros problemas não-coplanares. A seguir é analisada uma estrutura em que uma das lâminas intercepta a geratriz do problema.

\subsubsection{6) Reservatório elevado.}

Um reservatório elevado engastado nas extremidades das paredes em contato com os apoios está submetido a um carregamento unitário uniformemente distribuído ao longo do domínio das lâminas, que formam a estrutura retentora de líquido conforme indicada na figura 7.33. Para análise desse problema são utilizados duas discretizações distintas (tipo 3 e 4). Os resultados, indicados nas figuras 7.35-43, são expressos em função do triedros locais $(s, n, w)$ e globais $\left(x_{1}, x_{2}, x_{3}\right)$ das subregiões indicadas na figura 7.34.
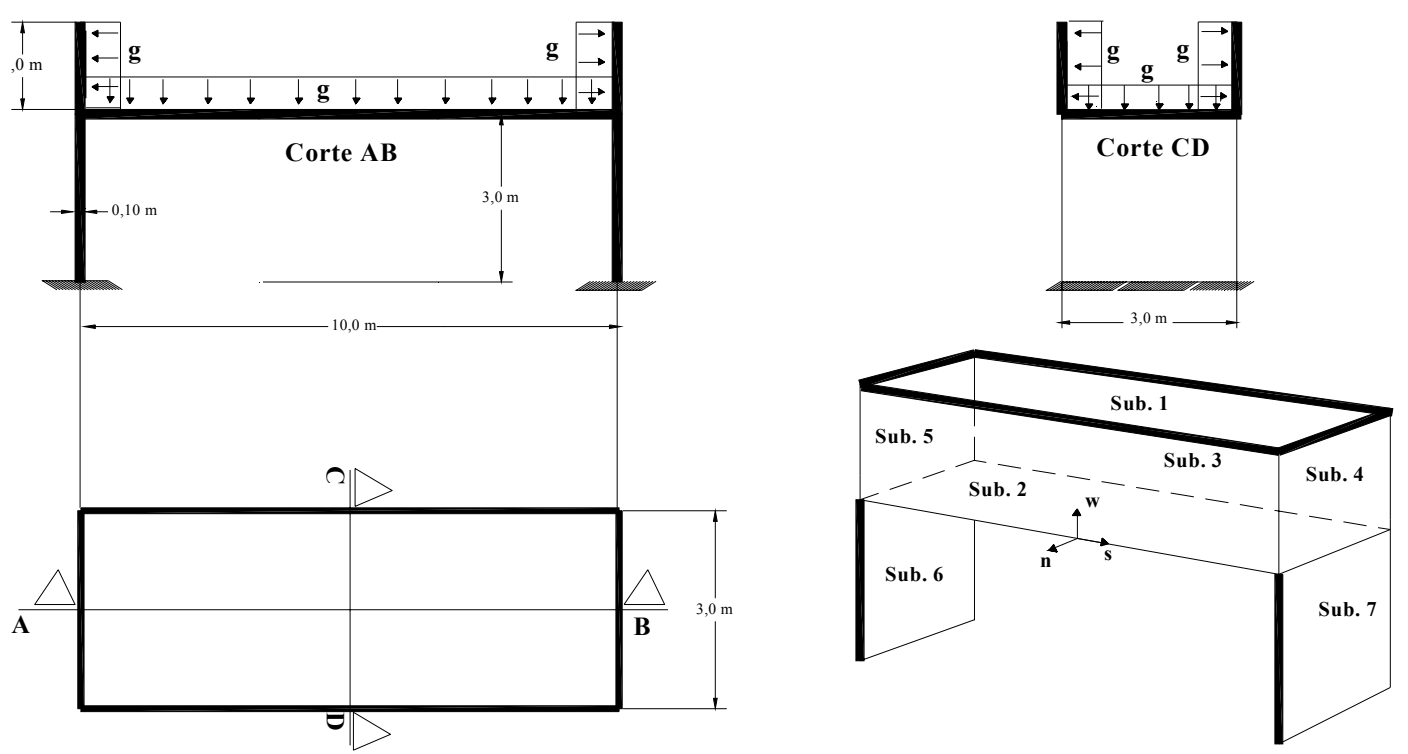

Figura 7.33- Esquema Representativo do Reservatório. 


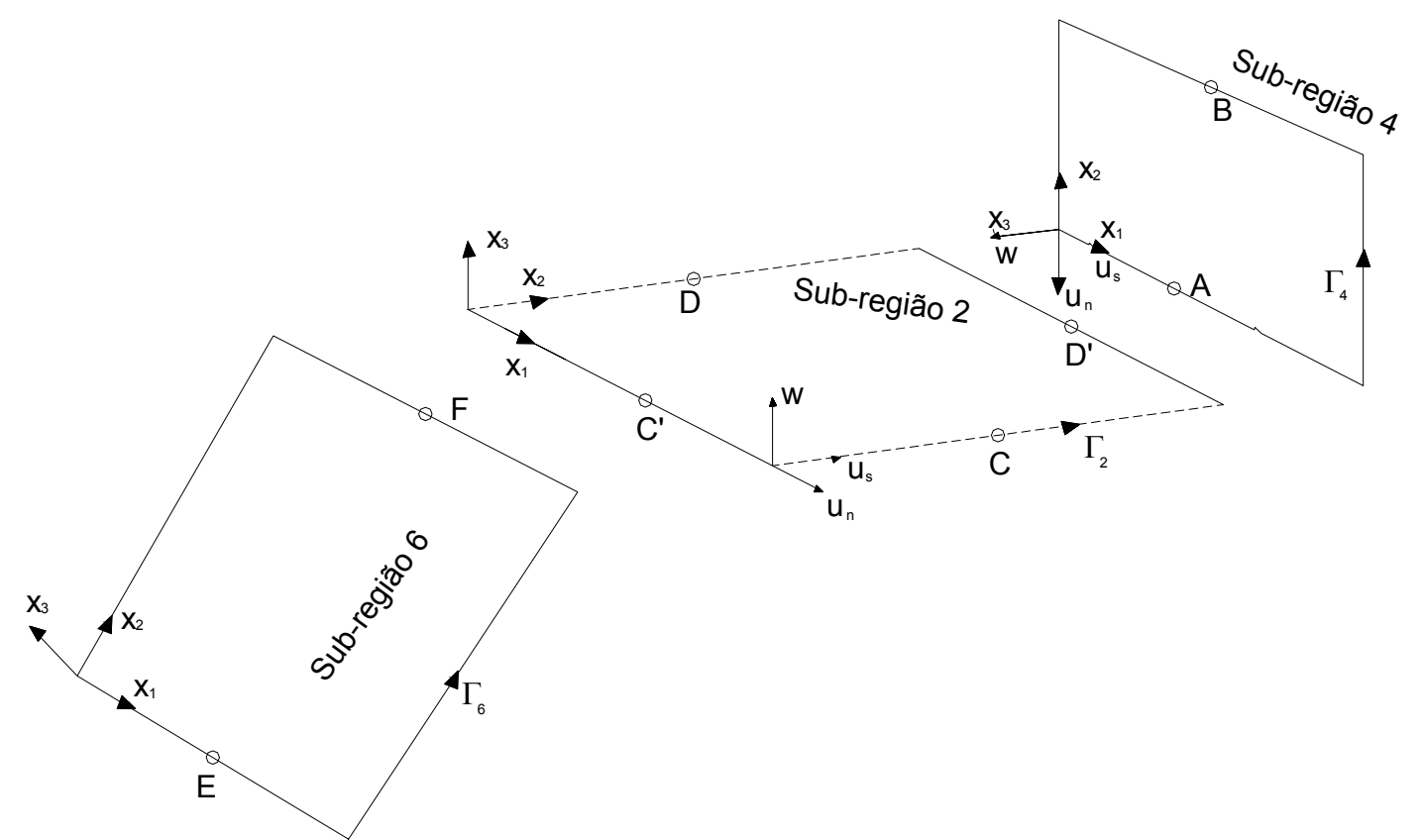

Figura 7.34- Orientação de Parte das Lâminas do Reservatório.

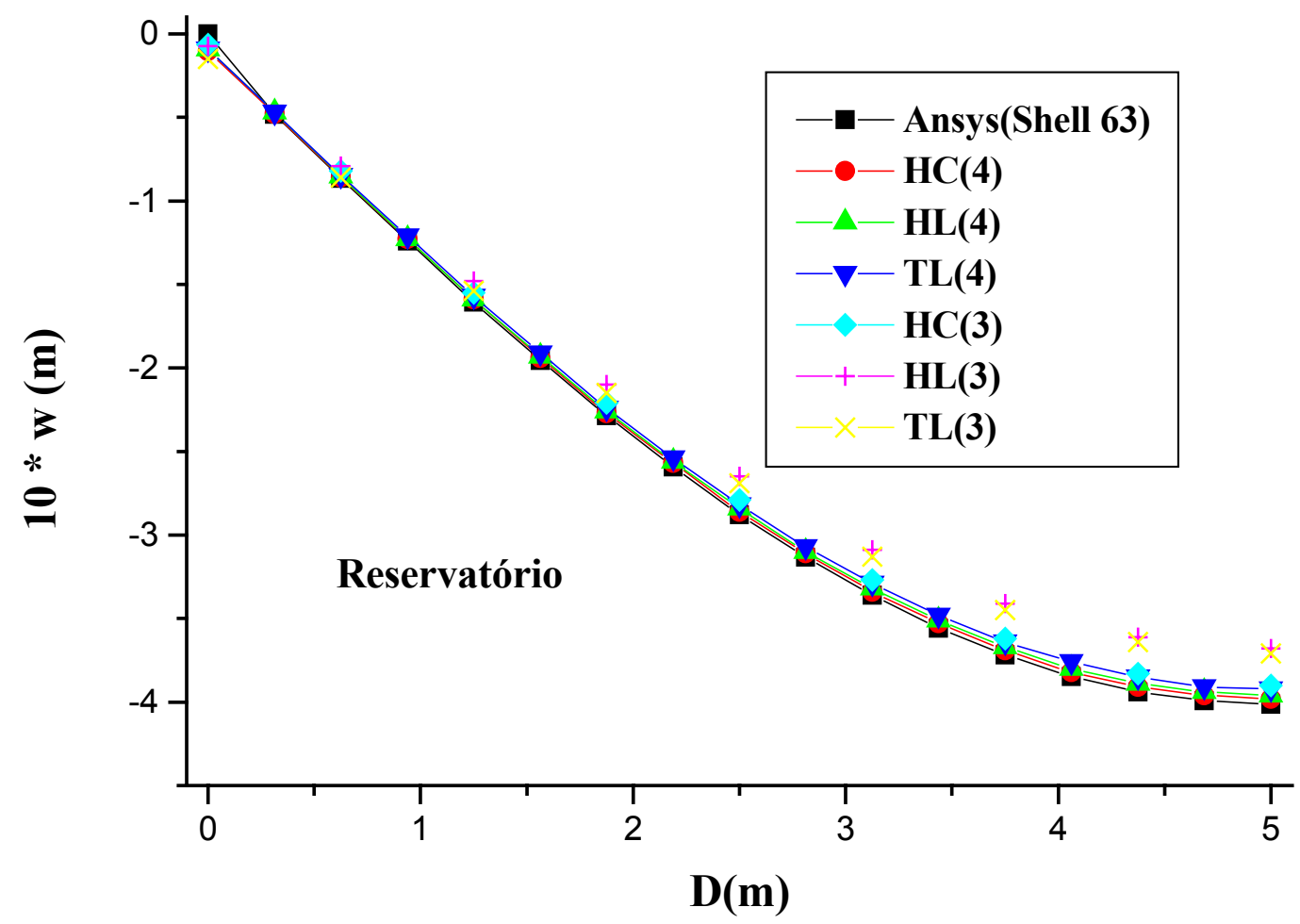

Figura 7.35- Deslocamento Transversal na Interface $2 \mathrm{C}$ do Reservatório. 


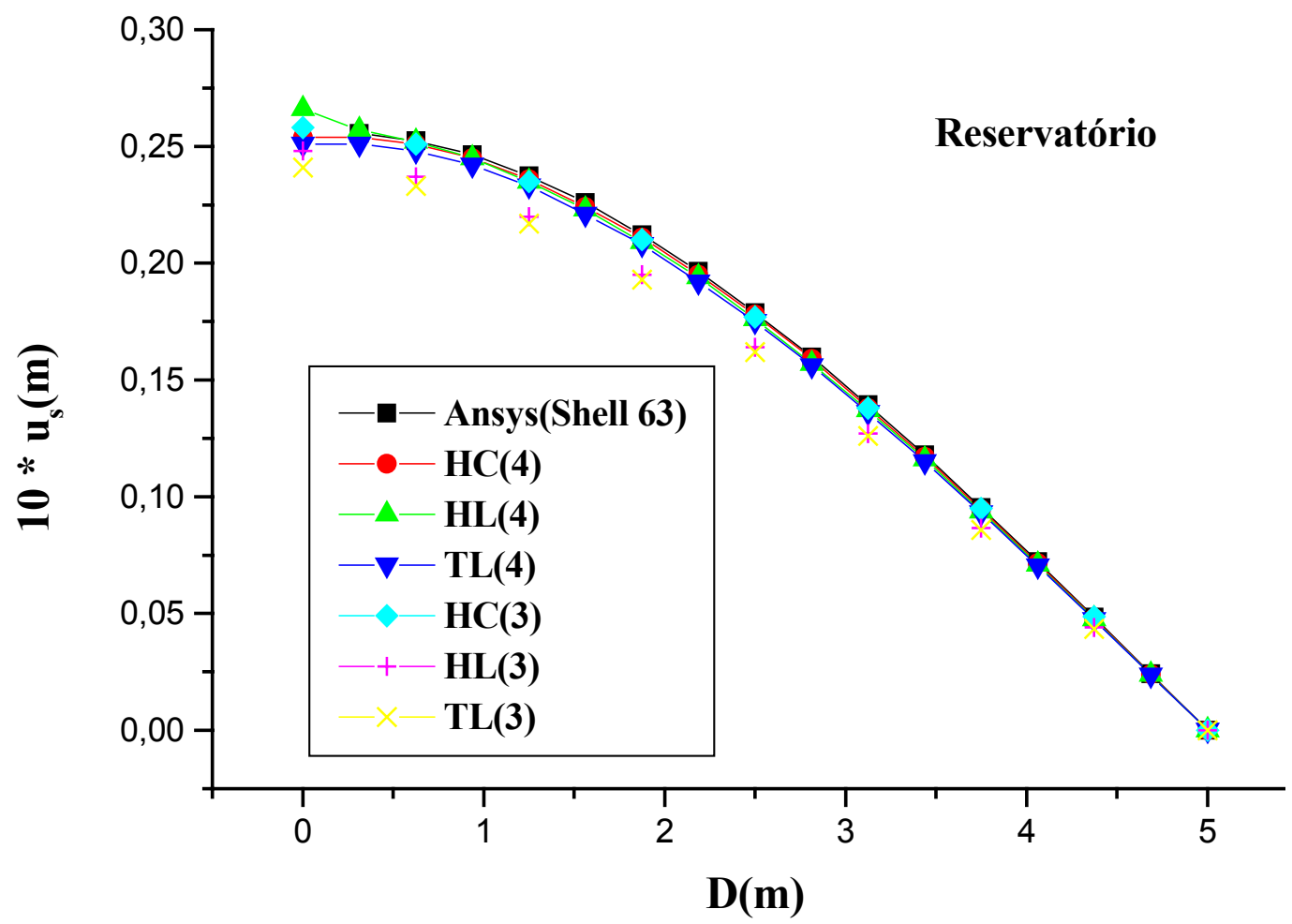

Figura 7.36- Deslocamento Tangencial na Interface 2C do Reservatório.

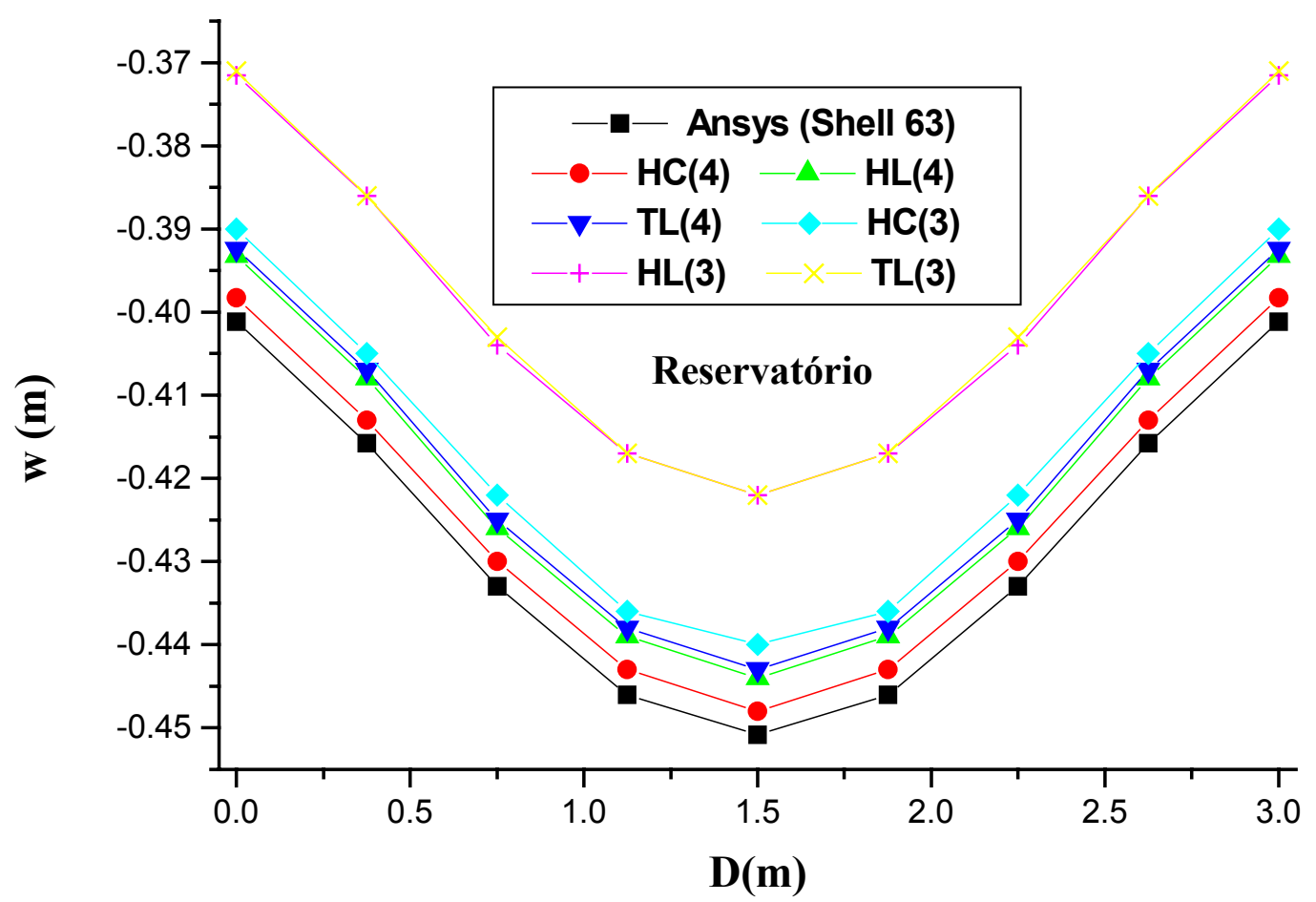

Figura 7.37- Deslocamento Transversal ao longo de C'D' do Reservatório. 


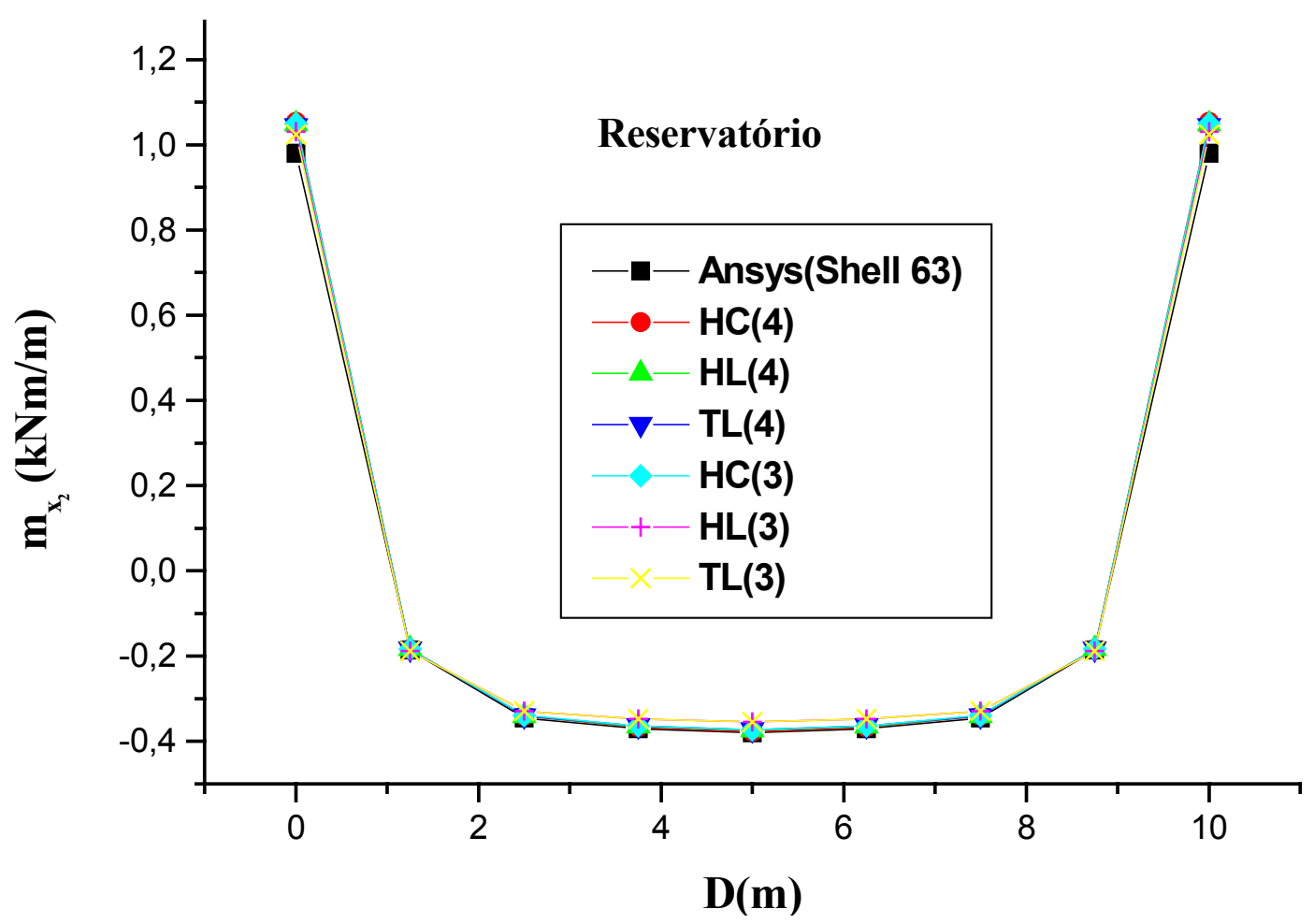

Figura 7.38 Momento fletor $m_{x_{2}}$ ao longo de C'D' do Reservatório.

Tabela 7.15- Diferença relativa para deslocamentos e momentos

\begin{tabular}{|c|c|c|c|c|c|c|}
\hline \multicolumn{7}{|c|}{ Drel $(\%)$} \\
\hline D(m) & HC(4) & HL(4) & TL(4) & HC(3) & HL(3) & TL(3) \\
\hline \multicolumn{7}{|c|}{ Deslocamento Tangencial $\left(u_{s}\right)$, Interface 2C } \\
\hline 0,625 & 2,16 & 0,22 & 1,79 & 0,59 & 6,15 & 7,74 \\
\hline \multicolumn{7}{|c|}{ Deslocamento Transversal( $(w)$, Interface 2C } \\
\hline 5,00 & 0,70 & 1,29 & 2,29 & 4,04 & 8,27 & 7,53 \\
\hline \multicolumn{7}{|c|}{ Deslocamento Transversal $(w)$, linha C'D' } \\
\hline 1,125 & 0,67 & 1,58 & 1,81 & 2,26 & 6,52 & 6,52 \\
\hline \multicolumn{7}{|c|}{ Momento fletor $\left(m_{x_{2}}\right)$, ,inha C'D' } \\
\hline 0,0 & 7,55 & 7,05 & 6,67 & 7,09 & 5,23 & 4,52 \\
\hline 5,0 & 1,72 & 1,45 & 1,72 & 1,72 & 6,72 & 6,72 \\
\hline
\end{tabular}

A partir das figuras 7.35-38, pode-se notar, de um modo geral, um bom desempenho entre o MEC e o MEF. Contudo, uma melhor concordância foi obtida entre a formulação $\mathrm{HC}$ e o Ansys. Aparentemente, as diferenças de $w$ ao longo de C'D', figura 7.37, são maiores que os resultados associados aos demais graus de liberdade apresentados em outros gráficos do reservatório. Contudo tal fato aparente é devido ao intervalo de plotagem, uma vez que ao consultar a tabela 7.15 pode-se observar que as diferenças relativas estão numa mesma ordem de grandeza. 


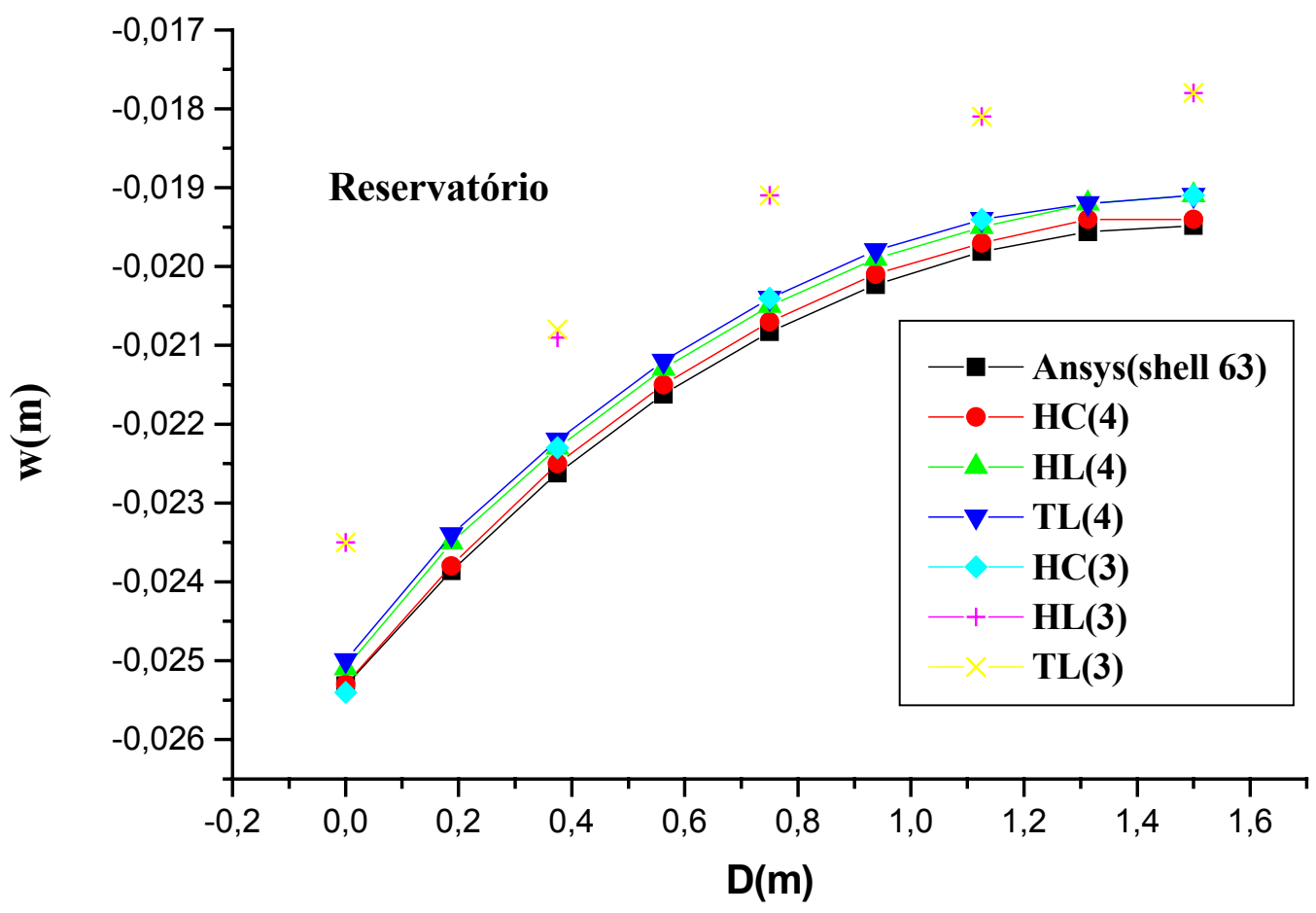

Figura 7.39-Deslocamento Transversal na Interface 4A do Reservatório.

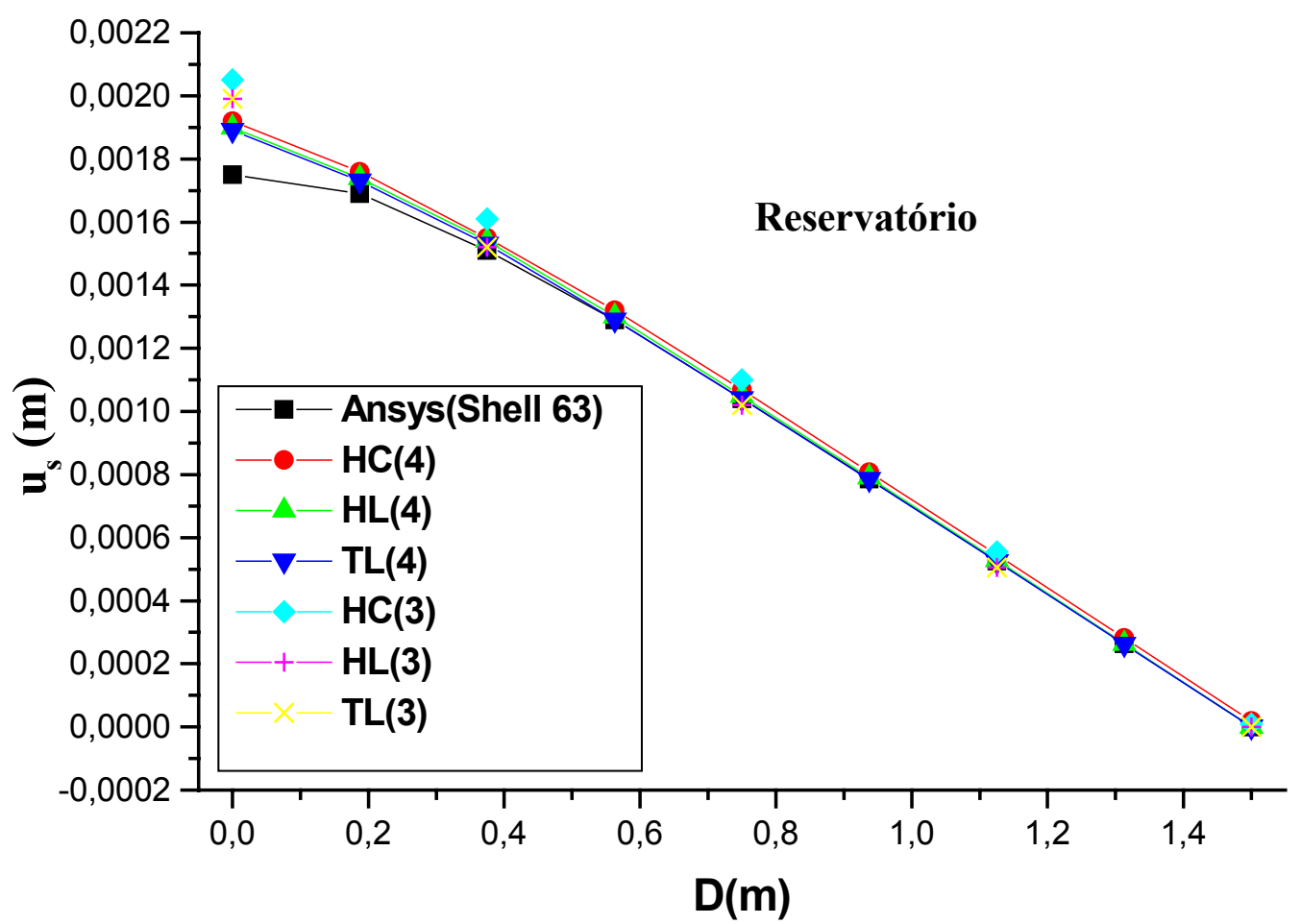

Figura 7.40- Deslocamento Tangencial na Interface 4A do Reservatório. 


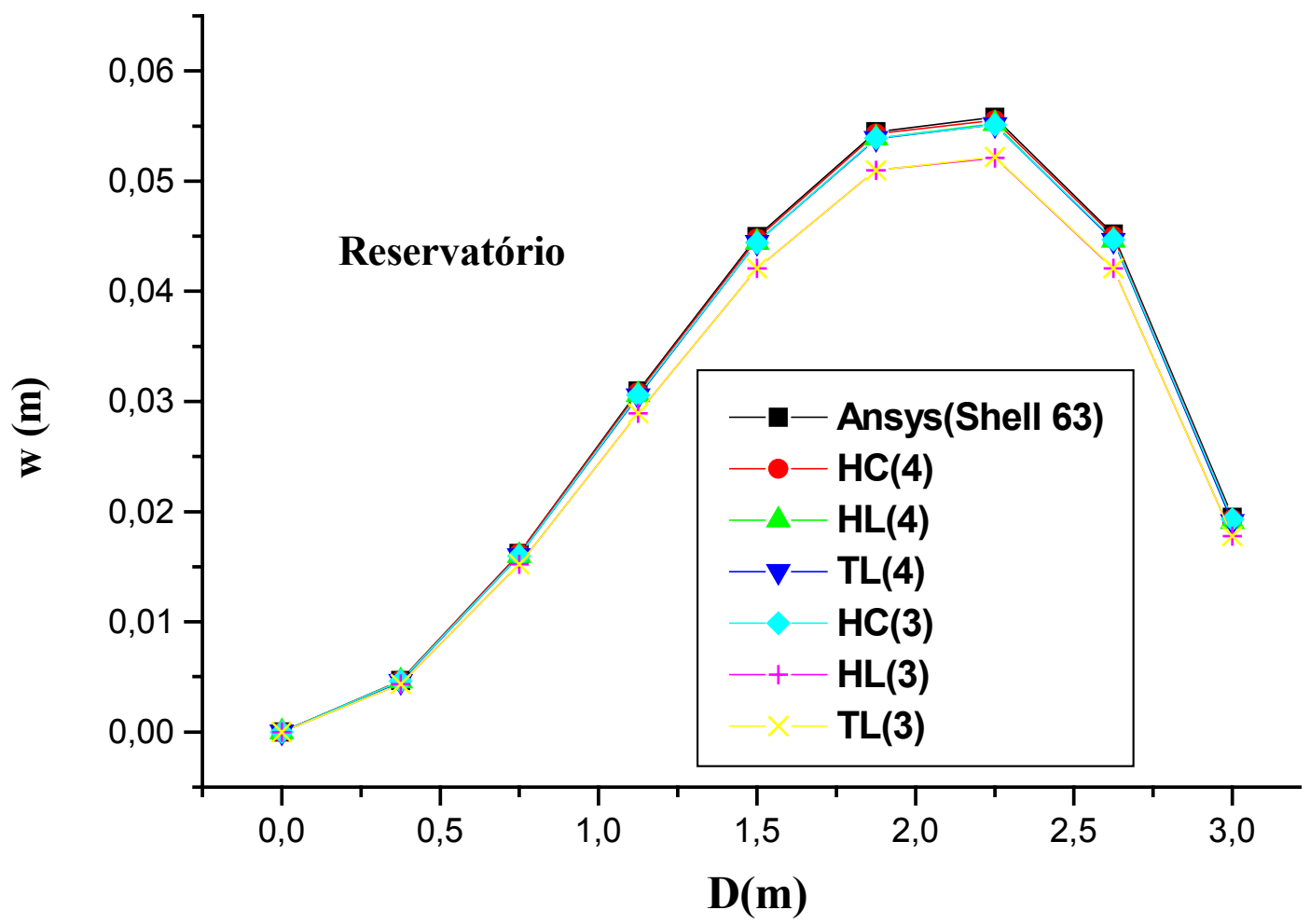

Figura 7.41- Deslocamento Transversal ao longo EF do Reservatório.

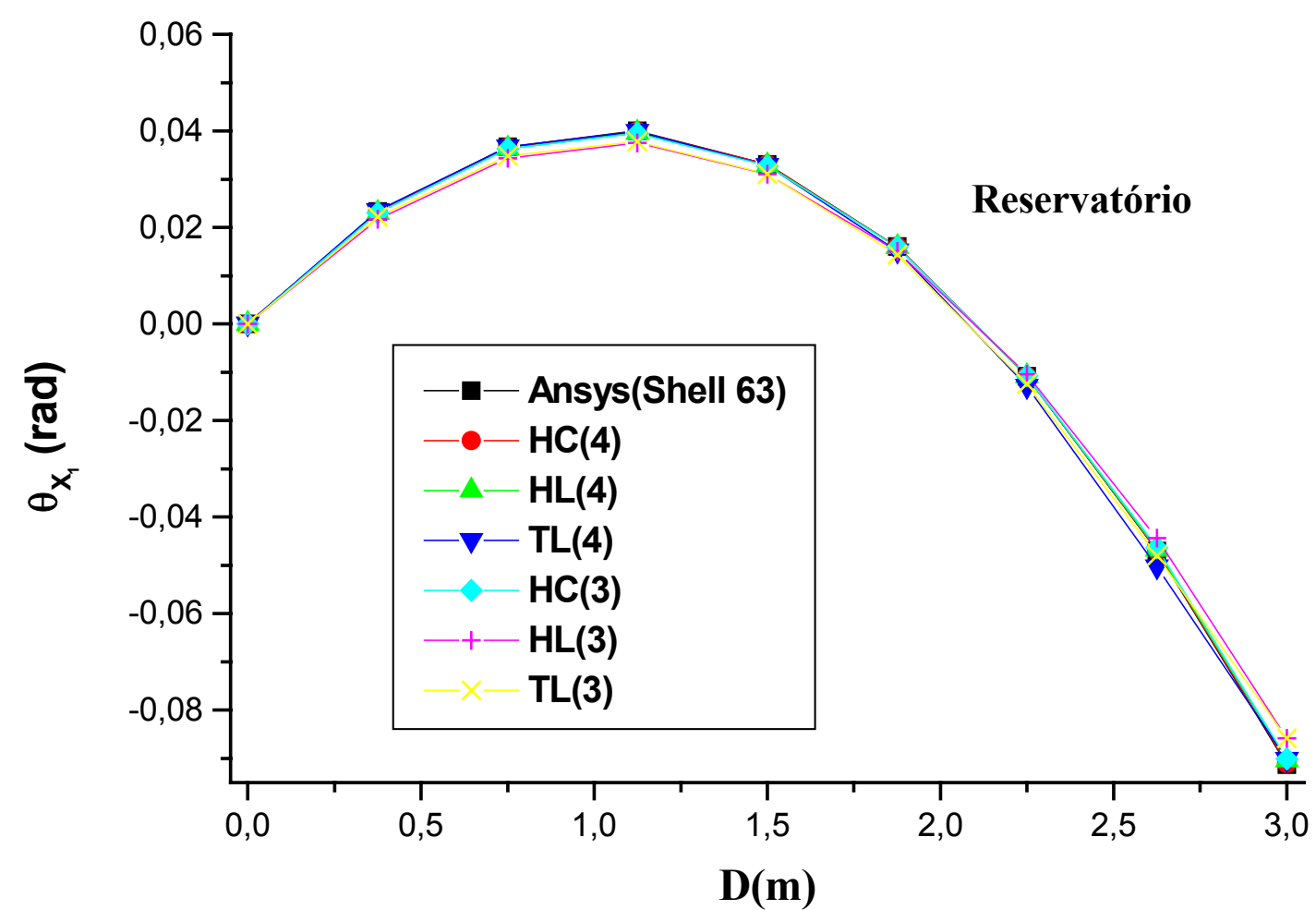

Figura 7.42- $\theta_{x_{I}}$ ao longo EF do Reservatório. 


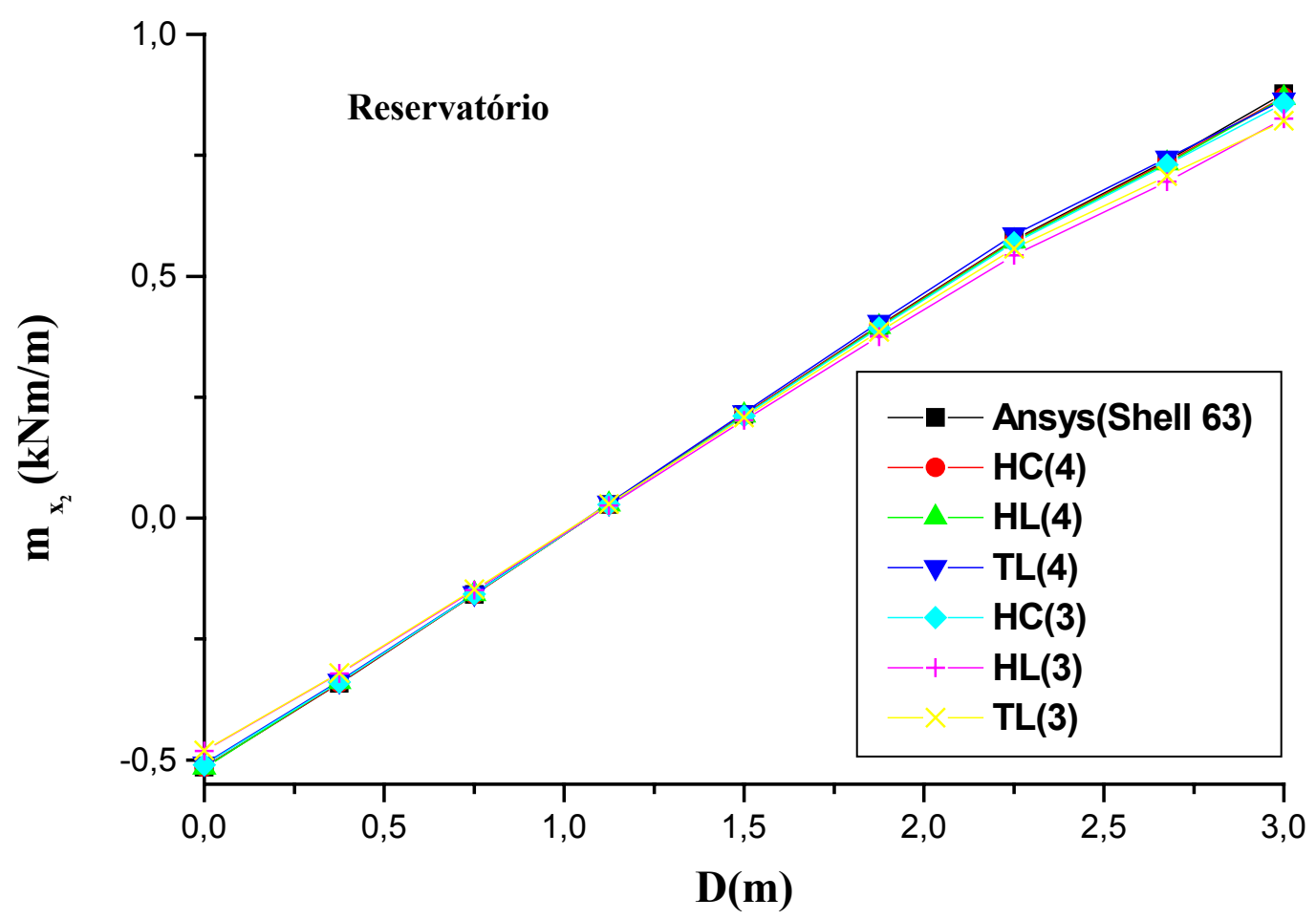

Figura 7.43- Momento fletor $m_{x 2}$ ao longo EF do Reservatório.

Tabela 7.16- Deslocamentos e momentos.

\begin{tabular}{|c|c|c|c|c|c|c|}
\hline \multicolumn{7}{|c|}{$\operatorname{Drel}(\%)$} \\
\hline $\mathbf{D}(\mathbf{m})$ & HC(4) & HL(4) & TL(4) & HC(3) & HL(3) & TL(3) \\
\hline 0,0 & 8 & 8,57 & 8 & 15,43 & 13,71 & 13,71 \\
\hline \multicolumn{7}{|c|}{ Deslocamento Tangencial $\left(u_{s}\right)$, Interface $4 \mathrm{~A}$} \\
\hline 0,0 & 8 & 8,57 & 8 & 15,43 & 13,71 & 13,71 \\
\hline 0,375 & 1,32 & 1,99 & 1,32 & 5,30 & 0,66 & 0,66 \\
\hline \multicolumn{7}{|c|}{ Deslocamento Transversal $(w)$ Interface 4A } \\
\hline 0,75 & 0,62 & 1,58 & 2,06 & 1,10 & 8,31 & 8,30 \\
\hline \multicolumn{7}{|c|}{ Deslocamento Transversal $(w)$, linha AB } \\
\hline 2,25 & 0,48 & 1,02 & 1,20 & 1,38 & 6,58 & 6,40 \\
\hline 3,00 & 0,92 & 1,95 & 1,95 & 1,44 & 8,62 & 8,62 \\
\hline \multicolumn{7}{|c|}{ Rotação( $\left.\theta_{x_{1}}\right), \operatorname{linha} \mathrm{EF}$} \\
\hline 1,875 & 0,37 & 0,93 & 5,73 & 1,18 & 6,53 & 10,9 \\
\hline 3,00 & 0,32 & 0,97 & 1,19 & 1,30 & 6,01 & 6,01 \\
\hline \multicolumn{7}{|c|}{ Momento fletor $\left(m_{x_{2}}\right)$, linha EF } \\
\hline 2,625 & 0,40 & 0,81 & 0,68 & 1,22 & 5,82 & 4,19 \\
\hline 3,0 & 0,50 & 1,10 & 1,48 & 1,33 & 5,99 & 6,44 \\
\hline
\end{tabular}

Os resultados para deslocamentos, rotações e momentos apresentados nas figuras 7.39-43 indicam, de um modo geral, um melhor desempenho da formulação HC em relação às HL e TL, quando são comparadas com as respostas do Ansys. 


\section{2) Lâminas planas submetidas a campos iniciais de temperatura.}

Nesta seção, alguns problemas de flexão e de membrana serão analisados quando submetidos a campos térmicos em regime permanente.

\subsection{1) Chapa com acréscimo constante de temperatura}

Uma chapa quadrada- de lado $L=1 \mathrm{~m}$ e espessura $t=0,1 \mathrm{~m}$, vide figura 7.44- está submetida a um acréscimo constante de temperatura ao longo da espessura de $\Delta T=10^{\circ} C$, de forma que um campo das resultantes de tensões $N_{11}^{0}=N_{22}^{0}=2 G t \alpha \Delta T\left(\frac{3-2 v}{1-2 v}\right)=250,00 \mathrm{kN} / \mathrm{m}$ é mobilizado no corpo. A chapa tem propriedades elásticas e térmicas $E=2,5 \mathrm{GPa}, \quad v=0,0$ e $\alpha=10^{-5}{ }^{o} \mathrm{C}^{-1}$. A discretização do domínio com 32 células está indicada na figura 7.45 e os resultados estão mostrados na tabela 7.17

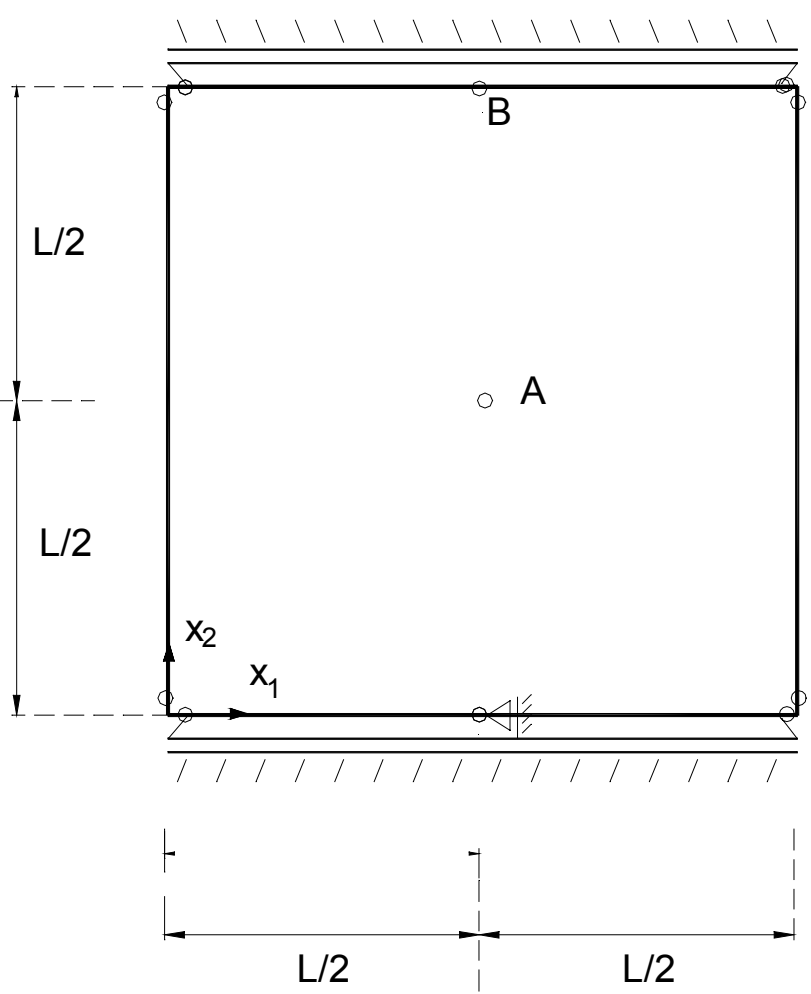

Figura 7.44- Chapa submetida ao campo térmico permanente 
Figura 7.45 - Discretização do plano médio das células.

Tabela 7.17 Deslocamentos e resultantes de tensão verdadeiras em pontos chapa

\begin{tabular}{|c|c|c|}
\hline & Analítico & Presente Trabalho \\
\hline \multicolumn{3}{|c|}{ Ponto A } \\
\hline$u_{1}(m)$ & 0 & $0,53702 \mathrm{E}-18$ \\
\hline$u_{2}(m)$ & 0 & $-0,68821 \mathrm{E}-21$ \\
\hline$N_{11}(k N / m)$ & $-250,00$ & $-250,0000$ \\
\hline$N_{22}(k N / m)$ & $0,0 \quad$ Ponto B \\
\hline \multicolumn{2}{|c|}{} & $-0,65475 \mathrm{E}-06$ \\
\hline$p_{n}(k N / m)$ & $250,0 \quad 250,00$ \\
\hline
\end{tabular}

Um excelente desempenho pode ser notado entre as respostas numéricas do presente trabalho e da solução analítica.

\subsection{2) Placa apoiada com gradiente de temperatura}

Considere uma placa quadrada, de lado $a=2 \mathrm{~m}$ e espessura $t=0,2 \mathrm{~m}$, simplesmente apoiada que está submetida a um gradiente de temperatura ao longo da espessura de $\Delta T=8^{\circ} C$, resultando em um campo de momentos iniciais de $m_{11}^{0}=m_{22}^{0}=0,9525 \mathrm{kNm} / \mathrm{m}$. As propriedades elásticas da placa são $E=2,5 \mathrm{GPa}$ e $v=0,3$. Este problema foi analisado numericamente por RIBEIRO(1992) via MEF e por CHUEIRI(1994) utilizando-se o MEC. Na tabela 7.18, os deslocamentos e os momentos verdadeiros, no ponto $A$, obtidos por essas abordagens e pela presente formulação são comparados; a discretização do domínio está indicada na figura 7.45. 
Tabela 7.18- Deslocamento e momentos verdadeiros no ponto central da placa

\begin{tabular}{|c|c|c|c|c|}
\hline \multirow[b]{2}{*}{ Núm. Células } & \multirow{2}{*}{$\begin{array}{c}\text { RIBEIRO(1992) } \\
(200)\end{array}$} & \multicolumn{2}{|c|}{ CHUEIRI(1994) } & \multirow{2}{*}{$\begin{array}{c}\text { Presente Trab. } \\
\text { (32) }\end{array}$} \\
\hline & & (8) & (72) & \\
\hline$w(\mathrm{~mm})$ & 0,1533 & 0,1497 & 0,1523 & 0,1545 \\
\hline$m_{11}(k N m / m)$ & $-0,3332$ & $-0,3459$ & $-0,3420$ & $-0,3300$ \\
\hline$m_{22}(k N m / m)$ & $-0,3332$ & $-0,3459$ & $-0,3420$ & $-0,3300$ \\
\hline
\end{tabular}

A partir da tabela 7.18, um bom nível de concordância de resultados pode ser observado entre as respostas da presente formulação e as do MEC e do MEF descritas, respectivamente, em Chueiri e Ribeiro.

\subsection{3) Placa engastada com gradiente de temperatura}

Se a vinculação do problema anterior for alterada para engastamento ao longo de todo contorno, em TIMOSHENKO(1940) está disponível uma solução para valores constantes de campos permanentes de temperatura: $m_{11}=m_{22}=-D(1+v) \alpha \Delta T / t$ e $m_{12}=0$, onde $\alpha$ é o coeficiente de dilatação linear e $\Delta T$ é o gradiente de temperatura na espessura $t$ da placa. RIBEIRO(1992) e CHUEIRI(1994) analisaram numericamente o problema em que as propriedades elásticas e térmicas foram: $E=250 \mathrm{GPa}, v=0,2$ e $\alpha=10^{-5}{ }^{\circ} \mathrm{C}^{-1}$. Além disso, o lado da placa foi $a=2 m$ e espessura $t=0,1 m$; Tomando-se um gradiente de temperatura $\Delta T=38,4^{0} \mathrm{C}$ resultam em momentos iniciais de $m_{11}^{0}=m_{22}^{0}=10 \mathrm{kNm} / \mathrm{m}$ distribuídos no domínio. Os resultados da análise para o deslocamento e momentos verdadeiros estão indicados na tabela 7.19. Na presente formulação é utilizada a discretização do domínio com 32 células conforme indicado na figura 7.44.

Tabela 7.19 Deslocamento e momentos verdadeiros no ponto central da placa

\begin{tabular}{|c|c|c|c|c|}
\hline Núm. Células & $\begin{array}{c}\text { TIMOSHENKO } \\
\text { Analítico }\end{array}$ & $\begin{array}{c}\text { RIBEIRO } \\
\mathbf{( 1 2 8 )}\end{array}$ & $\begin{array}{c}\text { CHUEIRI } \\
\mathbf{( 8 )}\end{array}$ & $\begin{array}{c}\text { Presente Trab. } \\
\mathbf{( 3 2 )}\end{array}$ \\
\hline$w(m)$ & 0 & $2,469 \mathrm{E}-8$ & $3,633 \mathrm{E}-8$ & $7,6952 \mathrm{E}-13$ \\
\hline$m_{11}(k N m / m)$ & -10 & $-9,987$ & $-9,998$ & $-10,0000$ \\
\hline$m_{22}(k N m / m)$ & -10 & $-10,013$ & $-9,998$ & $-10,0000$ \\
\hline
\end{tabular}


As formulações do MEC forneceram respostas muito próximas da solução analítica conforme pode ser constatado na tabela 7.19 .

\section{3) Análise Elastoplástica}

Inicialmente, são analisados problemas para alguns casos de estruturas isoladas em regime elastoplástico; em seguida, o domínio desses problemas é segmentado, a fim de criar uma estrutura coplanar multiconectada.

\subsection{1) Chapa em regime elastoplástico com encruamento linear}

Uma chapa simplesmente tracionada no estado plano de tensão(EPT) está indicada na figura 7.46 e seu material tem como propriedades mecânicas $E=100000 \mathrm{~Pa}, v=0,25$ e tensão de escoamento $\sigma_{0}=0,45 \mathrm{~Pa}$.

Além disso, o encruamento do material é admitido linear, com módulo de elasticidade tangente $E_{t}=10000 \mathrm{~Pa}$; com evolução representada por 'work hardening' e a superfície de plastificação representada pelo modelo de Von Mises. O carregamento total é aplicado monotônica e incrementalmente em 30 passos; à norma dos erros, é admitida uma tolerância de $0,1 \%$.

Na figura 7.45 está indicada a malha utilizada e na figura 7.47 está mostrado o comportamento do deslocamento versus carregamento do ponto $A$; os valores obtidos pela formulação proposta rotulada como $\mathrm{MEC}(2 \mathrm{D})$ são comparados com os da solução analítica, que pode ser escrita como:

$$
p=\left\{\begin{array}{c}
E S \frac{\Delta l_{e}}{l}, \text { se } \Delta l_{t} \leq \Delta l_{\text {lim }} \\
E S \frac{\Delta l_{e}}{l}+\frac{H^{\prime}}{l} S\left(\Delta l_{t}-\Delta l_{e}\right), \Delta l_{t}>\Delta l_{l i m}
\end{array}\right.
$$

onde $l$ é o comprimento inicial da chapa; $H^{\prime}=E_{t} /\left(1-E_{t} / E\right)$ é o parâmetro de encruamento; $\Delta l_{e}$ é a elongação elástica; $\Delta l_{t}$ é a elongação total; $\Delta l_{\text {lim }}$ deslocamento limite de proporcionalidade. 


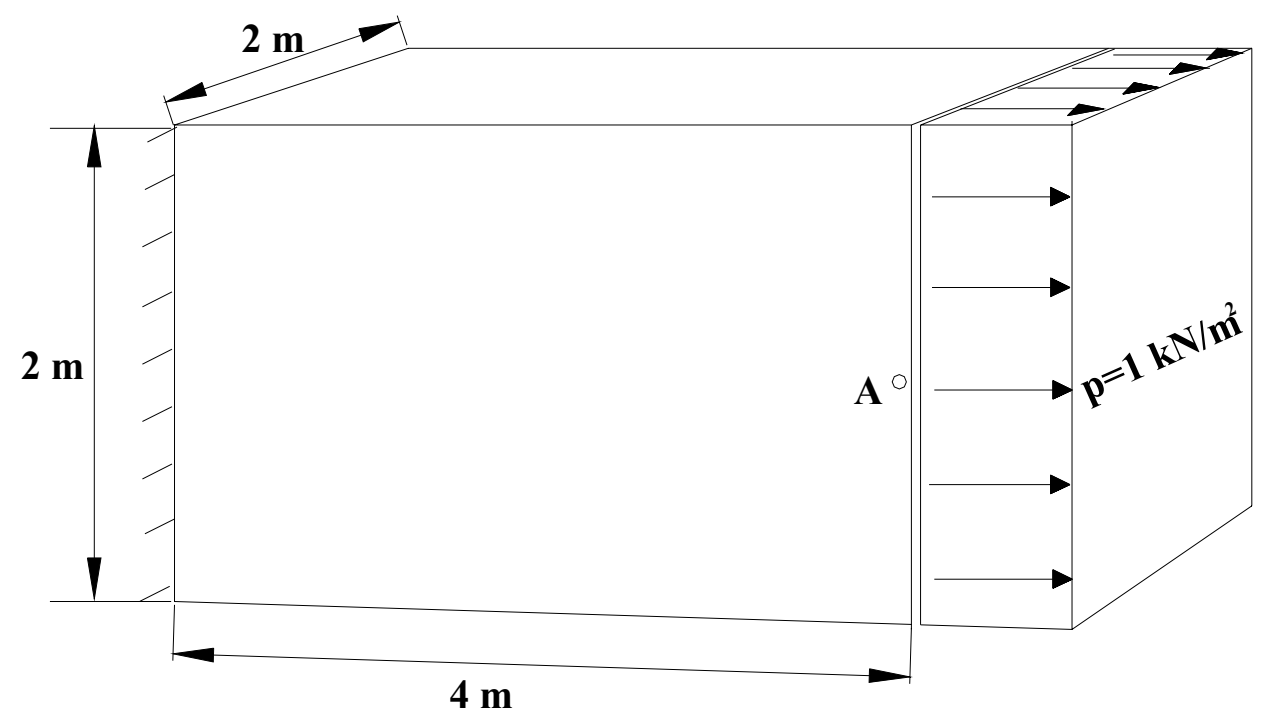

Figura 7.46 - Chapa Simplesmente Tracionada.

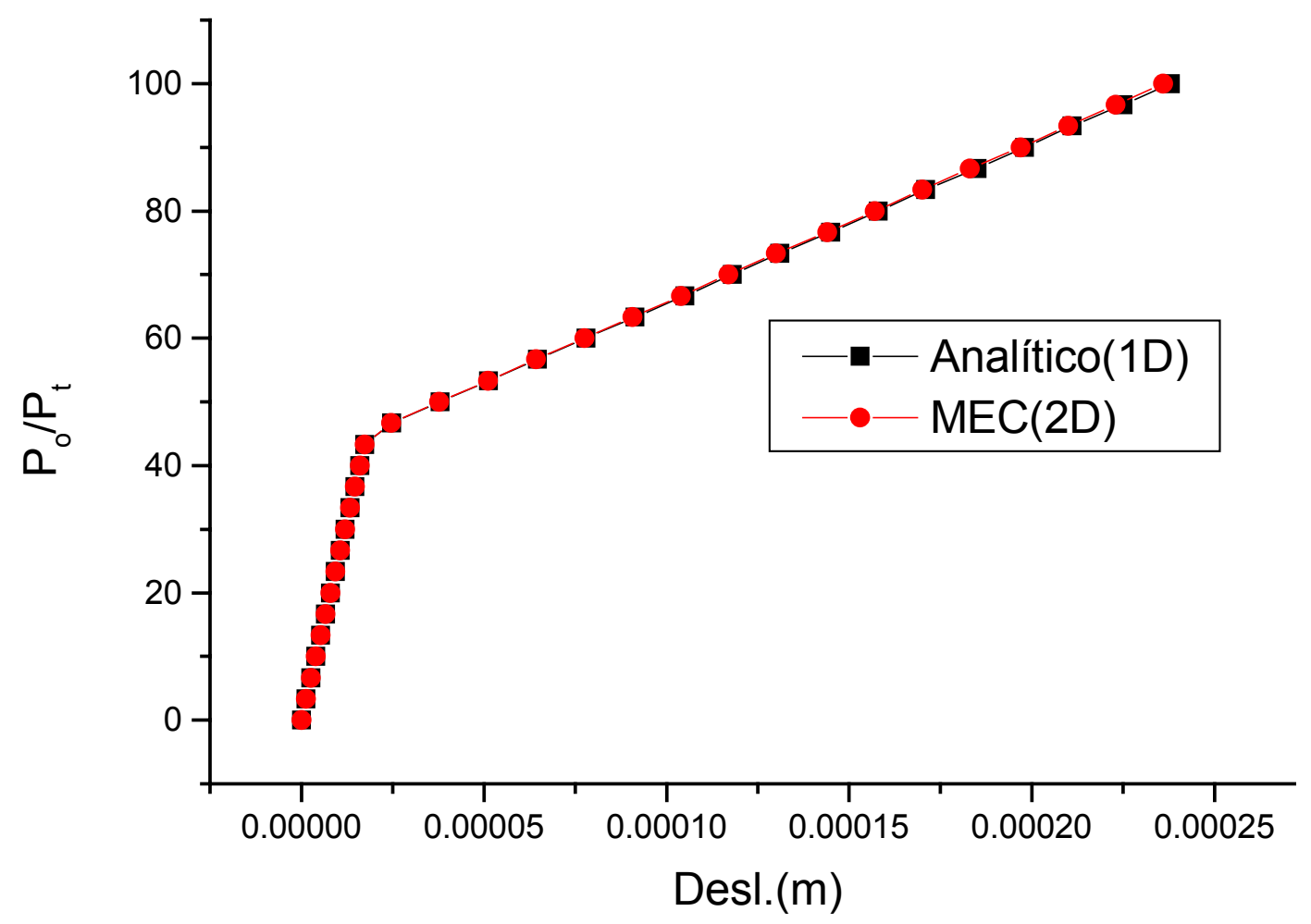

Figura 7.47 - Evolução Carga-Deslocamento do nó $A$.

Pode-se notar uma excelente concordância entre os resultados da análise numérica e os da solução analítica. 


\subsection{2) Tubo pressurizado em regime elastoplástico perfeito}

Conforme discutido nos capítulos anteriores, o problema de chapas pode ser analisado no estado plano de tensão(EPT, regime de membrana) ou no de deformação(EPD). Assim, nesta seção é modelado um caso do $\operatorname{EPD}^{2}$ a fim de ressaltar que esse estado plano também foi incorporado no código computacional deste trabalho. O exemplo analisado consiste em um tubo pressurizado em que é admitido um comportamento elastoplástico perfeito para seu material constituinte e com as seguintes propriedades mecânicas: $E=210 \mathrm{GPa}, v=0,3$ e tensão de escoamento $\sigma_{0}=240 \mathrm{MPa}$. $\mathrm{Na}$ figura 7.48 , estão indicadas as configurações geométricas e de carregamento da quarta parte do tubo, valendo-se das simetrias para reduzir o número total de graus de liberdade. Na figura 7.49, estão indicados os desempenhos da formulação proposta, da formulação tridimensional CISILINO[1995] e por fim pela solução analítica do problema apresentada por PRAGER \& HODGE[1951].

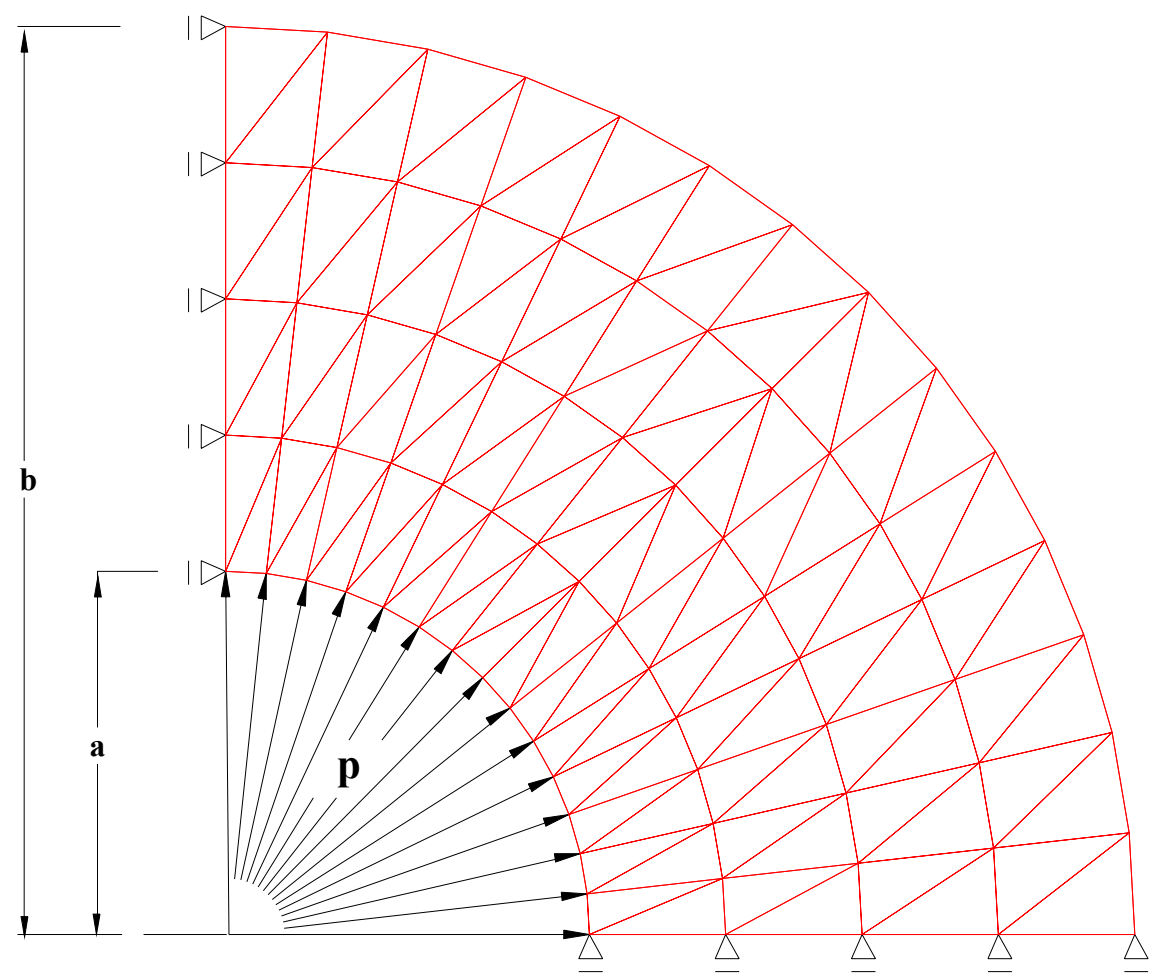

Figura 7.48 -Tubo Pressurizado.

\footnotetext{
${ }^{2}$ Convém notar que os problemas de folhas poliédricas são descritos pelo EPT, se forem utilizadas as hipóteses da elasticidade bidimensional para modelar cada lâmina-base.
} 


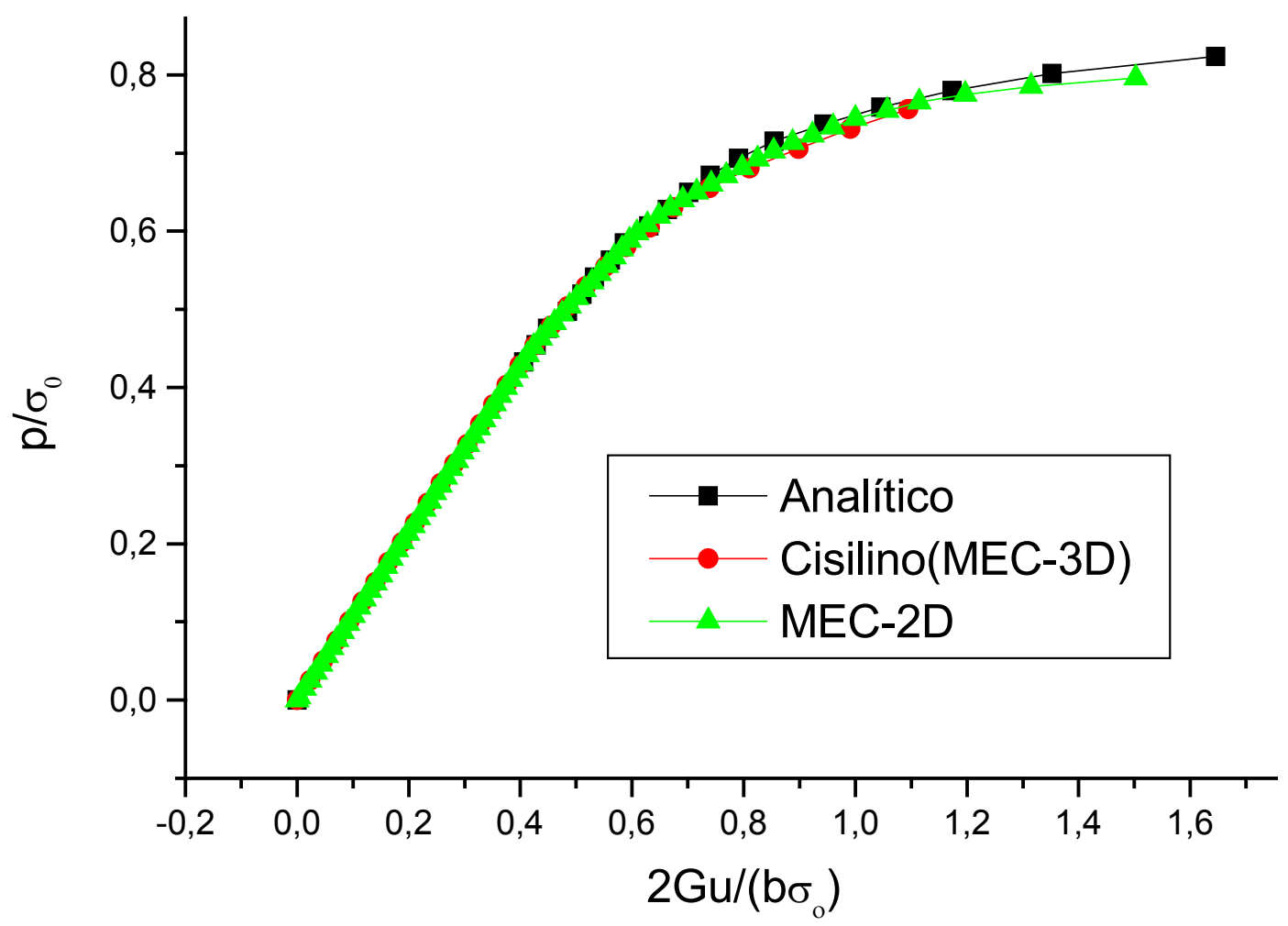

Figura 7.49 -Curva Carga-Deslocamento.

Pode-se notar que os resultados da análise numérica bidimensional via MEC tiveram um comportamento próximo das respostas numéricas da análise tridimensional modelada pelo MEC e pela solução analítica do problema.

\subsection{3) Placa em regime elastoplástico perfeito}

Neste exemplo é analisada uma placa quadrada de lado $(l=1,0 m)$, espessura $t=0,01 \mathrm{~m}$ e simplesmente apoiada, conforme indicada na figura 7.1. O material é admitido sob as hipóteses do regime elastoplástico perfeito, cuja superfície de plastificação é a de Von Mises. As constantes mecânicas são $E=10,92 \mathrm{MPa}, v=0,3$ e a tensão de escoamento $\sigma_{0}=1600 \mathrm{MPa}$. Além disso, a tolerância para a norma dos erros é tol $=0,1 \%$ com incrementos de carga $\Delta p=0,01 \mathrm{kN} / \mathrm{m}^{2}$. Para representação da tensão plástica ao longo da espessura são utilizadas 18 camadas. A discretização das células é mostrada na figura 7.45; as curvas deslocamento versus carregamento estão indicadas na figura 7.50 para a formulação triparamétrica de placas com aproximação cúbica(TC) e para a formulação biparamétrica com interpolação linear(BL). 
Além disso, o rótulo $1 \mathrm{R}$ denota que o problema é composto por uma única região.

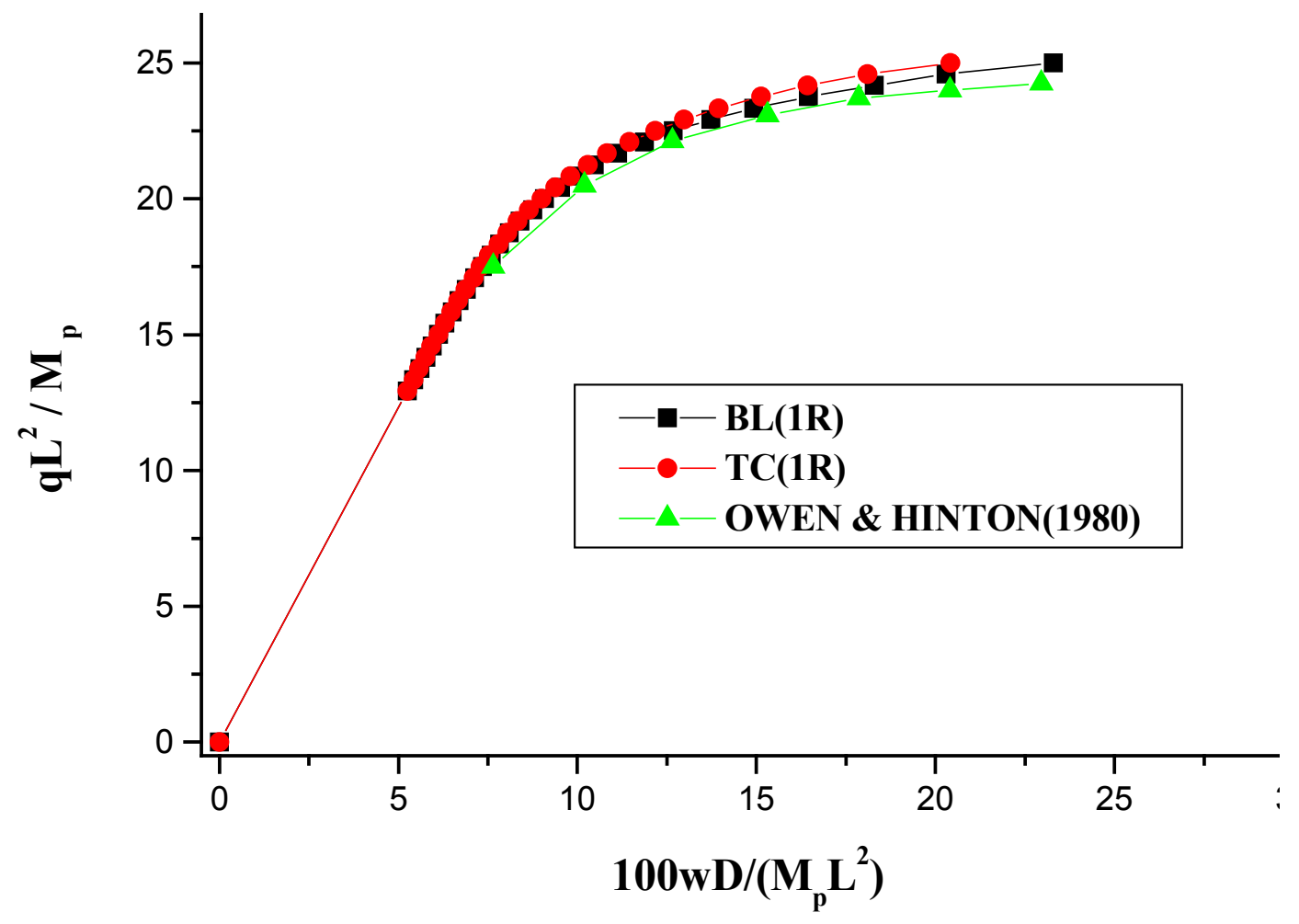

Figura 7.50- Curva Deslocamento-Carregamento para o Ponto Central.

Resultados próximos podem ser observados, na figura 7.33, para análises obtidas via formulação proposta MEC e a do MEF descrita em OWEN \& HINTON[1980].

Após a análise de algumas estruturas isoladas, parte-se doravante para modelagem de estruturas obtidas pela segmentação do domínio de alguns problemas apresentados anteriormente.

\subsection{4) Chapa com duas regiões em regime elastoplástico com encruamento}

Neste exemplo, o problema discutido em 7.3.1 tem seu domínio dividido em duas regiões equivalentes, conforme indicado na figura 7.51. Convém ressaltar que todos os parâmetros mecânicos e de carregamento foram mantidos inalterados. $\mathrm{Na}$ figura 7.52, a discretização da malha é mostrada, e na figura 7.53, tem-se a evolução da curva deslocamento-carregamento para o ponto $A$, tanto para a solução analítica dada em (7.1) quanto pela formulação proposta rotulada como MEC_2R(2D). 


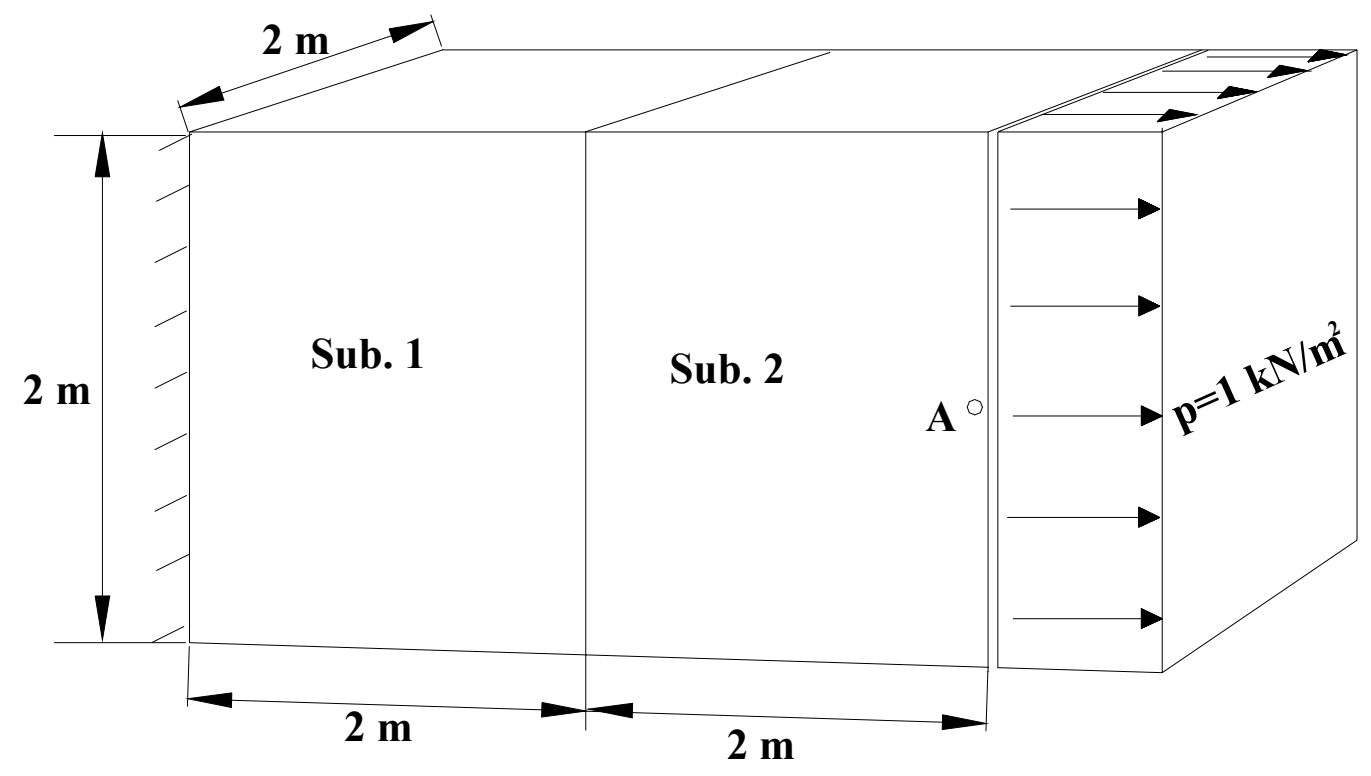

Figura 7.51- configuração da chapa simplesmente tracionada com 2 regiões.

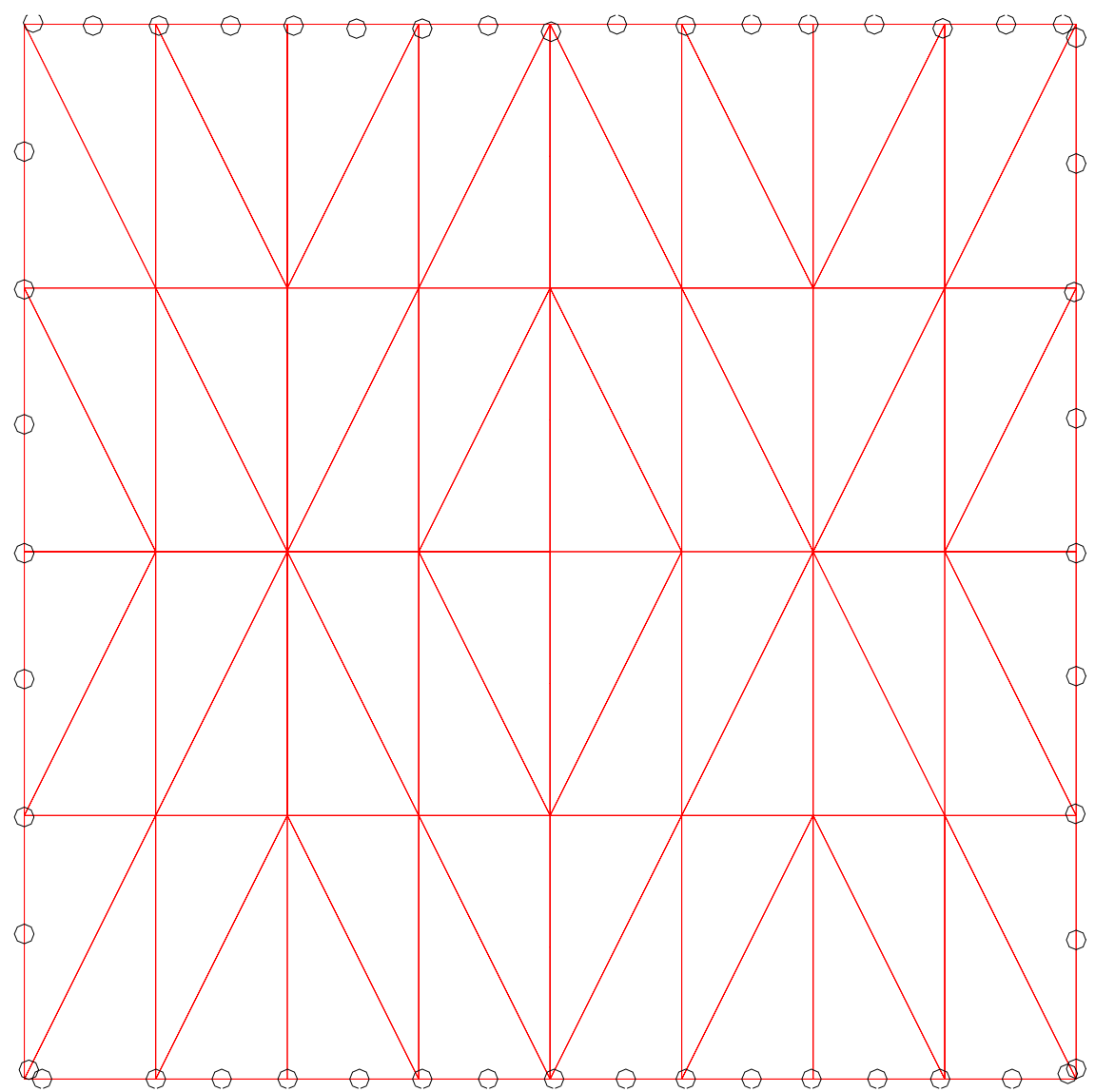

Figura 7.52- Discretização da chapa simplesmente tracionada com 2 regiões. 


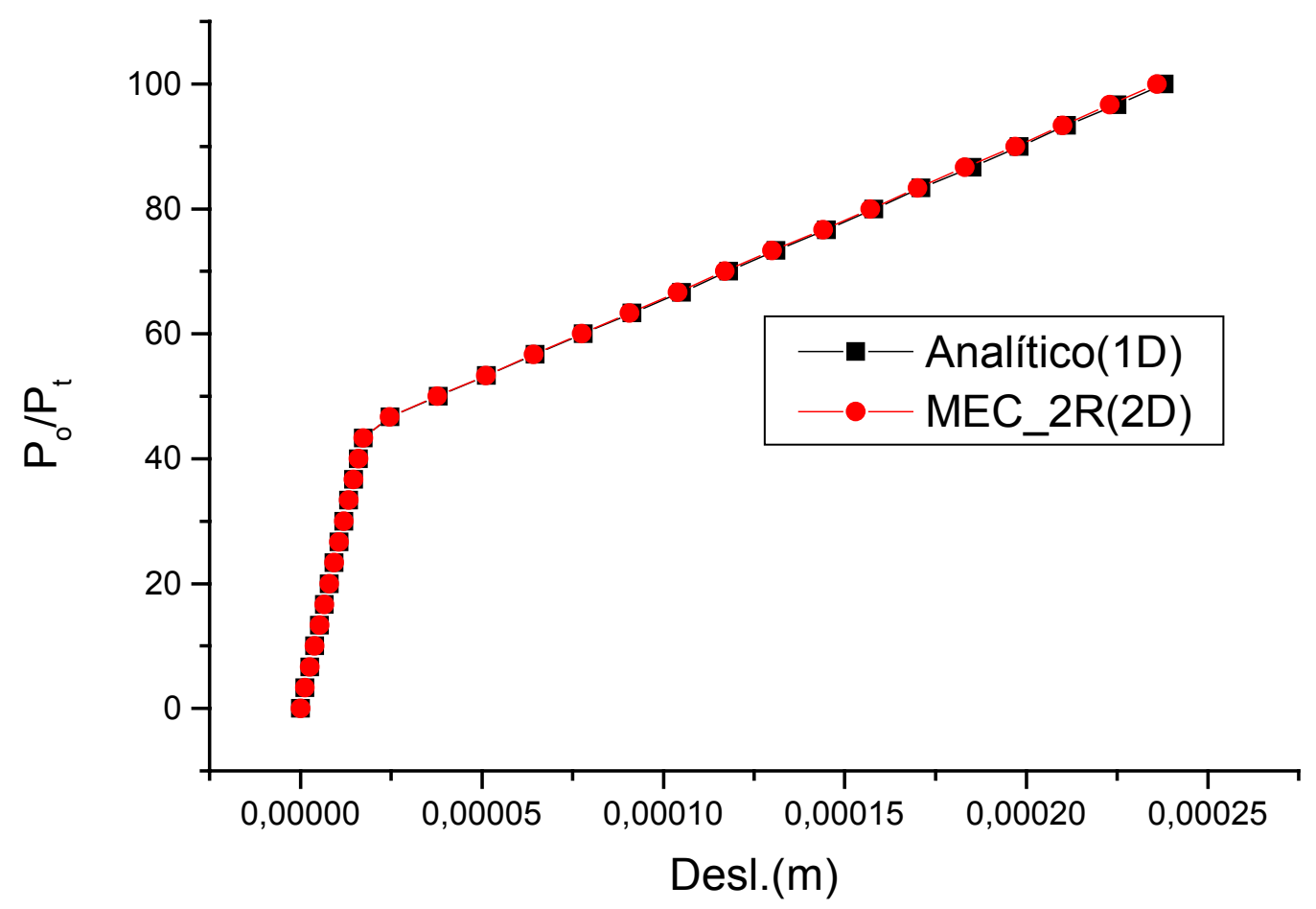

Figura 7.53 - Evolução Carga-Deslocamento do nó $A$.

Pode-se notar que o desempenho da formulação não se alterou quando houve a partição do domínio. Um dos motivos que favoreceu tal comportamento foi provavelmente devido às condições especiais de geometria e carregamento do problema.

\subsection{5) Placa com duas regiões em regime elastoplástico perfeito}

Neste exemplo, o problema de 7.3.3 tem seu domínio dividido em duas regiões iguais, figura 7.54 e os mesmos parâmetros mecânicos e de carregamento são mantidos. Na figura 7.52, está indicada a discretização das células utilizada e na figura 7.55 é indicada a curva deslocamento-carregamento para o ponto $b$; Essa curva é obtida a partir das análises do problema para uma única região - via formulações bi e triparamétrica, respectivamente, BL(1R) e TC(1R) - e pela aplicação da formulação triparamétrica cúbica TC(2R) no problema biconectado. 

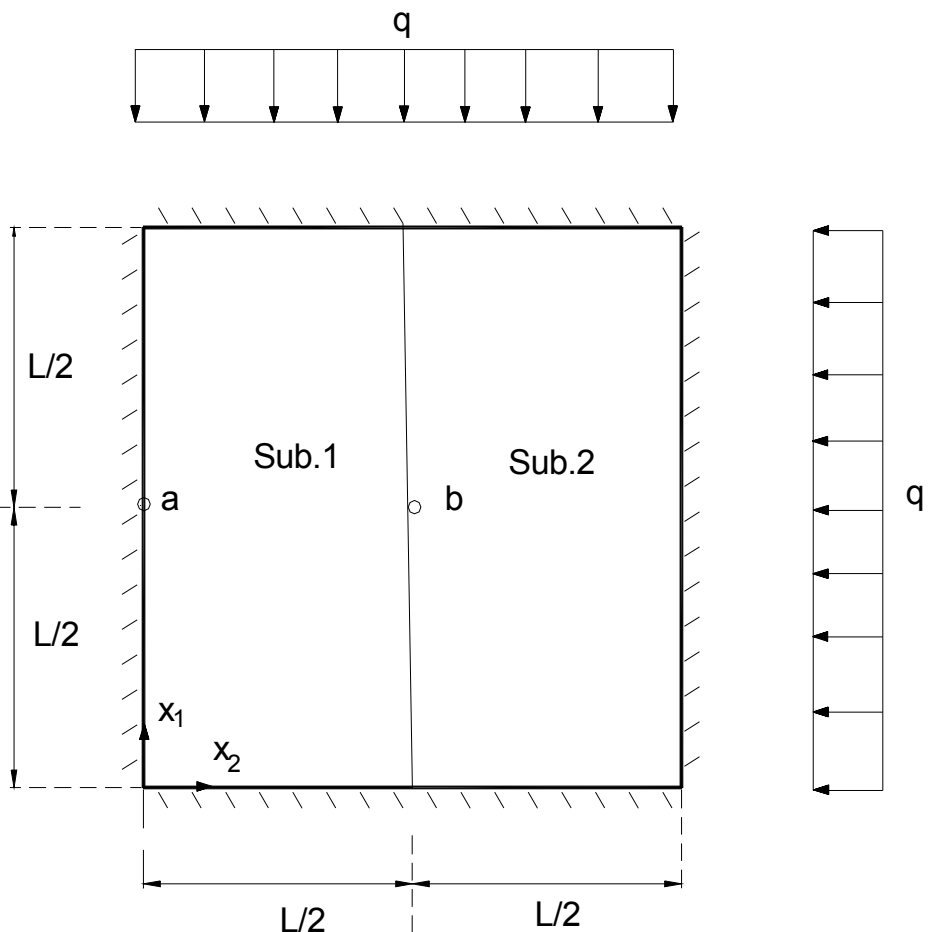

Figura 7.54- Configuração placa com duas regiões.

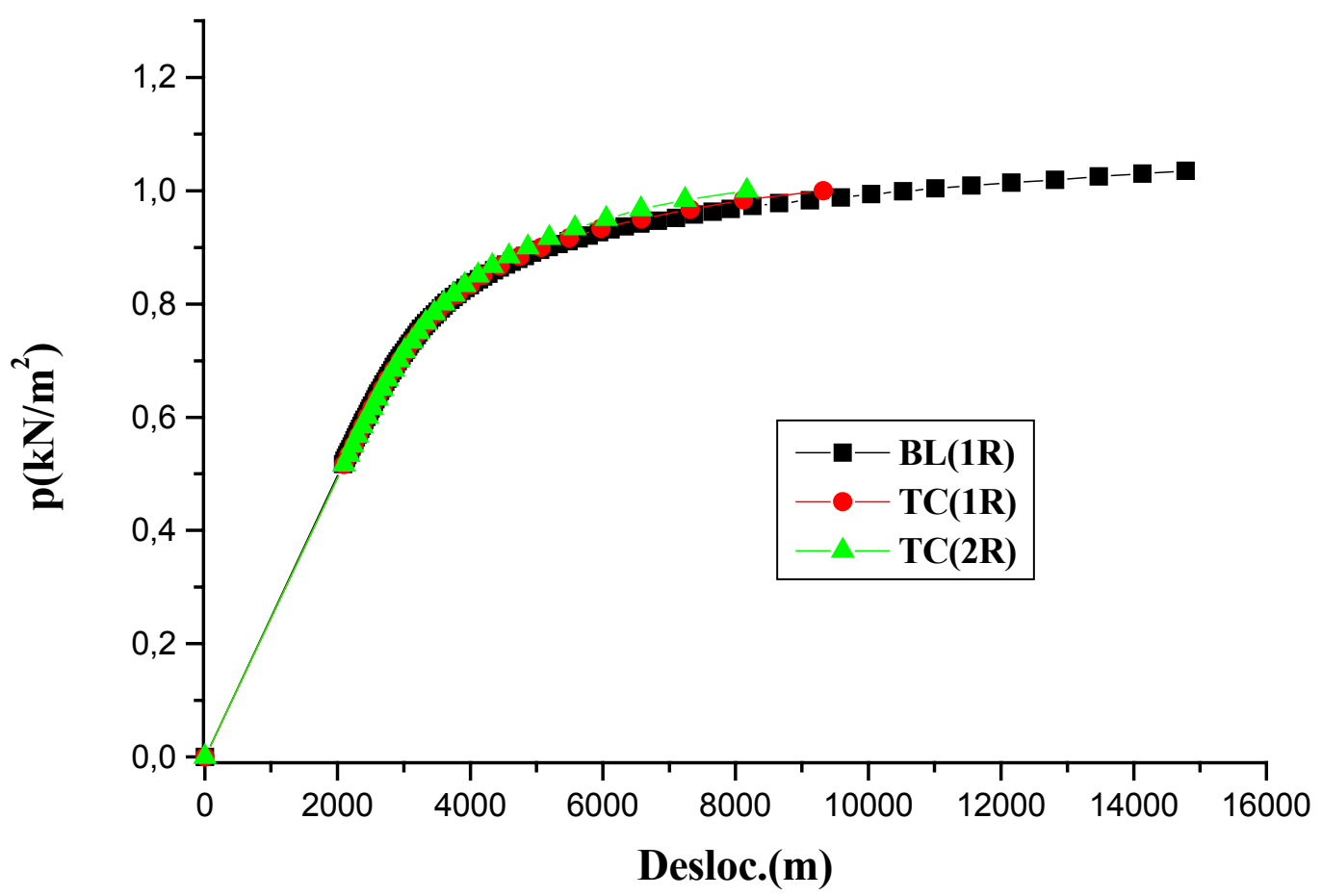

Figura 7.55- Curva Deslocamento-Carregamento para o Ponto Central. 
Convém notar que a formulação triparamétrica de placas apresentou um bom desempenho quando o domínio do problema foi bipartido. Contudo, pequenas alterações podem ser observadas entre as respostas desse problema e as do caso simplesmente conectado. Um dos fatores para tal comportamento é que os campos obtidos com a interpolação empregada nas interfaces das regiões do problema biconectado não correspondem mais àqueles valores, associados aos pontos de domínio, obtidos na análise do problema original simplesmente conectado. 


\section{CONCLUSÕES}

Neste trabalho, inicialmente foram desenvolvidas e implementadas duas formulações para análise elástica de estruturas compostas por lâminas planas de espessuras constantes pelo método dos elementos de contorno(MEC). A primeira formulação chamada de Hexaparamétrica incorpora seis graus de liberdade no vetor de deslocamento- em chapas: deslocamentos normal e tangencial e rotação zenital; em placas, deslocamento transversal e rotações normal e tangencial- e quatro graus de liberdade no vetor dos esforços (em chapas: forças normal e tangencial; em placas: força equivalente de Kirchhoff e momento fletor). Devido à diferença numérica entre os graus de liberdade nos vetores dos deslocamentos e dos esforços foram inseridas variáveis fictícias a fim de compatibilizar a ordem das matrizes de influência do Problema. A partir da aplicação da técnica de sub-regiões e a adoção de uma hierarquia conveniente de sistemas de referência o sistema de equações da estrutura laminar plana é montado. Após manipulações algébricas convenientes no sistema de equações do problema e a imposição de valores nulos às variáveis espúrias, as variáveis do problema podem ser determinadas.

A segunda formulação chamada de Tetraparamétrica foi obtida a partir da supressão das duas equações integrais associadas às rotações tangencial (placas) e zenital (chapa), de forma que os vetores dos deslocamentos e de esforços têm suas dimensões compatíveis, dispensando, portanto, a inclusão de qualquer variável adicional. $\mathrm{Na}$ montagem do sistema de equações é utilizada uma hierarquia de sistemas de referência similar à formulação hexaparamétrica. Além disso, para os casos de estruturas não-coplanares, as forças de interação chapa-placa discretas (reações de canto) foram desprezadas em ambas formulações.

Em ambas formulações, foram modelados diversos problemas com domínio simplesmente conectado, coplanarmente conectados e com geometria não co-planar. Os resultados foram comparados com soluções analíticas (quando disponíveis) e com aquelas fornecidas pelo método dos elementos finitos incorporado no software ANSYS (versão 5.5). Pode-se notar um desempenho satisfatório de ambas formulações do MEC, especialmente a da hexaparamétrica. 
$\mathrm{Na}$ segunda parte do trabalho, as formulações para o regime elástico são estendidas para analisar folhas planas coplanares com espessuras constantes com campos iniciais: problemas térmicos permanentes e elastoplásticos utilizando-se modelos clássicos para representar o fluxo plástico.

Exemplos (chapas e placas) são analisados para campos térmicos associados a tensões/momentos iniciais e a resolução do problema é feita diretamente. Já para a análise elástoplástica, na solução problema não-linear, foi implementado um algoritmo incremental-iterativo baseado no método de tensões/momentos iniciais. Optou-se por uma estratégia simples, conhecida no MEF por rigidez inicial, em que as matrizes de influência envolvidas não são atualizadas, sendo, portanto, montadas uma única vez. Tal procedimento conduz a um número superior de iterações para se atingir a convergência em relação àqueles que corrigem as matrizes de influência nas iterações e/ou incrementos de campos. Além disso, para representação das forças/momentos plásticas, as tensões inelásticas são integradas ao longo da espessura utilizando-se o método das camadas. O número de camadas empregado tem papel importante na análise, principalmente no caso do regime de flexão.

Alguns exemplos envolvendo fluxos elastoplásticos perfeitos e com encruamento isótropo foram analisados; resultados satisfatórios foram obtidos quando comparados com soluções analíticas (quando disponíveis) e com respostas do MEF.

Um outro aspecto importante nas respostas numéricas está associado à operacionalidade da técnica. Nesse trabalho, notou-se que à medida que o número de lâminas era acrescido, o tempo de análise era fortemente aumentado. Tal fato decorre, dentre outros fatores, de características intrínsecas do sistema de equações associado à não-simetria introduzida pela discretização e/ou pelo método da colocação (kernels não-simétricos) utilizada na formulação clássica dos métodos elementos de contorno.

Além disso, com introdução da técnica das subregiões, o sistema final nãosimétrico da estrutura tem sua esparsidade aumentada em função do acréscimo do número de graus de liberdade nas interfaces. Na figura 8.1, está indicado o mapeamento de valores nulos e não-nulos na matriz das incógnitas para o caso do problema do reservatório elevado com uma malha tipo 4 , vide(figura 7.12). 


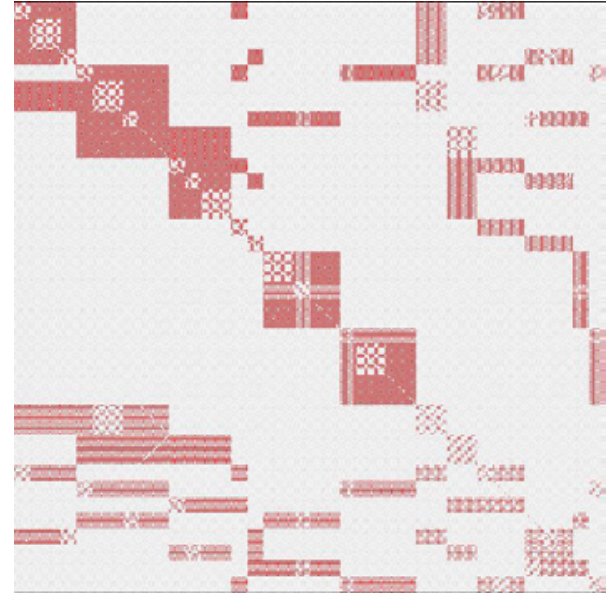

Matriz Hexaparamétrica

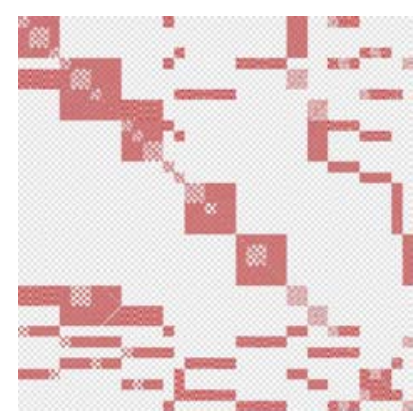

Matriz Tetraparamétrica

Figura 8.1 Mapeamento da matriz das incógnitas.

Nesse trabalho, não foi utilizada nenhuma técnica especial para otimizar o tempo de resolução do sistema, isto é, tirando proveito das regiões de valores nulos da matriz das incógnitas. No caso, partiu-se para o emprego de uma técnica direta de resolução. 


\section{REFERÊNCIAS BIBLIOGRÁFICAS}

ABEL, N. H. (1881) “Oeuvres completes”. Norvegien Christiania, Vol.1.

ANTES, H. (1981) “ On boundary integral formulation for circular cylindrical shell” In: BOUNDARY ELEMENT METHOD. C. A. Brebbia (ed.). Berlin:SpringerVerlag, p.224-238.

ASSOCIAÇÃO BRASILEIRA DE CIMENTO PORTLAND(1967) “Vocabulário de teoria de estruturas". São Paulo.

ALIABADI, M. H.; HALL, W. S.; PHEMISTER, T. G. “ Taylor expansions for singular Kernels in the boundary element method" Int. J. Num. Meth. Engng., Vol.21, pp.2221-2236.

ALTIERO, N. J.; Sikarskie(1978)"A boundary integral method applied to plates of arbitrary plan form ” Comp. Structures, Vol. 9, pp.163-168.

ARISTODEMO, M. ; TURCO, E. (1994)"Boundary element discretization of plane elasticity and plate bending problems” Int. J. Num. Meth. Engng., Vol.37, 965-987.

BALAS, J. et al.(1989) "Stress analysis by boundary element methods", Studies in Applied Mechanics, 23, Elsevier.

BACARJI, E.(2001) “Aplicação do método dos elementos de contorno à análise de pavimentos”, São Carlos, Tese(doutorado) - Escola de Engenharia de São Carlos, Universidade de São Paulo.

BANERJEE, P. K.; CATHIE, D. N.; DAVIES, T. G.(1979) "Two- and threedimensional problems of elasto-plasticity" Developments. $\mathrm{n}$ boundary element, Vol1, pp.65-95. 
BANERJEE, P. K. ; RAVEENDRA, S. T(1986) “Advanced Boundary Element analysis of two- and three-dimensional problems of elastoplasticity" Int. J. Num. Meth. Engng., Vol.23, pp.985-1002.

BANERJEE, P. K., WILSON, R. B. ; RAVEENDRA, S. T.(1986) “Advanced application of BEM of three-dimensional problems of monotonic and cyclic plasticity” Int. J. Num. Meth. Engng., Vol.23, pp.985-1002.

BANERJEE, P. K. ; RAVEENDRA, S. T(1987) "New boundary element formulation for 2-D elastoplastic analysis" J. Engng. Mech., ASCE, Vol.113, n.2, Feb., pp.252-265.

BELL, J. F. (1973) "Experimental foundations of solid mechanics " In: Handbuch der Physik, Vol. Via, Berlin Springer-Verlag.

BESKOS, D.E.(1991) “ Static and dynamic analysis of shells” In: BOUNDARY ELEMENT ANALYSIS OF PLATES AND SHELL, Beskos(ed.), Berlin:SpringerVerlag, p.91-139.

BERGMAN, P. G.; FELIPPA, C. A.(1985) “ A triangular membrane element with rotational degrees of freedom” Comp. Meths. in Applied Mech. Eng., v.50, p.25-69.

BERGMAN, S.; SCHIFFER, M. (1953) “ Kernel functions and elliptic differential equations in mathematical physics" Academic Press Inc., New York.

BERNADOU,M; BOISSERIE, J. M;(1982) “ The finite element method in thin shell theory: application to arch dam simulation”. Birkhäuser, Boston.

BETTI(1872), E. “Teoria della elasticità". Il Nuovo Cimento, Serie 2, 7 \& 8:5-21, pp.69-97. 
BEZINE, G. (1978) "Boundary integral formulation for plate flexure with na arbitrary boundary conditions " Mech. Res. Comm., Vol.5, pp.197-206.

BEZINE, G. (1981) “A boundary integral equation method for plate flexure with conditions inside the domain” Int. J. Num. Meth. Engng., Vol.17, pp.1647-1657.

BOUSSINESQ, J.(1885) “ Applications des potentials à L'etude de L'equilibre et du Moviment des Solides Elastique. Gualtier-Villars, Paris.

BREBBIA, C. A.(1978) “ The boundary element method for engineers” Pentech Press, London.

BREBBIA, C. A; WALKER, S.(1980) “ The boundary element techniques in engineering" Newes-Butterworths, London.

BUI, H. D.(1978) "Some remarks about the formulation of three-dimensional thermoelastoplastic problems by integral equations" Int. J. Solids Structures., Vol.14, n.8, Aug., pp.935-939.

BULL, J. N. (1989)“Finite element application to thin-walled strucutures" Elsevier, Boston and N. York.

CARMO(2001), R “Determinação de rigidez de estruturas de pavimentos através do método dos elementos de contorno". São Carlos, Dissertação (doutorado) - Escola de Engenharia de São Carlos, Universidade de São Paulo.

CERRUTI, V.(1882) “Acc. Lincei., Mem. Fis. Mat.”, Roma.

CHAVES, E.W.V.(1997) "Análise de placas com variação de espessura através do método dos elementos de contorno". São Carlos, Dissertação (mestrado) - Escola de Engenharia de São Carlos, Universidade de São Paulo. 
CHEN, W. F.; HAN, D. J. (1988) “ Plasticity for structural engineers”, SpringerVerlag, New York.

CHEN, G.; ZHOU, J. (1992) “ Boundary element methods”. Academic Press INC. , london.

CHEUNG, Y. K. "Folded plate structures by the finite strip method". Am. Soc. Civ. Eng., vol. 96, 2963-79,1969.

CHUEIRI, L.H.M.(1994)“Formulação do método dos elementos de contorno para análise elastoplástica de placas", São Carlos, Tese (doutorado) - Escola de Engenharia de São Carlos, Universidade de São Paulo.

CISILINO, A. P.; ALIABADI, M. H AND OTHEGUI, J. L.(1998) “A direct formulation for 3D-dimensional elastoplastic boundary elements" In: BEM XX , pp.169-179.

CLOUGH, R. W; WILSON, E. L. (1971) "Dynamic finite element analysis of arbitrary thin shells". Comp. \& Structures, vol.1.

CODA, H.B.(1993)“ Análise tridimensional transiente de estruturas pela combinação entre o método dos elementos de contorno e o método dos elementos finitos.", São Carlos, Tese (doutorado) - Escola de Engenharia de São Carlos, Universidade de São Paulo.

CORRÊA, M.R.S.(1991)“Aperfeiçoamento de modelos usualmente empregados no projeto de sistemas estruturais de edifícios", São Carlos, Tese (doutorado) - Escola de Engenharia de São Carlos, Universidade de São Paulo.

CRUSE, T. A.(1969) “ Numerical solutions in the three dimensional elastostatics" Int. J. Solids Structures, Vol.5, pp.1259-1274. 
DALLNER, R.(1993)“Behandlung inelasticher 3D-probleme mittels Randelementmethode" VDI Fortschrittberichte Reihe 18: Mechanik/Bruchmechanik Nr. 126, VDI-Verlag, Düsseldorf .

DANSON, D. J.(1979) “Analysis of plate bending problems by direct boundary element method". Southampton. Dissertation(M.Sc). University of Southampton, U.K.

DIRGANTARA, T;ALIABADI, M. H.(1999) “A new boundary element formulation for shear deformable shells analysis” Int. J. Num. Meth. Engng., vol. 45, p.1257-1275.

DOMINGUEZ, J; BREBBIA, C. A.(1989) "Boundary elements: An introductory course" Computacional mechanics piblications, Southampton and Boston.

DONG.,Y. F; GEA, H. C.(1998) “A non-hypersingular boundary integral formulation for displacement gradients in linear elasticity". Acta Mechanica, 129, 187-205.

DRUCKER, D. C. ; PRAGER, W. (1952) “ Soils mechanics and plastic analysis or limit design "Quart. Appl. Math., Vol. 10, pp. 157-165.

DU, Q.; YAO, Z.; SONG G.(1984) "Solution of some plate bending problems using the boundary element method" Appl. Math. Modelling, Vol.8, Feb., pp.15-22.

ELLING, R. E. (1973)“Concentrated loads applied to shallow shells” J. Engng. Mech. Div., ASCE, vol.99, p.319-330.

FERNANDES, G.R.(1998)“ O método dos elementos de contorno aplicado à análise não-linear de placas”, São Carlos, Dissertação (mestrado) - Escola de Engenharia de São Carlos, Universidade de São Paulo. 
FERNANDES, G.R; VENTURINI, W. S.(2002) "Stiffened plate bending analysis by the boundary element method" Computational Mechanics, vol.28, n.3-4, p.275-281.

FOLLAND, G. B.(1992) “Fourier analysis and its applications”. Wadsworth \& Brooks, Pacific Grove, USA

FOLTRAN, C. E.(1999) “ Análise de problemas planos em regime elasto-plástico pelo método dos elementos de contorno". Campinas. Dissertação(mestrado)Faculdade de Engenharia Civil, Universidade Estadual de Campinas.

FRANGI, A. (1996)"A new regularized BE formulation for Kirchhoff plates" Eur. J. Mech. A/solids, Vol.15, n.5, pp.915-931.

FREDHOLM, I.(1903) “ Sur une classe d'équations fonctionelles”, Acta Math.,Vol.27, pp. 365-390.

FU, K.; HARB, A.,I.(1990) “Integral equation method for spherical shells under axisymetric loads" Journal of Engineering Mechanics, ASCE, v.116, n.2, p.324-323.

GALERKIN, B. G.(1930) “Contribution à la solution générale du problème de l'’elasticité dans le cas de tris dimensions". Comptes Rendus, Vol.190. pp.10471048.

GALUTA, E. M.; CHEUNG, M. S. (1995) “Combined boundary element and finite element analysis of composite box girder bridges". Computers \& Structures, v. 57, n.3, pp.427-437.

GHOSH, N.; RAJIYAH, H.; GHOSH, S. AND MUKHERJEE S (1986) "A new boundary element method formulation for linear elasticity" J. Appl. Mech., ASME, Vol.53, Mar., pp.69-76. 
GOSPODINOV, G.(1984) "The boundary element method applied to shallow spherical shells" In: BOUNDARY ELEMENTS VI, p. 3.65-3.77, Brebbia, C. A., Eds, Spring-Verlag, Berlin.

GOULD, P., L. (1985)“Finite element analysis of shells of revolution” University press Ltd, Belfast.

GUIGGIANI, M.; KRISHNASAMY, G.; RUDOLPHI, T. J.; RIZZO, F. L. (1991) “ Hypersingular boundary integral equations : A new approach to their numerical treatment”. In: IABEM 1990, Morino \& Piva (eds), Springer, Berlin.

GUIGGIANI, M(1998) “ Formulation and numerical treatment of boundary integral equations with hypersingular kernels" In: "Singular integral in boundary element methods" Eds, Sladek, V., Sladek, J., Computational Mechanics Publications, Boston and N. York.

JASWON, M. A. (1963) “Integral equation methods in potential theory”. Proc. Roy. Soc., Serie A, Vol.275, pp.23-32.

JASWON, M. A.; PONTER, A. R. S. (1963) “ Integral equation solution of the torsion problem”. Proc. Roy. Soc., Serie A, Vol.275, pp.237-246.

JASWON, M. A.; MAITI, M.; SYMM, G. T. (1967) “ Numerical biharmonic analysis and some applications”. Int. J. Solids Structures, Vol.3, pp.309-332.

JASWON, M. A.(1981)"Some theoretical aspects of boundary integral equations" Appl. Math. Modelling, Vol.5, Dec. , pp.409-411.

JIAN-FAN, X. ; YOUNG-LI, W.(1992) “A new type of boundary integral equation for plane problems of elasticity including rotational forces". Comp. Struct., Vol.43, n.3, pp.531-537. 
JUN, L.; BEER, G; MEEK, J. L. (1985) “ Efficient evaluation of integrals of order $1 / r, 1 / r^{2}, 1 / r^{3}$ using Gauss quadrature” Eng. Anal., Vol. 2, pp.118-123.

HARB, A.,I.; FU, K.(1990) “ Analysis and optimal design of spherical shells under axisymetric loads" Journal of Engineering Mechanics, ASCE, v.116, n.2, p.324-323.

HADJIKOV, L. M.; MARGINOV, S.; BEKYARORA, P.T.(1985) “Cubic spline boundary element method for circular cylindrical shells" In: BOUNDARY ELEMENTS VII, p. 4.93-4.102, Brebbia, C. A., Maier, G., Eds, Spring-Verlag, Berlin.

HART, E. W. " Constitutive relations for the nonelastic deformation of metals" J. Engng. Mat. Tech., Vol.98, n.3, July, pp.193-202.

HARTMANN, F(1980) “ Computing the C-matrix on non-smooth boundary points" In: Brebbia, C. A. (ed.), CML publ.

HARTMANN, F.; ZOTEMANTEL, R (1986) "The direct boundary element method in plate bending” Int. J. Num. Meth. Engng., Vol.23, pp.2049-2069.

HAYAMI, K.; BREBBIA, C. A.(1987) “ A new coordinate transformation method for singular and quasi-singular integrals over general curved boundary elements. In: BEM IX, Vol.1, Springer-Verlag, Berlin.

HENCKY, H. Z. (1924) “ Zur Theorie plastischer deformationen und der hierdurch im Material hervorgerufenen Nachspannungen” Zeitschrift Ang. Mech. Math., Vol. 4, pp.323-334.

HENRY, D. P. ; BANERJEE, P. K. (1998) “A new BEM formulation for two- and three-dimensional elastoplasticity using particular integrals" Int. J. Num. Meth. Engng., Vol.26, pp.2079-2096. 
HESS, J. L.; SMITH, A., M., O.(1962) "Calculation of non-lifting potential flow about arbitrary three-dimensional bodies”. Report No. E.S. 40622, Douglas Aircraft Co., Long Beach.

HIGASHIMACHI,T. et al. (1983) “ Interactive strucutral analysis system using the advanced boundary element method” In: BEM V, Springer-Verlag, Berlin.

HUANG, H-C.(1989) "Static and dynamic analysis of plates and shells: theory, software ans applications”. Springer-Verlag, Berlin.

HUBER, M. T. (1904) Czasopismo Techniczne, Lemberg, Austria, Vol. 22, pp. 181.

HUBER, O.; DALlNER, R.; PARTHEYMÜLLER, P.; KUHN, G.(1996) "Evaluation of the stress tensor in 3D-dimensional elastoplasticity by direct solving of hypersingular integrals" Int. J. Num. Meth. Engng., Vol.39, pp.2555-2573.

KELLOG. O. D.(1929) “Foundations of potential theory”. Springer, Berlin.

KIRCHHOFF, G. (1850) “ Über das Gleichgewicht und die Bewegung einer elastischen Scheibe" J. Crelle, Vol.40, pp.51-88.

KOMATSU, S.; NAGAI M. (1982) “Analytical combination of boundary element method and thin-walled segment method and its application to box girder bridges". IN: BEM IV, Southampton, U.K.

KRAMIN, T. ; KRAMIN, M. V.(1997) "The investigation of the thin-walled threedimensional structures of complex shape using BEM'In: BEM XIX, pp.35-44, MARCHETTI et al. (Eds), CMP, London.

KUPRADZE, V. D. (1965). " Potential methods in the theory of elasticity”. Israel Programm for Scientific for Translations, Jerusalem. 
LACHAT, J.C.; WATSON, J. O.(1976) "Effective numerical treatment of boundary integral equations: a formulation for three dimensional elastostatics” Int. J. Num. Meth. Engng., Vol. 10, pp. 991-1005.

LACHAT, J.C.; WATSON, J. O.(1977) "Progress in the use of boundary integral methods, illustrated by examples" Comp. Meth. Appl. Mech. Engng., Vol.10, pp.273-289.

LAURICELLA, G.(1909) “Sur l'intégration de l'équations relative à l'équilibre des plaques élastiques encastrées” Acta Math., Vol. 32, pp.201-256.

LEI, X. (1994) “A new BEM approach for linear elasticity” Int. J. Solids Struct., Vol.31, n.24, pp.3333-3343.

LEKHNITSKII, S. G. (1981) “ Theory of elasticity of an anisotropic plate, MIR Publishers, Moscow.

LIU, Y. (1998) "Analysis of shell-like structures by the boundary element method based on 3D elasticity: formulation and verification" Int. J. Num. Meth. Engng., Vol.41, pp. 541-558.

LOVE, A. E. H. (1944) " Treatise on the mathematical theory of elasticity". Cambriged Unibersity Press. UK.

LU, P.; HUANG M. (1991) “Computational of the fundamental solution for shallow shells involving shear deformation" Int. J. Solids and Structures, Vol.28, n.5, p.631645.

LU, P.; MAHRENHOLTZ, O. (1994) “ The fundamental solution for theory of orthotropic shallow shells involving shear deformation” Int. J. Solids and Structures, Vol.31, n.7, p.913-923. 
MATSUI, T.; MATSUOKA, O. (1978) “ The fundamental solution in the theory of shallow shells" Int. J. Solids Struct., Vol.14, p.971-986.

MATSUMOTO, T ; YUUKI, R.(1986)"Accurate boundary element analysis of twodimensional elasto-plastic problems” In:BETECH 86, pp.205-214.

MAZARS, J. (1984) “Application de la mécanique de l'endommagemnet du comportement nou linéaire et à la rupture du beton" Paris, Thèse ( Doctorat détat), université Paris 6.

MCCARTNEY, L. N.(1983) “A new boundary element technique for solving plane problems of linear elasticity: 1. Theory” Appl. Math. Modelling, Vol.7, pp.441-451.

MCCARTNEY, L. N.(1984) “A new boundary element technique for solving plane problems of linear elasticity: improved theory and an application to fracture mechanics" Appl. Math. Modelling, Vol.8, pp.243-250.

MELAN, E. (1932) “ Der Spannungzustand der durch eine Einzelkraft im Innern beanspruchten Halbscheibe" Zeitschrift Ang. Mech. Math., Vol. 12, pp. 343-346.

MENDELSON, A. (1968) “Plasticity and application “. McMilann, New YorkLondon.

MENDELSON, A. (1973) “ Boundary integral methods in elasticity and plasticity, Report No. NASA TN D-7418, NASA.

MENDELSON, A.; ALBERS, L. U. (1975) “ Application of boundary integral equation $\mathrm{s}$ to elastoplastic problems . In: BOUNDARY INTEGRAL-METHOD: COMPUTATIONAL APPLICATION IN APPLIED MECHANICS. (Cruse and Rizzo eds), Applied Mechanics Division, Vol. 11, ASME,. New York. 
NEWTON, D. A.; TOTTENHAM(1968) "Boundary value problems in thin shallow shells of arbitrary plan form" Journal engineering mathematics, vol.2, p.211-213.

MIKHLIN, S. G.(1957) “Integral equations”, Pergamon, NY.

MIKHLIN, S. G.(1962) “Singular Integral equations”, Am. Math. Soc. Trans. Series 1, Vol. 10, pp.84-197.

MIKHLIN, S. G.(1965) “ Multidimensional singular integrals and integral equations", Pergamon Press, London.

MINDLIN, R. D. (1935) “ Contribuition au problème d'équilibrie d'élasticité d'um indéfini limité par um plan”. Comptes Rendus, Vol. 201, pp. 536-537.

MINDLIN, R. D.(1936 a) “Force at a point in the interior of a semi-infinite solid”. J. Physics, vol. 7.

MINDLIN, R. D.(1936 b) “ Note on the Galerkin and Papkovitch stress functions”. Bull. Amer. Soc., Vol. 42, pp.373-379.

MISES, R.(1913) “ Mechanik der fester Körper im plastisch deformablen Zustand” Nach. Ges. Wiss. Goettingen, pp. 582-592.

MORJARIA, M.; MUKHERJEE, S.(1980)"Inelastic analysis of transverse deflection of plates by the boundary element method" J. Appl. Mech., ASME, Vol.47, Jun, pp.291-296.

MOSHAIOV, A.; VORUS, W. S.(1986)"Elasto-plastic plate bending analysis by the boundary element method with initial plastic moments" Int. J. Solids Structures, Vol.22, n.11, pp.1213-1229. 
MOSHAIOV, A.; VORUS, W. S.(1986b)"Thermo-elastic-plastic plate bending by a boundary element method with initial plastic moments”'In: BETECH 86, pp.567-594.

MROZ, Z. (1967) “ On the description of anisotropic work hardening” J. Mech. Phys. Solids, Vol.15, pp.163-175.

MUKHELISHVILI, N. I.(1945) “Integral equations”, Pergamon, NY.

MUKHELISHVILI, N. I.(1953) "Some basic problem of the mathematical theory of elasticity”, P. Noordhoff, Groningen.

MUKHERJEE, S.(1977) "Corrected boundary-integral equations in planar thermoelastoplasticity” Int. J. Solids Structures, Vol.13, pp.331-335.

NARDINI, D.; BREBBIA, C. A.(1982) “ A new approach to free vibration analysis using a boundary element method" In: BOUNDARY ELEMENT METHOS IN ENGINEERING., p. 312-326, Eds, Brebbia, C. A.

NAVARRA, E. O. I.(1995) “ Calculo de estructuras por el metodo de elementos finitos”. Centro Internacional de Métodos Numéricos Ingeniería. Barcelona.]

NAYAK, G. C. ; ZIENKIEWICZ, O. C. (1972) “ Convenient form of stress invariants for plasticity “ J. Struct. Div., ASME, Vol. 98, pp. 949-954.

NEUBER, H.(1934) “ Ein neuer Ansatz zür losung räumlicher Probleme der Elastizitätstheorie”. Zeitschrift Ang. Mech. Math., Bd. 14, 203-214.

NEWTON, D. A; TOTTENHAM, H.(1968) “ Boundary value problems in thin shallow shells of arbitrary plan form” Journal Engng. Math., v.2, p.211-223.

NING, H.(1992) "An effective boundary method for the analysis of elastoplastic problems” Appl. Math. Mech., Vol.13, n.8, Aug., pp.737-744. 
OCHIAI, Y.; SEKIYA, T.(1995) "Generation of free-form surface in CAD for dies" Adv. Engng. Software, Vol. 22, pp.113-118.

OCHIAI, Y.; KOBAYASHI, T.(1998)"'Inelastic analysis without internal cell by improved multiple-reciprocity BEM"In: BEM XX, Vol.4, pp.73-83.

OWEN, D. R. J. \& HINTON, E.(1980) “ Finite element in plasticity: Theory and practice”. Pineridge Press Limited. Swansea, U.K.

OHGA, M.; SHIGEMATSU, T; TAKASHI, H. (1991) "Boundary element- transfer matrix method for plated strucutures". ASCE, J. Eng. Mech., v.117, n. 11, pp.25092526.

OLIVEIRA NETO, L. (1991) “Análise de placas de borda curva pelo do método dos elementos de contorno". São Carlos, Dissertação (mestrado) - Escola de Engenharia de São Carlos, Universidade de São Paulo.

OLIVEIRA NETO, L. (1998)“Uma formulação do método dos elementos de contorno com três parâmetros nodais em deslocamentos para placas delgadas e suas aplicações em engenharia estrutural". Tese(Doutorado). Escola de Engenharia de São Carlos, Universidade de São Paulo, São Carlos, SP.

PAIVA, J. B.(1987))“Formulação do método dos elementos de contorno para flexão de placas e suas aplicações em engenharia de estruturasl". Tese(Doutorado). Escola de Engenharia de São Carlos, Universidade de São Paulo, São Carlos, SP.

PAIVA, J.B.(1991) "Boundary element formulation for plate analysis with special distribution of reactions along the boundary". Advances in Engineering Software and Workstations 13, pp. 162-168, July.

PAIVA, J. B.; OLIVEIRA NETO, L. (1995)“ An alternative boundary element formulation for plate bending analysis”. In: BETECH 95 , Adelaide, Australia. 
PALERMO Jr, M. (1989). “ Análise de peças de seção delgada como associação de placas pelo método dos elementos de contorno". Tese(Doutorado). Escola de Engenharia de São Carlos, Universidade de São Paulo, São Carlos, SP.

PALERMO Jr., L.; RACHID, M.; VENTURINI, W. S. (1992) "Analysis of thin walled structures using the boundary element method”. Eng. Anal. Bound. Elem., 9, pp.359-363.

PALIZZOTO, C. (1982) "An alternative formulation of boundary element method" Appl. Math. Modelling, Vol.6, Apr, pp.97-99.

PAPKOVITCH, P.F (1932 a) “ Solution générale das équations différentielles findaments d'élasticité , exprimée par trois fonctions harmoniques". Comptes Rendus, Vol.195. pp.513-515.

PAPKOVITCH, P.F (1932 b) "Expressions générales des composantes tensions, ne refermant comme finctions arbitraires que des fonctions harmoniques". Comptes Rendus, Vol.195. pp.754-756.

PARIS, F.; LEÓN, S. (1986) "Simply Supported plates by boundary integral equation method” Int. J. Num. Meth. Engng., Vol.23, 173-191.

PARIS, F.; LEÓN, S. (1987)"Boundary element method applied to the analysis thin plates" Comp. Struct., Vol.25, n.2, pp.225-233.

PARIS, F.; LEÓN, S. (1996)"Thin plates by the boundary element method by means of two Poisson equations" Eng. Anal. Bound. Elem., Vol.17,n.2, p.225-233.

PENG, X.; HE, G. (1986)" Computational of fundamental solution if the boundary element method for shallow shells" Appl. Mathematical Modelling, Vol.10, p.185189. 
PODDAR, B; MUKHERJEE, S.(1989) “ An integral equation analysis of inelastic shells”. Computational. Engineering, Vol. 4, pp. 261-275.

POTR, I. (1987)”Thermo-plasticity by boundary elements” In: BEM IX, pp.373-384.

PRAGER, W.(1928) "Die druckverteilung na Körpern in ebener Potentialströmung" Physikalische Zeitschrift, Vol. 29, pp. 865-869.

PRAGER, W.(1955) “ Theory of plasticity : a survey of recent achievement” Proc. Inst. Mech. Engineers, Vol. 169, pp.493-498.

PRANDTL, L. (1924) “ Spannungsverteilung in plastischen Koerpern “ In: $1^{\text {ST }}$ INTERNATIONAL CONGRESS ON APPLIED MECHANICS, Delft, pp.43-54.

RAJAMOHAN, C. ; RAAMACHANDRAN, J.(1997)"Boundary element analysis of skew plates using a new fundamental solution" Mech. Res. Comm., Vol.24, n.4, pp.407-414.

REINSSER, E. (1994) "Note on the theorem of the symmetry of stress tensor". J. Math. Phys., Vol.24, pp.192-194.

REUSS, A. (1930) “ Beruecksichtung der elastischen Formaenderungen in der Plastizitaetstheorie” Zeitschrift Ang. Mech. Math., Vol. 10, pp.266-276.

RIBEIRO, G. O (1992)“Sobre a formulação do método dos elementos de contorno para a flexão de placas usando as hipóteses de Reissner", São Carlos, Tese(Doutorado) - Escola de Engenharia de São Carlos, Universidade de São Paulo.

RICCARDELLA, P.C.(1973) "An implementation of the boundary integral technique for planar problems in elasticity and elastoplasticity . Report No. SM-7310, Dept. Mech. Engng, Carnegie Mellon University, Pittsburg, U.S.A. 
RIZZO, F. J.(1967) “An integral equation approach to boundary value problems of classical elastostatics”. Quart. Appl. Math., Vol.25, n.1, pp.83-95.

SEGEDIN, C. M.; BRICKELL, G. A.(1968) "Integral equation method for a corner plate” J. Struct. Div., ASCE, Vol.94, n. ST1, Jan., pp.41-51.

SILVA, N. A.(1996) "Aplicação do método dos elementos de contorno aplicado às placas utilizando a teoria de Reissner", São Carlos, Tese(Doutorado) - Escola de Engenharia de São Carlos, Universidade de São Paulo.

SIMMONDS, J.; BRADLEY, M. (1976) “ The fundamental solution for a shallow shells with an arbitrary quadratic midsurface” Appl. Mech., Trans. ASME, vol.43, p. 286-290.

SIMONS, N.; SADEGH, A. M.(1989) “ An indirect boundary integral equation applied to nonshallow spherical shell problem with arbitrary boundary constraints" Journal of Applied Mechanics, Trans. of ASME, v.56, p.918-925.

SISSON, J. M. C. (1990) “Accurate interior point computations in the boundary integral equation method" Comp. Meth. Appl. Mech. Engng., Vol. 79, pp.281-307.

SHI, G.; BEZINE, G.(1989) “A direct boundary element method for the bending analysis of arbitrary planform plates with square or circular opening”. Eur. J. Mech., A/Solids, 8, n.5, 341-359.

SLADEK, V.; SLADEK, J.(1992) "Nonsingular formulation of BIE for plate bending problem" Eur. J. Mech. A/Solids, Vol.11, n.3, pp.335-348.

SLADEK, V.; SLADEK, J. ; BALAS, J.(1982) “ Three-dimensional crack analysis for anisotropic body" Appl. Math. Modelling, Vol.6, pp.374-380. 
SLADEK, V.; SLADEK, J.(1992) "Non-singular boundary integral representation of stresses” Int. J. Num. Meth. Engng., Vol.33, pp.1481-1499.

SLADEK, V.; SLADEK, J.(1998) "Singular integral in boundary element methods" Eds, Sladek, V., Sladek, J., Computational Mechanics Publications, Boston and N. York.

SOMIGLIANA, C.(1886)“ Sopra l'equilibrio di un corpo elastico isotropo”. Il Nuovo Cimento, t. 17-20.

SONG, GUO-SHU; MUKHERJEE, S.(1986) "Boundary element method analysis of bending of elastic plates of arbitrary shape with general boundary conditions".

Engng. Analysis, Vol. 3, pp. 36-44.

SONG, GUO-SHU; MUKHERJEE, S.(1989) "Boundary element method analysis of bending of inelastic plates with general boundary conditions".

Computational. Engineering, Vol. 5, pp. 104-112.

SOUZA, V.J.B.(2001)“Algoritmos de integração eficientes para o método dos elementos de contorno tridimensional”, São Carlos, Dissertação (mestrado) - Escola de Engenharia de São Carlos, Universidade de São Paulo.

STERN, M. (1979) "A general boundary integral formulations for the numerical solution of plate bending problems", Int. J. Sol. Struct., Vol. 15, pp. 769-782.

STERN, M. (1989) " Static analysis of beam, plates and shells", In: BOUNDARY ELEMENT METHOS IN STRUCTURAL ANALYSIS, pp. 41-64.Eds, Beskos, D.E., ASCE, N. York.

SWEDLOW, J. L.; CRUSE, T. A.(1971) "Formulation of boundary integral equation for three-dimensional elasto-plastic flow" Int. J. Solids Struc., Vol.7, pp.1673-1683. 
TANAKA, M.; BERCIN, A. N. (1998) "Static bending analysis of stiffned plates using the boundary element method”. Eng. Anal. Bound. Elem., 21, pp.147-154.

TANAKA, M.; TANAKA, K.(1981) "On a new boundary element solution scheme for elastoplasticity" Ing. Archiv, Vol.50, pp.289-293.

TANG, S.; KITCHING, R.(1993)"Elastoplastic analysis of two-dimensional problems with hole by boundary element method using complex variables" Int. J. Mech. Sci., Vol.35, n.7, pp.577-586.

TELlES, J. C. F.; BREBBIA, C. A. (1979) "On the application of the boundary element method to plasticity” Appl. Math. Modelling, Vol.3, Dec., pp.466-470.

TELLES, J. C. F. (1981) "On the application of the boundary element method to inelastic problems". Southampton, Ph.D. Thesis, Faculty of Engineering and Applied Science University of Southampton.

TELlES, J. C. F.; BREBBIA, C. A. (1981a) "The boundary element method in plasticiticity” Appl. Math. Modelling, Vol.5, Aug., pp.275-281.

TELLES, J. C. F.; BREBBIA, C. A. (1981b) "Boundary elements: new deveplopments in elastoplastic analysis" Appl. Math. Modelling, Vol.5, Oct., pp.376382 .

TELLES, J. C. F.; BREBBIA, C. A. (1981c) “Triomensional platicity using BIEM" Appl. Math. Modelling, Vol.5, Dec., pp.442-447.

TELLES, J. C. F. (1987) “ A self-adaptative coordinate transformation for efficient numerical evaluations of general boundary element integrals" Int. J. Num. Meth. Engng., Vol. 24, pp.959-973. 
TEPAVITCHAROV, A., D.(1985) "Fundamental solutions and boundary integral equations in the bending theory of shallow spherical shells" In: BOUNDARY ELEMENTS VII, p. 4.53-4.62, Brebbia, C. A., Maier, G., Eds, Spring-Verlag, Berlin.

TIMOSHENKO, S. (1940)“ Theory of plates and shells”. Mcgraw-Hill, New York.

TOSAKA, N; MIYAKE, S.(1983) “A boundary integral equation formulation for elastic shallow shell bending problems" In: BOUNDARY ELEMENTS, p.527-538, brebbia, C. A., Futagami, T.; Tanaka, M., Eds, Spring-Verlag, Berlin.

TOTTENHAM, H(1979). "The boundary element methods for plates and shells". Developments in Boundary Elements, Vol.1, pp.173-205, Banerjee, P. K. \& Butterfield, R., Eds, Elsevier Applied Science Published, London.

TREFFTZ, E.(1917) “Über die Kontraktion kreisförmigen Flüssigkeitsstrahlen”, Zeit. Math. Physik, Vol. 64, pp.34-61.

TRICOMI, F.(1928) “Equazioni integrali contenenti il valor principali di um integrale doppio “, Vol. 19, Bd. 27, Comptes Rendus Acc. Sciences U.R.S.S.

VABLE M. ; ZHANG, Y. (1992) “ A boundary element method for plate bending analysis" Int. J. Solids and Structures, Vol. 29, n.3.

VANDER WEEËN, F.(1982) “ Application of the boundary integral equation method to Reissner's plate model” Int. J. Num. Meth. Engng., Vol.18, p.1-10.

VENTURINI, W.S.(1982) "Application of the boundary element formulation to solve geomechnical problems", Southampton, Ph.Thesis. University of Southhampton, 
VENTURINI, W.S.(1988) "Um estudo sobre o método dos elementos de contorno e suas aplicações em problemas de Engenharia”. Tese (Livre-Docência). Escola de Engenharia de São Carlos, Universidade de São Paulo, São Carlos, SP.

VOLTERRA, V.(1956) “Opere mathematiche” Acad. Naz. Lincei, Rome, Vol.2, pp.216-275.

WANG, Y., C.; CAI, M.; XING, Z.F. (1988) “ Spline integral equation for the analysis of shallow shell by coupling the bending plate and the plane-stress sheet" In: BOUNDARY ELEMENT METHODS: PRINCIPLES AND APPLICATIONS. p.393-404, Eds, Tanaka, M. DU, Q., Pergamon Press.

WEARING, J. L. AND BETTAHAR, O. (1995) "The analysis of plate bending problems using the regular direct boundary element method" Eng. Anal. Bound. Elem., Vol.16, pp.261-271.

WEN, P. H.; ALIABADI, M.H; ROOKE, D.P.(1998) “ A new method for transformation of domain integral to boundary integral in boundary element method" Comm. Num. Meth. Engng., Vol.14, p.1055-1065.

WEN, P. H.; ALIABADI, M.H; YOUNG, A.(2000a) “ appliacation of dual reciprocity method to plates and shells" Eng. Anal. B. Elements, Vol.24, p.583-590.

WEN, P. H.; ALIABADI, M.H; YOUNG, A.(2000b) “Plane stress and plate bending coupling in BEM analysis of shallow shells" Int. J. Num. Meth. Engng., Vol.48, p.1107-1125.

WESTERGAARD, H. M.(1935) “ General solution of the problem of elastostatics of an n-dimensional homogeneous isotropic solid in an n-dimensional space”. Bull. Amer. Soc., Vol.41, pp.695-699.

WU, B. C.; ALTIERO, N. J.(1979)"'A boundary integral method applied to plates of arbitrary plan form and arbitrary boundary conditions" Comp. Structures, Vol.10, pp.703-707. 
YE, J. (1988) "A new approach for the bending problem for shallow shell by the boundary element method" Appl. Mathematical Modelling, Vol.12, p. 467-470.

YOKOYAMA, K.; MIYAKE, S.; TOSAKA, N. (1988) "boundary element analysis for shallow shell by the displacement method" In: BOUNDARY ELEMENT METHODS: PRINCIPLES AND APPLICATIONS. p.269-278, Eds, Tanaka, M. DU, Q., Pergamon Press.

YOUNG, A. (1996) "An improved numerical method for the traction boundary integral equation by application of Stokes' theorem" Int. J. Num. Meth. Engng., Vol.15, n.5, pp.915-931.

YU, H. S. (1994) “ A closed-form solution of stiffness matrix for Tresca and MohrCoulomb plasticity models” Comp. Struct., Vol. 53, n. 3, pp.755-757.

ZIEGLER, H. (1959) “A modification of Prager's hardening rule” Quart. Appl. Math., Vol.17, n.1, pp.55-65.

ZIENKIEWICZ, O. C.; VALLIAPAN, S.; KING, I. P.(1969) “ Elasto-plastic solutions of engineering problems 'initial stress' finite element approach" Int. J. Num. Meth. Engng., Vol.1, pp.75-100.

ZHANG, J.D.; ATLURI, S.N. (1986)“ A boundary/interior element method for quase-static and transient response analyses of shallow shells" Computer \& Strucutures, vol.24, p.213-223.

ZIENKIEWICZ, O. C.(1991) “The finite element method”. 4ª edição, Mcgraw Hill.

ZUO-HUI, W.(1993) "Nonsingular Kernel boundary element method for thin-plate bending problems" Appl. Math. Mech., Vol.14, n.8, Aug., pp.767-776. 


\section{ANEXO I}

Neste anexo encontram-se as integrações analíticas dos Kernels remanescentes no elemento singular na abordagem isoparamétrica linear de placas, cujas funções aproximadoras são dadas em (4.9).

Assim, para a derivada direcional dos momentos fletores interpolados pela função $\varphi_{1}$, tem-se que:

$$
\int_{\Gamma_{k}} m_{n, m}^{*} \varphi_{2} d \Gamma_{k}=\frac{1+v}{4 \pi} r_{, m}
$$

A integração dos momentos volventes conduz a resultados similares aos dos fletores, uma vez que seus respectivos kernels no elemento singular são parecidos diferindo-se apenas por constantes pela derivada direcional do raio vetor. Assim, pode-se escrever que:

$$
\begin{gathered}
\int_{\Gamma_{k}} m_{n s, m}^{*} \varphi_{1} d \Gamma_{k}=-\frac{1-v}{4 \pi} r_{, s} \\
\int_{\Gamma_{k}} m_{n s, m}^{*} \varphi_{2} d \Gamma_{k}=\frac{1-v}{4 \pi} r_{, s}
\end{gathered}
$$

Já a integração dos kernels dos momentos fletores ponderados por $\varphi_{2}$ pode ser escrita como:

$$
\int_{\Gamma_{k}} m_{n}^{*} \varphi_{2} d \Gamma_{k}=\int_{-a}^{-\varsigma} \frac{1}{4 \pi L}[(1+v) \ln r+v](a+\varsigma) d \varsigma+\int_{\varsigma}^{b} \frac{1}{4 \pi L}[(1+v) \ln r+v](a+\varsigma) d \varsigma
$$

Lembrando-se que $r=-\varsigma$ para parte negativa do sistema de referência $\varsigma$,e utilizando-se mudanças de variáveis, o conceito de PFH, conforme descrito nos procedimentos aplicados nos kernels anteriores, a expressão (I-4) pode ser escrita como: 


$$
\begin{gathered}
\int_{\Gamma_{k}} m_{n}^{*} \varphi_{2} d \Gamma_{k}=\frac{a^{2}}{2 L}\left[(1+v)\left(\ln a-\frac{3}{2}\right)+v\right]-\frac{1+v}{4 \pi L}\left[a b(\ln b-1)-\frac{b^{2}}{2}\left(\ln b-\frac{1}{2}\right)\right]- \\
\frac{v b}{4 \pi L}\left(a+\frac{b}{2}\right)=f(b, a)
\end{gathered}
$$

Para a obtenção da integração do kernel do momento fletor por $\varphi_{1}$ basta permutar $a$ e $b$ em (I-5), isto é:

$$
\int_{\Gamma_{k}} m_{n}^{*} \varphi_{1} d \Gamma_{k}=f(a, b)
$$

A integração dos kernels do deslocamento e suas derivadas direcionais podem ser expressas por:

$$
\begin{gathered}
\int_{\Gamma_{k}} w^{*} \varphi_{1} d \Gamma_{k}=f_{1}(a, b)=-\frac{a^{3}}{8 \pi D L}\left[\frac{(a+b)}{3}-\frac{a}{4}\left(\ln a-\frac{1}{4}\right)-\frac{b}{3}\left(\ln a-\frac{1}{3}\right)\right]+ \\
\frac{b^{4}}{72 \pi D L}\left(\ln b-\frac{13}{12}\right) \\
\int_{\Gamma_{k}} w^{*} \varphi_{2} d \Gamma_{k}=f_{1}(b, a) \\
\int_{\Gamma_{k}} w_{, m}^{*} \varphi_{1} d \Gamma_{k}=f_{2}(a, b)=\frac{r_{, m}}{8 \pi D L}\left\{a^{2}\left[\frac{b}{2}\left(\ln a-\frac{1}{2}\right)+\frac{a}{3}\left(\ln a-\frac{1}{3}\right)\right]-b^{3}\left(\frac{\ln b}{3}-\frac{5}{18}\right)\right\} \\
\int_{\Gamma_{k}} w_{, m}^{*} \varphi_{2} d \Gamma_{k}=f_{2}(b, a) \\
\int_{\Gamma_{k}} \theta_{p, m}^{*} \varphi_{2} d \Gamma_{k}=f_{3}(b, a)
\end{gathered}
$$

As integrações dos kernels da derivada direcional da rotação normal são dadas por:

$$
\int_{\Gamma_{k}} \theta_{p, m}^{*} \varphi_{1} d \Gamma_{k}=f_{3}(a, b)=-\frac{m_{i} n_{i}}{16 \pi D L}\left\{[2(a+2 b) \ln a-4 b-a]+b^{2}(2 \ln b-3)\right\} ; i=1,2
$$




\section{ANEXO II}

As integrais dos Kernels dos deslocamentos e forças de superfície em coordenadas globais para interpolação isoparamétrica linear de chapas são escritas como:

$$
\begin{gathered}
\int_{\Gamma_{k}} u_{i j}^{*} \varphi_{1} d \Gamma_{k}=\left\{\left(3-4 v_{p}\right)\left[2 a b(\ln a-1)+a^{2}\left(\ln a-\frac{1}{2}\right)+4 b^{2} \ln b-3 b^{2}\right] \delta_{i j}+\right. \\
\left.b^{2} r_{, i} r_{, j}\right\} \frac{-1}{16 \pi\left(1-v_{p}\right) G t}=f_{3}(a, b) ; \quad i=1,2 \\
\int_{\Gamma_{k}} p_{i j}^{*} u_{i j}^{*} \varphi_{2} d \Gamma_{k}=\frac{1-2 v}{4 \pi\left(1-v_{p}\right)}\left[1+\frac{b}{L} \ln \left(\frac{a}{b}\right)\right](j-i)=f_{3}(b, a) \\
\int_{\Gamma_{k}} p_{i j}^{*} \varphi_{2} d \Gamma_{k}=f_{4}(b, a)
\end{gathered}
$$

As integrais dos kernels das derivadas direcionais dos deslocamentos e forças de superfície para interpolação isoparamétrica linear são dadas por:

$$
\begin{gathered}
\int_{\Gamma_{k}} u_{i j p}^{*} \varphi_{1} d \Gamma_{k}=\frac{(a-b)}{8 \pi\left(1-v_{p}\right) G t L}\left[\left(3-4 v_{p}\right) \delta_{i p} r_{, j}-\delta_{i j} r_{, p}-\delta_{p k} r_{, i}+2 r_{, i} r_{, j} r_{, p}\right]=f_{5}(a, b) ; \\
i, j, p=1,2 \\
\int_{\Gamma_{k}} u_{i j p}^{*} \varphi_{2} d \Gamma_{k}=f_{5}(b, a) ; \\
\int_{\Gamma_{k}} p_{i j p}^{*} \varphi_{1} d \Gamma_{k}=\frac{-1}{4 \pi\left(1-v_{p}\right) L}\left(1+\frac{b}{a}\right)\left\{\left(1-2 v_{p}\right)+\left[\delta_{i p} n_{j}+\delta_{j p} n_{i}-2 r_{, j}\left(r_{, p} n_{i}-r_{, i} n_{p}\right)\right]+\right. \\
\left.2 r_{, i} r_{, p} n_{j}\right\}=f_{6}(a, b) ; i, j, p=1,2 \\
\int_{\Gamma_{k}} p_{i j p}^{*} \varphi_{2} d \Gamma_{k}=f_{6}(b, a)
\end{gathered}
$$




\section{ANEXO III}

Neste anexo é mostrado o cálculo das integrações presentes nos elementos da matriz descrita pela expressão(4.68) afetados pelas interpolações hiperparamétricas.

$$
\begin{aligned}
& \int_{\Gamma_{k}} f_{11} d \Gamma_{k}=\frac{1}{8 \pi\left(a^{3}+b^{3}\right)}\left\{\left[\left(b^{2}-a^{2}\right)-6(a+b)(b-a)-4 b^{2}\left(1+\frac{b}{a}\right)\right]+\right. \\
& \left.(1-v)\left[\frac{3}{2}\left(a^{2}-b^{2}\right)-6(a-b)^{2}\right]\right\} \\
& \int_{\Gamma_{k}} f_{13} d \Gamma_{k}=\frac{1}{8 \pi\left(a^{3}+b^{3}\right)}\left\{\left[a\left(b^{2}-a^{2}\right)+2(a+b)\left(a b-a^{2}\right)\right]+\right. \\
& \left.(1-v)\left[\frac{3}{2}\left(a^{2}-b^{2}\right)+2(a+b)\left(2 b^{2}+a b-a^{2}\right)\right]\right\} \\
& \int_{\Gamma_{k}} f_{14} d \Gamma_{k}=\frac{1}{8 \pi\left(a^{3}+b^{3}\right)}\left\{\left[\left(a^{2}-b^{2}\right)-6(a+b)(b-a)-4 a^{2}\left(1+\frac{a}{b}\right)\right]+\right. \\
& \left.(1-v)\left[\frac{11}{2}\left(a^{2}-b^{2}\right)\right]\right\} \\
& \int_{\Gamma_{k}} f_{16} d \Gamma_{k}=\frac{1}{8 \pi\left(a^{3}+b^{3}\right)}\left\{\left[b\left(b^{2}-a^{2}\right)+2(a+b)\left(b^{2}-2 a^{2}\right)+4 a^{2}(a+b)\right]+\right. \\
& \left.(1-v)\left[\frac{3}{2}\left(a^{2}-b^{2}\right)+2(a+b)\left(b^{2}-2 a^{2}\right)\right]\right\}
\end{aligned}
$$

onde as funções $f_{i j}$ são dadas em (4.69) e (4.70). 


\section{ANEXO IV}

O cálculo das integrações da matriz descrita em (4.73) está expresso a seguir:

$$
\begin{gathered}
\int_{\Gamma_{k}} a_{c d} \phi_{1} d \Gamma_{k}=\frac{A}{6} R_{c i}\left(r_{, i} n_{j}-r_{, j} n_{i}\right) Q_{j d}\left[2\left(b^{3}-a^{3}\right)-9\left(a^{2}+b^{2}\right)(b-a)-18 a b(b-a)\right] \\
i, j=1,2 ; c=1,2 ; d=2 \\
\int_{\Gamma_{k}} a_{c d} \phi_{2} d \Gamma_{k}=\frac{A}{6} R_{c i}\left(r_{, i} n_{j}-r_{, j} n_{i}\right) Q_{j d}\left[2 a\left(b^{3}-a^{3}\right)-3\left(a^{2}+b^{2}\right)\left(2 b^{2}+a b-a^{2}\right)+\right. \\
\left.6(b-a)\left(2 b^{3}-2 a b^{2}-b a^{2}\right)\right] ; i, j=1,2 ; c=1,2 ; d=2 \\
\int_{\Gamma_{k}} a_{c d} \phi_{3} d \Gamma_{k}=\frac{A}{6} R_{c i}\left(r_{, i} n_{j}-r_{, j} n_{i}\right) Q_{j d}\left[-2\left(b^{3}-a^{3}\right)+9\left(a^{2}+b^{2}\right)(b-a)+18 a b(b-a)\right] \\
\quad i, j=1,2 ; c=1,2 ; d=2 \\
\int_{\Gamma_{k}} a_{c d} \phi_{4} d \Gamma_{k}=\frac{A}{6} R_{c i}\left(r_{, i} n_{j}-r_{, j} n_{i}\right) Q_{j d}\left[2 b\left(b^{2}-2 a^{2}\right)-3\left(a^{2}+b^{2}\right)\left(b^{2}-2 a^{2}\right)+\right. \\
\left.6(b-a)\left(2 a^{3}-2 b a^{2}-a b^{2}\right)\right] ; i, j=1,2 ; c=1,2 ; d=2
\end{gathered}
$$

onde:

$$
\begin{gathered}
A=\frac{1-2 v}{8 \pi\left(1-v_{p}\right)\left(a^{3}+b^{3}\right)} \\
\int_{\Gamma_{h}} a_{32} \phi_{1} d \Gamma_{h}=q_{i} C_{i j k} m_{j}\left[\left(b^{2}-a^{2}\right)-6\left(b^{2}-a^{2}\right)-4 b^{3}\left(\frac{1}{a}+\frac{1}{b}\right)\right] ; i, j=1,2 ; \\
c=1,2 ; d=2 \\
C_{i j k}=\frac{1}{16 \pi\left(1-v_{p}\right)\left(a^{3}+b^{3}\right)}\left\{\left(1-2 v_{p}\right)+\left[\delta_{i k} n_{j}+\delta_{j k} n_{i}-2 r_{, j}\left(r_{, k} n_{i}-r_{, i} n_{k}\right)\right]+2 r_{, i} r_{, k} n_{j}\right\} ; \\
i, j, k=1,2
\end{gathered}
$$




$$
\begin{gathered}
\int_{\Gamma_{h}} a_{32} \phi_{2} d \Gamma_{h}=q_{i} C_{i j k} m_{j}\left[a\left(b^{2}-a^{2}\right)-2(a+b)\left(2 b^{2}+a b-a^{2}\right)+4 a b^{3}\left(\frac{1}{a}+\frac{1}{b}\right)\right] ; \\
i, j=1,2 ; c=1,2 ; d=2 \\
\int_{\Gamma_{h}} a_{32} \phi_{3} d \Gamma_{h}=-q_{i} C_{i j k} m_{j}\left[\left(b^{2}-a^{2}\right)-6\left(b^{2}-a^{2}\right)+4 a^{3}\left(\frac{1}{a}+\frac{1}{b}\right)\right] ; \\
i, j=1,2 ; c=1,2 ; d=2 \\
\int_{\Gamma_{h}} a_{32} \phi_{4} d \Gamma_{h}=q_{i} C_{i j k} m_{j}\left[b\left(b^{2}-a^{2}\right)-2(a+b)\left(b^{2}-2 a^{2}\right)-4 b a^{3}\left(\frac{1}{a}+\frac{1}{b}\right)\right] \\
i, j=1,2 ; c=1,2 ; d=2
\end{gathered}
$$




\section{ANEXO V}

As transformações da integral de domínio da célula em integral definida ao longo de seu contorno para as representações integrais de tensões, curvaturas, podem ser expressas como:

$$
\int_{\Omega_{h}} g(p) q_{i} D_{i j k}^{*}(p, S) m_{j} d \Omega_{h}=\int_{\Gamma_{k c e l}} \lambda_{c \sigma}(R) \frac{p_{i} r_{i}}{R} d \Gamma_{k c e l} ; i=1,2
$$

onde

$$
\begin{gathered}
\lambda_{c \sigma}(R)=\frac{q_{i} m_{j} R}{4 \pi\left(1-v_{p}\right)}\left[\left(1-2 v_{p}\right)\left(\delta_{i k} r_{, j}-\delta_{i j} r_{, k}+\delta_{j k} r_{i}\right)+2 r_{i, j} r_{, k} r_{, k}\left[D_{k}+\frac{1}{2} R\left(A_{k} r_{, l}+B_{k} r_{, 2}\right)\right] ;\right. \\
i, j, k, \alpha=1,2 \\
\int_{\Omega_{h}} g(p) q_{i} w_{, j}^{*}(p, S) m_{j} d \Omega_{h}=\int_{\Gamma_{k c e l}} \lambda_{p w}(R) \frac{p_{\alpha} r_{\alpha}}{R} d \Gamma_{k c e l} ; i, j, \alpha=1,2 \\
\lambda_{p w j}(R)=K_{l}\left\{\frac{D_{3}}{4}\left[(2 \ln R-1) \delta_{i j}+2 r_{, i} r_{j}\right]+\frac{1}{9} R\left(A_{3} r_{,}+B_{3} r_{, 2}\right)\left[(3 \ln R-1) \delta_{i j}+3 r_{, i} r_{j}\right]\right\} ; i, j=1,2
\end{gathered}
$$

onde

$$
k_{1}=\frac{q_{i} m_{j} R^{2}}{4 \pi D} ; i, j=1,2
$$

As integrais de carregamento definidas em linhas são calculadas utilizandose técnicas análogas àquelas empregadas nos elementos de contorno, de forma que a integração sobre a célula singular pode ser calculada como:

$$
\begin{gathered}
\int_{\Omega_{L h}} q_{i} D_{i j k}^{*} m_{j} \varphi_{p} d \Omega_{L h}=\frac{q_{i} m_{j}}{4 \pi\left(1-2 v_{p}\right)}\left[\left(1-2 v_{p}\right)\left(\delta_{i k} r_{, j}+\delta_{k j} r_{, i}-\delta_{i j} r_{, k}\right)+2 r_{, i} r_{, j} r_{, k}\right] ; i, \mathrm{j}, \mathrm{k}, \mathrm{p}=12 \\
\int_{\Omega_{L k}} \Delta w_{, m}^{*} \varphi_{1} d \Omega_{L k}=\int_{\Omega_{L k}} \Delta w_{, m}^{*} \varphi_{2} d \Omega_{L k}=-\frac{m_{i} r_{, i}}{4 \pi D} ; i=1,2
\end{gathered}
$$




$$
\begin{gathered}
\int_{\Omega_{L h}} w_{, m q}^{*} \varphi_{1} d \Omega_{L h}=\frac{1}{8 \pi D L}\left\{(a+b)^{2} r_{, m} r_{, q}+m_{k} q_{k}\left[b^{2}\left(\ln b-\frac{5}{2}\right)+2 a b(\ln a-1)+a^{2}\left(\ln a-\frac{1}{2}\right)\right]\right\}(\mathrm{V}-8) \\
; k=1,2 \\
\int_{\Omega_{L h}} w_{, m q}^{*} \varphi_{1} d \Omega_{L h}=\frac{1}{8 \pi D L}\left\{(a+b)^{2} r_{, m} r_{, q}+m_{k} q_{k}\left[b^{2}\left(\ln b-\frac{5}{2}\right)+2 a b(\ln a-1)+a^{2}\left(\ln a-\frac{1}{2}\right)\right]\right\} ;(\mathrm{V}-9) \\
k=1,2 \\
\int_{\Omega_{L h}} w_{, m q}^{*} \varphi_{2} d \Omega_{L h}=\frac{1}{8 \pi D L}\left\{(a+b)^{2} r_{, m} r_{, q}+m_{k} q_{k}\left[a^{2}\left(\ln a-\frac{5}{2}\right)+2 a b(\ln b-1)+b^{2}\left(\ln b-\frac{1}{2}\right)\right]\right\} ;(\mathrm{V}-10) \\
k=1,2
\end{gathered}
$$

